Article

\title{
Desalination of Water Using ZVI $\left(\mathrm{Fe}^{0}\right)$
}

\section{David D. J. Antia}

DCA Consultants Ltd., Haughend, Bridge of Earn Road, Dunning, Perthshire PH2 9BX, UK;

E-Mail: dcacl@btconnect.com; Tel.: +44-176-468-4664

Academic Editor: Nicholas Hankins

Received: 15 February 2015 / Accepted: 15 June 2015 / Published: 14 July 2015

\begin{abstract}
Batch treatment of water $(0.2$ to $240 \mathrm{~L})$ using $\mathrm{Fe}^{0}(44,000-77,000 \mathrm{~nm})$ in a diffusion environment operated (at -8 to $25^{\circ} \mathrm{C}$ ) using: (a) no external energy; (b) pressurized $(<0.1 \mathrm{MPa})$ air; (c) pressurized $(<0.1 \mathrm{MPa})$ acidic gas $\left(\mathrm{CO}_{2}\right)$; (d) pressurized $(<0.1 \mathrm{MPa})$ anoxic gas $\left(\mathrm{N}_{2}\right)$; (e) pressurized $(<0.1 \mathrm{MPa})$ anoxic, acidic, reducing gas $\left(\mathrm{H}_{2}+\mathrm{CO}+\mathrm{CO}_{2}+\right.$ $\mathrm{CH}_{4}+\mathrm{N}_{2}$ ), reduces the salinity of water. Desalination costs increase with increasing $\mathrm{NaCl}$ removal. The cost of reducing water salinity from: (i) 2.65 to $1.55 \mathrm{~g} \cdot \mathrm{L}^{-1}$ (over $1-24 \mathrm{~h}$ ) is $\$ 0.002-\$ 0.026 \mathrm{~m}^{-3}$; (ii) 38.6 to $0.55 \mathrm{~g} \cdot \mathrm{L}^{-1}$ (over 210 days) is $\$ 67.6-\$ 187.2 \mathrm{~m}^{-3}$. Desalination is accompanied by the removal, from the water, of one or more of: nitrate, chloride, fluoride, sulphate, phosphate, As, B, Ba, Ca, Cd, Co, Cu, Fe, Mg, Mn, Na, Ni, P, S, Si, Sr, Zn. The rate of desalination is enhanced by increasing temperatures and increasing $\mathrm{HCO}_{3}{ }^{-} / \mathrm{CO}_{3}{ }^{2-}$ concentrations. The rate of desalination decreases with increasing $\mathrm{SO}_{4}{ }^{2-}$ removal under acidic, or $\mathrm{pH}$ neutral, operating conditions.
\end{abstract}

Keywords: desalination; zero valent metal; $\mathrm{Eh} ; \mathrm{pH}$; electrical conductivity $(\mathrm{EC}) ; \mathrm{Fe}^{0} ; \mathrm{Al}^{0}$; $\mathrm{Cu}^{0} ; \mathrm{FeOOH}$

\section{Introduction}

Water treatment using zero valent metals $(\mathrm{ZVM})$ in a reactor (or water body) [1-6], by aquifer injection/infiltration [7-14], or by placement in a permeable reactive barrier (PRB) located within an aquifer [15-17], results in an increase in water $\mathrm{pH}[5-7,18]$ and a change in water Eh [5-7,18]. This is accompanied by a change in water electrical conductivity (EC) $[5-7,18]$ which is associated with: (i) the removal of cations and anions from the water by the ZVM (water treatment) [5-7,18]; (ii) dissolution of part of the ZVM into the water body $[5,19]$. Assessment of how the results of this 
study impact on the removal of microbiota, cations and anions from the water by the ZVM (water treatment) is addressed in Section 6 and Appendix A. ZVM includes $\mathrm{Fe}^{0}, \mathrm{Cu}^{0}$, and $\mathrm{Al}^{0}$. In all the trials used in this study, the dominant ZVM is zero valent iron, ZVI $\left(\mathrm{Fe}^{0}\right)$. The abbreviation ZVI is used for Zero Valent Iron $\left(\mathrm{Fe}^{0}\right)$.

Analyses of the salinity of water in aquifers passing through PRB's and in reactors containing ZVM have established that both $\mathrm{Na}^{+}$and $\mathrm{Cl}^{-}$can be removed from water by ZVM [6,15,20-25], or mixtures of ZVM + ion exchange material such as aluminium silicates (e.g., Ca-montmorillonite) [5]. The ZVM is considered to form anodic and cathodic sites in water [18,22-24]. The $\mathrm{Cl}^{-}$ions are interpreted as attaching to the anodic sites [22,23]. The iron corrosion rate increases with water velocity [26]. Electrical conductivity (EC) measurements can be used to assess both water salinity and the release of iron corrosion products into the water [20,27].

This study evaluates the partial desalination of water using: (i) 44,000-77,000 $\mathrm{nm} \mathrm{Fe}^{0}$ powders which are derived from carbon steel; and (ii) a control/reference air stable $50 \mathrm{~nm} n$-Fe $\mathrm{Fe}^{0}$ powder (PS7) which is impregnated with polyvinylpyrrolidone (PVP) and coated with tetraethylorthosilicate (TEOS) [28].

$\mathrm{Na}: \mathrm{Fe}: \mathrm{C}$ electrochemical capacitor studies have demonstrated that a high capacitance is associated with: (i) structures where a $\mathrm{Fe}^{\mathrm{III}}$ corrosion product is templated onto $\mathrm{Fe}^{0}$ [29]; (ii) and structures containing a $\mathrm{Fe}^{\mathrm{III}}$ corrosion product and carbon [29].

\subsection{Potential Agricultural Application for Partial Desalination by ZVI}

Agricultural water usage for irrigation, livestock and cleaning represents about $70 \%$ of global water usage [30] (i.e., about 2600 billion $\cdot \mathrm{m}^{3} \cdot \mathrm{a}^{-1}$ [31]). This is projected to rise to between 2800 and 3900 billion $\cdot \mathrm{m}^{3} \cdot \mathrm{a}^{-1}$ by 2050 [31]. 260-1000 billion $\cdot \mathrm{m}^{3} \cdot \mathrm{a}^{-1}$ of global arable irrigation water is adversely affected by salinity [32-35]. Any reduction in irrigation water salinity, or livestock feed water salinity, can be expected to result in an increase in crop, or livestock, yield (Appendix B, Figures B1 and B2).

A series of background Figures (Figure B1a-p) have been provided (Appendix B) to show the UN FAO (Food and Agricultural Organization) estimates of the relationship between crop yield and water salinity. This is to demonstrate:

(1) The impact of a decrease in water salinity on the crop yields;

(2) The impact of a small decrease in water salinity on the number of crops which could be grown on an agricultural holding.

For example, a reduction in water salinity from:

(1) 8 to $4 \mathrm{~g} \cdot \mathrm{L}^{-1}$ has the potential (Appendix B, Figure B1a) to increase the possible crop yield $\left(\mathrm{t} \cdot \mathrm{ha}^{-1}\right.$ ) associated with wheat by $300 \%$.

(2) 4 to $2 \mathrm{~g} \cdot \mathrm{L}^{-1}$ has the potential (Appendix B, Figure B1i) to increase the possible crop yield $\left(\mathrm{t} \cdot \mathrm{ha}^{-1}\right.$ ) associated with potato by $>200 \%$.

(3) 3 to $1 \mathrm{~g} \cdot \mathrm{L}^{-1}$ has the potential (Appendix B, Figure B1g) to increase the possible crop yield ( $\mathrm{t} \cdot \mathrm{ha}^{-1}$ ) associated with soft fruit such as blackberry, raspberry or strawberry by $>800 \%$. 
These changes in crop yield with reduced salinity indicate that if the salinity of saline irrigation water can be reduced for a reasonable cost using a solution that utilises existing reservoirs, impoundments and tanks, then it may be possible to:

(i) Significantly reduce the proportion of global agricultural land which is adversely affected by salinity;

(ii) Increase crop yields on individual agricultural holdings (Appendix B);

(iii) Increase the range of crops that can be grown commercially on a specific agricultural holding (Appendix B).

Irrigation water, supplied as desalinated water produced by large $\left(>100,000 \mathrm{~m}^{3} \cdot \mathrm{d}^{-1}\right)$ reverse osmosis (RO), or multistage flash distillation (MSFD) desalination plants, has a delivery cost of US\$0.9$3 \mathrm{~m}^{-3}[36-38]$.

An agricultural holding may require an irrigation rate of $1000 \mathrm{~m}^{3} \cdot \mathrm{ha}^{-1} \cdot \mathrm{a}^{-1}$, but may not have access to the finance, or energy, required to operate a suitably sized RO, or MSFD, desalination plant. ZVM desalination has the potential to: (i) reduce the irrigation cost; (ii) utilise existing tanks, ponds and impoundments on the agricultural holding, thereby removing a requirement for new capital investment; (iii) undertake desalination without requiring an energy source (electricity or heat); and (iv) provide an economically viable partial desalination solution for agricultural holdings utilizing 10 to more than 100,000 $\mathrm{m}^{3} \cdot \mathrm{a}^{-1}$ of irrigation water.

\subsection{Background}

\subsubsection{Historical ZVI Desalination Experiments}

There have been five experimental studies which have evaluated desalination associated with ZVI and $\mathrm{ZVM}\left(\mathrm{Fe}^{0}+\mathrm{Al}^{0}+\mathrm{Cu}^{0}\right)$. They are:

(1) ZVM $\left(\mathrm{Fe}^{0}+A l^{0}+\mathrm{Cu}\right)$-Ca-montmorillonite combination and ZVI $\left(\mathrm{Fe}^{0}\right)$-Ca-montmorillonite. This study [5] demonstrated (Temperature, $T=12-25{ }^{\circ} \mathrm{C}$; Brunauer-Emmett-Teller (BET) surface area, $a_{\mathrm{s}}=0.00289-0.01732 \mathrm{~m}^{2} \cdot \mathrm{g}^{-1} ; \mathrm{ZVI}\left(\mathrm{Fe}^{0}\right)$ concentration, $\left.P_{\mathrm{w}}=90 \mathrm{~g} \cdot \mathrm{L}^{-1}\right)$ (in an open, unstirred, static flow, batch diffusion reactor operated at ambient temperatures) declines in salinity of $25 \%-50 \%$ over 60 days from an initial salinity of about $1 \mathrm{~g} \cdot \mathrm{L}^{-1}$.

(2) $Z V M\left(F e^{0}\right.$ and $\left.F e^{0}+A l^{0}+C u^{0}\right)$. This study [6] demonstrated $\left(T=8-20{ }^{\circ} \mathrm{C} ; a_{\mathrm{s}}=\right.$ $\left.0.00289-0.01732 \mathrm{~m}^{2} \cdot \mathrm{g}^{-1} ; P_{\mathrm{w}}=90 \mathrm{~g} \cdot \mathrm{L}^{-1}\right)$ in an open, unstirred, static flow, batch diffusion reactor operated at ambient temperatures with an initial salinity of about $1 \mathrm{~g} \cdot \mathrm{L}^{-1}$, no effective decline in salinity over 60 days.

(3) ZVI $\left(F e^{0}\right)$. This study [20] established $\left(T=15.3{ }^{\circ} \mathrm{C} ; a_{\mathrm{s}}=77.26 \mathrm{~m}^{2} \cdot \mathrm{g}^{-1} ; P_{\mathrm{w}}=3.33 \mathrm{~g} \cdot \mathrm{L}^{-1}\right)$ in an open, unstirred, static flow, batch diffusion reactor over $48 \mathrm{~h}$ a decline in $\mathrm{Cl}^{-}$concentration from 1.52913 to $1.19831 \mathrm{~g} \cdot \mathrm{L}^{-1}$. This was associated with an increase in electrical conductivity (EC) from 3.9 to $4.51 \mathrm{mS} \cdot \mathrm{cm}^{-1}$, and an increase in $\mathrm{pH}$ from 6.47 to 9.59 .

(4) $Z V I\left(F e^{0}\right)$. This study [21] established $\left(T=20-22{ }^{\circ} \mathrm{C} ; a_{\mathrm{s}}=77.26 \mathrm{~m}^{2} \cdot \mathrm{g}^{-1} ; P_{\mathrm{w}}=8 \mathrm{~g} \cdot \mathrm{L}^{-1}\right)$ in an open, continuously stirred, batch diffusion reactor over a $24 \mathrm{~h}$ period a statistical relationship between 
$\mathrm{Cl}^{-}$concentration in the feed water $\left[C_{\mathrm{F}}\right]$ and product water $\left[C_{\mathrm{R}}\right]$ over a $24 \mathrm{~h}$ period, where $C_{\mathrm{R}}$, $\mathrm{mg} \cdot \mathrm{L}^{-1}=1.1 C_{\mathrm{F}}^{0.98}\left[R^{2}=0.99\right]$ [21]. The absorbed $\mathrm{Cl}^{-}, \mathrm{mg} \cdot \mathrm{L}^{-1}\left(C_{L}\right)=C_{\mathrm{F}}-C_{\mathrm{R}}$.

(5) $Z V I\left(n-F e^{0}\right)$. This study [25] established over a $3 \mathrm{~h}$ period using highly reduced $n$-Fe $\mathrm{e}^{0}$, (structured with a $\mathrm{Fe}^{0}$ core and an outer carbon coating $\left(P_{\mathrm{w}}=1.25 \mathrm{~g} \cdot \mathrm{L}^{-1} ; 0.1 \mathrm{gNO}_{3}^{-} \cdot \mathrm{L}^{-1}\right)$, in a fluidised, batch diffusion reactor saturated with argon), a linear relationship between $\mathrm{Cl}^{-}$removal $\left[C_{\mathrm{L}}\right](\mathrm{g}$ $\left.\mathrm{Cl}^{-} \cdot \mathrm{g}^{-1} \mathrm{Fe}^{0}\right)$ and $\mathrm{NaCl}$ concentration $\mathrm{g} \cdot \mathrm{L}^{-1} \cdot C_{L}=$ Adsorbed $\mathrm{Cl}^{-}, \mathrm{gCl}^{-} \cdot \mathrm{g}^{-1} n-\mathrm{Fe}^{0}$; after $3 \mathrm{~h} C_{L}=0.055$ $\mathrm{g}$ Feed $\mathrm{NaCl} \cdot \mathrm{L}^{-1}$. At a salinity of $20 \mathrm{gNaCl} \cdot \mathrm{L}^{-1}$, after $3 \mathrm{~h} \quad\left[C_{\mathrm{L}}\right]=$ $1.1 \mathrm{gCl}^{-} \cdot \mathrm{g}^{-1} \mathrm{Fe}^{0}$. This implies a $\mathrm{NaCl}$ removal of $1.77 \mathrm{gNaCl} \cdot \mathrm{g}^{-1} \mathrm{Fe}^{0}$.

These studies establish five important points:

(1) The rate of desalination increases with increasing ZVM particle surface area. This indicates that the desalination is either an adsorption process [20,21,25], or a reaction which involves ZVM catalysis on the particle surface [18];

(2) The rate of desalination increases with increasing fluid flow rates through the $\mathrm{Fe}^{0}[6,21,25]$. This indicates [26] that desalination is associated with a corrosion reaction on the $\mathrm{Fe}^{0}$ particle surface;

(3) The rate of desalination increases with increasing water salinity $[21,25]$. This indicates that the reaction rate is a function of electrolyte $[\mathrm{NaCl}]$ strength.

(4) The rate of desalination can be significantly increased by combining ZVM with ion exchange material (e.g., aluminium silicates such as Ca-montmorillonite) [5].

(5) Desalination associated with $\mathrm{Fe}^{0}$ can be accompanied by an increase in EC [20]. This indicates that the $\mathrm{EC}$ reduction associated with the removal of $\mathrm{NaCl}$ [27] has been more than offset by the increase in EC associated with the release of ions $\left(\mathrm{Fe}^{n^{+}}\right)$[19] into the water [27].

\subsubsection{ZVI Composition}

Most low cost commercial iron powders $(<0.1 \mathrm{~mm}$ diameter) are constructed from electrolytic iron, or milled iron (44,000-77,000 nm), or iron carbonyl (1000-10,000 nm spheres).

The iron powders will typically contain $<0.4$ wt $\% \mathrm{Mn} ;<0.35$ wt $\% \mathrm{O} ;<0.03$ wt $\% \mathrm{~S} ;<0.1$ wt $\% \mathrm{Si}$; $<0.04$ wt \% C; $<0.03$ wt \% P, e.g., [39-42].

The carbonyl iron will typically contain $0.01-2 \mathrm{wt} \% \mathrm{C} ; 0.01-2.5 \mathrm{wt} \% \mathrm{~N}$, and $0.15-0.5 \mathrm{wt} \% \mathrm{O}$ [43].

Milled iron produced from carbon steel will have a composition which varies with the grade. For example Q235C/U12358 grade (Chinese Standard GB/T 700-2006 [44]) can contain 0.17 wt \% C; 0.35 wt \% Si; 1.4 wt \% Mn; 0.04 wt \% P; 0.04 wt \% S; 0.3 wt \% Cr; 0.3 wt \% Ni; 0.3 wt \% Mo; 0.3 wt \% Cu, e.g., [45,46].

\subsubsection{ZVI Cost}

The price of $\mathrm{Fe}^{0}$ powders is a function of particle size, quantity purchased, purity, packaging, stabilization, supplier, and prevailing commodity prices. Indicative FOB (free on board) prices on www.alibaba.com for volume purchases $(>10 t)$ were:

(i) $1-100 \mathrm{~nm} n-\mathrm{Fe} 0$ powders $=\mathrm{US} \$ 1,000->\$ 500,000 \mathrm{t}^{-1}$ (e.g., [47-51]).

(ii) $1000-10,000 \mathrm{~nm}$ carbonyl iron powders $=\mathrm{US} \$ 1,000-\$ 150,000 \mathrm{t}^{-1}$ (e.g., $[43,52-55]$. 
(iii) 44,000-77,000 $\mathrm{nm}$ iron powders $=\mathrm{US} \$ 150-\$ 3,500 \mathrm{t}^{-1}$ (e.g., [56-60]).

The price of small quantities $(<5 \mathrm{~kg})$ of chemical grade Fe powders varies with particle size and can fall in the range $\$ 50$ to greater than $\$ 10,000 / \mathrm{kg}$ for some powders with a particle size of $1-100 \mathrm{~nm}$ (e.g., $[47,48,61])$.

The term FOB is defined, for international trade, by the Incoterms ${ }^{\circledR} 2010$ [62-64]. The Incoterms ${ }^{\circledR}$ 2010 define FOB as meaning that the seller delivers the goods on board the vessel nominated by the buyer at the named port of shipment, or to a named destination. The risk of loss, or of damage, to the goods passes to the buyer when the goods arrive on board the vessel, or arrive at the nominated destination. The buyer bears all costs from that moment onwards. The Incoterms ${ }^{\circledR} 2010$ define a number of other alternative international contract structures [62-64], which can be applied to the pricing and sale of ZVM powders.

\subsubsection{Potential Cost of Partial Desalination Using ZVI}

The cost of partial water desalination is a function of: (i) the cost of the ZVI $\left(\$ \cdot \mathrm{t}^{-1}\right)$; (ii) the ZVI loading, $P_{\mathrm{w}}, \mathrm{g} \cdot \mathrm{L}^{-1}\left(\mathrm{~kg} \cdot \mathrm{m}^{-3}\right)$; (iii) length of time required to achieve the required level of desalination; and (iv) the number of times a specific batch of ZVI can be reused.

This study establishes (for a salinity reduction of $<4 \mathrm{gNaCl} \cdot \mathrm{L}^{-1} \cdot \mathrm{d}^{-1}$ ), that it is possible to reuse a batch of ZVI at least 18 times. This allows achievement of an effective partial desalination cost for irrigation water of $<\$ 0.1 \mathrm{~m}^{-3}$.

\subsection{Study Structure}

This study includes the results from 137 separate desalination trials and 144 control trials. Trial data, detailed methodology descriptions and background information has been placed in the Appendices in order to improve text readability. The Appendices comprise:

(a) Appendix A: Microbiota, cations, and anions removed by ZVM.

(b) Appendix B: Impact of changing water salinity of arable crop yields and changing feed water salinity on livestock yields;

(c) Appendix C: Trial results: feed and product water cations and anion analyses, gas flow rates, Eh, $\mathrm{pH}, \mathrm{EC}$, salinity vs. time, UV-visible spectroscopy analyses of entrained particles.

(d) Appendix D: ZVM compositional and pre-treatment details; Control Reactor Trials;

(e) Appendix E: Interpretation of salinity from electrical conductivity and UV-visible absorbance data.

(f) Appendix F: Fe, Al, Cu corrosion in saline water; Relationship between EC (salinity) and reaction kinetics;

(g) Appendix G: Corrosion species involved in desalination;

(h) Appendix H: Identification of radicals removed during desalination;

Reference to a specific figure or table in an Appendix is prefixed by the Appendix letter, e.g., Figure $\mathrm{C} 1$ is located in Appendix C. 


\subsubsection{ZVM TP and ZVM TPA}

This study examines if it is possible to:

1. Treat the iron powders (and ZVM combinations) prior to use to form air stable, attrition resistant porous pellets which can partially desalinate water over a 30-250 day trial period. This treated ZVM is termed ZVM TP in this study; TP = treatment product;

2. Use a combination of untreated $\mathrm{Fe}^{0}$ and potassium aluminium silicate powder (K-feldspar) to force partial desalination to occur with a $1-24 \mathrm{~h}$ period. This combination of untreated $\mathrm{Fe}^{0}+\mathrm{K}$-feldspar is termed ZVM TPA in this study; TPA = treatment product, Type A.

The desalination results associated with:

a. The ZVM TP are provided in Sections 4 and 6, Appendix C (Tables C1-C4; Figures C1-C18), Appendix D (Figures D1-D6), Appendix F.

b. The ZVM TPA are provided in Section 5, Appendix C (Tables C5-C13; Figures C19-C37), Appendix H.

\subsubsection{Partial Desalination Information Provided in This Study}

a. Control Trials and Reference Data (Section 2, Tables C1-C4, Figure D1)

i. Natural spring water used to construct the synthetic saline water used in the trials;

ii. Initial Control Data Set: Variation in $\mathrm{Eh}, \mathrm{pH}, \mathrm{EC}$ of untreated $\mathrm{ZVM}\left(\mathrm{Fe}^{0}, \mathrm{Al}^{0}, \mathrm{Fe}^{0}+\mathrm{Al}^{0}\right.$, $\left.\mathrm{Fe}^{0}+\mathrm{Cu}^{0}, \mathrm{Fe}^{0}+\mathrm{Al}^{0}+\mathrm{Cu}^{0}\right)$ in fresh water and saline water;

iii. Trial Control Data Set: Variation in Eh, $\mathrm{pH}, \mathrm{EC}$ of treated particulate ZVM TP (P1) in fresh water (P1c) and saline water (P1);

iv. Saline feed water used in the trials, at the trial onset and trail conclusion;

b. ZVM TP (Sections 4 and 6, Tables C1-C4; Figures C1-C18, Tables D1 and D2, Figures D1-D6)

i. Impact of ZVM pre-treatment on desalination rates;

ii. Variation in EC (salinity) with time;

iii. Variation in Eh and $\mathrm{pH}$ with time;

iv. Relationship between desalination and ZVM TP loading $\left(\mathrm{g} \cdot \mathrm{L}^{-1}\right)$;

v. Relationship between desalination, particle size and capacitance;

vi. Economics of partial desalination using ZVM TP.

c. ZVM TPA (Section 5, Tables C5-C13, Figures C19-C37, Table D3)

i. Relationship between desalination rate, ZVM TPA reuse, and time;

ii. Economics of partial desalination.

d. Mechanism of desalination (Sections 4 and 5, Appendices F-H)

i. Removal of $\mathrm{NaCl}$ by incorporation into Fe corrosion products;

ii. Removal of $\mathrm{NaCl}$ by inclusion in a hydration shell; 
e. Implications for the co-removal of cations and anions contained in the water (Section 6, Tables C1-C4, Figure C18)

i. Water containing other cations, anions, and microbiota;

ii. Water enriched in sulphates;

iii. Water enriched in carbonates.

\section{Materials, Methods and Equipment}

Tabulated and graphical experimental/trial data used in this study are provided in Appendix $\mathrm{C}$ (Tables C1-C13; Figures C1-C37). All particles used to construct the ZVM TP and ZVM TPA were powdered (44,000-77,000 nm particle size). Details of the ZVM TP and ZVM TPA compositions are provided in Appendix D (Tables D1-D3).

\subsection{Feed Water}

The natural untreated spring water used in the trials was extracted from a well located in fractured andesites and acid (rhyolitic) pyroclastics (Devonian, Old Red Sandstone Volcanic Series, Ochil Hills, Scotland). This water has previously been used in ZVM studies [5,6]. The variation in EC, Eh, and $\mathrm{pH}$ with time of this water source is documented elsewhere [6]. The cation and anion composition of the natural spring water water is provided in Tables $\mathrm{C} 1-\mathrm{C} 4$. The term freshwater in this study is used to refer to this natural spring water.

\subsection{Equipment}

Eh, pH, EC, and temperature were measured using equipment manufactured or branded by Hanna Instruments Ltd. (Leighton Buzzard, Bedfordshire LU7 4AD, UK), Extech Instruments (Nashua, NH, USA), HM-Digital Inc. (Culver City, CA, USA) and Oakton Instruments (Vernon Hills, IL, USA). EC, Eh and $\mathrm{pH}$ calibration standards used were manufactured or branded by Hanna Instruments, HM-Digital, Milwaukee Instruments Inc. (Rocky Mount, NC, USA). Eh is calibrated to the standard hydrogen electrode (SHE) (Appendix D2.1). Current, voltage, resistance and capacitance of the ZVM TP were measured using equipment manufactured or branded by Philex Electronic (UK) Ltd. (Bedford, UK). Cation and anion analyses were contracted to Forest Research (Farnham, Surrey, UK), the commercial laboratories of the UK Forestry Commission. Anions were determined using Dionex Ion Chromatography (Thermo Fischer Scientific Inc. (Waltham, MA, USA)). Cations were determined using a Thermo Icap 6500 Spectrometer.

Real time salinity changes were determined using EC (Figures C1-C17 and D1-D6) and UV-visible spectroscopy (Figures C19-C36) analysed using a YXUV-5200 spectrometer supplied by Shanghai Selon Scientific Instruments, Shanghai University National Science Park, Shanghai, China. The gas compositions $\left(\mathrm{CH}_{4}, \mathrm{CO}, \mathrm{CO}_{2}, \mathrm{~N}_{2}, \mathrm{H}_{2}\right)$ entering and leaving the water from the $3.5 \mathrm{~L}, 5.4 \mathrm{~L}$ and $8 \mathrm{~L}$ capacity reactors were monitored using a SRI 8610C TCD GC (manufactured by SRI Instruments Inc. (Torrance, CA, USA)) with a silica gel column and He carrier gas. GC = gas chromatograph, $\mathrm{TCD}=$ Thermal Conductivity Detector). Gases and gas calibration standards used in this study were purchased from BOC/Linde, (Guildford, Surrey, UK). 


\subsection{Control and Reference Trials}

\subsubsection{Reference Trials: Feedwater Analysed at the Start and End of Each Trial}

The trials used saline water which was constructed by either dissolving $\mathrm{NaCl}$ into natural spring water (control trials and ZVM TP trials), or by dissolving halite into natural spring water (ZVM TPA trials). Cation and anion compositions are provided in Tables $\mathrm{C} 1-\mathrm{C} 4$ for the saline feed water constructed using $\mathrm{NaCl}$. The amount (wt) of $\mathrm{NaCl} /$ halite dissolved into the water was recorded.

The EC, Eh, pH and temperature of the saline water was determined prior to each trail. Some of the saline feed water used in each trial was stored as a control. At the conclusion of the trial the EC, $\mathrm{pH}$ and temperature of the saline feed water was redetermined. In each instance the redetermined $\mathrm{pH}$ reading was within 0.1 units of the original reading and the redetermined EC reading was within $2 \%$ of the original reading. The redetermined results are within the margins of error of the analytical tools used. The reference trials establish that any differences in $\mathrm{pH}$ and $\mathrm{EC}$ between the original feed water and the product water containing ZVM, or ZVM TP, or ZVM TPA, arise from the presence of the ZVM, ZVM TP and ZVM TPA.

\subsubsection{Initial Control Trials Using Untreated ZVM}

A series of batch reactors were constructed where each reactor contained $\mathrm{ZVM}$ powders $\left(\mathrm{Fe}^{0}, \mathrm{Al}^{0}\right.$, $\mathrm{Fe}^{0}+\mathrm{Al}^{0}, \mathrm{Fe}^{0}+\mathrm{Cu}^{0}$ and $\left.\mathrm{Fe}^{0}+\mathrm{Al}^{0}+\mathrm{Cu}^{0}\right)+$ water. Each reactor was not sealed, was open to the air and had an air-water contact. The water was not stirred and the principal interaction between the water and ZVM was by diffusion. These control trials are documented in [6]. Two of the trials (containing $\mathrm{Fe}^{0}$ and $\mathrm{Fe}^{0}+\mathrm{Al}^{0}+\mathrm{Cu}^{0}$ ) were undertaken in both saline water and freshwater [6] to identify the differences which arise with time in Eh, pH and EC. The EC declines recorded over 60 days in the freshwater and saline water were similar [6]. Therefore it is reasonable to conclude that no noticeable desalination had occurred during the trials with untreated ZVM.

In order to allow comparison with the earlier trials documented in references [5,6], the untreated $\mathrm{Fe}^{0}$, $\mathrm{Al}^{0}$, and $\mathrm{Cu}^{0}$ powders used (and illustrated [5]) in references [5,6] were used to construct the ZVM TP (containing treated ZVM) and ZVM TPA (containing a mixture of untreated ZVM and ion exchange material). The ZVM TPA operating procedure effectively treats the ZVM during desalination.

\subsubsection{Control Trial Using ZVM TP}

A control trial was established where two trials were run simultaneously (PS1 (Figure C1) and PS1C (Figure D1)) under the same temperature and pressure conditions. In each trial the ZVM TP powder was placed in an unsealed, unstirred, reactor containing a batch of water, and an air-water contact. Reactor PS1 contained saline water. Reactor PS1C contained fresh water. Both Reactors displayed a rapid increase in $\mathrm{pH}$ with time (Figure D1), and an initial decrease in Eh followed by a rise in Eh (Figure D1). PS1 displayed a general decrease in EC with time due to desalination (Figure D1), while PS1C displayed a general increase in EC with time due to the release of $\mathrm{Fe}^{n^{+}}$(aq) ions (Figure D1). Water consumption in PS1C was higher than in PS1. 35\% of the feed water was consumed in PS1C within 42 days. 
Cross plots of Eh vs. pH, Eh vs. EC, and $\mathrm{pH} v s$. EC (Figure D1) indicate that PS1C had a consistently higher $\mathrm{pH}$ than PS1 and operated with an Eh over a wider range. The $\mathrm{pH}$ in PS1 reduced as the salinity reduced towards the $\mathrm{pH}$ of the initial feed water. The $\mathrm{pH}$ in PS1C remained at elevated levels. The bulk of the salinity reduction in PS1 occurred at $\mathrm{Eh}>0 \mathrm{mV}$. The Eh in PS1 reduced below $0 \mathrm{mV}$ when the EC fell below $3 \mathrm{mS} \cdot \mathrm{cm}^{-1}$ (Figure D1).

The performance (Eh, pH, EC) of PS1C was similar to that observed for untreated ZVM [6].

These control trials demonstrated that pre-treatment of the ZVM (when compared with the performance of untreated ZVM [6]) can result in a major decrease in EC (salinity) when the treated ZVM TP is placed in saline water (Figures C1 and D1).

\subsection{ZVM TP Trials}

\subsubsection{Temperatures and Pressures Used in the ZVM TP Trials and ZVM TP Control Trial}

The reactors were all placed in an external environment. The temperatures and pressures used in the ZVM TP trials (Appendix C) and ZVM TP control trials (Figure D1) are provided in Figure 1.
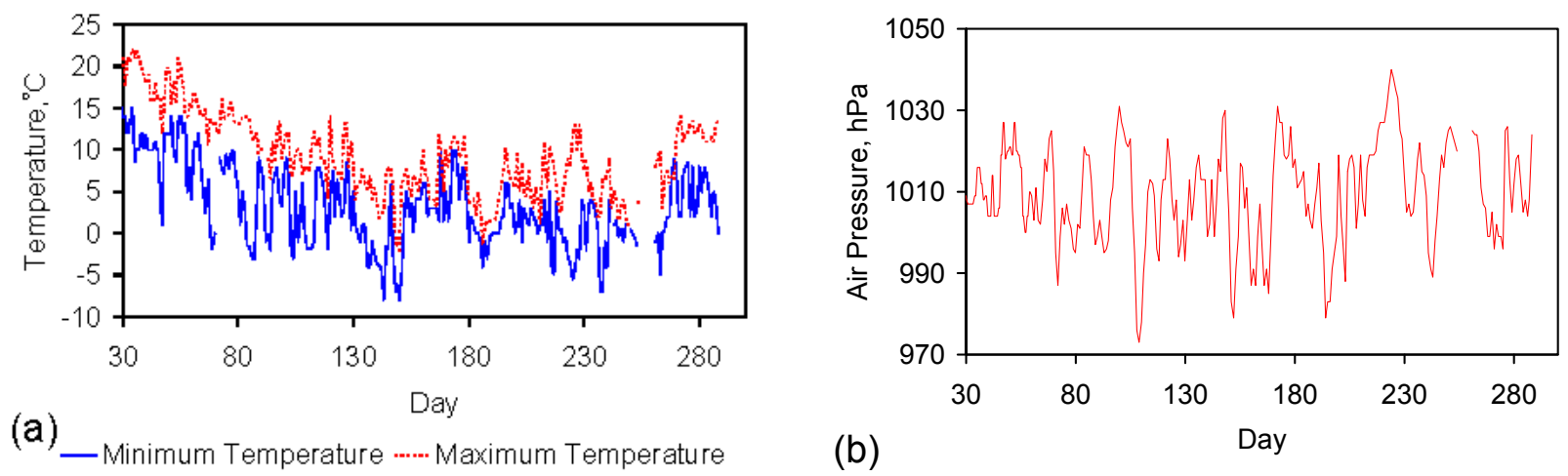

Figure 1. Diabatic operating conditions. (a) Temperature; (b) Air Pressure. Data Source: Strathallan weather station (www.weatheronline.com). All trials are referenced to Day 1, where Day 1 is 17 July 2012.

\subsubsection{Manufacture of ZVM TP}

ZVM TP particles and pellets were manufactured by placing the raw ZVM in saline water which was saturated with either:

1. Type A: $\left[16.79 \% \mathrm{CH}_{4}+16.88 \% \mathrm{H}_{2}+11.97 \% \mathrm{CO}+8.33 \% \mathrm{CO}_{2}+46.03 \% \mathrm{~N}_{2}\right]$, Trials: AS1-AS3, PS5; Manufacturing time = 17 days; Manufacturing time for Trial PS15 = 35 Days;

2. Type B: $\left[16.79 \% \mathrm{CH}_{4}+16.88 \% \mathrm{H}_{2}+11.97 \% \mathrm{CO}+8.33 \% \mathrm{CO}_{2}+46.03 \% \mathrm{~N}_{2}\right.$ for 110 days $]$ followed by [ $80 \% \mathrm{~N}_{2}+20 \% \mathrm{CO}_{2}$ for 135 days] followed by [ $100 \% \mathrm{~N}_{2}$ for 46 days]; Trials: ST1ST7, AS4-AS6, PS1-PS4, PS1C; Manufacturing time = 291 days; Manufacturing time for Trial PS16 = 65 Days;

3. Type C: $\left[\mathrm{N}_{2}\right]$ Trials: PS8-PS10, ST8, MT1, MT2; Manufacturing time $=34$ days;

4. Type D: [air] Trials: PS11, PS12, PS13, MT3, MT4; Manufacturing time $=42$ days. 
During the manufacturing process the ZVM was maintained at a temperature which varied within the range -8 to $25^{\circ} \mathrm{C}$, and at a pressure which was between atmospheric pressure and $0.1 \mathrm{MPa}$.

\subsubsection{ZVM Composition Used to Manufacture ZVM TP (Tables D1 and D2)}

The molar ZVM compositions entered into the manufacturing reactor to construct the ZVM TP are referenced to $\mathrm{Fe}^{0}$. The recovered ZVM TP was used as particulate matter (Figure 2) or was placed in the water as either:

(i) Copper sheathed pellets (Figure 2),

(ii) MDPE sheathed pellets,

(iii) A cartridge.
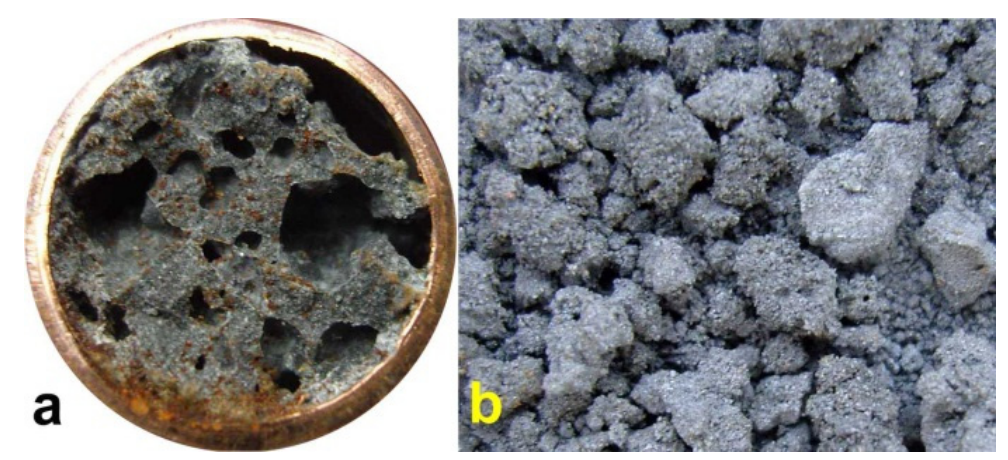

Figure 2. Macroporous ZVM TP (a) End view of a partially oxidized $\mathrm{Cu}$ sheathed ST1a-ST5j series ZVM TP pellet (15 mm OD; OD = Outer diameter). Porosity produced by degassing during manufacture; (b) Particulate ZVM TP (PS1-PS4, PS1C, PS15, PS16), field of view $=2 \mathrm{~cm}$.

\subsubsection{Reactors: ZVM TP Tests at Ambient Temperatures}

The reactors used for testing the ZVM TP pellets and particles were containers with capacities of 0.3 , 2.3 and $10 \mathrm{~L}$. Each container had an air-water contact and was operated at atmospheric pressure and temperature (Figure 1). The ZVM TP was placed in the reactors and settled at their base. The water in the reactors was not stirred or agitated during the desalination. The upper surface of the reactor was not sealed. This allowed fresh air to continually interact with the water body.

\subsubsection{Reactors: ZVM TP Tests Using Pressured Reactors where a Gas Is Used to Maintain the Pressure}

Sealed reactors (3.5 and $8 \mathrm{~L}$ ) containing particulate ZVM TP held in a cartridge, were used for ZVM TP trials CSD1 (8 L reactor), PS15, and PS16. Trials PS15 and PS16 used a reactor with a capacity of 3.5 L. Both reactors had a $1.5 \mathrm{~m}$ water column above the gas distributor with $>0.5 \mathrm{~m}$ gas located above the gas-water contact. The ZVM TP cartridges were located below the gas distributors.

The $8.0 \mathrm{~L}$ reactor contained a heat exchanger which allowed the water temperature to be increased into the range 30 to $70{ }^{\circ} \mathrm{C}$. 


\subsection{ZVM TPA Trials}

\subsubsection{Cartridge and Particle Manufacture: ZVM TPA (Table D3)}

The ZVM TPA was constructed by mixing untreated ZVM with ion exchange material (Figure 3) prior to placement in cartridges. This series of tests determined if this ZVM combination could partially desalinate water over a $1 \mathrm{~h}$ to $24 \mathrm{~h}$ period, and whether a specific batch of ZVM TP could be used multiple times without regeneration.

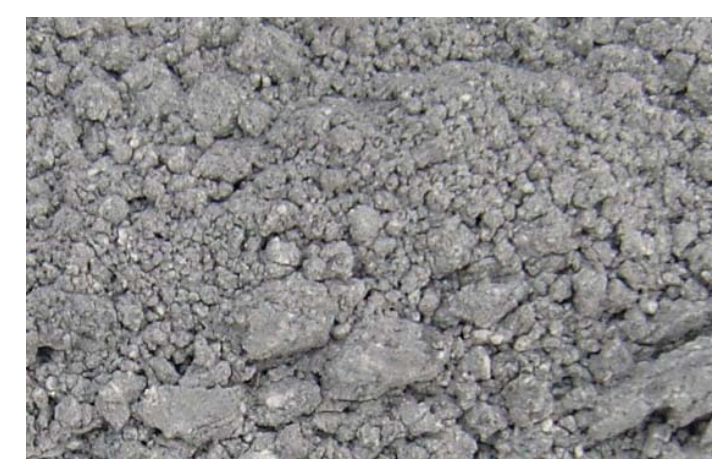

Figure 3. ZVM TPA powder used in the initial commercial trials (E145, E146, Tables C5-C12 and D3), prior to placement in the cartridges. Field of view $=2 \mathrm{~cm}$.

\subsubsection{Reactors: Used for Testing ZVM TPA}

The reactors used for testing the ZVM TPA cartridges had capacities of 5.4, 8.0, 114 and $240 \mathrm{~L}$. Each reactor contained a ZVM TPA cartridge and a gas $\left(80 \% \mathrm{~N}_{2}+20 \% \mathrm{CO}_{2}\right.$, or air) was bubbled through the reactor during operation. The 5.4 and $8.0 \mathrm{~L}$ reactors were structured to allow no interaction between air and the gas-water contact in the reactor. The 114 and $240 \mathrm{~L}$ reactors were not sealed. They were specifically structured to allow some interaction between atmospheric air and the water body.

\section{Interpretation of Salinity}

The methodology used to interpret the real time salinity in the trials is detailed in Appendix E, (Figures E1-E4, Table E1).Two methods are used. They are determination of salinity using EC and determination of salinity using absorbance determined by UV-visible spectroscopy (Figure E1). The basic equations used to calculate salinity are:

(a) Salinity at time $t=n$ calculated using EC:

$$
\mathrm{EC}_{t=n}=[A]+[B]+[C]-[D]-[E]
$$

where $[A]=\mathrm{EC}$ due to salinity at time $t=0 ;[B]=\mathrm{EC}$ due to other components in the water at time $t=0 ;[C]=$ EC added to the water by the ZVM, ZVM TP, ZVM TPA between time, $t=0$ and time, $t=n ;[D]=$ EC due to salinity which has been removed from the water between time, $t=0$ and time, $t=n ;[E]=\mathrm{EC}$ due to other components in the feed water which has been removed from the water between time, $t=0$ and time, $t=n$.

EC is related to salinity (Appendix E, Figure E3) using a regression equation of the form: 


$$
\text { Salinity }=a[\mathrm{EC}]+b
$$

$a$ and $\mathrm{b}$ are constants where $b$ is a function of $[B] . a$ is feed water specific and may vary with temperature.

(b) Salinity at time $t=n$ calculated using Absorbance at wavelength $x \mathrm{~nm}$

$$
\text { Absorbance }_{t=n}=[A]_{\mathrm{a}}+[B]_{\mathrm{a}}+[C]_{\mathrm{a}}-[D]_{\mathrm{a}}-[E]_{\mathrm{a}}
$$

where $[A]_{\mathrm{a}}=$ Absorbance due to salinity at time $t=0 ;[B]_{\mathrm{a}}=$ Absorbance due to other components in the water at time $t=0 ;[C]_{\mathrm{a}}=$ Absorbance added to the water by the ZVM, ZVM TP, ZVM TPA between time, $t=0$ and time, $t=n ;[D]_{\mathrm{a}}=$ Absorbance due to salinity which has been removed from the water between time, $t=0$ and time, $t=n ;[E]_{\mathrm{a}}=$ Absorbance due to other components in the feed water which has been removed from the water between time, $t=0$ and time, $t=n$;

Absorbance is related to salinity (Appendix E, Table E1) using a regression equation of the form:

$$
\text { Salinity }=a[\text { absorbance }]+b \text {, or Salinity }=a[\text { absorbance }]^{n} \ldots \ldots e[\text { absorbance }]+f
$$

where $a, e$ and $f$ are constants, $n$ is a polynomial number. The regression equation (and applicable equation type, linear, polynomial, etc.) which is applicable will vary with water composition. Different relationships will apply at different wavelengths. Measurement accuracy is enhanced by calculating salinity at multiple wavelengths [65] and then using the average calculated salinity as the salinity of the water [65]. In this study, each salinity value calculated from absorbance is the average of the salinity indicated by 27 different wavelengths (Table E1, Figures E1 and E2). The absorbance attributable to $\left([A]_{\mathrm{a}}-[D]_{\mathrm{a}}\right)$ is 0 when the salinity is zero.

Absorbance due to nano particles in the water was analysed (e.g. Figure E4) in accordance with the UV-Visible spectroscopy standard best practice methodology [66].

\section{Results: ZVM TP}

Placement of ZVM TP in a static water body at ambient temperatures, utilising no external energy, established a general decline in salinity with time (Figures $\mathrm{C} 1-\mathrm{C} 17$ ). The process produces product water and used ZVM TP. The magnitude of the salinity declines (documented in Tables C1-C4, Figures C1-C17 and D1-D6) indicates that ZVM TP pellets or powders have a potential application in the desalination of irrigation water (Appendix B). Salinity declines of up to $8 \mathrm{gNaCl} \cdot \mathrm{L}^{-1}$ are recorded in Figures C1-C17. Example analyses are summarised in Table 1.

The economic effectiveness of ZVM TP as a potential desalination agent for irrigation water is a function of:

(1) The weight of $\mathrm{NaCl}$ removed/unit weight $\mathrm{ZVM} \mathrm{TP}\left(Q_{\mathrm{e}}\right)$;

(2) The ZVM TP loading in the water body (weight of ZVM TP/unit volume of water, $P_{\mathrm{w}}$ );

(3) The time, $t$, taken to achieve the required level of desalination;

(4) The amount of water consumed during desalination;

(5) The number of times the ZVM TP can be reused;

(6) The residual value of the ZVM TP;

(7) The cost of the ZVM TP. 
$Q_{\mathrm{e}}$ and $P_{\mathrm{w}}$ and the inter-relationship between $Q_{\mathrm{e}}, P_{\mathrm{w}}, \mathrm{pH}$, Eh, surface charge, and ZVM TP capacitance are used to assess the economic effectiveness of different pre-treatment methods. The relationship between surface charge/capacitance and EC decline rates is used to provide a measure of quality control for the ZVM TP (i.e., $Q_{\mathrm{e}}, P_{\mathrm{w}}$ and the length of time required to achieve a targeted level of desalination).

The significance of Eh, $\mathrm{pH}, \mathrm{EC}, P_{\mathrm{w}}, Q_{\mathrm{e}}$, temperature, pre-treatment, EC decline rates, and surface charge/capacitance, is discussed here in the context of established Fe corrosion theory in order to demonstrate the mechanism which ZVM TP uses to facilitate desalination and to facilitate the manufacture of more effective ZVM TP desalination pellets and particles.

Table 1. Changes in water salinity associated with ZVM TP. Gross $Q_{\mathrm{e}}$ is calculated from the gross salinity reduction after consideration of water reduction. EC and Salinity Data: Figures $\mathrm{C} 1-\mathrm{C} 17$; Tables $\mathrm{C} 1-\mathrm{C} 4$. Colour coding reflects the manufacturing process, which is defined in Table D1: Yellow $=$ Type A; Blue $=$ Type B; Tan $=$ Type C; Green $=$ Type D.

\begin{tabular}{|c|c|c|c|c|c|c|c|c|c|c|c|c|}
\hline Trial & $\begin{array}{c}\text { Feed } \\
\text { Water }\end{array}$ & $\begin{array}{c}\text { Feed } \\
\text { Water Na } \\
+\mathbf{K}+\mathbf{C l}\end{array}$ & $\begin{array}{l}\text { Product } \\
\text { Water }\end{array}$ & $\begin{array}{c}\text { Product } \\
\text { Water Na } \\
+\mathbf{K}+\mathbf{C l}\end{array}$ & $\begin{array}{c}\text { Number of } \\
\text { Days }\end{array}$ & $\begin{array}{c}\text { Reduction in } \\
\text { Water } \\
\text { Volume }\end{array}$ & $\begin{array}{c}\text { Salinity } \\
\text { Reduction }\end{array}$ & $\begin{array}{c}\text { EC } \\
\text { Reduction }\end{array}$ & $Q_{\mathrm{e}}$ & $\begin{array}{c}\text { Gross } \\
\text { Salinity } \\
\text { Reduction }\end{array}$ & Gross $Q_{\mathrm{e}}$ & $\begin{array}{c}\text { ZVM } \\
\text { TP }\end{array}$ \\
\hline & $\begin{array}{c}\mathrm{EC} \\
\mathrm{mS} \cdot \mathbf{c m}^{-1} \\
\end{array}$ & $\mathbf{m g} \cdot \mathbf{L}^{-1}$ & $\mathbf{m S} \cdot \mathbf{c m}^{-1}$ & $\mathbf{m g} \cdot \mathbf{L}^{-1}$ & & $\%$ & $\mathbf{m g} \cdot \mathbf{L}^{-1}$ & $\mathbf{m S} \cdot \mathbf{c m}^{-1}$ & $\mathbf{m g ~ \mathbf { g } ^ { - 1 }}$ & $\mathbf{m g} \cdot \mathbf{L}^{-1}$ & $\mathrm{mg} \mathrm{g}^{-1}$ & $\mathbf{g} \cdot \mathbf{L}^{-1}$ \\
\hline MT1b & 14.65 & $7,823.30$ & 12.53 & $6,614.80$ & 100 & $17 \%$ & $1,208.50$ & 2.12 & 28.1 & $2,359.48$ & 54.87 & 43 \\
\hline MT2b & 12.66 & $6,475.88$ & 10.93 & $5,922.57$ & 98 & $21 \%$ & 553.31 & 1.73 & 4.56 & $1,785.20$ & 14.72 & 121.3 \\
\hline MT3d & 7.23 & $3,465.60$ & 6.46 & $3,308.2$ & 98 & $17 \%$ & 157.40 & 0.77 & 2.5 & 733.03 & 11.65 & 62.9 \\
\hline MT4d & 7.84 & 3988.07 & 6.57 & $3,149.62$ & 57 & $9 \%$ & 838.45 & 1.27 & 9.31 & $1,112.47$ & 12.35 & 90.1 \\
\hline $\mathrm{ST} 3 \mathrm{~b}$ & 18.84 & $11,049.49$ & 6.73 & $3,374.48$ & 126 & $25 \%$ & $7,675.01$ & 12.11 & 307 & $8,518.63$ & 340.75 & 25 \\
\hline ST3f & 18.84 & $11,049.49$ & 6.66 & $3,052.11$ & 126 & $25 \%$ & $7,997.38$ & 12.18 & 139.08 & $8,760.41$ & 152.35 & 57.5 \\
\hline ST6d & 16.59 & $9,089.82$ & 15.74 & $8,550.01$ & 120 & $17 \%$ & 539.81 & 0.85 & 105.85 & $2,027.51$ & 397.55 & 5.1 \\
\hline ST8e & 12.35 & $6,380.24$ & 10.95 & $5,814.14$ & 98 & $6 \%$ & 566.10 & 1.4 & 15.51 & 903.32 & 24.75 & 36.5 \\
\hline PS4 & 19.71 & $10,001.69$ & 5.05 & $2,195.88$ & 150 & $45 \%$ & $7,805.81$ & 14.66 & 141.92 & $8,793.96$ & 159.89 & 55 \\
\hline PS5 & 15.18 & $7,609.68$ & 5.32 & $2,633.33$ & 150 & $45 \%$ & $4,976.35$ & 9.86 & 165.88 & $6,161.35$ & 205.38 & 30 \\
\hline PS7 & 14.05 & $7,391.68$ & 4.7 & $1,941.37$ & 198 & $45 \%$ & 5450.30 & 9.35 & 2180.12 & $6,323.93$ & 2529.57 & 2.5 \\
\hline PS11 & 7.84 & $3,988.07$ & 5.43 & $2,664.32$ & 57 & $7 \%$ & $1,323.75$ & 2.41 & 49.95 & $1,515.58$ & 57.19 & 26.5 \\
\hline PS14 & 6.41 & $3,162.04$ & 5.66 & $3,024.48$ & 57 & $22 \%$ & 137.56 & 0.75 & 13.49 & 793.87 & 77.83 & 10.2 \\
\hline PS15 & 57.49 & $23,707.28$ & 31.12 & $17,284.81$ & 79 & $33 \%$ & $6,422.47$ & 26.37 & 47.93 & $12,212.88$ & 91.14 & 134 \\
\hline PS16 & 78.18 & $38,577.1$ & 1.09 & 576.48 & 210 & $74 \%$ & $38,000.62$ & 77.09 & 182.7 & $38,424.33$ & 184.73 & 208 \\
\hline
\end{tabular}

The $\mathrm{NaCl}$ is removed by the ZVM TP and is not present as a separate precipitate within the water. This demonstrates that the $\mathrm{NaCl}$ interacts with, and is bound into, a reaction product associated with the corrosion of ZVM TP in water.

$\mathrm{The} \mathrm{NaCl}$ is removed by one or more of:

(1) Incorporation into a Fe corrosion product. Green Rust One $\left(\mathrm{Cl}^{-}\right), \mathrm{GR} 1$, incorporates $\mathrm{Cl}^{-}$ions in its crystal structure. $\beta$-FeOOH requires the presence of $\mathrm{Cl}^{-}$ions to form. All other Fe corrosion products do not incorporate $\mathrm{Cl}^{-}$ions within their crystal structure. In this instance $Q_{\mathrm{e}}<70 \mathrm{mg}$ $\mathrm{NaCl}$ removed $\mathrm{g}^{-1} \mathrm{ZVM}$ [67-100]. 
(2) Incorporation into the hydration shell of a Fe corrosion product (e.g., green rust, FeOOH) [96]. A hydrated amorphous $\mathrm{FeOOH}$ corrosion product containing 46 wt $\% \mathrm{H}_{2} \mathrm{O}$ will contain 5 hydration shells. Radicals containing $\mathrm{Na}^{+}$and $\mathrm{Cl}^{-}$can substitute for $\mathrm{H}_{2} \mathrm{O}$ in the hydration lattice [96]. This may potentially allow $Q_{\mathrm{e}}$ to exceed $3 \mathrm{gNaCl}$ removed $\mathrm{g}^{-1} \mathrm{ZVM}$ [96].

(3) Concentration of $\mathrm{NaCl}$ in the pore waters within the ZVM TP/ZVM TPA corrosion product bed, when the ZVM interacts with the overlying water body by diffusion. This may potentially allow $Q_{\text {e }}$ to exceed $20 \mathrm{gNaCl} \cdot$ removed $\cdot \mathrm{g}^{-1} \mathrm{ZVM}$. This method of $\mathrm{NaCl}$ removal is investigated in the ZVM TP trials CSD1 and ZVM TPA trials E143, and E144 (Section 5).

The method of $\mathrm{NaCl}$ removal is considered in the context of established iron corrosion theory (Section 4.2).

\subsection{Pre-Treatment}

The relative effectiveness of a treatment process can be evaluated using a standardized measure of salinity reduction, $Q_{\mathrm{e}},\left(\mathrm{mgNaCl} \cdot\right.$ removed $\left.\cdot \mathrm{g}^{-1} \mathrm{ZVM}\right)$. The relative effectiveness of different pre-treatments (for similar sized ZVM particles) is demonstrated by the data in Table 1 and reference [6] to be:

$$
\left[\mathrm{H}_{2}+\mathrm{CH}_{4}+\mathrm{CO}+\mathrm{CO}_{2}+\mathrm{N}_{2}\right]>\left[\mathrm{N}_{2}\right]>[\text { air }]>\text { no pretreatment }
$$

The pre-treatment is designed to increase the amount of $\mathrm{NaCl}$ incorporated into the hydration shell of a Fe corrosion product during desalination.

Example Calculation of the Relative Efficiency of a Pre-Treatment: ST1a, MT2b

The rate of decline in salinity is a measure of the size of the facilities required to process a specific volume of water over a specific time period. For example, a reduction in the length of time taken to achieve a reduction of $x \mathrm{~g} \cdot \mathrm{L}^{-1}$ from 100 days to 20 days, allows:

1. The size of the desalination tanks (water bodies) required to be reduced by $80 \%$ (e.g., from 1000 to $200 \mathrm{~m}^{3}$ );

2. The land take required for the desalination tanks to be reduced from $100-500 \mathrm{~m}^{2}$ to $50-150 \mathrm{~m}^{2}$.

The EC declines associated with ZVM TP can be analysed in accordance with the methodology in Section F3, where $\left[a_{t+1}\right]$ is a normalized measure of the relative efficiency of the desalination process. $\left[a_{t+1}\right]$ increases with increasing desalination efficiency. This analysis, summarised in Table 2 and Figure 4 for example calculations using ST1a and MT2b, establishes:

1. The expected value of $\left[a_{t+1}\right]$ if the $Z \mathrm{VM}$ is used at a specific $P_{\mathrm{w}}$, without pre-treatment;

2. The expected value of $\left[a_{t+1}\right]$ following pre-treatment without considering water losses;

3. The expected value of $\left[a_{t+1}\right]$ following pre-treatment after consideration of water losses.

This analysis demonstrates the benefit of pre-treatment, and allows the effectiveness of different types of pre-treatment to be evaluated. In this example, a Type B pre-treatment is more effective than a Type C pre-treatment. 
Table 2. Assessed Impact of Pre-Treatment on the desalination rate using $\left[a_{t+1}\right]$ is an adjustable variable. Data: Figure $4 \mathrm{a}-\mathrm{d}$. Reference data set without pre-treatment: [6,21]: $a_{\mathrm{s}}=0.017 \mathrm{~m}^{2} \cdot \mathrm{g}^{-1}[6] ;$ Methodology: Appendix F3.

\begin{tabular}{|c|c|c|c|c|c|}
\hline \multirow{2}{*}{ Trial } & \multirow{2}{*}{$\begin{array}{c}\text { Expected } \\
\text { without } \\
\text { Pre-Treatment }\end{array}$} & $\begin{array}{c}\text { With } \\
\text { Pre-Treatment }\end{array}$ & \multirow{2}{*}{$\begin{array}{l}\text { Adjusted for } \\
\text { Water } \\
\text { Consumption }\end{array}$} & $\begin{array}{l}\text { Improvement Due } \\
\text { to Pre-Treatment }\end{array}$ & $\begin{array}{l}\text { Improvement Due } \\
\text { to Pre-Treatment }\end{array}$ \\
\hline & & Observed & & Observed & $\begin{array}{c}\text { Adjusted for Water } \\
\text { Consumption }\end{array}$ \\
\hline ST1a & 0.00020 & 0.12000 & 0.15000 & $60,000 \%$ & $75,000 \%$ \\
\hline MT2b & 0.00134 & 0.02000 & 0.10000 & $1498 \%$ & $7491 \%$ \\
\hline
\end{tabular}

The data required to calculate $\left[a_{t+1}\right]$ is:

1. The surface area, $a_{\mathrm{s}}$, and $P_{\mathrm{w}}$ of the ZVI used in the reference desalination data set using untreated ZVI (Sections 1.2.1 and 2.3.2 [21]);

2. The $a_{\mathrm{s}}$ and $P_{\mathrm{w}}$ of the ZVI used in the control desalination data using untreated ZVI (Section 2.3.2 [6]);

3. $Q_{\mathrm{e}}$ and $P_{\mathrm{w}}$ for the individual trial (Table 1, Figures C1-C16).

The desalination is associated with changes in Eh (Figures C5 and C14). Changes in Eh reflect changes in the rate of hydrolysis, where decreases in Eh represent increased hydrolysis, and increases in Eh represent reduced hydrolysis [67]. They indicate that $\mathrm{NaCl}$ removal is associated with the $\mathrm{OH}$ radical and related species (e.g., $\mathrm{HO}_{2}^{-}$) [67]. This is confirmed by the [ $\left.a_{t+1}\right]$ analysis in Table 2 where hydrolysis improves the effective $\mathrm{NaCl}$ removal efficiency of a Type $\mathrm{B}$ pre-treatment by $25 \%$, and a Type $\mathrm{C}$ pretreatment by $500 \%$.
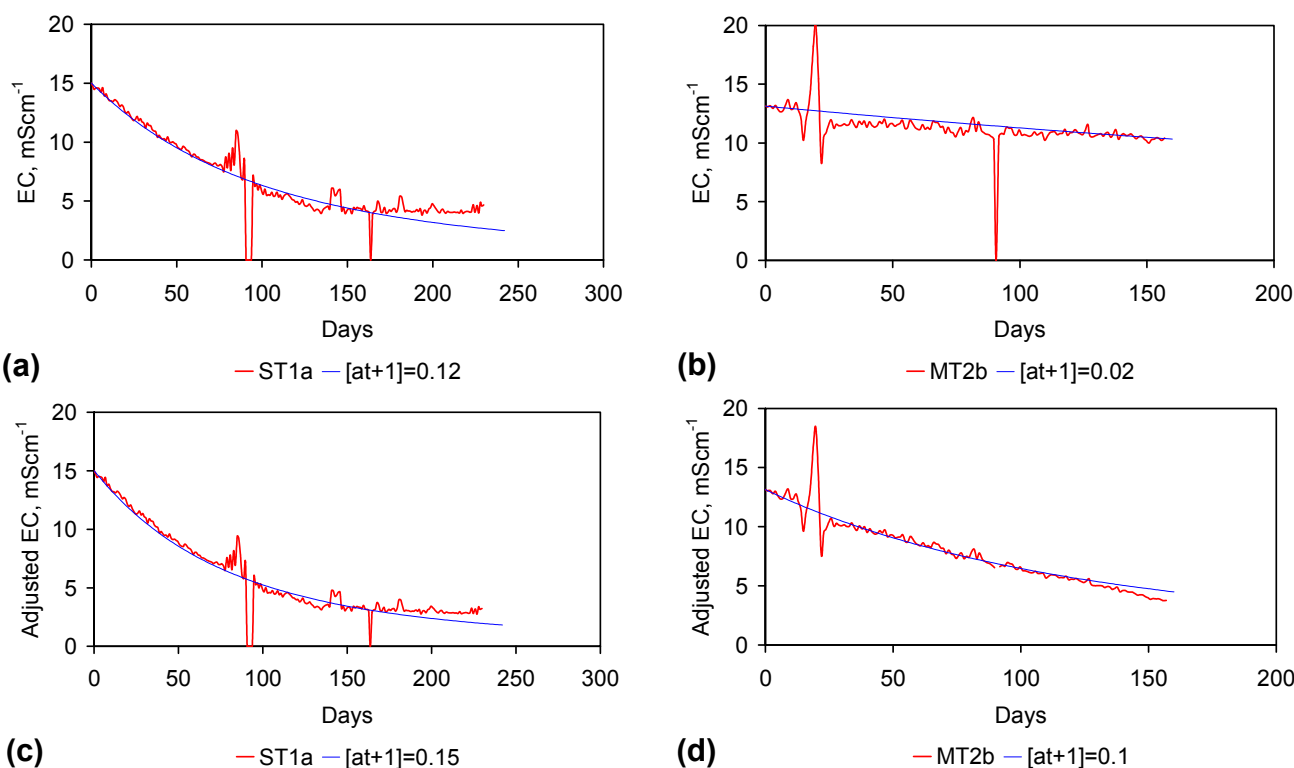

(c)

$-\mathrm{ST} 1 \mathrm{a}-[\mathrm{at}+1]=0.15$

(d)

$-\mathrm{MT} 2 \mathrm{~b}-[\mathrm{at}+1]=0.1$

Figure 4. Example EC changes vs. time. (a) ST1a; (b) MT2b; (c) ST1a, adjusted for water losses; (d) MT2b, adjusted for water losses. Spikes where the EC rises represent periods when the water was partially frozen. Spikes where the EC reduces to zero represent periods when the entire water body was frozen. Data: Figures C5 and C14. Methodology: Appendix F3. 
PS14 (Figure F1) used a Type A gaseous pre-treatment (Table D1). A $[a+t]$ analysis (Section F3), normalising the particle size in PS14, to the particle size used in ST1a, and setting a $P_{\mathrm{w}}$ of $20 \mathrm{~g} \cdot \mathrm{L}^{-1}$, indicates that PS14 would be expected to provide a $Q_{\mathrm{e}}$ of $346 \mathrm{mgNaCl} \cdot \mathrm{g}^{-1} \mathrm{ZVM}$ TP. Similar values of $Q_{e}$ are recorded for ST3b (Table 1) which was manufactured using a Type B pre-treatment. The Type A pre-treatment undertaken in a gaseous environment can be as effective as a Type B pre-treatment undertaken in an aqueous environment.

\subsection{Iron Corrosion in Saline Water}

The removal of $\mathrm{NaCl}$ is associated with ZVM TP corrosion. The rate of corrosion, the nature of the ZVM TP corrosion products, and the nature of the Eh and $\mathrm{pH}$ environment created by the ZVM TP controls the rate of desalination [18,19,67-100].

Two roles have been proposed for $\mathrm{Cl}^{-}$during iron corrosion, they are:

1. A role as a catalyser [68]: $\mathrm{Fe}^{0}+n \mathrm{Cl}^{-}=\mathrm{Fe}^{{ }^{+}} n \mathrm{Cl}^{-}+n \mathrm{e}^{-}$and $\mathrm{Fe}^{n+} n \mathrm{Cl}^{-}=\mathrm{Fe}^{n^{+}}+n \mathrm{Cl}^{-}$when the $\mathrm{Fe}^{0}$ is in direct contact with the saline water. This results in the release of $\mathrm{Fe}^{n^{+}}$ions into the water $[19,68]$.

2. A role as phase distributor [68]. As the surface rust $(\mathrm{FeOOH})$ species grows the $(-\mathrm{OH})$ groups on the surface of the rust change to $\left(-\mathrm{OH}_{2}\right)^{+}$groups. This both attracts $\mathrm{Cl}^{-}$ions and allows $\mathrm{Cl}^{-}$ ions to migrate through the rust to the metal surface [68].

Appendices F1, F2 and G consider the principal corrosion products associated with ZVM TP and ZVI in the Eh and pH environment created by the ZVM TP (Figures C1-C16).

\subsubsection{Pourbaix Relationships}

Eh and $\mathrm{pH}$ define the stable (equilibrium) phases of iron which will be present in the pore waters and ZVM TP body [19]. They also define the corrosion sequence that occurs [19]. Analysis of aqueous ion (and ion adduct) equilibrium using temperature, pressure, $\mathrm{pH}$ and $\mathrm{Eh}$ is termed a Pourbaix analysis [19]. For any aqueous reaction involving one or more of ions, ion adducts (precipitates) and gaseous species, a Pourbaix analysis defines [19] the equilibrium constant, $K$, the Reaction Quotient, $Q$, the Gibbs Free Energy, $G$, the heat of formation, $H$, and the enthalpy, $S$, associated with the reaction (Appendix F2). Therefore, if two or more reaction products are theoretically possible a Pourbaix analysis will identify which species is the equilibrium product [19]. A Pourbaix analysis will allow the equilibrium ion concentrations and gas partial pressures to be determined for a specific Eh and pH [19].

Iron, as it corrodes, adjusts the $\mathrm{Eh}$ and $\mathrm{pH}$ of the water with time $[5,6,18]$. The initial change is an increase in $\mathrm{pH}$ followed by a subsequent decrease in $\mathrm{pH}[5,6,18]$. The Eh either initially drops, or remains stable, before rising and then falling [5,6,18]. These changes are associated with the progressive formation in fresh water of [19]:

$$
\mathrm{Fe}^{0} \rightarrow \mathrm{Fe}(\mathrm{OH})_{2} \rightarrow \mathrm{FeOOH}
$$

The Eh and $\mathrm{pH}$ at any moment in time defines [19] the equibrium constants for $\mathrm{Fe}(\mathrm{OH})_{2}$ and $\mathrm{FeOOH}$. During periods when Eh and pH are constantly changing (e.g., Figures C1-C17 and C19-C36) the water is in disequilibria [19]. Once the $\mathrm{Eh}$ and $\mathrm{pH}$ values achieve a stable level (at a 
constant temperature and pressure (e.g., Figures $\mathrm{C} 1-\mathrm{C} 17$ and $\mathrm{C} 19-\mathrm{C} 36)$ ) the water is in a chemical equilibrium [19].

Eh, $\mathrm{pH}$ relationships do not define reaction rates (though the rate of change and direction of change is a reflection of underlying reaction rates) [19]. They do define the equilibrium product species and where two, or more, species can occur, the equilibrium molar ratios between the products [19].

A byproduct of iron corrosion is the removal and consumption of water [19]. Water removal was observed in the trials associated with both ZVM TP and ZVM TPA (Appendix C). The principle reactions are [19]:

$$
\begin{gathered}
\mathrm{Fe}^{0} \rightarrow \mathrm{Fe}^{n^{+}}+n \mathrm{e}^{-} \\
\mathrm{H}_{2} \mathrm{O}=\mathrm{H}^{+}+\mathrm{OH}^{-}
\end{gathered}
$$

The rate of water ionisation is higher than the rate of iron ionisation [19] and the amount (wt) of water removed can exceed the weight of Fe placed in the reaction environment (e.g., Table 1, Appendix C).

\subsection{2. $\mathrm{Fe}^{0}$ Corrosion Series}

The established redox $(\mathrm{Eh}, \mathrm{pH})$ boundaries for the stable phases of iron [19,69-75] in saline water are shown in Figure 5a. The stable equilibrium species are $\mathrm{Fe}^{0}, \mathrm{Fe}^{2+}$ ions, $\mathrm{Fe}(\mathrm{OH})_{2}$, Green Rust One (GR1, GR:Cl), and FeOOH. During corrosion (oxidation), the sequential reaction series in saline water which is free of sulphates and bicarbonates/carbonates is [19,69-75]:

$$
\mathrm{Fe}^{0} \rightarrow \mathrm{Fe}(\mathrm{OH})_{2} \rightarrow \mathrm{GR} 1\left(\mathrm{Cl}^{-}\right) \rightarrow \mathrm{FeOOH}
$$

The GR1 either [43-49]:

1. transforms directly to $\beta-\mathrm{FeOOH}$ (akaganeite), or,

2. adopts the reaction series, GR1 $\rightarrow \alpha-\mathrm{FeOOH}$ (goethite) $\rightarrow \beta-\mathrm{FeOOH}$, or,

3. adopts the reaction series GR $1 \rightarrow \gamma-\mathrm{FeOOH}$ (lepidocrocite) $\rightarrow \alpha-\mathrm{FeOOH} \rightarrow \beta-\mathrm{FeOOH}$

In the presence of sulphate the corrosion reaction series is:

$$
\begin{gathered}
\mathrm{Fe}^{0} \rightarrow \mathrm{Fe}(\mathrm{OH})_{2} \rightarrow \mathrm{GR} 1\left(\mathrm{Cl}^{-}\right) \rightarrow \mathrm{GR} 1\left(\mathrm{SO}_{3}{ }^{2-}\right) \rightarrow \mathrm{GR} 2\left(\mathrm{SO}_{4}{ }^{2-}\right) \rightarrow \\
\mathrm{FeOOH}(\gamma-\mathrm{FeOOH} \text { and } / \text { or } \alpha-\mathrm{FeOOH})
\end{gathered}
$$

In the presence of carbonate/bicarbonate the corrosion reaction series is:

$$
\mathrm{Fe}^{0} \rightarrow \mathrm{Fe}(\mathrm{OH})_{2} \rightarrow \mathrm{GR} 1\left(\mathrm{Cl}^{-}\right) \rightarrow \mathrm{GR} 1\left(\mathrm{CO}_{3}{ }^{2-}\right) \rightarrow \mathrm{FeOOH}(\gamma-\mathrm{FeOOH} \text { and } / \text { or } \alpha-\mathrm{FeOOH})
$$

The corrosion of $\mathrm{Fe}^{0}$ in the presence of sulphate, carbonate, and bicarbonate is addressed in Section 6.

The trials analysed in Sections 4 and 5 were operated in saline water containing $<11 \mathrm{mgSO}_{4}{ }^{2-} \cdot \mathrm{L}^{-1}$ (Table $\mathrm{C} 1$ ) and $<100 \mathrm{mgHCO}_{3}{ }^{-} \cdot \mathrm{L}^{-1}$.

The corrosion of $\mathrm{Fe}^{0}$ to $\mathrm{FeOOH}$ produces adsorbed hydrogen $\left(\mathrm{Fe}+2 \mathrm{H}_{2} \mathrm{O}=\mathrm{FeOOH}+3 \mathrm{H}^{+}+3 \mathrm{e}^{-}\right)[19]$. The adsorbed hydrogen can interact with $\mathrm{Fe}^{\mathrm{n}+}$ ions at the $\mathrm{FeOOH}-$ water boundary to initiate the templated growth of GR1 growing from a FeOOH corroded ZVM particle (Figure F1) [69-75]:

$$
\mathrm{FeOOH} \rightarrow \mathrm{GR} 1\left(\mathrm{Cl}^{-}\right) \rightarrow \mathrm{FeOOH}
$$


Excess $\mathrm{H}_{2}$ (gas) formed as $2 \mathrm{H}^{+}+2 \mathrm{e}^{-}=\mathrm{H}_{2}$ [19], can form small trapped accumulations of hydrogen [5,18] within the pore space of the ZVM TP (e.g., Figure F1). This hydrogen interacts with the $\mathrm{FeOOH}$ corrosion products to produce $\mathrm{Fe}_{3} \mathrm{O}_{4}$ (e.g., Figure F1) $[19,83]$ :

$$
3 \mathrm{FeOOH}+0.5 \mathrm{H}_{2} \rightarrow \mathrm{Fe}_{3} \mathrm{O}_{4}+2 \mathrm{H}_{2} \mathrm{O}
$$

The corrosion environment associated with both iron corrosion and desalination is complex and dynamic. The trials documented in Figures $\mathrm{C} 1-\mathrm{C} 16$ used water which contained trace quantities of sulphates (Table $\mathrm{C} 1$ ) and bicarbonates/carbonates.

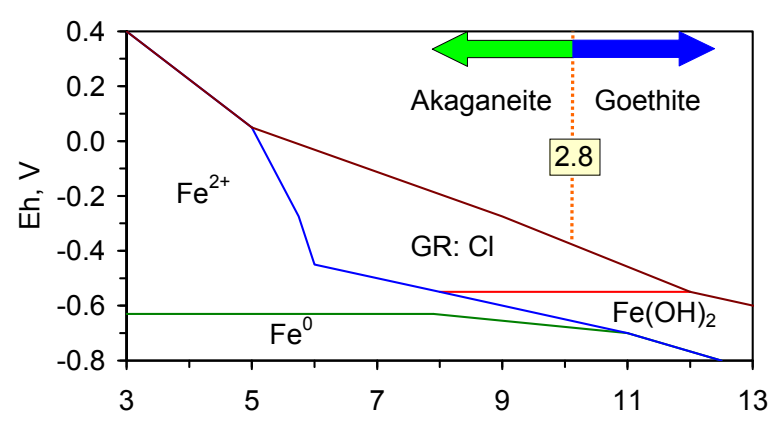

(a)

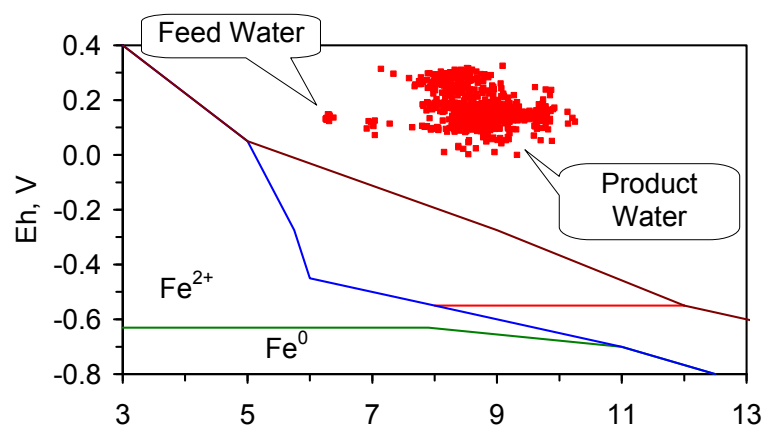

(c)

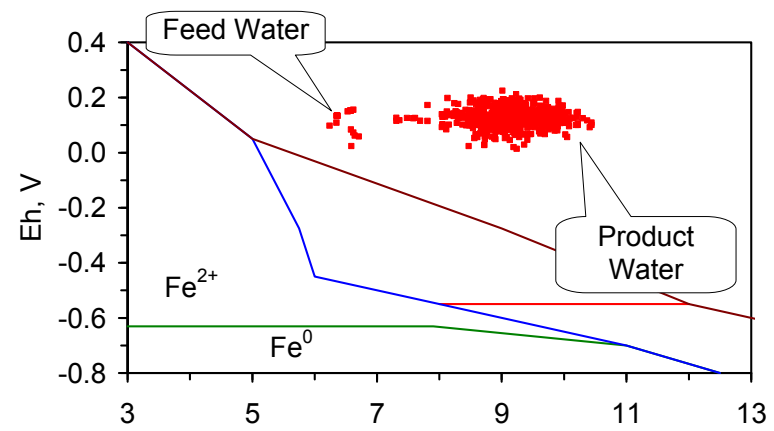

(e)

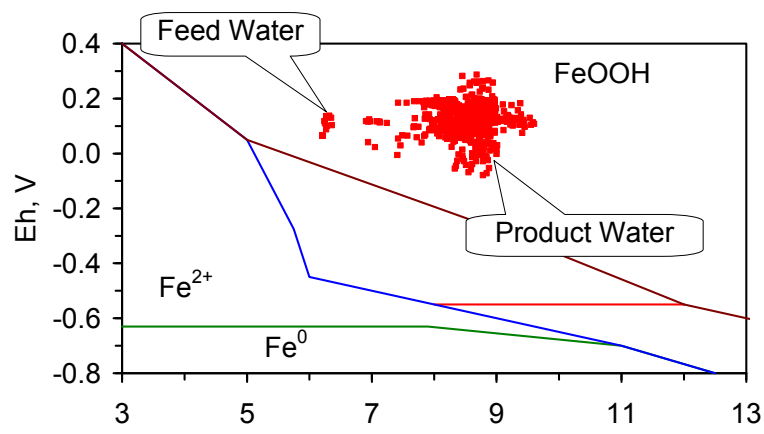

(b)

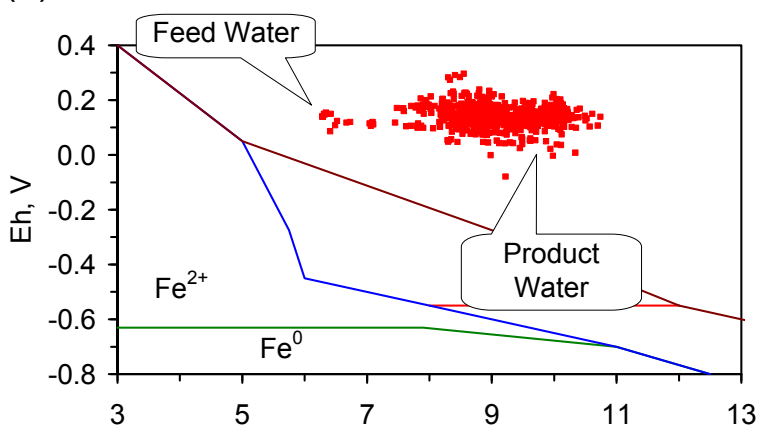

(d)

$\mathrm{pH}$

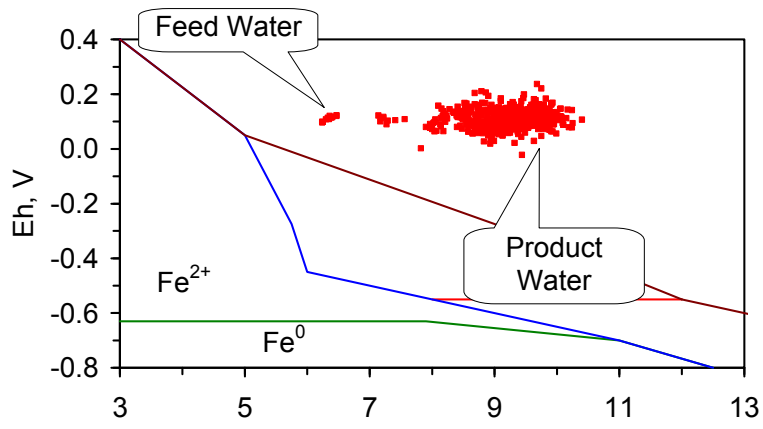

(f)

$\mathrm{pH}$

Figure 5. Eh vs. $\mathrm{pH}$ for the ST1 to ST5 series of ZVM TP trials (Figures C5-C9). (a) Pourbaix diagram identifying the dominant Fe species phase as a function of Eh and $\mathrm{pH}[19,69-75] . \mathrm{GR}=$ green rust. $2.8=2.8 \mathrm{mgCl}^{-} \cdot \mathrm{L}^{-1}$ for $R=8$; (b) ST1; (c) ST2; (d) ST3; (e) ST4; (f) ST5. Increasing the concentration of $\mathrm{Cl}^{-}$(salinity) increases the $\mathrm{pH}$ required to achieve $R=8$, and increases the $\mathrm{pH}$ range where akaganeite is the dominant $\mathrm{FeOOH}$ corrosion species. Data taken for the time period between the date the ZVM TP was added to the water to the date the partial freezing event identified in Figures C5-C9. This is to demonstrate the Eh vs. $\mathrm{pH}$ redox regime during the principal desalination phase. 


\subsubsection{Transformation from $\alpha-\mathrm{FeOOH} \rightarrow \beta-\mathrm{FeOOH}$}

The transformation from $\alpha-\mathrm{FeOOH} \rightarrow \beta-\mathrm{FeOOH}$ is a function of the $\mathrm{pH}$ and $\mathrm{Cl}^{-}$concentration in the water [69-71]. The molar ratio, $R, \log \left(\mathrm{Cl}^{-} / \mathrm{OH}^{-}\right)$in the feed water has been proven to be an accurate predictor of the dominant (equilibrium) precipitated $\mathrm{FeOOH}$ species [69-71]. These studies have established that when:

$1 \quad R \leq 1.16$ the only equilibrium $\mathrm{FeOOH}$ species which will be present is $\alpha-\mathrm{FeOOH}$ [69-71].

$21.16<R<2.25$, then the observed equilibrium $\mathrm{FeOOH}$ will contain $\alpha-\mathrm{FeOOH}+\beta-\mathrm{FeOOH}[69,70]$.

$32.25<R<8$, the stable equilibrium $\mathrm{FeOOH}$ species is $\beta$-FeOOH [69-71]

$4 \quad R \geq 8$, the only equilibrium $\mathrm{FeOOH}$ species which will be present is $\beta$-FeOOH [71].

The transformation from $\alpha-\mathrm{FeOOH} \rightarrow \beta-\mathrm{FeOOH}$ is not instantaneous, therefore analyses of $\mathrm{FeOOH}$ species prior to equilibrium being achieved may show the presence of $\alpha-\mathrm{FeOOH}$.

At a $\mathrm{pH}$ of $10, R=8$ corresponds to a $\mathrm{Cl}^{-}$concentration of $2.8 \mathrm{mgCl}-\mathrm{L}^{-1}\left(4.5 \mathrm{mgNaCl} \cdot \mathrm{L}^{-1}\right)$ (Figure 5a). In all the examples (ZVM TP and ZVM TPA) considered in this study (Figures C1-C17, C19-C36 and D1-D6), $R$ is greater than 8 , when the water $\mathrm{pH}<13$.

\subsubsection{Dominant Corrosion Species Associated with ZVM TP}

The Eh vs. pH cross plots (Figure 5) from 50 trials (ST1a to ST5j) indicate that the water chemistry throughout the trials was in the $\mathrm{FeOOH}$ precipitation zone [19]. The dominant Fe corrosion product surrounding the $\mathrm{Fe}^{0}$ core will be $\mathrm{FeOOH}$ [19]. $R>8$, therefore any entrained n-Fe particles will be $\beta-\mathrm{FeOOH}[19,69-71]$. Similar Eh, $\mathrm{pH}$ observations were made in the trials documented in Figures $\mathrm{C} 1-\mathrm{C} 4$, C10-C17 and C19-C36.

The corrosion product reaction sequences result in a series of concentric halos of different corrosion products surrounding the $\mathrm{Fe}^{0}$ particle core [68]. Example halos associated with ZVM TP are illustrated in Figure F1. In this example the initial particle corrosion results in a structure where an $\mathrm{Fe}^{0}$ core is surrounded by $\mathrm{Fe}(\mathrm{OH})_{2}$ and the $\mathrm{Fe}(\mathrm{OH})_{2}$ is then surrounded by $\beta$-FeOOH (e.g., Figure $\mathrm{F} 1$ ). The $\beta-\mathrm{FeOOH}$ acts as a template for the growth of Schiller sheets of GR1. These are transformed at their margins to $\beta$ FeOOH (e.g., Figure F1) [76,77,87,88]. Figure F1 demonstrates the presence of, and growth of, spherulitic, amorphous, entrained particles of $\beta-\mathrm{FeOOH}$. These particles display the characteristic colour of $\beta$-FeOOH (Figure F1). The margins of the Schiller sheets have a purple colour (Figure F1). This colour is a characteristic of $\mathrm{Na}$ incorporation in the lattice (see Appendix $\mathrm{H}$ ).

This corrosion structuring in saline water is demonstrated for ZVM TP (PS14) with a $Q_{\text {e }}$ of $77.83 \mathrm{mg} \cdot \mathrm{L}^{-1}$ (Table 1) in Figure F1. This demonstrates that desalination is part of the normal corrosion process.

\subsubsection{NaCl Removal in the Hydrated Layers Surrounding ZVM TP}

The Pourbaix analysis [19,69-75] has established that desalination is associated with green rust and FeOOH corrosion species. Figure F1 demonstrates incorporation of $\mathrm{Cl}^{-}$ions into entrained amorphous $\beta$-FeOOH and incorporation of $\mathrm{Na}^{+}$ions into $\mathrm{Fe}^{\mathrm{III}}$ species associated with growing Schiller sheets within a ZVM TP body. Incorporation into these species is unable to account for the high levels 
of $\mathrm{NaCl}$ removal (e.g., PS14 (Table 1, Figure F1) $Q_{\mathrm{e}}=77.83 \mathrm{mg} \cdot \mathrm{g}^{-1}$ ) observed (Table 1, Figures $\mathrm{C} 1-\mathrm{C} 16)$. The removed $\mathrm{NaCl}$ is located principally in the hydration shells associated with $\mathrm{ZVM}$ TP and its corrosion products $[87,88,96]$.

The hydrated shells surrounding $\mathrm{FeOOH}$ can remove $\mathrm{NaCl}$ by adsorption [78-80] or by concentration in the pore water within the ZVM body, surrounding the ZVM particles (e.g., Figure D1).

Analysis of ZVM TP will be expected (e.g., Figure F1) to contain a mixture of $\mathrm{Fe}^{0}, \mathrm{Fe}^{\mathrm{II}}$ and $\mathrm{Fe}^{\mathrm{III}}$ species. The entrained $\mathrm{Fe}^{\mathrm{III}}$ species will be expected to contain a mixture of $\gamma-\mathrm{FeOOH}$, $\alpha$-FeOOH, $\beta$-FeOOH.

\subsubsection{Identification of $\mathrm{FeOOH}$ or Other Fe Species Involved in $\mathrm{NaCl}$ Removal}

Fe corrosion species have been identified from solid material using a number of different techniques including: Raman spectroscopy; X-Ray diffraction (XRD), Differential scanning calorimetry, FTIR, UV-Visible spectroscopy, fluorospectroscopy, vibrating sample magnetometry, electron paramagentic resonance, optical analyses, Mossbauer, Synchron X-ray powder analyses etc. Entrained Fe corrosion products in aqueous solutions are commonly identified using UV-Visible-NIR Spectroscopy. The identification of specific species in aqueous solution is addressed in Appendix $\mathrm{H}$.

Figure F1 clearly illustrates the problem of using a tool such as XRD to analyse the corrosion products. This problem arises as a number of different species are present which represent different stages in the corrosion process and different products in each of the different micro-environments contained in the ZVM TP.

The use of Fe derived from carbon steel in this study results in the characteristic XRD pattern for $\beta-\mathrm{FeOOH}$ changing in the presence of carbon from having dominant peaks (CPS) at 2-Theta of $11.90^{\circ}$ (110), $26.77^{\circ}(310), 33.94^{\circ}(400)$, and minor peaks at $16.92^{\circ}(200), 35.20^{\circ}(211), 39.31^{\circ}$ (301) [80-82], to a dominant peak at $26.65^{\circ}$ and a minor peak at $35.31^{\circ}$ [80]. The other peaks are either absent or within the noise range of the spectra [80]. The numbers in brackets refer to crystal faces. The $\mathrm{FeOOH}$ peaks are labeled and indexed to a tetragonal FeOOH phase (JCPDS File No. 34-1266) [81,82]. Highly hydrated amorphous green rust, $\gamma-\mathrm{FeOOH}, \alpha-\mathrm{FeOOH}, \beta-\mathrm{FeOOH}$ have either no XRD peaks, or very subdued peaks. The presence of other species such as carbon, further complicates the interpretation of the traces.

XRD analyses, and similar analyses, are suited to analyses associated with incorporation of $\mathrm{Na}$ and $\mathrm{Cl}$ in the crystal lattices. They are not suitable for the analysis of ions contained within the hydration shells of the crystallites. In these circumstances, the most reliable identification tool for the entrained FeOOH species is UV-Visible-NIR spectrography, which is used in this study.

The concentration of these entrained $n$-Fe corrosion species in the product water body associated with ZVM TP was less than $0.05 \mathrm{mg} \cdot \mathrm{L}^{-1}$ in the product water. This is demonstrated in Table $\mathrm{C} 2$.

The reference standard UV-Visible-NIR spectra for GR1 $\left(\mathrm{Cl}^{-}\right)$, GR2 $\left(\mathrm{SO}_{4}{ }^{2-}\right)$, hematite, $\gamma-\mathrm{FeOOH}, \alpha-$ $\mathrm{FeOOH}, \beta-\mathrm{FeOOH}$ (including hydrated polyionic $\beta$-FeOOH) are provided in Table 3 . Hydrated polyionic $\beta-\mathrm{FeOOH}$ demonstrates a dominant absorption peaks at $225 / 8 \mathrm{~nm}$. Minor peaks may be present at 350 and $500 \mathrm{~nm}$, but are commonly absent. 
Table 3. UV-Visible Spectral Bands Associated with GR1, GR2 and associated iron corrosion species. Data: [90,92,101-107].

\begin{tabular}{|c|c|c|c|c|c|c|c|c|c|c|}
\hline Species & $\begin{array}{c}\text { Hydrated Ligand } \\
\text { Field Transition } \\
\qquad \mathbf{F e}^{3+}\end{array}$ & $\begin{array}{c}\text { Ligand Field } \\
\text { Transition } \mathbf{F e}^{3+}\end{array}$ & $\begin{array}{c}\text { Ligand Field } \\
\text { Transition } \\
\mathbf{F e}^{3+}\end{array}$ & $\begin{array}{c}\text { Ligand Field } \\
\text { Transition } \mathbf{F e}^{3+}\end{array}$ & $\begin{array}{c}\text { Excitation to an } \\
\text { Fe-Fe Pair }\end{array}$ & $\begin{array}{c}\mathrm{Fe}(\mathrm{II})-\mathrm{Fe}(\mathrm{III}) \\
\text { Intervalence and } \\
\mathrm{Fe}(\mathrm{III}) \text { Absorption }\end{array}$ & $\begin{array}{c}\mathrm{Fe}(\mathrm{II})- \\
\mathrm{Fe}(\mathrm{III}) \\
\text { Intervalence }\end{array}$ & $\begin{array}{l}\text { Excitation to } \\
\text { an Fe-Fe Pair }\end{array}$ & $\begin{array}{l}\text { Excitation to } \\
\text { an Fe-Fe Pair }\end{array}$ & $\begin{array}{c}\text { Excitation to } \\
\text { an Fe-Fe } \\
\text { Pair }\end{array}$ \\
\hline Hematite & - & 300 & 370 & 430 & 485 & - & - & 555 & - & 900 \\
\hline Ferrate & - & - & - & 450 & & - & - & 550 & 800 & - \\
\hline $\begin{array}{l}\text { Akaganeite } \\
\text { (hydrated) }\end{array}$ & 225 & - & 350 & - & 500 & - & - & - & - & - \\
\hline $\begin{array}{c}\text { Akaganeite } \\
\text { (low hydration) }\end{array}$ & - & - & - & - & 500 & - & - & - & - & - \\
\hline Goethite & - & 300 & - & 450 & - & - & - & 590 & 760 & 910 \\
\hline Lepidocrocite & - & 300 & 350 & 420 & 485 & - & - & - & - & - \\
\hline $\mathrm{GR} 2-\mathrm{SO}_{4}$ & - & - & 320 & 410 & - & 550 & 690 & - & - & - \\
\hline GR1-Cl & - & - & 350 & 485 & - & 550 & 690 & - & - & - \\
\hline
\end{tabular}


The major difference in spectral behaviour between the different FeOOH species (see Section 5, and Table 3 allows UV-Visible-NIR spectra to be used (Figure C37, Appendix H) to provide a first level identification of the dominant entrained $\mathrm{Fe}^{\mathrm{III}}$ corrosion species within the water. The spectra (Figure C37) identified hydrated polyionic $\beta-\mathrm{FeOOH}$ as the dominant entrained species. Both $\alpha-\mathrm{FeOOH}$ and ferrate were identified as minor entrained Fe corrosion species (Figure C37).

FeOOH species have a high capacitance, and are widely used as adsorbant and catalytic material [80].

These observations identify two areas of investigation which may assist in increasing $Q_{\mathrm{e}}$. They are an analysis of $\mathrm{pH}$ and an analysis of the parameters associated with capacitance (e.g., voltage, current, surface charge).

\subsubsection{Significance of $\mathrm{pH}$ Change}

Desalination is associated with an initial increase in $\mathrm{pH}$, followed by a gradual decline in $\mathrm{pH}$ to an equilibrium or constant level (Figures $\mathrm{C} 1-\mathrm{C} 17$ ). The decrease in $\mathrm{pH}$ results in:

1. An increase in surface protonation $\left(\mathrm{H}^{+},\left(-\mathrm{OH}_{2}\right)^{+}\right)$, with an increase in $\mathrm{Cl}^{-}$ions adsorbed on the FeOOH surface [84].

2. The competition between $\mathrm{Cl}^{-}$ions and $\mathrm{OH}^{-}$ions for the protonated sites decreasing due to both a decreased relative availability of $\mathrm{OH}^{-}$and increased surface protonation resulting in an increase in the number of available adsorption sites [84].

3. The replacement of blocking $\mathrm{OH}^{-}$ions and $\mathrm{H}_{2} \mathrm{O}$ at the entrances to tunnels within the $\beta-\mathrm{FeOOH}$ by $\mathrm{Cl}^{-}$ions [84].

The change in $\mathrm{Cl}^{-}$resulting from incorporation in the $\mathrm{Fe}$ corrosion products, as the $\mathrm{pH}$ changes, can be assessed from the equation: $\mu \mathrm{mol} \cdot \mathrm{Cl}^{-} \cdot \mathrm{m}^{-2} \mathrm{FeOOH}=0.0375 \mathrm{pH}^{2}-0.75 \mathrm{pH}+3.7125$ [84].

Adsorption of ions from water by $\mathrm{FeOOH}$ increases as the FeOOH surface charge increases [84].

\subsubsection{Significance of Water Consumption}

The water consumption rates increased as:

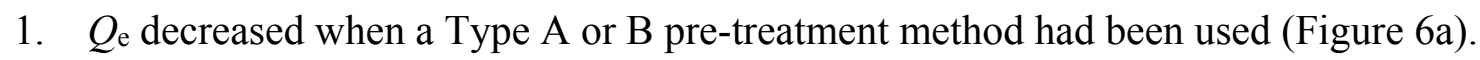

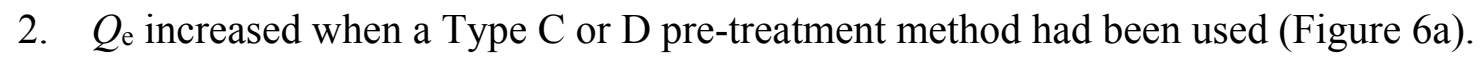

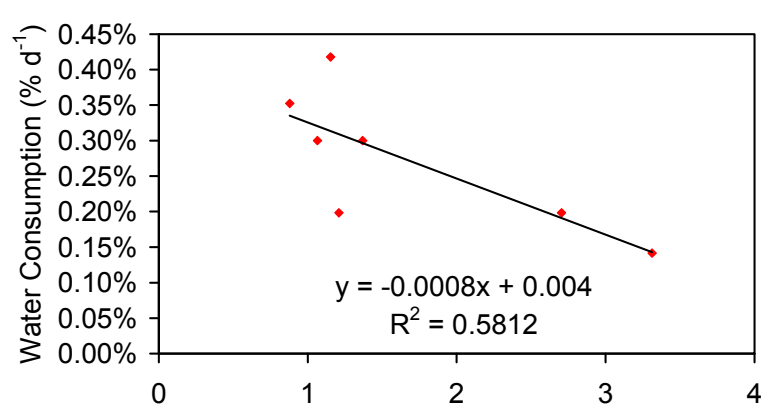

(a)

$\mathrm{Q}_{\mathrm{e}}\left(\mathrm{mg} \mathrm{NaCl} \mathrm{g}^{-1}\right.$ ZVM TP d $\left.^{-1}\right)$

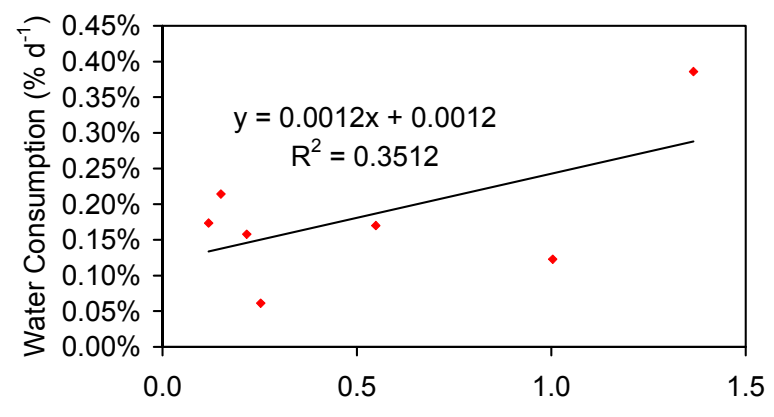

(b)

Figure 6. Water consumption vs. $Q_{\text {e. }}$ (a) Type A + B Pre-treatment; (b) Type C + D Pre-treatment. Data: Table 1. 
This demonstrates that the Type C pre-treatment, or D pre-treatment methods create a ZVM TP product which increasingly removes $\mathrm{NaCl}$ as the surface charge increases, while a Type A pre-treatment or B pre-treatment method creates a ZVM TP product which replaces water consumption with $\mathrm{NaCl}$ consumption in the Fe corrosion products. These observations demonstrate that the removed $\mathrm{NaCl}$ is concentrated in the hydration shells of the Fe corrosion products.

\subsubsection{Significance of Surface Charge}

The surface charge on $\mathrm{FeOOH}$ increases with increasing $\mathrm{NaCl}$ concentration and decreasing $\mathrm{pH}[58,59]$. Adsorption on the $\mathrm{FeOOH}$ proton active site $\mathrm{FeOH}^{0.5-}$ takes the form [85]

1. Protonation: $\mathrm{FeOH}^{0.5-}+\mathrm{H}^{+}=\mathrm{FeOH}_{2}{ }^{0.5+}$;

2. $\mathrm{Cl}^{-}$capture: $\mathrm{FeOH}_{2}{ }^{0.5+}+\mathrm{Cl}^{-}=\left[\left(\mathrm{FeOH}_{2}{ }^{0.5+}\right)\left(\mathrm{Cl}^{-}\right)\right]$;

3. $\mathrm{Na}^{+}$capture: $\mathrm{FeOH}^{0.5-}+\mathrm{Na}^{+}=\left[\left(\mathrm{FeOH}^{0.5-}\right)\left(\mathrm{Na}^{+}\right)\right]$.

The highest concentrations of the $\mathrm{Cl}^{-}$ions associated with the $\beta$-FeOOH crystallites, are held within 0.25 and $0.4 \mathrm{~nm}$ of an $-\mathrm{OH}_{2}{ }^{+}$site $[85,96]$, while the highest concentrations of the $\mathrm{Na}^{+}$ions are held with 0.05 and $0.1 \mathrm{~nm}$ of the $-\mathrm{OH}$ site $[85,96]$. Both $\mathrm{Cl}^{-}$and $\mathrm{Na}^{+}$ions are also held in the hydrated shell around the crystallite $[85,96]$.

The relative ratio, $R_{\mathrm{A}}$, of active $\mathrm{FeOH}_{2}{ }^{0.5+}: \mathrm{FeOH}^{0.5-}$ sites, is demonstrated by the cation $\left(\mathrm{Na}^{+}+\mathrm{K}^{+}\right)$ and anion $\left(\mathrm{Cl}^{-}\right)$removal analyses (Tables $\mathrm{C} 1$ and $\mathrm{C} 2$ ). $R_{\mathrm{A}}$ approximates 1.0 for most desalination examples (Figure 7) where $R_{\mathrm{A}}=$ Moles $\left[\mathrm{Na}^{+}+\mathrm{K}^{+}\right]$Removed/Moles $\mathrm{Cl}^{-}$Removed.

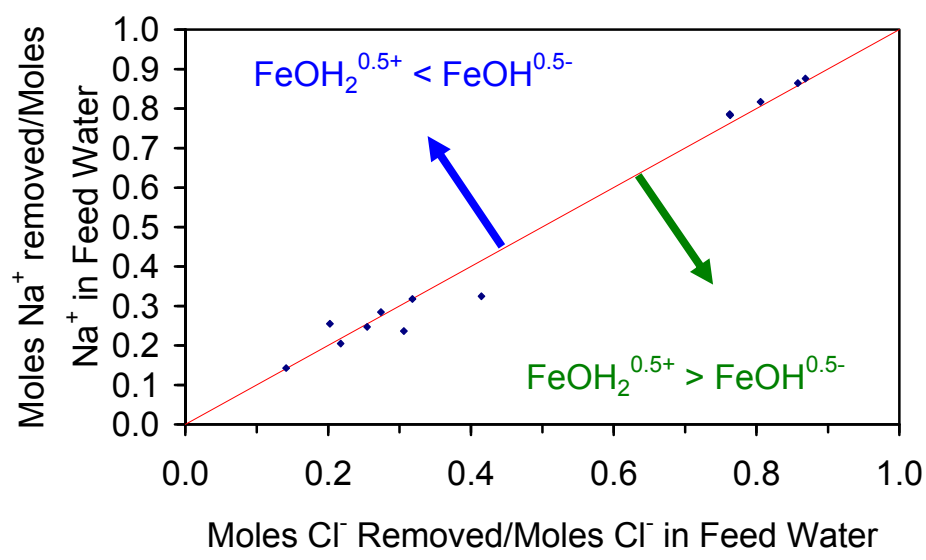

Figure 7. Relative removal ratios associated with $\mathrm{Cl}^{-}$and $\mathrm{Na}^{+}$ions in saline water. Data: Tables $\mathrm{C} 1$ and $\mathrm{C} 2$.

\subsubsection{Recovery of Adsorbed $\mathrm{NaCl}$ from ZVM TP}

The adsorbed $\left[\mathrm{Na}^{+}+\mathrm{K}^{+}+\mathrm{Cl}^{-}\right]$can be recovered from the hydration shells by:

1. Increasing $\mathrm{pH}$ and reducing the surface charge. This releases adsorbed products associated with $\mathrm{FeOOH}[86]$.

2. Extensive washing of $\beta-\mathrm{FeOOH}$. This removes incorporated $\mathrm{Cl}^{-}$ions and $\mathrm{Cl}^{-}$ions held in the hydration shells $[87,88]$. 
3. Actively discharging the capacitance charge held in the FeOOH. This removes incorporated $\mathrm{Na}^{+}$ ions (and adsorbed $\mathrm{Na}^{+}$ions held in the hydration shell) [89].

These observations demonstrate that it is possible to:

1. recover the $\mathrm{Na}^{+}$and $\mathrm{Cl}^{-}$ions separately from the used ZVM TP;

2. recover the charge held in the ZVM TP following desalination;

3. regenerate the ZVM TP for reuse following desalination.

Regeneration can involve reduction to $\mathrm{Fe}^{0}$, or changing the dominant $\mathrm{Fe}$ corrosion species within the recovered ZVM TP to facilitate corrosion via GR1 to FeOOH, or change the density and structure of active sites on the ZVM TP, or changes to the capacitance structure of the ZVM TP to facilitate removal of $\mathrm{NaCl}$.

\subsection{Removal of $\mathrm{NaCl}$ from Water in the Hydration Shells}

$\mathrm{NaCl}$ removal is related to: $\mathrm{pH}, Q_{e}$, water consumption, surface charge and capacitance. $\mathrm{NaCl}$ removal in hydration shells can be analysed using an adsorption model (e.g., Langmuir, Freudlich, and Redlich-Peterson) [78-80]:

$$
\begin{gathered}
\text { Langmuir: } Q_{\mathrm{e}}=\left[Q_{\max } K_{\mathrm{L}} C_{\mathrm{e}}\right] /\left[1+K_{\mathrm{L}} C_{\mathrm{e}}\right] \\
\text { Freudlich: } Q_{\mathrm{e}}=K_{\mathrm{F}} C_{\mathrm{e}}{ }^{1 / n} \\
\text { Redlich-Peterson: } Q_{\mathrm{e}}=\left[\mathrm{A} C_{\mathrm{e}}\right] /\left[1+\mathrm{B} C_{\mathrm{e}^{\mathrm{g}}}\right] \\
Q_{\mathrm{e}}(\mathrm{mg} / \mathrm{g})=\left[\left(C_{0}-C_{e}\right) V\right] / m=V\left[\left(C_{0}-C_{\mathrm{e}}\right) / m\right] K_{\mathrm{R}}=1 /\left[1+K_{\mathrm{L}} C_{0}\right] \\
\text { Removal Efficiency }(\%)=100-100 C_{\mathrm{e}} / C_{0}
\end{gathered}
$$

where $Q_{\mathrm{e}}=$ the quantity of $\mathrm{NaCl}$ absorbed per unit weight of solid absorbent at equilibrium; $Q_{\max }=$ the maximum quantity of $\mathrm{NaCl}$ which could be absorbed per unit weight of solid absorbent; $K_{\mathrm{L}}=$ the Langmuir adsorption equilibrium constant, $\mathrm{L} \cdot \mathrm{mg}^{-1} ; K_{\mathrm{F}}=$ the amount adsorbed at unit concentration (i.e., $1 \mathrm{mg} \cdot \mathrm{L}^{-1}$ ); $n=$ adsorption intensity, $1 / n<1.0 ; C_{0}=$ The initial concentration of the solute $(\mathrm{NaCl})$ in the water, $\mathrm{mg} \cdot \mathrm{L}^{-1} ; C_{\mathrm{e}}=$ The equilibrium concentration of the solute $(\mathrm{NaCl})$ in the water, $\mathrm{mg} \cdot \mathrm{L}^{-1} ; V=$ volume of the adsorbate, $\mathrm{L} ; m=$ mass of the adsorbent, $\mathrm{g} \cdot \mathrm{L}^{-1} ; \mathrm{A}, \mathrm{B}$ and $\mathrm{g}$ (where $0<\mathrm{g}<1$ ) are constants. $K_{\mathrm{R}}=$ dimensionless separation (or equilibrium) factor. $K_{\mathrm{R}}$ indicates the shape of the isotherm, where $K_{\mathrm{R}}>1$, is unfavorable; $K_{\mathrm{R}}=1$, is linear; $0<K_{\mathrm{R}}<1$, is favorable; $K_{\mathrm{R}}=0$, is irreversible [79]. Adsorption on $\beta$-FeOOH can decrease with increasing temperature [78], though $K_{\mathrm{R}}$ commonly decreases with increasing temperature [79].

An adsorption isotherm results in a general decline in the rate of adsorption (as absorbent sites $\left[a_{\mathrm{a}}\right]$ are utilized) until the adsorbent is saturated. At that point adsorption ceases or proceeds at a reduced rate. This pattern of EC decline is observed in Figures C1-C17.

\subsubsection{Characteristics of $\mathrm{NaCl}$ Removal by Adsorption in the Hydration Shells}

Pre-treatment Type B trials, ST1a to ST5j (Figures C5-C9), established that, $Q_{\mathrm{e}}$ :

1. is not influenced (Figure $8 \mathrm{a}$ ) by the initial $\mathrm{NaCl}$ concentration;

2. is influenced by the concentration of ZVM TP in the water (Figure 8b);

3. increases with decreasing $\mathrm{pH}$ (Figure 8c,d); 
4. is not influenced by changes in Eh (Figure 8g,h).

The EC, Eh and pH in each example (Figures C5-C9) were stable during the last 50 days of each trial. This demonstrated [19] that a stable chemical equilibrium position had been reached in the reaction environment. The final $\mathrm{Eh}$ and $\mathrm{pH}$ measurements made in each trial were representative of these equilibrium conditions. The term equilibrium is used in Figure 8 to refer to this $\mathrm{Eh}$, or $\mathrm{pH}$, in the final equilibrium phase of operation (See Section F2 for further analysis). The term maximum $\mathrm{pH}$ refers to the maximum $\mathrm{pH}$ recorded in Figures $\mathrm{C} 5-\mathrm{C} 9$. The term minimum Eh refers to the minimum Eh recorded in Figures C5-C9.

In a conventional adsorbent model, increasing the amount of adsorbent will increase the amount of $\mathrm{NaCl}$ removed. Figure $8 \mathrm{~b}$ establishes that this assumption is not applicable to desalination as:

1. $Q_{e}$ decreases with increasing $P_{\mathrm{w}}$;

2. $\mathrm{pH}$ increases as $P_{\mathrm{w}}$ increases (Figure 8e,f);

3. $Q_{\mathrm{e}}$ decreases with increasing $\mathrm{pH}$ (Figure $\left.8 \mathrm{c}, \mathrm{d}\right)$;

4. $Q_{\mathrm{e}}$ is not affected by changing Eh (Figure $8 \mathrm{~g}, \mathrm{~h}$ ).

These observations demonstrate that the surface charge associated with the hydration shells controls the effective desalination rate and total amount of desalination that occurs.

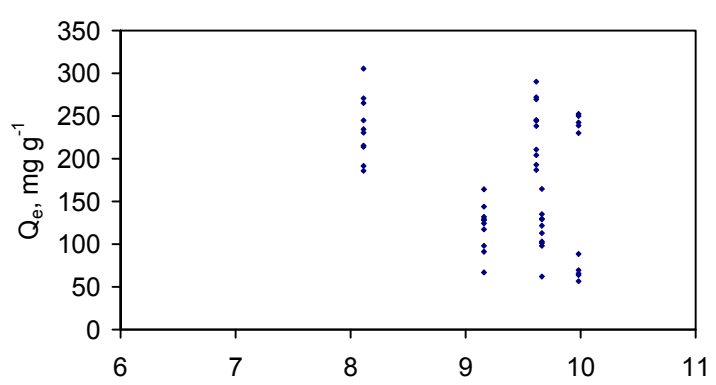

(a)

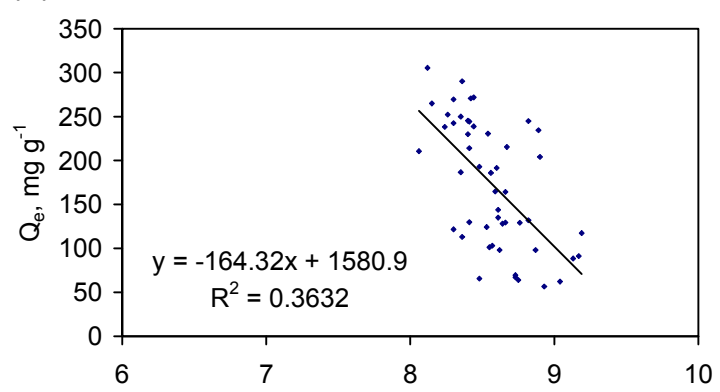

(c)

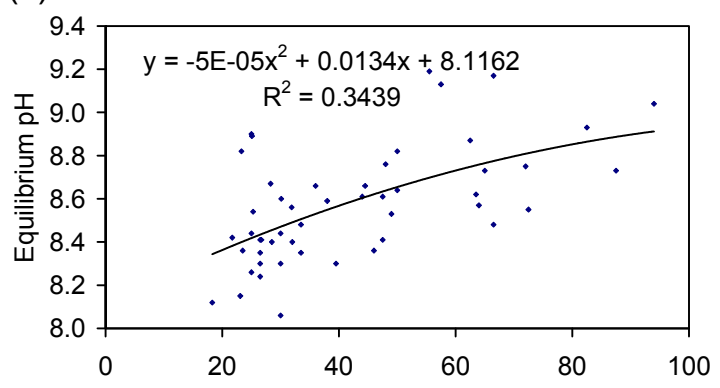

(e)

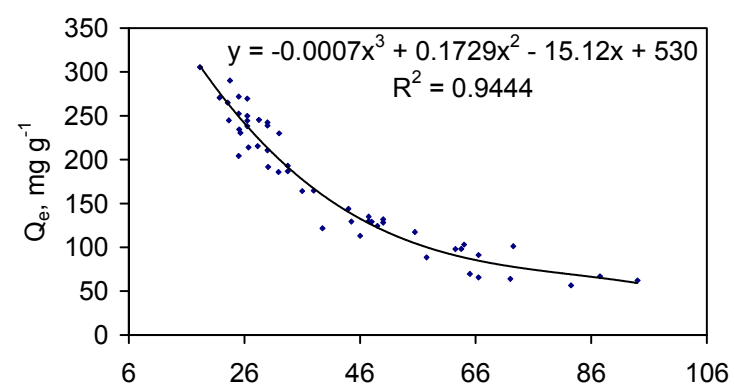

(b)

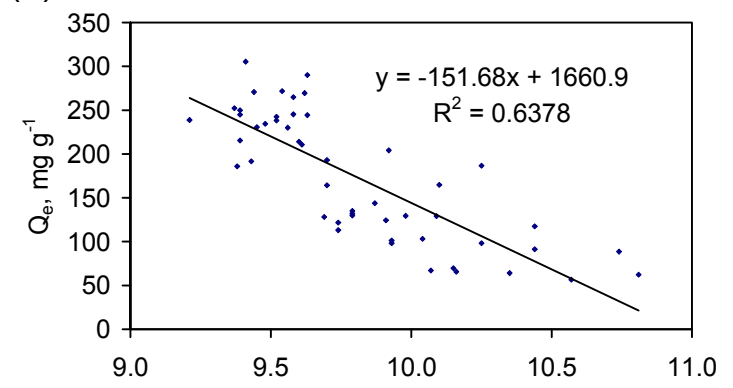

(d)

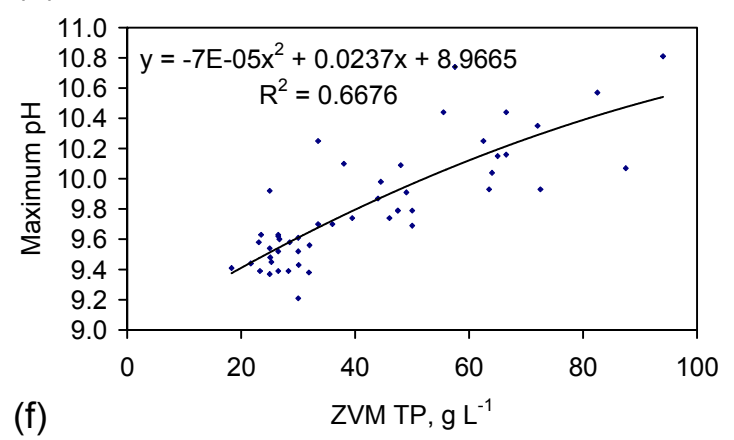

Figure 8. Cont. 

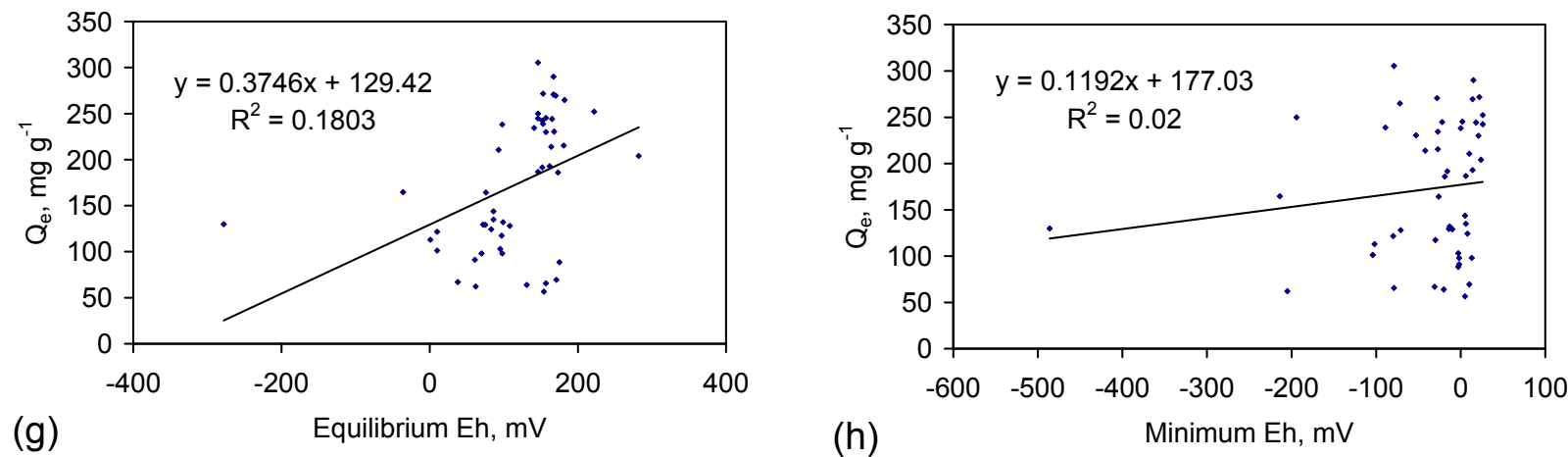

Figure 8. Observed Relationships: between desalination $\left(Q_{\mathrm{e}}\right)$ and: (a) Desalination $\left(Q_{\mathrm{e}}\right) v s$. $C_{0}$; (b) Desalination $\left(Q_{\mathrm{e}}\right)$ vs. ZVM TP concentration; (c) Desalination $\left(Q_{\mathrm{e}}\right)$ vs. Equilibrium $\mathrm{pH}$; (d) Desalination $\left(Q_{\mathrm{e}}\right)$ vs. Maximum $\mathrm{pH}$; (e) ZVM TP concentration vs. Equilibrium $\mathrm{pH}$; (f) ZVM TP concentration vs. Maximum pH; (g) Desalination $\left(Q_{\mathrm{e}}\right)$ vs. Equilibrium Eh; (h) Desalination $\left(Q_{\mathrm{e}}\right) v s$. Minimum Eh. Data: ST1a to ST5j Figures C5-C9. $n=50$ samples; All trials operated under identical conditions. Water losses are not considered in calculating $\left(Q_{\mathrm{e}}\right)$ (see Appendix $\mathrm{C}$ for further details of water losses).

\subsubsection{Impact of Water Consumption}

The analysis in Figure 8 does not consider water consumption during desalination. Integrating (into Figure 8) the salinity data in Table 1 (Tables $\mathrm{C} 1$ and $\mathrm{C} 2$ ), demonstrates that $Q_{\mathrm{e}}$ reaches a maxima at a ZVM TP concentration $\left[P_{\mathrm{w}}\right]$ of between 15 and $20 \mathrm{~g} \cdot \mathrm{L}^{-1}$ (Figure $9 \mathrm{a}$ ).

The relationship between $Q_{\mathrm{e}}$ calculated both before and after water loss consideration (Figure $9 \mathrm{~b}$ ) provides an estimate of:

1. the adjusted value of $Q_{\mathrm{e}}$ as a function of ZVM TP concentration (Figure $9 \mathrm{c}$ ) and

2. the total amount of $\mathrm{NaCl}$ removed as a function of ZVM TP concentration (Figure 9d).

This analysis demonstrates that the total amount of $\mathrm{NaCl}$ removed can approximate $10 \mathrm{~g} \cdot \mathrm{L}^{-1}$ for $\mathrm{ZVM}$ TP concentrations above $40 \mathrm{~g} \cdot \mathrm{L}^{-1}$ (Figure $9 \mathrm{~d}$ ).

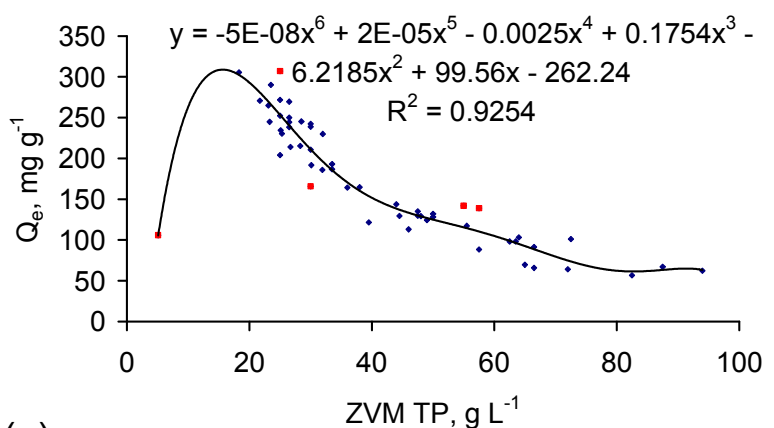

(a)

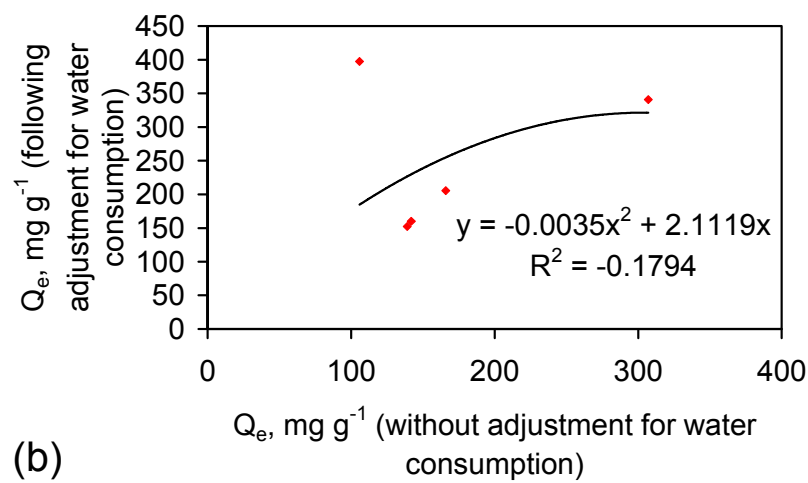

(b) consumption)

Figure 9. Cont. 


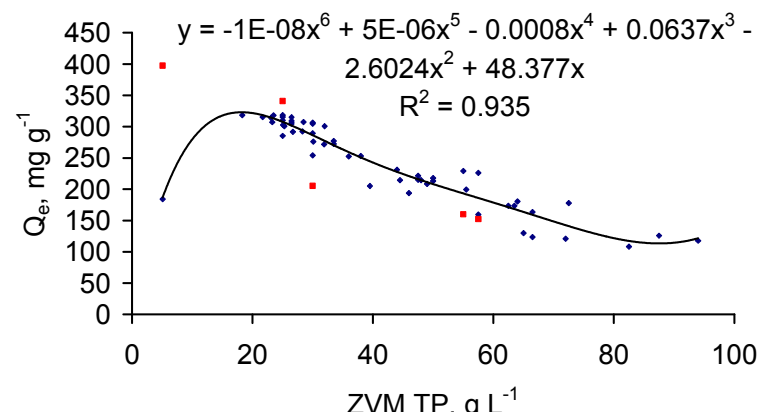

(c)

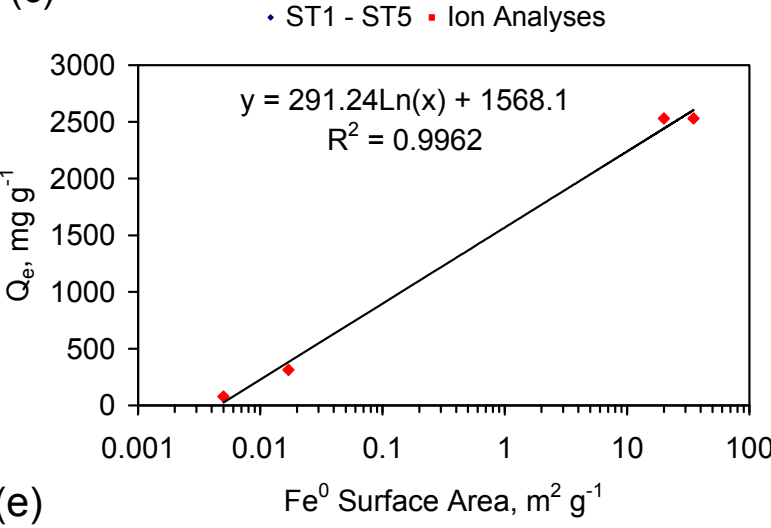

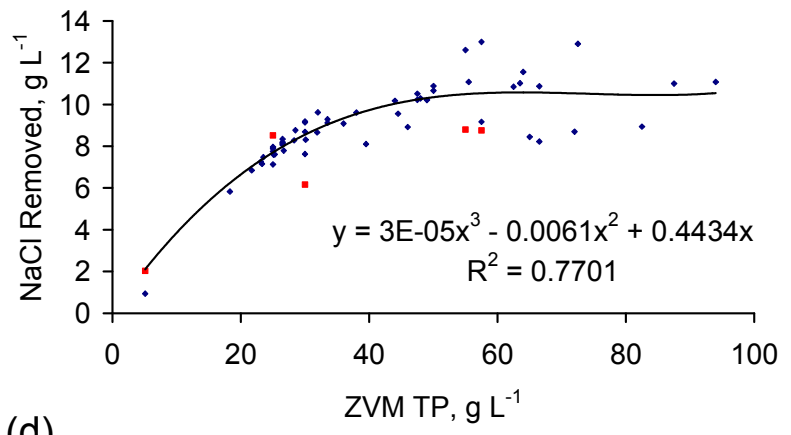

(d)

- ST1 - ST5 - Ion Analyses

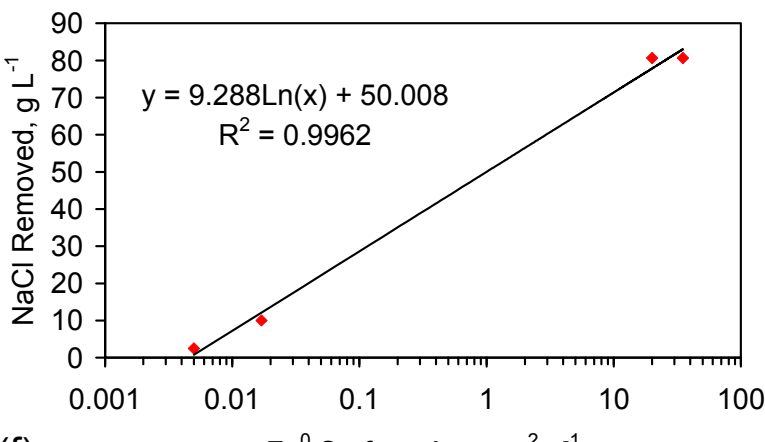

(f)

$\mathrm{Fe}^{0}$ Surface Area, $\mathrm{m}^{2} \mathrm{~g}^{-1}$

Figure 9. (a) $Q_{\mathrm{e}}$ (without adjustment for water consumption) vs. ZVM TP concentration; (b) Measured relationship (Table 1) between $Q_{\mathrm{e}}$ (without adjustment for water consumption) vs. $Q_{\mathrm{e}}$ (with adjustment for water consumption); (c) $Q_{\mathrm{e}}$ (with adjustment for water consumption) $v s$. ZVM $\mathrm{TP}$ concentration; (d) Total $\mathrm{NaCl}$ removed, $\mathrm{g} \cdot \mathrm{L}^{-1} v s$. ZVM TP concentration; (e) $Q_{\mathrm{e}}$ (with adjustment for water consumption) $v s . \mathrm{Fe}^{0} \mathrm{BET}$ surface area, based on a ZVM TP concentration of $10 \mathrm{~g} \cdot \mathrm{L}^{-1}$ (for ST1-ST5, PS14) and $2.5 \mathrm{~g} \cdot \mathrm{L}^{-1}$ for PS7; (f) Total NaCl removed, $\mathrm{g} \cdot \mathrm{L}^{-1}$ vs. $\mathrm{Fe}^{0}$ surface area for a nominal ZVM TP concentration of $40 \mathrm{~g} \cdot \mathrm{L}^{-1}$. Ion analyses samples are: ST3b, ST3f, ST6d, PS4, PS5, PS7 (Table 1): Data: Appendix C. Surface Area Data: ST1-ST5 [6]; PS14 [6]; PS7 [28].

\subsubsection{Impact of ZVM Particle Size}

The $\left[a_{t+1}\right]$ analysis established that $\mathrm{NaCl}$ removal is a function of $a_{\mathrm{s}}$ and $P_{\mathrm{w}}$ (Appendix F3). The measured relationship between $Q_{\mathrm{e}}$ and $a_{\mathrm{s}}$ (Figure 9e,f), demonstrates that $Q_{\mathrm{e}}$ increases with $a_{\mathrm{s}}$.

This relationship confirms that it is possible for $1 \mathrm{~g} \mathrm{ZVM}$ to remove $>1 \mathrm{~g} \mathrm{NaCl}$ [25]. This observation is consistent with a model of accretionary, polyionic, akaganeite/FeOOH nano rod formation where the bulk of the adsorbed $\mathrm{NaCl}$ is electrostatically bound in the hydration shells and the ionic layer surrounding each $\mathrm{FeOOH}$, e.g., [22,23,25,78,79,90-100,108].

\subsection{Desalination Associated with NaCl Concentration in the Pore Waters within the ZVM TP Bed}

Molecular modeling demonstrates [96] that when the water contains $0.05-0.1 \mathrm{M} \mathrm{NaCl} \cdot \mathrm{L}^{-1}$, the $\mathrm{Cl}^{-}$concentrations associated with the ionic layer at the akaganeite crystal end (001) face are 7.34 $\mathrm{M} \mathrm{Cl}^{-} \cdot \mathrm{L}^{-1}$ [96]. The $\mathrm{Cl}^{-}$concentrations in the hydrated shell adjacent to the longitudinal (100), (110) crystal faces are $1.47 \mathrm{M} \mathrm{Cl}^{-} \cdot \mathrm{L}^{-1}[96]$. 
This situation can only arise if the $\mathrm{Fe}\left(\mathrm{H}_{2} \mathrm{O}\right) 6^{3+}$ species create chemical gradients in the water which physically attract $\mathrm{NaCl}$ to the $\mathrm{Fe}\left(\mathrm{H}_{2} \mathrm{O}\right)_{6}{ }^{3+}$ species to enable akaganeite formation and growth [96].

The molecular modeling [96] for akaganeite formation creates an osmotic gradient between the hydrated shells surrounding the akaganeite and the surrounding water body [108]. Osmotic theory would expect the $\mathrm{Cl}^{-}$ions to migrate from the akaganeite water shell (and ionic layer) into the surrounding water body $[108,109]$.

\subsubsection{Osmotic Pressure}

The osmotic pressure created between fresh water and the longitudinal water shell of the akaganeite nano-crystals is $3.6 \mathrm{MPa}$, where osmotic pressure $\left[O_{\mathrm{p}}\right]$ is calculated as $\left[O_{\mathrm{p}}\right](\mathrm{MPa})=[c] R T[82,83]$, where $[c]=$ salt concentration in the water $\left(\mathrm{M} \cdot \mathrm{L}^{-1}\right), R=$ gas constant, $T=$ temperature, $\mathrm{K}$. At $25^{\circ} \mathrm{C}$, $R T=2.480 \mathrm{~kJ} \cdot \mathrm{M}^{-1}[108,109]$, and $\left[O_{\mathrm{p}}\right](\mathrm{MPa})=2.480[c]$.

Experiments which have examined the molar relationship between $\mathrm{OH}: \mathrm{Fe}$ in water, in conjunction with the molar relationship between $\mathrm{Cl}: \mathrm{Fe}$ in water, have established [110] that:

1. $\mathrm{Cl}^{-}$is removed in $\mathrm{Fe}^{\mathrm{III}}$ polymers (general form $\left.\left[\mathrm{Fe}_{m}\left(\mathrm{H}_{2} \mathrm{O}\right)_{6 m-n}(\mathrm{OH})_{n}\right]^{3 m-n}\right)[110]$.

2. $\mathrm{No} \mathrm{Cl}^{-}$is observed in the first co-ordination shell of $\mathrm{Fe}$ in the polymers when $\mathrm{OH}: \mathrm{Fe}>2$ [110].

3. Increasing the $\mathrm{Fe}^{3+}: \mathrm{Cl}^{-}$ratio in the water results in water molecules in the first hydration shell being exchanged for $\mathrm{Cl}^{-}$[110]. The resultant polymers and ferric hydroxide gels (e.g., orange spheroids in Figure F1) possess an akaganeite, or goethite, structure [110].

These observations indicate that the critical control on the rate of desalination is the rate of discharge of $\mathrm{Fe}^{n^{+}}$ions into the pores within the ZVM mass and the ability of those pores to access saline water from the overlying water body. This process creates an effective osmotic gradient between the water body and the pore water surrounding the $\mathrm{ZVM}$, which results in a net migration of $\mathrm{NaCl}$ into the pore waters surrounding the ZVM.

This mechanism predicts that in a diffusion environment [the salinity of the hydration shells] $>$ [the salinity of hydrated ZVM TP + associated pore waters] $>$ [Salinity of the principal water body].

\subsubsection{Role of Hydration Shells}

The $\beta$-FeOOH polymorph is an unstable structure, which is stabilized by $\mathrm{Cl}^{-}$[111]. When $\mathrm{Cl}^{-}$is absent, or drops below a critical level in the pore waters within the ZVM TP, another FeOOH species (e.g., goethite) will form [111].

The $\mathrm{Al}^{0}$ in the $\mathrm{ZVM}$ TP corrodes in water to produce $\mathrm{Al}\left(-\mathrm{OH}_{2}\right)^{n^{+}}$sites and is able to remove both $\mathrm{Na}^{+}$ and $\mathrm{Cl}^{-}$ions as: $\left[\left(\mathrm{AlOH}_{2}{ }^{0.5+}\right)\left(\mathrm{Cl}^{-}\right)\right],\left[\left(\mathrm{Al}_{3} \mathrm{O}^{0.5-}\right)\left(\mathrm{Na}^{+}\right)\right]$, and $\left[\left(\mathrm{Al}_{3} \mathrm{OH}^{0.5+}\right)\left(\mathrm{Cl}^{-}\right)\right][112]$. Both $\mathrm{Fe}$ and $\mathrm{Al}$ adopt similar and complementary surface sites [111-113].

The precipitated $\mathrm{FeOOH}$ species form a repeating sequence of atoms and radicals [113]:

1. terminal surface (no hydration, e.g., $\mathrm{FeOH}^{0.5-}$ ): $(\mathrm{OH})-(\mathrm{OH})-\mathrm{Fe}-\mathrm{O}-\mathrm{O}-\mathrm{Fe}-\mathrm{R}$ (where $\mathrm{R}=$ a repeat of the stoichiometric atomic layer sequence, or tethering surface. $\mathrm{R}$ can included hydrated layers);

2. interface terminal surface (no hydration, e.g., $\left.\mathrm{FeOH}_{2}{ }^{0.5+}\right):\left(\mathrm{H}_{2} \mathrm{O}\right)-\left(\mathrm{H}_{2} \mathrm{O}\right)-\left(\mathrm{OH}_{2}\right)-(\mathrm{OH})-\mathrm{Fe}-\mathrm{O}-\mathrm{O}-\mathrm{Fe}-\mathrm{R}$

3. double hydrated terminal surface: $\left(\mathrm{H}_{2} \mathrm{O}\right)-\left(\mathrm{H}_{2} \mathrm{O}\right)-(\mathrm{OH})-(\mathrm{OH})-\mathrm{Fe}-\mathrm{O}-\mathrm{O}-\mathrm{Fe}-\mathrm{R}$

4. double hydrated interface terminal surface: $\left(\mathrm{H}_{2} \mathrm{O}\right)-\left(\mathrm{H}_{2} \mathrm{O}\right)-\left(\mathrm{OH}_{2}\right)-(\mathrm{OH})-\mathrm{Fe}-\mathrm{O}-\mathrm{O}-\mathrm{Fe}-\mathrm{R}$ 
The $\mathrm{Na}^{+}$ions are removed within the $\left(\mathrm{H}_{2} \mathrm{O}\right)-\left(\mathrm{H}_{2} \mathrm{O}\right)-(\mathrm{OH})-(\mathrm{OH})-\mathrm{Fe}-\mathrm{O}-\mathrm{O}-\mathrm{Fe}-\mathrm{R}$ sequence. The $\mathrm{Cl}^{-}$ ions are removed within the $\left(\mathrm{H}_{2} \mathrm{O}\right)-\left(\mathrm{H}_{2} \mathrm{O}\right)-\left(\mathrm{OH}_{2}\right)-(\mathrm{OH})-\mathrm{Fe}-\mathrm{O}-\mathrm{O}-\mathrm{Fe}-\mathrm{R}$ sequence.

The example illustrates two hydration shells. The actual number of hydration shells can exceed 2, i.e.,

$$
\begin{gathered}
\left(\mathrm{H}_{2} \mathrm{O}\right)-\ldots . . .-\left(\mathrm{H}_{2} \mathrm{O}\right)-(\mathrm{OH})-(\mathrm{OH})-\mathrm{Fe}-\mathrm{O}-\mathrm{O}-\mathrm{Fe}-\mathrm{R} \text { and }\left(\mathrm{H}_{2} \mathrm{O}\right)-\ldots . .-\left(\mathrm{H}_{2} \mathrm{O}\right)-\left(\mathrm{OH}_{2}\right)- \\
(\mathrm{OH})-\mathrm{Fe}-\mathrm{O}-\mathrm{O}-\mathrm{Fe}-\mathrm{R}
\end{gathered}
$$

The hydration shells can account for $>41 \%$ of the weight of FeOOH [114], and increase the effective surface area of the FeOOH [114]. 5 hydration shells approximate to $46 \mathrm{wt} \%$ of $\mathrm{FeOOH} \cdot m \mathrm{H}_{2} \mathrm{O}$.

This general phase structuring allows $\mathrm{NaCl}$ removal to be undertaken at the terminal sites and within the corrosion zone. It potentially allows any hydrated FeOOH species to be structured to form an effective desalination agent.

$\mathrm{FeO}_{x} \mathrm{H}_{y}$ nano-particles rapidly aggregate in saline water [115]. The aggregated colloidal particle size increases with increasing water salinity [115].

\subsection{Role of Surface Charge and Capacitance in Assessing Desalination Efficiency}

This section considers:

1. the observed surface charge and capacitance associated with desalination;

2. the capacitance characteristics of ZVM TP prior to use for desalination;

3. the capacitance characteristics of the ZVM TP following desalination.

The trial results in Appendix $\mathrm{C}$ indicate that an understanding of surface charge and capacitance may allow elucidation of the ZVM TP characteristics required to maximize $Q_{\mathrm{e}}$ and reduce the time required to achieve a specific level of $Q_{\text {e }}$.

\subsubsection{Observations Made during Desalination}

The increase in $Q_{\mathrm{e}}$ which is associated with a decrease in $\mathrm{pH}$ (Figure 8c,d) can be linked to surface charge and proton uptake associated with $\mathrm{FeOOH}$, i.e.,

1. the proton uptake increases with both increasing salinity and decreasing $\mathrm{pH}$; (e.g., at $0.1 \mathrm{M}(5.844$ $\left.\mathrm{g} \cdot \mathrm{L}^{-1}\right) \mathrm{NaCl}$ proton uptake $\left(\left[\mathrm{H}^{+}\right]_{\text {ads }}(\mu \mathrm{M} \mathrm{NaCl})^{-1} \cdot \mathrm{m}^{-2}=-0.7006 \mathrm{pH}+4.3174\right.$; at $0.01 \mathrm{M}(0.5844$ $\left.\mathrm{g} \cdot \mathrm{L}^{-1}\right) \mathrm{NaCl}$ proton uptake $\left(\left[\mathrm{H}^{+}\right]_{\mathrm{ads}}(\mu \mathrm{M} \mathrm{NaCl})^{-1} \cdot \mathrm{m}^{-2}=-0.7006 \mathrm{pH}+3.8174\right.$ [116]), $\mathrm{M}=$ moles $\mathrm{NaCl} \cdot \mathrm{L}^{-1} ; \mathrm{m}^{-2}$ refers to the BET surface area;

2. the surface charge $\left(\mathrm{C} \cdot \mathrm{m}^{-2}\right)$ increases (at $0.1 \mathrm{M}\left(5.844 \mathrm{~g} \cdot \mathrm{L}^{-1}\right) \mathrm{NaCl}$ ) with decreasing $\mathrm{pH}$ (e.g., Surface charge, $\mathrm{C} \cdot \mathrm{m}^{-2}=-0.0009 \mathrm{pH}^{2}-0.033 \mathrm{pH}+0.2957$ [116]).

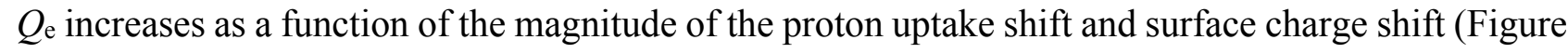
$10 \mathrm{a}, \mathrm{b})$. The $Q_{\mathrm{e}}$ increase is also a function of $\mathrm{pH}$ (Figure 10c-j). A statistical correlation is present between $Q_{\mathrm{e}}$ and the change in surface charge (i.e., the difference between the surface charge at the maximum $\mathrm{pH}$ and the equilibrium $\mathrm{pH}$ ) (Figure $10 \mathrm{~g}$ ).

Decreases in salinity removal with time (e.g., Figures $\mathrm{C} 1-\mathrm{C} 17$ ) can be interpreted as being related to a decrease in the surface charge and a decrease in the availability of $\mathrm{H}^{+}$sites. 


\subsubsection{Impact of Changes in Surface Charge on $Q_{e}$ during Desalination}

$Q_{\mathrm{e}}$ is maximized under conditions where the change in surface charge and change in proton adsorption (associated with the change in redox environment between the maximum $\mathrm{pH}$ and equilibrium $\mathrm{pH}$ ) is minimized (Figure 10e-g).

The surface charge is proportional to the capacitance [117]. The capacitance increases with BET surface area of the FeOOH [91], e.g., Inner Layer Capacitance, $C, \mu \mathrm{F} \mathrm{cm}{ }^{-2}=-1.629 a_{\mathrm{s}}+208.955$; $a_{\mathrm{s}}=-0.61939 C+128.27 ; C=$ Surface Charge $/\left(D_{1}-\mathrm{D}_{2}\right) ; D_{1}=$ potential at the 0 plane. $D_{2}=$ potential at the beta plane [117]. Surface Charge $=C\left(D_{1}-D_{2}\right)$ [117].

The surface area was calculated for the case where $\left(D_{1}-D_{2}\right)=1$ (Figure 10k). This analysis demonstrates that the surface area increases as $Q_{\mathrm{e}}$ increases (Figure 10k), and the effectve surface charge decreases as surface area increases (Figure 10a).

The formation of $\mathrm{FeOOH}$ species such as goethite and ledidocrocite (which have a lower capacity for $\mathrm{Cl}^{-}$adsorption) may result in different surface charge relationships and lower $\mathrm{NaCl}$ adsorption rates $[116,118]$.

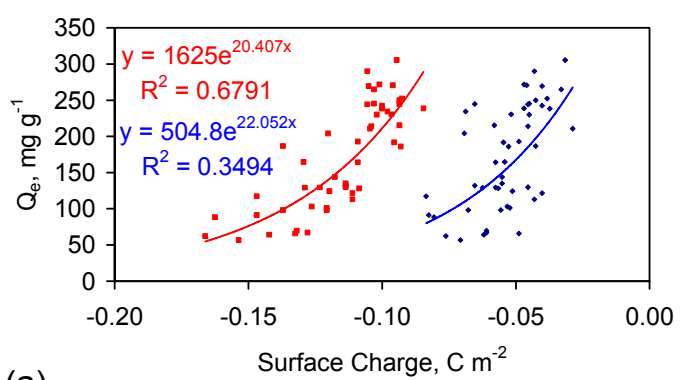

(a)

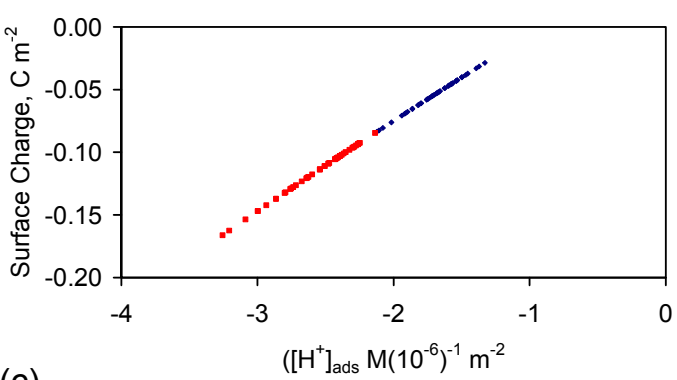

(c)

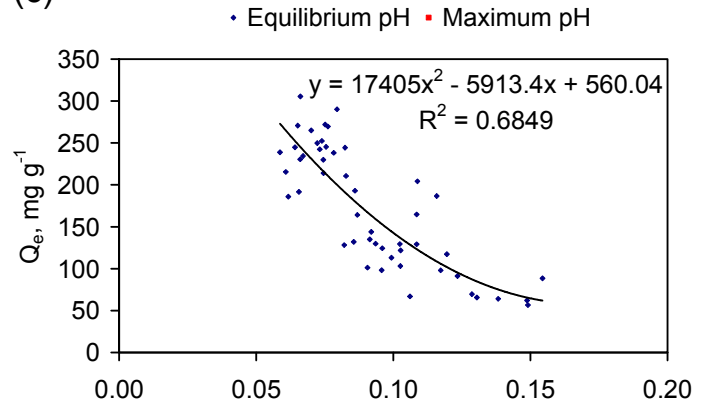

(e)

Change in Surface Charge, $\mathrm{C} \mathrm{m}^{-2}$

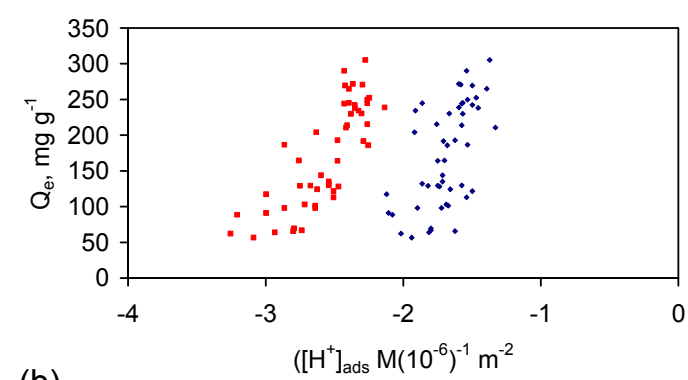

(b)

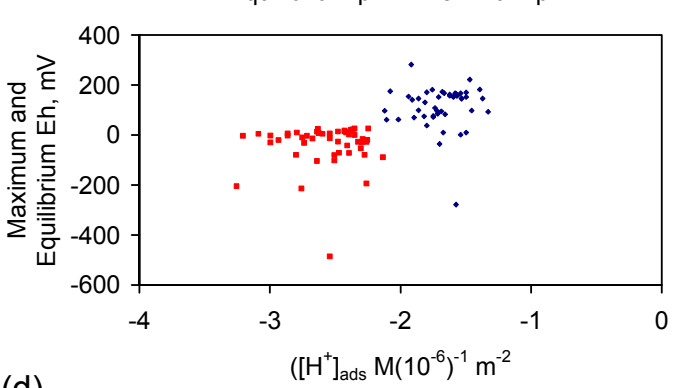

(d)

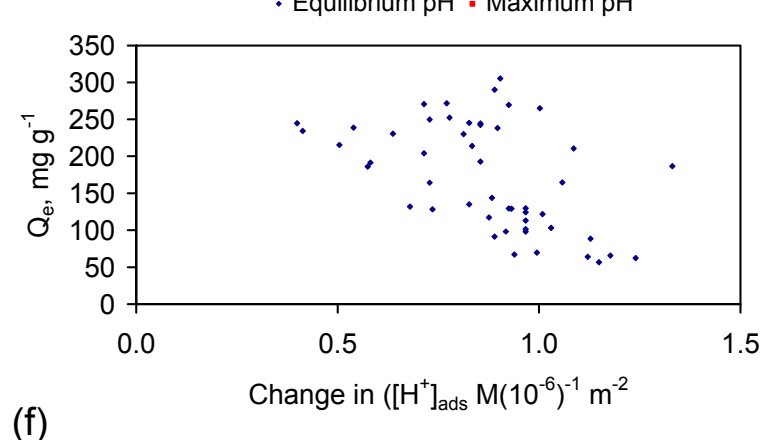

Figure 10. Cont. 


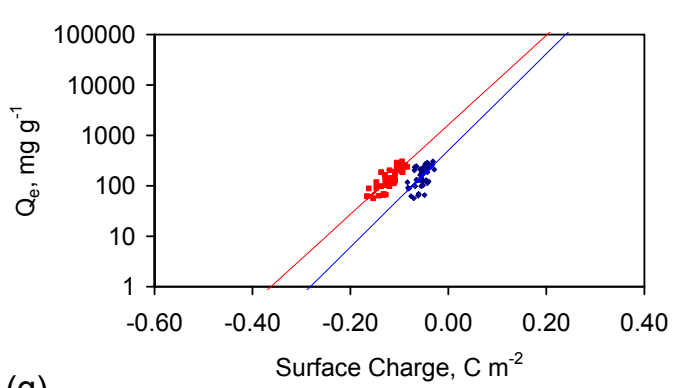

(g)

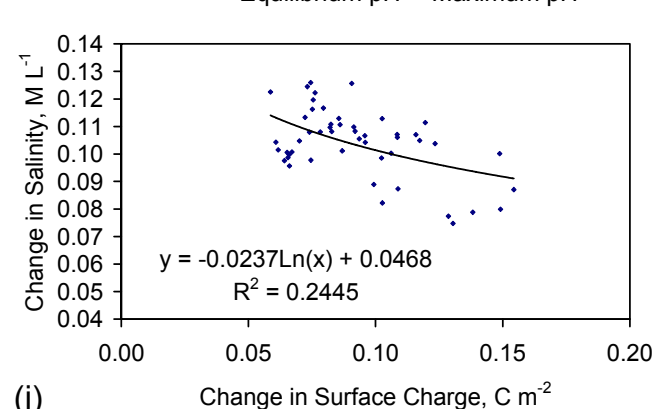

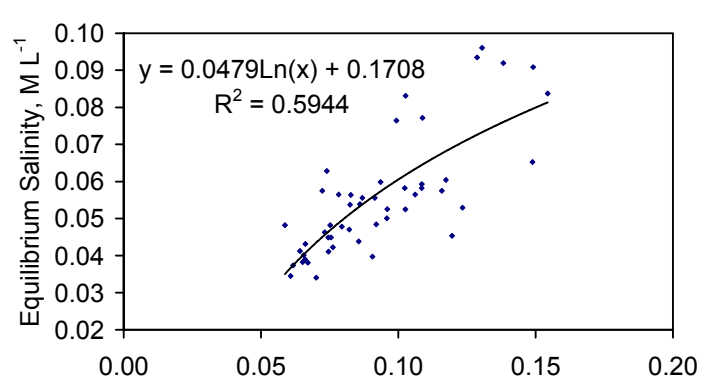

(h)

Change in Surface Charge, $\mathrm{C} \mathrm{m}^{-2}$

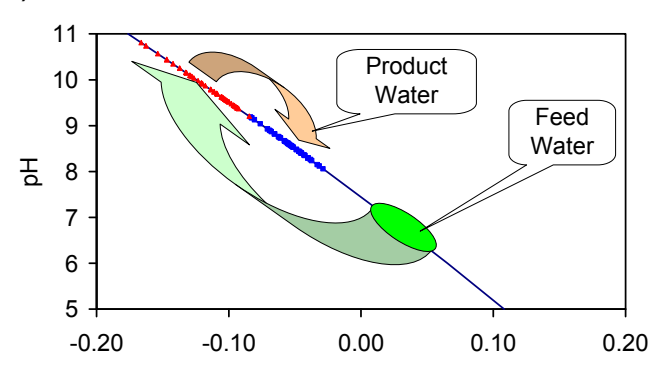

(j) Surface Charge, $\mathrm{C} \mathrm{m}^{-2}$

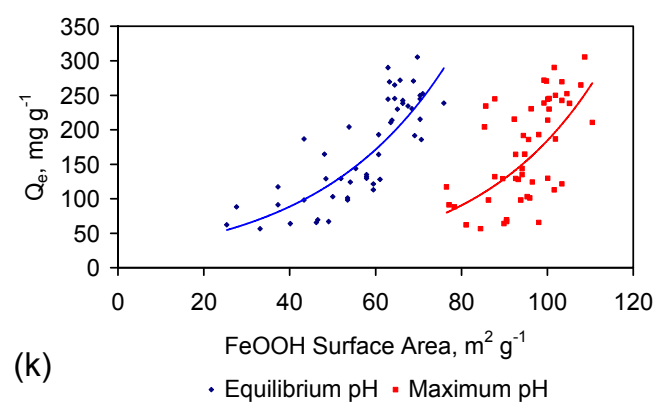

Figure 10. ZVM TP: Surface charge and $Q_{\mathrm{e}}$ during desalination. (a) $Q_{\mathrm{e}}$ (without adjustment for water consumption) vs. surface charge; (b) Measured relationship $Q_{\mathrm{e}}$ (without adjustment for water consumption) vs. proton adsorption; (c) Surface charge vs. proton adsorption; (d) Maximum and equilibrium Eh vs. proton adsorption; (e) $Q_{\mathrm{e}}$ (without adjustment for water consumption) vs. change in surface charge; (f) Measured relationship $Q_{\mathrm{e}}$ (without adjustment for water consumption) $v s$. change in proton adsorption; (g) Expected $Q_{\mathrm{e}}$ (without adjustment for water consumption) vs. surface charge; (h) Equilibrium salinity vs. change in surface; (i) Change in salinity $v s$. change in surface charge; (j) Desalination cycle shown by water $\mathrm{pH}$ $v s$. surface charge; (k) $Q_{\mathrm{e}} v s$. calculated FeOOH surface area, when $\left(D_{1}-D_{2}\right)=1$. Data: ST1a-ST5j.

\subsubsection{Measured Capacitance of the ZVM TP Prior to Usage for Desalination}

Figure 10 demonstrates that $Q_{\mathrm{e}}$ is a function of surface charge and capacitance. Two randomly selected $\mathrm{Cu}^{0}$ sheathed pellets (from the ZVM TP used in the analysis series ST1 to ST5 (which demonstrate desalination in Figures C5-C9)) were converted into dry cells by placing a steel electrode in the centre of the ZVM and a second steel electrode on the $\mathrm{Cu}^{0}$ shell of the pellet. The cell was placed on non conductive material (PVC) and attached to a multi-meter. The size of the current and voltage varied between pellets and with time. 
1. Cell 1: $7.5 \mathrm{~cm} \times 1.5 \mathrm{~cm} \mathrm{OD}$; total weight $=56 \mathrm{~g} \mathrm{ZVM}$ product $+\mathrm{Cu}^{0}$ sheath. The two ends of the dry cell were exposed to air (Figure 11).

2. Cell 2: $5 \mathrm{~cm} \times 1.5 \mathrm{~cm}$ OD containing $11 \mathrm{~g} \mathrm{ZVM}$ product $+5 \mathrm{~g} \mathrm{NaCl}+2 \mathrm{~g} \mathrm{H} \mathrm{H}_{2} \mathrm{O}$. The two ends of the dry cell were sealed with PVC (Figure 11).

These cells established that fresh ZVM TP pellets (manufactured by a Type B pre-treatment) placed in the saline water (Appendix C) were electrically active (Figure 11). The dry cells also established that the treated ZVM displayed significantly higher levels of electrical activity in the presence of $\mathrm{NaCl}+\mathrm{H}_{2} \mathrm{O}$ (Figure 11).

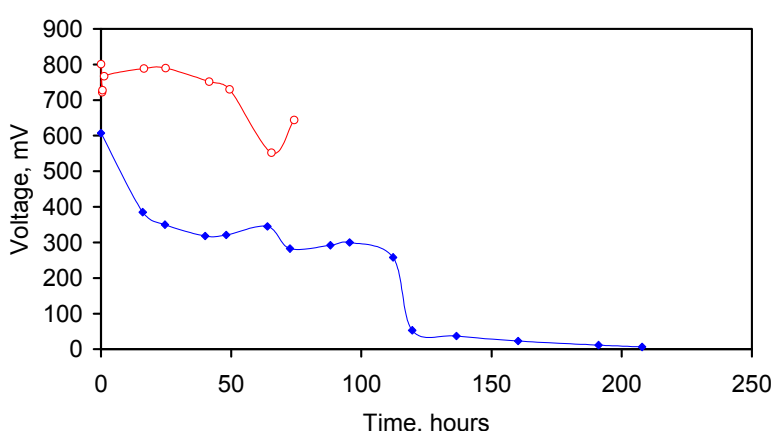

(a)

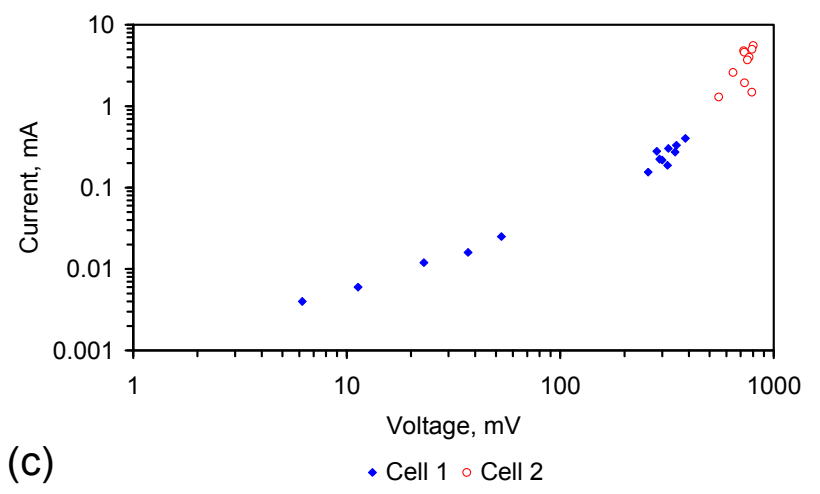

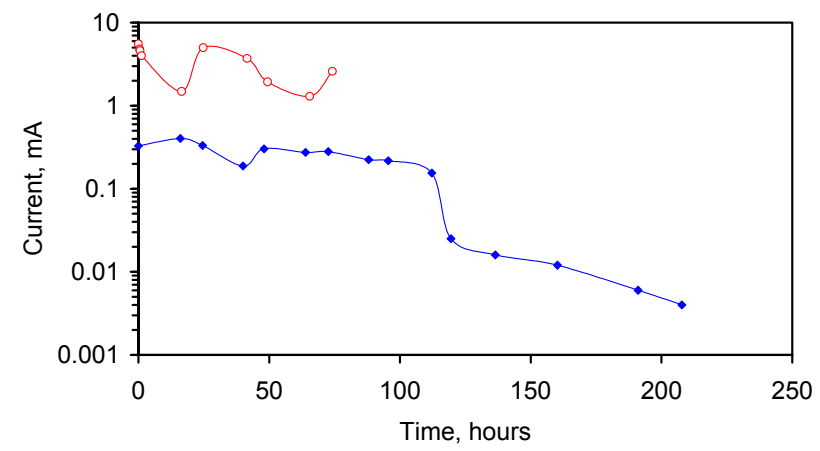

(b)

Figure 11. Measured currents and voltages as a function of time, associated with ZVM TP (ST1 to ST5 series) prior to usage for desalination. (a) Voltage vs. Time; (b) Current vs. Time. (c) Current vs. Voltage.

\subsubsection{Relationship between Capacitance and Desalination}

The electrical analysis (Figure 11) demonstrates that ZVM TP can act as a charge receiver and storage unit (i.e., a capacitor or battery). In carbon steels (and carbon steel powders) the carbon content is typically within the range $0.15 \%-1.3 \%$ [119]. When the carbon content is $<0.9 \%$ the corrosion sequence is $\mathrm{Fe}^{0} \rightarrow \mathrm{Fe}^{\mathrm{II}} \rightarrow \mathrm{Fe}^{\mathrm{III}}$ [119]. When the carbon content is $>0.9 \%$ the corrosion sequence is $\mathrm{Fe}^{0} \rightarrow \mathrm{Fe}^{\mathrm{III}}$ [119]. The $\mathrm{Fe}^{\mathrm{III}}$ species act as an anodic layer and carbon acts as a cathode.

The ZVM TP (formed from carbon steel) during desalination is effectively structured as a $\mathrm{Fe}^{0}: \mathrm{Fe}_{2} \mathrm{O}_{3}: \mathrm{C}$ capacitor, where the saline water acts as an electrolyte. Fe capacitor studies place $\mathrm{Fe}^{\mathrm{III}}$ species within their generic group $\left(\mathrm{Fe}_{2} \mathrm{O}_{3}[19]\right)$.

Under this model (e.g., [120]) $\mathrm{NaCl}$ removal at anodic sites $\left(\mathrm{Fe}_{2} \mathrm{O}_{3}\right)$ will be associated with capacitor charging (e.g., formation of $\mathrm{Fe}^{3+}$ ion adduct species) while capacitor discharge will be associated with 
releases of $\mathrm{NaCl}$ into the water [120]. These gross changes are reflected in the $\mathrm{EC}$ measurements where a general EC decline is associated with oscillations between higher and lower EC values (Figures C1-C17).

\subsubsection{Capacitance}

The capacitance can be calculated $[121,122]$ as:

$$
C_{s}=i /(m(\Delta E / \Delta t)
$$

where $C_{\mathrm{s}}=$ specific capacitance, $\mathrm{F} \cdot \mathrm{g}^{-1}, i=$ average current $\left(\mathrm{mA} \cdot \mathrm{s}^{-1}\right)$ applied, $m=$ mass of ZVM, $\Delta E / \Delta t=$ average slope of the discharge curve after $i R$ drop where $i$ and $R$ are current and resistance.

The Energy Density, $E,\left(\mathrm{Wh} \cdot \mathrm{kg}^{-1}\right)$ is [121]:

$$
E=0.5 C_{s}(\Delta V)^{2}
$$

where $(\Delta V)(\mathrm{V})=$ the potential range. The power density, $P\left(\mathrm{~kW} \cdot \mathrm{kg}^{-1}\right)$ is [121]:

$$
P=E / t_{d}
$$

$t_{d}=$ time (s) to discharge.

The dry cells in Figure 11 analyze two situations:

1. Cell 1 represents the typical capacitance associated with discharged ZVM TP prior to placement in saline water.

2. Cell 2 demonstrates that in saline water (following, or during desalination), the presence of $\mathrm{NaCl}$ around the ZVM TP has the effect of charging the cell and increasing its specific capacitance. These features are quantified in Table 4.

Table 4. Specific capacitance, energy density and power density associated with ZVM TP

\begin{tabular}{|c|c|c|c|}
\hline \multicolumn{2}{|c|}{ Variable } & Cell 1 & Cell 2 \\
\hline Current & $\mathrm{mA}$ & $0.08 \exp ^{(-0.24 x)}$ & $4.33 \exp ^{(-0.0119 x)}$ \\
\hline \multicolumn{2}{|c|}{$R^{2}$} & 0.8463 & 0.408 \\
\hline Voltage & $\mathrm{mV}$ & $947.23 \exp ^{(-0.0216 x)}$ & $781.47 \exp ^{(-0.0028 x)}$ \\
\hline \multicolumn{2}{|c|}{$R^{2}$} & 0.858 & 0.494 \\
\hline$i$ & $\mathrm{~mA}$ & 0.016 & 2.860 \\
\hline$m$ & $\mathrm{~g}$ & 56.000 & 11.000 \\
\hline \multicolumn{2}{|c|}{$(\Delta E / \Delta t)$} & 0.01531 & 0.00081 \\
\hline$C_{s}$ & $\mathrm{~F} \cdot \mathrm{g}^{-1}$ & 0.018 & 321.208 \\
\hline$\Delta V$ & V & 0.199 & 0.734 \\
\hline$E$ & $\mathrm{Wh} \cdot \mathrm{kg}^{-1}$ & 0.00036 & 86.411 \\
\hline$t_{d}$ & $\mathrm{~s}$ & 12,469 & 4452 \\
\hline$P$ & $\mathrm{~kW} \cdot \mathrm{kg}^{-1}$ & 0.00000003 & 0.01941 \\
\hline
\end{tabular}
pellets prior to use in desalination. These pellets were used in ST1a to ST5j (Appendix C), Cell 1 and Cell 2. $x=$ hours since start of measurement.

Table 4 demonstrates that the net impact of $\mathrm{NaCl}$ is to increase $C_{s}, E$ and $P$. The energy density $(E)$ of Cell 2 is comparable with the energy density recorded from $\mathrm{Fe}_{2} \mathrm{O}_{3}: \mathrm{C}$ composite capacitors (Figure 12). 


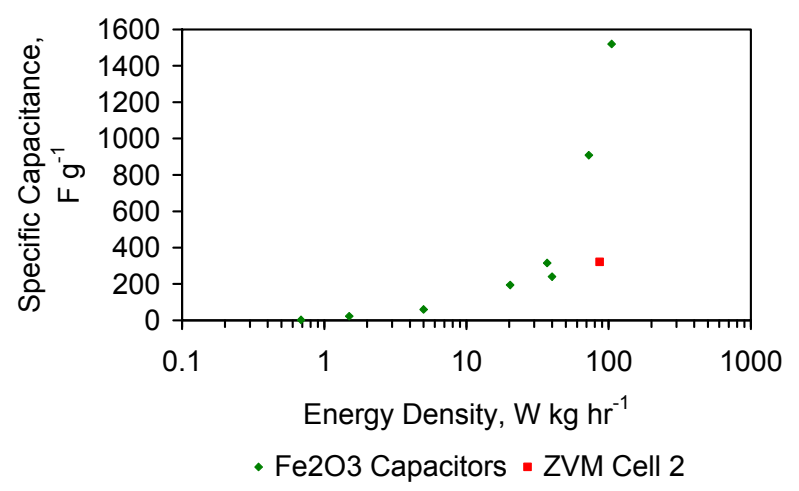

Figure 12. Energy densities and specific capacitance recorded by $\mathrm{Fe}_{2} \mathrm{O}_{3}: \mathrm{C}$ composite capacitors. Reference Data Sources: [121-142]. ZVM Cell $2=$ unused ZVM TP prior to use for desalination.

\subsubsection{Voltage/Current Changes Associated with the Cessation of Desalination}

The gradual removal of $\mathrm{Na}^{+}$and $\mathrm{Cl}^{-}$from the water will result in the gradual reduction in both the specific capacitance and the columbic efficiency with time. These factors when combined with the trapping of $\mathrm{Na}^{+}$within the ZVM, will result in a major fading of the desalination rate after either a critical number of charge:discharge cycles (Eh:pH oscillations) has occurred [143], or the salinity (electrolyte concentration) drops below a specific level. This situation was demonstrated in all the trial examples when the desalination period was extended to Day 250 (Figures C1-C17).

The effective floor on desalination (or cessation of desalination) indicates that a minimum salinity (or electrolyte concentration) is required in order to drive the discharge reaction. Similar observations are associated with $\mathrm{Na}-\mathrm{Fe}_{2} \mathrm{O}_{3}: \mathrm{C}$ battery analyses [143,144].

The current and voltage associated with discharge from the fresh pellets declined with time from a Level, $\mathrm{L}_{1}$ to a Level, $\mathrm{L}_{2}$ (Figure 13) In the presence of $\mathrm{NaCl}$ the initial current and voltage increased from a Level $\mathrm{L}_{1}$ to a Level $\mathrm{L}_{3}$ (Figure 13).

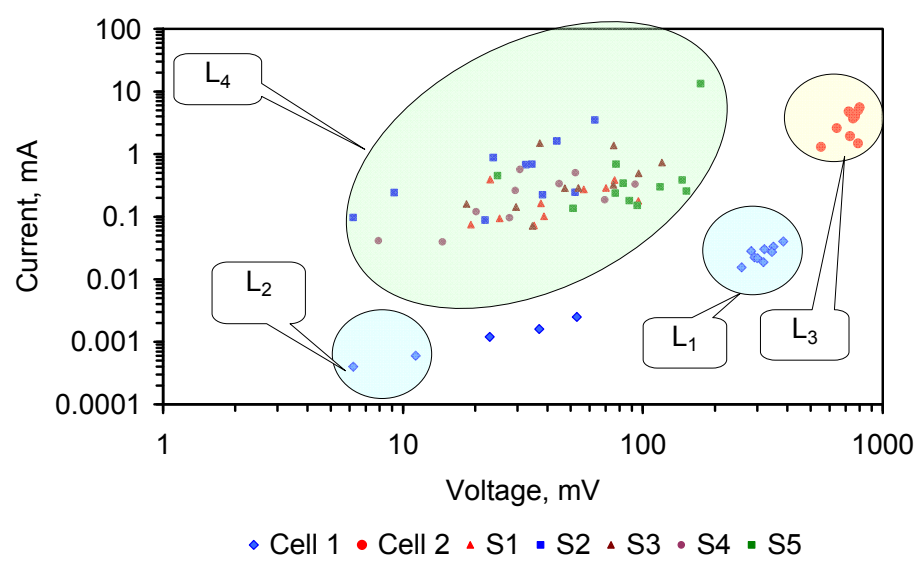

Figure 13. Relationship between voltage and current associated with used ZVM TP pellets following desalination (ST1a to ST5j), L4, and the unused ZVM TP prior to desalination, Cell $1\left(\mathrm{~L}_{1}, \mathrm{~L}_{2}\right)$ and Cell $2\left(\mathrm{~L}_{3}\right)$. The pellet series are labeled $\mathrm{S} 1$ to $\mathrm{S} 5$ to distinguish them from the analyses (ST1a to ST5j) in Appendix C, as the measurements were made 2 years after termination of the desalination trials. 
The voltage and current produced by the pellets associated with ST1a to ST5j were measured two years after the conclusion of the desalination trials in order to investigate the impact of desalination on capacitance.

The measured current clustered at a Level L4 (Figure 13). The measured voltage was between $\mathrm{L}_{2}$ and $\mathrm{L}_{1}$. The ZVM pellets following conclusion of the desalination trials were in a discharged state where the discharged voltage is intermediate between $\mathrm{L}_{1}$ and $\mathrm{L}_{2}$. This demonstrates $[143,144]$ that the effective cessation of desalination (Figure 13) is associated with a partially discharged capacitor. Appendix $\mathrm{H}$ addresses the significance of this observation for $\mathrm{Na}$ ion removal.

This interpretation (supported by electrical measurements) demonstrates that the initial model of $\mathrm{NaCl}$ removal by adsorption $[20,21,25]$ is over-simplistic, and that focussing on the capacitance of the ZVM TP during manufacture will allow $Q_{e}$ to be increased and allow the time required to desalinate water to a specific salinity to be reduced.

\subsubsection{ZVM TP Pellet Capacitance Following Desalination}

The capacitance of each ZVM TP pellet used in trials ST1a to ST5j (Figures C5-C9) was measured following the cessation of desalination and the amount of charge stored in the pellets was calculated as:

$$
\begin{gathered}
\text { Energy Stored, } E_{\mathrm{s}},(\text { Joules })=0.5\left[\text { Measured Capacitance }(F) \times(\text { Voltage }(\mathrm{V}))^{2}\right] \\
\text { Potential Power Generated }(\mathrm{W})=E_{\mathrm{s}} / \text { Dissipation time, } \mathrm{s}
\end{gathered}
$$

This analysis (Figure 14) establishes that the recovered (discharged) pellets have a stored charge in the range 0.00001 to $0.3 \mathrm{~J}$. It was observed that if the pellets were subsequently moistened, the capacitance $(F)$ increased by a factor of 100-1000. The dry pellets had a measured capacitance in the range $0.1-20 \times 10^{-6} \mathrm{~F}$. The pellets when in operation in a water body (at the conclusion of the desalination trials) had a capacitance $(F)$ of between 10 and $20,000 \times 10^{-6} \mathrm{~F}$ and had an effective stored charge within the range 0.00001 to $0.3 \mathrm{~kJ}\left(E=0.0006\right.$ to $\left.16.7 \mathrm{Wh} \cdot \mathrm{kg}^{-1}\right)$.

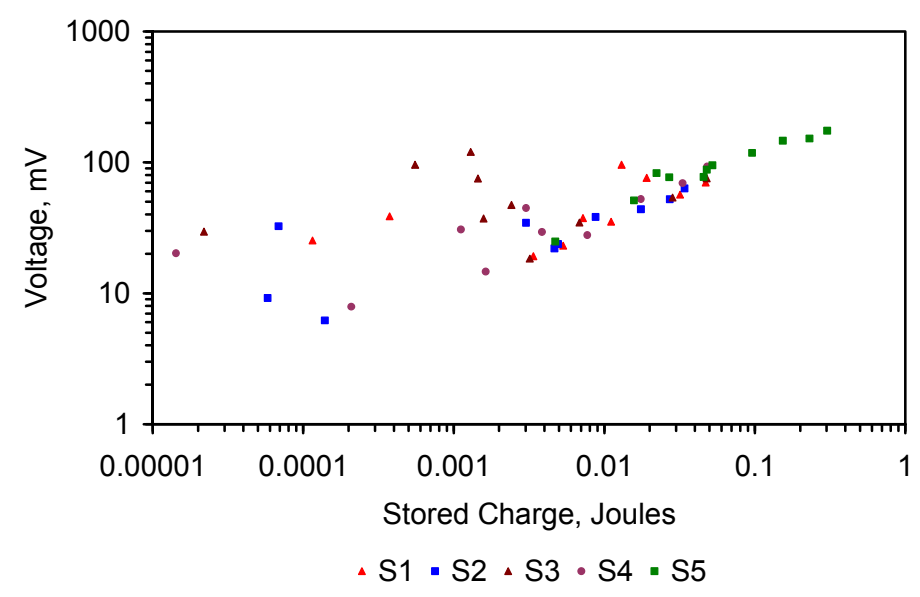

Figure 14. Relationship between measured voltage and stored charge associated with ZVM pellets.

This observation is consistent with a desalination model where the capacitance comes from charge storage at the ZVM TP-electrolyte (water) interface [143] and the specific capacitance and current 
density reduces with time. This is discussed further in Appendices F2.2 and H and is illustrated in Figures F2, F3 and H1.

\subsubsection{Desalination Model Associated with ZVM TP}

In $\mathrm{Fe}^{0}: \mathrm{Na}-\mathrm{Fe}_{2} \mathrm{O}_{3}: \mathrm{C}$ capacitors $[143,144]$ structural dislocations resulting from $\mathrm{Na}^{+}$release reduce the permeability (and efficiency) of the capacitor with time. The $\mathrm{Fe}_{2} \mathrm{O}_{3}$ section of the $\mathrm{Fe}^{0}: \mathrm{Na}_{-}-\mathrm{Fe}_{2} \mathrm{O}_{3}: \mathrm{C} \mathrm{ZVM}$ unit can be schematically viewed [89] as a composite slab (Figure 15) composed of different $\mathrm{Fe}_{n} \mathrm{O}_{2}$ layers (AB, CA, BC).

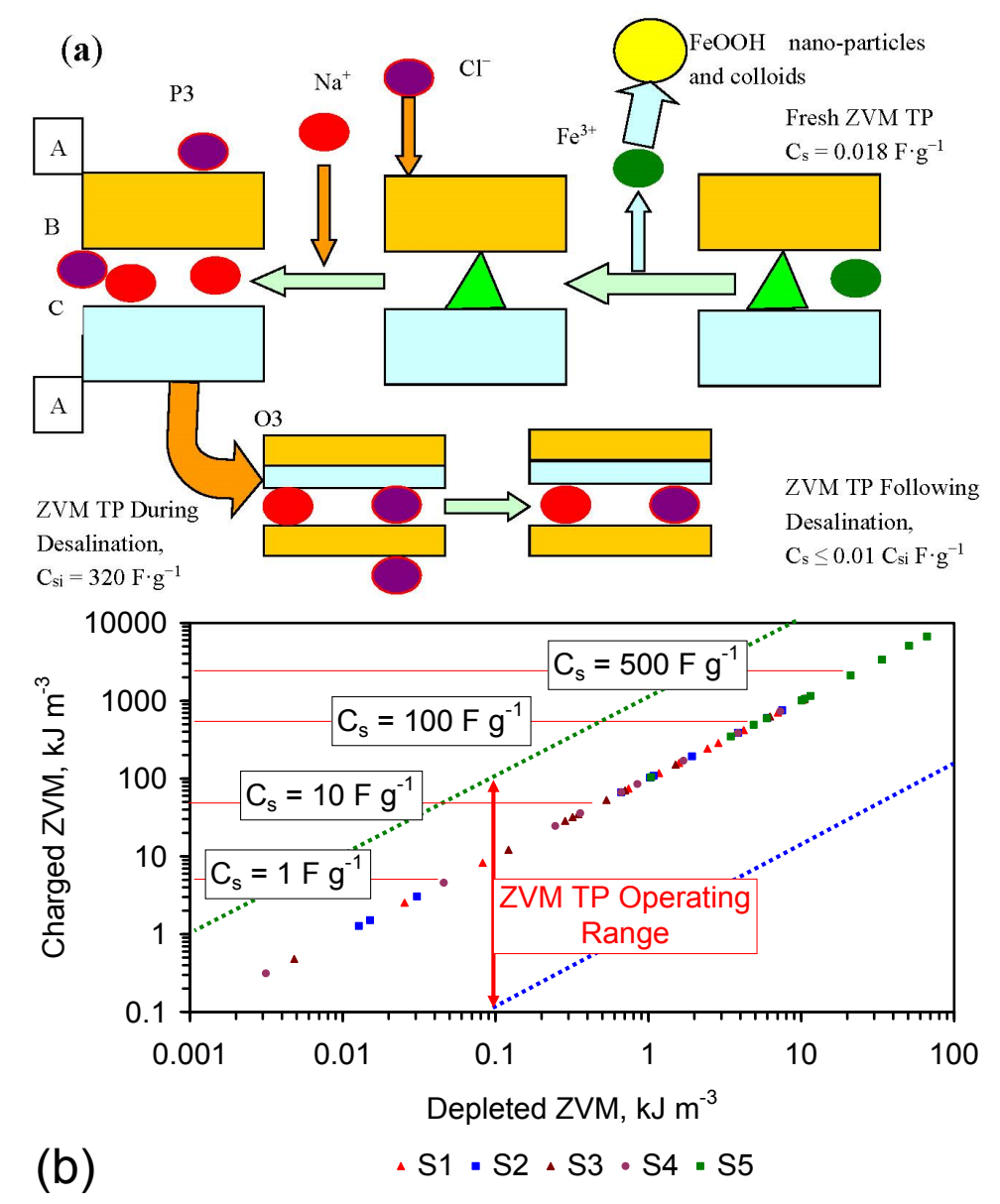

Figure 15. (a) Schematic representation of the structural changes which occur in the anodic $\mathrm{Fe}_{2} \mathrm{O}_{3}$ schiller sheets (Figure F1) during desalination of water. $C_{\mathrm{s}}$ values are taken from Table 4 and Figure 15b; (b) Stored energy contained in the ZVM TP during desalination and following desalination.

The first stage in the desalination process is the formation of prismatic structures (e.g., colloidal nanoparticles, or Schiller sheets) containing tetrahedral sites occupied by $\mathrm{Fe}^{3+}$. $\mathrm{FeOOH}$ grows as Schiller sheets, when templated on a substrate $[87,88]$.

The initial $\mathrm{Fe}_{2} \mathrm{O}_{3}$ corrosion product adopts a cuboid structure (P3) dominated by prismatic sites of the form $(\mathrm{AB}, \mathrm{BC}, \mathrm{AC})$ (Figure 15) during the initial part of the charge cycle [89]. The $\mathrm{Na}^{+}$ions are accommodated at the octahedral sites located between the $\mathrm{Fe}_{n} \mathrm{O}_{2}$ layers $(\mathrm{AB}, \mathrm{CA}, \mathrm{AB})$ [89]. This $\mathrm{O}_{3}$ structure develops during cell charging (desalination) [89]. The prismatic sites are energetically 
stabilized by the $\mathrm{Na}_{x} \mathrm{O}$ ions [89]. The glide vectors of the $\mathrm{Fe}_{n} \mathrm{O}_{2}$ layers during this transition can create a variety of staking faults in the crystal structures particularly during $\mathrm{Na}^{+}$extraction (reversals of the desalination process) [89] caused by temperature, Eh and $\mathrm{pH}$ oscillations [5,6,18]. During $\mathrm{Na}^{+}$extraction vacant face sharing tetrahedral sites are formed between the $\mathrm{Fe}_{n} \mathrm{O}_{2}$ layers (Figure 15) [89]. These sites are filled by $\mathrm{Fe}^{3+}$ (and other cations contained in the water) [89]. The $\mathrm{Fe}_{2} \mathrm{O}_{3}-$ water interface is characterized by an outer layer of adsorbed $\mathrm{H}^{+}$ions [145]. This positively charged surface attracts the negatively charged $\mathrm{Cl}^{-}$ions (which are present as $\mathrm{Na}^{+}: \mathrm{Cl}^{-}$dissolved ion adducts [145].

These observations demonstrate the type of Fe corrosion structure required in the ZVM TP to maximise $\mathrm{NaCl}$ removal.

\subsection{Statistical Analysis of the Change in Salinity with Time}

The analyses in $\mathrm{C} 1$ to $\mathrm{C} 17$ (collated in Figure 16) indicate that passive diabatic desalination at ambient temperatures is gradual with a progressive increase in the amount of $\mathrm{NaCl}$ removed with time. A proportion of trials showed an initial increase in EC due to the release of ions from the ZVM TP into the water. All of the trials established some level of desalination after 120-150 days. The highest levels of desalination were associated with the most saline water (i.e., the rate of desalination increases with increasing water salinity) (Figure 16).
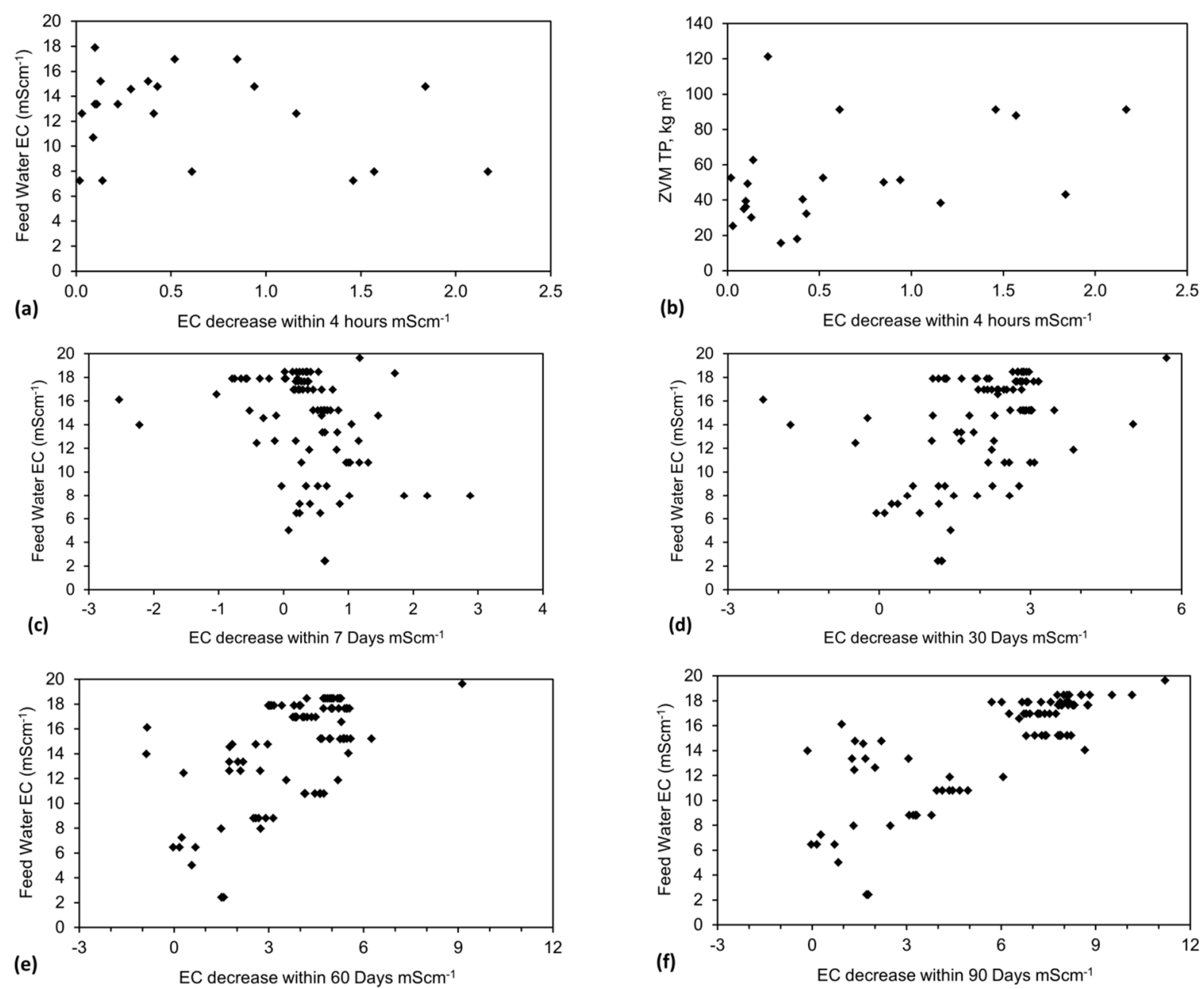

Figure 16. Cont. 

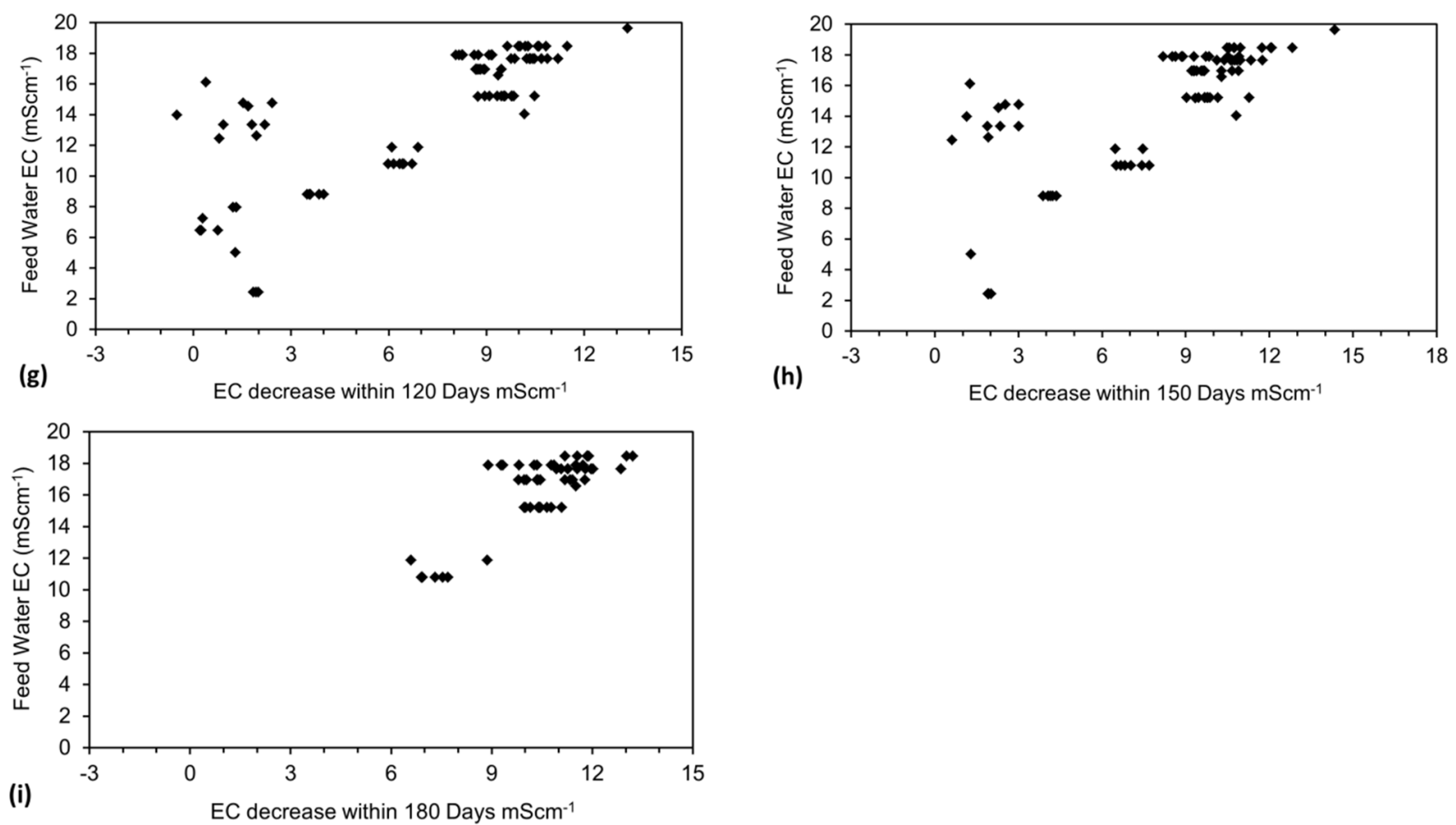

Figure 16. Statistical Trials: Relationship between EC change and the time interval which has lapsed following placement of the ZVM TP in the water. (a) Observed EC declines within 4 h; (b) ZVM TP concentrations associated with declines observed in a 4 h period; (c) Observed EC changes within 7 days; (d) Observed EC changes within 30 days; (e) Observed EC changes within 60 days; (f) Observed EC changes within 90 days; (g) Observed EC changes within 120 days; (h) Observed EC changes within 150 days; (i) Observed EC changes within 180 days; All the trials were undertaken simultaneously. Temperature: Figure 1.

\subsection{Cost of Desalination Using ZVM TP}

Figures 16 and $\mathrm{C} 1-\mathrm{C} 17$ have established that placement of ZVM TP in water will result in a decline in water EC and salinity. The magnitude of the salinity decline is sufficient to have a substantial impact on crop yields (Figure B1) if the water is used for irrigation, or livestock yields if the water is used as livestock feed water (Figure B2).

\subsubsection{Economics of ZVM TP without Reuse or Regeneration}

The cost of $\mathrm{Fe}^{0}$ powders varies with time, grade, and location. The desalination cost is:

$$
\text { Desalination Cost, } \$ \cdot \mathrm{m}^{-3}=\left(\left(\left(W_{\mathrm{s}} / Q_{\mathrm{e}}\right)\left(P_{\mathrm{Fe}}\right)\right) / R_{\mathrm{u}}\right)-\left(P_{\mathrm{w}} R_{\mathrm{v}}\right)
$$

where $W_{\mathrm{s}}=$ water salinity drop required, $\mathrm{kg} \cdot \mathrm{m}^{-3} ; P_{\mathrm{FE}}=\mathrm{ZVM}$ cost, $\$ \cdot \mathrm{t}^{-1} ; R_{\mathrm{u}}=$ number of times the ZVM TP is reused; $R_{\mathrm{v}}=$ Residual value, $\$ \cdot \mathrm{t}^{-1}$, of the ZVM TP. The desalination cost reduces as $W_{\mathrm{s}}$ reduces, $P$ Fe reduces, $Q_{\mathrm{e}}$ increases, $R_{\mathrm{u}}$ increases, $P_{\mathrm{w}}$ decreases, and $R_{\mathrm{v}}$ increases.

For example, if the $\mathrm{Fe}^{0}$ powders are sourced for $\$ 400-\$ 900 \mathrm{t}^{-1}$, then based on $Q_{\mathrm{e}}=300 \mathrm{~kg} \cdot \mathrm{t}^{-1}$, $1 \mathrm{t} \mathrm{Fe}^{0}$ will be expected to remove $300 \mathrm{~kg} \mathrm{NaCl}$. The cost of desalination $\left(\$ \cdot \mathrm{m}^{-3}\right)$ is a function of the salinity reduction required (Figure 17) and the number of times a batch of ZVM TP can be reused. 


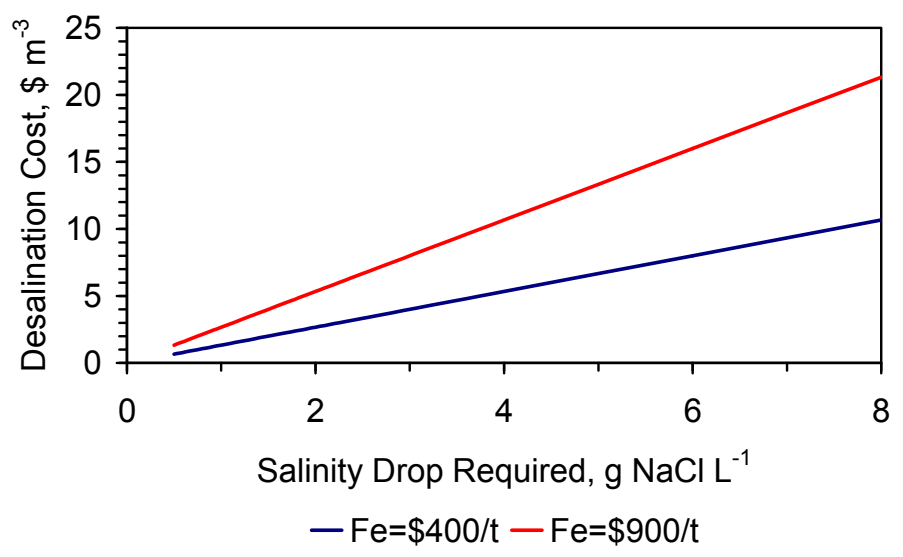

Figure 17. Desalination cost using ZVM TP, assuming no residual value for the ZVM TP and no reuse of the ZVM TP. $P_{\mathrm{w}}$ of $20 \mathrm{~g} \cdot \mathrm{L}^{-1}$, and $Q_{\mathrm{e}}=300 \mathrm{mg} \cdot \mathrm{g}^{-1}$.

\subsubsection{Reuse of the ZVM TP}

The residual ZVM TP can be reused as a water treatment agent, or reprocessed for reuse as a desalination agent, or can be reused as an iron ore feedstock, or can be reused as a gas desulphurization agent (e.g., in an iron sponge), or reused in the construction of semi-conductors. The used ZVM TP can be regenerated as $\mathrm{Fe}^{0}$ (by reduction) or restructured (e.g., by $\mathrm{NaCl}$ removal) to allow reuse for desalination, or another purpose. An example life cycle for a batch of ZVM TP is illustrated in Figure 18.

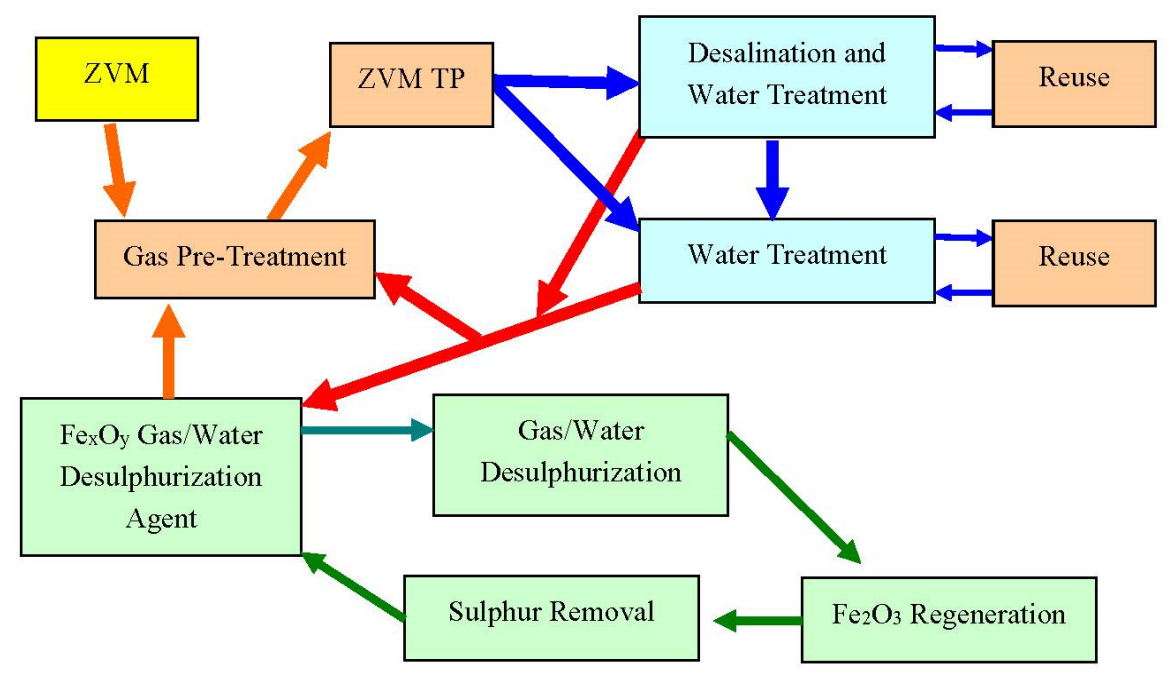

Figure 18. Example Life Cycle of a batch of ZVM TP which is used to desalinate water.

This residual value associated with reuse is location and application specific and will reduce the desalination cost further.

\subsubsection{Reuse of ZVM TP as an Iron Sponge}

The iron sponge gas desulphurization process has been in commercial use for $>100$ years [146]. It is based on the reaction $[147,148]$ : 


$$
\begin{gathered}
\text { In gas: } \mathrm{Fe}_{x} \mathrm{O}_{y}(\mathrm{~s})+y \mathrm{H}_{2} \mathrm{~S}(\mathrm{~g})=\mathrm{Fe}_{x} \mathrm{~S}_{y}(\mathrm{~s})+y \mathrm{H}_{2} \mathrm{O} \\
\text { In water: } \mathrm{H}_{2} \mathrm{~S}(\mathrm{~g})+\mathrm{H}_{2} \mathrm{O}=\mathrm{H}_{2} \mathrm{~S}(\mathrm{aq})=\mathrm{HS}^{-}+\mathrm{H}^{+} \\
2 \mathrm{Fe}^{3+}\left(\text { e.g., } \mathrm{Fe}_{2} \mathrm{O}_{3}\right)+\mathrm{HS}^{-}=2 \mathrm{Fe}^{2+}\left(\text { e.g., } \mathrm{Fe}_{3} \mathrm{O}_{4}\right)+\mathrm{H}^{+}+\mathrm{S}(\mathrm{s})
\end{gathered}
$$

$1 \mathrm{t} \mathrm{Fe}$ (contained in ZVM TP) may remove 0.3 to $0.83 \mathrm{t} \mathrm{S}$ contained in a gas (or water) before regeneration. The sulphur is recovered by floatation from water [148]. Regeneration of the iron sponge by blowing air through the iron sulphide product [146,148], or by blowing air through water containing the $2 \mathrm{Fe}^{2+}$ (e.g., $\left.\mathrm{Fe}_{3} \mathrm{O}_{4}\right)[148]$ :

$$
\begin{gathered}
2 \mathrm{Fe}_{2} \mathrm{~S}_{3}(\mathrm{~s})+3 \mathrm{O}_{2}(\text { air })=2 \mathrm{Fe}_{2} \mathrm{O}_{3}(\mathrm{~s})+6 \mathrm{~S}+\text { heat } \\
2 \mathrm{Fe}_{3} \mathrm{O}_{4}(\mathrm{~s})+0.5 \mathrm{O}_{2}(\text { air })=3 \mathrm{Fe}_{2} \mathrm{O}_{3}(\mathrm{~s})
\end{gathered}
$$

Treatment of the $n \mathrm{Fe}_{2} \mathrm{O}_{3}(\mathrm{~s})+m \mathrm{~S}$ mixture with water under $\mathrm{H}_{2}$ or $\mathrm{N}_{2}$ at a pressure of $10.1 \mathrm{MPa}$ (and elevated temperature) will result in the $\mathrm{Fe}_{2} \mathrm{O}_{3}$ catalysing the reaction [149]:

$$
n \mathrm{~S}(\mathrm{~s})+2 \mathrm{H}_{2} \mathrm{O}=\mathrm{SO}_{2}+(n-1) \mathrm{H}_{2} \mathrm{~S}+(3-n) \mathrm{H}_{2}
$$

This cyclic process allows the ZVM TP to be reused for desulphurization, desalination and water treatment. A potential life cycle for a batch of ZVM is shown in Figure 18. The full life cycle allows the costs (depending on location and market conditions) associated with the ZVM and pre-treatment to be amortized over the various reuse/reapplication stages (Figure 18). Equation (21) demonstrates that any $\mathrm{HS}^{-}$ions in the water will be reformulated during desalination to release sulphur and $\mathrm{H}^{+}$ions. This may allow both desulphuristion and desalination to be undertaken simultaneously.

The $\mathrm{H}_{2} \mathrm{~S}$ removal operating costs for a sour gas producer using Fe based technologies vary with gas composition, competition between suppliers, field, and geographical location. An indicative operating cost is in the range $\$ 10,000-30,000 \mathrm{t}^{-1}$ sulphur removed. This indicates that if the ZVM TP (following desalination) can be sold for reuse as a sulphur removal agent for $\$ 400-\$ 950 \mathrm{t}^{-1}$, the effective cost of desalinating the water will reduce to $\$ 0 \mathrm{~m}^{-3}$. The gross sales price is $\$ 550-\$ 1,350 \mathrm{t}^{-1}$ sulphur removed.

\subsubsection{Reducing the Capital Costs Associated with Desalination}

$Q_{\mathrm{e}}$ and $P_{\mathrm{w}}$ define the amount of ZVM TP required to achieve a specific level of desalination. The time taken to achieve the required level of desalination is defined by the EC decline rate. The size of desalination facilities required is therefore a function of the amount of desalinated water required per unit time and the time taken to process a batch of water to a specific salinity level.

Trials ST1a to ST5j established that the salinity declined to a stable or equilibrium level and then abruptly ceased (Figures C5-C9). A number of freezing or partial freezing events occurred during the trials. The general decline in EC between the onset of the trial and the first freezing event was examined. In order to distinguish discussion of part of the trial, from the full trial data set, the following notation is used; (i) ST is replaced by S, i.e., ST1 becomes S1; (ii) The individual trial within a salinity grouping is labelled $\mathrm{T} 1$ to T10, i.e., ST1a becomes S1:T1. The individual plots of EC vs. time for each of these trials are provided as Figures D2-D6.

The decline in EC with time in each example can be modelled with a polynomial equation of the form:

$$
\mathrm{EC}, \mathrm{mS} \cdot \mathrm{cm}^{-1}=\left(\mathrm{A} x^{2}-\mathrm{B} x+\mathrm{C}\right) / F
$$


where $x=$ day number. In this study the first day of the trial is Day 59. A, B and C are constants. $\mathrm{C}$ represents the salinity $(\mathrm{EC})$ at Day $=0 . \mathrm{C}$ can be replaced with salinity of the water at the onset of desalination. In this instance $x$ can be replaced with the number of days since the onset of desalination. $F=$ a factor required to the change units in the equation to $\mathrm{mS} \cdot \mathrm{cm}^{-1}$ (e.g., Figure E3) The observed polynomial regression equations for each trial are provided in Figures D2-D6.

The same data set (Figures D2-D6) could be interpreted using a regression power, or exponential function. The general exponential equation is:

$$
\mathrm{EC}, \mathrm{mS} \cdot \mathrm{cm}^{-1}=\left(\mathrm{C} \cdot \mathrm{e}^{(-\mathrm{D} x)}\right) / \mathrm{F}
$$

where $\mathrm{D}=$ constant. The observed values of $\mathrm{D}$ ranged between 0.0042 and 0.0109 (Figure 19). $R^{2}$ (for the exponential equation) was typically $>0.91$, but ranged between 0.604 and 0.995 (Figures D2-D6). Constant D reduces as the concentration of ZVM TP, or ZVM TP $+\mathrm{Cu}^{0}$ copper sheathing increases (Figure 19). The observed values of $\mathrm{D}$ and $R^{2}$ are provided in Figures D2-D6 for Trials ST1a-ST5j).

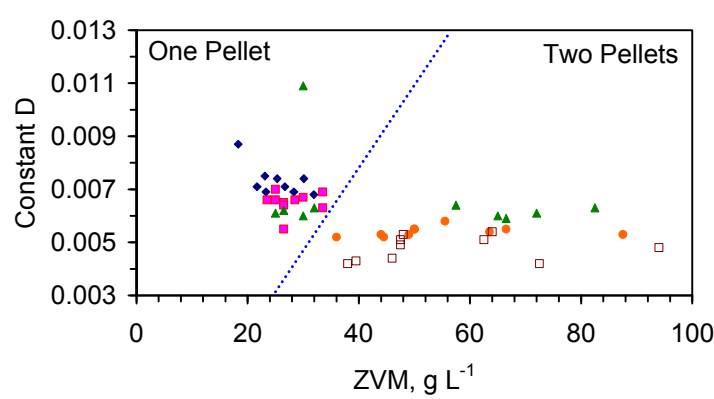

(a)

-S1: -S2: $\triangle \mathrm{S} 3: \cdot \mathrm{S} 4: \square \mathrm{S} 5:$

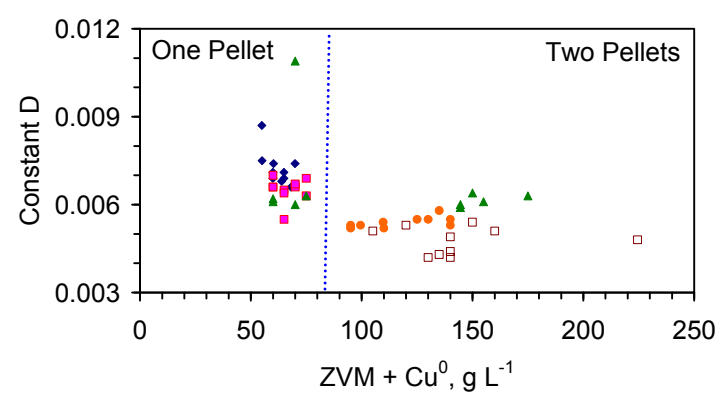

(c)

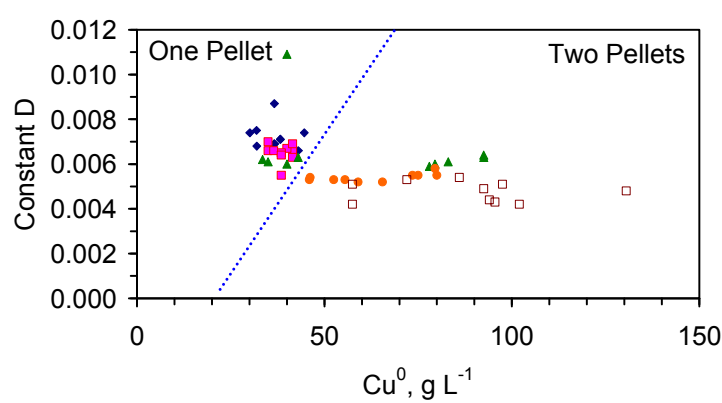

(b)

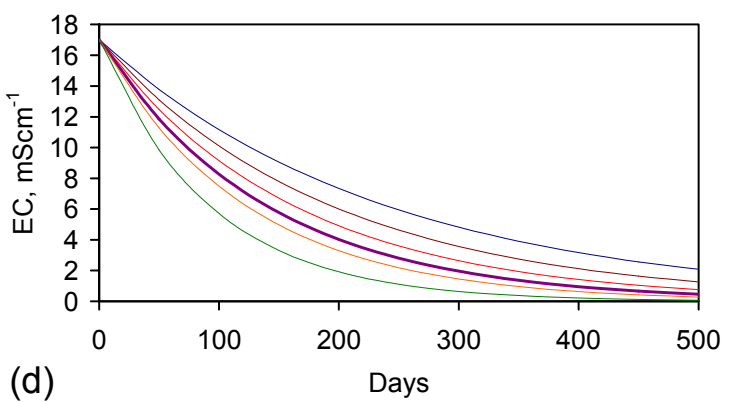

$-0.0042-0.0052-0.0062-0.0072-0.0082-0.0109$

Figure 19. Redox desalination constants (D) associated with an exponential regression correlation. (a) Constant D vs. ZVM concentration; (b) Constant D vs. weight of $\mathrm{Cu}^{0}$ pellet sheath; (c) Constant $\mathrm{D}$ vs. weight of $\mathrm{ZVM}+\mathrm{Cu}^{0}$ pellet sheath; (d) $\mathrm{EC}$ vs. Length of desalination period (days), for the observed range of values of Constant $\mathrm{D}$, and Constant $\mathrm{C}$ (initial salinity) $=17 \mathrm{mS} \cdot \mathrm{cm}^{-1}$ at $t=0$ days.

The unit cost of desalination $\left(\$ \cdot \mathrm{m}^{-3}\right)$ decreases as $P_{\mathrm{w}}$ decreases. The size of the facilities required to process a specific volume of water each year (and the length of time required to process a batch of water) decreases as Constant D increases.

$Q_{\mathrm{e}}$ and $P_{\mathrm{w}}$ control the amount of $\mathrm{NaCl}$ that can be removed by a specific batch of $\mathrm{ZVM}$ and control operating costs. Constant $\mathrm{D}$ controls the size of the facilities required (capital costs), and associated land take required, to deliver a specific volume of water per unit time. 
Trials PS15, and PS16 (see Section 6) demonstrate that Constant D can be increased to $>0.04$ by operating the desalination process in a pressured reactor (operated at $<0.1 \mathrm{MPa}$ ) where air is replaced by $\mathrm{CO}_{2}$ and $\mathrm{N}_{2}$. For example, processing of $1000 \mathrm{~m}^{3}$ in an open tank or reservoir with Constant $\mathrm{D}=0.07$ (Figure 19) will take 148 days to reduce the salinity from 10 to $3.68 \mathrm{~g} \cdot \mathrm{L}^{-1}$. Operating the same ZVM TP (PS16) in a pressured reactor increases Constant D (Section 6) to 0.462. This will allow the same volume of water to be processed to the same salinity level $\left(3.68 \mathrm{~g} \cdot \mathrm{L}^{-1}\right)$ in 22 days. This would allow delivery of $1000 \mathrm{~m}^{3}$ of partially desalinated water over 148 days using a pressured batch reactor with a treatment capacity of $152 \mathrm{~m}^{3}$.

\subsubsection{Improving the Economics of Partial Desalination by Increasing the Operating Temperature}

The desalination can be defined in terms of a rate constant ( $\left.k_{\text {observed }}\right)$ [18] which is linked to both the amount of ZVM and surface area of the ZVM in the water, where $\left[R_{\mathrm{ad}}\right]=\left(\left[a_{\mathrm{s}}\right] \cdot\left[a_{\mathrm{a}}\right]\right) .\left[R_{\mathrm{ad}}\right]$ represents the number of available reaction or adsorption sites on the ZVM TP. It follows that:

$$
k_{\text {observed }}=k_{\text {actual }} \times\left[P_{\mathrm{w}}\right] \times\left[R_{\mathrm{ad}}\right]
$$

At a constant $\left[P_{\mathrm{w}}\right]$ the reduction of $\mathrm{NaCl}$ to products must therefore adopt the general form [150]:

$$
\text { Rate }=k \times[\mathrm{NaCl}]^{m}
$$

where $m=$ the reaction order, $k=$ rate constant. The [Rate] according to the Rate law relates the rate of reaction to the concentration of reactants (and catalyst) raised to various powers [150]. It therefore follows that if the concentration of $\mathrm{NaCl}$ in the water is changed from a concentration $\left[C_{1}\right]$ to a concentration $\left[C_{2}\right]$ the [Rate] of desalination must change to [150]:

$$
\text { Rate }=\left(\left[C_{2}\right] /\left[C_{1}\right]\right)^{m} \times k \times[\mathrm{NaCl}]^{m}
$$

The change in $\left(\left[C_{2}\right] /\left[C_{1}\right]\right)^{m}$ accounts for all or part of the decline in the rate of desalination with time associated with different starting salinity concentrations.

The [Rate] can be calculated [90] as:

$$
\text { Rate }=-\Delta[\mathrm{NaCl}] / \Delta t=\left(\left[C_{2}\right] /\left[C_{1}\right]\right)^{m} \times k \times[\mathrm{NaCl}]^{m}
$$

The Arrhenius equation requires that [124]:

$$
k=A \mathrm{e}^{[-E / R T]}
$$

where $A=$ frequency factor, $E=$ activation energy, $\mathrm{kJ} \cdot \mathrm{M}^{-1}, R=$ gas constant, $T=$ temperature, $\mathrm{K}$. It follows that the desalination rate will vary with temperature, and $E$, where different ZVM combinations will have different values of $E$.

The desalination reaction will progress to equilibrium, where the equilibrium constant $\left(K_{\mathrm{c}}\right)$ is $[18,150]$

$$
\begin{gathered}
K_{\mathrm{c}}=[\text { Products }]^{\mathrm{a} /}[\text { Reactants }]^{\mathrm{b}} \\
\Delta G^{0}=-R T \cdot\left(\ln K_{\mathrm{c}}\right) \\
\Delta E^{0}=-R T / n \mathrm{~F} \cdot\left(\ln K_{\mathrm{c}}\right)
\end{gathered}
$$

where $\Delta E^{0}=$ standard electropotential; $n=$ number of electrons transferred; $\mathrm{F}=$ Faraday constant; $\Delta G^{0}=$ Standard Gibbs Free Energy. A change in state (e.g., $T$, Eh and $\mathrm{pH}$ ) changes $\Delta G, \Delta E$ and $K_{\text {c }}$. 


\subsubsection{Relationship between EC (Salinity) Reduction and Temperature}

Equations (26)-(31) demonstrate that the desalination rate is a function of temperature. Therefore operation of a reactor at elevated temperatures may increase the rate of desalination.

A trial (CSD series (Tables D1, D2 and 5)) was established using a reactor containing $8 \mathrm{~L}$ saline water and a $0.4 \mathrm{~L}$ cartridge containing ZVM TP constructed from $224 \mathrm{~g} \mathrm{Fe}^{0}+35 \mathrm{~g} \mathrm{Al}^{0}$ (Tables D1 and D2) The partial pressure in the water was maintained within the range 0-0.1 MPa. The same ZVM TP batch was reused in each of Trials CSD1a to CSD1d. The operating parameters were:

1. Trial CSD1a: The trial duration was $15 \mathrm{~h}$ during which time the water temperature was raised from 5 to $50{ }^{\circ} \mathrm{C}$. Air was bubbled through the water at a rate of $55 \mathrm{~mL} \cdot \mathrm{min}^{-1}$.

2. Trial CSD1b: The trial duration was $124 \mathrm{~h}$ during which time the water temperature was raised from 5 to $44{ }^{\circ} \mathrm{C}$. Air was bubbled through the water at a rate of $64 \mathrm{~mL} \cdot \mathrm{min}^{-1}$.

3. Trial CSD1c: The trial duration was $30 \mathrm{~h}$ during which time the water temperature was raised from 7 to $39^{\circ} \mathrm{C}$. Air was bubbled through the water at a rate of $60 \mathrm{~mL} \cdot \mathrm{min}^{-1}$.

4. Trial CSD1d: The trial duration was $11 \mathrm{~h}$ during which time the water temperature was raised from 7 to $36{ }^{\circ} \mathrm{C}$. Air was bubbled through the water at a rate of $22 \mathrm{~mL} \cdot \mathrm{min}^{-1}$ for $4.7 \mathrm{~h}$ followed by $15 \mathrm{~mL} \cdot \mathrm{min}^{-1} 80 \% \mathrm{~N}_{2}+20 \% \mathrm{CO}_{2}$.

The gases were not bubbled through the ZVM TP. The trial results are summarized in Table 5. This trial established that increasing temperature:

1. increases the rate of desalination;

2. allows the ZVM TP to be reused to sequentially partially desalinate batches of saline water;

3. allows the salinity of the product water to reduce below $0.2 \mathrm{gNaCl} \cdot \mathrm{L}^{-1}$.

Table 5. Feed and product water compositions: CSD Trials.

\begin{tabular}{|c|c|c|c|c|c|c|c|c|c|}
\hline \multirow{2}{*}{ Trial } & \multicolumn{2}{|c|}{ Feed Water } & \multirow{2}{*}{$\begin{array}{c}\mathrm{EC} \\
\mathbf{m S} \cdot \mathbf{c m}^{-1}\end{array}$} & \multirow{2}{*}{$\begin{array}{c}\text { Salinity, } \\
\mathrm{g} \cdot \mathbf{L}^{-1}\end{array}$} & \multicolumn{2}{|c|}{ Product Water } & \multirow{2}{*}{$\begin{array}{c}\mathrm{EC} \\
\mathbf{m S} \cdot \mathbf{c m}^{-1}\end{array}$} & \multirow{2}{*}{$\begin{array}{l}\text { Salinity, } \\
\mathbf{g} \cdot \mathbf{L}^{-1}\end{array}$} & \multirow{2}{*}{$\begin{array}{c}\mathrm{NaCl} \\
\text { Removed, } \\
\mathrm{g} \cdot \mathrm{L}^{-1}\end{array}$} \\
\hline & Eh, V & pH & & & Eh, V & pH & & & \\
\hline CSD1a & 0.277 & 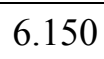 & 4 & 00 & 0 & 6 & 0 & 4 & 2.306 \\
\hline CSD1b & 0.188 & 5.920 & 4.540 & 2.500 & 0.130 & 6.900 & 0.556 & 0.200 & 2.300 \\
\hline CSD1c & 0.088 & 6.700 & 4.760 & 2.625 & 0.219 & 6.020 & 1.830 & 0.888 & 1.737 \\
\hline CSD1d & 0.174 & 5.970 & 5.450 & 3.000 & 0.233 & 5.440 & 3.670 & 1.882 & 1.118 \\
\hline
\end{tabular}

The cost of reducing the average feed water salinity from $2.65 \mathrm{gNaCl} \cdot \mathrm{L}^{-1}$ to an average salinity of $0.791 \mathrm{~g} \cdot \mathrm{L}^{-1}$ (CSD1a-CSD1d) (based on a $\mathrm{Fe}^{0}$ price of $\left.\$ 400 \mathrm{t}^{-1}\right)$ is $\$ 2.8 \mathrm{~m}^{-3}\left(\$ 2.28-\$ 6.3 \mathrm{~m}^{-3}\right.$ at a Fe price of $\left.\$ 325-\$ 900 \mathrm{t}^{-1}\right)$.

The product water from Examples CSDla and CSD1b (Table 5) meet the EU, WHO and Indian definition of potable water. These results indicate that ZVM TP can be used to create potable water at temperatures of $<50^{\circ} \mathrm{C}$ over a period of $<24 \mathrm{~h}$. The cost of providing the potable water in CSD1a $+\mathrm{CSD} 1 \mathrm{~b}$ (based on a $\mathrm{Fe}^{0}$ price of $\$ 400 \mathrm{t}^{-1}$ ) is $\$ 5.6 \mathrm{~m}^{-3}\left(\$ 4.55-\$ 12.6 \mathrm{~m}^{-3}\right.$ at a $\mathrm{Fe}^{0}$ price of $\$ 325-\$ 900 \mathrm{t}^{-1}$ ).

Potable water definitions vary with country. Examples include:

1. $\mathrm{EU}[151]$ : Salinity $=0.45 \mathrm{gNaCl} \cdot \mathrm{L}^{-1}, \mathrm{EC}<2.5 \mathrm{mS} \cdot \mathrm{cm}^{-1}, 6.5<\mathrm{pH}<9.5$; 
2. WHO [152,153]: Salinity $\leq 0.6 \mathrm{gCl}^{-} \cdot \mathrm{L}^{-1}+$ less than $0.2 \mathrm{gNa}^{+} \cdot \mathrm{L}^{-1}, \mathrm{pH}=$ no restriction [146];

3. India [154]: Salinity $=0.25 \mathrm{gCl}^{-} \cdot \mathrm{L}^{-1}$ (may be locally extended to $1 \mathrm{~g} \cdot \mathrm{L}^{-1}$ ), $6.5<\mathrm{pH}<8.5$ (may be locally extended to $\mathrm{pH} 9.2$ ).

Trials CSD1a and CSD1b established that a reduction in temperature from 50 to $44{ }^{\circ} \mathrm{C}$ increased the length of time required to produce potable water $\left(<0.2 \mathrm{gNaCl} \cdot \mathrm{L}^{-1}\right)$ (feed water salinity $\left.=2.5 \mathrm{~g} \cdot \mathrm{L}^{-1}\right)$ from 15 to $124 \mathrm{~h}$. Trial CSD1 demonstrates that operating ZVM TP (CSD1a) at a temperature in the range 50-75 ${ }^{\circ} \mathrm{C}$ will produce potable water within $15 \mathrm{~h}$ for a cost of $<\$ 2.8 \mathrm{~m}^{-3}$ from a small (e.g., $<10 \mathrm{~m}^{3}$ ) or large scale (e.g., $>10,000 \mathrm{~m}^{3}$ ) heated water tank.

Following completion of trial CSD1d, the residual water $(0.4 \mathrm{~L})$ in the manifold and ZVM cartridge was recovered (on recovery: $\mathrm{Eh}=0.097 \mathrm{~V} ; \mathrm{pH}=5.84 ; \mathrm{EC}=10.650 \mathrm{mS} \cdot \mathrm{cm}^{-1}$; after 6 weeks storage: $\left.\mathrm{Eh}=0.166 \mathrm{~V} ; \mathrm{pH}=7.41 ; \mathrm{EC}=17.12 \mathrm{mS} \cdot \mathrm{cm}^{-1}\right)$. These observations demonstrate the presence of a halocline between the main water body $\left(\mathrm{EC}=3.67 \mathrm{mS} \cdot \mathrm{cm}^{-1}\right)$ and the manifold and $\mathrm{ZVM}$ container $\left(\mathrm{EC}=10.650 \mathrm{mS} \cdot \mathrm{cm}^{-1}\right)$. They also demonstrate that:

1. The ZVM TP modifies the salinity of the water adjacent to the ZVM TP by removing $\mathrm{NaCl}$ from the overlying water body.

2. The removal of $\mathrm{NaCl}$ can occur when the water body is static (e.g., ST1a-ST5j series of trials) or when the bulk of the water body is in constant movement due to gas bubbling and the water column connecting the ZVM TP to the moving water body is static.

\section{Results: ZVM TPA}

The ZVM TP analyses established that the rate of desalination could be enhanced to allow partial desalination in less than $24 \mathrm{~h}$ if:

1. The main water body was kept in a state of constant movement by an acid oxygenating $\left(\mathrm{N}_{2}: \mathrm{CO}_{2}\right)$, or oxygenating $\left(\mathrm{N}_{2}: \mathrm{O}_{2}\right)$ gas which was bubbled through the water;

2. The ZVM TP was held in a container which was separated from the main water body by a static water column.

Earlier studies [21,25] had established that high rates of desalination occurred in a continuously stirred water column [21], or a water column which was subject to argon gas bubbling [25]. In both the earlier studies the ZVM was fluidised by the water movement in the reactor.

High rates of desalination were also observed when ZVM was mixed with ion exchange material (Camontmorillonite) [5] in a static water environment.

The ZVM TPA trials were designed to create a reaction environment where the main water body was kept in a state of constant movement by an acid oxygenating $\left(\mathrm{N}_{2}: \mathrm{CO}_{2}\right)$, or oxygenating $\left(\mathrm{N}_{2}: \mathrm{O}_{2}\right)$ gas which was bubbled through the water and the ZVM TPA was held in a container which was separated from the main water body by a static water column.

\subsection{Desalination Using ZVI + Ion Exchange Material (ZVM TPA)}

Experiments using mixtures of ZVM and Ca-montmorillonite (ion exchange material) [5,6] have established that the presence of the ion exchange material limits the maximum $\mathrm{pH}$ (attributable to ZVM) 
and creates a low variation between the maximum $\mathrm{pH}$ and the equilibrium $\mathrm{pH}$. This can be reinforced by the addition of $\mathrm{Al}^{0}$ to the ZVM-ion exchange medium mixture [5]. The ZVM TP analysis has established that this will result in a low surface charge and a high $Q_{\text {e. }}$

Layered aluminium silicates (e.g., feldspars, feldspar derivatives (clays), and zeolites) contain charged sites (when placed in water). These sites (and associated hydration layers) allow them to attract $\left[\mathrm{Fe}\left(\mathrm{H}_{2} \mathrm{O}\right)_{6}\right]^{3+}$ ions and act as nuclei for Fe species growth.

Switching from ZVM TP to ZVM TPA allows the [ZVI-ion exchange material] combination to be used to facilitate (and accelerate) $\mathrm{NaCl}$ removal at ambient temperatures.

\subsection{Oxygenation and $\mathrm{CO}_{2}$}

\subsubsection{Oxygenated Water}

In an oxygenated environment radicals which include $\mathrm{NaO}^{-}, \mathrm{ClO}^{-}$(Figure $\mathrm{C} 37$, Appendix $\mathrm{H}$ ) develop:

$$
\begin{gathered}
\mathrm{Na}^{+}+0.5 \mathrm{O}_{2}+n \mathrm{H}_{2} \mathrm{O}+2 \mathrm{e}^{-}=\left[(\mathrm{NaO})\left(\mathrm{H}_{2} \mathrm{O}\right)_{n}\right] \bullet^{1^{-}} \\
\mathrm{Na}^{+}+0.5 \mathrm{O}_{2}{ }^{2-}+n \mathrm{H}_{2} \mathrm{O}+\mathrm{e}^{-}=\left[(\mathrm{NaO})\left(\mathrm{H}_{2} \mathrm{O}\right)_{n}\right]^{\bullet-} \\
\mathrm{Na}^{+}+0.5 \mathrm{O}_{2}{ }^{-}+n \mathrm{H}_{2} \mathrm{O}+1.5 \mathrm{e}^{-}=\left[(\mathrm{NaO})\left(\mathrm{H}_{2} \mathrm{O}\right)_{n}\right]^{\bullet^{1-}} \\
\mathrm{Cl}^{-}+(1+n) \mathrm{H}_{2} \mathrm{O}=\left[(\mathrm{ClO})\left(\mathrm{H}_{2} \mathrm{O}\right)_{n}\right]^{\bullet^{1-}}+2 \mathrm{H}^{+}+\mathrm{e}^{-} \\
\mathrm{Cl}^{-}+\mathrm{Na}^{+}+0.5 \mathrm{O}_{2}+(1+n+m) \mathrm{H}_{2} \mathrm{O}=\left[(\mathrm{NaO})\left(\mathrm{H}_{2} \mathrm{O}\right)_{n}\right]^{\bullet-}+\left[(\mathrm{ClO})\left(\mathrm{H}_{2} \mathrm{O}\right)_{m}\right] \bullet^{1-}+2 \mathrm{H}^{+}
\end{gathered}
$$

\subsubsection{Acid Oxygenated Water}

In the presence of $\mathrm{CO}_{2}$ the radicals which include $\mathrm{HCO}_{3}{ }^{-}, \mathrm{CO}_{3}{ }^{2-}, \mathrm{NaO}^{-}$and $\mathrm{ClO}^{-}$(Figure $\mathrm{C} 37$, Appendix H) develop:

$$
\begin{aligned}
& \mathrm{Na}^{+}+\mathrm{CO}_{2}+(2+n) \mathrm{H}_{2} \mathrm{O}=\left[\left(\mathrm{CO}_{3}\right)(\mathrm{NaO})\left(\mathrm{H}_{2} \mathrm{O}\right)_{n}\right]^{\cdot{ }^{1-}}+4 \mathrm{H}^{+}+2 \mathrm{e}^{-} \\
& \mathrm{Na}^{+}+\mathrm{CO}_{2}+(2+n) \mathrm{H}_{2} \mathrm{O}=\left[\left(\mathrm{HCO}_{3}\right)(\mathrm{NaO})\left(\mathrm{H}_{2} \mathrm{O}\right)_{n}\right]^{\cdot{ }^{1-}}+3 \mathrm{H}^{+}+2 \mathrm{e}^{-}
\end{aligned}
$$

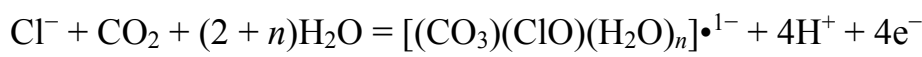

$$
\begin{aligned}
& \mathrm{Cl}^{-}+\mathrm{CO}_{2}+(2+n) \mathrm{H}_{2} \mathrm{O}=\left[\left(\mathrm{HCO}_{3}\right)(\mathrm{ClO})\left(\mathrm{H}_{2} \mathrm{O}\right)_{n}\right]^{1^{--}}+3 \mathrm{H}^{+}+4 \mathrm{e}^{-} \\
& \mathrm{Cl}^{-}+\mathrm{Na}^{+}+2 \mathrm{CO}_{2}+(4+n+m) \mathrm{H}_{2} \mathrm{O}=\left[\left(\mathrm{CO}_{3}\right)(\mathrm{NaO})\left(\mathrm{H}_{2} \mathrm{O}\right)_{n}\right]^{\bullet^{1-}}+\left[\left(\mathrm{CO}_{3}\right)(\mathrm{ClO})\left(\mathrm{H}_{2} \mathrm{O}\right)_{m}\right]^{\bullet^{1-}}+8 \mathrm{H}^{+}+6 \mathrm{e}^{-}
\end{aligned}
$$

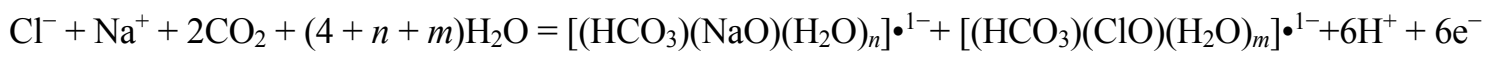

5.2.3. Reaction Quotient Associated with Desalination in Oxygenated or Acid Oxygenated Water

The reaction quotient, $Q$, is defined $[19,124]$ as:

$$
\begin{gathered}
Q=\left(\left[\mathrm{NaO}^{-}\right] \times\left[\mathrm{ClO}^{-}\right] \times\left[\mathrm{H}^{+}\right]^{2}\right) /\left(\left[\mathrm{Na}^{+}\right] \times\left[\mathrm{Cl}^{-}\right] \times\left[\mathrm{PO}_{2}\right]^{0.5}\right) \\
Q=\left(\left[\mathrm{NaO}^{-}\right] \times\left[\mathrm{ClO}^{-}\right] \times\left[\mathrm{CO}_{3}{ }^{2-}\right]^{2} \times\left[\mathrm{H}^{+}\right]^{8}\right) /\left(\left[\mathrm{Na}^{+}\right] \times\left[\mathrm{Cl}^{-}\right] \times\left[P_{\mathrm{CO} 2}\right]^{2}\right)
\end{gathered}
$$

5.2.4. Secondary Reaction Associated with Oxygenation by Air or Oxygen

Oxygenation of water creates the secondary reactions:

$$
\begin{gathered}
0.5 \mathrm{O}_{2}+\mathrm{H}_{2} \mathrm{O}+2 \mathrm{e}^{-}=2 \mathrm{OH}^{-} \\
2 \mathrm{OH}^{-}=\mathrm{H}_{2} \mathrm{O}_{2}+2 \mathrm{e}^{-} \\
\mathrm{OH}^{-}+\mathrm{H}^{+}=\mathrm{H}_{2} \mathrm{O}
\end{gathered}
$$


These result in a gradual increase in $\mathrm{pH}$ with oxidation to an equilibrium level (Figures $\mathrm{C} 18-\mathrm{C} 36$ ).

\subsubsection{Adverse Impact of $\mathrm{CO}_{2}$ Demonstrated by ZVM TP}

ZVM TP Trial CSD1c (Table 5) established that increasing the amount of $\mathrm{H}^{+}$in the product water decreased the amount of desalination. This was confirmed by trial CSD1d (Table 5) where $\mathrm{CO}_{2}$ is used to supply a source of $\mathrm{H}^{+}[19]$ :

$$
\begin{aligned}
& \mathrm{CO}_{2}+\mathrm{H}_{2} \mathrm{O}=\mathrm{HCO}_{3}{ }^{-}+\mathrm{H}^{+} \\
& \mathrm{CO}_{2}+\mathrm{H}_{2} \mathrm{O}=\mathrm{CO}_{3}{ }^{2-}+2 \mathrm{H}^{+}
\end{aligned}
$$

This adverse effect on desalination was not observed when the trials used ZVM TPA (Figures C33-C36).

\subsection{Primary Desalination Mechanism Associated with ZVM TPA}

Equation (32), Figure C37, and Appendix $\mathrm{H}$ demonstrate that the primary desalination mechanism involves oxidation of both $\mathrm{Na}^{+}$and $\mathrm{Cl}^{-}$and the $\mathrm{NaCl}$ is removed as $\left[(\mathrm{NaO})\left(\mathrm{H}_{2} \mathrm{O}\right)\right]^{{ }^{1-}},\left[(\mathrm{ClO})\left(\mathrm{H}_{2} \mathrm{O}\right)\right]^{{ }^{1-}}$, $\left[(\mathrm{ClO}-\mathrm{ClO})\left(\mathrm{H}_{2} \mathrm{O}\right)\right]^{\bullet},\left[(\mathrm{ClO}-\mathrm{ClO})\left(\mathrm{H}_{3} \mathrm{O}\right)\right]^{{ }^{1+}}$ radicals. These radicals are removed by electrostatic attraction to the ZVI [68] and ion exchange material. This allows $Q_{\mathrm{e}}>1.0$ [25]. It also allows a single charge of ZVM TPA to be reused multiple times at ambient temperatures.

This desalination mechanism was demonstrated using saline water (constructed using Cheshire halite ( $\mathrm{NaCl}$, rock salt)) and ZVM TPA, constructed from ZVM $+\mathrm{K}$-feldspar (held in cartridges) using four series of trials. The four series of trials are: E143, E144, E145 and E146 (Tables C5-C13, D3; Figures C18-C36).

Trials E143 and E144 were operated in a reactor containing 5.4 L water, with a basal ZVM TPA cartridge attached to the reactor via a manifold.

Trial E145 used a $114 \mathrm{~L}$ reactor containing $12 \mathrm{~g} \cdot \mathrm{L}^{-1} \mathrm{ZVM}$ TPA. The test results from E145 indicated that a larger reactor (Trial E146) utilizing $240 \mathrm{~L}$ and a lower ZVM TPA concentration (1.67 $\mathrm{g} \cdot \mathrm{L}^{-1}$ ZVM TPA (Table C3)) would be more effective. The ZVM TPA in Trial E145 and E146 was held in a cartridge. In Trial E146, the ZVM TPA cartridge was separated from the main water column by a static water body.

\subsection{Initial Trial: E143}

The ZVM TPA charge $\left(P_{\mathrm{w}}=25 \mathrm{gFe}^{0} \cdot \mathrm{L}^{-1}\right)$ was reused 11 times in the E143 series of trials (Tables C5-C8, Table D3). Details of the trial feed water parameters, product water parameters, salinity change, water consumption, gas charge, gas composition, trial duration, temperature, and product water stability are provided in Tables C5-C8. The treatment:

1. Achieved $Q_{\mathrm{e}(\text { apparent })}=0.738 \mathrm{gNaCl} \cdot \mathrm{g}^{-1} \mathrm{Fe}^{0} ; Q_{\text {e(after adjustment for water consumption })}=1.735 \mathrm{gNaCl} \cdot \mathrm{g}^{-1} \mathrm{Fe}^{0}$;

2. Processed $2.4 \mathrm{~L}$ water $\cdot \mathrm{g}^{-1} \mathrm{Fe}^{0}$;

3. Processed $59.4 \mathrm{~L}$ feed water $\left(3.96 \mathrm{gNaCl} \cdot \mathrm{L}^{-1}\right.$ average salinity) to produce $48.28 \mathrm{~L}$ product water $\left(2.28 \mathrm{gNaCl} \cdot \mathrm{L}^{-1}\right)$.

4. Demonstrated a partial desalination cost of $\$ 0.9 \mathrm{~m}^{-3}$ feed water (for a $\mathrm{Fe}^{0}$ cost of $\$ 400 \mathrm{t}^{-1}$ ). 
Specific observations are:

1. Product water $\mathrm{pH}>$ feed water $\mathrm{pH}$ when the $\mathrm{CO}_{2}$ content of the feed gas is $0 \%$, otherwise Product water $\mathrm{pH}<$ feed water $\mathrm{pH}$.

2. $\mathrm{NaCl}$ removal decreased with increasing usage of the ZVM TPA.

3. $\mathrm{NaCl}$ removal is associated with relatively high water consumption.

4. The $\mathrm{NaCl}$ removal reaction is partially reversible. Some trials (Table C8) demonstrated increases in product water salinity when one, or more, of the water $\mathrm{Eh}, \mathrm{pH}$ and/or temperature changed;

5. The product water composition is stable and initial $\mathrm{pH}$ values in the range 5-6, are changed after 6 weeks to $\mathrm{pH}$ values in the range 6-7 and remained stable at that level thereafter.

\subsubsection{Munsell Analysis}

Following completion of the Trial E143k the manifold and ZVM TPA cartridge were drained separately and analyzed.

1. $0.3 \mathrm{~L}$ (light orange colored; Munsell Parameters: hue $=5 \mathrm{YR}$; chroma $=12$; value $=7$ ) water was recovered from the manifold (on recovery: $\mathrm{Eh}=0.222 \mathrm{~V} ; \mathrm{pH}=5.31 ; \mathrm{EC}=44.75 \mathrm{mS} \cdot \mathrm{cm}^{-1}$; after 4 weeks storage: $\left.\mathrm{Eh}=0.275 \mathrm{~V} ; \mathrm{pH}=6.47 ; \mathrm{EC}=50.17 \mathrm{mS} \cdot \mathrm{cm}^{-1}\right)$.

2. $0.1 \mathrm{~L}$ (deep orange colored; Munsell Parameters: hue $=5 \mathrm{YR}$; chroma $=8$; value $=4$ ) water was recovered from the cartridge (on recovery: $\mathrm{Eh}=0.263 \mathrm{~V} ; \mathrm{pH}=5.15 ; \mathrm{EC}=425.4 \mathrm{mS} \cdot \mathrm{cm}^{-1}$ $\left(3.92 \mathrm{M} \mathrm{NaCl} \cdot \mathrm{L}^{-1}\right)$; after 4 weeks storage: $\left.\mathrm{Eh}=0.225 \mathrm{~V} ; \mathrm{pH}=6.48 ; \mathrm{EC}=350.37 \mathrm{mS} \cdot \mathrm{cm}^{-1}\right)$.

These observations confirm that $\mathrm{NaCl}$ is concentrated in the static water beside the $\mathrm{ZVI}$.

The Munsell parameters confirm that the nano-particles are akaganeite [155]. Akaganeite nano-particles darken in color as the particle size decreases [155], i.e., the Munsell value decreases [155]. The YR hue indicates that the $n-\mathrm{Fe}(\mathrm{OH})$ crystallites adopt a needle, or rod like, morphology [155]. A 5YR hue is consistent with the hydrated akaganeite $(\mathrm{FeOOH})$ crystallites containing $>0.15 \mathrm{M} \mathrm{Na}^{+} \cdot \mathrm{M}^{-1} \mathrm{Fe}^{0}[155]$.

\subsubsection{Halocline Analysis}

The average concentration of $\mathrm{NaCl}\left(\mathrm{g} \cdot \mathrm{L}^{-1}\right)$ in the cartridge approaches the eutectic concentration of $\mathrm{NaCl}$ at $23.3 \mathrm{wt} \% \mathrm{NaCl}\left(37.6 \mathrm{wt} \%\right.$ dehydrate $\left.\left(\mathrm{NaCl}: 2 \mathrm{H}_{2} \mathrm{O}\right)\right)$ [156] and may exceed the critical dehydrate concentration of $37.6 \mathrm{wt} \%$ [156]. The ZVM cartridge and manifold acted as a collector of $\mathrm{NaCl}$. The high concentrations of $\mathrm{NaCl}$ indicate that direct $\mathrm{NaCl}$ precipitation can occur within the $\mathrm{ZVM}$ bed once the concentration of $\mathrm{NaCl}$ exceeds the eutectic concentration [156].

These observations demonstrate that the water body in the reactor can become structured during operation with separate haloclines forming between the main water body and the manifold, and the manifold/cartridge and the ZVM. Each of the three water zones identified has a separate density, with density increasing as salinity increases.

The major variable in each trial was the amount of, and type of dissolved gases $\left(\mathrm{N}_{2}, \mathrm{O}_{2}, \mathrm{CO}_{2}\right)$, entered into the water. The permeability of the water $\left(k_{\mathrm{w}}\right)$ to a migration location (within the water) away from the gas source decreases exponentially with increasing distance $\left(D_{\mathrm{w}}\right)$ [157]. The differences in oxygenation may also result in the development of a thermocline, where the temperature of the 
oxygenated layer is greater than the temperature of the anoxic layer [157]. Haloclines can be manufactured by placing less saline water on top of more saline water [158].

The observations in Tables C4-C8 together with the development of chemoclines is consistent with a model that dimeric/ion adducts, or radicals, of the structure $\left[(\mathrm{NaO})\left(\mathrm{H}_{2} \mathrm{O}\right)_{n}\right]^{\bullet^{1-}},\left[(\mathrm{Na})\left(\mathrm{H}_{2} \mathrm{O}\right)_{n}\right]^{\bullet^{1+}}$, $\left[(\mathrm{Cl})\left(\mathrm{H}_{2} \mathrm{O}\right)_{n}\right]^{\bullet^{1-}},\left[(\mathrm{ClO})\left(\mathrm{H}_{2} \mathrm{O}\right)_{n}\right]^{1^{1-}},\left[(\mathrm{ClO}-\mathrm{OCl})\left(\mathrm{H}_{2} \mathrm{O}\right)_{n}\right] \bullet$ are formed in the main water body and migrate (and are concentrated) by electrostatic attraction towards the ZVM TPA.

\subsection{Long Duration Trial: E144}

This trial sought to determine if increasing the treatment time using ZVM TPA $\left(P_{\mathrm{w}}=9.4 \mathrm{gFe}^{0} \cdot \mathrm{L}^{-1}\right)$, resulted in increased $\mathrm{NaCl}$ removal. The trial results (Tables C9-C12) established that:

1. Product water salinity based on EC overestimated the actual water salinity (calculated from UVvisible spectrometry) due to the formation of nano-particles in the water;

2. Desalination using ZVM TPA has an optimum treatment time within the range 1 to $24 \mathrm{~h}$, though the amount of $\mathrm{NaCl}$ removed increases with time.

The trial demonstrated:

1. ZVM TPA can be reused

2. $32.4 \mathrm{~L}$ of feed water $\left(3.02 \mathrm{gNaCl} \cdot \mathrm{L}^{-1}\right)$ produced $24.15 \mathrm{~L}$ of product water $\left(1.56 \mathrm{gNaCl} \cdot \mathrm{L}^{-1}\right)$

3. An achieved $Q_{\mathrm{e}(\text { apparent })}$ of $0.932 \mathrm{gNaCl} \cdot \mathrm{g}^{-1} \mathrm{Fe}^{0} ; Q_{\text {e(after adjustment for water consumption) }}=1.25 \mathrm{gNaCl} \cdot \mathrm{g}^{-1} \mathrm{Fe}^{0}$;

4. Processimg of $0.63 \mathrm{~L}$ water $\cdot \mathrm{g}^{-1} \mathrm{Fe}^{0}$;

\subsection{Initial Upscaled Trial: E145}

A trial (Figure C19) in a $114 \mathrm{~L}$ reactor containing $1.449 \mathrm{~kg}$ ZVM TPA held in 5 cartridges established an increase in $\mathrm{pH}$ to an equilibrium level, which was associated with a decrease in Eh. $\mathrm{EC}$ was found to increase to an equilibrium level. The UV-visible spectrometry established a salinity decline which was associated with nano particle formation (Figure C19).

This initial trial indicated (Figure C19) that the oxygenation level used would have been more effective in a larger water body containing less ZVM TPA.

\subsection{Upscaled Trial: E146}

Following completion of the trial E145, a cartridge containing $400 \mathrm{~g}$ ZVM TPA was removed from the reactor used in Trial E145. This cartridge was reused by being placed in a $240 \mathrm{~L}$ reactor $\left(P_{\mathrm{w}}=0.52 \mathrm{gFe}^{0} \cdot \mathrm{L}^{-1}\right)$. This trial series, termed Trial E146, (Table C13, Figures C20-C36) establishes that the cartridge can be used to treat 18 batches of water (average feed water salinity $=2.66 \mathrm{~g} \cdot \mathrm{L}^{-1}$; average product water salinity $=1.53 \mathrm{~g} \cdot \mathrm{L}^{-1}$ ). The desalination cost demonstrated was $\$ 0.011 \mathrm{~m}^{3}$ (for a $\mathrm{Fe}^{0}$ cost of $\$ 400 \mathrm{t}^{-1}$ ). The 18th usage of the cartridge removed $3.6 \mathrm{~g} \cdot \mathrm{L}^{-1}$ (Table $\mathrm{C} 13$ ). The trial established that the reduced ZVM TPA concentration reduces the total nano-particle discharge into the water.

All the trials were undertaken using an air feed gas. Some of the trials were operated with a parallel trial using the same feed water (in a 5.4 L reactor), the Trial E144 ZVM TPA cartridge, and a feed gas 
containing $20 \% \mathrm{CO}_{2}+80 \% \mathrm{~N}_{2}$ (Figures $\mathrm{C} 33-\mathrm{C} 36$ ). These trials demonstrated lower rates of desalination than the air fed trials. The lower rates of desalination were associated with lower $\mathrm{pH}$ values and higher Eh values (Figures C33-C36).

In each example, using an air feed (Figures $\mathrm{C} 20-\mathrm{C} 36$ ), the product water $\mathrm{pH}$ is 1 to 1.5 units higher than the feed water, while the product water Eh is lower than the feed water Eh. The product water EC is higher than the feed water EC due to the formation of nano-particles. UV-visible spectrometry was used to assess the associated decline in salinity (Figures C20-C36).

A cross plot of feed water salinity vs. product water salinity (Figure 20), indicates that $\mathrm{NaCl}$ removal is a function of feed water salinity, where the total amount of $\mathrm{NaCl}$ removed increases with increasing feed water salinity. Removal rates are within the range $0.2-1 \mathrm{gNaCl} \cdot \mathrm{L}^{-1} \cdot \mathrm{h}^{-1}$.

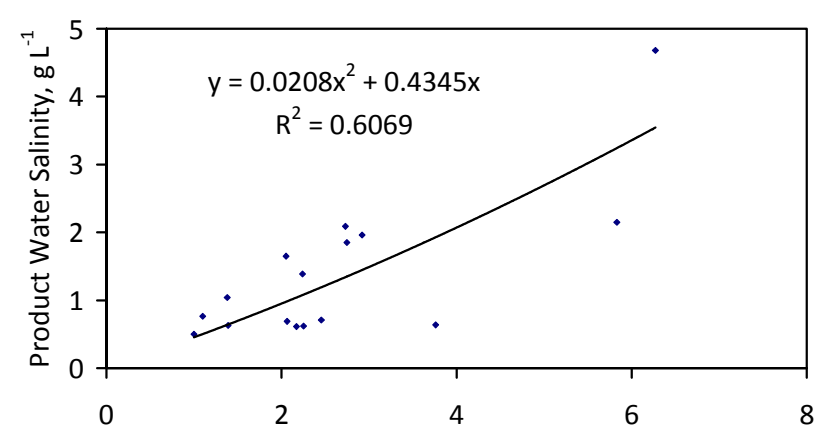

(a)

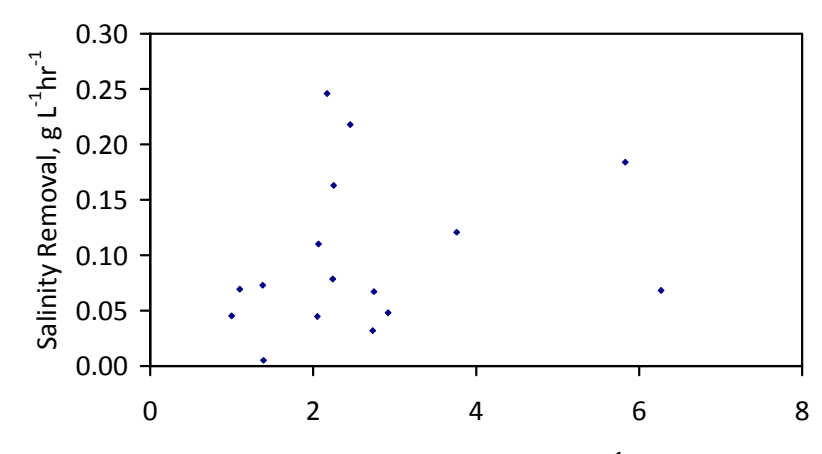

(b)

Figure 20. ZVM TPA example for the Trial Series E146a to E146q (Table C13). (a) Relationship between feed water salinity and product water salinity; (b) Relationship between feed water salinity and the rate of salinity removal.

Trials E145 and E146 confirmed the earlier observation [20] that placement of $\mathrm{Fe}^{0}$ powders in a circulating, oxygenated, water body will result in both an increase in EC and a decrease in salinity.

\subsection{Cost of ZVM TPA Desalination}

The economics of partial desalination using ZVM TPA is a function of both $P_{\mathrm{w}}$ and the number of times a specific charge can be reused. The number of times a specific charge can be reused will be a function of the feed water composition. Figures C19-C36 (Table C13) demonstrate that a single charge of $0.4 \mathrm{~kg}$ can be reused 18 times to partially desalinate $>4.0 \mathrm{~m}^{3}$ (i.e., $>10,500 \mathrm{~m}^{3} \cdot \mathrm{t}^{-1}$ ( $\mathrm{ZVM}+$ ion exchange material)). The ZVM TPA cost will vary with location, volume and commodity prices.

$\mathrm{K}$-feldspar prices (free on board (FOB)) range from $\$ 45-\$ 300 \mathrm{t}^{-1}$ [159-161]. The iron powder prices range from $\$ 325-\$ 900 \mathrm{t}^{-1} \mathrm{FOB}$. The ZVM TPA (Trial E146) material costs fall within the range \$132-\$1020 $\mathrm{t}^{-1} \mathrm{FOB}$, i.e., the partial desalination cost range demonstrated by Trial E146 (Table C13) is between $\$ 0.009$ and $\$ 0.026 \mathrm{~m}^{-3}$.

Trial E146 (Table C13) demonstrated that a single batch of $1 \mathrm{t}$ ZVM TPA could be used (with reuse) to partially desalinate $10,500 \mathrm{~m}^{3}$ water. Additional costs include transport, loading/unloading, ZVM TPA disposal, water tanks, air compression and monitoring costs. 
The ZVM TPA is designed for multiple reuse. The ZVM TP analyses established that a single use of a ZVM TP charge could result in high levels of desalination over a long time period. ZVM TPA Trials E144 and E145 (Figures 19-21, Table C13) establish that a more appropriate application for ZVM TPA is as a multiple use desalination agent.

The decreases in salinity, e.g., 40\%-55\% (Figure 21), indicate that the ZVM TPA can be used to partially desalinate irrigation water, or livestock feed water, within a $24 \mathrm{~h}$ period.

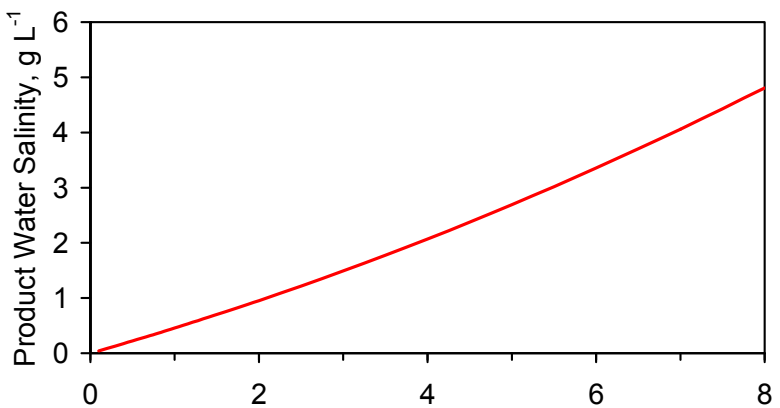

(a) Feed Water Salinity, $\mathrm{g} \mathrm{L}^{-1}$

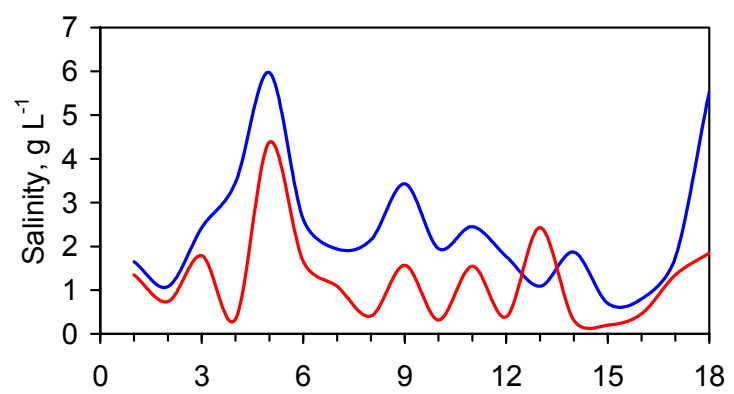

(c) Number of times the ZVM TPA has been reused - Feed Water - Product Water

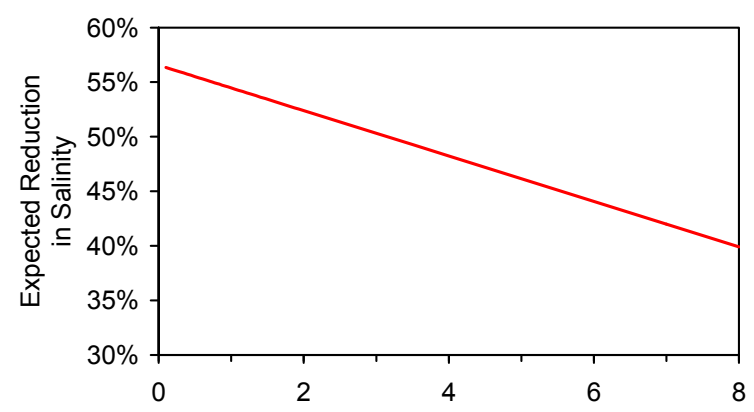

(b)

Feed Water Salinity, $\mathrm{g} \mathrm{L}^{-1}$

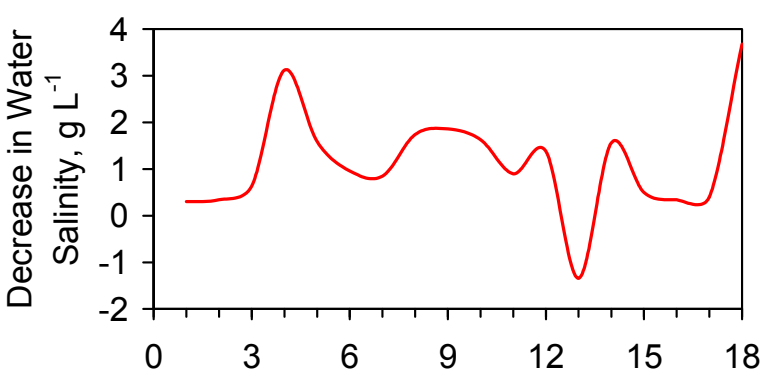

(d)
Number of times the ZVM TPA has been reused

Figure 21. Partial desalination of water using ZVM TPA: E146, $0.4 \mathrm{~kg}$ ZVM TPA; 240 L water. (a) Regression relationship between feed water salinity and product water salinity; (b) Regression relationship between the proportion of the salinity removed and the feed water salinity; (c) Feed and product water salinities vs. number of times a batch of ZVM TPA is reused; (d) Amount of $\mathrm{NaCl}$ removed vs. number of times a batch of ZVM TPA is reused.

The minimum cost of partially desalinated water used for irrigation on the basis of an irrigation requirement of $1000 \mathrm{~m}^{3}$ water $\mathrm{ha}^{-1} \cdot \mathrm{a}^{-1}$ is $\$ 12-\$ 98 \mathrm{~m}^{3} \cdot \mathrm{ha}^{-1} \cdot \mathrm{a}^{-1}$. This compares with about $\$ 3000 \mathrm{~m}^{3} \cdot \mathrm{ha}^{-1} \cdot \mathrm{a}^{-1}$ if the desalinated water is produced by a large scale $\left(>100,000 \mathrm{~m}^{3} \cdot \mathrm{d}^{-1}\right)$ desalination plant (reverse osmosis, or multi-stage flash distillation) at a sale price of $\$ 3 \mathrm{~m}^{-3}$ [36-38].

\section{Cations and Anions (Pollutants) Removed during Desalination by ZVM TP and ZVM TPA}

ZVM $\left(\mathrm{Fe}^{0}, \mathrm{Cu}^{0}, \mathrm{Al}^{0}\right)$ (and ZVM TP, ZVM TPA) will remove a variety of pollutants and microbial organisms from water (Appendix A). Removal is achieved by either direct precipitation [18,19], or by incorporation into ZVM corrosion products [18], or by reduction of a pollutant to a lower oxidation state (e.g., many organic anions) [18], or by oxidation of a pollutant to a higher oxidation state [18]. A detailed discussion of the mechanisms involved in these processes is beyond the scope of this study, 
but is addressed elsewhere $[18,19,162]$. These pollutants are not removed by the ZVM, but are removed by the effect the ZVM has on the surrounding water. These effects are the increase in availability of: (i) $\mathrm{e}^{-}$to facilitate/catalyze electron shuttle reactions [18,19,162]; (ii) $\mathrm{H}^{+}$(ads) to increase the number of potential anion removal sites within the water; (iii) $\mathrm{OH}^{-}$to increase the number of potential cation removal sites within the water; (iv) adjustment of water $\mathrm{Eh}$ and $\mathrm{pH}$ to change the stable equilibrium form of a specific pollutant species.

Appendix A summarises the microbiota, cations and anions that can be removed by $\mathrm{Eh}$ and $\mathrm{pH}$ changes in the water which result from the presence of ZVM [18,19,162].

This study has demonstrated that ZVM TP and ZVM TPA create the same Eh and $\mathrm{pH}$ changes in water as ZVM [5,6]. Therefore it is reasonable to assume that similar pollutant removal mechanisms will apply to all three groups of material.

\subsection{Cations and Anions (Pollutants) Removed during Desalination Using ZVM TP}

Placement of ZVM TP in water results in the removal of a variety of cations and anions (Tables $\mathrm{C} 1-\mathrm{C} 4)$. The proportion removed is a function of their original concentration, the composition of the water, treatment time, temperature and the ZVM TP composition.

The cations whose concentrations were reduced include: $\mathrm{As}, \mathrm{B}, \mathrm{Ba}, \mathrm{Ca}, \mathrm{Co}, \mathrm{Cu}, \mathrm{Mg}, \mathrm{Mn}, \mathrm{Na}, \mathrm{Ni}, \mathrm{P}$, $\mathrm{S}, \mathrm{Si}, \mathrm{Sr}$ (Tables $\mathrm{C} 2-\mathrm{C} 4$ ). The anions whose concentrations were reduced include: $\mathrm{Cl}, \mathrm{F}, \mathrm{NO}_{3}, \mathrm{NO}_{2}, \mathrm{PO}_{4}$, $\mathrm{SO}_{4}$ (Table $\mathrm{C} 1$ ). The concentrations of the cations and anions (apart from $\mathrm{Na}, \mathrm{Cl}$ ) in the water samples were low.

This ion removal data (Tables $\mathrm{C} 1-\mathrm{C} 4$ ) is cross plotted against $\mathrm{NaCl}$ removal in Figure $\mathrm{C} 18$. With the exception of sulphur (and sulphate) whose removal decreases with increasing $\mathrm{NaCl}$ removal, and manganese whose removal increases with increasing $\mathrm{NaCl}$ removal, there appears to be no direct correlation between cation/anion removal and $\mathrm{NaCl}$ removal. In all other cases, high levels of ion removal are associated with both low and high rates of $\mathrm{NaCl}$ removal.

The inter-relationship between desalination and the removal of other cations and anions in the water has not been specifically analysed in this study. The presence of high concentrations of other cations and anions (e.g., $1-400 \mathrm{~g} \cdot \mathrm{L}^{-1}$ ) may adversely impact on the rate of desalination.

\subsection{Impact of Sulphates: ZVM TP and ZVM TPA}

Sulphates can be present in chloride rich groundwater containing $\mathrm{Fe}, \mathrm{Na}$ and other cations. In the presence of ZVI, sulphate interacts with the green rust product to preferentially displace $\mathrm{Cl}$ from the ion lattices (at low pH). The sulphate rich green rust product is termed Green Rust 2 (GR2) [163]. In the presence of sulphates the dominant $\mathrm{FeOOH}$ species is goethite [96,163]. The initial molar ratio, $R$, of $\mathrm{SO}_{4}{ }^{2-} / \mathrm{OH}^{-}$, controls the formation of GR2 [163]. GR2 has only been observed when $R>0.5$ [163]. In an environment containing both $\mathrm{Cl}^{-}$and $\mathrm{SO}_{4}{ }^{2-}$ ions, the overall reaction sequence is an initial precipitation of $\mathrm{Fe}(\mathrm{OH})_{2}$. This then transforms to $\mathrm{GR} 1$. The $\mathrm{Cl}^{-}$ions are then replaced by $\mathrm{SO}_{4}{ }^{2-}$ ions to form GR2 and can be subsequently oxidised to form lepidocrocite $(\gamma-\mathrm{FeOOH})$ [164].

The boundary between GR1 and GR2 is defined by the relative concentration of $\mathrm{Cl}^{-}$and $\mathrm{SO}_{4}{ }^{2-}$ ions where $\mathrm{Eh}_{\mathrm{GR} 2}=-0.507+0.4137 \log \left[\mathrm{Cl}^{-}\right]-0.2364 \log \left[\mathrm{SO}_{4}{ }^{2-}\right][164]$. The initial transition from GR1 to 
GR2 is made by the replacement of $\mathrm{Cl}^{-}$by $\mathrm{SO}_{3}{ }^{2-}$ [165]. This maintains the GR1 structure [165]. The $\mathrm{SO}_{3}{ }^{2-}$ ions are replaced by $\mathrm{SO}_{4}{ }^{2-}$ ions as the GR2 structure forms [165].

This results in the effective desalination rate decreasing as the effective sulphate removal rate increases. This situation is demonstrated by the ZVM TP analyses (Figure C18) and indicates that the desalination process may be more effective in either desulphurized water or sulphurous water where the initial molar ratio $R<0.5$ [163] and $\mathrm{Eh}<\mathrm{EhGR}_{\mathrm{G} 2}$.

The transformation of GR 2 to lepidocrocite is controlled by the relative concentration of $\mathrm{SO}_{4}{ }^{2-}$, where $\mathrm{Eh}=0.55+0.0148 \log \left[\mathrm{SO}_{4}{ }^{2-}\right]-0.089 \mathrm{pH}[166]$. The relative position of this redox boundary is shown in Figure 22. The UV-visible spectral peaks [101] associated with each Green Rust (GR) species (GR1, GR2) are well defined (Table 3). These spectra allow the dominant entrained Fe corrosion species in the water to be identified (Table 3 ).

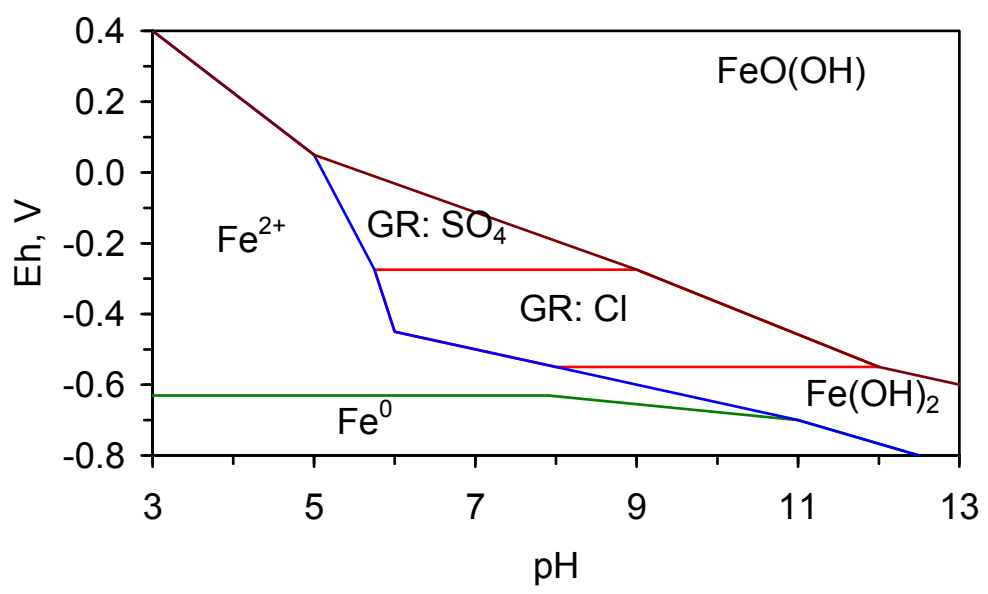

Figure 22. Pourbaix diagram showing the $\mathrm{Eh}, \mathrm{pH}$ regions where the dominant stable precipitate is $\mathrm{Fe}(\mathrm{OH})_{2}$, GR1, and GR2 in water containing both $\mathrm{Cl}^{-}$and $\mathrm{SO}_{4}{ }^{2-}$ ions.

The FeOOH chemistry is complex. In the absence of $\mathrm{Cl}^{-}$ions, lepidocrocite forms [166]. In the absence of $\mathrm{SO}_{4}{ }^{2-}$ ions, akaganeite forms, e.g., [167]. Lepidocrocite is replaced by goethite as the $\mathrm{SO}_{4}{ }^{2-}: \mathrm{Cl}^{-}$ratio increases at the transition from GR2 to $\mathrm{FeOOH}$ [167]. Akaganeite which forms at the GR1:FeOOH boundary is replaced by goethite as the $\mathrm{SO}_{4}{ }^{2-}: \mathrm{Cl}^{-}$ratio increases [167].

The presence of high concentrations of $\mathrm{SO}_{4}{ }^{2-}$ ions will reverse any $\mathrm{Cl}^{-}$desalination (by incorporation) which is associated with GR1 or akaganeite. $\mathrm{Na}^{+}$ions are incorporated with green rusts and the transformation from GR1 to GR2 is unlikely to expel the $\mathrm{Na}^{+}$ions [168]. Both $\mathrm{Na}^{+}$and $\mathrm{SO}_{4}{ }^{2-}$ ions are released as the GR2 transforms to goethite [168].

\subsection{Impact of Sulphides: ZVM TP and ZVM TPA}

In the presence of water, $\mathrm{Fe}_{2} \mathrm{O}_{3}$ (spp.) catalyse the transformation of $\mathrm{HS}^{-}$ions to elemental sulphur (Equation (21)). $\mathrm{HS}^{-}$is stable under reaction conditions [19] which have a significantly lower Eh than those observed in this study (Figures $\mathrm{C} 1-\mathrm{C} 17$ ). The lower Eh (without additional oxidation) is expected to adversely impact on the rate of formation of green rust and $\mathrm{FeOOH}$ species. $\mathrm{HS}^{-}$(without oxidation) can result in the formation of $\mathrm{Fe}_{1+x} \mathrm{~S}, \mathrm{Fe}_{1-x} \mathrm{~S}, \mathrm{Fe}_{3} \mathrm{~S}_{4}, \mathrm{Fe}_{3+x} \mathrm{~S}_{4}, \mathrm{FeS}_{2}$, The main iron sulphide precipitation 
zone is within the green rust/Fe(OH)2 precipitation zone, and can result in reassignment of some of the ZVM from desalination to sulphide removal (Figure 23).

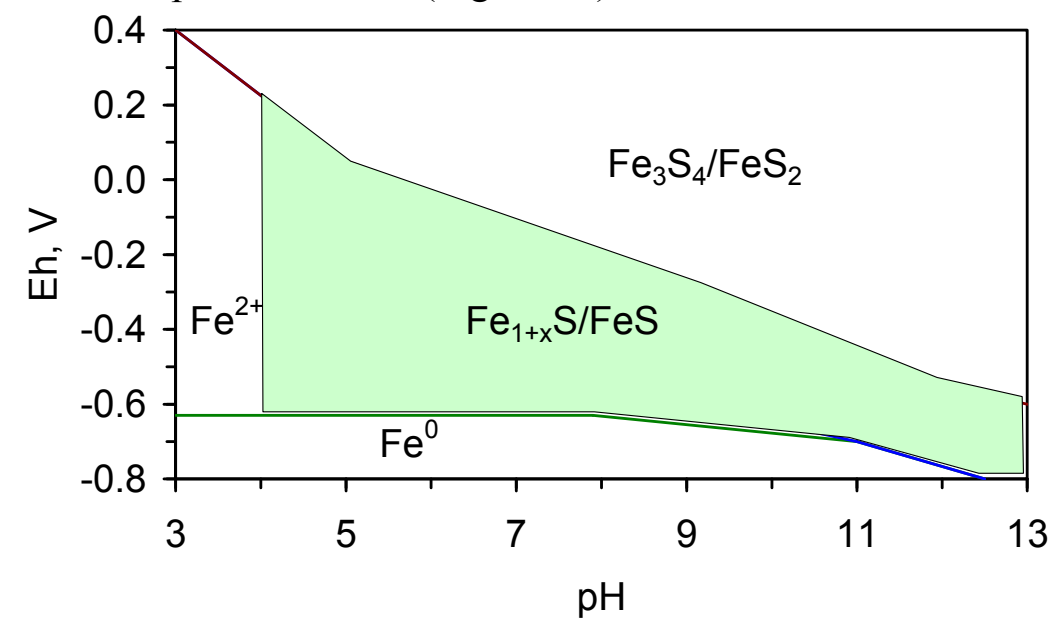

Figure 23. Pourbaix diagram showing the Eh, $\mathrm{pH}$ regions where the dominant stable precipitate is $\mathrm{FeS}_{2}, \mathrm{Fe}_{1+x} \mathrm{~S}$. Data: $[169,170]$.

\subsection{Impact of Bicarbonates: ZVM TP and ZVM TPA}

Bicarbonates $\left(\mathrm{HCO}_{3}{ }^{-}\right)$are a common constituent of most groundwater. In volcanic areas (such as those used to provide the base water in this study), the dissolved organic content is low (e.g., $1-18 \mathrm{mg} \cdot \mathrm{L}^{-1}$ ) [171]. Natural bicarbonate concentrations in this water are in the range $10-150 \mathrm{mg} \cdot \mathrm{L}^{-1}$.

\subsubsection{Trial E146: ZVM TPA}

The ZVM TPA Trials, E146, established that increasing the $\mathrm{HCO}_{3}{ }^{-}$content of the water (with associated acidification) either had (i) no effect on the rate of desalination, e.g., Figure C33; or (ii) reduced the amount of $\mathrm{NaCl}$ removed by $30 \%-50 \%$ (Figures $\mathrm{C} 34-\mathrm{C} 36$ ).

\subsubsection{Trials PS15 and PS16: ZVM TP}

Two ZVM TP trials (PS15, PS16) were undertaken, using a reactor containing $3.5 \mathrm{~L}$ water (Tables C1-C4). The reaction environment in Trial PS15 was saturated with $\left[16.79 \% \mathrm{CH}_{4}+16.88 \%\right.$ $\mathrm{H}_{2}+11.97 \% \mathrm{CO}+8.33 \% \mathrm{CO}_{2}+46.03 \% \mathrm{~N}_{2}$ for 79 days]. The reaction environment in Trial PS16 was saturated with [ $16.79 \% \mathrm{CH}_{4}+16.88 \% \mathrm{H}_{2}+11.97 \% \mathrm{CO}+8.33 \% \mathrm{CO}_{2}+46.03 \% \mathrm{~N}_{2}$ for 29 days] followed by $\left[80 \% \mathrm{~N}_{2}+20 \% \mathrm{CO}_{2}\right.$ for 135 days] followed by [ $100 \% \mathrm{~N}_{2}$ for 46 days].

The associated $\mathrm{Eh}, \mathrm{pH}$, and $\mathrm{EC}$ for the feed and product waters establish a general rise in $\mathrm{pH}$ (Table 6), indicating that the dominant carbonate species is a mixture of $\mathrm{HCO}_{3}{ }^{-}$and $\mathrm{CO}_{3}{ }^{2-}$ [19]. Both examples PS15 and PS16 demonstrated a substantial removal of $\mathrm{NaCl}$ (Table 6, Tables C1-C4).

Trial PS15 removed $9.51 \mathrm{gCl}^{-} \cdot \mathrm{L}^{-1}+1.29 \mathrm{gK}^{+} \cdot \mathrm{L}^{-1}+6.23 \mathrm{gNa}^{+} \cdot \mathrm{L}^{-1}$ over 79 days. The normalized molar removal ratio was: $1 \mathrm{Cl}^{-}: 1.26 \mathrm{Na}^{+}: 0.54 \mathrm{~K}^{+}$. The normalised removal ratio is calculated as (K or Na Removed/K or Na in Feed)/(Cl Removed/Cl in Feed). Trial PS 16 removed $23.07 \mathrm{gCl}^{-} \cdot \mathrm{L}^{-1}+$ $15.35 \mathrm{gNa}^{+} \cdot \mathrm{L}^{-1}$ over 121 days. The normalized molar removal ratio was: $1 \mathrm{Cl}^{-}: 1 \mathrm{Na}^{+}$. 
Trial PS16 reused the ZVM TP used in Trial PS15 and increased the amount of ZVM TP present (Table 6). These trials demonstrated:

1. ZVM TP can be reused if it is held in an oxygen free environment.

2. In an oxygen free environment, ZVM TP can increase the desalination rate [Constant D] to a value in the range $0.0128-0.0462$. This compares with a [Constant D] of 0.004-0.011 using ZVM TP from the same batch in an oxygenated environment.

3. Desalination using ZVM TP can occur when the water contains bicarbonate or carbonate ions.

Table 6. PS15, PS16. Particulate ZVM TP (Trial Group 1, Tables D1 and D2); (i) PS15:

$P_{\mathrm{w}}=134 \mathrm{~g} \cdot \mathrm{L}^{-1}$; Constant $\mathrm{D}=0.0128$; (ii) PS16: $P_{\mathrm{w}}=208 \mathrm{~g} \cdot \mathrm{L}^{-1}$. Constant $\mathrm{D}=0.0462$;

Operating temperature $=-8$ to $25^{\circ} \mathrm{C}$ (atmospheric temperature); Pressure $=0.1 \mathrm{MPa}$.

\begin{tabular}{|c|c|c|c|c|c|c|c|c|}
\hline \multirow{3}{*}{ Water } & Feed and Recovered & \multirow{3}{*}{ pH } & \multirow{3}{*}{$\begin{array}{c}\mathrm{EC} \\
\mathrm{mS} \cdot \mathrm{cm}^{-1}\end{array}$} & \multirow{3}{*}{$\begin{array}{l}\text { Storage } \\
\text { Period, } \\
\text { Years }\end{array}$} & \multirow{3}{*}{$\begin{array}{c}\begin{array}{c}\text { Product Water } \\
\text { Following Storage }\end{array} \\
\text { Eh, V }\end{array}$} & \multirow{3}{*}{ pH } & \multirow{3}{*}{$\begin{array}{c}\mathbf{E C}, \\
\mathbf{m S} \cdot \mathbf{c m}^{-1}\end{array}$} & \multirow{3}{*}{$\begin{array}{c}\mathrm{HCO}_{3}^{-}, \\
\mathrm{g} \cdot \mathrm{L}^{-1}\end{array}$} \\
\hline & Product Waters & & & & & & & \\
\hline & Eh, V & & & & & & & \\
\hline \multicolumn{9}{|c|}{ PS15 } \\
\hline Feed & 0.207 & 6.14 & 57.49 & - & - & - & - & - \\
\hline Product & 0.094 & 9.49 & 31.12 & 1.11 & 0.220 & 8.9 & 35.70 & $>10$ \\
\hline \multicolumn{9}{|c|}{ PS16 } \\
\hline Feed & 0.207 & 6.14 & 78.16 & - & - & - & - & - \\
\hline Product & -0.111 & 10.26 & 1.09 & 0.58 & 0.109 & 9.18 & 1.25 & 1.14 \\
\hline
\end{tabular}

\subsubsection{Desalination in an Alkaline Bicarbonate Saturated Anoxic Environment: ZVM TP}

In this anoxic environment the ZVM TP (PS15, PS16) will corrode to have a $\mathrm{Fe}_{3} \mathrm{O}_{4}$ interface between the $\mathrm{Fe}^{0}$ and the $\mathrm{Fe}^{\mathrm{II}} \mathrm{Fe}^{\mathrm{III}}$ corrosion layers [172]. High rates of desalination occur (Table 6). The $\mathrm{Fe}^{0}$ corrodes directly to form a GR1 structure containing $\mathrm{HCO}_{3}^{-}$[73,172]. In the presence of sulphate, the GR1 transforms to GR2 [172,173]. The redox boundary between GR1 $\left(\mathrm{CO}_{3}{ }^{2-}\right)$ and GR2 $\left(\mathrm{SO}_{4}{ }^{2-}\right)$ approximates to the redox boundary between GR1 $\left(\mathrm{Cl}^{-}\right)$and GR2 $\left(\mathrm{SO}_{4}{ }^{2-}\right)$ (Figure 18). When sulphate is absent, the dominant green rust is green rust carbonate containing some $\mathrm{Cl}^{-}$ ions [173]. GR1 $\left(\mathrm{Cl}^{-}\right)$is absent, even when the $\mathrm{Cl}^{-}: \mathrm{HCO}_{3}{ }^{-}$ratio is $>40$ [73]. The presence of carbonate-bicarbonate increases the rate of cathodic and anodic reactions and accelerates the rate of corrosion [174]. High corrosion rates are maintained by the interaction of $\mathrm{Fe}^{2+}$ species with $\mathrm{HCO}_{3}{ }^{-}$and the reduction of protons supplied by $\mathrm{HCO}_{3}{ }^{-}$ions [174]. A rapid decrease in corrosion rates is observed when the $\mathrm{pH}$ is decreased to move the reaction environment away from the $\mathrm{CO}_{3}{ }^{2-}: \mathrm{HCO}_{3}{ }^{-}$buffer zone [174]. When the water contains no $\mathrm{Cl}^{-}$ions the $\mathrm{GR} 1\left(\mathrm{CO}_{3}{ }^{2-}\right)$ will oxidize to the $\mathrm{FeOOH}$ species, goethite [73].

\subsubsection{Impact of $\mathrm{CaCO}_{3}$ or $\mathrm{MgCO}_{3}$ in the Water: ZVM TP and ZVM TPA}

The presence of $\mathrm{CaCO}_{3}$ or $\mathrm{MgCO}_{3}$ in the water (i.e., a $\mathrm{Ca}^{2+}-\mathrm{HCO}_{3}{ }^{-}$, or $\mathrm{Mg}^{2+}-\mathrm{HCO}_{3}{ }^{-}$groundwater type) will result in the formation of GR1 $\left(\mathrm{CO}_{3}{ }^{2-}\right)$ [172]. Trials PS15 and PS16 demonstrate that ZVM is able to desalinate a mixed ground water type containing $\left[\mathrm{HCO}_{3}{ }^{-}+\mathrm{Na}^{+}+\mathrm{K}^{+}+\mathrm{Cl}^{-}\right]$or $\left[\mathrm{HCO}_{3}{ }^{-}+\mathrm{Na}^{+}+\right.$ $\mathrm{Cl}^{-}$. 


\subsubsection{Impact of Chlorinated Organic Compounds in the Water: ZVM TP and ZVM TPA}

TCE (trichloroethylene) removal experiments in water containing $\mathrm{Ca}^{2+}-\mathrm{HCO}_{3}{ }^{-}$, or $\mathrm{Mg}^{2+}-\mathrm{HCO}_{3}{ }^{-}$, or $\mathrm{Na}^{+}-\mathrm{Cl}^{-}$have established that passivation of the ZVI surface by GR1 $\left(\mathrm{CO}_{3}{ }^{2-}\right)$ reduces the ability of ZVI to dechlorinate hydrocarbons [175]. This may indicate that the dechlorination process involves a $\mathrm{GR} 1\left(\mathrm{Cl}^{-}\right)$intermediate. In water containing high concentrations of $\mathrm{NaCl}$, hydrocarbon dechlorination rates are inhibited due to competition for available sites by $\mathrm{Cl}^{-}$ions [175].

\subsubsection{Bicarbonate/Carbonate Buffers: ZVM TP and ZVM TPA}

The carbonate environment contains an acidic $\left(\mathrm{H}_{2} \mathrm{CO}_{3}: \mathrm{HCO}_{3}{ }^{-}\right.$or $\left.\mathrm{CO}_{2}: \mathrm{HCO}_{3}{ }^{-}\right)$buffer, and an alkaline $\left(\mathrm{HCO}_{3}{ }^{-}: \mathrm{CO}_{3}{ }^{2-}\right.$ or $\left.\mathrm{CO}_{2}: \mathrm{CO}_{3}{ }^{2-}\right)$ buffer [19].

The $\mathrm{pH}$ in the proximity of the alkaline buffer is a function of the ratio of $\log \left(\mathrm{CO}_{3}{ }^{2-} / \mathrm{HCO}_{3}{ }^{-}\right)$or $\log \left(\mathrm{CO}_{3}{ }^{2-} / p \mathrm{CO}_{2}\right)$

Examples PS15 and PS16 (ZVM TP) were operated in the vicinity of the alkaline buffer, where: Observed $\mathrm{pH}=10.34+\log \left(\mathrm{CO}_{3}{ }^{2-} / \mathrm{HCO}_{3}{ }^{-}\right)[19]$, or in the presence of $\mathrm{CO}_{2}$, where: Observed $\mathrm{pH}=\left(18.14+\log \left(\mathrm{CO}_{3}{ }^{2-} / p \mathrm{CO}_{2}\right)\right) / 2[19]$.

The examples in Trials CSD1 and E146 (ZVM TP and ZVM TPA) were operated in the vicinity of the acidic buffer, where: Observed $\mathrm{pH}=6.38+\log \left(\mathrm{HCO}_{3}{ }^{-} / \mathrm{H}_{2} \mathrm{CO}_{3}\right)$ [19], or in the presence of $\mathrm{CO}_{2}$, where: Observed $\mathrm{pH}=\left(7.81+\log \left(\mathrm{HCO}_{3}{ }^{-} / p \mathrm{CO}_{2}\right)[19]\right.$.

The example MT1d (Figure C13) investigated the effect of acidified carbonate (formic acid + calcium carbonate) on desalination. This example demonstrated that first placing the water in the $\mathrm{H}_{2} \mathrm{CO}_{3}$ regime and then using $\mathrm{CaCO}_{3}$ to increase the $\mathrm{pH}$ to move the water across the $\mathrm{H}_{2} \mathrm{CO}_{3}: \mathrm{HCO}_{3}{ }^{-}$buffer and into the $\mathrm{HCO}_{3}{ }^{-}$buffer resulted in a progressive increase in $\mathrm{pH}$. As the $\mathrm{pH}$ increased above 7 and the Eh increased to $>0.1 \mathrm{~V}$, the EC demonstrated a rapid drop of $>5 \mathrm{mS} \cdot \mathrm{cm}^{-1}$ as dissolved species, $\mathrm{Fe}^{n^{+}}, \mathrm{Ca}^{2+}, \mathrm{Na}^{+}, \mathrm{Cl}^{-}$ were removed.

\subsubsection{Acid Bicarbonate Buffer: ZVM TP and ZVM TPA}

Example analyses at the acid bicarbonate buffer demonstrated (Trials CSD1d, E143, E144, E146) a very low $\mathrm{HCO}_{3}{ }^{-} / p \mathrm{CO}_{2}$ ratio which was accompanied by partial desalination of the water, e.g.,

Trial CSD1d demonstrated:

Table 5: $\mathrm{HCO}_{3}{ }^{-} / p \mathrm{CO}_{2}$ ratio $=0.004266: 1 ; \mathrm{HCO}_{3}{ }^{-} / \mathrm{H}_{2} \mathrm{CO}_{3}$ ratio $=0.1022 ;$ Feed water $=3 \mathrm{~g} \cdot \mathrm{L}^{-1}$; Product water $=1.88 \mathrm{~g} \cdot \mathrm{L}^{-1}$. Desalination time required $=16 \mathrm{~h}$;

Trial E143 demonstrated (Tables C5-C8):

1. E143b: $\mathrm{HCO}_{3}{ }^{-} / p \mathrm{CO}_{2}$ ratio $=0.1023: 1 ; \mathrm{HCO}_{3}{ }^{-} / \mathrm{H}_{2} \mathrm{CO}_{3}$ ratio $=2.74 ;$ Feed water $=4.44 \mathrm{~g} \cdot \mathrm{L}^{-1}$; Product water $=1.67 \mathrm{~g} \cdot \mathrm{L}^{-1}$. Desalination time required $=16.5 \mathrm{~h}$;

2. E143c: $\mathrm{HCO}_{3}{ }^{-} / p \mathrm{CO}_{2}$ ratio $=0.0109: 1 ; \mathrm{HCO}_{3}{ }^{-} / \mathrm{H}_{2} \mathrm{CO}_{3}$ ratio $=0.299 ;$ Feed water $=4.81 \mathrm{~g} \cdot \mathrm{L}^{-1}$; Product water $=2.11 \mathrm{~g} \cdot \mathrm{L}^{-1}$. Desalination time required $=15 \mathrm{~h}$;

3. E143d: $\mathrm{HCO}_{3}{ }^{-} / p \mathrm{CO}_{2}$ ratio $=0.0135: 1 ; \mathrm{HCO}_{3}{ }^{-} / \mathrm{H}_{2} \mathrm{CO}_{3}$ ratio $=0.343 ;$ Feed water $=5.37 \mathrm{~g} \cdot \mathrm{L}^{-1}$; Product water $=2.99 \mathrm{~g} \cdot \mathrm{L}^{-1}$. Desalination time required $=15.5 \mathrm{~h}$; 
4. E143e: $\mathrm{HCO}_{3}{ }^{-} / p \mathrm{CO}_{2}$ ratio $=0.0229: 1 ; \mathrm{HCO}_{3}{ }^{-} / \mathrm{H}_{2} \mathrm{CO}_{3}$ ratio $=0.594 ;$ Feed water $=6.48 \mathrm{~g} \cdot \mathrm{L}^{-1}$; Product water $=4.95 \mathrm{~g} \cdot \mathrm{L}^{-1}$. Desalination time required $=15.5 \mathrm{~h}$;

Trial E146 demonstrated:

1. 13th Reuse (Figure C33): $\mathrm{HCO}_{3}{ }^{-} / p \mathrm{CO}_{2}$ ratio $=0.00195: 1 ; \mathrm{HCO}_{3}{ }^{-} / \mathrm{H}_{2} \mathrm{CO}_{3}$ ratio $=0.063$; Feed water $=1 \mathrm{~g} \cdot \mathrm{L}^{-1}$; Product water $=0.35 \mathrm{~g} \cdot \mathrm{L}^{-1}$. Desalination time required $\leq 3 \mathrm{~h}$;

2. 14th Reuse (Figure $\mathrm{C} 34$ ): $\mathrm{HCO}_{3}{ }^{-} / p \mathrm{CO}_{2}$ ratio $=0.00219: 1 ; \mathrm{HCO}_{3}{ }^{-} / \mathrm{H}_{2} \mathrm{CO}_{3}$ ratio $=0.072$; Feed water $=1.1 \mathrm{~g} \cdot \mathrm{L}^{-1}$; Product water $=0.7 \mathrm{~g} \cdot \mathrm{L}^{-1}$. Desalination time required $\leq 4 \mathrm{~h}$;

3. 15th Reuse (Figure C35): $\mathrm{HCO}_{3}{ }^{-} / p \mathrm{CO}_{2}$ ratio $=0.00275: 1 ;$ Feed water $=2.05 \mathrm{~g} \cdot \mathrm{L}^{-1}$; Product water $=1.6 \mathrm{~g} \cdot \mathrm{L}^{-1}$. Desalination time required $\leq 9 \mathrm{~h}$;

4. 16th Reuse (Figure C36): $\mathrm{HCO}_{3}{ }^{-} / p \mathrm{CO}_{2}$ ratio $=0.00245: 1 ;$ Feed water $=5.83 \mathrm{~g} \cdot \mathrm{L}^{-1}$; Product water $=1.8 \mathrm{~g} \cdot \mathrm{L}^{-1}$. Desalination time required $\leq 17 \mathrm{~h}$;

Trial E143i (Tables C5-C8) established that if the ZVM TP had previously been operated in an environment containing a high $\mathrm{HCO}_{3}{ }^{-} / p \mathrm{CO}_{2}$ ratio $(0.524: 1)$ which is then reduced to $(0.0087: 1)$, this change is associated with a discharge of previously removed $\mathrm{NaCl}$ into the product water.E144 established (Tables C9-C12) that desalination ocurred at the acid bicarbonate buffer.

In each example the amount of $\mathrm{NaCl}$ removed was in the range $0.2-5 \mathrm{~g} \cdot \mathrm{L}^{-1}$. The E146 control trials (Figures C33-C36) where the trial was operated using $80 \% \mathrm{~N}_{2}+20 \% \mathrm{CO}_{2}$, and repeated using air (78\% $\mathrm{N}_{2}+21 \% \mathrm{O}_{2}$ ) demonstrated similar levels of desalination in each example. This indicates that the type of oxygenating gas does not markedly affect the rate of desalination over the $\mathrm{pH}$ range 5-8.

\subsubsection{Alkali Bicarbonate Buffer: ZVM TP}

Two trials (PS15, PS16) were operated at the alkali bicarbonate buffer (Table 6). Trial PS15 was operated with a $\left(\mathrm{CO}_{3}{ }^{2-} / p \mathrm{CO}_{2}\right)$ ratio of $6.92: 1$ and Trial PS16 was operated with a $\left(\mathrm{CO}_{3}{ }^{2-} / p \mathrm{CO}_{2}\right)$ ratio of 239.88:1. Trial PS16 demonstrates that high $\mathrm{NaCl}$ removal rates (Table 6) can be associated with a high $\left(\mathrm{CO}_{3}{ }^{2-} / p \mathrm{CO}_{2}\right)$. This example (Trial PS16) demonstrated a net reduction in salinity from 38.6 to 0.55 $\mathrm{gNaCl} \cdot \mathrm{L}^{-1}$ product water over 210 days (Table 1 , Tables $\mathrm{C} 1, \mathrm{C} 2$ ) which was associated with a ZVM desalination cost in the range $\$ 67.6-\$ 187.2 \mathrm{~m}^{-3}$ (based on a ZVM cost of $\$ 325-\$ 900 \mathrm{t}^{-1}$ ) + gas cost + reactor costs. Trial PS16 demonstrated a gross reduction in salinity (after consideration of water consumption during desalination) from 38.6 to $0.15 \mathrm{gNaCl} \cdot \mathrm{L}^{-1}$ of feed water (Table 1). Trial PS16 demonstrates $8.07 \mathrm{gSO}_{4}{ }^{2-} \cdot \mathrm{L}^{-1}$ removal (Table $\mathrm{C} 1$ ) and indicates that desalination of water with a high $\mathrm{g}$ $\mathrm{SO}_{4}{ }^{2-} \cdot \mathrm{L}^{-1}$ content is possible if the water has a $\left(\mathrm{CO}_{3}{ }^{2-} / p \mathrm{CO}_{2}\right)$ ratio of $239.88: 1$, or $\left(\mathrm{CO}_{3}{ }^{2-} / \mathrm{HCO}_{3}{ }^{-}\right)$ratio of 0.88:1 (i.e., the reactor is operated to ensure that GR2 is not an intermediate reaction product).

\subsection{Desalination of Water Containing Sulphates and Bicarbonates: ZVM TP and ZVM TPA}

GR2 $\left(\mathrm{SO}_{4}{ }^{2-}\right)$ can template on an $\mathrm{FeOOH}$ corrosion surface [176]. Its formation requires [176] the presence of an excess of $\mathrm{OH}^{-}$ions in the water, where $\mathrm{Fe}(\mathrm{OH})_{2}$ sheets grow parallel to the $\mathrm{FeOOH}$ or $\mathrm{Fe}^{0}$ substrate, trapping anions within the accreting layer (e.g., Figure F1). The water composition can be defined in terms of a ratio $R$, where $R=\left[\mathrm{OH}^{-}\right] /\left[\mathrm{Fe}^{n^{+}}\right]$, and in terms of the ratio of $\mathrm{Fe}^{3+} / \mathrm{Fe}^{n^{+}}$ions (Figure 20) [176]. The initial accreting product $\left(\mathrm{Fe}(\mathrm{OH})_{2}\right)$ will, under stable anoxic conditions, as the $\left[\mathrm{Fe}^{3+} / \mathrm{Fe}^{n^{+}}\right]$ ratio increases start to accrete green rust (Figure F1) [176]. As the $\left[\mathrm{Fe}^{3+} / \mathrm{Fe}^{n^{+}}\right]$ratio continues to increase 
these green rusts will either form $\mathrm{FeOOH}$ species (Figure $\mathrm{F} 1$ ), or will be reduced (by adsorbed $\mathrm{H}^{+}$and released $\mathrm{H}_{2}(\mathrm{~g})$ ) to form magnetite $\left(\mathrm{Fe}_{3} \mathrm{O}_{4}\right)$ (e.g., Figure F1) [176]. Entrained precipitates formed under these conditions will be dominantly $\mathrm{FeOOH}$ sp. (e.g., Figure F1) [176]. This sequence of progressive oxidation is summarized in Figure 24.

The initial FeOOH species can be lepidocrocite which is transformed into goethite and then subsequently akaganeite. Goethite and lepidocrocite are the dominant species when $\mathrm{Cl}^{-}$ions are absent or a relatively high level of $\mathrm{SO}_{4}{ }^{2-}$ ions are present [176].

While the exact ratio of $R$ required for each phase may be water composition dependent, the general reaction scheme remains the same (Figure 24), where the end points associated with green rust formation are either $\left(\mathrm{Fe}_{3} \mathrm{O}_{4}\right)$ resulting from reduction, or $\mathrm{FeOOH}$ formed from continued oxidation [176]. The presence of the initial $\left(\mathrm{Fe}(\mathrm{OH})_{2}\right)$, green rust intermediate and the $\mathrm{FeOOH}$ and $\left(\mathrm{Fe}_{3} \mathrm{O}_{4}\right)$ end points is illustrated in Figure F1.

The trial results have demonstrated that desalination will progress if the water contains $\mathrm{Cl}^{-}$, or $\left[\mathrm{Cl}^{-}+\mathrm{HCO}_{3}{ }^{-}, \mathrm{CO}_{3}{ }^{2-}, \mathrm{CO}_{2}\right]$. Sulphates will expel both $\mathrm{Cl}^{-}$and $\mathrm{CO}_{3}{ }^{2-}$ ions from the green rust structure and will change the final oxidized product to goethite or lepidocrocite. This change is associated with an inverse relationship where the rate of desalination decreases as the sulphate concentration of the water increases (Figure C18).

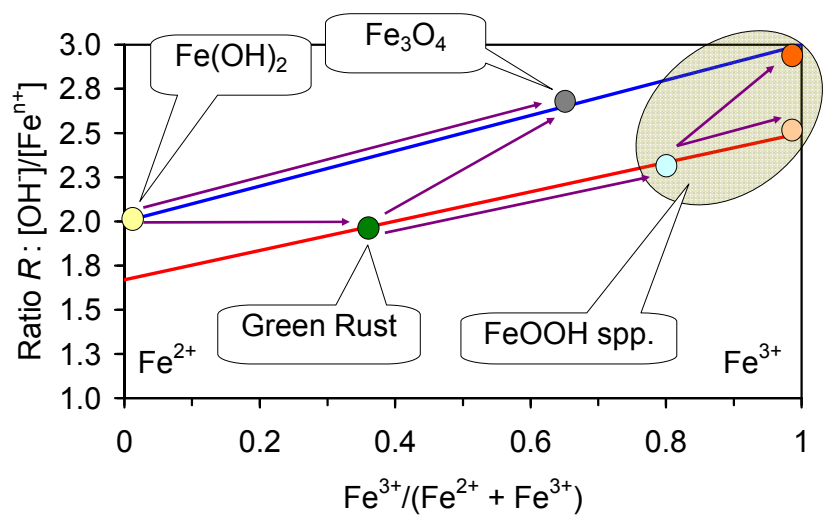

Figure 24. Relationship between Ratio $R$, and $\mathrm{Fe}^{3+}$ content surrounding ZVI and the nature of the corrosion products growing in the waters and accreting onto the ZVI. Data: [176].

This water can be desalinated if an absorbent is used to first remove the sulphur. The residual salinated (desulphurized) water can then be desalinated using ZVM TP. Alternatively, Trial PS16 demonstrates that if the desalination process is operated in a pressured, reducing acid environment, both $\mathrm{SO}_{4}{ }^{2-}$ and $\mathrm{NaCl}$ removal will occur, provided the reactor is operated with a $\mathrm{pH}$ around the alkaline bicarbonate buffer.

\section{Desalination Economics}

The trials have demonstrated desalination costs. For example water with a salinity of:

(1) $2.65 \mathrm{gNaCl} \cdot \mathrm{L}^{-1}$ can be desalinated to:

(a) ZVM TPA-multiple use: 
$1.55 \mathrm{~g} \cdot \mathrm{L}^{-1}$ (over $1-24 \mathrm{~h}$, Trial E146) and $6 \mathrm{gNaCl} \cdot \mathrm{L}^{-1}$ reduced (Trial E146) to $3.35 \mathrm{gNaCl} \cdot \mathrm{L}^{-1}$ ) for a cost of less than $\$ 0.009-\$ 0.026 \mathrm{~m}^{-3}$. This cost is based on the demonstrated 18 times reuse of the same ZVM TPA charge. The number of times a ZVM TPA charge can be reused needs to be demonstrated in field operation, but may be in the range 20 100 times. This would allow the desalination cost to fall within the range $\$ 0.002-\$ 0.024 \mathrm{~m}^{-3}$.

(b) ZVM TP-multiple use:

$0.791 \mathrm{~g} \cdot \mathrm{L}^{-1}$ (over $11-124 \mathrm{~h}$, Trials CSD1a-CSD1d) for a cost of $\$ 2.28-\$ 6.3 \mathrm{~m}^{-3}$. This cost is further reduced if the used ZVM TP is sold for sulphur removal, or is reprocessed for reuse. The number of times a ZVM TP charge can be reused needs to be demonstrated in field operation, but may be in the range 5-20 times. This allows the desalination cost to fall within the range $\$ 0.4-\$ 6.1 \mathrm{~m}^{-3}$. ZVM TP can be reused for sulphur removal from natural gas. This reuse application can result in a residual ZVM TP value which is greater than the cost of ZVM TP purchase and use as a desalination agent.

(c) ZVM TP — single use: $0.2 \mathrm{~g} \cdot \mathrm{L}^{-1}$ (over $<15 \mathrm{~h}$, Trial CSD1) for a cost of $\$ 4.55-\$ 12.6 \mathrm{~m}^{-3}$; Reuse of the ZVM TP for sulphur removal can reduce the cost of producing potable water to $<\$ 0.0$ $\mathrm{m}^{-3}$, depending on the resale value realised for the used ZVM TP.

(2) ZVM TP — single use: $11.05 \mathrm{gNaCl} \cdot \mathrm{L}^{-1}$ can be desalinated to $3.34 \mathrm{~g} \cdot \mathrm{L}^{-1}$ (over 126 days, Trial $\mathrm{ST3b}$ ) for a cost of $\$ 5.6-\$ 22.48 \mathrm{~m}^{-3}$. Reuse of the ZVM TP for sulphur removal can potentially reduce the cost of producing partially desalinated water to $<\$ 0.0 \mathrm{~m}^{-3}$, depending on the resale value realised for the used ZVM TP.

(3) ZVM TP_single use: $38.6 \mathrm{gNaCl} \cdot \mathrm{L}^{-1}$ can be desalinated to $0.55 \mathrm{~g} \cdot \mathrm{L}^{-1}$ (over 210 days, Trial PS16) for a cost of $\$ 67.6-\$ 187.2 \mathrm{~m}^{-3}$. Reuse of the ZVM TP for sulphur removal can potentially reduce the cost of producing partially desalinated water to $<\$ 3.0 \mathrm{~m}^{-3}$, depending on the resale value realised for the used ZVM TP.

These illustrative examples of costs demonstrated by the trials identify a number of potential market applications for the ZVM TP and ZVM TPA. They include:

1. Partial desalination of irrigation water for arable crops;

2. Partial desalination of livestock feed water;

3. Partial desalination of water for municipal activities and grey water applications;

4. Emergency water for people and livestock in areas affected by natural or anthropogenic disasters;

5. Desalination of saline water in impoundments (including flowback water from shale gas wells and reject brine from $\mathrm{RO}$ desalination plants);

The economics of desalination is impacted by: (i) the number of times a specific batch of ZVM TP/ZVM TPA can be reused; and (ii) the residual (resale or reuse) value of the ZVM TP/ZVM TPA.

ZVM TPA can potentially be used for the rapid partial desalination of large volumes of water in most areas (for agriculture, municipal applications and greywater applications) and allows partially desalinated water to be delivered for a cost which is in the range $\$ 0.002-\$ 0.026 \mathrm{~m}^{-3}$. 
ZVM TP can fulfil a similar role for a similar or lower price in areas where there is high value added reuse market for the used ZVM TP as a gas desulphurization agent (e.g., onshore oil and gas fields in the USA). The ZVM TP can have a role as a single use agent, or a multiple use agent.

ZVM TP can fulfil a role as a single use agent to produce desalinated or partially desalinated water from a wide range of saline water $\left(2-39 \mathrm{~g} \cdot \mathrm{L}^{-1}\right)$. It is cost competitive with technology such as reverse osmosis (RO) in areas which are remote from infrastructure (e.g., disaster relief areas), or where the water is heavily fouled with other components, or where the water salinity is outside the applicable range for an RO plant.

\subsection{Irrigation Market}

UN Water estimates that globally, there are more than 16,000 desalination plants producing 70 million $\cdot \mathrm{m}^{3} \cdot \mathrm{d}^{-1}\left(25.5 \mathrm{Bm}^{3} \cdot \mathrm{a}^{-1}\right)$ [177]. These plants consume $75.2 \mathrm{TWh}(0.5 \%$ of global electricity consumption [177]). The basic cost of desalination (excluding extraction, pre-treatment, post desalination treatment, storage, distribution and wastewater disposal) is estimated for large scale (e.g., $>100,000 \mathrm{~m}^{3} \cdot \mathrm{d}^{-1}$ ) plants at $\$ 0.5-2.5 \mathrm{~m}^{3}$ for seawater desalination, and $\$ 0.2-2 \mathrm{~m}^{3}$ for brackish water desalination [178-182]. Small scale $\left(<100 \mathrm{~m}^{3} \cdot \mathrm{d}^{-1}\right)$ desalination costs are estimated at $\$ 1$ to more than $12 \mathrm{~m}^{3}$ [183].

An indication of the full cycle costs associated with large scale desalination is provided by the volume supply costs to industrial users in countries which rely on desalinated water for the bulk of their water supply (e.g., United Arab Emirates (UAE)). In the UAE, the tariff [184] for the supply of more than 20,001 imperial gallons $\left(277.8 \mathrm{~m}^{3}\right.$ ) month $^{-1}$ is (April 2015) 4.6 fils/imperial gallon $\left(\$ 3.45 \mathrm{~m}^{3}\right.$ (based on an exchange rate of 1 Dirham $=$ US\$0.27)). This indicates that actual cost of delivered water is in the range 3 to 7 times the basic desalination cost associated with the desalination plant. The supply cost of desalinated water to an agricultural holding may therefore fall within the range $\$ 3.5-\$ 90 \mathrm{~m}^{3}$.

Desalinated water is currently used for agriculture in Spain $\left(308,000 \mathrm{~m}^{3} \cdot \mathrm{d}^{-1}\right)$, Kuwait $\left(130,000 \mathrm{~m}^{3} \cdot \mathrm{d}^{-1}\right)$, Italy $\left(986 \mathrm{~m}^{3} \cdot \mathrm{d}^{-1}\right)$, and Bahrain $\left(248 \mathrm{~m}^{3} \cdot \mathrm{d}^{-1}\right)$ [185]. Small quantities are also used in Qatar, and the USA [159]. Other countries such as Australia, Chile, and China are evaluating the feasibility of using water from desalination plants for agriculture [185].

In Australia, the sustainable potable groundwater resurce is about $10.2 \mathrm{Gm}^{3} \cdot \mathrm{a}^{-1}$, and the sustainable saline groundwater resource is about $15.5 \mathrm{Gm}^{3} \cdot \mathrm{a}^{-1}$ [185]. Current Australian agricultural water usage is $7.55 \mathrm{Gm}^{3} \cdot \mathrm{a}^{-1}$ [185]. This saline water resource is likely to be subeconomic for agricultural usage if the cost of extraction, desalination and delivery is $>$ US $\$ 0.96$ [185]. The desalination costs established by Trial E146, indicate that the cost of partially desalinating the sustainable saline groundwater resource of $15.5 \mathrm{Gm}^{3} \cdot \mathrm{a}^{-1}$ using ZVM TPA will be in the range $\$ 0.009-\$ 0.026 \mathrm{~m}^{-3}$ (\$140-\$400 million $\cdot \mathrm{a}^{-1}+$ extraction, tank, and distribution costs). This compares with the cost of water at the Melbourne desalination plant of $\$ 2.18 \mathrm{~m}^{-3}+$ distribution and storage costs [185].

It is estimated that four crops account for $>40 \%$ of global agricultural water usage (rice $=21.3 \%$; wheat $=12.4 \%$; maize $=8.6 \%$; soybeans $=4.6 \%$ ) $[181]$. Other major consumers of irrigated water include cotton and grazing pasture [185]. Existing usage of desalinated water for agriculture has focussed on high value added crops which can sustain a relatively high water supply cost. High value crops include grape, fruit trees, nut trees, berry fruits, and vegetables (e.g., tomatoes, pepper, etc.) have lower irrigation requirements [185]. 


\section{Ratios Used to Assess Irrigation Water Quality}

Standard guidelines for water suitability for irrigation focus on a number of parameters including EC, TDS (total dissolved solids), SAR $\left(\mathrm{Na}^{+} /\left(\left(\mathrm{Ca}^{2+}+\mathrm{Mg}^{2+}\right) / 2\right)^{0.5}\right)$, sodium percentage (100(Na $+\mathrm{K})) /(\mathrm{Ca}+\mathrm{Mg}+\mathrm{K}+\mathrm{Na}$ ), Wilcox plot (sodium percentage vs. EC), Kelly's ratio $(\mathrm{Na} /(\mathrm{Ca}+\mathrm{Mg}))$, magnesium adsorption ratio $((100 \mathrm{Mg}) /(\mathrm{Ca}+\mathrm{Mg}))$, Doneen's permeability index $\left(100\left(\mathrm{Na}+\left(\left(\mathrm{HCO}_{3}\right)^{0.5}\right)\right) /(\mathrm{Ca}+\mathrm{Mg}+\mathrm{Na})\right)$, chloroalkaline index $[\mathrm{CAI}-\mathrm{I}=(\mathrm{Cl}-(\mathrm{Na}+\mathrm{K})) / \mathrm{Cl}$; $\mathrm{CAI}-\mathrm{II}=(\mathrm{Cl}-(\mathrm{Na}+\mathrm{K})) /\left(\mathrm{SO}_{4}{ }^{2-}+\mathrm{CO}_{3}{ }^{2-}+\mathrm{NO}_{3}{ }^{-}\right)$, bicarbonate hazard index $\left(\mathrm{mg} \cdot \mathrm{L}^{-1} \mathrm{HCO}_{3}{ }^{-} / 6100\right)$, residual sodium carbonate index $\left(\left(\mathrm{CO}_{3}{ }^{2-}+\mathrm{HCO}_{3}{ }^{-}\right)-\left(\mathrm{Ca}^{2+}+\mathrm{Mg}^{2+}\right)\right)[27,186,187]$. Water which has been partially desalinated by ZVM will show declines in sodium percentage and chlorine percentage. Other ions, $\mathrm{Mg}, \mathrm{Ca}$, bicarbonate/carbonate, sulphate, nitrate are also removed by the desalination process (Tables $\mathrm{C} 1-\mathrm{C} 4$ ), therefore analyses of product water suitability for irrigation based solely on ratio analysis of $\mathrm{Na}, \mathrm{K}, \mathrm{Mg}, \mathrm{Ca}, \mathrm{Cl}, \mathrm{HCO}_{3} / \mathrm{CO}_{3}, \mathrm{SO}_{4}, \mathrm{NO}_{3}$ may not be meaningful. Desalination can remove $\mathrm{Mg}, \mathrm{Ca}, \mathrm{Cl}, \mathrm{HCO}_{3}$ at the same rate, or a faster rate, than $\mathrm{K}, \mathrm{Na}$ and $\mathrm{Cl}$.

\subsection{Cost of Irrigation Water}

\subsubsection{ZVM TP}

The ZVM TP analyses (Table 1, Figures C1-C17) demonstrate a base desalination cost (based on a single usage at $20 \mathrm{~kg} \cdot \mathrm{m}^{-3}$ ) of $\$ 6.5-\$ 18 \mathrm{~m}^{-3}$ (at a ZVM TP cost of $\$ 325-\$ 900 \mathrm{t}^{-1}$; desalination cost $=P_{\mathrm{w}} \times$ Price/number of times the ZVM TP is reused). Trial CSD1 establishes that the ZVM TP can be reused at least four times without reprocessing or regeneration. This reduces the effective desalination cost to $\$ 1.6-\$ 4.5 \mathrm{~m}^{-3}$.

Example ST3b (Table 1) demonstrates a reduction in salinity from $11.05 \mathrm{gNaCl} \cdot \mathrm{L}^{-1}$ to $3.34 \mathrm{~g} \cdot \mathrm{L}^{-1}$ (over 126 days) for a cost of $\$ 5.6-\$ 22.48 \mathrm{~m}^{-3}$. This change would increase the yields of barley, cotton, wheat, date palm, sugar beet, wheat grass, and Bermuda grass by between $300 \%$ and $800 \%$, and would allow the agricultural holding to diversify to produce one or more of soybean, safflower, sorghum, rice, sesbania, flax, beans, figs, olives, cantaloupe, corn, lettuce, pepper and a wide variety of grasses for pasture (Appendix B, Figure B1).

Widespread usage of ZVM TP as an agricultural desalination agent requires the effective ZVM TP cost (following regeneration and reprocessing, or resale as a desulphurization agent (or for another application)) to reduce to $<\$ 58 \mathrm{t}^{-1}$ or $P_{\mathrm{w}}$ to reduce to $<4.5 \mathrm{~g} \cdot \mathrm{L}^{-1}$.

\subsubsection{ZVM TPA}

The ZVM TPA analyses (Trial E146) demonstrated a partial desalination cost of \$0.009-\$0.022 $\mathrm{m}^{-3}$. This was associated with a regression relationship (Figure 20) which links feed water salinity to product water salinity. This regression equation indicates that feed water with a salinity of $6 \mathrm{~g} \cdot \mathrm{L}^{-1}$, will produce a product water with a salinity of $3.35 \mathrm{~g} \cdot \mathrm{L}^{-1}$. This change in water salinity would allow a crop such as rice which cannot be grown in water with a salinity of $>6 \mathrm{~g} \cdot \mathrm{L}^{-1}$ to be grown with a yield decrement of 40\% [188] (Figure B1). 


\subsection{Potential Use of ZVM TPA to Boost Rice Yields}

Rice yields and production costs vary with time, location and variety, but generally fall within the range: yield $=6-24 \mathrm{t} \cdot \mathrm{ha}^{-1}$; wholesale price $=\$ 300-400 \mathrm{t}^{-1}$; production cost $=\$ 300-\$ 400 \mathrm{ha}^{-1}$. Irrigation requirements for rice can fall within the range $5000-10,000 \mathrm{~m}^{3} \cdot \mathrm{ha}^{-1} \cdot \mathrm{a}^{-1}$ [189]. The cost of supplying partially desalinated irrigation water for rice paddy (based on Trial E146) is estimated to be $\$ 45-\$ 220 \mathrm{ha}^{-1} \cdot \mathrm{a}^{-1}$ (i.e., a total rice production cost of $\$ 350-\$ 420 \mathrm{ha}^{-1}$ ). These costings indicate (Table 7) that the ZVM TPA partial desalination technology could be used to provide water for rice cultivation in areas which contain brackish saline water. Coupling partial desalination with high yield rice varieities may allow the expected rice yield to fall in the range $10-15 \mathrm{t} \cdot \mathrm{ha}^{-1}$.

Field scale pilot trials are required to establish that the initial trials of ZVM TP and ZVM TPA technology can be upscaled to provide a low cost partial desalination approach for agricultural applications. The site specific water, including agricultural chemicals, fertilisers and microbiota, may interact with ZVM TP and ZVM TPA to accelerate, or retard, the desalination process.

Table 7. Potential impact of partial desalination on the economics of rice cultivation. Assumptions: ZVM TPA (Trial E146); Desalination determination: Figure 20.

\begin{tabular}{lcccc}
\hline \multicolumn{1}{c}{ Item } & \multicolumn{2}{c}{ No Desalination } & \multicolumn{2}{c}{ Partial Desalination } \\
\hline Irrigation, $\mathrm{m}^{3} \cdot \mathrm{ha}^{-1}$ & 5000 & 10,000 & 5000 & 10,000 \\
Feed Water salinity, $\mathrm{g} \cdot \mathrm{L}^{-1}$ & 6 & 6 & 6 & 6 \\
Irrigation Water Salinity, & 6 & 6 & 3.35 & 3.35 \\
$\mathrm{~g} \cdot \mathrm{L}^{-1}$ & - & - & - & - \\
Rice Yield, $\mathrm{t} \cdot \mathrm{ha}^{-1}$ & 6 & 6 & 6 & 6 \\
Low & 24 & 24 & 24 & 24 \\
High & $100 \%$ & $100 \%$ & $40 \%$ & $40 \%$ \\
\hline Yield Decrement & - & - & - & - \\
Actual rice yield, $\mathrm{t} \cdot \mathrm{ha}^{-1}$ & 0 & 0 & 3.6 & 3.6 \\
Low & 0 & 0 & 14.4 & 14.4 \\
High & - & - & - & - \\
\hline Production Cost, $\$ \cdot \mathrm{ha}^{-1}$ & 300 & 300 & 345 & 390 \\
Low & 400 & 400 & 500 & 620 \\
High & - & - & - & - \\
\hline Rice price, $\$ \cdot \mathrm{t}^{-1}$ & 300 & 300 & 300 & 300 \\
Low & 400 & 400 & 400 & 400 \\
High & - & - & - & - \\
\hline Net Sales Revenue, $\$ \cdot \mathrm{ha}^{-1}$ & -400 & -400 & 580 & 460 \\
Low & -300 & -300 & 5415 & 5370 \\
High & & & & \\
\hline
\end{tabular}

\subsection{Economic Implications of Corrosion Scale}

ZVI desalination has been associated with a high surface area [20,21,25,190], indicating that the contact area between the $\mathrm{Fe}^{0}$ and water surface is important [15,18,191,192]. Experiments using $\mathrm{Fe}+$ organic chemicals have demonstrated [5,6,193-200] that increases in water salinity are associated with in an increase in the rate of degradation of the organic chemicals and $\left(\mathrm{CO}_{x}, \mathrm{H}_{x} \mathrm{C}_{y} \mathrm{O}_{z}\right)$. This is associated with the construction of simple organic compounds $\left(\mathrm{C}_{x} \mathrm{H}_{y} \mathrm{O}_{z}\right.$, alkanes and alkenes), 
where carbon can act as both an intermediary and reactant and Fe acts as a catalyst [5,6,193-200]. Trials PS15 and PS16 demonstrate that the presence of $\mathrm{CO}, \mathrm{CO}_{2}$ and $\mathrm{CH}_{4}$ can be associated with increases in the rate of desalination.

This study has demonstrated that the ZVM TP is electrically active and contains both cathodic and anodic centres. Under these circumstances the potential cathodic half reactions [150] in saline water are:

$$
\begin{gathered}
\mathrm{Na}^{+}(\mathrm{aq})+\mathrm{e}^{-}=\mathrm{Na} \quad \Delta E^{0}=-2.71 \mathrm{~V} \\
2 \mathrm{H}_{2} \mathrm{O}(\mathrm{l})+2 \mathrm{e}^{-}=\mathrm{H}_{2}(\mathrm{~g})+2 \mathrm{OH}^{-} \quad \Delta E^{0}=-0.83 \mathrm{~V}
\end{gathered}
$$

Half reaction (Equation (38)) is favoured over half reaction (Equation (37)) [150]. This is confirmed by Figure D1 which demonstrates production of $\mathrm{H}_{2}(\mathrm{~g})+2 \mathrm{OH}^{-}$during desalination. Half reaction (Equation (38)) can result in a film of $\mathrm{NaOH}$ coating [201] the ZVI and a corrosion scale $\left(\mathrm{Fe}(\mathrm{OH})_{2}\right.$, GR1, FeOOH) coating the ZVI [18,68-77,87,88,93,94,96,110-112,167,172,173,176,191,202-204].

$$
\begin{gathered}
\mathrm{Na}^{+}+\mathrm{OH}^{-}=\mathrm{NaCl} \\
\mathrm{Fe}^{0}+n \mathrm{OH}^{-}=\mathrm{Fe}(\mathrm{OH})_{n} \\
\mathrm{Fe}(\mathrm{OH})_{2}=\mathrm{Fe}(\mathrm{OOH})+\mathrm{H}^{+}+\mathrm{e}^{-}
\end{gathered}
$$

The associated anodic half reactions are [124]:

$$
\begin{gathered}
2 \mathrm{Cl}^{-}(\mathrm{aq})=\mathrm{Cl}_{2}(\mathrm{~g})+2 \mathrm{e}^{-} \quad \Delta E^{0}=-1.36 \mathrm{~V} \\
2 \mathrm{H}_{2} \mathrm{O}(\mathrm{l})=\mathrm{O}_{2}(\mathrm{~g})+4 \mathrm{H}^{+}+4 \mathrm{e}^{-}
\end{gathered}
$$

$\mathrm{H}_{2} \mathrm{O}$ is oxidised in preference [150] to $\mathrm{Cl}^{-}$at the anodic sites. However, as $\mathrm{Cl}^{-}$concentrations increase, overcharging (development of $\mathrm{FeOOH}[18]$ ) at the anodic sites (corrosion scale) results in a switch from half reaction Equation (42) to half reaction Equation (41) [150]. Any $\mathrm{Cl}_{2}$ formed is removed, as demonstrated in Figure $\mathrm{C} 37$, by an anodic reaction as $\mathrm{ClO}^{-}$, e.g.,

$$
\mathrm{Cl}_{2}(\mathrm{aq})+2 \mathrm{OH}^{-}=2 \mathrm{ClO}^{-}+2 \mathrm{H}^{+}+2 \mathrm{e}^{-}
$$

This model [150] results (as demonstrated in Section 4) in the amount of $\mathrm{NaCl}$ removed (and corrosion scale formed on the ZVI particles) being directly proportional to the inherent charge generated by ZVM TP/ZVM TPA, via the Nernst relationships [150], where [150]:

$$
\text { Charge, coulombs }=\text { current }(\text { amperes }) \times \text { time (seconds) }
$$

The charge associated with desalination is [150]:

$$
\begin{gathered}
\text { Charge }=\left(1 / \text { Molecular weight }(\mathrm{MW}) \mathrm{Cl}^{-}\right) \times \text {Faraday Constant }(\mathrm{F}) \times \text { Weight }(\mathrm{W}) \text { of } \\
\qquad \mathrm{Cl}^{-} \text {Removed }
\end{gathered}
$$

For reactions involving other species associated with corrosion (e.g., formation of $\mathrm{Fe}(\mathrm{OH})_{2}$, GR1, $\mathrm{FeOOH})$ the charge is a function of $\mathrm{e}^{-}[150]$ :

Charge $=(1 / \mathrm{MW}($ species $)) \times \mathrm{F} / \mathrm{e}_{n} \times \mathrm{W}($ species $) \times \mathrm{e}_{n} /$ Moles Species Weight of Species formed or removed $=\left(1 / \mathrm{MW}(\right.$ species $) \times \mathrm{F} / \mathrm{e}_{n} \times \mathrm{e}_{n} /$ Moles Species $) /$ Charge $\mathrm{e}_{n}=$ Moles $\mathrm{e}^{-}$associated with removal of 1 mole of the contaminant species 
These relationships demonstrate that the rate of corrosion (and GR1, GR2, FeOOH scale formation around the $n-\mathrm{Fe}^{0}$ particles) will increase with increased contaminant concentration (e.g., $\mathrm{NaCl}$ ) and with increased oxidation of the water. This has been demonstrated experimentally $[205,206]$ and is used in this study (ZVM TPA, Section 5) to combine accelerated iron corrosion by oxidation with accelerated desalination. The charge associated with the development of the corrosion scale can be linked directly to the effective pseudo-specific capacitance (pSC) associated with the corrosion reactions as [207]:

$$
\mathrm{pSC}, \mathrm{F} \cdot \mathrm{g}^{-1}=\operatorname{charge} /\left(P_{\mathrm{w}}\left(\mathrm{Eh}_{t=0}-\mathrm{Eh}_{t=n}\right)\right)
$$

These relationships allow changes in the reaction quotient, $Q,[19,150]$, (by altering the composition (and concentrations) of dissolved gases in the water) to be used to accelerate desalination and corrosion product (or scale) formation.

\subsection{Applicability to Specific Sites}

This study has evaluated desalination in batch treatment sizes ranging from $0.2 \mathrm{~L}$ to $240 \mathrm{~L}$. Commercial applications will require larger plant sizes and may require the consideration of more complex water chemistries. Scale up performance into the $10-1000 \mathrm{~m}^{3}$ reactor/tank size range and application of the process using complex saline water (e.g., seawater, flowback water) has not been trialled at this time. The desalination rates at a larger scale and with more complex feed waters may be higher than, or lower than, the rates recorded in this study. This study has not optimized the rate of desalination, but has demonstrated a number of different routes which can be trialled to optimise the desalination rate. Facilities, offsites, and land requirements associated with commercializing this technology will be location, size and application specific [208,209].

\section{Conclusions}

This study has demonstrated that partial desalination of water (combined with water treatment (cation and anion removal)) using pellets, particles and cartridges, has the potential to be a green, sustainable, economically viable commercial treatment option for some saline water bodies. The operating limits evaluated in saline water include:

1. $\mathrm{pH}$ range $=2-12$,

2. Electrical conductivity range of the feed water $=2-78 \mathrm{mS} \cdot \mathrm{cm}^{-1}$,

3. Salinity range of the feed water $=1-39 \mathrm{gNaCl} \cdot \mathrm{L}^{-1}$,

4. Carbonate range in the feed water $=10 \mathrm{mg} \cdot \mathrm{L}^{-1}$ to $>10 \mathrm{~g} \cdot \mathrm{L}^{-1}$; sulphate $\leq 10.2 \mathrm{mg} \cdot \mathrm{L}^{-1}$.

5. Temperature range considered $=-8$ to $50^{\circ} \mathrm{C}$.

This treatment option can either be operated using:

1. No external energy, or

2. Pressurized $(<0.1 \mathrm{MPa})$ air, or

3. Pressurized $(<0.1 \mathrm{MPa})$ acidic gas $\left(\mathrm{CO}_{2}\right)$, or

4. Pressurized $(<0.1 \mathrm{MPa})$ anoxic gas $\left(\mathrm{N}_{2}\right)$, or

5. Pressurized $(<0.1 \mathrm{MPa})$ anoxic, acidic, reducing gas $\left(\mathrm{H}_{2}+\mathrm{CO}+\mathrm{CO}_{2}+\mathrm{CH}_{4}+\mathrm{N}_{2}\right)$.

The desalination rates observed: 
1. Increase with increasing temperature;

2. Increase with decreasing particle size (and increased particle BET surface area);

3. Are optimised using $P_{\mathrm{w}}=0.3-20 \mathrm{gFe}^{0} \cdot \mathrm{L}^{-1}$;

4. Are optimised by maintaining the ZVM TP/TPA in a static water body, while allowing the overlying water body to be circulating and pressurised using a reducing gas, or an oxidising gas.

The cost of reducing water salinity was demonstrated to fall in the range $\$ 0.002-\$ 190 \mathrm{~m}^{-3}$.

The technology has applications for the desalination of irrigation water (example cost: $\$ 0.002-\$ 0.026 \mathrm{~m}^{-3}$ ), desalination of livestock feed water (example cost: $\$ 0.002-\$ 0.026 \mathrm{~m}^{-3}$ ) and the provision of emergency water in areas following the destruction of infrastructure (example cost: $\left.\$ 4-\$ 190 \mathrm{~m}^{-3}\right)$.

\section{Acknowledgments}

This study was funded by DCA Consultants Ltd.

\section{Conflicts of Interest}

The author declares no conflict of interest.

\section{Appendix A. Microbiota, Cations and Anions that Can Be Removed by ZVM}

ZVM studies have established $[18,19,162]$ that placement of ZVM in water can remove:

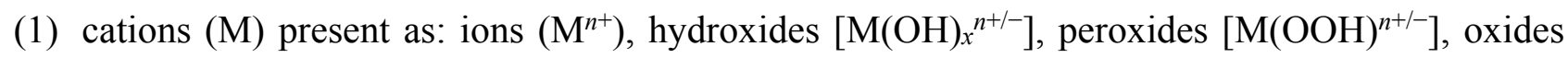
$\left[\mathrm{M}_{y} \mathrm{O}_{x}{ }^{n+-}\right]$, and hydrides $\left[\mathrm{M}_{y} \mathrm{H}_{x}{ }^{n+/}\right], \mathrm{M}$ is one or more of: $\mathrm{Ac}, \mathrm{Ag}, \mathrm{Al}, \mathrm{Am}, \mathrm{As} . \mathrm{Au}, \mathrm{B}, \mathrm{Ba}, \mathrm{Be}$, $\mathrm{Bi}, \mathrm{Ca}, \mathrm{Cd}, \mathrm{Ce}, \mathrm{Cm}, \mathrm{Co}, \mathrm{Cr}, \mathrm{Cs}, \mathrm{Cu}, \mathrm{Dy}, \mathrm{Er}, \mathrm{Eu}, \mathrm{Fe}, \mathrm{Ga}, \mathrm{Gd}, \mathrm{Ge}, \mathrm{Hf}, \mathrm{Hg}$, Ho, In, Ir, K, La, Lu, $\mathrm{Mg}, \mathrm{Mn}, \mathrm{Mo}, \mathrm{Na}, \mathrm{Nb}, \mathrm{Nd}, \mathrm{Ni}, \mathrm{Np}$, Os, P, Pa, Po, Pr, Pt, Pu, Re, Rh, Ru, S, Sb, Sc, Se, Si, Sm, Sn, Sr, Tb, Tc, Te, Th, Ti, Tl, Tm, U, V, Y, Yb, Zn, Zr, and nitrogen based cations, e.g., $\mathrm{NH}_{4}^{+}$. These ions are removed by precipitation, or by transfer into another ionic species.

(2) anions (A) present as:

(a) ions held in a monoatomic or polyatomic form: H, F, Cl, Br, I, At, O, S, Se, Te, N, P, As, $\mathrm{Sb}, \mathrm{C}, \mathrm{Si}, \mathrm{Ge}, \mathrm{B}$;

(b) oxides, e.g., arsenates $\left(\mathrm{AsO}_{4}{ }^{3-}\right)$, acetates $\left(\mathrm{C}_{2} \mathrm{H}_{3} \mathrm{O}_{2}{ }^{-}\right)$, bicarbonates $\left(\mathrm{HCO}_{3}{ }^{-}\right)$, carbonates $\left(\mathrm{CO}_{3}{ }^{2-}\right)$, chlorites $\left(\mathrm{ClO}_{2}{ }^{-}\right)$, chlorates $\left(\mathrm{ClO}_{3}{ }^{-}\right)$, chromates $\left(\mathrm{CrO}_{4}{ }^{2-}\right)$, hypochlorites $\left(\mathrm{ClO}^{-}\right)$, dichromates $\left(\mathrm{Cr}_{2} \mathrm{O}_{7}{ }^{2-}\right)$, hydrogen phosphates $\left(\mathrm{HPO}_{4}{ }^{2-}\right)$, nitrates $\left(\mathrm{NO}_{3}{ }^{-}\right)$, nitrites $\left(\mathrm{NO}_{2}{ }^{-}\right)$, $\mathrm{N}_{2} \mathrm{O}_{2}{ }^{2-}$, perchlorates $\left(\mathrm{ClO}_{4}^{-}\right)$, permanganates $\left(\mathrm{MnO}_{4}{ }^{-}\right)$, oxalates $\left(\mathrm{C}_{2} \mathrm{O}_{4}{ }^{2-}\right)$, phosphates $\left(\mathrm{PO}_{4}{ }^{3-}\right)$, sulphates $\left(\mathrm{SO}_{4}{ }^{2-}\right)$, sulphites $\left(\mathrm{SO}_{3}{ }^{2-}\right)$, thiosulphates $\left(\mathrm{S}_{2} \mathrm{O}_{3}{ }^{2-}\right), \mathrm{S}_{2} \mathrm{O}_{6}{ }^{2-}, \mathrm{S}_{2} \mathrm{O}_{8}{ }^{2-}, \mathrm{S}_{4} \mathrm{O}_{6}{ }^{2-}$, $\mathrm{HS}_{2} \mathrm{O}_{4}^{-}$, or $\left[\mathrm{M}_{z}\right]\left[\mathrm{O}_{n}\right]^{y^{-}}$;

(c) nitrogen based anions, e.g., thiocyanates $\left(\mathrm{CNS}^{-}\right)$, cyanides $\left(\mathrm{CN}^{-}\right)$;

(d) These ions are removed by precipitation, or by transfer into another ionic species.

(3) Dissolved organic species:, e.g., chloromethane (CM), trichloromethane (TCM), dichloromethane (DCM), tetrachloromethane, perchloroethylene (PCE), trichloroethylene (TCE), dichloroethylene (DCE), vinyl chloride (VC), hexachloroethane, tetrachloroethane, trichloroethane, dichloroethane, 
chloropropane (and related species), chlorobutane (and related species), chlorobenzene, (and related species), ethylene dibromide (EDB), perchlorate, polychlorinated biphenyls (PCB's), azo dyes, atrazine, cyclonite/hexogen (RDX), dinitrotoluene (DNT), nitrosodimethylamine (NDMA), nitrocellulose, tetramethylenetetranitramine (HMX), trinitrotoluene (TNT), disinfection by-products (DBP's), fertilizers, pesticides, herbicides, fungicides, methyl tert-butyl ether (MTBE), aromatics, hydrocarbons, hormonal pollutants. These species are removed by reduction and fragmentation to one or more compounds or ions.

ZVM is known to destroy or deactivate a variety of microbial organisms $[18,162]$ including:

(1) Alcaligenes eutrophus, Aspergillus versicolor, Bacillus cereuis, Bacillus subtilis var. niger, colliforms (e.g., Enterococcus faecium, Enterococcus faecilis), Cryptosporidium spp., Dehalococcoides spp., Daphnia magna, Dunaliella tertiolecta, Escherichia coli, Giardia spp., Hartmannella veriformis, Isochrysis galbbana, Klebsiella pneumoniae, Naeglaeria spp., Naeglaeria fowleri, Pseudokirchneriella subcapitata, Pseudomonas spp., Pseudomonas fluorescens, Pseudomonas aeruginosa, Salmonella typhimurium, Salmonella enterica, Salmonella paratyphi, Salmonella spp., Shigella spp., Staphylococcus aureus, Streptococci spp., Tetrahymena pyriformis, Thalassiorsria pseudonana, Vibrio parahaemolyticus, Vibrio cholerae,

(2) Aichi virus, adenovirus 41, MS-2, Hepatitis A, norovirus, phiX174/FX174, rotavirus, T1, f2 virus, fecal coliforms, fecal streptococci, fungi, prions, viruses, protozoa, bacteria, algae.

\section{Appendix B. Agricultural Significance of Partial Desalination}

The income associated with most agricultural units fluctuates annually as a function of climatic variations and commodity prices. These economic changes make it difficult to justify the capital investment required (or to obtain financing) to install a reverse osmosis desalination unit or multi-stage flash distillation unit. These desalination facilities are designed to produce a constant rate of high quality desalinated water.

Most agricultural sites do have access to water storage facilities and their water usage varies both within a year and between years. Furthermore, the relatively low value of the agricultural crop on individual holdings requires a low unit water cost for desalinated water.

The saline water used in agriculture can be derived from riparian sources or groundwater. Its salinity can vary with time. Water disposal to groundwater from agricultural units (e.g., from irrigation) can result in an increase in salinity of the aquifer as leached salts infiltrate with the infiltrating water.

There is therefore a requirement for a desalination system which is not capital intensive or energy intensive. This system ideally should be able to desalinate existing water tanks and ponds (and aquifers), while using a relatively technologically unskilled (low cost) workforce and existing equipment owned by the agricultural unit.

Crop yields (and livestock yields) increase as the water salinity is reduced. Irrigation water salinity can fluctuate both within and between years. The amount of irrigation water required for agriculture fluctuates with crop type, time, and location. For many crops, a relatively small decrease in soil or feed water salinity (e.g., $0.5-5 \mathrm{~g} \cdot \mathrm{L}^{-1}$ ) is sufficient to increase yields by $25 \%-75 \%$. Therefore an agricultural unit can substantially increase profitability by using partially desalinated water. 
Figure B1 provides an indication of the sensitivity of the principal groups of arable crops to soil water salinity. Specific crop varieties with show different relationships and yield may be affected by temperature, sunlight, and other components in the water and soils.

Livestock yields vary with drinking water salinity [210-215]. The exact relationship varies with species/variety, temperature, amount of water available and the presence of other minerals in the water. Figure B2 provides an indicative relationship for a variety of livestock types.

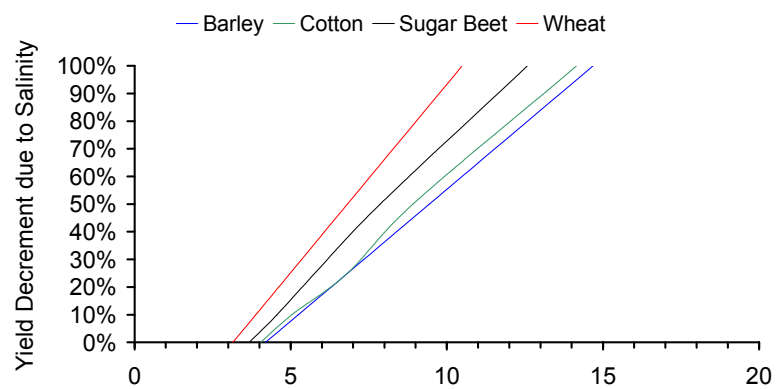

(a)

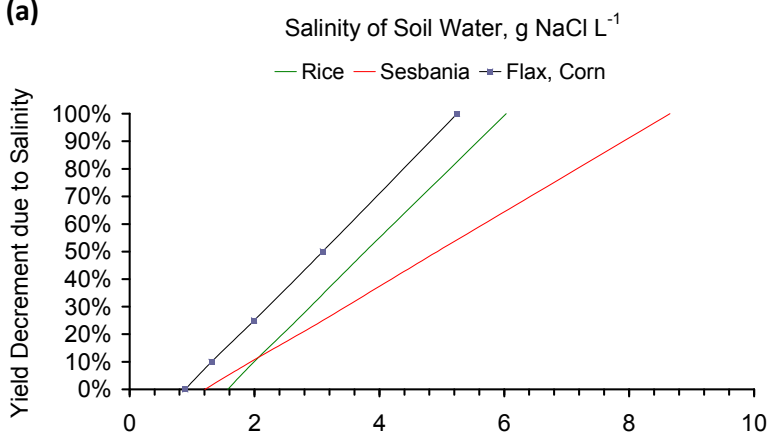

(c)

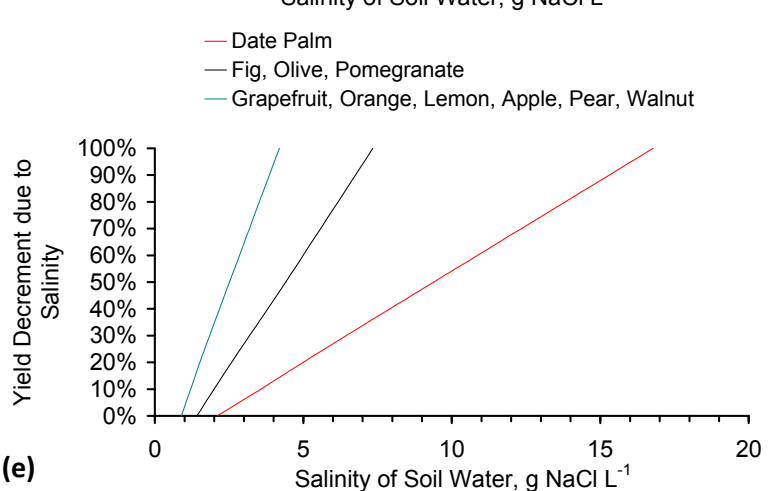

$\rightarrow$ Blackberry, Boysenberry $\rightarrow$ Avocado $\rightarrow$ Raspberry $*$ Strawberry

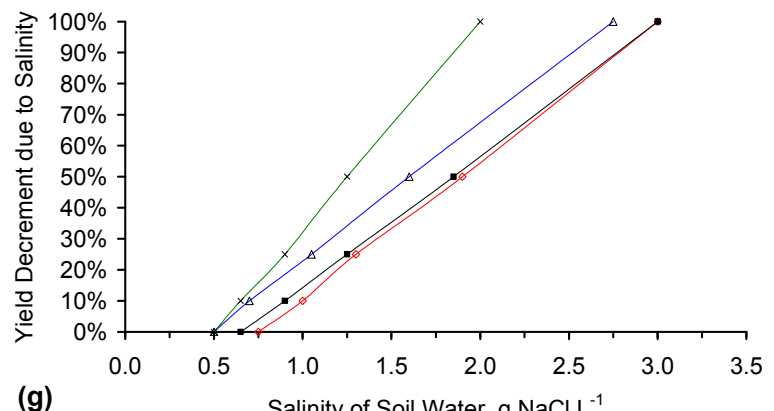

(g)

Salinity of Soil Water, $\mathrm{g} \mathrm{NaCl} \mathrm{L}^{-1}$

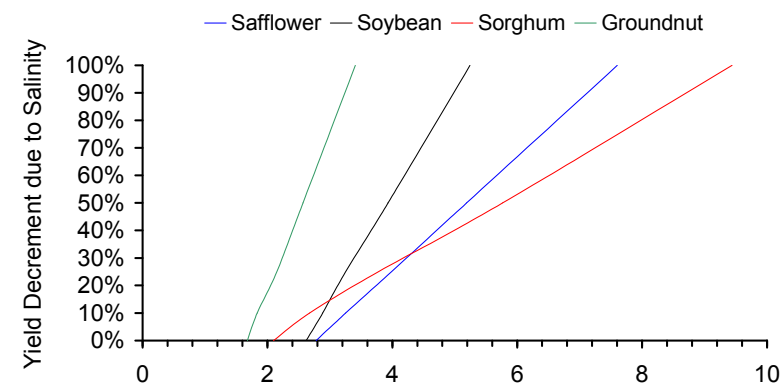

(b)

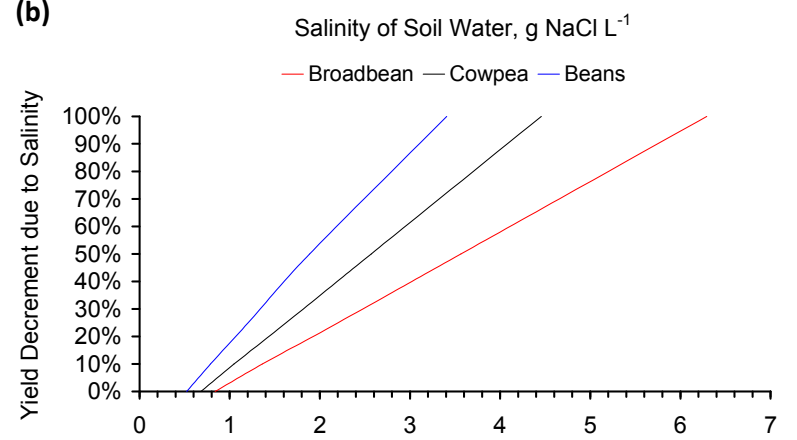

(d)

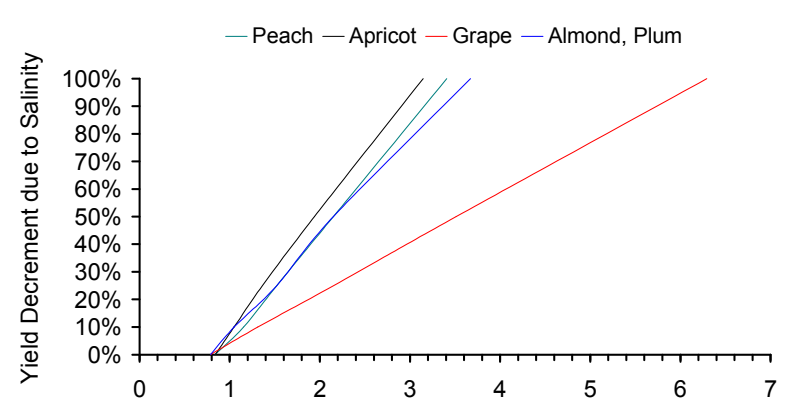

(f)

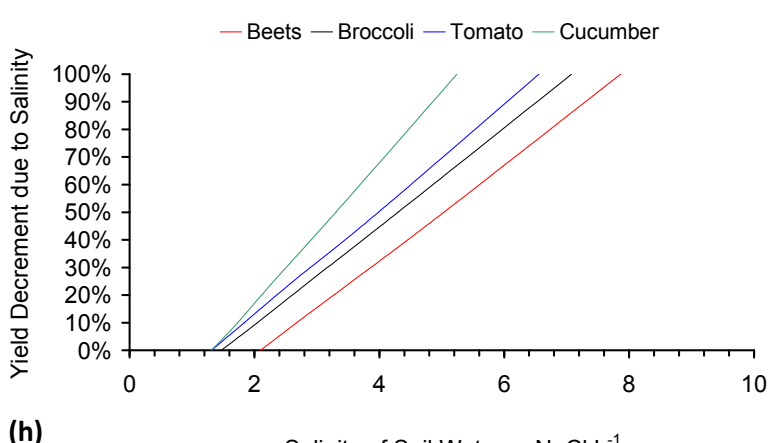

Salinity of Soil Water, $\mathrm{g} \mathrm{NaCl} \mathrm{L}^{-1}$

Figure B1. Cont. 

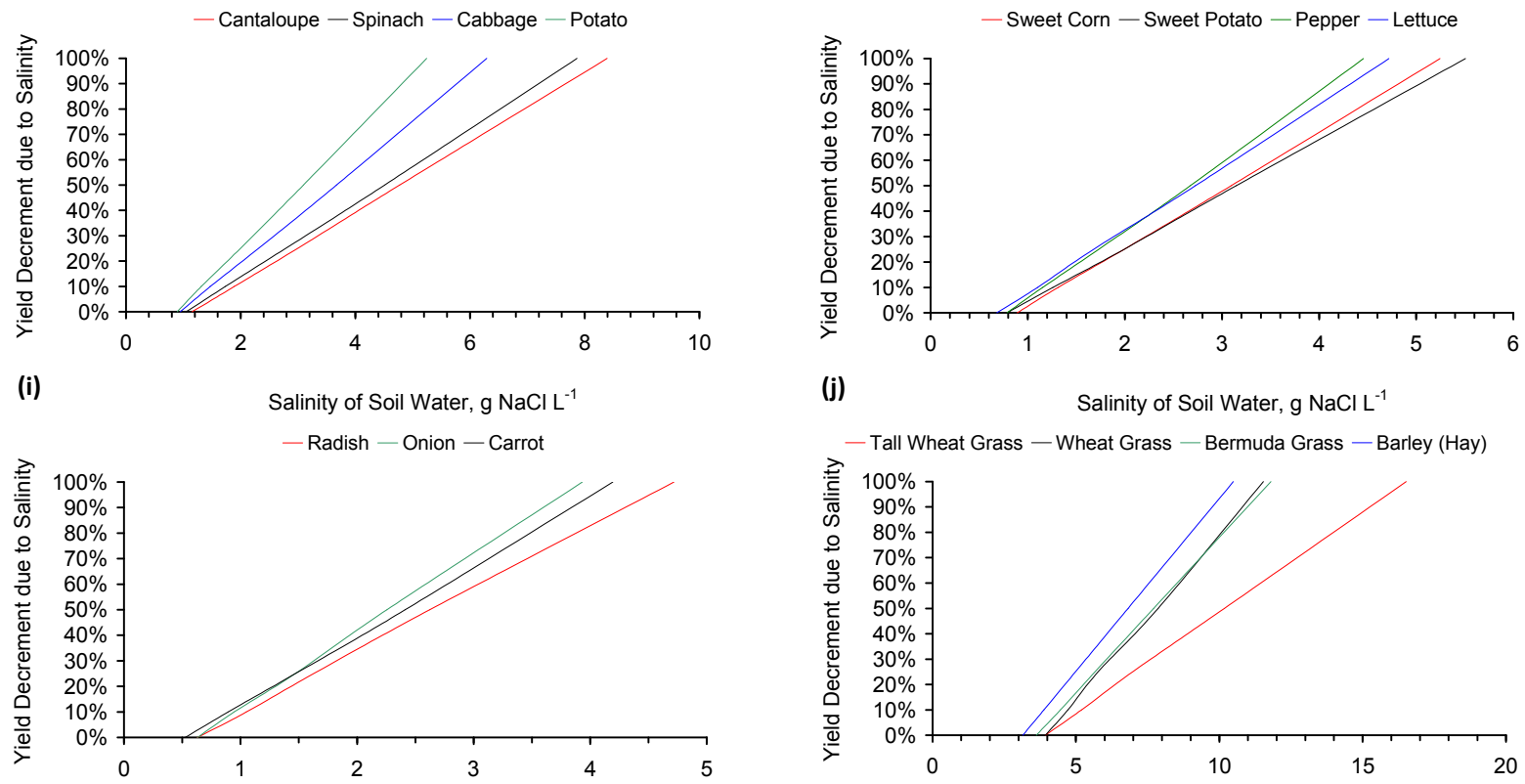

(k)

Salinity of Soil Water, $\mathrm{g} \mathrm{NaCl} \mathrm{L}^{-1}$

(I)

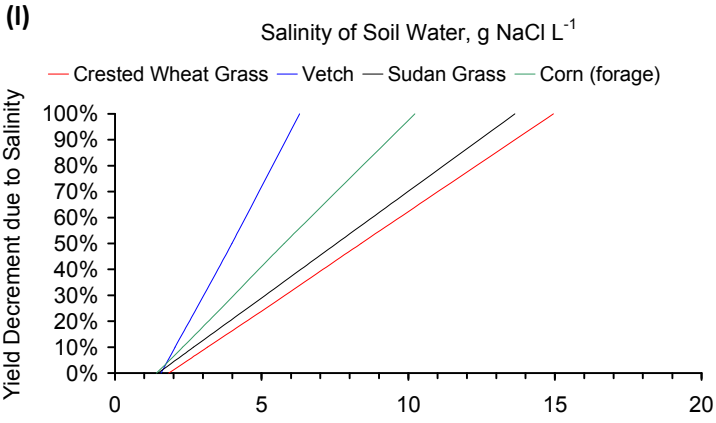

(m)

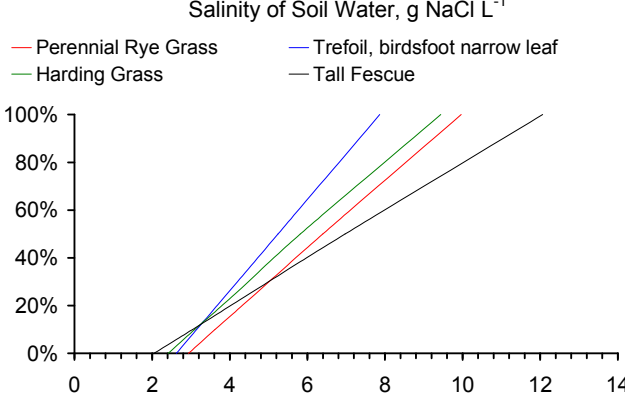

Salinity of Soil Water, $\mathrm{g} \mathrm{NaCl} \mathrm{L}{ }^{-1}$

(n)

—Wild Rye, beardless - Trefoil, big - Alfalfa — Lovegrass

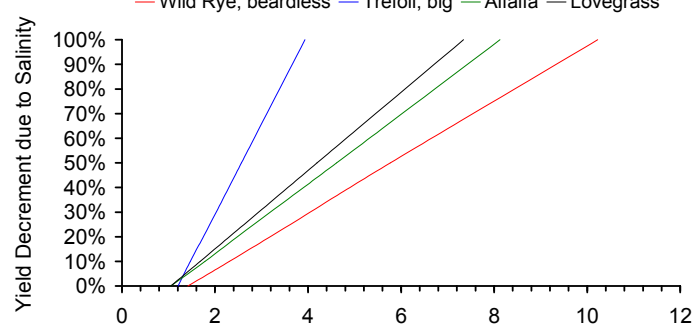

(o)

Salinity of Soil Water, $\mathrm{g} \mathrm{NaCl} \mathrm{L}^{-1}$

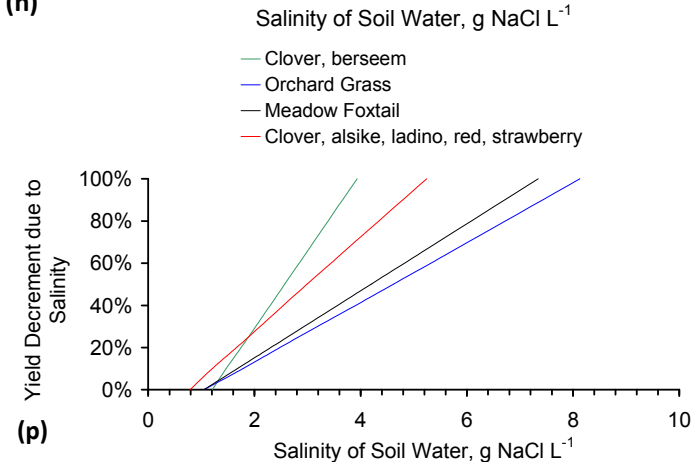

Figure B1. Indicative relationship between crop yield and soil water salinity. (a) Barley, Cotton, Sugar Beet, Wheat; (b) Safflower, Soybean, Sorghum, Groundnut; (c) Rice, Sebania, Flax; (d) Broad bean, Cowpea, Beans; (e) Date Palm, Fig, Pomegranite, Olive, Grapefruit, Orange, Lemon, Pear, Apple, Walnut; (f) Peach, Apricot, Grape, Almond, Plumb; (g) Blackberry, Boysenberry, Avocado, Raspberry, Strawberry; (h) Beets, Broccoli, Tomato, Cucumber; (i) Cantaloupe, Spinach, Cabbage, Potato; (j) Sweet Corn, Sweet Potato, Pepper, Lettuce; (k) Radish, Onion, Carrot; (l) Tall Wheat Grass, Wheat Grass, Barley (Hay), Bermuda Grass; (m) Perrenial Rye Grass, Harding Grass, Trefoil, birsdfoot narrow leaf, Tall Fescue; (n) Crested Wheat Grass, Vetch, Sudan Grass, Corn (forage); (o) Wid Rye, beardless, Trefoil, big, Alfalfa, Lovegrass; (p) Clover, berseem, alsike, ladino, red, strawberry, Orchard Grass, Meadow Foxtail. Data Source: [188]. 


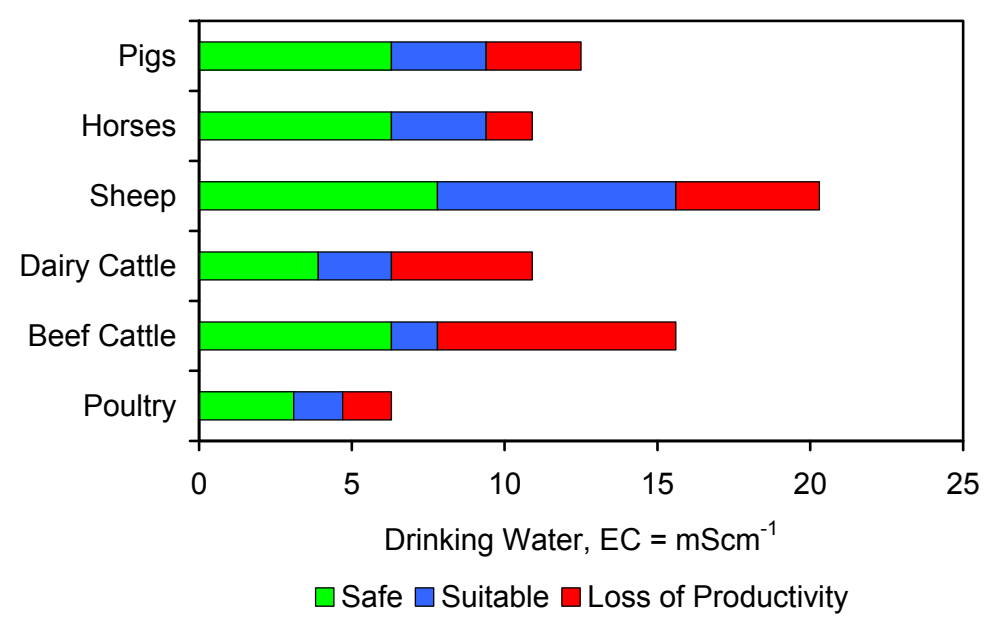

Figure B2. Variation in livestock yields with drinking water salinity. Data: [210-214].

\section{Appendix C. Trial Results}

The trial results are placed in Tables $\mathrm{C} 1-\mathrm{C} 13$ and Figures $\mathrm{C} 1-\mathrm{C} 37$.

Table C1. Measured Anion Concentrations in the Feed and Product Water.

\begin{tabular}{|c|c|c|c|c|c|c|c|}
\hline \multirow{2}{*}{ Water } & $\mathrm{Cl}$ & $\mathrm{N}\left(\mathrm{NO}_{3}\right)$ & $\mathrm{S}\left(\mathrm{SO}_{4}\right)$ & $\mathbf{P}\left(\mathrm{PO}_{4}\right)$ & $\mathbf{F}$ & $\mathrm{N}\left(\mathrm{NO}_{2}\right)$ & Product Water \\
\hline & $\mathrm{mg} / \mathrm{L}$ & $\mathrm{mg} / \mathrm{L}$ & $\mathrm{mg} / \mathrm{L}$ & $\mathrm{mg} / \mathrm{L}$ & $\mathrm{mg} / \mathrm{L}$ & $\mathrm{mg} / \mathrm{L}$ & (\% Feed Water) \\
\hline \multicolumn{8}{|c|}{ Fresh Spring Water } \\
\hline Base Water & 11.67 & 11.28 & 4.16 & $<0.10$ & 0.024 & 0.04 & - \\
\hline \multicolumn{8}{|c|}{ PS4 } \\
\hline Feed Water & 6004.17 & 11.28 & 4.16 & $<0.10$ & 0.024 & 0.04 & - \\
\hline Product Water & 1434.2 & 0.12 & 3.12 & $<0.10$ & 0.03 & 2.48 & $55.00 \%$ \\
\hline \multicolumn{8}{|c|}{ PS5 } \\
\hline Feed Water & 4568.84 & 11.28 & 4.16 & $<0.10$ & 0.024 & 0.04 & - \\
\hline Product Water & 1613.63 & 0.73 & 2.32 & $<0.10$ & $<0.020$ & 3.17 & $55.00 \%$ \\
\hline \multicolumn{8}{|c|}{ PS11 } \\
\hline Feed Water & 2464.2 & 1.38 & 1.7 & 0.229 & $<0.020$ & 2.49 & - \\
\hline Product Water & 1554.33 & 1.53 & 2.78 & $<0.10$ & 0.046 & 2.7 & $92.80 \%$ \\
\hline \multicolumn{8}{|c|}{ PS14 } \\
\hline Feed Water & 1914.05 & 10.81 & 4.46 & $<0.10$ & 0.024 & 3 & - \\
\hline Product Water & 1822.42 & 0.13 & 4.84 & $<0.10$ & 0.024 & 3.22 & $78.30 \%$ \\
\hline \multicolumn{8}{|c|}{ ST3b } \\
\hline Feed Water & 6519 & 8.41 & 4.5 & $<0.010$ & 0.023 & 2.2 & - \\
\hline Product Water & 2060 & 0.16 & 1.32 & $<0.010$ & 0.017 & 1.31 & $75.00 \%$ \\
\hline \multicolumn{8}{|c|}{ ST3f } \\
\hline Feed Water & 6519 & 8.41 & 4.5 & $<0.010$ & 0.023 & 2.2 & - \\
\hline Product Water & 2066 & 3.69 & 2.48 & $<0.010$ & 0.025 & 2.08 & $75.00 \%$ \\
\hline
\end{tabular}


Table C1. Cont.

\begin{tabular}{|c|c|c|c|c|c|c|c|}
\hline \multirow[b]{2}{*}{ Water } & $\mathrm{Cl}$ & $\mathrm{N}\left(\mathrm{NO}_{3}\right)$ & $\mathrm{S}\left(\mathrm{SO}_{4}\right)$ & $\mathbf{P}\left(\mathrm{PO}_{4}\right)$ & $\mathbf{F}$ & $\mathrm{N}\left(\mathrm{NO}_{2}\right)$ & \multirow{2}{*}{$\begin{array}{c}\text { Product Water } \\
\text { (\% Feed } \\
\text { Water }) \\
\end{array}$} \\
\hline & $\mathrm{mg} / \mathrm{L}$ & $\mathrm{mg} / \mathrm{L}$ & $\mathrm{mg} / \mathrm{L}$ & $\mathrm{mg} / \mathrm{L}$ & $\mathbf{m g} / \mathbf{L}$ & $\mathrm{mg} / \mathrm{L}$ & \\
\hline \multicolumn{8}{|c|}{ ST6d } \\
\hline Feed Water & 5457.6 & 11.28 & 4.16 & $<0.10$ & 0.024 & 0.04 & - \\
\hline Product Water & 5269.3 & 3.33 & 4.27 & $<0.10$ & $<0.020$ & 2.34 & $82.60 \%$ \\
\hline \multicolumn{8}{|c|}{ ST8e } \\
\hline Feed Water & 3983.85 & 10.04 & 4.72 & $<0.10$ & $<0.020$ & 0.29 & - \\
\hline Product Water & 3631.88 & 0.09 & 4.74 & $<0.10$ & 0.034 & 0.02 & $94.20 \%$ \\
\hline \multicolumn{8}{|c|}{ MT1b } \\
\hline Feed Water & 4769 & 11.03 & 4.86 & $<0.010$ & 0.015 & 1.06 & - \\
\hline Product Water & 3937 & 4.61 & 4.58 & $<0.010$ & 0.067 & 2.21 & $82.60 \%$ \\
\hline \multicolumn{8}{|c|}{ MT2b } \\
\hline Feed Water & 4037.39 & 10.5 & 4.51 & $<0.10$ & $<0.020$ & $<0.020$ & - \\
\hline Product Water & 3700.83 & 0.53 & 4.49 & $<0.10$ & $<0.020$ & 0.08 & $79.20 \%$ \\
\hline \multicolumn{8}{|c|}{ MT3d } \\
\hline Feed Water & 2092.1 & 10.81 & 4.55 & 0.436 & $<0.020$ & 2.4 & - \\
\hline Product Water & 1982.02 & 9.77 & 7.35 & $<0.10$ & 0.079 & 2.43 & $82.60 \%$ \\
\hline \multicolumn{8}{|c|}{ MT4d } \\
\hline Feed Water & 2464.2 & 1.38 & 1.7 & 0.229 & $<0.020$ & 2.49 & - \\
\hline Product Water & 1873.3 & 1.39 & 5.5 & $<0.10$ & 0.041 & 2.42 & $91.30 \%$ \\
\hline \multicolumn{8}{|c|}{ PS15 } \\
\hline Feed Water & $16,243.98$ & 27.55 & 10.15 & $<0.10$ & 0.06 & 0.09 & - \\
\hline Product Water & $10,076.22$ & 3.94 & 6.04 & $<0.10$ & 0.13 & 2.47 & $66.80 \%$ \\
\hline \multicolumn{8}{|c|}{ PS16 } \\
\hline Feed Water & $23,162.04$ & 26.03 & 9.59 & $<0.10$ & 0.06 & 0.09 & - \\
\hline Product Water & 348.03 & 0.64 & 1.52 & 0.15 & 0.03 & 0.20 & $26.50 \%$ \\
\hline
\end{tabular}

Table C2. Measured Cation Concentrations in the Feed and Product Water.

\begin{tabular}{|c|c|c|c|c|c|c|c|}
\hline \multirow{2}{*}{ Water } & $\mathbf{K}$ & $\mathbf{C a}$ & $\mathrm{Mg}$ & $\mathbf{N a}$ & Al & $\mathbf{F e}$ & Mn \\
\hline & $\mathrm{mg} / \mathrm{L}$ & $\mathrm{mg} / \mathrm{L}$ & $\mathrm{mg} / \mathrm{L}$ & $\mathrm{mg} / \mathrm{L}$ & $\mu g / L$ & $\mu g / L$ & $\mu g / L$ \\
\hline \multicolumn{8}{|c|}{ Fresh Spring Water } \\
\hline Base Water & 1.69 & 32.91 & 10.54 & 6.32 & $<150.0$ & $<30.0$ & 1.70 \\
\hline \multicolumn{8}{|c|}{ PS4 } \\
\hline Feed Water & 1.69 & 32.91 & 10.54 & 3995.83 & $<150.0$ & $<30.0$ & 1.70 \\
\hline Product Water & 15.71 & 10.79 & 16.45 & 899.63 & $<150.0$ & 47.6 & 2.10 \\
\hline \multicolumn{8}{|c|}{ PS5 } \\
\hline Feed Water & 1.69 & 32.91 & 10.54 & 3039.15 & $<150.0$ & $<30.0$ & 1.70 \\
\hline Product Water & 10.11 & 20.52 & 7.58 & 1009.59 & 173.4 & $<30.0$ & 5.50 \\
\hline \multicolumn{8}{|c|}{ PS11 } \\
\hline Feed Water & 1.80 & 9.27 & 2.13 & 1522.07 & $<150.0$ & $<30.0$ & 2.80 \\
\hline Product Water & 2.37 & 3.64 & 44.29 & 1107.61 & $<150.0$ & $<30.0$ & 2.10 \\
\hline
\end{tabular}


Table C2. Cont.

\begin{tabular}{|c|c|c|c|c|c|c|c|}
\hline Water & $\begin{array}{c}\mathrm{K} \\
\mathrm{mg} / \mathrm{L}\end{array}$ & \begin{tabular}{|c|}
$\mathrm{Ca}$ \\
$\mathrm{mg} / \mathrm{L}$
\end{tabular} & \begin{tabular}{|c|}
$\mathrm{Mg}$ \\
$\mathrm{mg} / \mathrm{L}$
\end{tabular} & $\begin{array}{c}\mathrm{Na} \\
\mathrm{mg} / \mathrm{L}\end{array}$ & $\begin{array}{c}\mathrm{Al} \\
\mu \mathrm{g} / \mathrm{L}\end{array}$ & $\begin{array}{c}\mathrm{Fe} \\
\mu \mathrm{g} / \mathrm{L}\end{array}$ & $\begin{array}{c}M n \\
\mu \mathrm{g} / \mathrm{L}\end{array}$ \\
\hline \multicolumn{8}{|c|}{ PS14 } \\
\hline Feed Water & 2.67 & 31.13 & 9.6 & 1245.32 & $<150.0$ & $<30.0$ & 2.80 \\
\hline Product Water & 4.92 & 6.94 & 3.58 & 1197.14 & $<150.0$ & $<30.0$ & 1.80 \\
\hline \multicolumn{8}{|c|}{ ST3b } \\
\hline Feed Water & 3.49 & 26.65 & 7.65 & 4527 & $<150.0$ & $<30.0$ & 8.00 \\
\hline Product Water & 5.48 & 3.26 & 2.49 & 1309 & $<150.0$ & $<30.0$ & 13.00 \\
\hline \multicolumn{8}{|c|}{ ST3f } \\
\hline Feed Water & 3.49 & 26.65 & 7.65 & 4527 & $<150.0$ & $<30.0$ & 8.00 \\
\hline Product Water & 7.76 & 17.63 & 7.38 & 1293 & $<150.0$ & $<30.0$ & 5.90 \\
\hline \multicolumn{8}{|c|}{ ST6d } \\
\hline Feed Water & 1.69 & 32.91 & 10.54 & 3630.53 & $<150.0$ & $<30.0$ & 32.90 \\
\hline Product Water & 5.53 & 32.48 & 9.58 & 3275.18 & $<150.0$ & $<30.0$ & 69.90 \\
\hline \multicolumn{8}{|c|}{ ST8e } \\
\hline Feed Water & 5.89 & 31.26 & 9.5 & 2390.85 & $<150.0$ & 34.7 & 14.20 \\
\hline Product Water & 6.97 & 14.36 & 4.5 & 2175.29 & $<150.0$ & $<30.0$ & 3.30 \\
\hline \multicolumn{8}{|c|}{ MT1b } \\
\hline Feed Water & 2.30 & 31.16 & 9.54 & 3052 & $<150.0$ & 42.1 & 2.90 \\
\hline Product Water & 156.80 & 6.08 & 49.23 & 2521 & 377 & $<30.0$ & 2.40 \\
\hline \multicolumn{8}{|c|}{ MT2b } \\
\hline Feed Water & 4.18 & 30.17 & 9.09 & 2434.31 & $<150.0$ & $<30.0$ & 4.30 \\
\hline Product Water & 23.05 & 12.27 & 3.85 & 2198.69 & 2085.2 & $<30.0$ & 2.90 \\
\hline \multicolumn{8}{|c|}{ MT3d } \\
\hline Feed Water & 2.80 & 30.55 & 9.42 & 1370.7 & $<150.0$ & $<30.0$ & 5.10 \\
\hline Product Water & 7.04 & 33.65 & 0.41 & 1319.14 & 10,720 & $<30.0$ & 1.40 \\
\hline \multicolumn{8}{|c|}{ MT4d } \\
\hline Feed Water & 1.80 & 9.27 & 2.13 & 1522.07 & $<150.0$ & $<30.0$ & 2.80 \\
\hline Product Water & 3.24 & 2.84 & 35.75 & 1273.08 & $<150.0$ & $<30.0$ & 2.00 \\
\hline \multicolumn{8}{|c|}{ PS15 } \\
\hline Feed Water & 4087.42 & 80.39 & 25.75 & 8406.66 & $<150.0$ & $<30.0$ & 4.15 \\
\hline Product Water & 3266.23 & 25.51 & 6.23 & 4197.07 & $<150.0$ & $<30.0$ & 23.90 \\
\hline \multicolumn{8}{|c|}{ PS16 } \\
\hline Feed Water & 3.89 & 75.94 & 24.33 & $15,411.17$ & $<150.0$ & $<30.0$ & 3.92 \\
\hline Product Water & 5.24 & 7.46 & 1.82 & 223.21 & 288.8 & $<30.0$ & 4.00 \\
\hline
\end{tabular}

Table C3. Measured Cation Concentrations in the Feed and Product Water.

\begin{tabular}{cccccccc}
\hline \multirow{2}{*}{ Water } & $\mathbf{P}$ & $\mathbf{S}$ & $\mathbf{B}$ & $\mathbf{B a}$ & $\mathbf{C d}$ & $\mathbf{C o}$ & $\mathbf{C r}$ \\
\cline { 2 - 8 } & $\mathbf{m g} / \mathbf{L}$ & $\mathbf{m g} / \mathbf{L}$ & $\boldsymbol{\mu g} / \mathbf{L}$ & $\boldsymbol{\mu g} / \mathbf{L}$ & $\boldsymbol{\mu g} / \mathbf{L}$ & $\boldsymbol{\mu g} / \mathbf{L}$ & $\boldsymbol{\mu g} / \mathbf{L}$ \\
\hline \multicolumn{7}{c}{ Fresh Spring Water } \\
\hline Base Water & $<0.005$ & 4.31 & 29.40 & 135.60 & $<0.2$ & $<0.2$ & $<2.0$ \\
\hline Feed Water & $<0.005$ & 4.31 & 29.40 & 135.60 & $<0.2$ & $<0.2$ & $<2.0$ \\
Product Water & 0.01 & 3.3 & 12.00 & 15.10 & $<0.2$ & 1.30 & $<2.0$ \\
\hline
\end{tabular}


Table C3. Cont

\begin{tabular}{|c|c|c|c|c|c|c|c|}
\hline \multirow{2}{*}{ Water } & $\mathbf{P}$ & $\mathbf{S}$ & B & $\mathbf{B a}$ & $\mathrm{Cd}$ & $\mathrm{Co}$ & $\mathrm{Cr}$ \\
\hline & $\mathrm{mg} / \mathrm{L}$ & $\mathrm{mg} / \mathrm{L}$ & $\mu g / L$ & $\mu \mathrm{g} / \mathrm{L}$ & $\mu \mathrm{g} / \mathrm{L}$ & $\mu g / L$ & $\mu g / L$ \\
\hline \multicolumn{8}{|c|}{ PS5 } \\
\hline Feed Water & $<0.005$ & 4.31 & 29.40 & 135.60 & $<0.2$ & $<0.2$ & $<2.0$ \\
\hline Product Water & 0.01 & 2.55 & $<10$ & $<15$ & $<0.2$ & 1.50 & $<2.0$ \\
\hline \multicolumn{8}{|c|}{ PS11 } \\
\hline Feed Water & 0.25 & 1.89 & $<10$ & 16.40 & $<0.2$ & 1.80 & $<2.0$ \\
\hline Product Water & 0.04 & 3.15 & 25.80 & $<15$ & $<0.2$ & 1.40 & $<2.0$ \\
\hline \multicolumn{8}{|c|}{ PS14 } \\
\hline Feed Water & 0.03 & 4.51 & 22.20 & 117.10 & $<0.2$ & 1.50 & $<2.0$ \\
\hline Product Water & 0.01 & 4.8 & $<10$ & $<15$ & $<0.2$ & 1.50 & $<2.0$ \\
\hline \multicolumn{8}{|c|}{ ST3b } \\
\hline Feed Water & 0.07 & 4.59 & 14.90 & 103.10 & 0.9 & 3.30 & $<2.0$ \\
\hline Product Water & 0.01 & 1.56 & 59.40 & $<15.0$ & 1.2 & 1.20 & $<2.0$ \\
\hline \multicolumn{8}{|c|}{ ST3f } \\
\hline Feed Water & 0.07 & 4.59 & 14.90 & 103.10 & 0.9 & 3.30 & $<2.0$ \\
\hline Product Water & 0.02 & 2.63 & 17.50 & $<15.0$ & 1.0 & 1.60 & $<2.0$ \\
\hline \multicolumn{8}{|c|}{ ST6d } \\
\hline Feed Water & $<0.005$ & 4.31 & 29.40 & 135.60 & $<0.2$ & $<0.2$ & $<2.0$ \\
\hline Product Water & 0.01 & 4.31 & $<10$ & 68.50 & $<0.2$ & 3.90 & $<2.0$ \\
\hline \multicolumn{8}{|c|}{ ST8e } \\
\hline Feed Water & 0.01 & 4.8 & 28.90 & 118.70 & $<0.2$ & 2.20 & $<2.0$ \\
\hline Product Water & 0.01 & 4.9 & 34.60 & $<15$ & $<0.2$ & 1.10 & $<2.0$ \\
\hline \multicolumn{8}{|c|}{ MT1b } \\
\hline Feed Water & 0.04 & 4.79 & 20.80 & 102.80 & 0.4 & 1.30 & $<2.0$ \\
\hline Product Water & 0.01 & 4.79 & 70.40 & $<15.0$ & 0.4 & 1.60 & $<2.0$ \\
\hline \multicolumn{8}{|c|}{ MT2b } \\
\hline Feed Water & 0.02 & 4.66 & 15.80 & 115.40 & $<0.2$ & 2.40 & $<2.0$ \\
\hline Product Water & 0.01 & 4.68 & 11.30 & $<15$ & $<0.2$ & 2.20 & $<2.0$ \\
\hline \multicolumn{8}{|c|}{ MT3d } \\
\hline Feed Water & 0.47 & 4.66 & 36.00 & 118.90 & 0.3 & 0.80 & $<2.0$ \\
\hline Product Water & 0.03 & 7.55 & 22.30 & $<15$ & $<0.2$ & 1.80 & $<2.0$ \\
\hline \multicolumn{8}{|c|}{ MT4d } \\
\hline Feed Water & 0.25 & 1.89 & $<10$ & 16.40 & $<0.2$ & 1.80 & $<2.0$ \\
\hline Product Water & 0.02 & 6.02 & 97.30 & $<15$ & $<0.2$ & 2.40 & $<2.0$ \\
\hline \multicolumn{8}{|c|}{ PS15 } \\
\hline Feed Water & $<0.005$ & 10.52 & 71.82 & 331.20 & $<0.2$ & $<0.2$ & $<2.0$ \\
\hline Product Water & 0.01 & 6.12 & 38.10 & 55.20 & 10.2 & 3.60 & $<2.0$ \\
\hline \multicolumn{8}{|c|}{ PS16 } \\
\hline Feed Water & $<0.005$ & 9.94 & 67.80 & 312.90 & $<0.2$ & $<0.2$ & $<2.0$ \\
\hline Product Water & $<0.005$ & 3.74 & 109.60 & $<15$ & $<0.2$ & 0.20 & $<2.0$ \\
\hline
\end{tabular}


Table C4. Measured Cation Concentrations in the Feed and Product Water.

\begin{tabular}{|c|c|c|c|c|c|c|c|}
\hline Water & $\begin{array}{c}\mathrm{Cu} \\
\mu \mathrm{g} / \mathrm{L}\end{array}$ & $\begin{array}{c}\mathrm{Ni} \\
\mu \mathrm{g} / \mathrm{L}\end{array}$ & $\begin{array}{c}\mathrm{Pb} \\
\mu \mathrm{g} / \mathrm{L}\end{array}$ & $\begin{array}{c}\mathrm{Si} \\
\mathrm{mg} / \mathrm{L}\end{array}$ & $\begin{array}{c}\mathrm{Sr} \\
\mu \mathrm{g} / \mathrm{L}\end{array}$ & $\begin{array}{c}\mathrm{Zn} \\
\mu \mathrm{g} / \mathrm{L}\end{array}$ & $\begin{array}{c}\mathrm{As} \\
\mathrm{g} / \mathrm{L}\end{array}$ \\
\hline \multicolumn{8}{|c|}{ Fresh Spring Water } \\
\hline Base Water & 77.7 & $<3$ & $<10$ & 5.21 & 144.9 & 37.4 & \\
\hline \multicolumn{8}{|c|}{ PS4 } \\
\hline Feed Water & 77.7 & $<3$ & $<10$ & 5.21 & 144.9 & 37.4 & \\
\hline Product Water & $<20$ & $<3$ & $<10$ & 0.05 & 76 & $<4$ & \\
\hline \multicolumn{8}{|c|}{ PS5 } \\
\hline Feed Water & 77.7 & $<3$ & $<10$ & 5.21 & 144.9 & 37.4 & \\
\hline Product Water & 54.3 & $<3$ & $<10$ & 0.09 & 54.2 & 33.8 & \\
\hline \multicolumn{8}{|c|}{ PS11 } \\
\hline Feed Water & $<20$ & $<3$ & $<10$ & 1.43 & 28.5 & 137.5 & \\
\hline Product Water & $<20$ & $<3$ & $<10$ & 0.9 & 4.3 & 14.1 & \\
\hline \multicolumn{8}{|c|}{ PS14 } \\
\hline Feed Water & 122.1 & $<3$ & $<10$ & 4.77 & 136.1 & 125.6 & \\
\hline Product Water & $<20$ & $<3$ & $<10$ & 0.04 & 54 & $<4$ & \\
\hline \multicolumn{8}{|c|}{ ST3b } \\
\hline Feed Water & 45.1 & 3.7 & $<10$ & 3.99 & 112.4 & 337.6 & 2.3 \\
\hline Product Water & $<20.0$ & $<3.0$ & $<10$ & 0.29 & 15.6 & $<4.00$ & 5.4 \\
\hline \multicolumn{8}{|c|}{ ST3f } \\
\hline Feed Water & 45.1 & 3.7 & $<10$ & 3.99 & 112.4 & 337.6 & 2.3 \\
\hline Product Water & $<20.0$ & $<3.0$ & $<10$ & 0.62 & 103.4 & $<4.00$ & 5.3 \\
\hline \multicolumn{8}{|c|}{ ST6d } \\
\hline Feed Water & 77.7 & $<3$ & $<10$ & 5.21 & 144.9 & 37.4 & - \\
\hline Product Water & 736.5 & $<3$ & $<10$ & 0.41 & 134.6 & 68.2 & - \\
\hline \multicolumn{8}{|c|}{ ST8e } \\
\hline Feed Water & 41 & $<3$ & $<10$ & 4.89 & 138 & 286.9 & - \\
\hline Product Water & $<20$ & $<3$ & $<10$ & 0.28 & 32.5 & 29 & - \\
\hline \multicolumn{8}{|c|}{ MT1b } \\
\hline Feed Water & 52.9 & $<3.0$ & $<10$ & 4.92 & 139.9 & 170 & 4.8 \\
\hline Product Water & $<20.0$ & $<3.0$ & $<10$ & 0.37 & 6.7 & 17.6 & 2.5 \\
\hline \multicolumn{8}{|c|}{ MT2b } \\
\hline Feed Water & 93.1 & $<3$ & $<10$ & 4.67 & 133.3 & 101.1 & - \\
\hline Product Water & $<20$ & $<3$ & $<10$ & 0.06 & 10.2 & 5.1 & - \\
\hline \multicolumn{8}{|c|}{ MT3d } \\
\hline Feed Water & 74.9 & $<3$ & $<10$ & 4.83 & 134.3 & 342 & - \\
\hline Product Water & $<20$ & $<3$ & $<10$ & 0.12 & 209.1 & $<4$ & - \\
\hline \multicolumn{8}{|c|}{ MT4d } \\
\hline Feed Water & $<20$ & $<3$ & $<10$ & 1.43 & 28.5 & 137.5 & - \\
\hline Product Water & $<20$ & $<3$ & $<10$ & 0.44 & 0.8 & 7.7 & - \\
\hline \multicolumn{8}{|c|}{ PS15 } \\
\hline Feed Water & 189.80 & $<3$ & $<10$ & 12.73 & 353.9 & 91.36 & - \\
\hline Product Water & 31.80 & $<3$ & $<10$ & 0.22 & 86.1 & 205.10 & - \\
\hline \multicolumn{8}{|c|}{ PS16 } \\
\hline Feed Water & 179.30 & $<3$ & $<10$ & 12.03 & 334.4 & 86.30 & - \\
\hline Product Water & 29.00 & $<3$ & $<10$ & 0.35 & 30.6 & 828.50 & - \\
\hline
\end{tabular}


Table C5. ZVM TPA Example (Trial E143): Feed Water Composition.

\begin{tabular}{|c|c|c|c|c|c|}
\hline \multirow{2}{*}{ Trial } & \multirow{2}{*}{$\begin{array}{c}\text { Water Charge } \\
\mathbf{L} \\
\end{array}$} & \multirow{2}{*}{$\begin{array}{l}\text { Feed Water } \\
\mathrm{NaCl}, \mathrm{g} \cdot \mathrm{L}^{-1} \\
\end{array}$} & \multirow{2}{*}{ Eh, mV } & \multirow{2}{*}{ pH } & \multirow{2}{*}{$\mathrm{EC}, \mathrm{mS} \cdot \mathrm{cm}^{-1}$} \\
\hline & & & & & \\
\hline E143a & 5.4 & 5.74 & 0.2 & 5.66 & 11.15 \\
\hline E143b & 5.4 & 4.44 & 0.193 & 6.61 & 8.63 \\
\hline E143c & 5.4 & 4.81 & 0.199 & 6.11 & 9.35 \\
\hline E143d & 5.4 & 5.37 & 0.214 & 5.59 & 10.43 \\
\hline E143e & 5.4 & 6.48 & 0.22 & 5.78 & 12.59 \\
\hline E143f & 5.4 & 1.85 & 0.166 & 5.65 & 3.59 \\
\hline E143g & 5.4 & 2.59 & 0.188 & 6.46 & 5.04 \\
\hline E143h & 5.4 & 2.63 & 0.176 & 6.46 & 5.04 \\
\hline E143i & 5.4 & 2.96 & 0.185 & 6.18 & 5.75 \\
\hline E143j & 5.4 & 3.33 & 0.17 & 5.18 & 6.63 \\
\hline E143k & 5.4 & 3.35 & 0.219 & 6.19 & 6.63 \\
\hline
\end{tabular}

Table C6. ZVM TPA Example (Trial E143): Product Water Composition.

\begin{tabular}{|c|c|c|c|c|c|c|c|}
\hline \multirow{2}{*}{ Trial } & \multirow{2}{*}{ Eh, mV } & \multirow{2}{*}{$\mathbf{p H}$} & \multirow{2}{*}{$\mathrm{EC}, \mathrm{mS} \cdot \mathrm{cm}^{-1}$} & \multirow{2}{*}{$\frac{\text { Storage }}{\text { Weeks }}$} & \multirow{2}{*}{$\frac{\text { Stored Water Analysis }}{\mathrm{Eh}, \mathrm{mV}}$} & \multirow{2}{*}{$\mathbf{p H}$} & \multirow{2}{*}{$\mathrm{EC}, \mathrm{mS} \cdot \mathrm{cm}^{-1}$} \\
\hline & & & & & & & \\
\hline E143a & 0.214 & 6.80 & 0.725 & 6 & 0.232 & 6.82 & 0.814 \\
\hline E143b & 0.226 & 6.19 & 3.29 & 4 & 0.214 & 7.00 & 3.62 \\
\hline E143c & 0.248 & 5.22 & 4.10 & 4 & 0.227 & 6.86 & 4.25 \\
\hline E143d & 0.258 & 5.31 & 5.73 & 4 & 0.243 & 6.51 & 5.80 \\
\hline E143e & 0.224 & 5.54 & 9.35 & 4 & 0.238 & 6.58 & 9.57 \\
\hline E143f & 0.185 & 6.68 & 6.71 & 4 & 0.220 & 6.96 & 7.01 \\
\hline E143g & 0.197 & 6.76 & 4.70 & 4 & 0.215 & 7.13 & 4.75 \\
\hline E143h & 0.201 & 6.90 & 6.27 & 4 & 0.219 & 7.05 & 6.28 \\
\hline E143i & 0.165 & 5.12 & 9.51 & 4 & 0.261 & 6.13 & 9.52 \\
\hline E143j & 0.212 & 5.31 & 6.15 & 4 & 0.271 & 6.17 & 6.19 \\
\hline E143k & 0.207 & 6.04 & 6.56 & 4 & 0.261 & 6.34 & 6.47 \\
\hline
\end{tabular}

Table C7. ZVM TPA Example (Trial E143): Product Water Volume Recovered, Trial Duration, Temperature, Gas Flows.

\begin{tabular}{|c|c|c|c|c|c|c|c|c|}
\hline \multirow[t]{2}{*}{ Trial } & $\begin{array}{c}\text { Water } \\
\text { Recovered }\end{array}$ & $\begin{array}{c}\text { Water } \\
\text { Consumed }\end{array}$ & Duration & $\begin{array}{c}\text { Air } \\
\text { Flow }\end{array}$ & $\mathrm{CO}_{2}$ Flow & $\begin{array}{c}\text { Air Flow } \\
\text { Rate }\end{array}$ & $\begin{array}{c}\mathrm{CO}_{2} \text { Flow } \\
\text { Rate }\end{array}$ & \multirow[t]{2}{*}{ Temperature } \\
\hline & $\mathbf{L}$ & $\mathbf{L}$ & $\mathbf{h}$ & $\mathbf{h}$ & $\mathbf{h}$ & $L \cdot h^{-1}$ & $L \cdot h^{-1}$ & \\
\hline E143a & 4.60 & 0.80 & 9.00 & 9.00 & 0.00 & 13.2 & 3.3 & $5-12{ }^{\circ} \mathrm{C}$ \\
\hline E143b & 4.60 & 0.80 & 8.33 & 5.05 & 3.28 & 13.2 & 3.3 & $5-10^{\circ} \mathrm{C}$ \\
\hline E143c & 4.70 & 0.70 & 4.37 & 2.56 & 1.81 & 13.2 & 3.3 & $5-10^{\circ} \mathrm{C}$ \\
\hline E143d & 4.80 & 0.60 & 4.02 & 1.76 & 2.26 & 13.2 & 3.3 & $5-10^{\circ} \mathrm{C}$ \\
\hline E143e & 4.70 & 0.70 & 3.87 & 1.71 & 2.16 & 13.2 & 3.3 & $5-10^{\circ} \mathrm{C}$ \\
\hline E143f & 4.65 & 0.75 & 2.70 & 2.70 & 0.00 & 13.2 & 3.3 & $5-10^{\circ} \mathrm{C}$ \\
\hline E143g & 4.50 & 0.90 & 3.08 & 3.08 & 0.00 & 13.2 & 3.3 & $5-10^{\circ} \mathrm{C}$ \\
\hline E143h & 3.90 & 1.50 & 14.30 & 14.30 & 0.00 & 13.2 & 3.3 & $5-10^{\circ} \mathrm{C}$ \\
\hline E143i & 4.00 & 1.40 & 8.90 & 4.50 & 4.40 & 13.2 & 3.3 & $5-10^{\circ} \mathrm{C}$ \\
\hline E143j & 3.90 & 1.50 & 7.50 & 2.20 & 5.30 & 13.2 & 3.3 & $5-10^{\circ} \mathrm{C}$ \\
\hline E143k & 3.90 & 1.50 & 3.58 & 2.58 & 1.00 & 13.2 & 3.3 & $5-10^{\circ} \mathrm{C}$ \\
\hline
\end{tabular}


Table C8. ZVM TPA Example (Trial E143): Salinity Changes calculated from changes in $\mathrm{EC}$ and changes in water volume.

\begin{tabular}{|c|c|c|c|c|c|c|}
\hline \multirow{2}{*}{ Trial } & $\begin{array}{c}\text { Product } \\
\text { Water }\end{array}$ & $\begin{array}{c}\text { Apparent } \mathrm{NaCl} \\
\text { Removed }\end{array}$ & $\begin{array}{c}\text { Actual NaCl } \\
\text { Removed } \\
\end{array}$ & $\begin{array}{c}\text { Cumulative } \\
\text { NaCl Removed }\end{array}$ & $\begin{array}{c}\text { Cumulative Water } \\
\text { Processed }\end{array}$ & Cumulative \\
\hline & $g \cdot \mathbf{L}^{-1}$ & $g \cdot \mathbf{L}^{-1}$ & $g \cdot \mathbf{L}^{-1}$ & $g \cdot \mathbf{L}^{-1}$ & $\mathbf{L}$ & $\begin{array}{c}\mathrm{NaCl} \text { in Feed } \\
\mathrm{g} \cdot \mathrm{L}^{-1}\end{array}$ \\
\hline E143a & 0.064 & 5.68 & 5.686 & 5.69 & 5.4 & 5.74 \\
\hline E143b & 1.514 & 2.93 & 3.154 & 8.84 & 10.8 & 10.19 \\
\hline E143c & 1.933 & 2.88 & 3.132 & 11.97 & 16.2 & 15.00 \\
\hline E143d & 2.786 & 2.58 & 2.894 & 14.87 & 21.6 & 20.37 \\
\hline E143e & 4.686 & 1.80 & 2.403 & 17.27 & 27.0 & 26.85 \\
\hline E143f & 3.491 & -1.64 & -1.154 & 16.12 & 32.4 & 28.70 \\
\hline E143g & 2.363 & 0.23 & 0.623 & 16.74 & 37.8 & 31.30 \\
\hline E143h & 3.248 & -0.62 & 0.284 & 17.02 & 43.2 & 33.93 \\
\hline E143i & 4.948 & -1.98 & -0.702 & 16.32 & 48.6 & 36.89 \\
\hline$E 143 j$ & 3.028 & 0.31 & 1.146 & 17.47 & 54.0 & 40.22 \\
\hline E143k & 3.268 & 0.08 & 0.992 & 18.46 & 59.4 & 43.57 \\
\hline
\end{tabular}

Table C9. ZVM TPA Example (Trial E144): Feed Water Composition.

\begin{tabular}{|c|c|c|c|c|c|}
\hline \multirow{2}{*}{ Trial } & \multirow{2}{*}{ Water Charge, L } & \multirow{2}{*}{$\begin{array}{c}\text { Feed Water } \\
\mathrm{NaCl}, \mathrm{g} \cdot \mathbf{L}^{-1}\end{array}$} & \multirow{2}{*}{ Eh, $\mathbf{m V}$} & \multirow{2}{*}{ pH } & \multirow{2}{*}{$\mathbf{E C}, \mathbf{m S} \cdot \mathbf{c m}^{-1}$} \\
\hline & & & & & \\
\hline E144a & 5.4 & 4.07 & 0.203 & 6.50 & 7.91 \\
\hline E144b & 5.4 & 4.07 & 0.192 & 6.35 & 7.94 \\
\hline E144c & 5.4 & 1.00 & 0.181 & 6.31 & 2.16 \\
\hline E144d & 5.4 & 1.10 & 0.191 & 6.16 & 2.34 \\
\hline E144e & 5.4 & 2.05 & 0.218 & 6.37 & 4.04 \\
\hline E144f & 5.4 & 5.83 & 0.192 & 6.34 & 11.25 \\
\hline
\end{tabular}

Table C10. ZVM TPA Example (Trial E144): Product Water Composition.

\begin{tabular}{|c|c|c|c|c|c|c|c|}
\hline \multirow{2}{*}{ Trial } & \multirow{2}{*}{ Eh, mV } & \multirow{2}{*}{$\mathbf{p H}$} & \multirow{2}{*}{$\mathrm{EC}, \mathbf{m S} \cdot \mathbf{c m}^{-1}$} & \multirow{2}{*}{ Storage Weeks } & \multirow{2}{*}{$\begin{array}{c}\text { Stored Water Analysis } \\
\text { Eh, } \mathbf{m V}\end{array}$} & \multirow{2}{*}{ pH } & \multirow{2}{*}{$\mathrm{EC}, \mathrm{mS} \cdot \mathrm{cm}^{-1}$} \\
\hline & & & & & & & \\
\hline E144a & 0.199 & 5.64 & 7.03 & 3 & 0.282 & 6.51 & 5.8 \\
\hline E144b & 0.222 & 6.64 & 7.32 & 3 & 0.282 & 6.57 & 6.6 \\
\hline E144c & 0.154 & 5.23 & 3.92 & - & - & - & - \\
\hline E144d & 0.169 & 5.38 & 2.74 & - & - & - & - \\
\hline E144e & 0.153 & 5.30 & 4.08 & - & - & - & - \\
\hline E144f & 0.080 & 5.56 & 8.58 & - & - & - & - \\
\hline
\end{tabular}


Table C11. ZVM TPA Example (Trial E144): Product Water Volume Recovered, Trial Duration, Temperature, Gas Flows.

\begin{tabular}{lcccccccc}
\hline Trial & $\begin{array}{c}\text { Water } \\
\text { Recovered }\end{array}$ & $\begin{array}{c}\text { Water } \\
\text { Consumed }\end{array}$ & Duration & $\begin{array}{c}\text { Air } \\
\text { Flow }\end{array}$ & $\begin{array}{c}\mathbf{C O}_{2} \\
\text { Flow }\end{array}$ & $\begin{array}{c}\text { Air Flow } \\
\text { Rate }\end{array}$ & $\begin{array}{c}\mathbf{C O}_{2} \text { Flow } \\
\text { Rate }\end{array}$ & Temperature \\
\cline { 2 - 8 } & $\mathbf{L}$ & $\mathbf{L}$ & $\mathbf{h}$ & $\mathbf{h}$ & $\mathbf{h}$ & $\mathbf{L} \cdot \mathbf{h}^{-\mathbf{1}}$ & $\mathbf{L}^{-\mathbf{1}}$ & ${ }^{\mathbf{1}} \mathbf{C}$ \\
\hline E144a & 4.00 & 1.40 & 5.1 & 3.8 & 1.3 & 13.2 & 3.3 & $5-12$ \\
E144b & 4.00 & 1.40 & 104.3 & 70.5 & 33.8 & 13.2 & 3.3 & $8-15$ \\
E144c & 4.50 & 0.90 & 690.0 & 0.0 & 690.0 & 13.2 & 3.3 & $11-15$ \\
E144d & 4.15 & 1.25 & 291.0 & 0.0 & 291.0 & 13.2 & 3.3 & $12-16$ \\
E144e & 4.00 & 1.40 & 537.0 & 0.0 & 537.0 & 13.2 & 3.3 & $16-19$ \\
E144f & 3.50 & 1.90 & 1295.0 & 0.0 & 1295.0 & 13.2 & 3.3 & $13-19$ \\
\hline
\end{tabular}

Table C12. ZVM TPA Example (Trial E144): Salinity changes calculated from changes in

$\mathrm{EC}$, spectrometry, and changes in water volume.

\begin{tabular}{|c|c|c|c|c|c|c|c|}
\hline \multirow[t]{2}{*}{ Trial } & $\begin{array}{c}\text { Product Water } \\
\text { Salinity Based } \\
\text { on EC } \\
\end{array}$ & $\begin{array}{c}\text { Product Water } \\
\text { Salinity Based } \\
\text { on Spectrometry }\end{array}$ & $\begin{array}{l}\text { Apparent } \\
\text { NaCl } \\
\text { Removed }\end{array}$ & $\begin{array}{c}\text { Actual } \\
\text { NaCl } \\
\text { Removed }\end{array}$ & $\begin{array}{c}\text { Cumulative } \\
\text { NaCl Removed }\end{array}$ & \multirow{2}{*}{$\begin{array}{c}\text { Cumulative } \\
\text { Water } \\
\text { Processed }\end{array}$} & Cumulative \\
\hline & $\mathbf{g} \cdot \mathbf{L}^{-1}$ & $\mathbf{g} \cdot \mathbf{L}^{-1}$ & $g \cdot \mathbf{L}^{-1}$ & $g \cdot \mathbf{L}^{-1}$ & $g \cdot \mathbf{L}^{-1}$ & & $\begin{array}{c}\mathrm{NaCl} \text { in } \\
\text { feed } g \cdot \mathrm{L}^{-1}\end{array}$ \\
\hline E144a & 3.55 & - & 0.52 & 1.44 & 1.44 & 5.4 & 4.07 \\
\hline E144b & 3.69 & - & 0.38 & 1.34 & 2.78 & 10.8 & 8.15 \\
\hline E144c & 1.90 & 0.53 & 0.47 & 0.56 & 3.34 & 16.2 & 9.15 \\
\hline E144d & 1.27 & 1.04 & 0.06 & 0.30 & 3.64 & 21.6 & 10.25 \\
\hline $\mathrm{E} 144 \mathrm{e}$ & 2.03 & 1.30 & 0.75 & 1.09 & 4.73 & 27.0 & 12.30 \\
\hline E144f & 4.35 & 2.77 & 3.06 & 4.04 & 8.77 & 32.4 & 18.13 \\
\hline
\end{tabular}

Table C13. ZVM TPA Example (Trial E146): Feed Water and Product Water Composition. $\mathrm{The} \mathrm{NaCl}$ in the feed water is dissolved halite (Cheshire). The product water contains a settled layer of precipitant including clays and Fe hydroxides/peroxides derived from the halite. The apparent increase in salinity in Trial E1461 is due to the rate of nano-particle formation exceeding the rate of desalination.

\begin{tabular}{|c|c|c|c|c|c|c|c|c|c|c|}
\hline \multirow{3}{*}{ Trial } & \multirow{3}{*}{$\begin{array}{c}\text { Water } \\
\text { Charge, L }\end{array}$} & \multirow{3}{*}{$\begin{array}{c}\text { Feed } \\
\text { Water }\end{array}$} & \multirow{3}{*}{$\begin{array}{l}\text { Eh, } \\
\text { mV }\end{array}$} & \multirow{3}{*}{ pH } & \multirow{3}{*}{$\begin{array}{c}\mathrm{EC} \\
\mathrm{mS} \cdot \mathbf{c m}^{-1}\end{array}$} & \multirow{3}{*}{$\begin{array}{c}\text { Product } \\
\text { Water } \\
\text { Eh, mV }\end{array}$} & \multirow{3}{*}{$\mathbf{p H}$} & \multirow{3}{*}{$\begin{array}{c}\mathrm{EC} \\
\mathbf{m S} \cdot \mathbf{c m}^{-1}\end{array}$} & \multirow{3}{*}{$\begin{array}{c}\mathrm{NaCl}, \\
\mathrm{g} \cdot \mathbf{L}^{-1}\end{array}$} & \multirow{3}{*}{$\begin{array}{c}\text { Desalination } \\
\mathrm{NaCl}, \mathbf{g} \cdot \mathrm{L}^{-1}\end{array}$} \\
\hline & & & & & & & & & & \\
\hline & & & & & & & & & & \\
\hline E146a & 240 & 1.38 & 0.188 & 6.83 & 2.88 & 0.152 & 8.01 & 4.24 & 1.04 & 0.34 \\
\hline E146b & 240 & 2.73 & 0.164 & 6.67 & 5.4 & 0.151 & 8.31 & 5.35 & 2.09 & 0.64 \\
\hline E146c & 240 & 3.76 & 0.202 & 6.92 & 7.34 & 0.172 & 8.29 & 10.16 & 0.64 & 3.12 \\
\hline E146d & 240 & 6.27 & 0.156 & 6.99 & 12.2 & 0.178 & 8.27 & 18.19 & 4.68 & 1.59 \\
\hline E146e & 240 & 2.92 & 0.196 & 6.96 & 5.76 & 0.156 & 8.10 & 6.51 & 1.96 & 0.96 \\
\hline E146f & 240 & 2.24 & 0.162 & 6.90 & 4.47 & 0.142 & 8.19 & 5.29 & 1.39 & 0.85 \\
\hline E146g & 240 & 2.45 & 0.164 & 6.89 & 4.94 & 0.145 & 8.15 & 5.73 & 0.71 & 1.74 \\
\hline E146h & 240 & 3.73 & 0.164 & 6.97 & 7.39 & 0.157 & 8.37 & 8.62 & 1.87 & 1.86 \\
\hline
\end{tabular}


Table C13. Cont.

\begin{tabular}{|c|c|c|c|c|c|c|c|c|c|c|}
\hline \multirow{3}{*}{ Trial } & \multirow{3}{*}{$\begin{array}{c}\text { Water } \\
\text { Charge, } L\end{array}$} & \multirow{3}{*}{$\begin{array}{c}\text { Feed } \\
\text { Water } \\
\mathrm{NaCl}, \\
\mathrm{g} \cdot \mathbf{L}^{-1}\end{array}$} & \multirow{3}{*}{$\begin{array}{l}\text { Eh, } \\
\text { mV }\end{array}$} & \multirow{3}{*}{$\mathbf{p H}$} & \multirow{3}{*}{$\begin{array}{c}\mathbf{E C} \\
\mathbf{m S} \cdot \mathbf{c m}^{-1}\end{array}$} & \multirow{3}{*}{$\begin{array}{c}\text { Product } \\
\text { Water } \\
\text { Eh, mV }\end{array}$} & \multirow{3}{*}{$\mathbf{p H}$} & \multirow{3}{*}{$\begin{array}{c}\mathrm{EC} \\
\mathbf{m S} \cdot \mathbf{c m}^{-1}\end{array}$} & \multirow{3}{*}{$\begin{array}{l}\mathrm{NaCl}, \\
\mathrm{g} \cdot \mathbf{L}^{-1}\end{array}$} & \multirow{3}{*}{$\begin{array}{c}\text { Desalination } \\
\mathrm{NaCl}, \mathbf{g} \cdot \mathbf{L}^{-1}\end{array}$} \\
\hline & & & & & & & & & & \\
\hline & & & & & & & & & & \\
\hline E146i & 240 & 2.25 & 0.164 & 7.08 & 4.56 & 0.134 & 8.57 & 4.84 & 0.62 & 1.63 \\
\hline E146j & 240 & 2.75 & 0.176 & 6.19 & 5.48 & 0.155 & 7.57 & 5.57 & 1.85 & 0.90 \\
\hline E146k & 240 & 2.07 & 0.176 & 6.34 & 4.25 & 0.174 & 7.50 & 4.59 & 0.69 & 1.38 \\
\hline E1461 & 240 & 1.39 & 0.181 & 6.24 & 2.9 & 0.173 & 7.65 & 3.69 & 2.73 & -1.34 \\
\hline E146m & 240 & 2.17 & 0.181 & 6.33 & 4.38 & 0.174 & 7.50 & 4.59 & 0.61 & 1.56 \\
\hline E146n & 240 & 1.00 & 0.181 & 6.31 & 2.26 & 0.117 & 6.86 & 2.86 & 0.5 & 0.50 \\
\hline E146o & 240 & 1.10 & 0.191 & 6.16 & 2.34 & 0.134 & 7.10 & 3.14 & 0.76 & 0.34 \\
\hline E146p & 240 & 2.05 & 0.218 & 6.37 & 4.04 & 0.129 & 7.05 & 4.77 & 1.65 & 0.40 \\
\hline E146q & 240 & 5.83 & 0.192 & 6.35 & 11.25 & 0.099 & 7.40 & 12.27 & 2.15 & 3.68 \\
\hline
\end{tabular}

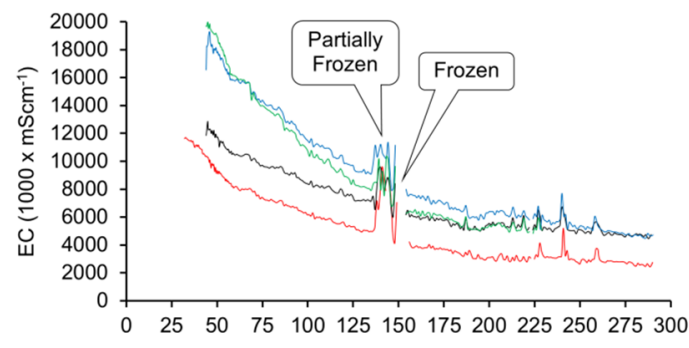
Day

(a)

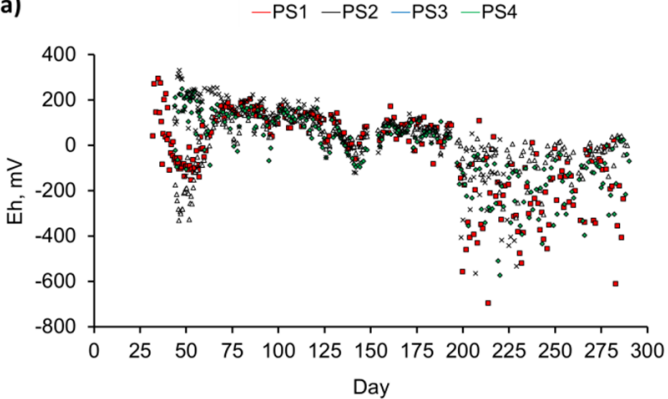

(c)

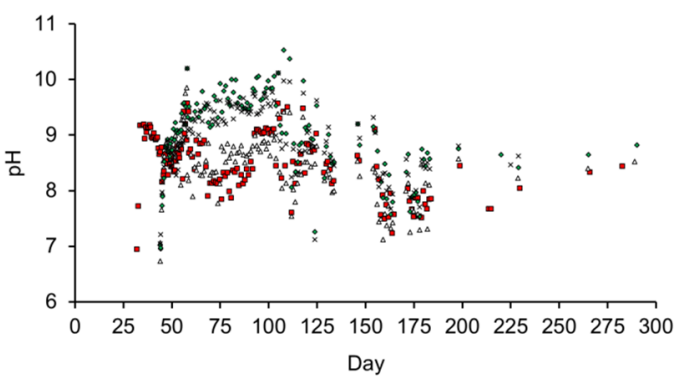

(b)

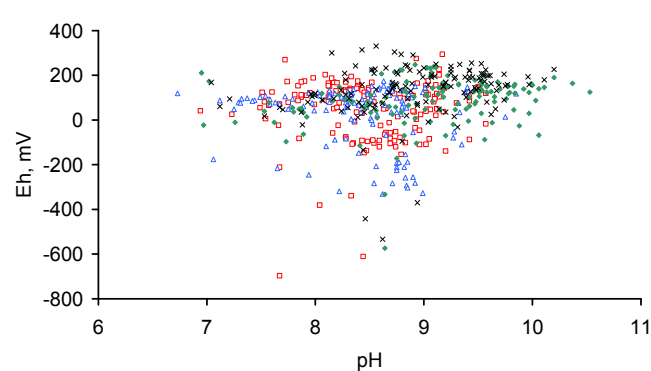

(d)

Figure C1. (a) EC vs. day; (b) Eh vs. day; (c) $\mathrm{pH}$ vs. day; (d) $\mathrm{pH}$ vs. Eh. ZVM TP = particulate material placed in water at a concentration of PS1 $=30 \mathrm{~g} \cdot \mathrm{L}^{-1}$; PS2 $=30 \mathrm{~g} \cdot \mathrm{L}^{-1}$; PS3 $=65 \mathrm{~g} \cdot \mathrm{L}^{-1}$; PS4 $=55 \mathrm{~g} \cdot \mathrm{L}^{-1}$. Reactor Size: $0.3 \mathrm{~L}$; Feed Water volume: $0.2 \mathrm{~L}$.

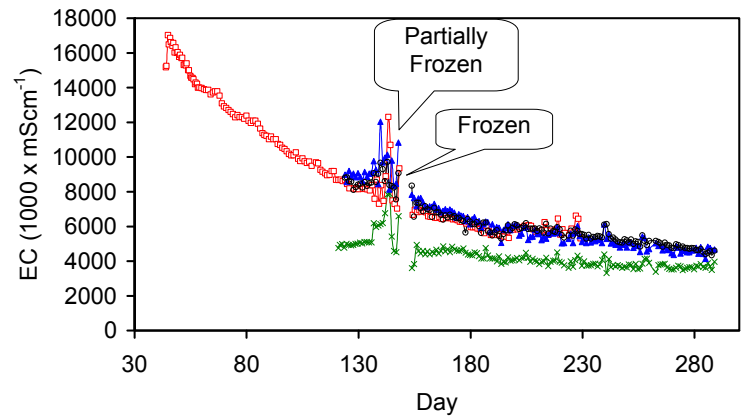

(a)

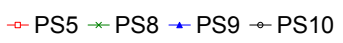

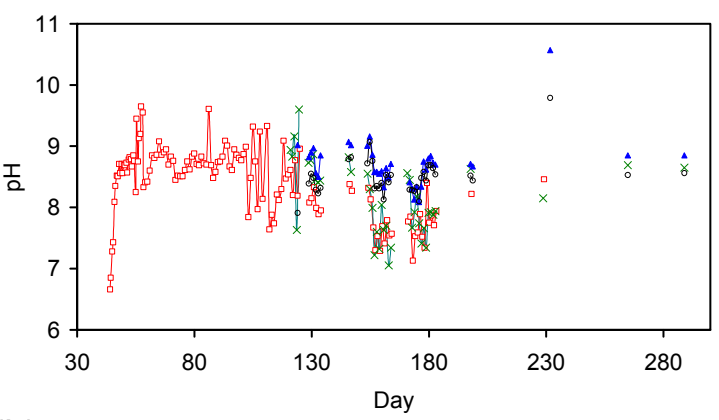

(b) 
Figure C2. Cont.

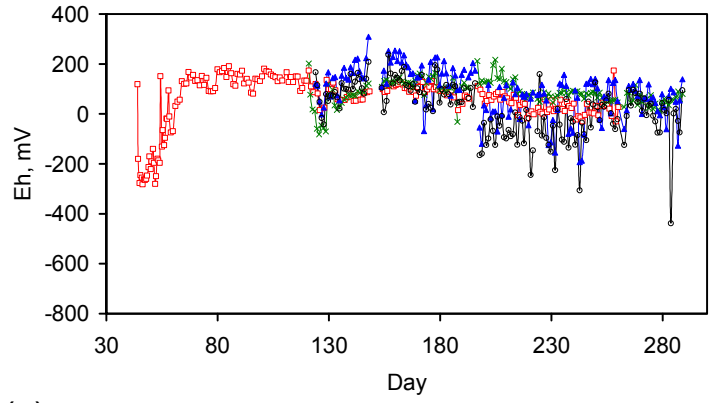

(c)

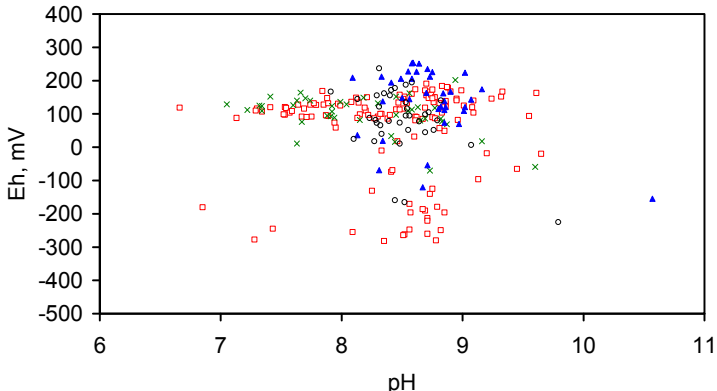

(d)

- PS5 × PS8 ^ PS9 。PS10

Figure C2. (a) EC vs. day; (b) Eh vs. day; (c) $\mathrm{pH}$ vs. day; (d) $\mathrm{pH}$ vs. Eh; ZVM TP $=$ particulate material placed in water at a concentration of PS5 $=30 \mathrm{~g} \cdot \mathrm{L}^{-1}$; PS8 $=30 \mathrm{~g} \cdot \mathrm{L}^{-1}$; PS9 $=60 \mathrm{~g} \cdot \mathrm{L}^{-1}$; Reactor Size: $0.3 \mathrm{~L}$; Feed Water volume: $0.2 \mathrm{~L}$.

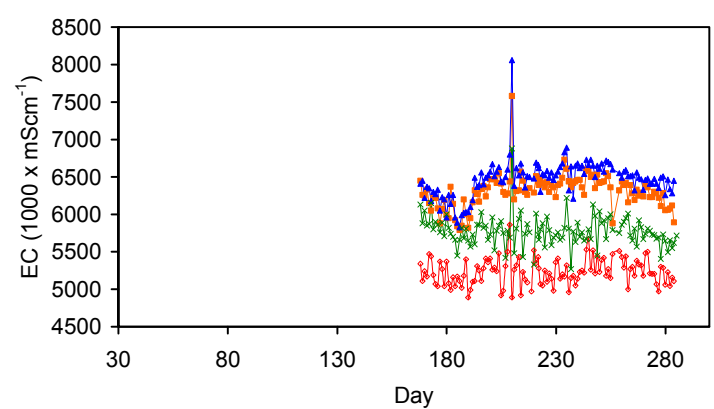

(a)

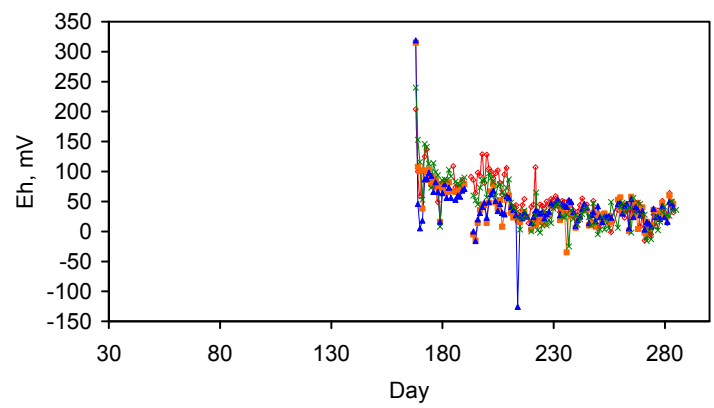

(c)

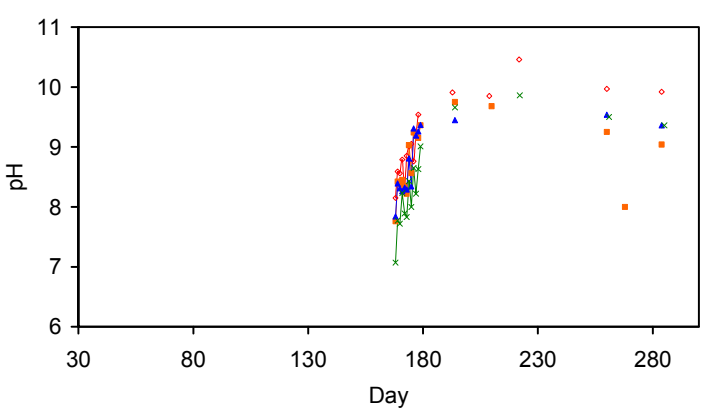

(b)

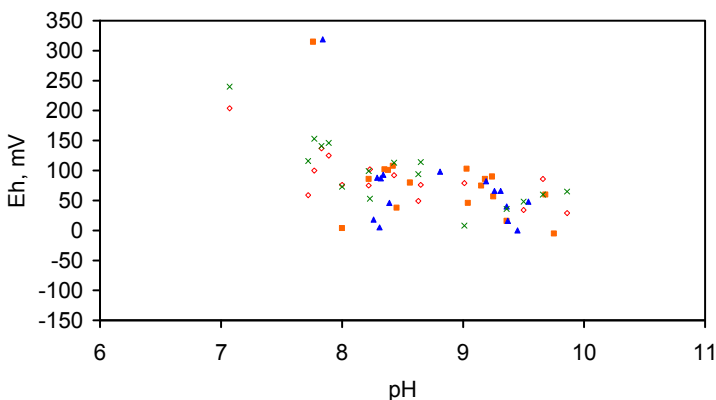

(d)

Figure C3. (a) EC vs. day; (b) Eh vs. day; (c) $\mathrm{pH} v s$. day; (d) $\mathrm{pH}$ vs. Eh. ZVM TP = particulate material placed in water at a concentration of PS11 $=26.5 \mathrm{~g} \cdot \mathrm{L}^{-1}$; PS12 $=14.3 \mathrm{~g} \cdot \mathrm{L}^{-1}$; PS13 $=5.65 \mathrm{~g} \cdot \mathrm{L}^{-1}$; PS14 $=10.2 \mathrm{~g} \cdot \mathrm{L}^{-1}$. Reactor Size: $2.3 \mathrm{~L}$; Feed Water volume: $2.3 \mathrm{~L}$.

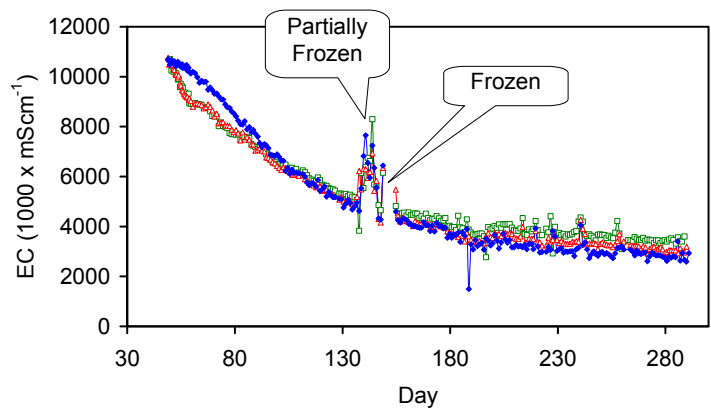

(a)

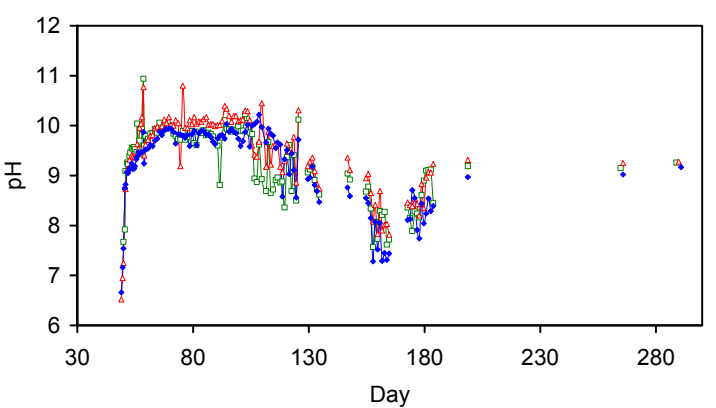

(b) 
Figure C4. Cont.

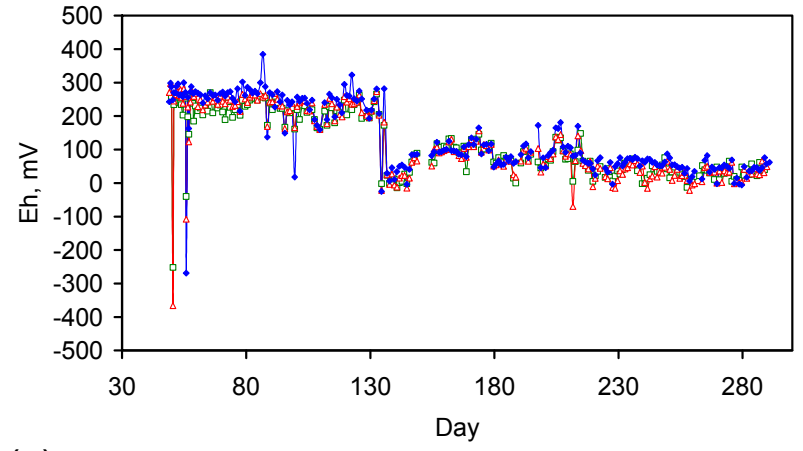

(c)

$$
\rightarrow \text { AS4 } \rightarrow \text { AS5 - AS6 }
$$

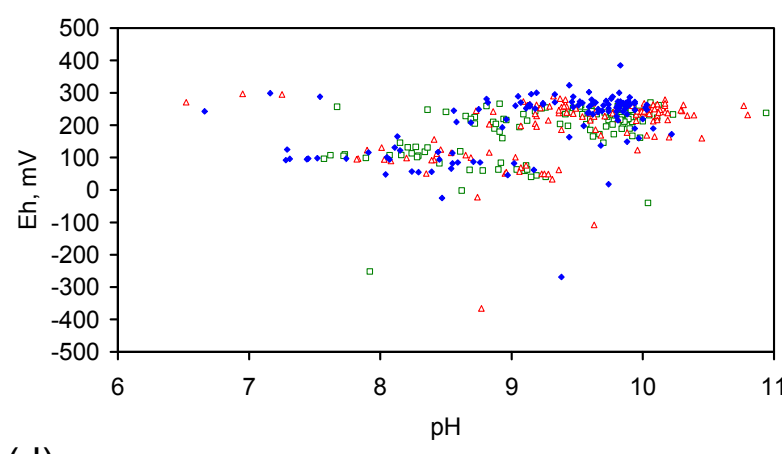

(d)

Figure C4. (a) EC vs. day; (b) Eh vs. day; (c) $\mathrm{pH} v s$. day; (d) $\mathrm{pH} v s$. Eh. AS4 $=42 \mathrm{~g} \cdot \mathrm{L}^{-1}$; AS5 $=59 \mathrm{~g} \cdot \mathrm{L}^{-1}$; AS6 $=35 \mathrm{~g} \cdot \mathrm{L}^{-1}$. Reactor Size: $0.3 \mathrm{~L}$; Feed Water volume: $0.2 \mathrm{~L}$.
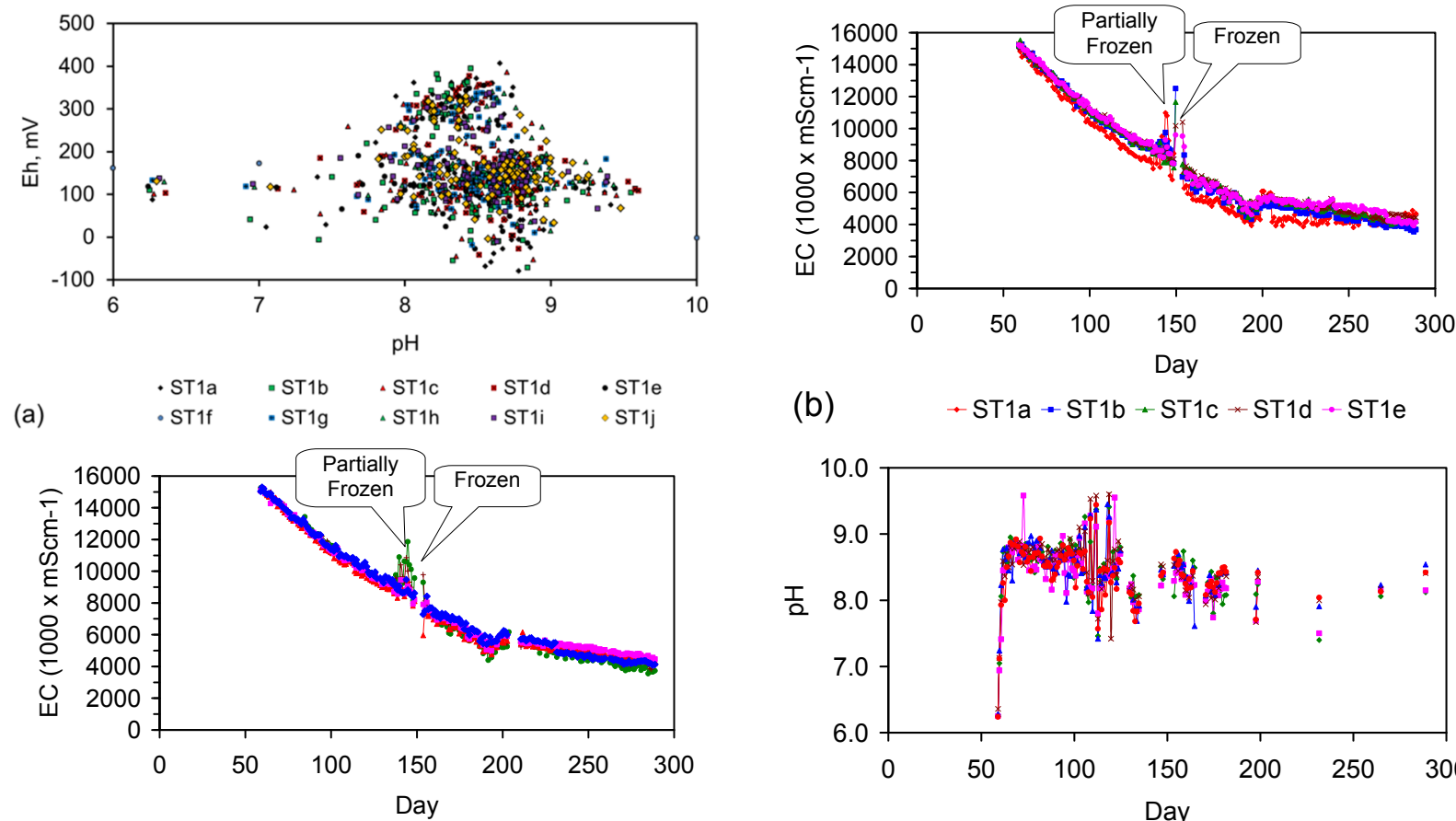

(b) $\quad+\mathrm{ST} 1 \mathrm{a}-\mathrm{ST} 1 \mathrm{~b}+\mathrm{ST} 1 \mathrm{c} * \mathrm{ST} 1 \mathrm{~d}+\mathrm{ST} 1 \mathrm{e}$

(c) $\quad \rightarrow \mathrm{ST} 1 \mathrm{f}+\mathrm{ST} 1 \mathrm{~g} \rightarrow \mathrm{ST} 1 \mathrm{~h} \rightarrow \mathrm{ST} 1 \mathrm{i} \rightarrow \mathrm{ST} 1 \mathrm{j}$

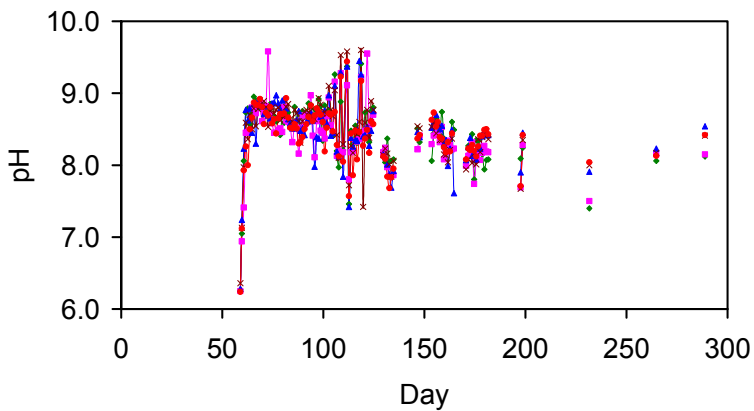

(d) $\quad \rightarrow \mathrm{ST} 1 \mathrm{a}=\mathrm{ST} 1 \mathrm{~b}+\mathrm{ST} 1 \mathrm{C} * \mathrm{ST} 1 \mathrm{~d} \rightarrow \mathrm{ST} 1 \mathrm{e}$

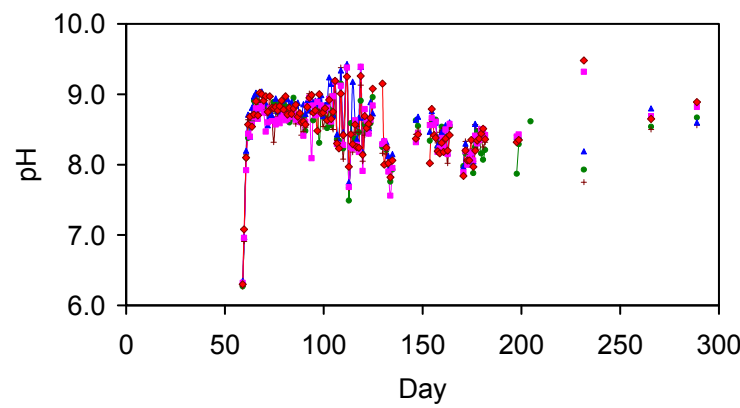

(e) $\quad \rightarrow \mathrm{ST} 1 \mathrm{f}+\mathrm{ST} 1 \mathrm{~g}+\mathrm{ST} 1 \mathrm{~h} \rightarrow \mathrm{ST} 1 \mathrm{i} \rightarrow \mathrm{ST} 1 \mathrm{j}$

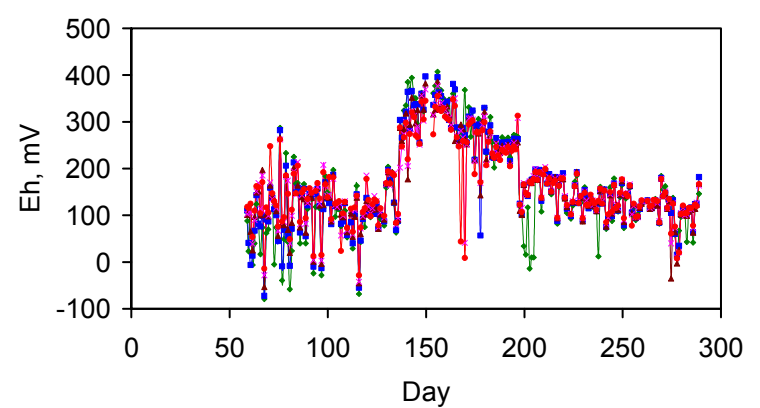

(f)

$* \mathrm{ST} 1 \mathrm{a} * \mathrm{ST} 1 \mathrm{~b}+\mathrm{ST} 1 \mathrm{c} * \mathrm{ST} 1 \mathrm{~d} * \mathrm{ST} 1 \mathrm{e}$

Figure C5. Cont. 


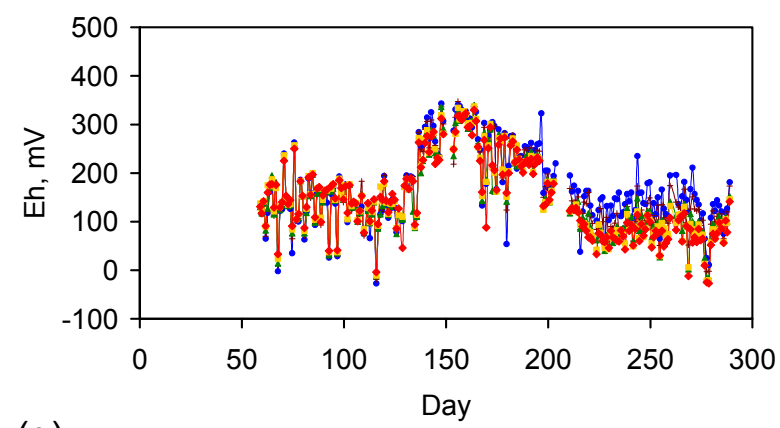

(g)

$\rightarrow \mathrm{ST} 1 \mathrm{f}+\mathrm{ST} 1 \mathrm{~g}+\mathrm{ST} 1 \mathrm{~h}=\mathrm{ST} 1 \mathrm{i}+\mathrm{ST} 1 \mathrm{j}$

Figure C5. (a) $\mathrm{pH}$ vs. Eh; (b) EC vs. day, ST1a-ST1e; (c) EC vs. day, ST1f-ST1j; (d) pH vs. day, ST1a-ST1e; (e) pH vs. day; ST1f-ST1j; (f) Eh vs. day, ST1a-ST1e; (g) Eh vs. day, ST1f-ST1j. ZVM TP = copper sheathed pellets $(15 \mathrm{~mm}$ OD) placed in water at a concentration of ST1a $=18.3 \mathrm{~g} \cdot \mathrm{L}^{-1} ; \mathrm{ST} 1 \mathrm{~b}=23.1 \mathrm{~g} \cdot \mathrm{L}^{-1} ; \mathrm{ST} 1 \mathrm{c}=25.3 \mathrm{~g} \cdot \mathrm{L}^{-1}$; ST1d $=$ $26.7 \mathrm{~g} \cdot \mathrm{L}^{-1} ; \mathrm{ST} 1 \mathrm{e}=21.7 \mathrm{~g} \cdot \mathrm{L}^{-1} ; \mathrm{ST} 1 \mathrm{f}=28.3 \mathrm{~g} \cdot \mathrm{L}^{-1} ; \mathrm{ST} 1 \mathrm{~g}=31.9 \mathrm{~g} \cdot \mathrm{L}^{-1} ; \mathrm{ST} 1 \mathrm{~h}=30.1 \mathrm{~g} \cdot \mathrm{L}^{-1}$; $\mathrm{ST} 1 \mathrm{i}=23.3 \mathrm{~g} \cdot \mathrm{L}^{-1}$; ST1j $=25.1 \mathrm{~g} \cdot \mathrm{L}^{-1}$. Reactor Size: $0.3 \mathrm{~L}$; Feed Water volume: $0.2 \mathrm{~L}$.
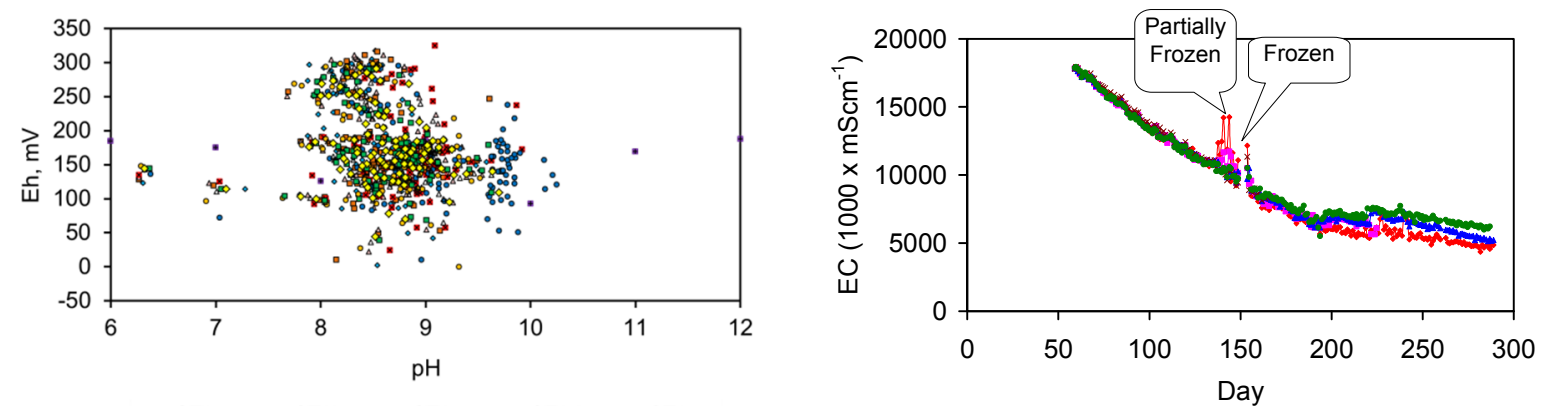

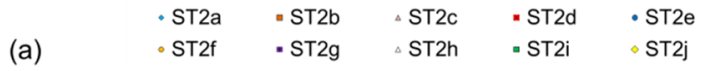

(b)
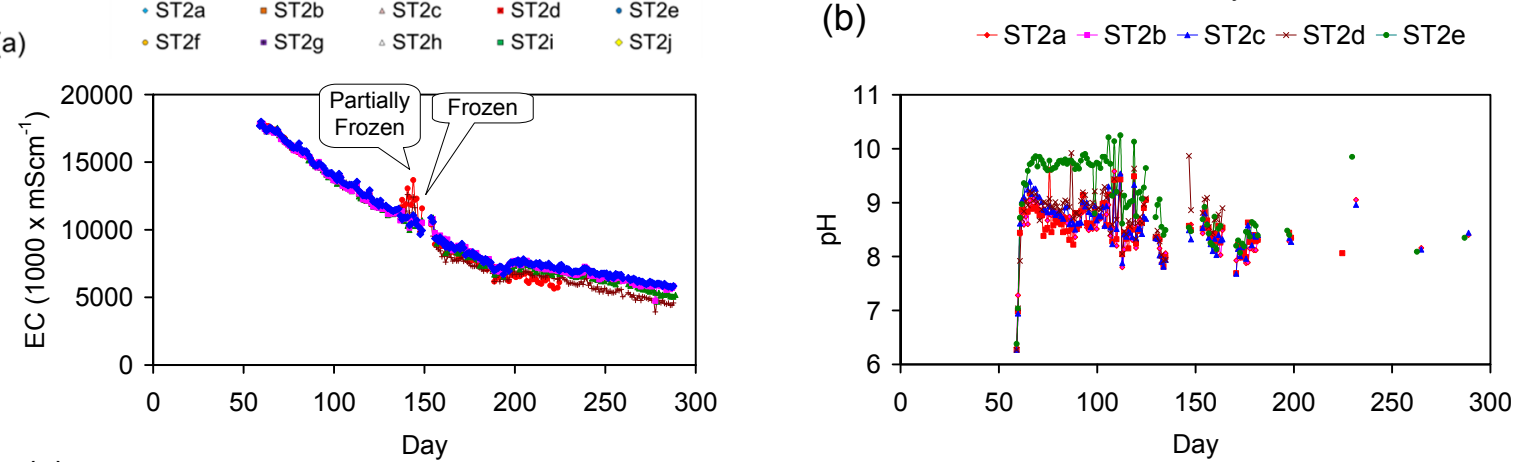

(c)

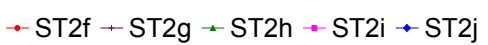

(d)
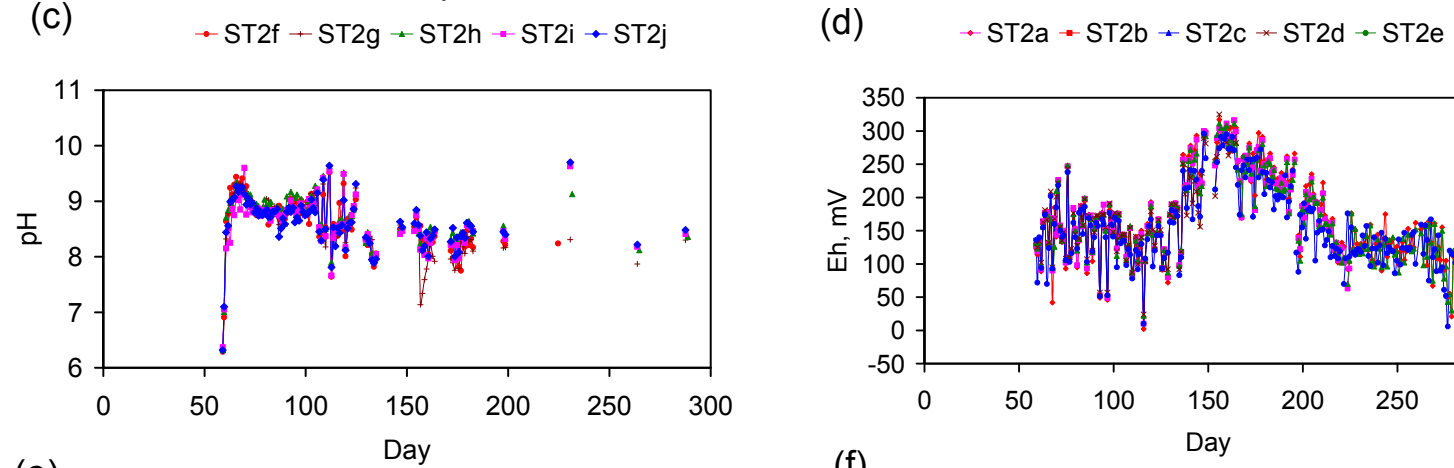

(e)

$$
\rightarrow \mathrm{ST} 2 \mathrm{f}+\mathrm{ST} 2 \mathrm{~g}+\mathrm{ST} 2 \mathrm{~h}=\mathrm{ST} 2 \mathrm{i}+\mathrm{ST} 2 \mathrm{j}
$$

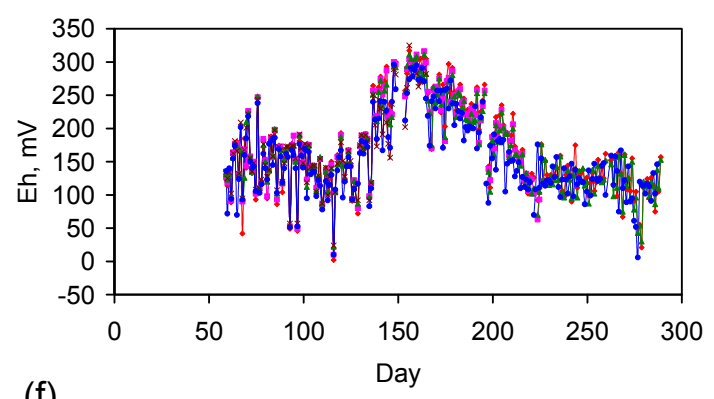

(f)

$\rightarrow \mathrm{ST} 2 \mathrm{a} \rightarrow \mathrm{ST} 2 \mathrm{~b}+\mathrm{ST} 2 \mathrm{c} * \mathrm{ST} 2 \mathrm{~d}+\mathrm{ST} 2 \mathrm{e}$

Figure C6. Cont. 


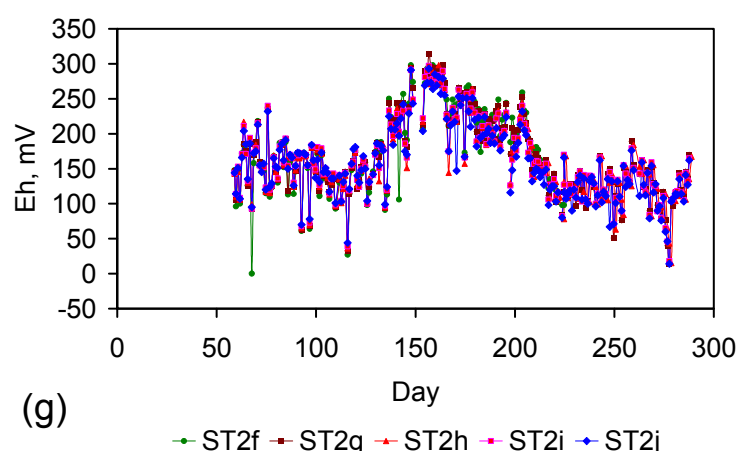

Figure C6. (a) $\mathrm{pH}$ vs. Eh; (b) EC vs. day, ST2a-ST2e; (c) EC vs. day, ST2f-ST2j; (d) pH vs. day, ST2a-ST2e; (e) pH vs. day, ST2f-ST2j; (f) Eh vs. day, ST2a-ST2e; (g) Eh vs. day, ST2f-ST2j. ZVM TP = copper sheathed pellets $(15 \mathrm{~mm}$ OD) placed in water at a concentration of ST2a $=28.5 \mathrm{~g} \cdot \mathrm{L}^{-1} ; \mathrm{ST} 2 \mathrm{~b}=30 \mathrm{~g} \cdot \mathrm{L}^{-1} ; \mathrm{ST} 2 \mathrm{c}=25 \mathrm{~g} \cdot \mathrm{L}^{-1} ; \mathrm{ST} 2 \mathrm{~d}=25 \mathrm{~g} \cdot \mathrm{L}^{-1}$; ST2e $=33.5 \mathrm{~g} \cdot \mathrm{L}^{-1} ;$ ST2f $=26.5 \mathrm{~g} \cdot \mathrm{L}^{-1} ; \mathrm{ST} 2 \mathrm{~g}=26.5 \mathrm{~g} \cdot \mathrm{L}^{-1} ; \mathrm{ST} 2 \mathrm{~h}=23.5 \mathrm{~g} \cdot \mathrm{L}^{-1}$; $\mathrm{ST} 2 \mathrm{i}=26.5 \mathrm{~g} \cdot \mathrm{L}^{-1} ; \mathrm{ST} 2 \mathrm{j}=33.5 \mathrm{~g} \cdot \mathrm{L}^{-1}$. Reactor Size: $0.3 \mathrm{~L}$; Feed Water volume: $0.2 \mathrm{~L}$.
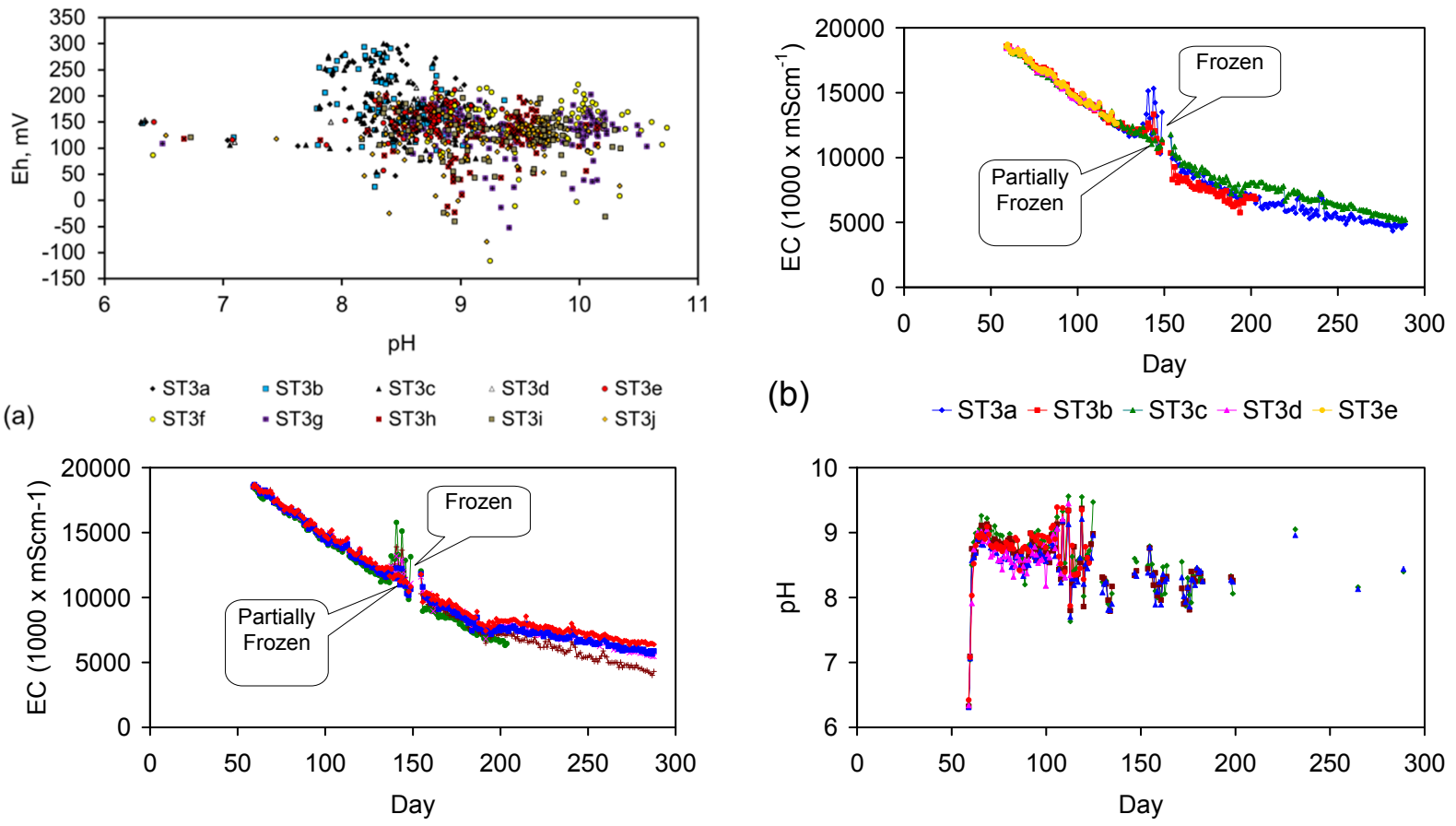

(b)

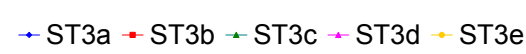

(C) $\quad \rightarrow \mathrm{ST} 3 \mathrm{f}+\mathrm{ST} 3 \mathrm{~g} * \mathrm{ST} 3 \mathrm{~h} \rightarrow \mathrm{ST} 3 \mathrm{i} \rightarrow \mathrm{ST} 3 \mathrm{j}$
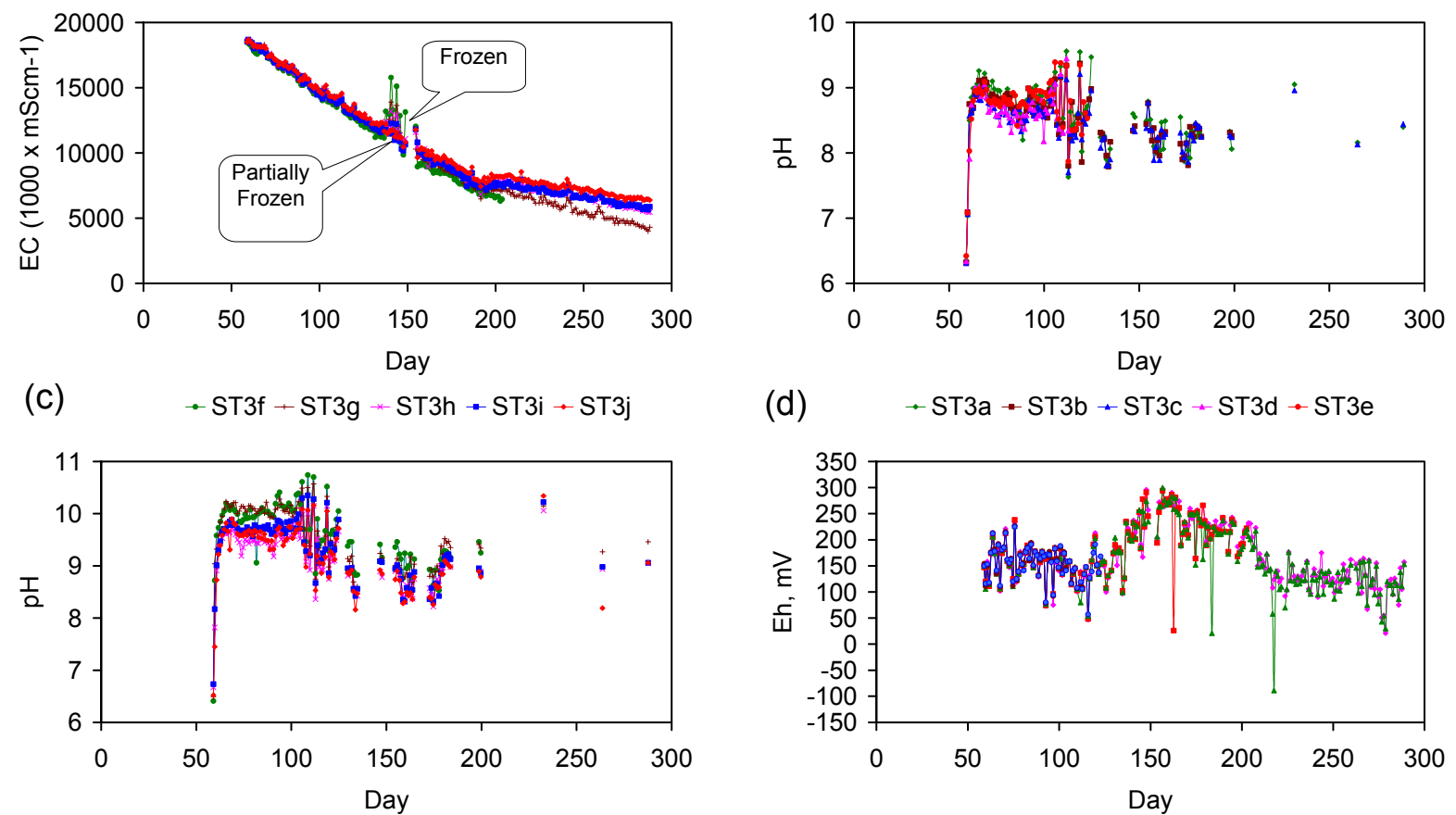

(d) $\quad \rightarrow \mathrm{ST} 3 \mathrm{a}+\mathrm{ST} 3 \mathrm{~b}+\mathrm{ST} 3 \mathrm{c}+\mathrm{ST} 3 \mathrm{~d}+\mathrm{ST} 3 \mathrm{e}$

(e) $\quad \rightarrow \mathrm{ST} 3 \mathrm{f}+\mathrm{ST} 3 \mathrm{~g} * \mathrm{ST} 3 \mathrm{~h}-\mathrm{ST} 3 \mathrm{i} \rightarrow \mathrm{ST} 3 \mathrm{j}$

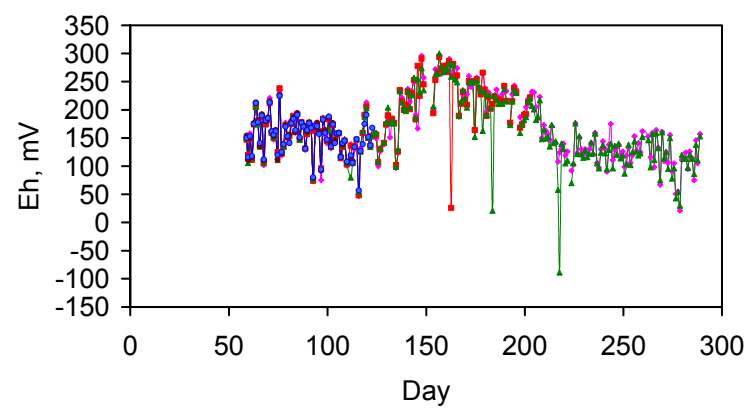

(f)

$\rightarrow \mathrm{ST} 3 \mathrm{a}+\mathrm{ST} 3 \mathrm{~b}+\mathrm{ST} 3 \mathrm{c}+\mathrm{ST} 3 \mathrm{~d} \rightarrow \mathrm{ST} 3 \mathrm{C}$

Figure C7. Cont. 


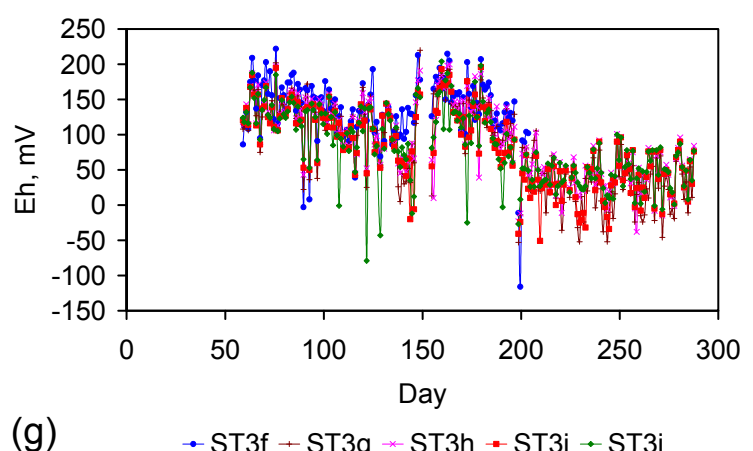

Figure C7. (a) pH vs. Eh; (b) EC vs. day, ST3a-ST3e; (c) EC vs. day, ST3f-ST3j; (d) pH vs. day, ST3a-ST3e; (e) pH vs. day, ST3f-ST3j; (f) Eh vs. day, ST3a-ST3e; (g) Eh vs. day, ST3f-ST3j. ZVM TP = copper sheathed pellets $(15 \mathrm{~mm}$ OD) placed in water at a concentration of ST3a $=32 \mathrm{~g} \cdot \mathrm{L}^{-1}$; ST3b $=25 \mathrm{~g} \cdot \mathrm{L}^{-1} ; \mathrm{ST} 3 \mathrm{c}=30 \mathrm{~g} \cdot \mathrm{L}^{-1}$; ST3d $=30 \mathrm{~g} \cdot \mathrm{L}^{-1}$; ST3e $=26.5 \mathrm{~g} \cdot \mathrm{L}^{-1} ; \quad \mathrm{ST} 3 \mathrm{f}=57.5 \mathrm{~g} \cdot \mathrm{L}^{-1} ; \quad \mathrm{ST} 3 \mathrm{~g}=82.5 \mathrm{~g} \cdot \mathrm{L}^{-1} ; \quad \mathrm{ST} 3 \mathrm{~h}=65 \mathrm{~g} \cdot \mathrm{L}^{-1}$; $\mathrm{ST} 3 \mathrm{i}=72 \mathrm{~g} \cdot \mathrm{L}^{-1}$; ST3j $=66.5 \mathrm{~g} \cdot \mathrm{L}^{-1}$. Reactor Size: $0.3 \mathrm{~L}$; Feed Water volume: $0.2 \mathrm{~L}$.
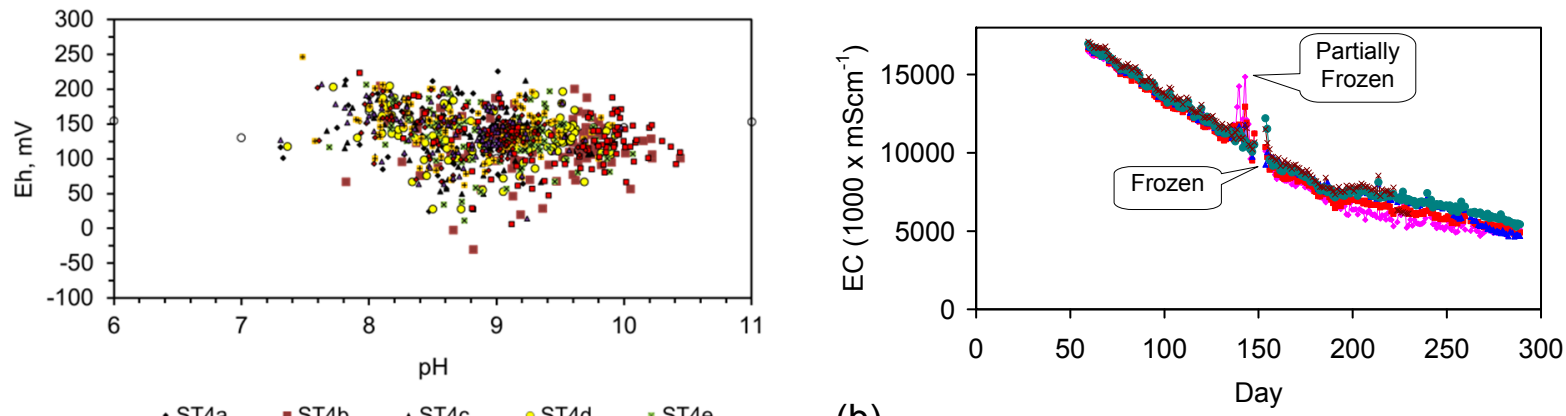

(a)

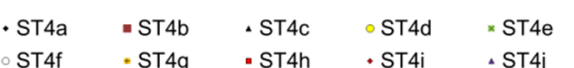

(b)
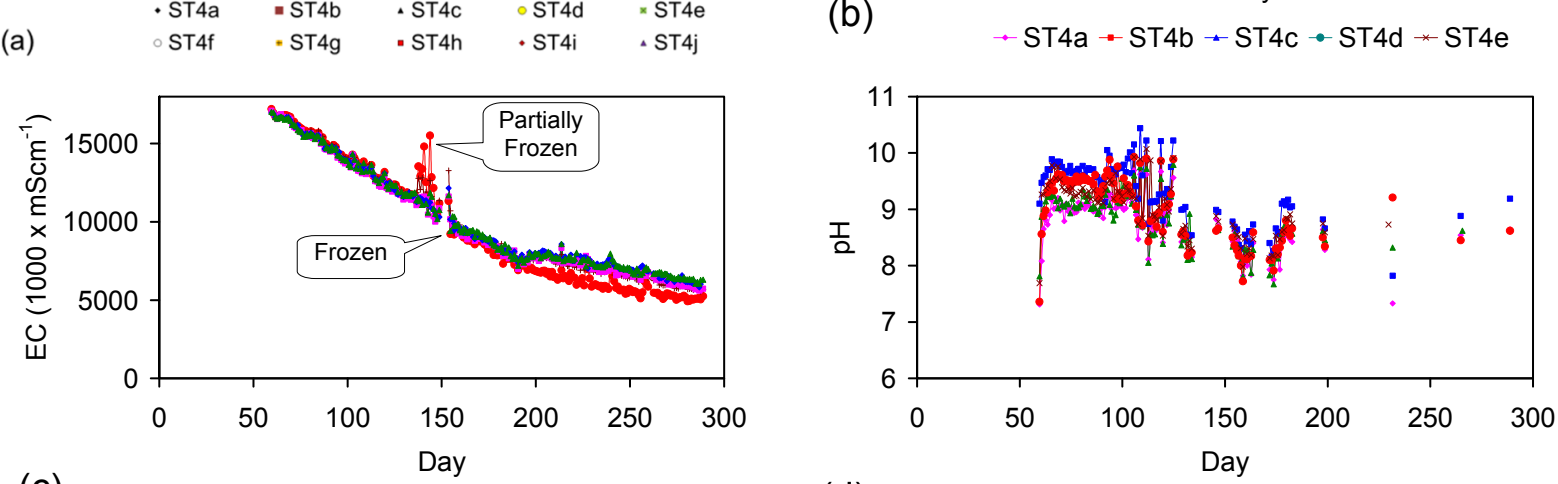

(c)

$\bullet \mathrm{ST} 4 \mathrm{f}+\mathrm{ST} 4 \mathrm{~g}=\mathrm{ST} 4 \mathrm{~h}+\mathrm{ST} 4 \mathrm{i}+\mathrm{ST} 4 \mathrm{j}$

(d)

$\rightarrow \mathrm{ST} 4 \mathrm{a}-\mathrm{ST} 4 \mathrm{~b}+\mathrm{ST} 4 \mathrm{c}-\mathrm{ST} 4 \mathrm{~d} * \mathrm{ST} 4 \mathrm{e}$

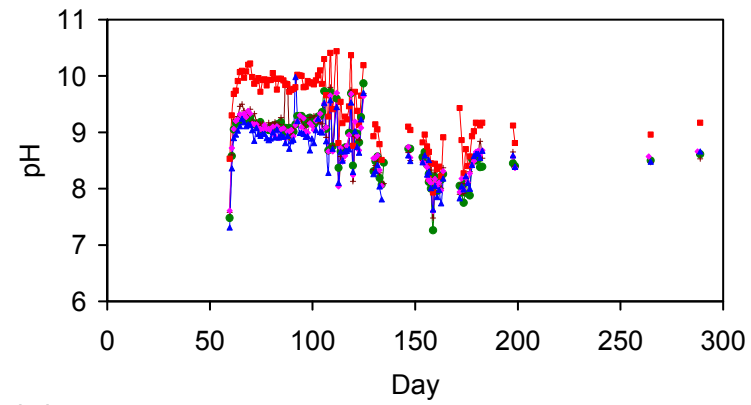

(e)

$$
\text { - ST4f }+\mathrm{ST} 4 \mathrm{~g}-\mathrm{ST} 4 \mathrm{~h} \rightarrow \mathrm{ST} 4 \mathrm{i}+\mathrm{ST} 4 \mathrm{j}
$$

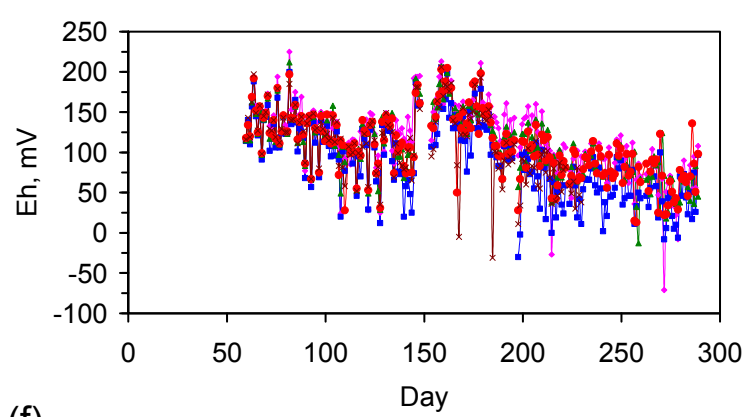

(f)

Figure C8. Cont. 


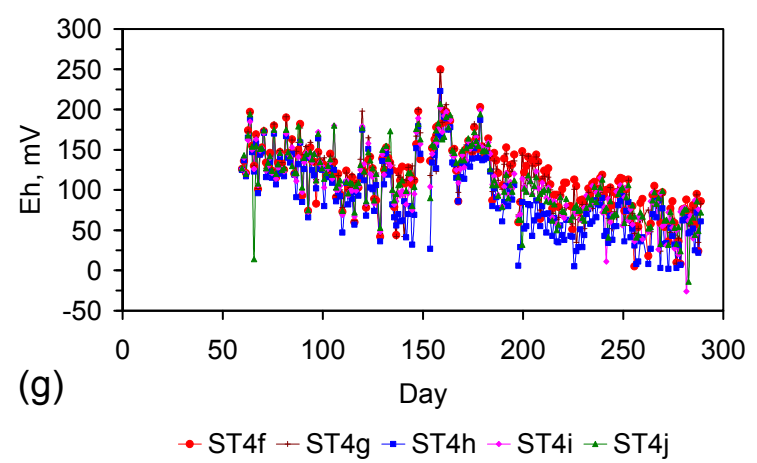

Figure C8. (a) $\mathrm{pH}$ vs. Eh; (b) EC vs. day, ST4a-ST4e; (c) EC vs. day, ST4f-ST4j; (d) pH vs. day, ST4a-ST4e; (e) pH vs. day, ST4f-ST4j; (f) Eh vs. day, ST4a-ST4e; (g) Eh vs. day, ST4f-ST4j. ZVM TP = copper sheathed pellets $(15 \mathrm{~mm}$ OD) placed in water at a concentration of ST4a $=50 \mathrm{~g} \cdot \mathrm{L}^{-1} ; \mathrm{ST} 4 \mathrm{~b}=55.5 \mathrm{~g} \cdot \mathrm{L}^{-1} ; \mathrm{ST} 4 \mathrm{c}=50 \mathrm{~g} \cdot \mathrm{L}^{-1}$; ST4d $=63.5 \mathrm{~g} \cdot \mathrm{L}^{-1}$; $\mathrm{ST} 4 \mathrm{e}=87.5 \mathrm{~g} \cdot \mathrm{L}^{-1} ; \mathrm{ST} 4 \mathrm{f}=44 \mathrm{~g} \cdot \mathrm{L}^{-1} ; \mathrm{ST} 4 \mathrm{~g}=49 \mathrm{~g} \cdot \mathrm{L}^{-1} ; \mathrm{ST} 4 \mathrm{~h}=66.5 \mathrm{~g} \cdot \mathrm{L}^{-1} ; \mathrm{ST} 4 \mathrm{i}=36 \mathrm{~g} \cdot \mathrm{L}^{-1}$; $\mathrm{ST} 4 \mathrm{j}=44.5 \mathrm{~g} \cdot \mathrm{L}^{-1}$. Reactor Size: $0.3 \mathrm{~L}$; Feed Water volume: $0.2 \mathrm{~L}$.
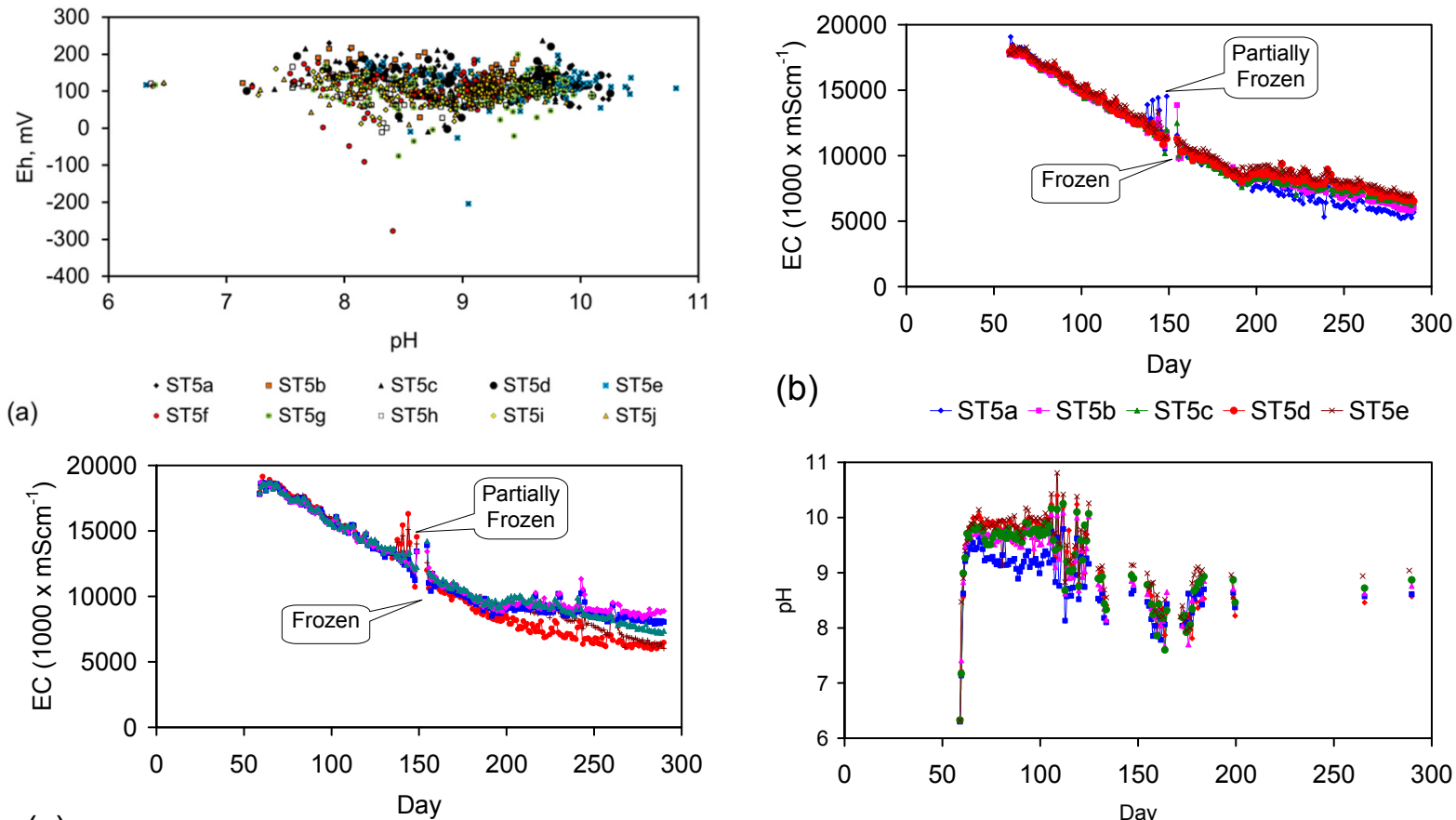

(b)
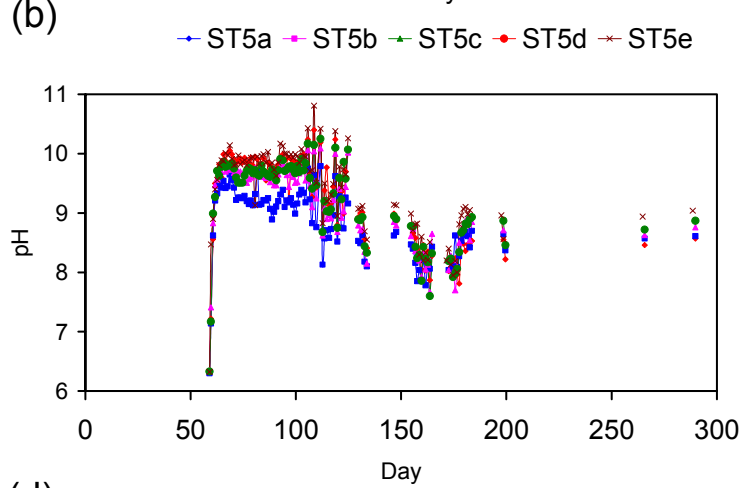

(d)

$\rightarrow \mathrm{ST} 5 \mathrm{a} \rightarrow \mathrm{ST} 5 \mathrm{~b} \rightarrow \mathrm{ST} 5 \mathrm{c} \rightarrow \mathrm{ST} 5 \mathrm{~d} * \mathrm{ST} 5 \mathrm{e}$

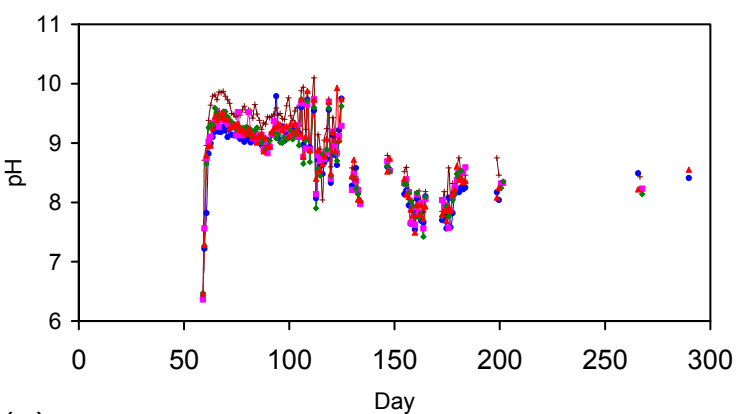

(e)

$\rightarrow$ ST5f + ST5g $\rightarrow$ ST5h $\rightarrow$ ST5i $\rightarrow$ ST5j

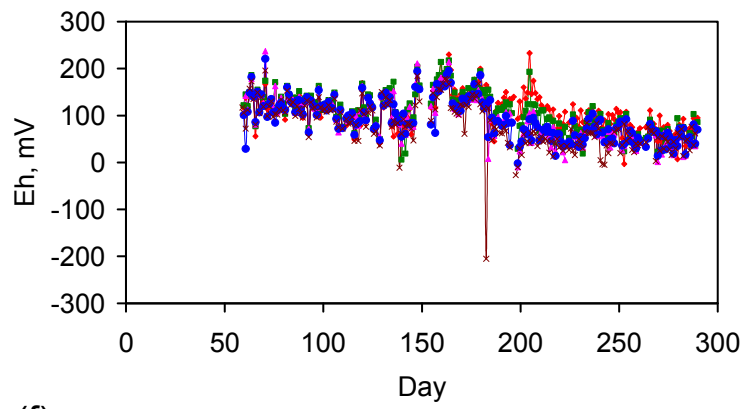

(f)

$\rightarrow$ ST5a $\rightarrow$ ST $5 \mathrm{~b} \rightarrow$ ST5c $*$ ST5d $*$ ST5e

Figure C9. Cont. 


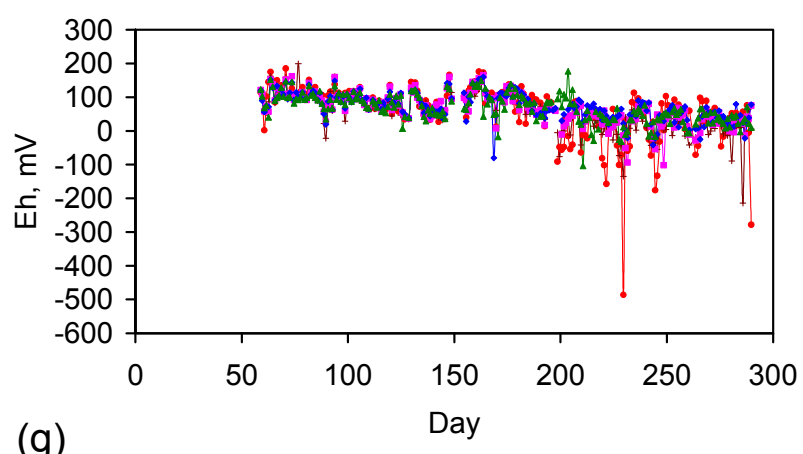

(g)

$$
\rightarrow \text { ST5f }+ \text { ST5g } \rightarrow \text { ST5h } \rightarrow \text { ST5i } \leftarrow \text { ST5j }
$$

Figure C9. (a) $\mathrm{pH}$ vs. Eh; (b) EC vs. day, ST5a-ST5e; (c) EC vs. day, ST5f-ST5j; (d) pH vs. day, ST5a-ST5e; (e) pH vs. day, ST5f-ST5j; (f) Eh vs. day, ST5a-ST5e; (g) Eh vs. day, ST5f-ST5j. ZVM TP = copper sheathed pellets $(15 \mathrm{~mm}$ OD) placed in water at a concentration of ST5a $=64 \mathrm{~g} \cdot \mathrm{L}^{-1}$; ST5b $=47.5 \mathrm{~g} \cdot \mathrm{L}^{-1}$; ST5c $=48 \mathrm{~g} \cdot \mathrm{L}^{-1}$; ST5d $=62.5 \mathrm{~g} \cdot \mathrm{L}^{-1}$; $\mathrm{ST} 5 \mathrm{e}=94 \mathrm{~g} \cdot \mathrm{L}^{-1} ; \mathrm{ST} 5 \mathrm{f}=47.5 \mathrm{~g} \cdot \mathrm{L}^{-1} ; \mathrm{ST} 5 \mathrm{~g}=38 \mathrm{~g} \cdot \mathrm{L}^{-1} ; \mathrm{ST} 5 \mathrm{~h}=46 \mathrm{~g} \cdot \mathrm{L}^{-1}$; ST5i $=39.5 \mathrm{~g} \cdot \mathrm{L}^{-1}$; $\mathrm{ST} 5 \mathrm{j}=72.5 \mathrm{~g} \cdot \mathrm{L}^{-1}$. Reactor Size: $0.3 \mathrm{~L}$; Feed Water volume: $0.2 \mathrm{~L}$.

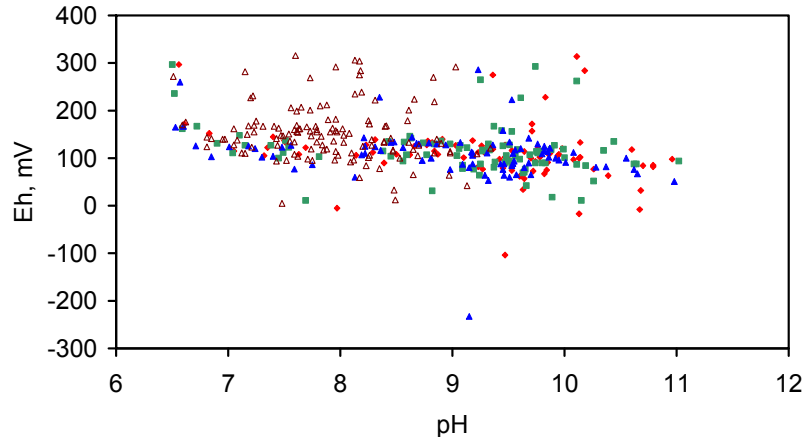

(a)

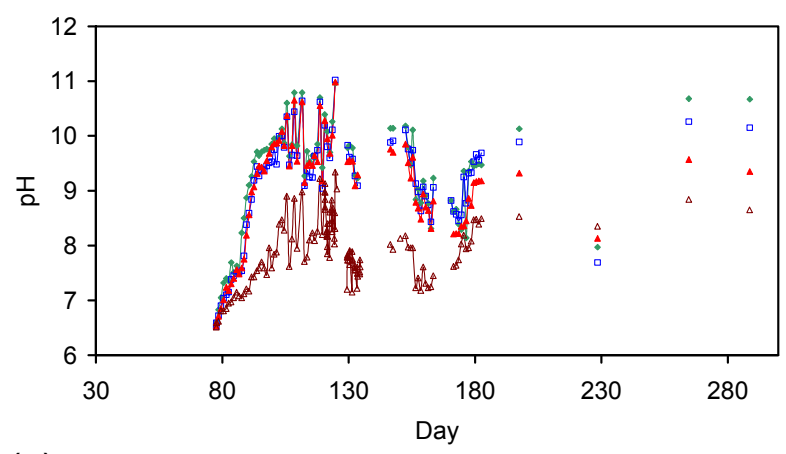

(c)

$\rightarrow$ ST6a $\rightarrow$ ST6b $\rightarrow$ ST6c $\rightarrow$ ST6d

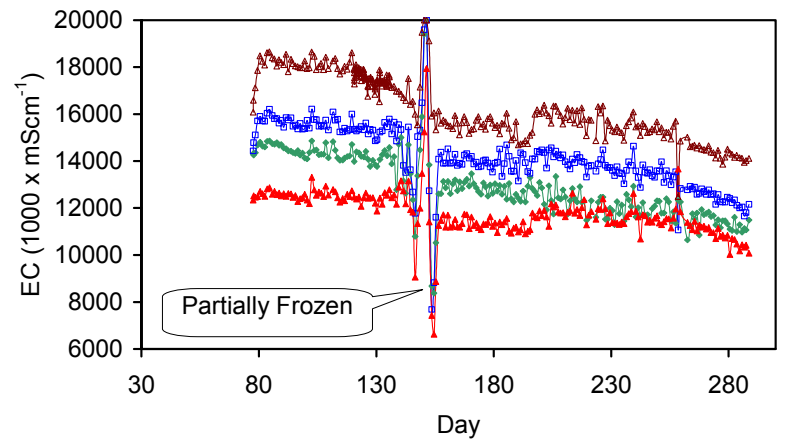

(b)

$\rightarrow$ ST6a $\rightarrow$ ST6b $\rightarrow$ ST6c $\rightarrow$ ST6d

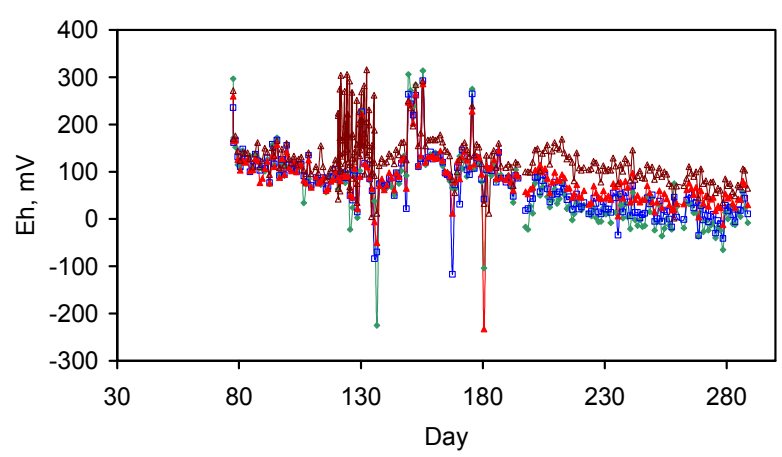

(d)

Figure C10. Cont. 


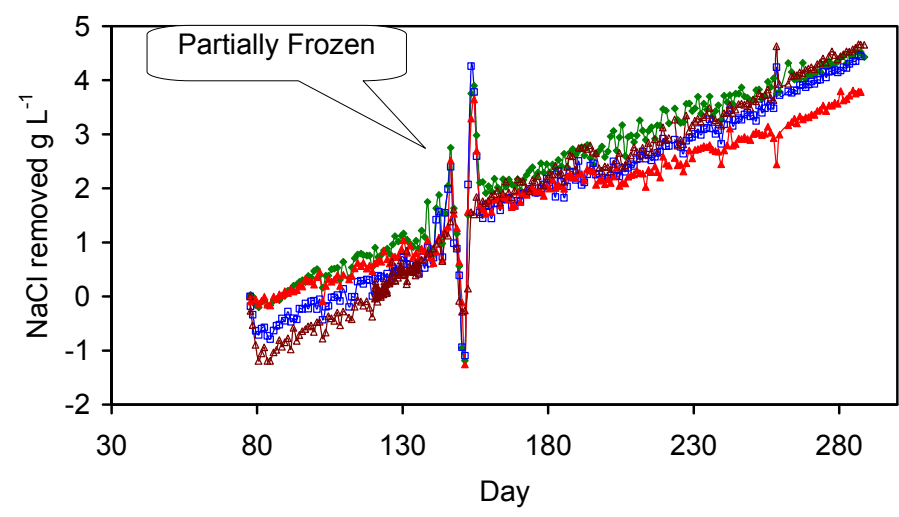

(e)

$$
\rightarrow \text { ST6a } \rightarrow \text { ST6b } \rightarrow \text { ST6c } \rightarrow \text { ST6d }
$$

Figure C10. (a) $\mathrm{pH}$ vs. Eh; (b) EC vs. day; (c) $\mathrm{pH}$ vs. day; (d) Eh vs. day; (e) NaCl Removed (calculated from EC and residual water volume) $v$ s. day. ZVM TP $=$ copper sheathed pellets (15 mm OD) placed in water at a concentration of ST6a $=15.7 \mathrm{~g} \cdot \mathrm{L}^{-1}$; ST6b $=15.1 \mathrm{~g} \cdot \mathrm{L}^{-1}$; ST6c $=6.8 \mathrm{~g} \cdot \mathrm{L}^{-1}$; ST6d $=5.1 \mathrm{~g} \cdot \mathrm{L}^{-1}$. Reactor Size: $2.3 \mathrm{~L}$; Feed Water volume: $2.3 \mathrm{~L}$.

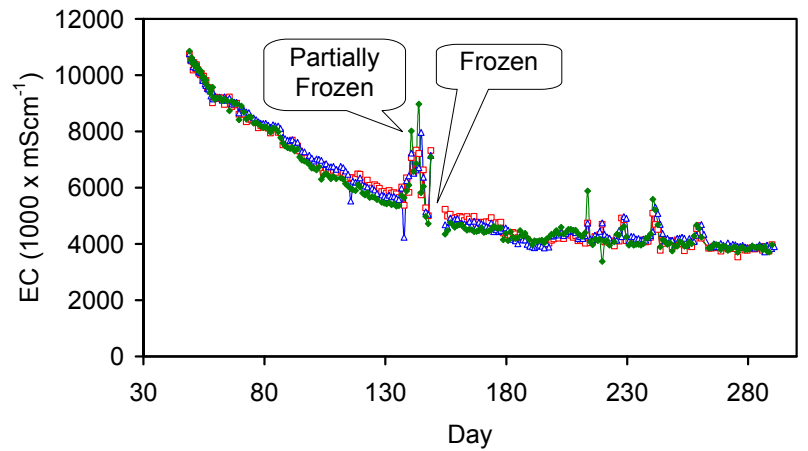

(a)

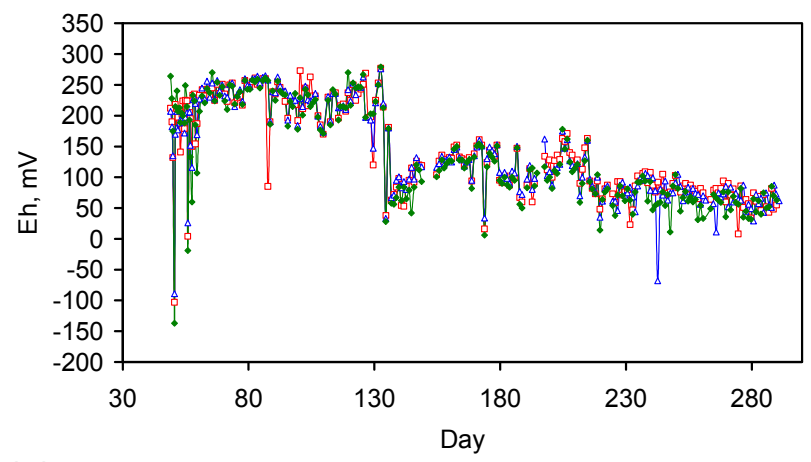

(c)

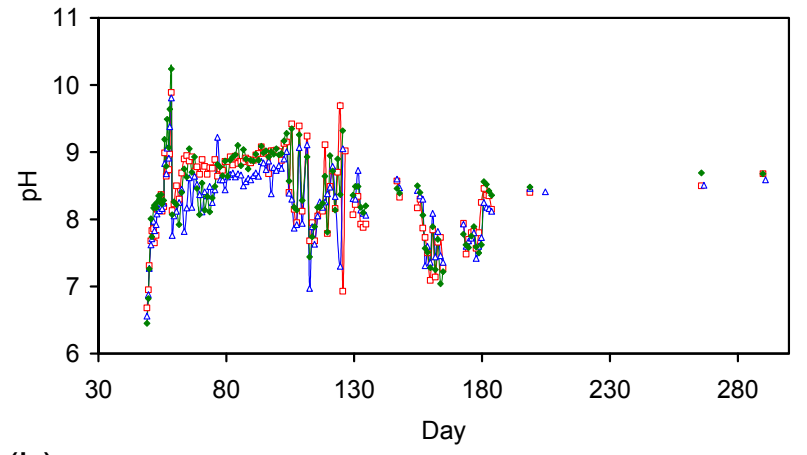

(b)

$\rightarrow \mathrm{AS} 1 \rightarrow \mathrm{AS} 2 \rightarrow \mathrm{AS} 3$

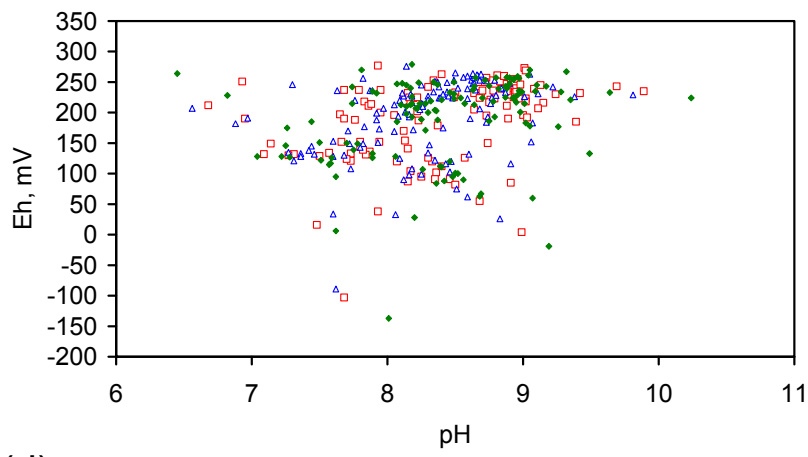

(d)

Figure C11. (a) EC vs. day; (b) Eh vs. day; (c) $\mathrm{pH} v s$. day; (d) $\mathrm{pH} v s$. Eh. AS1 $=44 \mathrm{~g} \cdot \mathrm{L}^{-1}$; AS2 $=55 \mathrm{~g} \cdot \mathrm{L}^{-1}$; AS3 $=49 \mathrm{~g} \cdot \mathrm{L}^{-1}$. Reactor Size: $0.3 \mathrm{~L}$; Feed Water volume: $0.2 \mathrm{~L}$. 


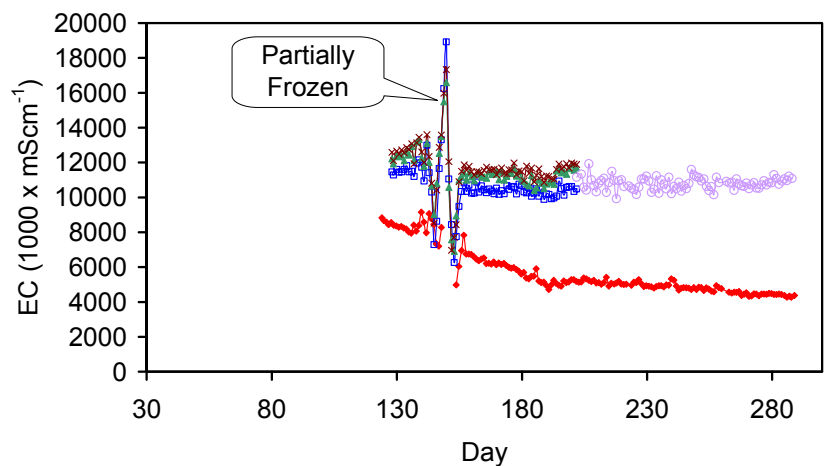

(a)

$\rightarrow$ ST8a $\rightarrow$ ST8b $\neq$ ST8C $*$ ST8d - ST8e

(b)
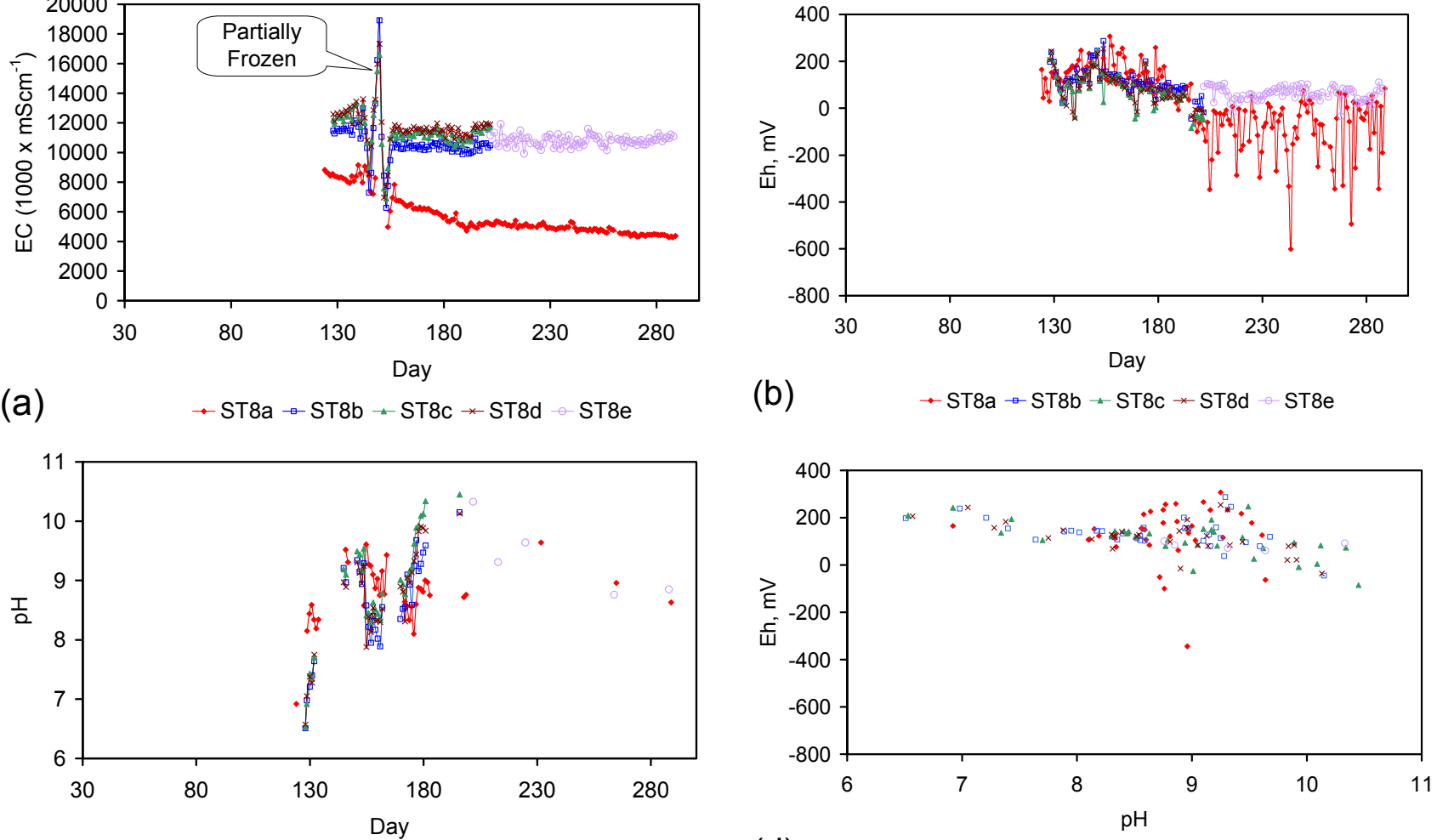

(c)

$\rightarrow \mathrm{ST} 8 \mathrm{a}=\mathrm{ST} 8 \mathrm{~b} \rightarrow \mathrm{ST} 8 \mathrm{c} * \mathrm{ST} 8 \mathrm{~d}-\mathrm{ST} 8 \mathrm{e}$

$\cdot \mathrm{ST} 8 \mathrm{a} \square \mathrm{ST} 8 \mathrm{~b} \triangle \mathrm{ST} 8 \mathrm{c} \times \mathrm{ST} 8 \mathrm{~d} \circ \mathrm{ST} 8 \mathrm{e}$

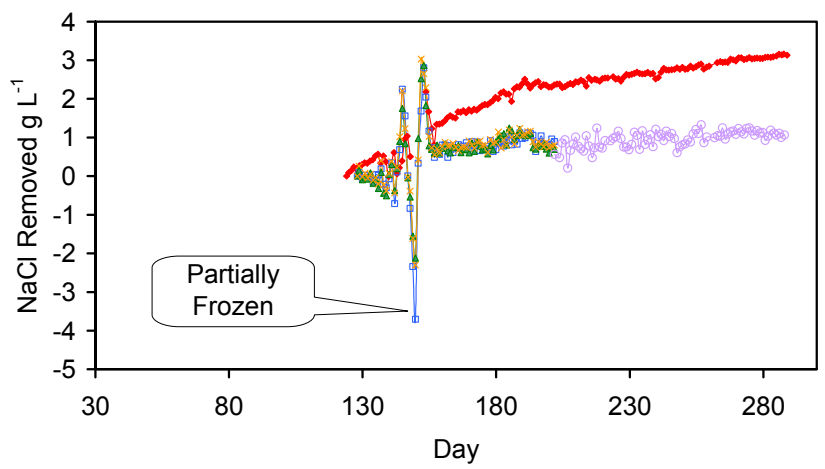

(e)

$\rightarrow$ ST8a $\rightarrow$ ST8b $\leadsto$ ST8C $*$ ST8d $\circ$ ST8e

Figure C12. (a) EC vs. day; (b) Eh vs. day; (c) $\mathrm{pH}$ vs. day; (d) $\mathrm{pH}$ vs. Eh; (e) $\mathrm{NaCl}$ Removed (calculated from $\mathrm{EC}$ and residual water volume) vs. day. $\mathrm{ST} 8 \mathrm{a}=37 \mathrm{~g} \cdot \mathrm{L}^{-1} ; \quad \mathrm{ST} 8 \mathrm{~b}=43 \mathrm{~g} \cdot \mathrm{L}^{-1} ; \quad \mathrm{ST} 8 \mathrm{c}=40.4 \mathrm{~g} \cdot \mathrm{L}^{-1} ; \quad \mathrm{ST} 8 \mathrm{~d}=26 \mathrm{~g} \cdot \mathrm{L}^{-1}$; $\mathrm{ST} 8 \mathrm{e}=36.5 \mathrm{~g} \cdot \mathrm{L}^{-1}$. Reactor Size (ST8a): $0.3 \mathrm{~L}$; Feed Water volume: $0.2 \mathrm{~L}$. Reactor Size (ST8b-ST8d): 2.3 L; Feed Water volume: 2.3 L. Reactor Size (ST8e): 10 L; Feed Water volume: $6.9 \mathrm{~L}$. 


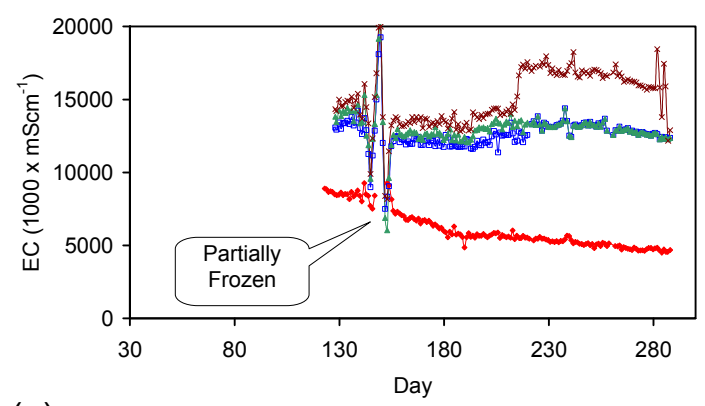

(a)

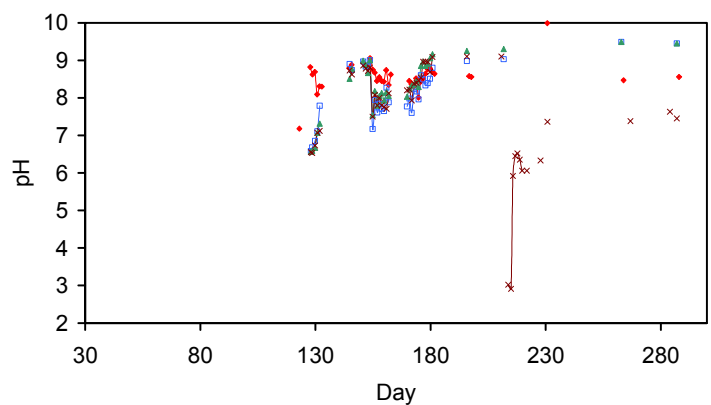

(c)

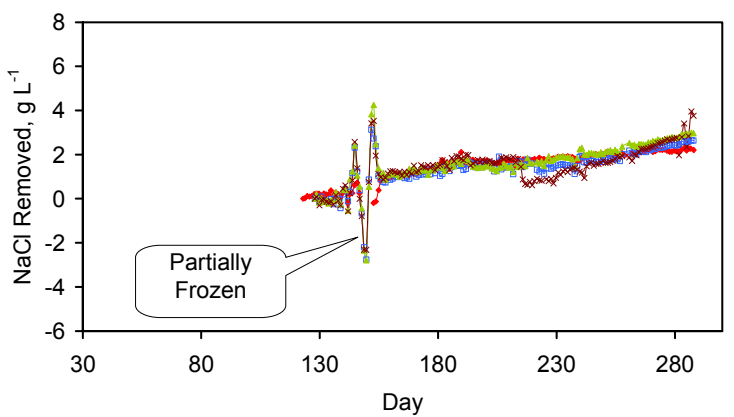

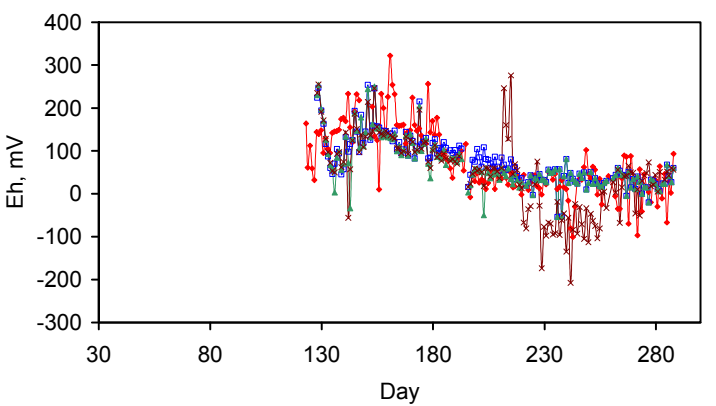

(b)

$\rightarrow \mathrm{MT} 1 \mathrm{a} \rightarrow \mathrm{MT} 1 \mathrm{~b} \rightarrow \mathrm{MT} 1 \mathrm{c} * \mathrm{MT} 1 \mathrm{~d}$

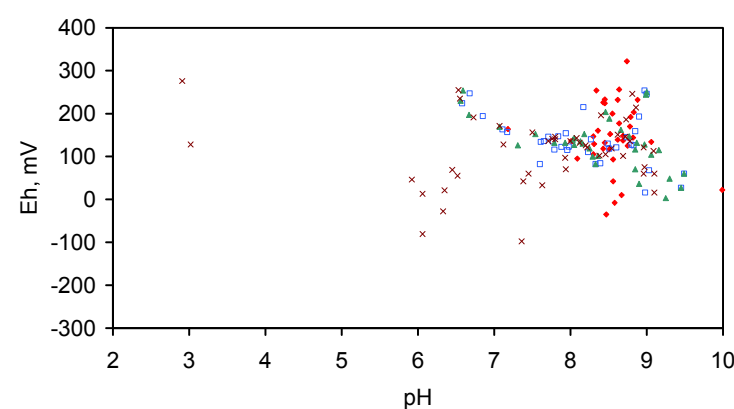

(d)

(e)

$\rightarrow$ MT1a $\rightarrow$ MT1b $\rightarrow$ MT1C $*$ MT1d

Figure C13. (a) EC vs. day; (b) Eh vs. day; (c) $\mathrm{pH} v$. day; (d) $\mathrm{pH} v s$. Eh; (e) NaCl Removed (calculated from EC and residual water volume) $v$ s. day. MT1a $=45 \mathrm{~g} \cdot \mathrm{L}^{-1} ; \mathrm{MT} 1 \mathrm{~b}=43 \mathrm{~g} \cdot \mathrm{L}^{-1}$; MT1c $=51.3 \mathrm{~g} \cdot \mathrm{L}^{-1} ; \mathrm{MT} 1 \mathrm{~d}=30.4 \mathrm{~g} \cdot \mathrm{L}^{-1}$. MT1d was successively acidized (using $\mathrm{CH}_{2} \mathrm{O}_{2}$ ) and alkalized (using $\mathrm{CaCO}_{3}$ ) after Day 200. Reactor Size (MT1a): 0.3 L; Feed Water volume: 0.2 L. Reactor Size (MT1b-MT1d): 2.3 L; Feed Water volume: 2.3 L.

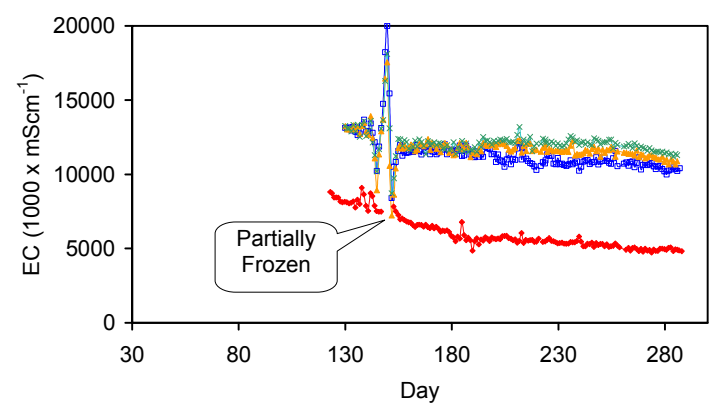

(a)

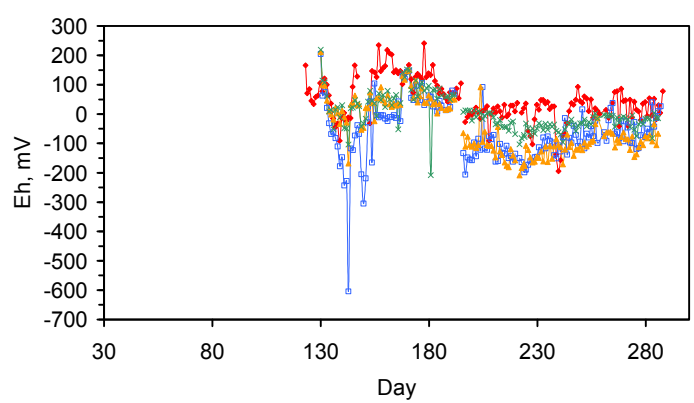

(b) $\rightarrow \mathrm{MT} 2 \mathrm{a} \rightarrow \mathrm{MT} 2 \mathrm{~b} \rightarrow \mathrm{MT} 2 \mathrm{c} * \mathrm{MT} 2 \mathrm{~d}$

Figure C14. Cont. 


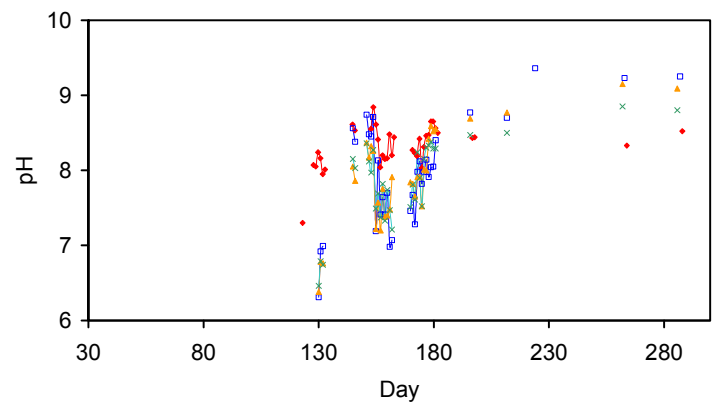

(c)

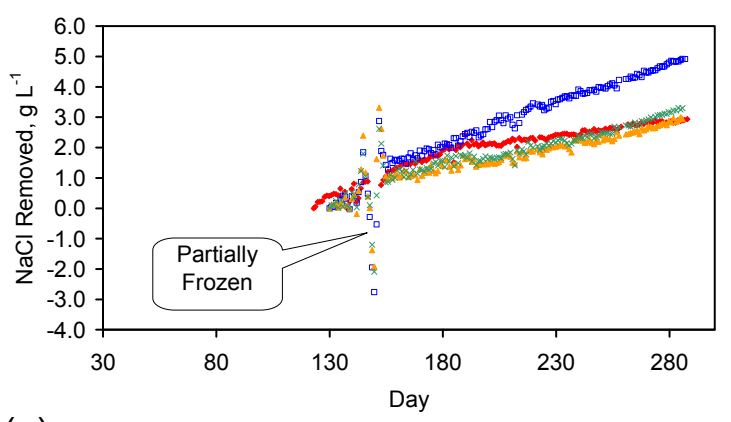

(e)

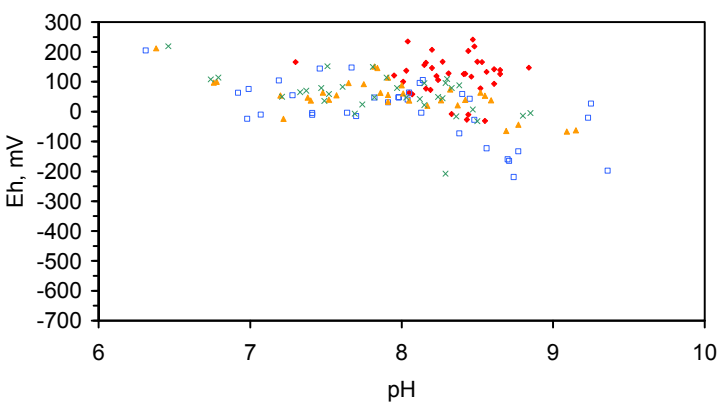

(d)

Figure C14. (a) EC vs. day; (b) Eh vs. day; (c) $\mathrm{pH}$ vs. day; (d) $\mathrm{pH} v s$. Eh; (e) NaCl Removed (calculated from EC and residual water volume) $v s$. day. MT2a $=79.5 \mathrm{~g} \cdot \mathrm{L}^{-1} ; \mathrm{MT} 2 \mathrm{~b}=121.3$ $\mathrm{g} \cdot \mathrm{L}^{-1} ;$ MT2c $=49.5 \mathrm{~g} \cdot \mathrm{L}^{-1}$; MT2d $=36.1 \mathrm{~g} \cdot \mathrm{L}^{-1}$. Reactor Size (MT2a): $0.3 \mathrm{~L}$; Feed Water volume: 0.2 L. Reactor Size (MT2b-MT2d): 2.3 L; Feed Water volume: 2.3 L.

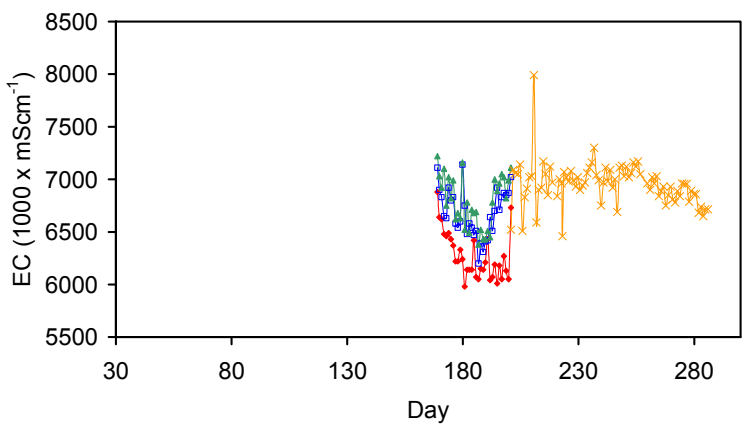

(a)

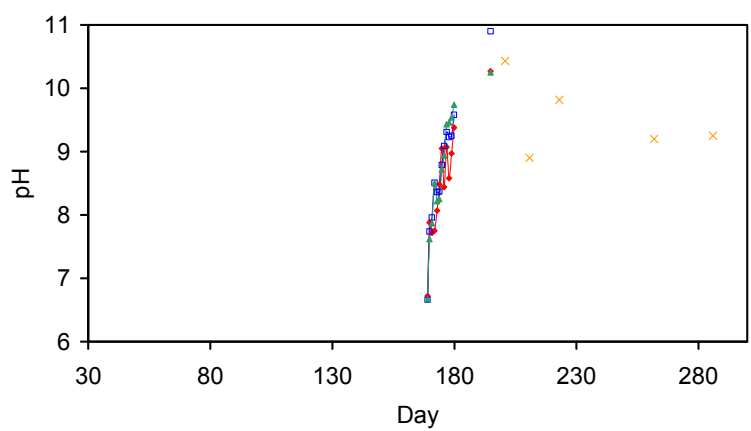

(c)

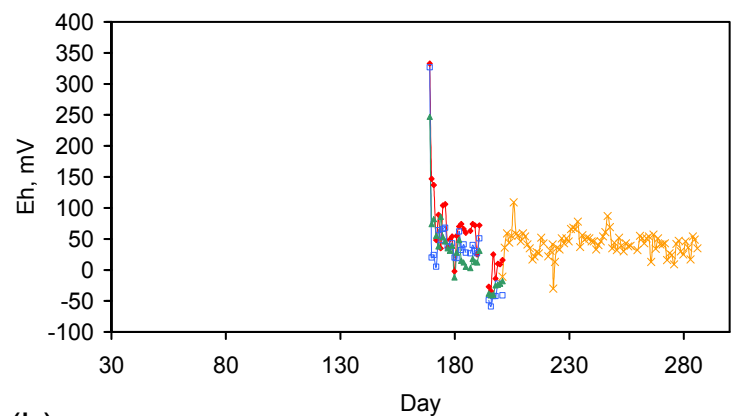

(b)

$\rightarrow$ MT3a $\rightarrow$ MT3b $\rightarrow$ MT3c $*$ MT3d

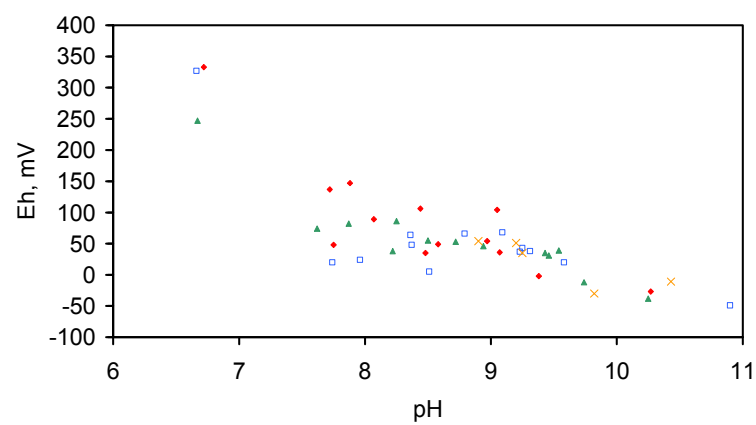

(d)

Figure C15. Cont. 


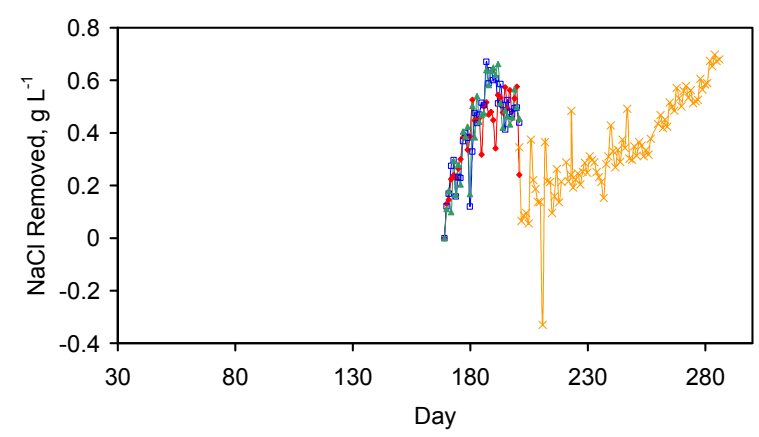

(e)

$\rightarrow \mathrm{MT} 3 \mathrm{a} \rightarrow \mathrm{MT} 3 \mathrm{~b} \rightarrow \mathrm{MT} 3 \mathrm{c} * \mathrm{MT} 3 \mathrm{~d}$

Figure C15. (a) EC vs. day; (b) Eh vs. day; (c) pH vs. day; (d) pH vs. Eh; (e) NaCl Removed (calculated from EC and residual water volume) $v$ s. day. MT3a $=73.5 \mathrm{~g} \cdot \mathrm{L}^{-1}$; MT3b $=62.6$ $\mathrm{g} \cdot \mathrm{L}^{-1} ;$ MT3c $=52.6 \mathrm{~g} \cdot \mathrm{L}^{-1}$; MT3d $=62.9 \mathrm{~g} \cdot \mathrm{L}^{-1}$. Reactor Size (MT3a-MT3c): $2.3 \mathrm{~L}$; Feed Water volume: 2.3 L. Reactor Size (MT3d): 10 L; Feed Water volume: 6.9 L.

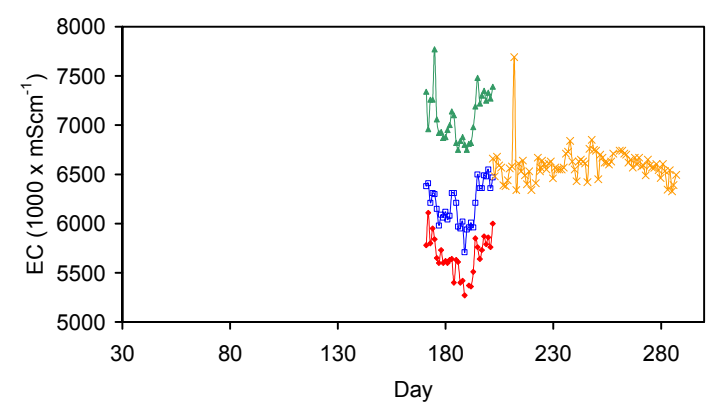

(a)

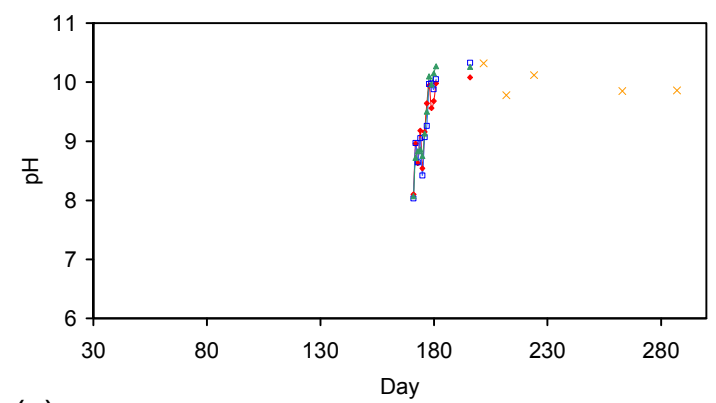

(c)
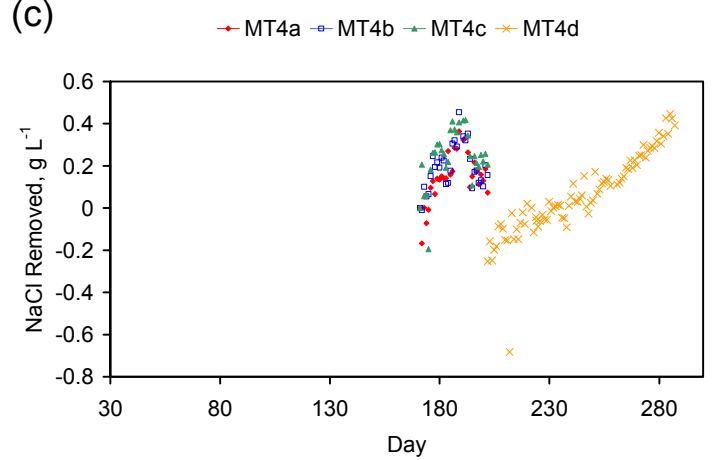

(e)

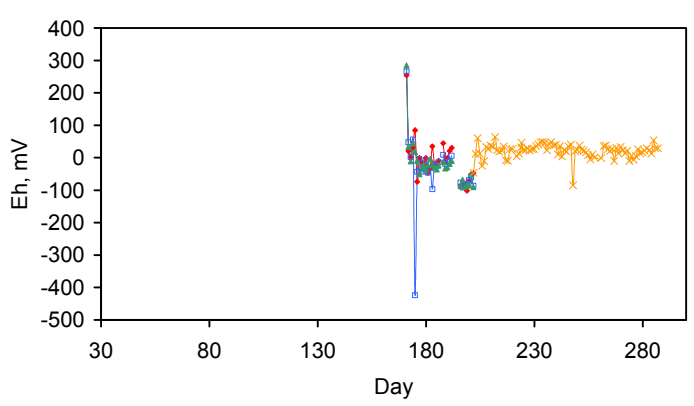

(b)

$\rightarrow \mathrm{MT} 4 \mathrm{a} \rightarrow \mathrm{MT} 4 \mathrm{~b} \rightarrow \mathrm{MT} 4 \mathrm{c} * \mathrm{MT} 4 \mathrm{~d}$

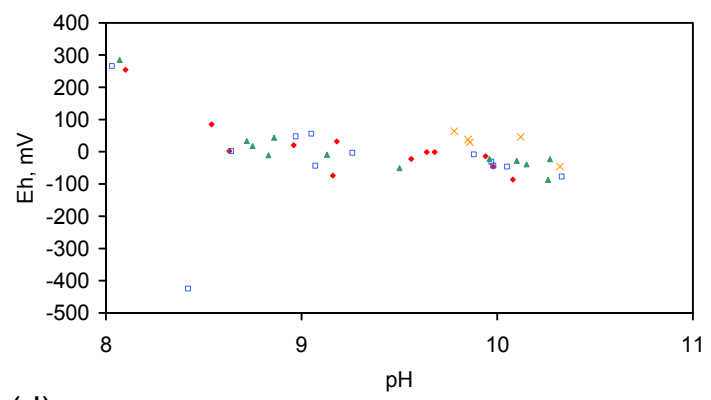

(d)

Figure C16. (a) EC vs. day; (b) Eh vs. day; (c) pH vs. day; (d) pH vs. Eh; (e) NaCl Removed (calculated from EC and residual water volume) vs. day. MT4a $=91.3 \mathrm{~g} \cdot \mathrm{L}^{-1}$; MT4b $=87.8$ $\mathrm{g} \cdot \mathrm{L}^{-1} ;$ MT4c $=91.3 \mathrm{~g} \cdot \mathrm{L}^{-1}$; MT4d $=90.1 \mathrm{~g} \cdot \mathrm{L}^{-1}$. Reactor Size (MT4a-MT4c): $2.3 \mathrm{~L}$; Feed Water volume: 2.3 L. Reactor Size (MT4d): 10 L; Feed Water volume: 6.9 L. 


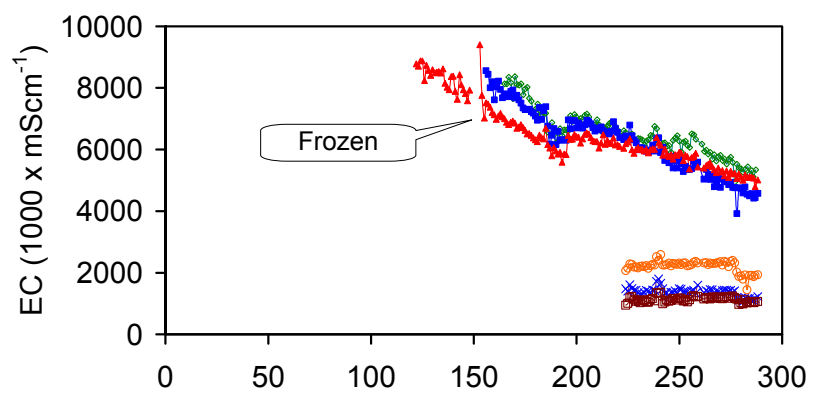

(a)

$\rightarrow \mathrm{ST7} a+\mathrm{ST7b} \rightarrow \mathrm{ST7}+\mathrm{ST7d}-\mathrm{ST7e}+\mathrm{ST7f}$

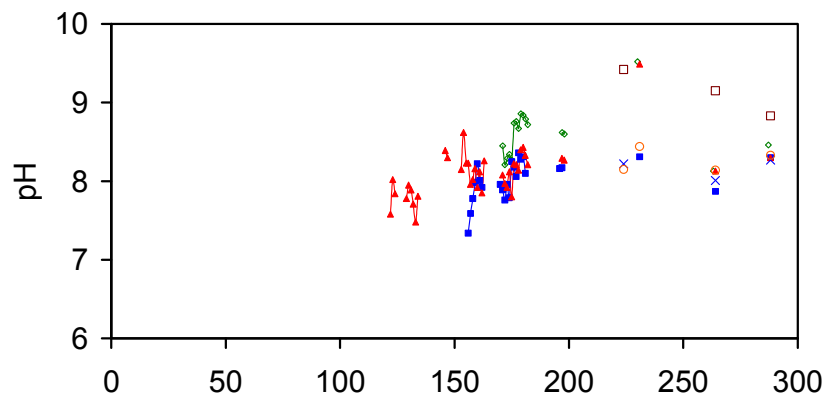

(c)

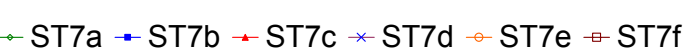

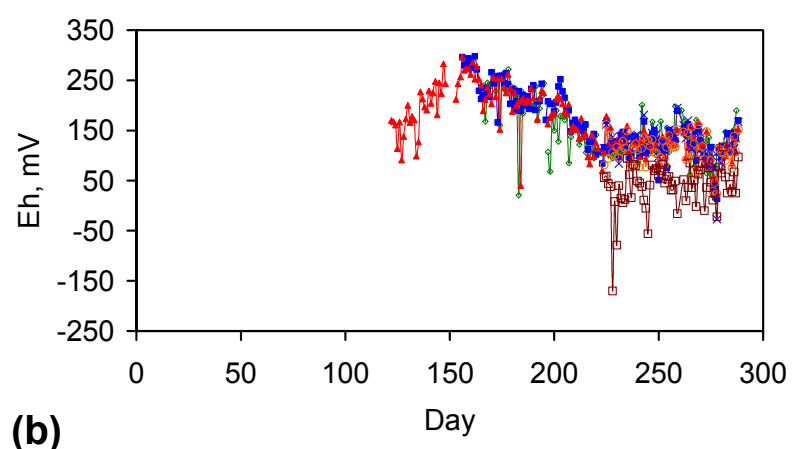

$\rightarrow \mathrm{ST7} a+\mathrm{ST7b} \rightarrow \mathrm{ST7c} * \mathrm{ST7d}-\mathrm{ST7e}+\mathrm{ST7f}$

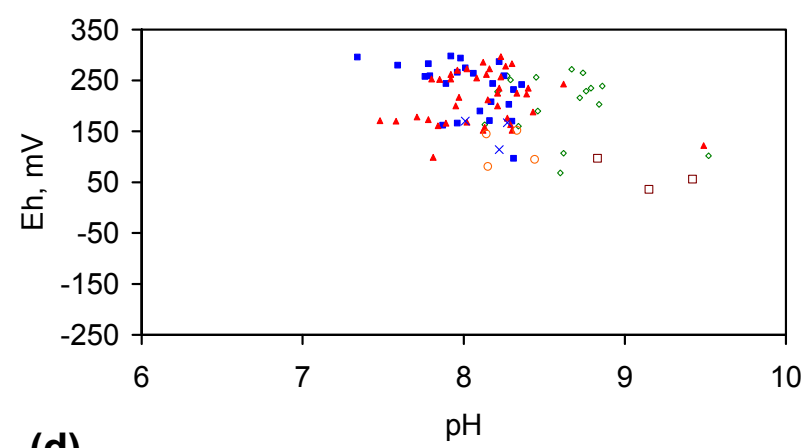

(d)

Figure C17. (a) EC vs. day; (b) Eh vs. day; (c) $\mathrm{pH} v s$. day; (d) $\mathrm{pH} v s$. Eh. Reactor Size: $0.3 \mathrm{~L}$; Feed Water volume: $0.2 \mathrm{~L}$.
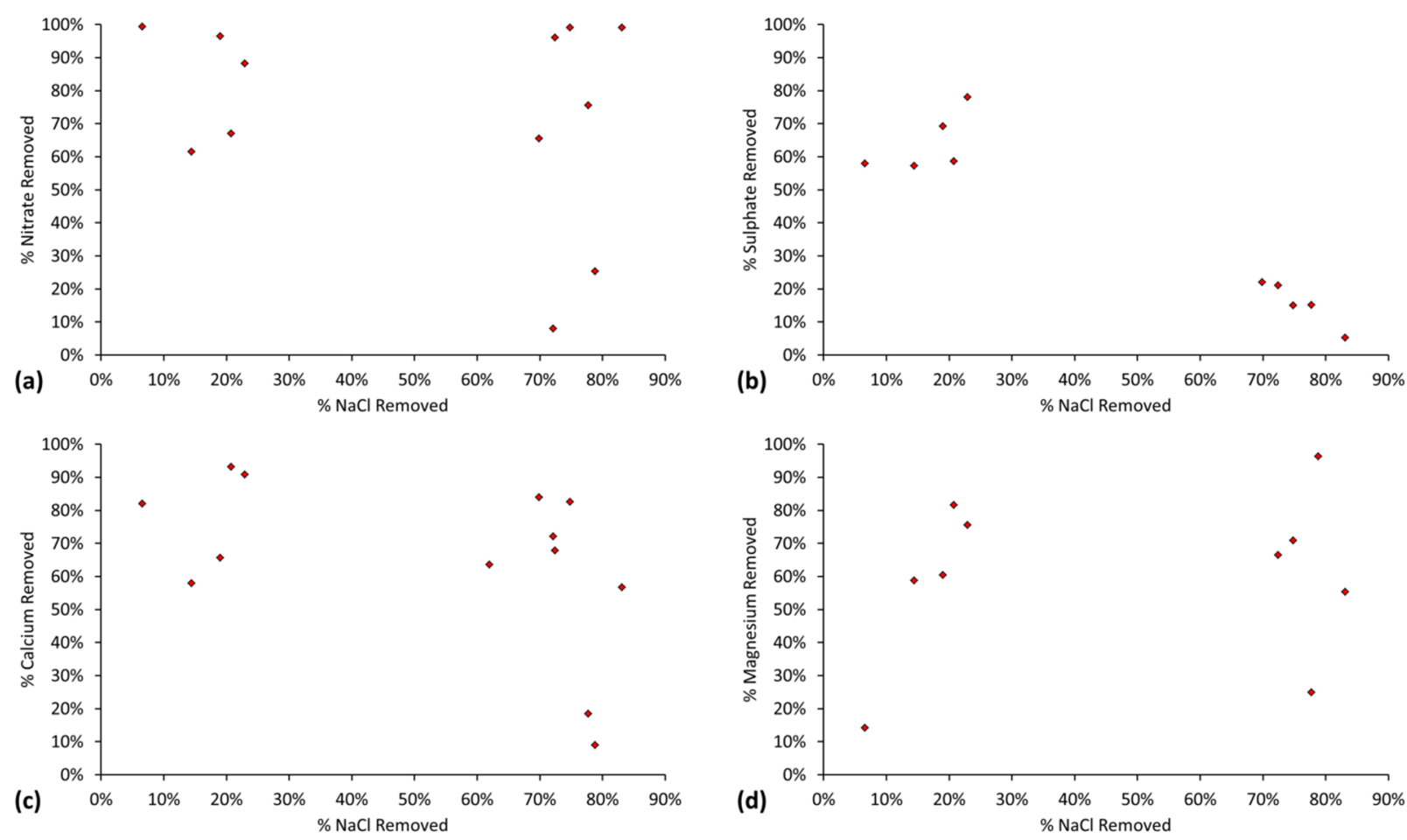

Figure C18. Cont. 

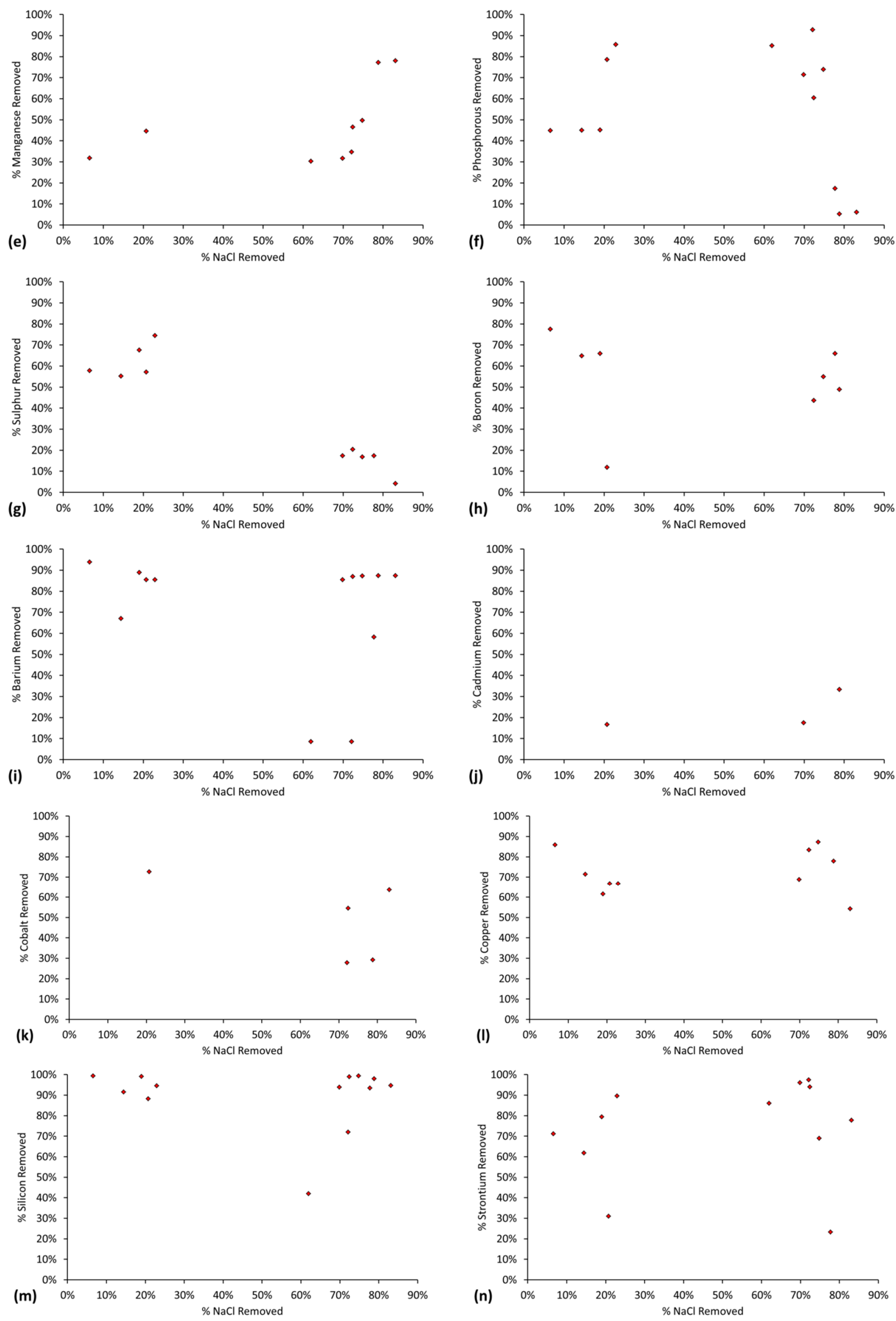

Figure C18. Cont. 

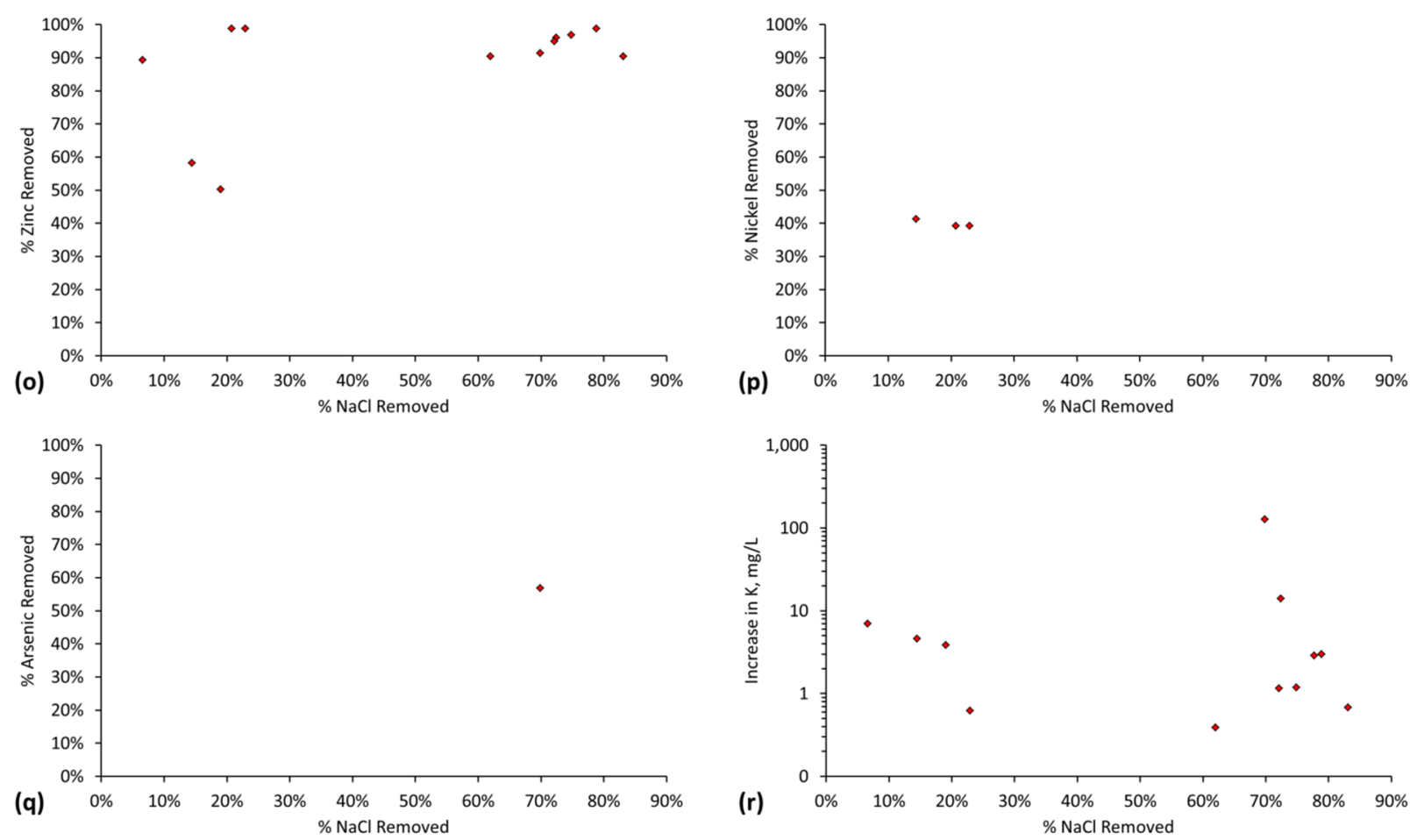

Figure C18. Observed anion and cation removal associated with $\mathrm{NaCl}$ removal. (a) nitrates; (b) sulphates; (c) calcium; (d) magnesium; (e) manganese; (f) phosphorous; (g) sulphur; (h) boron; (i) barium; (j) cadmium; (k) cobalt; (l) copper; (m) silicon; (n) strontium; (o) zinc; (p) nickel; (q) arsenic; (r) potassium increases are due to desorption from ZVM TP.
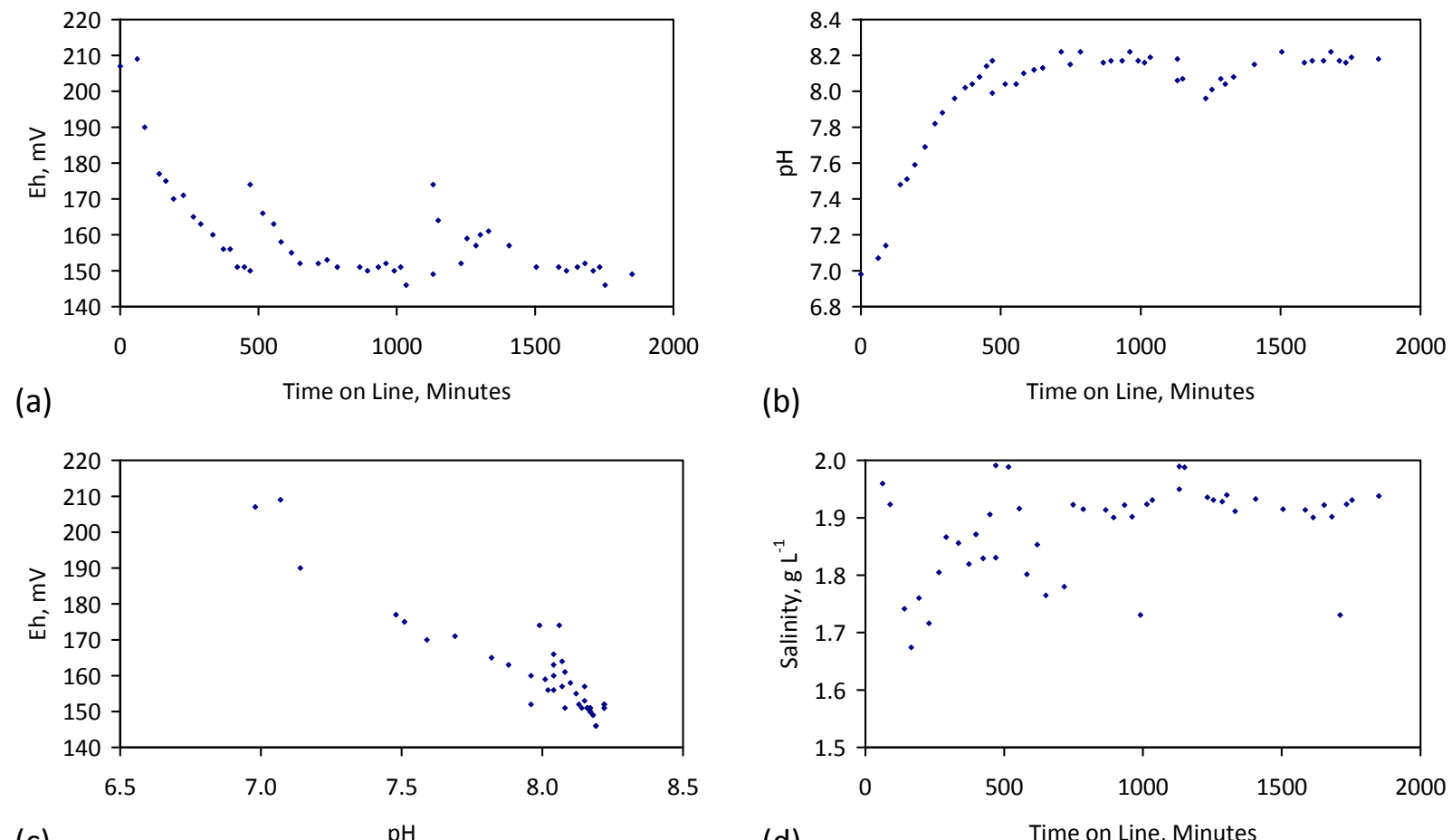

(c)

$\mathrm{pH}$

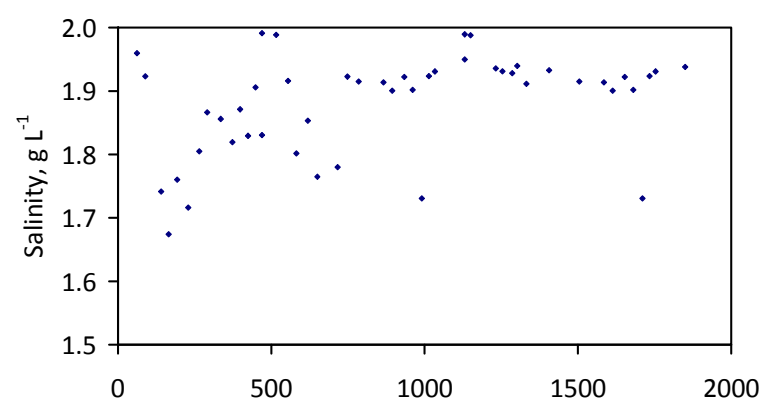

(d)

Time on Line, Minutes

Figure C19. Cont. 


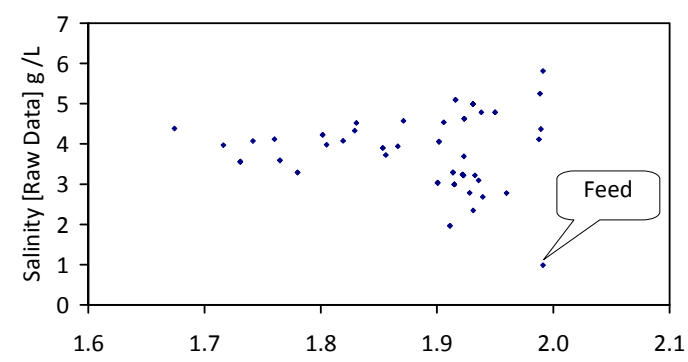

(e) Salinity [Normalised Data] g/L

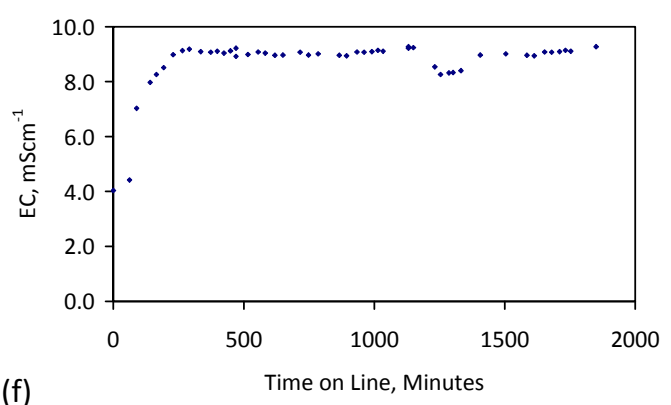

(f)

Figure C19. ZVM TPA Trial E145 Example. Initial Batch Run; Operating Temperature: $13-17{ }^{\circ} \mathrm{C}$; Oxidising Environment: Water volume in the reactor $=0.114 \mathrm{~m}^{3} ; \mathrm{ZVM}$ TP in a cartridge $=1.449 \mathrm{~kg}$; Air flow $=120 \mathrm{~L} \cdot \mathrm{h}^{-1}$. (a) Eh vs. time; (b) $\mathrm{pH} v s$. time; (c) $\mathrm{pH}$ vs. Eh; (d) Salinity $v s$. time; (e) Salinity calculated from normalised data $v s$. salinity calculated from raw data; (f) EC vs. time.
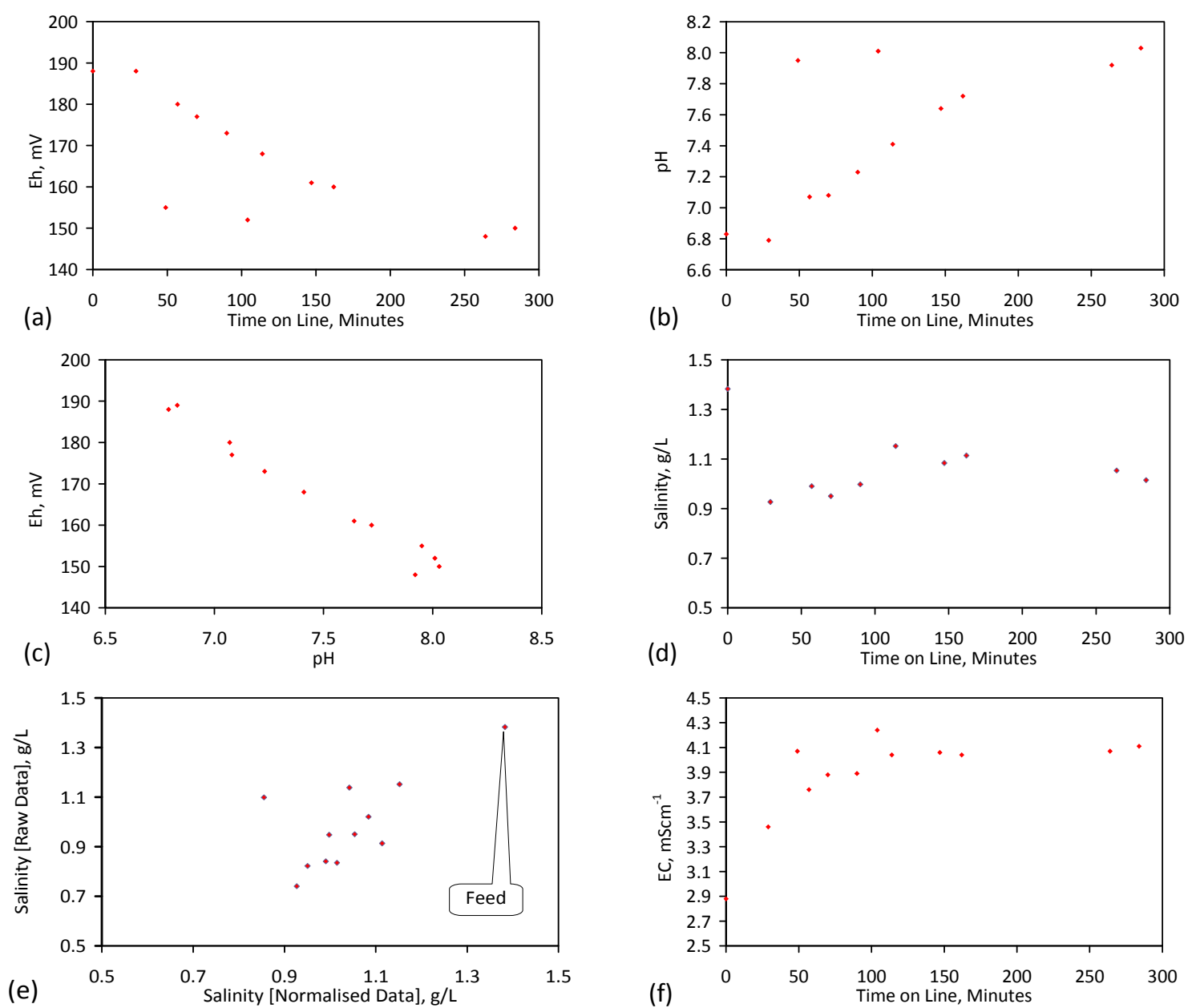

Figure C20. ZVM TPA Example, Trial E146. Initial Batch Run; Operating Temperature: $17-20{ }^{\circ} \mathrm{C}$; Oxidising Environment: Water volume in the reactor $=0.24 \mathrm{~m}^{3}$; ZVM TP in a cartridge $=0.4 \mathrm{~kg}$. The cartridge (and ZVM TPA) had previously been used in Trial E145. Air flow $=120 \mathrm{~L} \cdot \mathrm{h}^{-1}$. (a) Eh vs. time; (b) $\mathrm{pH} v s$. time; (c) $\mathrm{pH} v s$. Eh; (d) Salinity $v s$. time; (e) Salinity calculated from normalised data $v s$. salinity calculated from raw data. (f) EC vs. time. 

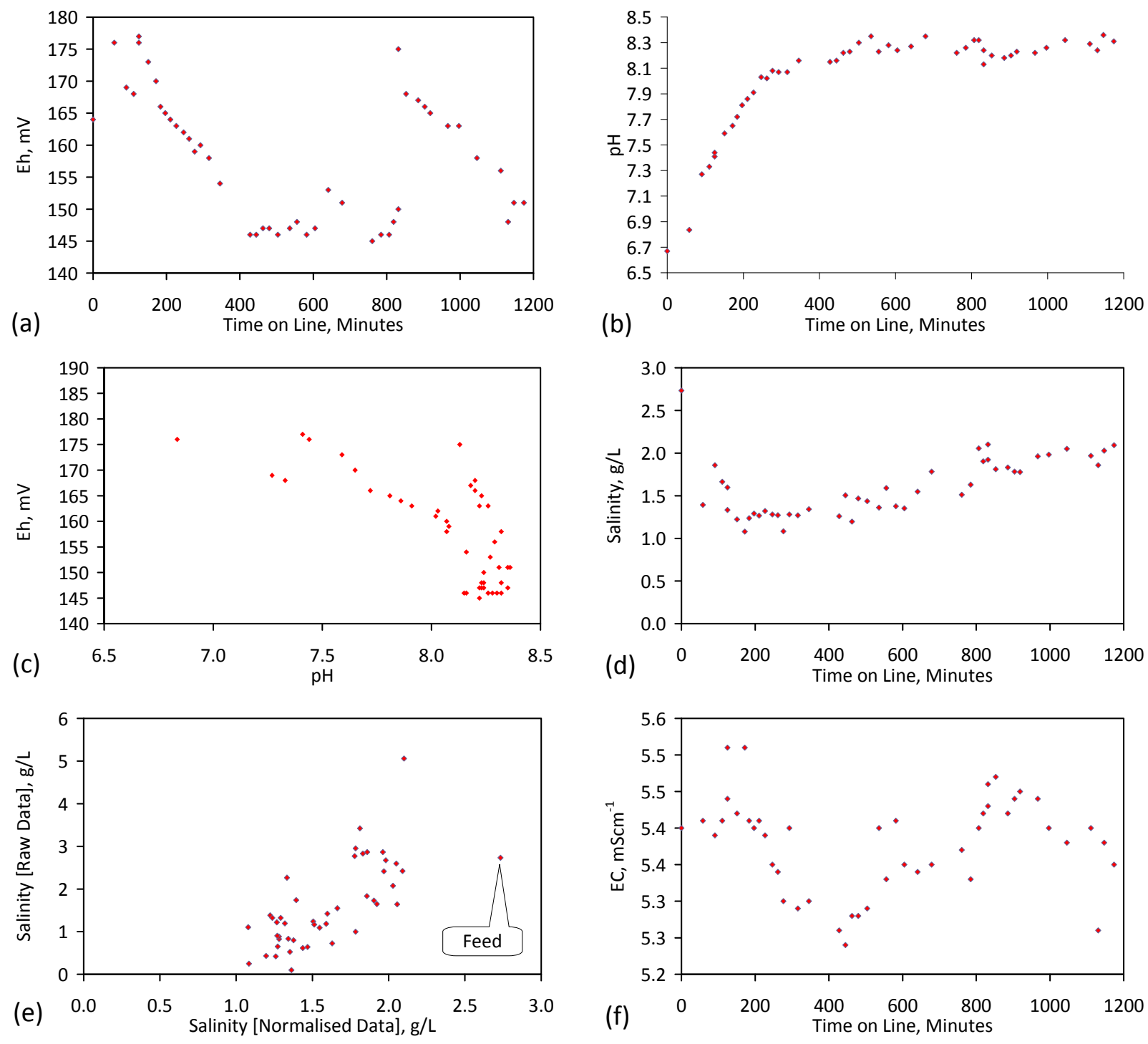

Figure C21. ZVM TPA example Trial E146. 1st Reuse; Operating Temperature: $15-20{ }^{\circ} \mathrm{C}$; Oxidising Environment: Water volume in the reactor $=0.24 \mathrm{~m}^{3}$; ZVM TPA from Trial E145 in a cartridge $=0.4 \mathrm{~kg}$; Air flow $=120 \mathrm{~L} \cdot \mathrm{h}^{-1}$; (a) Eh vs. time; (b) $\mathrm{pH} v s$. time; (c) $\mathrm{pH}$ vs. Eh; (d) Salinity vs. time; (e) Salinity calculated from normalised data $v s$. salinity calculated from raw data; (f) EC vs. time.
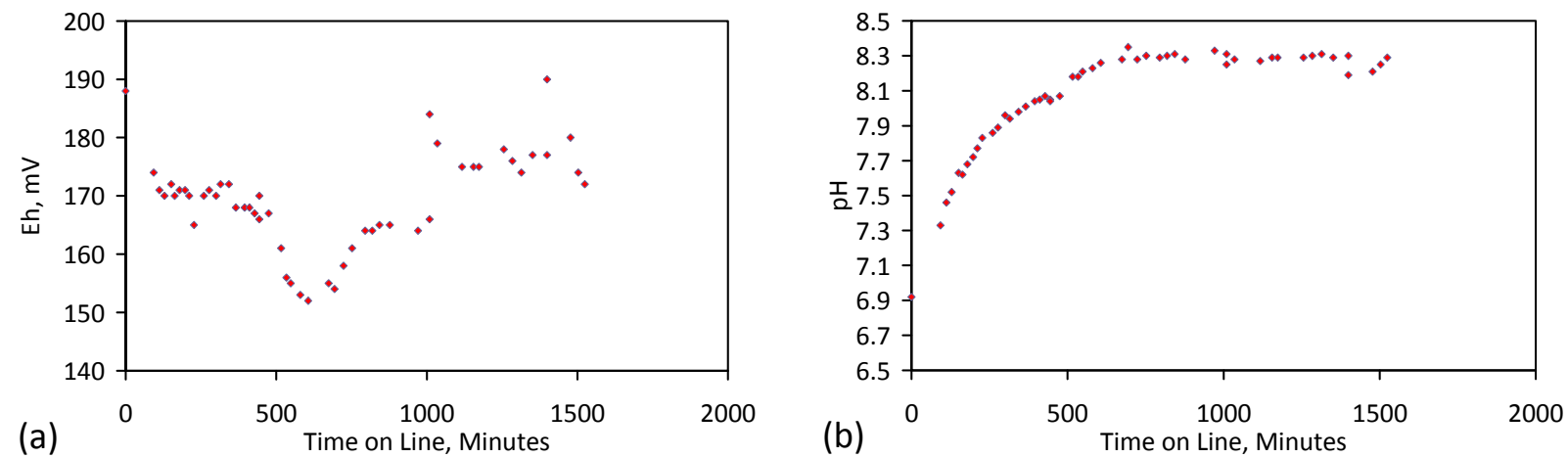

Figure C22. Cont. 

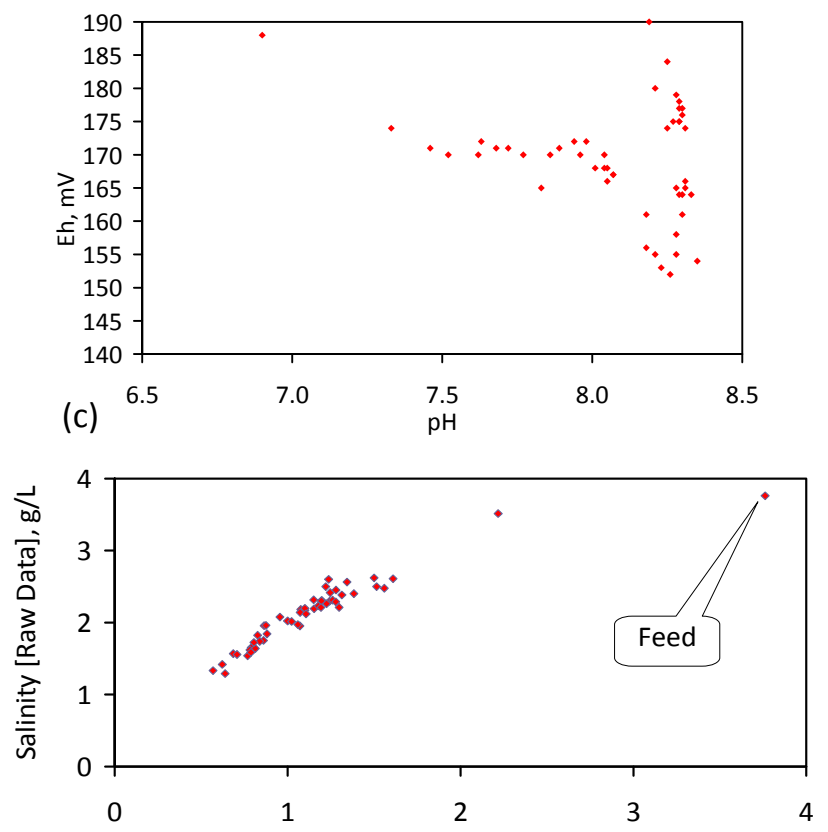

(e)

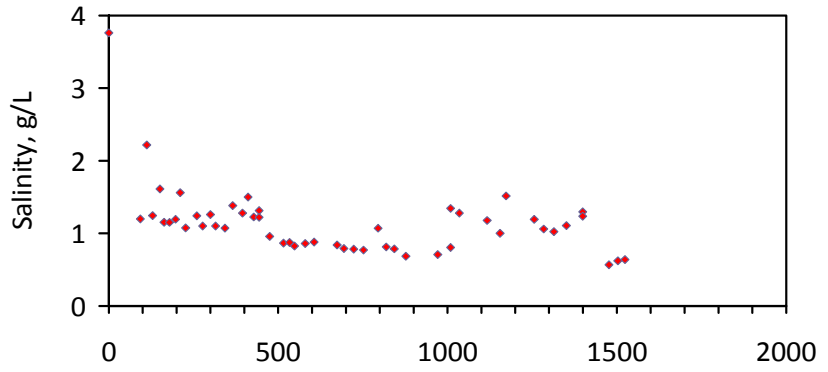

(d)

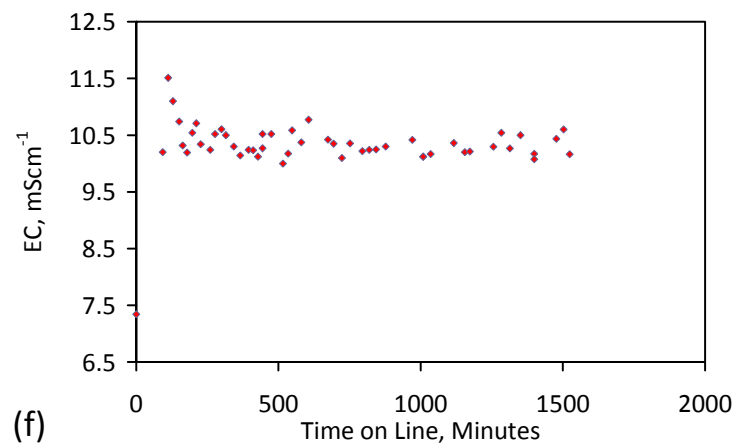

Figure C22. ZVM TPA example Trial E146. 2nd Reuse; Operating Temperature: $15-22{ }^{\circ} \mathrm{C}$; Oxidising Environment: Water volume in the reactor $=0.24 \mathrm{~m}^{3}$; ZVM TPA from Trial E145 in a cartridge $=0.4 \mathrm{~kg}$; Air flow $=120 \mathrm{~L} \cdot \mathrm{h}^{-1}$. (a) Eh vs. time; (b) $\mathrm{pH} v s$. time; (c) $\mathrm{pH}$ vs. Eh; (d) Salinity vs. time; (e) Salinity calculated from normalised data vs. salinity calculated from raw data; (f) EC vs. time.
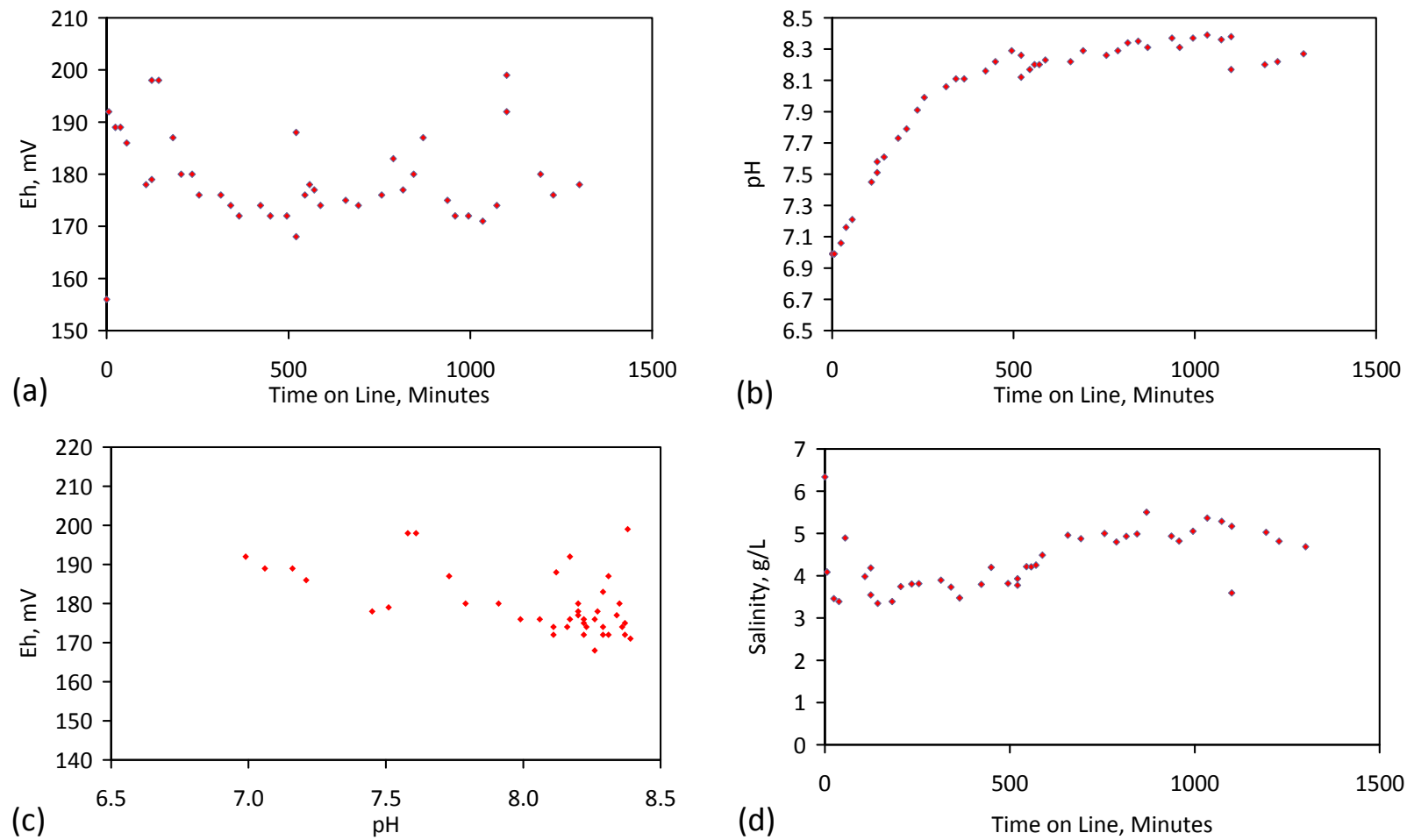

Figure C23. Cont. 


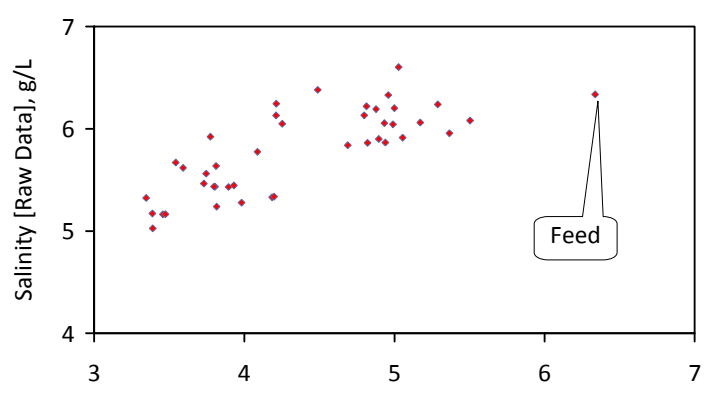

(e)

Salinity [Normalised Data], g/L

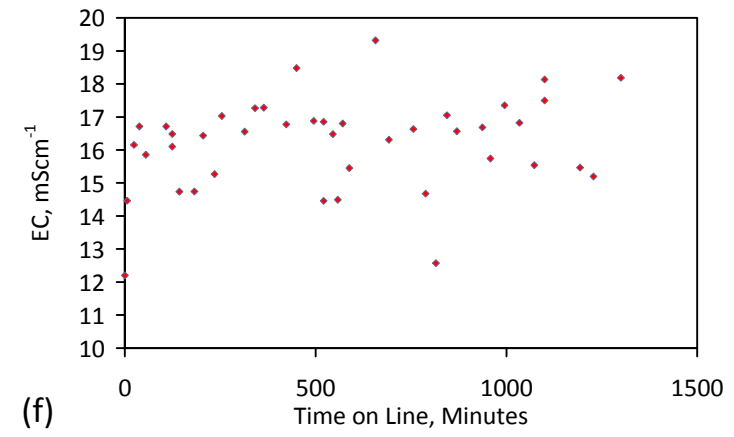

Figure C23. ZVM TPA example Trial E146. 3rd Reuse; Operating Temperature: 15-21 C; Oxidising Environment: Water volume in the reactor $=0.24 \mathrm{~m}^{3} ; \mathrm{ZVM}$ TPA from Trial E145 in a cartridge $=0.4 \mathrm{~kg}$; Air flow $=120 \mathrm{~L} \cdot \mathrm{h}^{-1}$. (a) Eh $v s$. time; (b) $\mathrm{pH} v s$. time; (c) $\mathrm{pH} v s$. Eh; (d) Salinity $v s$. time; (e) Salinity calculated from normalised data $v s$. salinity calculated from raw data; (f) EC vs. time.
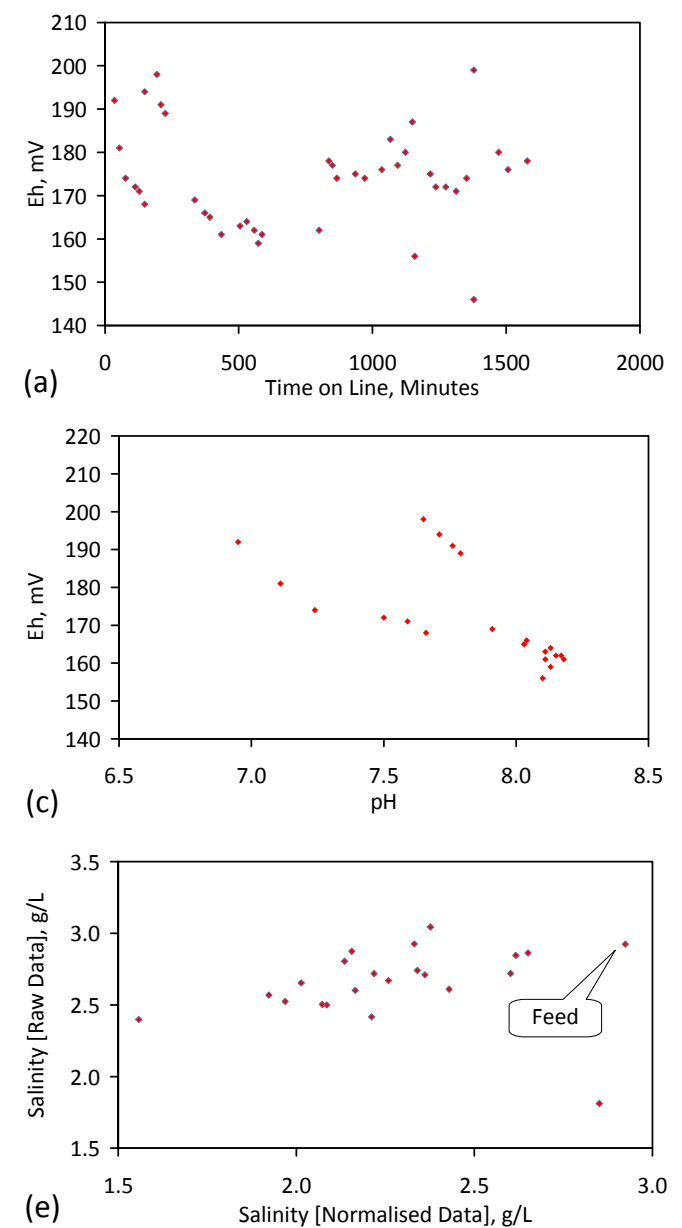
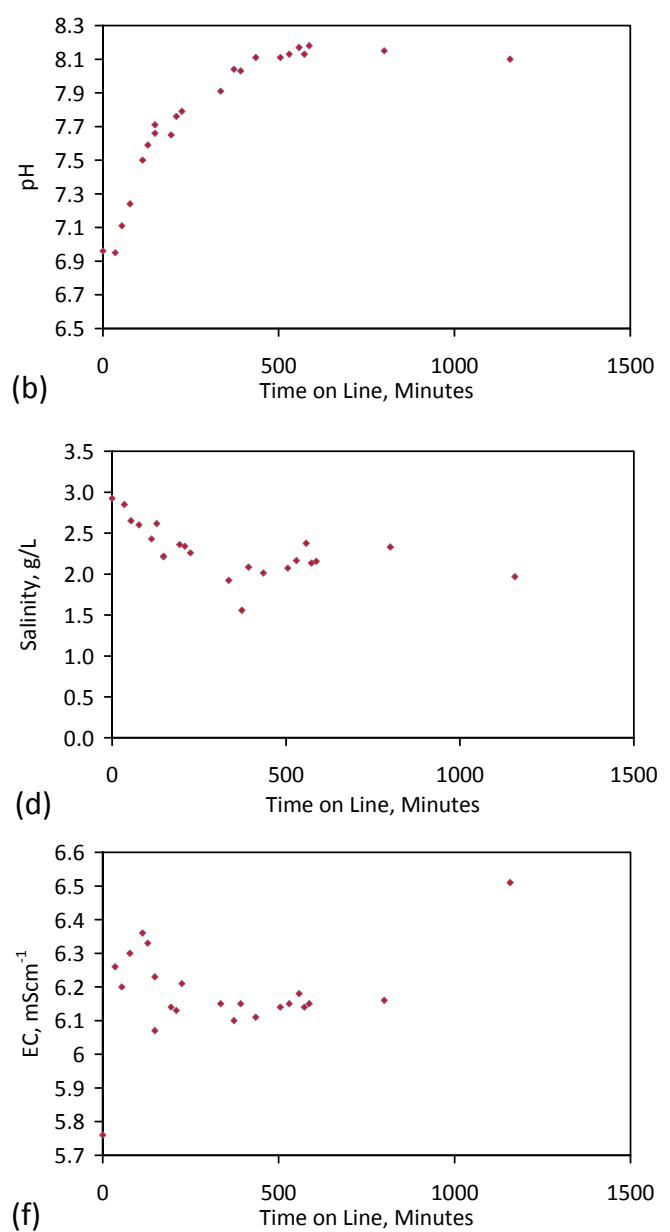

Figure C24. ZVM TPA example Trial E146. 4th Reuse; Operating Temperature: $15-22{ }^{\circ} \mathrm{C}$; Oxidising Environment: Water volume in the reactor $=0.24 \mathrm{~m}^{3} ; \mathrm{ZVM}$ TPA from Trial E145 in a cartridge $=0.4 \mathrm{~kg}$; Air flow $=120 \mathrm{~L} \cdot \mathrm{h}^{-1}$. (a) Eh $v s$. time; (b) $\mathrm{pH} v \mathrm{~s}$. time; (c) $\mathrm{pH}$ vs. Eh; (d) Salinity vs. time; (e) Salinity calculated from normalised data vs. salinity calculated from raw data; (f) EC vs. time. 

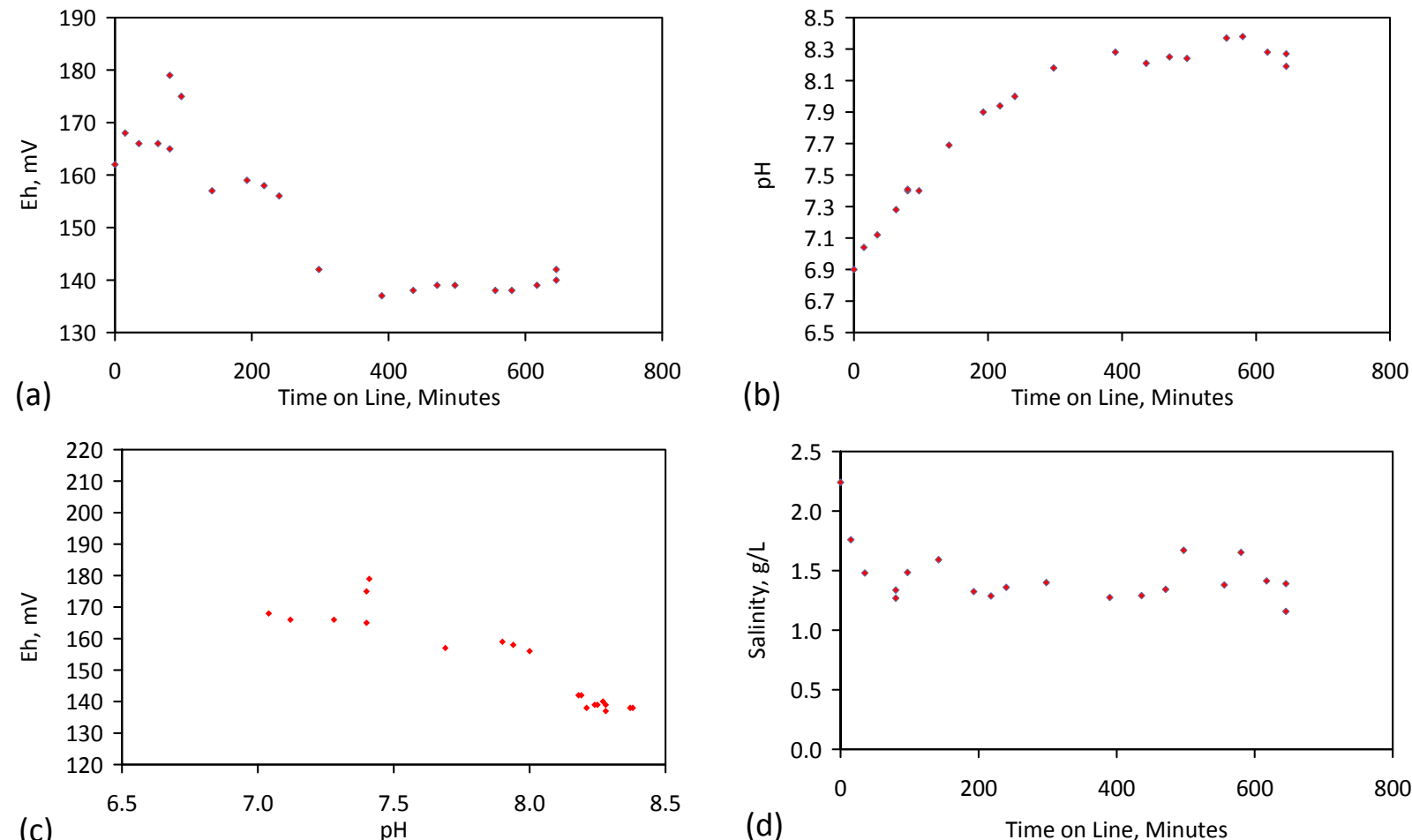

(d)

Time on Line, Minutes
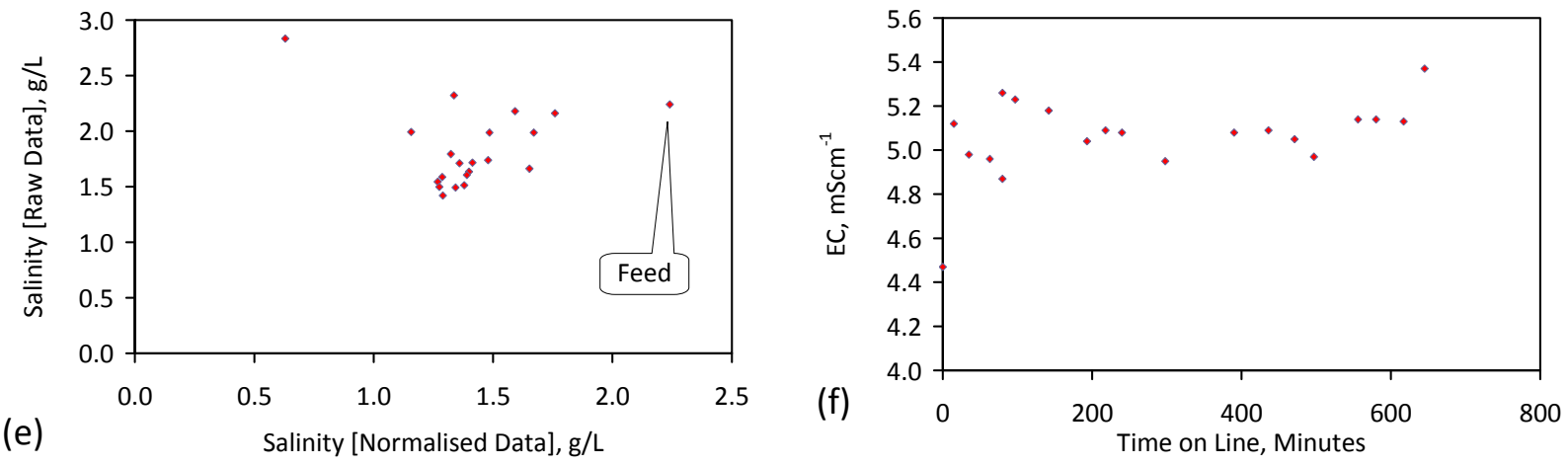

Figure C25. ZVM TPA example Trial E146. 5th Reuse; Operating Temperature: $17-23{ }^{\circ} \mathrm{C}$; Oxidising Environment: Water volume in the reactor $=0.24 \mathrm{~m}^{3}$; ZVM TPA from Trial E145 in a cartridge $=0.4 \mathrm{~kg}$; Air flow $=120 \mathrm{~L} \cdot \mathrm{h}^{-1}$. (a) Eh $v s$. time; (b) $\mathrm{pH} v s$. time; (c) $\mathrm{pH} v s$. Eh; (d) Salinity vs. time; (e) Salinity calculated from normalised data $v s$. salinity calculated from raw data; (f) EC vs. time.
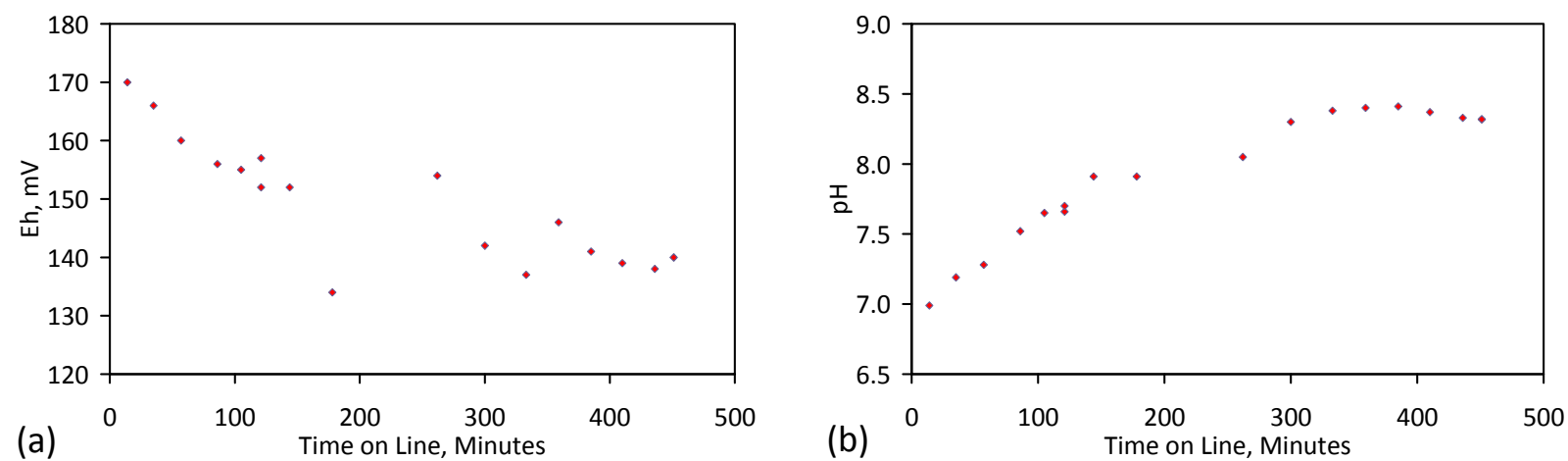

Figure C26. Cont. 

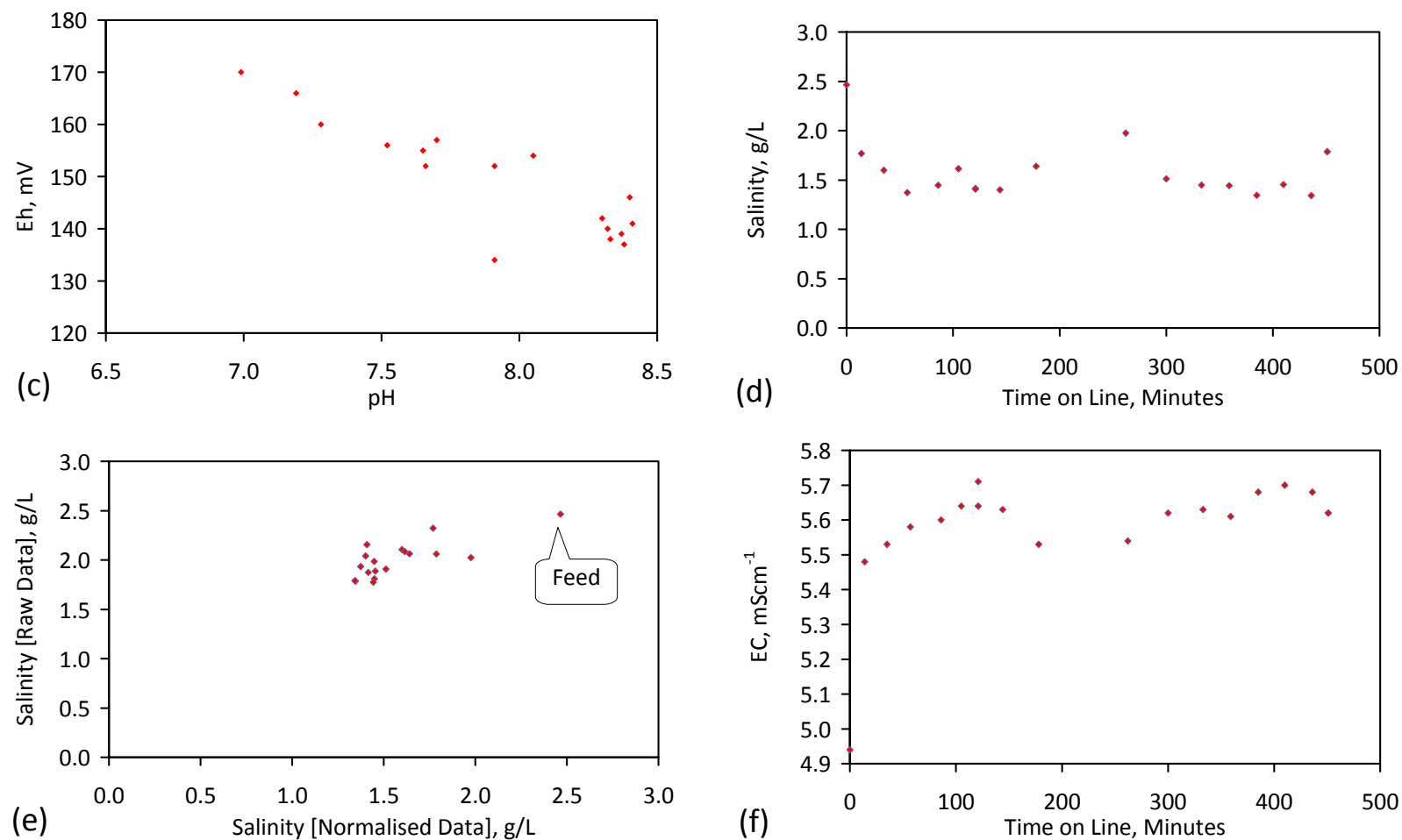

Figure C26. ZVM TPA example Trial E146. 6th Reuse; Operating Temperature: $19-25{ }^{\circ} \mathrm{C}$; Oxidising Environment: Water volume in the reactor $=0.24 \mathrm{~m}^{3}$; ZVM TPA from Trial E145 in a cartridge $=0.4 \mathrm{~kg}$; Air flow $=120 \mathrm{~L} \cdot \mathrm{h}^{-1}$. (a) Eh $v s$. time; (b) $\mathrm{pH}$ vs. time; (c) $\mathrm{pH}$ vs. Eh; (d) Salinity $v$ s. time; (e) Salinity calculated from normalised data vs. salinity calculated from raw data; (f) EC vs. time.
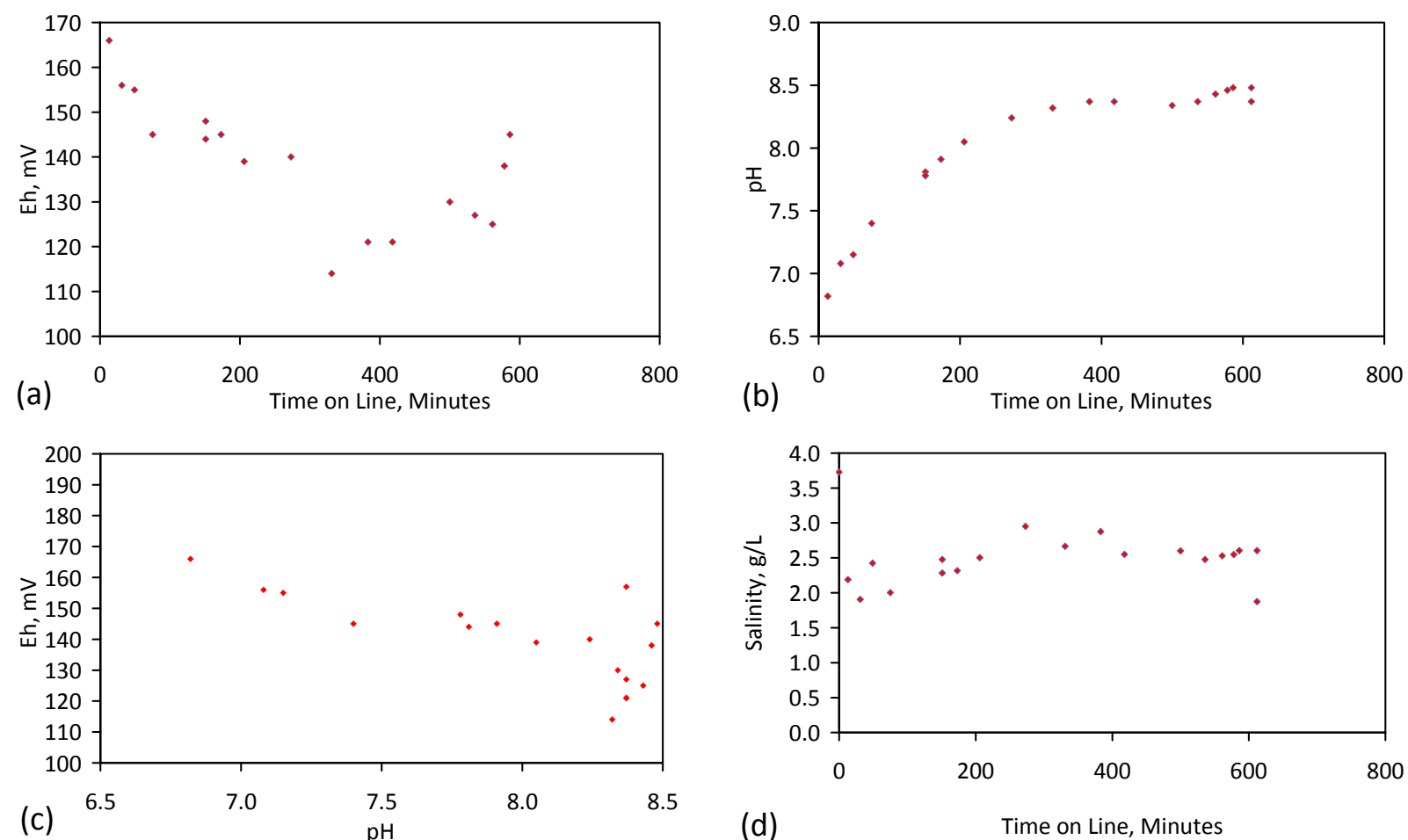

Figure C27. Cont. 

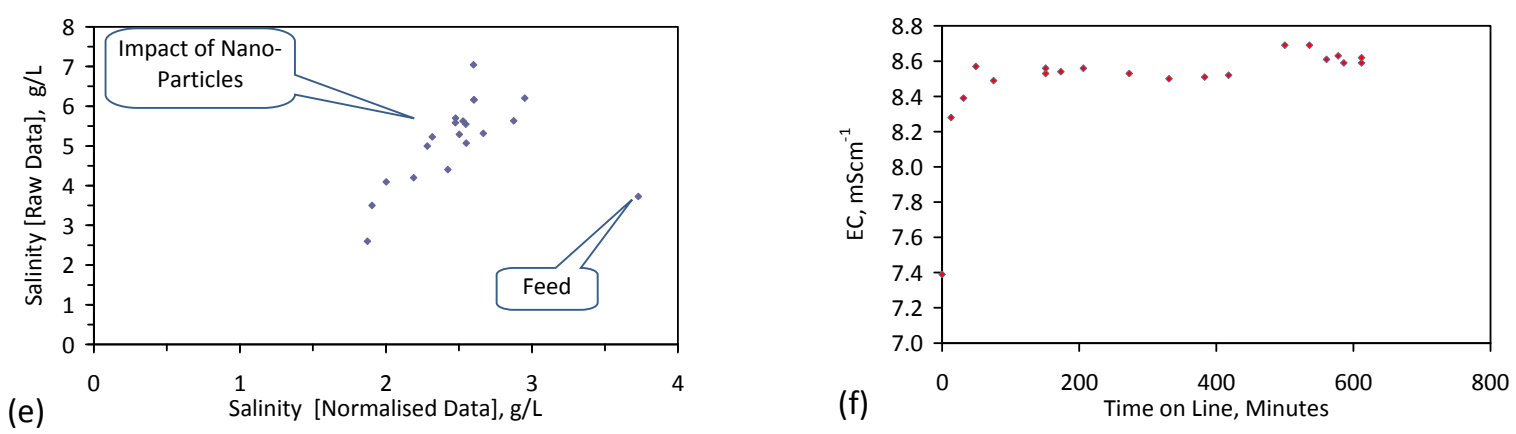

Figure C27. ZVM TPA example Trial E146. 7th Reuse; Operating Temperature: $18-22{ }^{\circ} \mathrm{C}$; Oxidising Environment: Water volume in the reactor $=0.24 \mathrm{~m}^{3}$; ZVM TPA from Trial E145 in a cartridge $=0.4 \mathrm{~kg}$; Air flow $=120 \mathrm{~L} \cdot \mathrm{h}^{-1}$. (a) Eh vs. time; (b) $\mathrm{pH} v s$. time; (c) pH vs. Eh; (d) Salinity vs. time; (e) Salinity calculated from normalised data vs. salinity calculated from raw data; (f) EC vs. time.
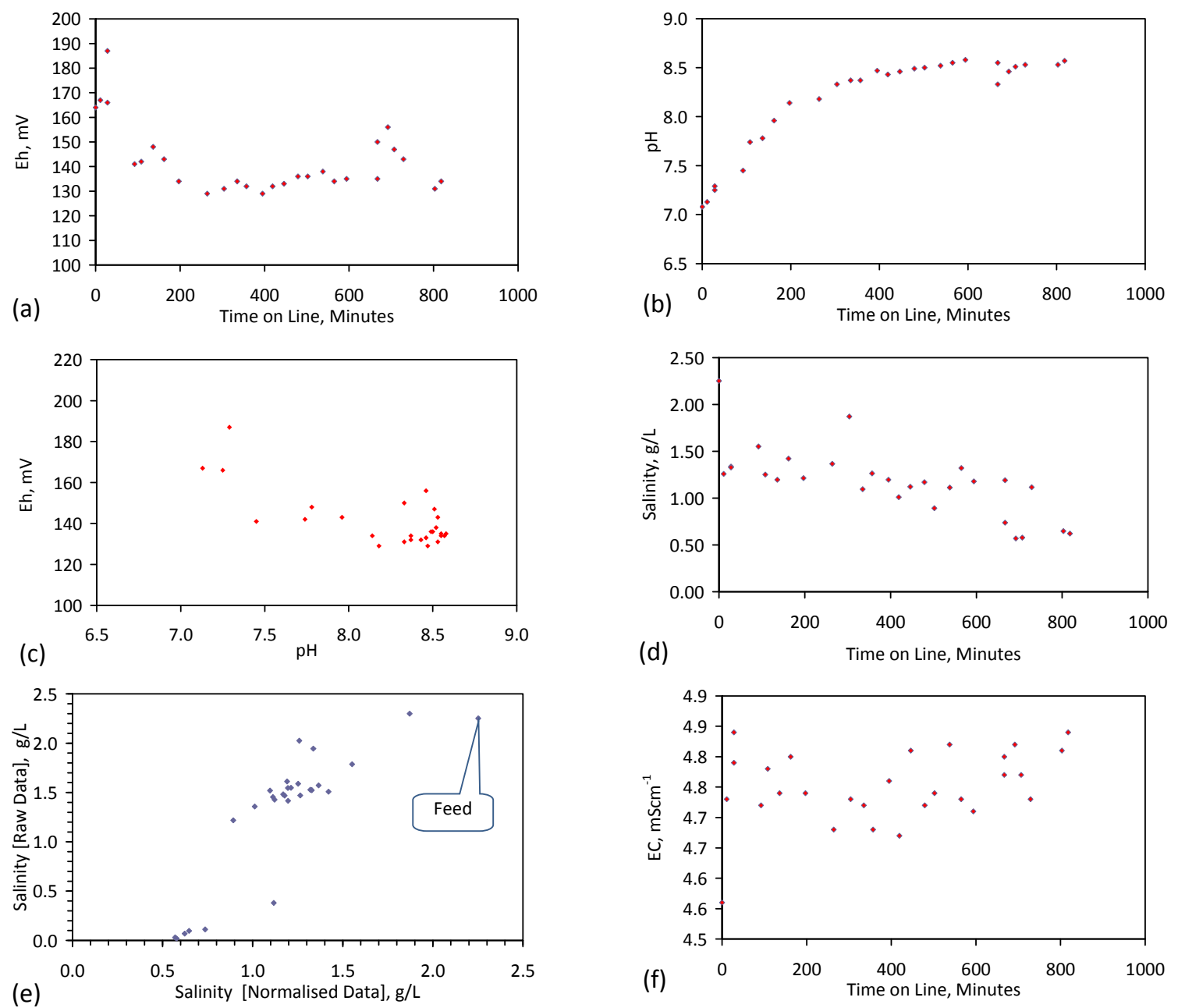

Figure C28. ZVM TPA example Trial E146. 8th Reuse; Operating Temperature: $15-21{ }^{\circ} \mathrm{C}$; Oxidising Environment: Water volume in the reactor $=0.24 \mathrm{~m}^{3}$; ZVM TPA from Trial E145 in a cartridge $=0.4 \mathrm{~kg}$; Air flow $=120 \mathrm{~L} \cdot \mathrm{h}^{-1}$. (a) Eh $v s$. time; (b) $\mathrm{pH} v s$. time; (c) pH vs. Eh; (d) Salinity vs. time; (e) Salinity calculated from normalised data vs. salinity calculated from raw data; (f) EC vs. time. 

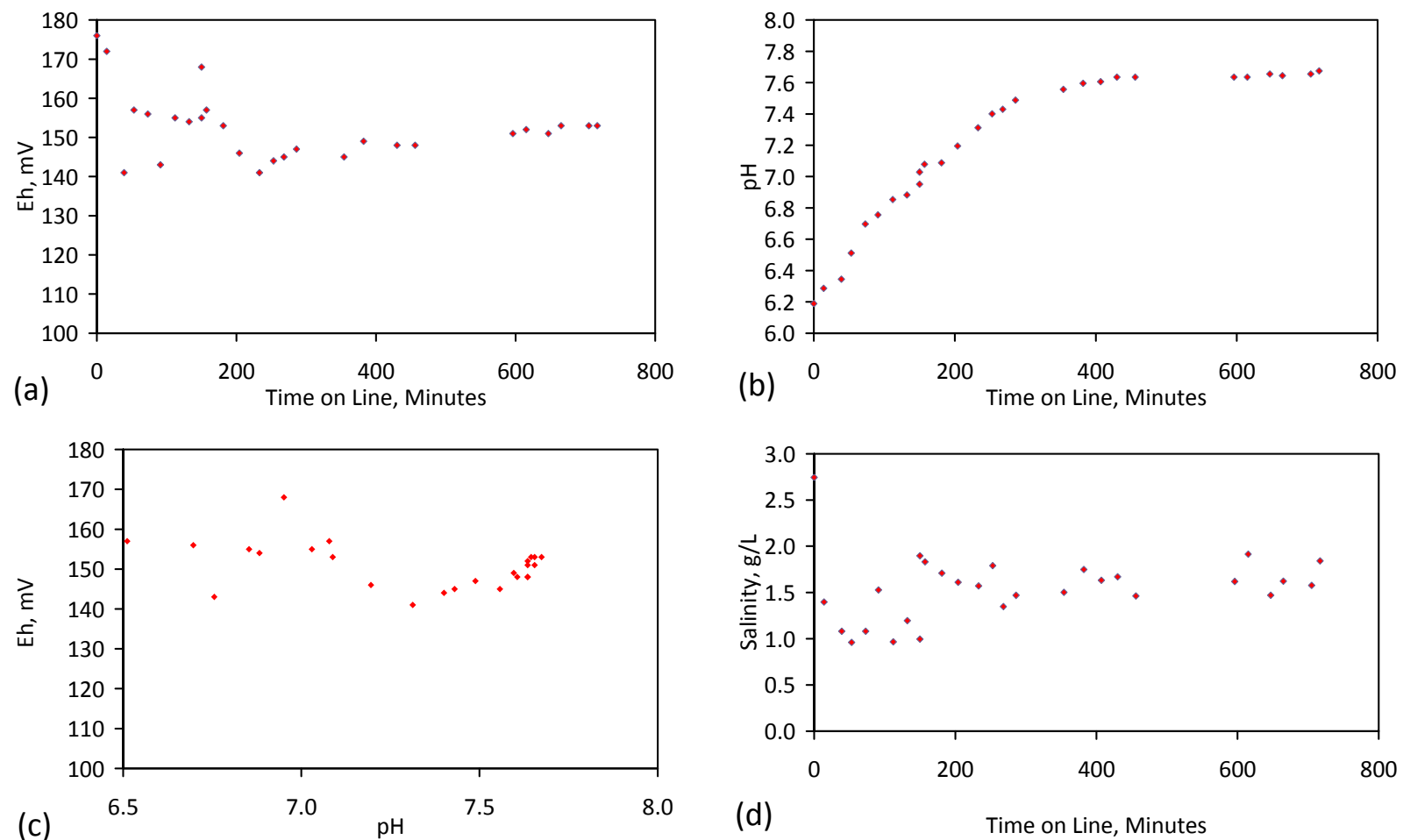

(d)

Time on Line, Minutes
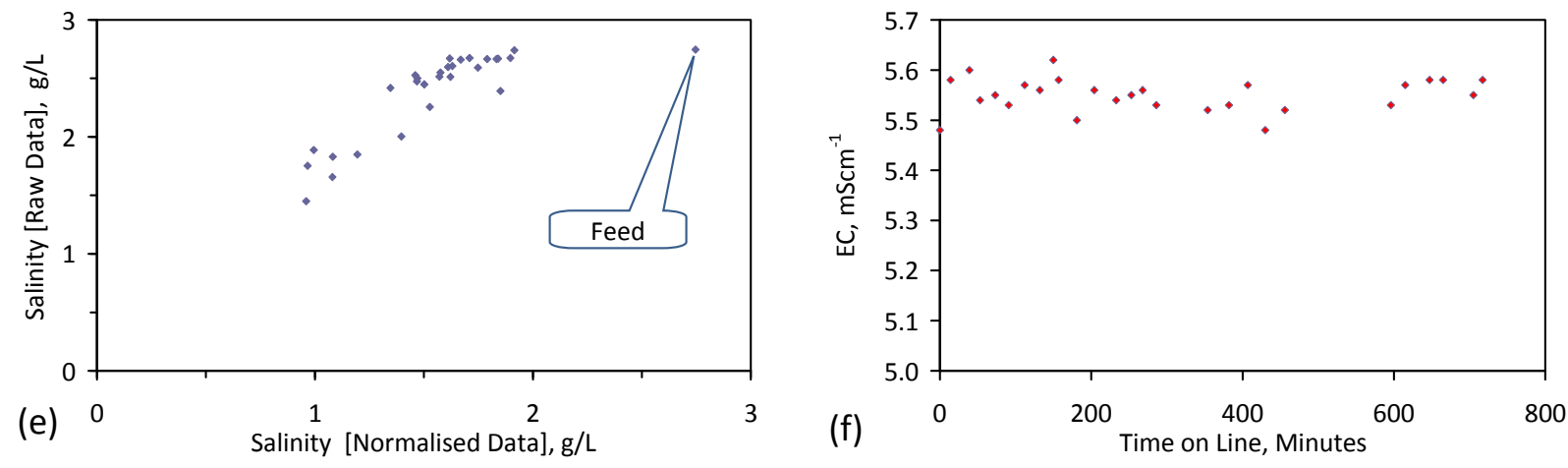

Figure C29. ZVM TPA example Trial E146. 9th Reuse; Operating Temperature: 16-20 ${ }^{\circ} \mathrm{C}$; Oxidising Environment: Water volume in the reactor $=0.24 \mathrm{~m}^{3}$; ZVM TPA from Trial E145 in a cartridge $=0.4 \mathrm{~kg}$; Air flow $=120 \mathrm{~L} \cdot \mathrm{h}^{-1}$. (a) Eh vs. time; (b) $\mathrm{pH} v \mathrm{~s}$. time; (c) pH vs. Eh; (d) Salinity vs. time; (e) Salinity calculated from normalised data $v s$. salinity calculated from raw data; (f) EC vs. time.
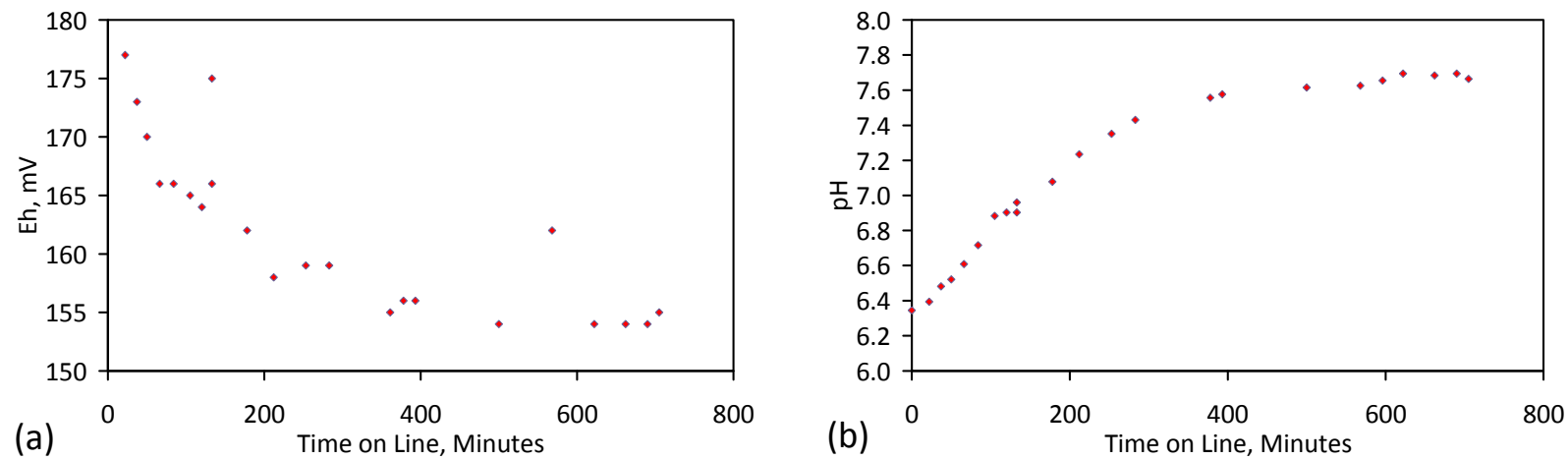

Figure C30. Cont. 

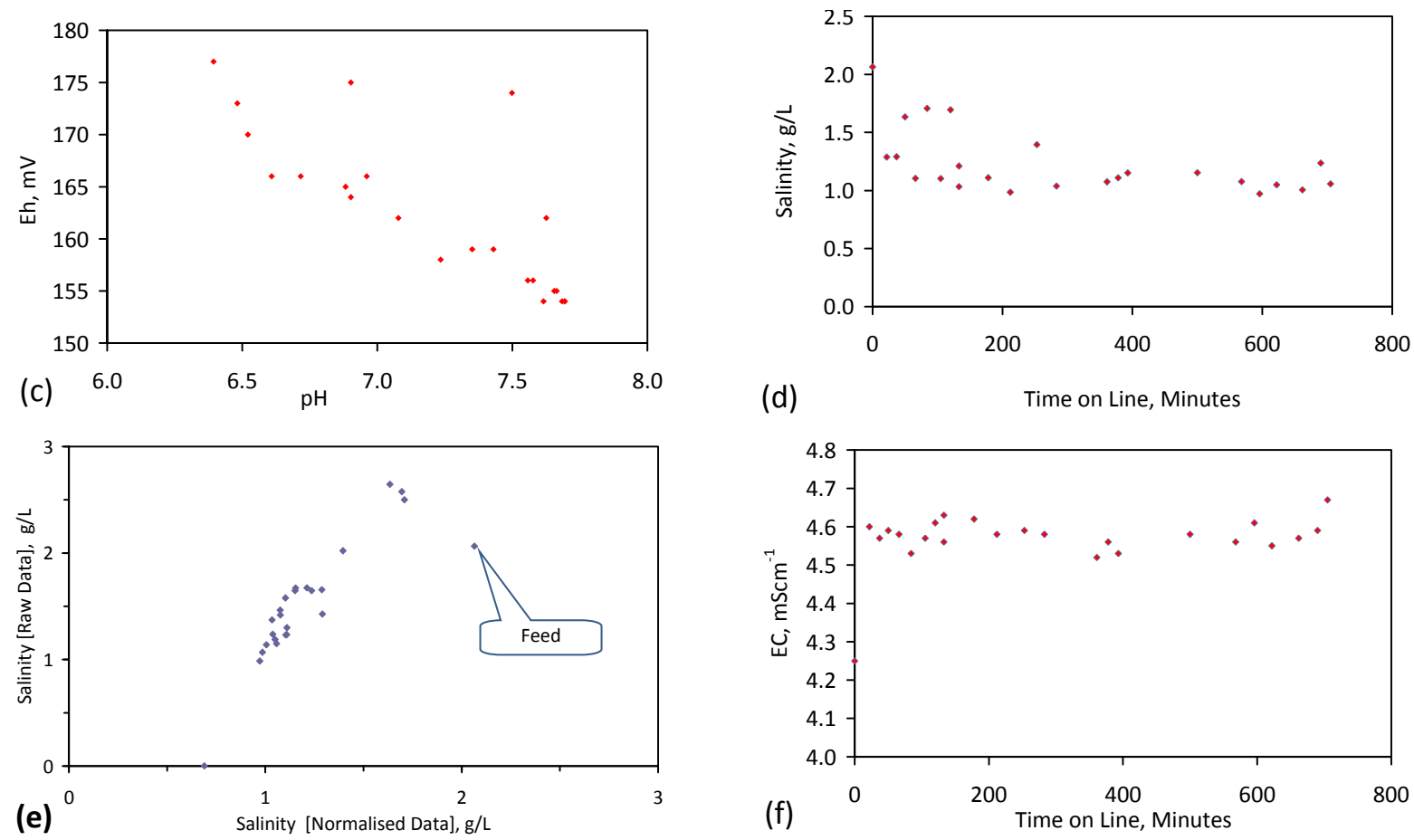

Figure C30. ZVM TPA example Trial E146. 10th Reuse; Operating Temperature: $16-21{ }^{\circ} \mathrm{C}$; Oxidising Environment: Water volume in the reactor $=0.24 \mathrm{~m}^{3}$; ZVM TPA from Trial E145 in a cartridge $=0.4 \mathrm{~kg}$; Air flow $=120 \mathrm{~L} \cdot \mathrm{h}^{-1}$. (a) Eh $v s$. time; (b) $\mathrm{pH} v s$. time; (c) $\mathrm{pH} v s$. Eh; (d) Salinity vs. time; (e) Salinity calculated from normalised data vs. salinity calculated from raw data; (f) EC vs. time.
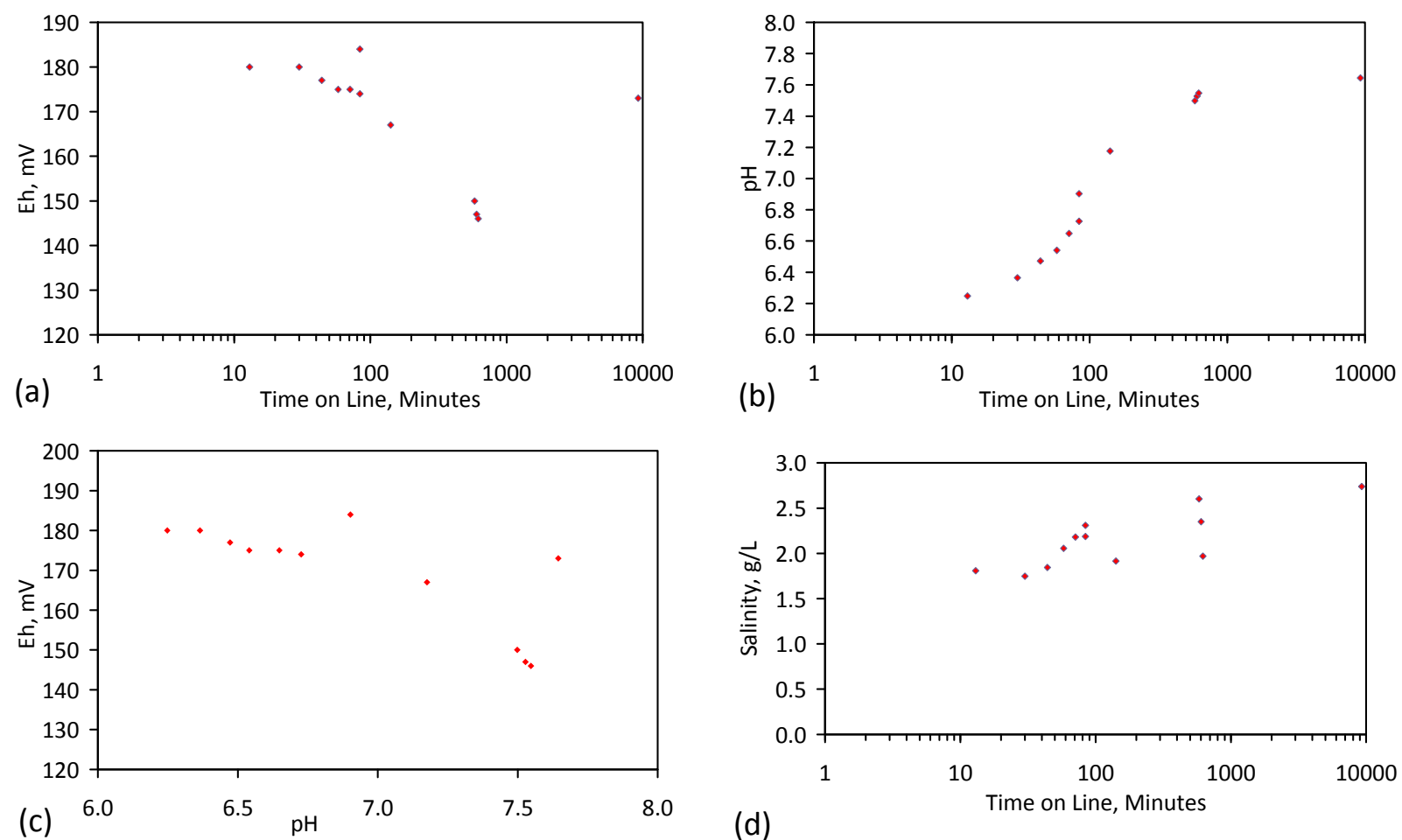

Figure C31. Cont. 

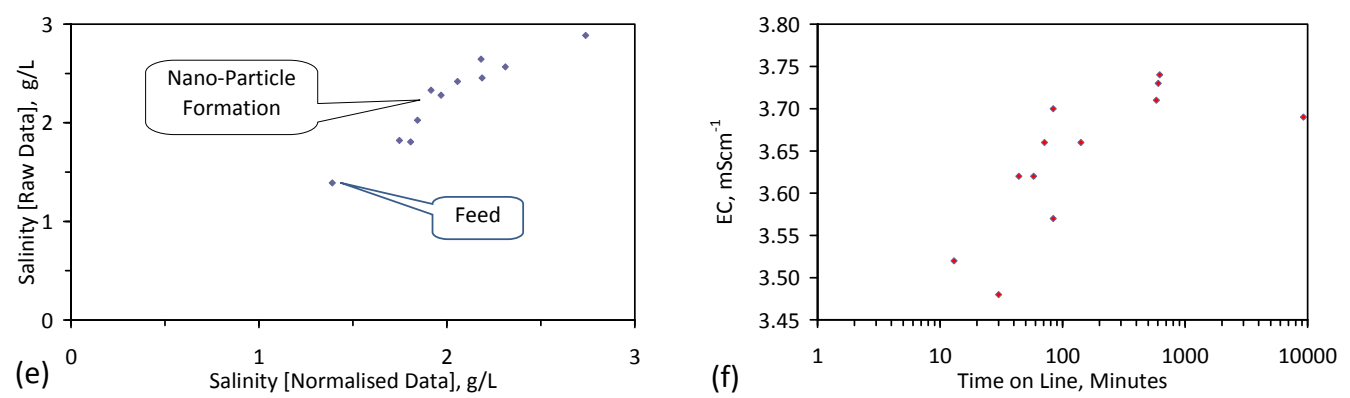

Figure C31. ZVM TPA example Trial E146. 11th Reuse; Operating Temperature: $15-20{ }^{\circ} \mathrm{C}$; Oxidising Environment: Water volume in the reactor $=0.24 \mathrm{~m}^{3}$; ZVM TPA from Trial E145 in a cartridge $=0.4 \mathrm{~kg}$; Air flow $=120 \mathrm{~L} \cdot \mathrm{h}^{-1}$. (a) Eh vs. time; (b) $\mathrm{pH} v s$. time; (c) pH vs. Eh; (d) Salinity vs. time; (e) Salinity calculated from normalised data vs. salinity calculated from raw data; (f) EC vs. time. The rise in absorbance is associated with a rise in EC.
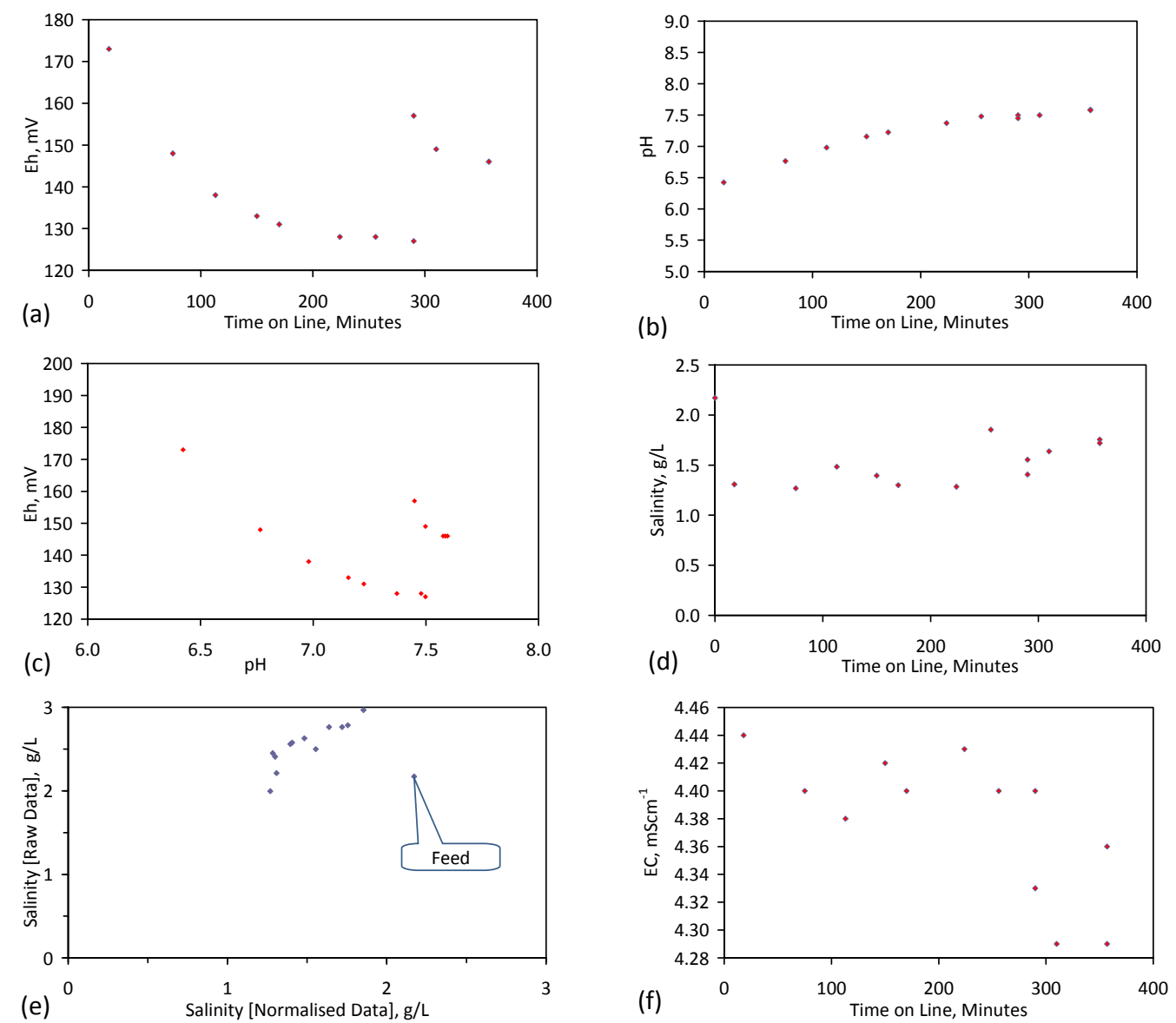

Figure C32. ZVM TPA example Trial E146. 12th Reuse; Operating Temperature: $14-20{ }^{\circ} \mathrm{C}$; Oxidising Environment: Water volume in the reactor $=0.24 \mathrm{~m}^{3}$; ZVM TPA from Trial E145 in a cartridge $=0.4 \mathrm{~kg}$; Air flow $=120 \mathrm{~L} \cdot \mathrm{h}^{-1}$. Acid Oxidising Environment: Water volume in the reactor $=5.5 \mathrm{~L}$; ZVM TP in a cartridge $=0.1 \mathrm{~kg}$; Gas flow $\left(80 \% \mathrm{~N}_{2}+20 \%\right.$ $\left.\mathrm{CO}_{2}\right)=1.8 \mathrm{~L} \cdot \mathrm{h}^{-1}$. (a) Eh vs. time; (b) $\mathrm{pH}$ vs. time; (c) $\mathrm{pH}$ vs. Eh; (d) Salinity $v s$. time; (e) Salinity calculated from normalised data $v s$. salinity calculated from raw data; (f) EC vs. time. 

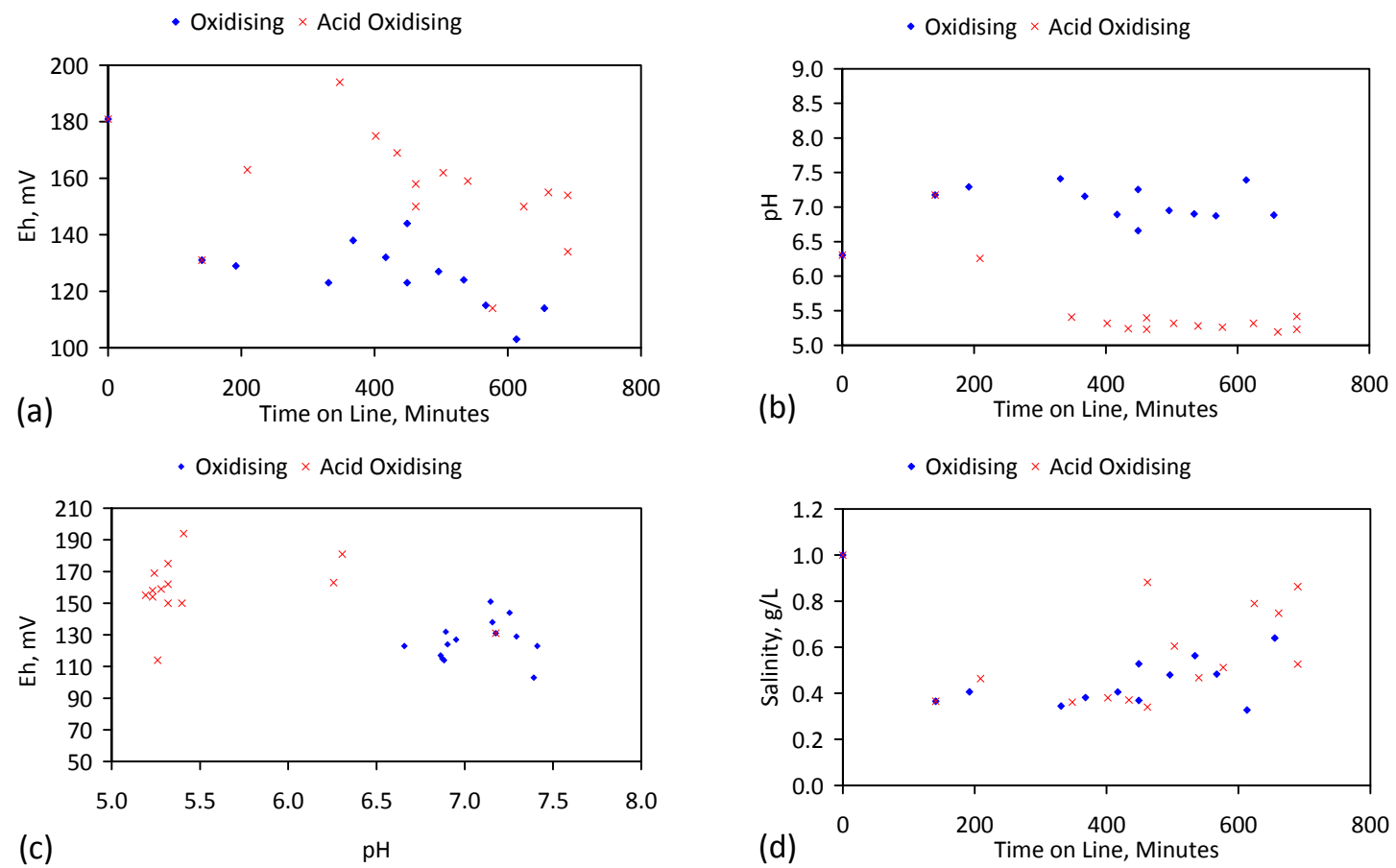

(c)

$\mathrm{pH}$

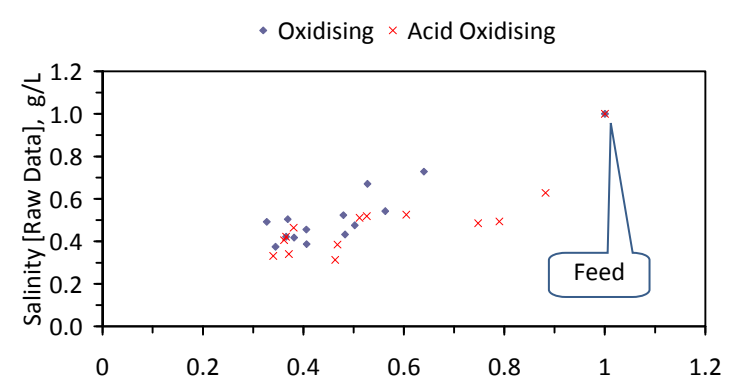

(e)

Salinity [Normalized Data], g/L

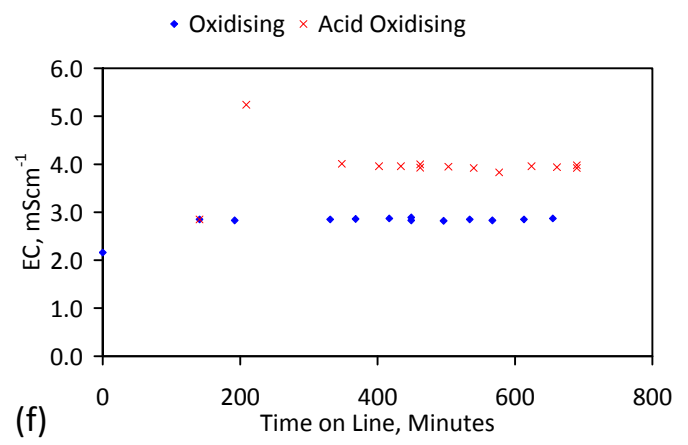

Figure C33. ZVM TPA example Trial E146. 13th Reuse; Operating Temperature: $11-19{ }^{\circ} \mathrm{C}$; Oxidising Environment: Water volume in the reactor $=0.24 \mathrm{~m}^{3}$; ZVM TPA from Trial E145 in a cartridge $=0.4 \mathrm{~kg}$; Air flow $=120 \mathrm{~L} \cdot \mathrm{h}^{-1}$. Acid Oxidising Environment: Water volume in the reactor $=5.4 \mathrm{~L} ; \mathrm{ZVM}$ TPA from Trial E144 in a cartridge $=0.4 \mathrm{~L}$; Gas flow $\left(80 \% \mathrm{~N}_{2}+20 \% \mathrm{CO}_{2}\right)=3.3 \mathrm{~L} \cdot \mathrm{h}^{-1}$. (a) Eh vs. time; (b) $\mathrm{pH} v s$. time; (c) $\mathrm{pH} v s$. Eh; (d) Salinity $v s$. time; (e) Salinity calculated from normalised data $v s$. salinity calculated from raw data; (f) EC vs. time.
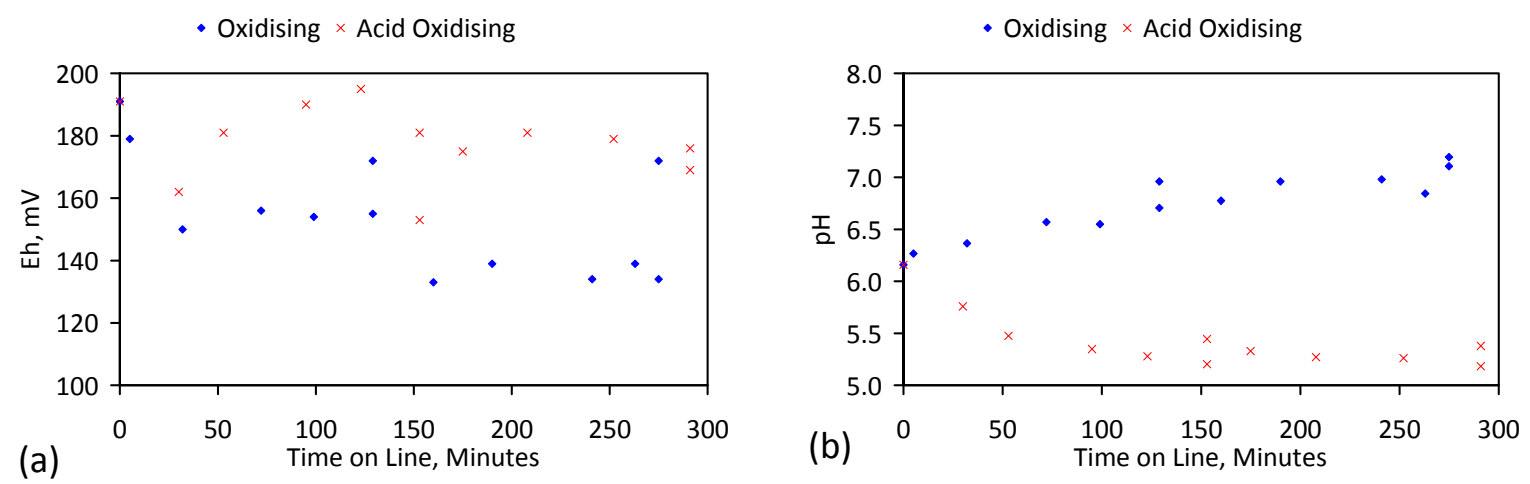

Figure C34. Cont. 

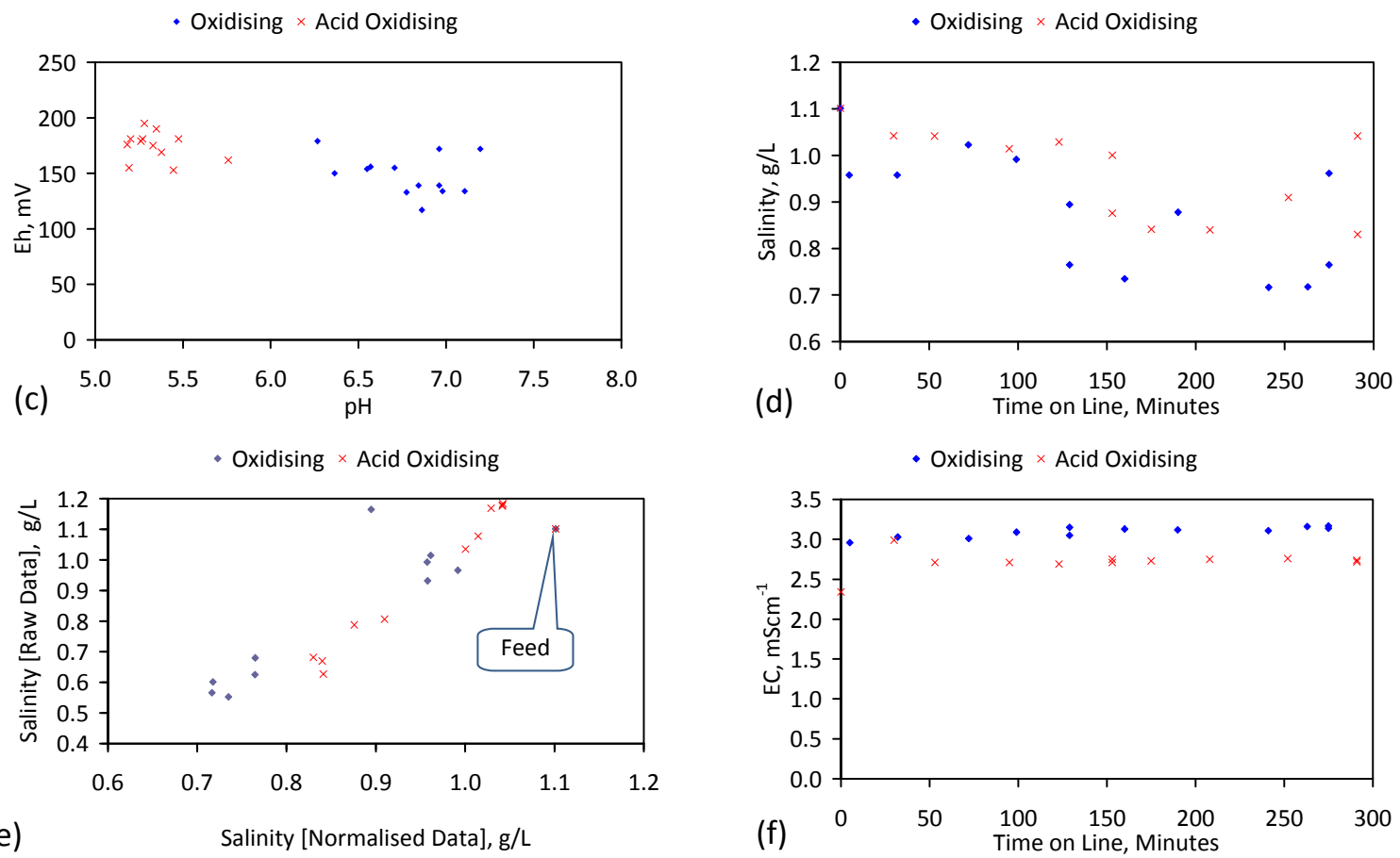

(e)

Salinity [Normalised Data], g/L

Figure C34. ZVM TPA example Trial E146. 14th Reuse; Operating Temperature: $12-16{ }^{\circ} \mathrm{C}$; Oxidising Environment: Water volume in the reactor $=0.24 \mathrm{~m}^{3}$; ZVM TPA from Trial E145 in a cartridge $=0.4 \mathrm{~kg}$; Air flow $=120 \mathrm{~L} \cdot \mathrm{h}^{-1}$. Acid Oxidising Environment: Water volume in the reactor $=5.4 \mathrm{~L}$; ZVM TPA from Trial E144 in a cartridge $=0.4 \mathrm{~L}$; Gas flow $\left(80 \% \mathrm{~N}_{2}+20 \% \mathrm{CO}_{2}\right)=3.3 \mathrm{~L} \cdot \mathrm{h}^{-1}$. (a) Eh vs. time; (b) $\mathrm{pH} v s$. time; (c) $\mathrm{pH} v$ s. Eh; (d) Salinity $v s$. time; (e) Salinity calculated from normalised data $v s$. salinity calculated from raw data; (f) EC vs. time.
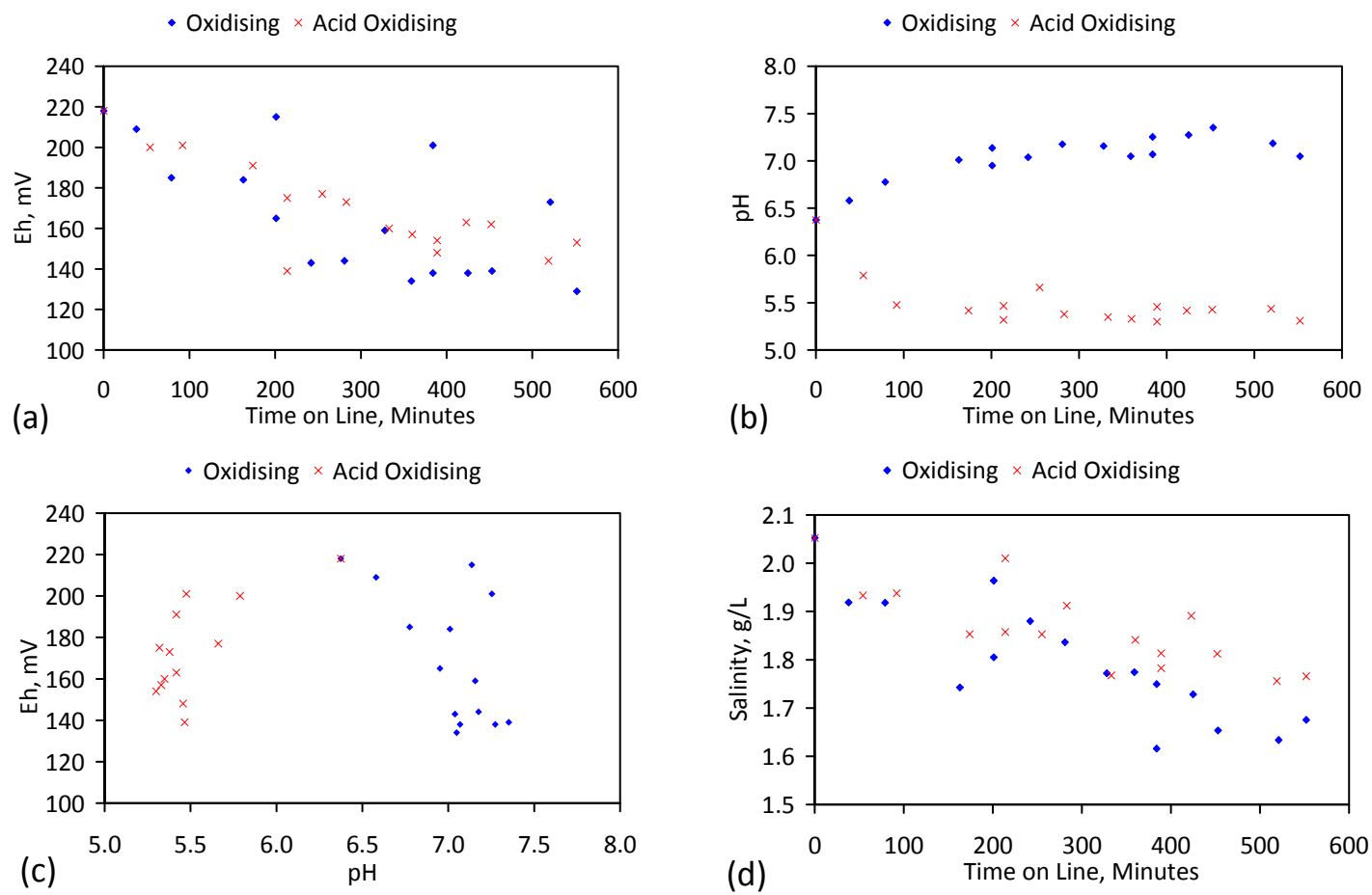

Figure C35. Cont. 


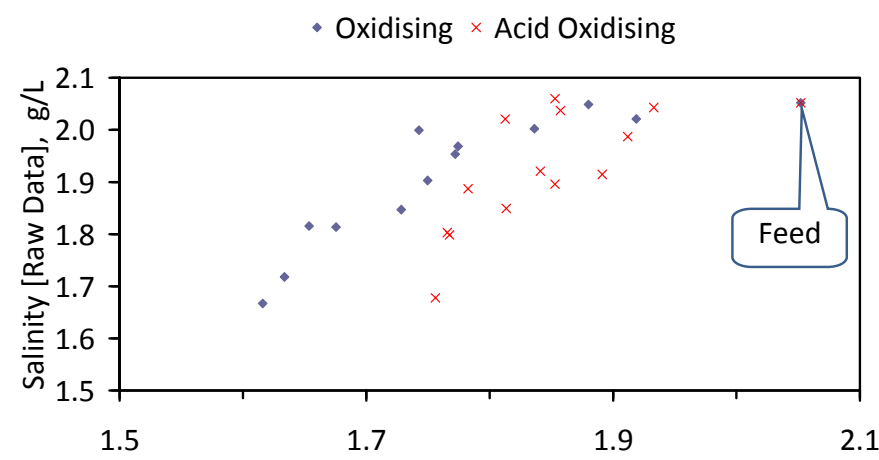

(e) Salinity [Normalised Data], g/L

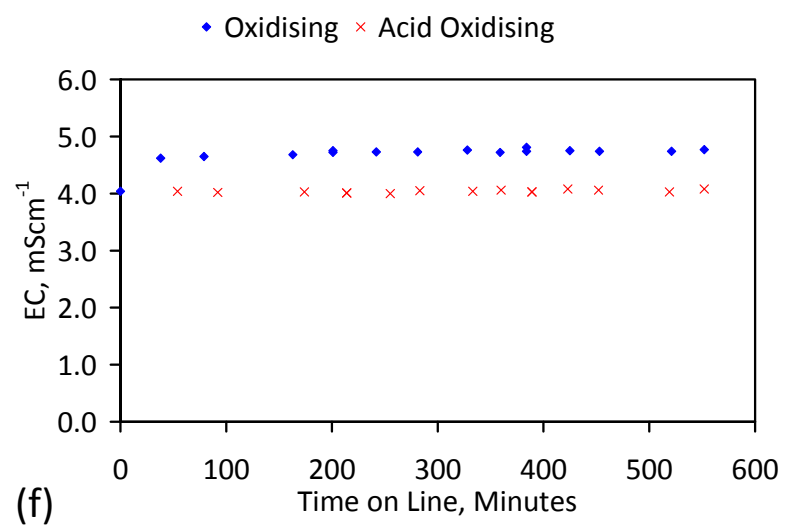

Figure C35. ZVM TPA example Trial E146. 15th Reuse; Operating Temperature: $16-20{ }^{\circ} \mathrm{C}$; Oxidising Environment: Water volume in the reactor $=0.24 \mathrm{~m}^{3}$; ZVM TPA from Trial E145 in a cartridge $=0.4 \mathrm{~kg}$; Air flow $=120 \mathrm{~L} \cdot \mathrm{h}^{-1}$. Acid Oxidising Environment: Water volume in the reactor $=5.4 \mathrm{~L}$; ZVM TPA from Trial E144 in a cartridge $=0.4 \mathrm{~L}$; Gas flow $\left(80 \% \mathrm{~N}_{2}+20 \% \mathrm{CO}_{2}\right)=3.3 \mathrm{~L} \cdot \mathrm{h}^{-1}$. (a) Eh $v s$. time; (b) $\mathrm{pH} v s$. time; (c) $\mathrm{pH} v s$. Eh; (d) Salinity vs. time; (e) Salinity calculated from normalised data $v s$. salinity calculated from raw data. (f) EC vs. time.
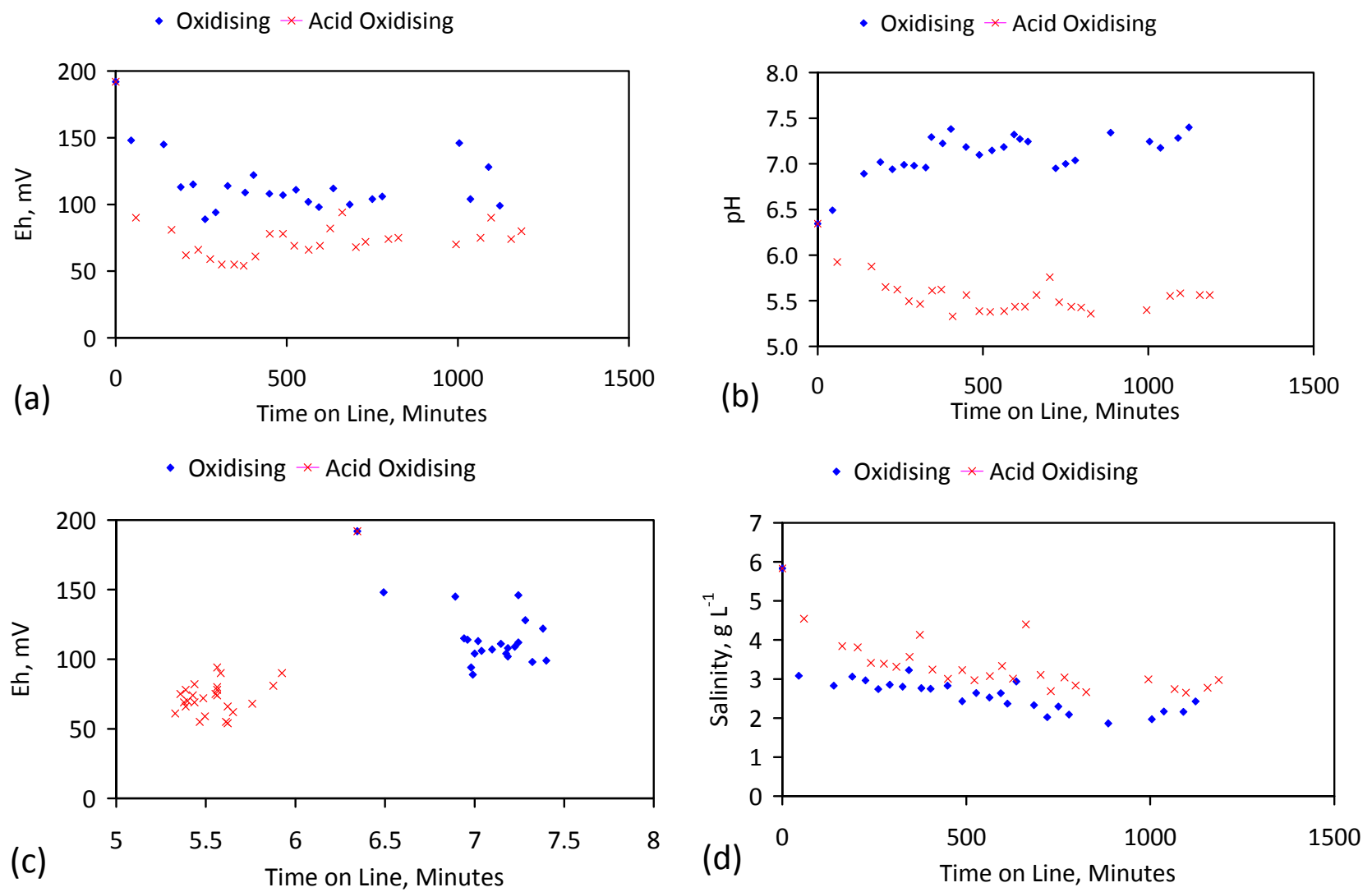

Figure C36. Cont. 

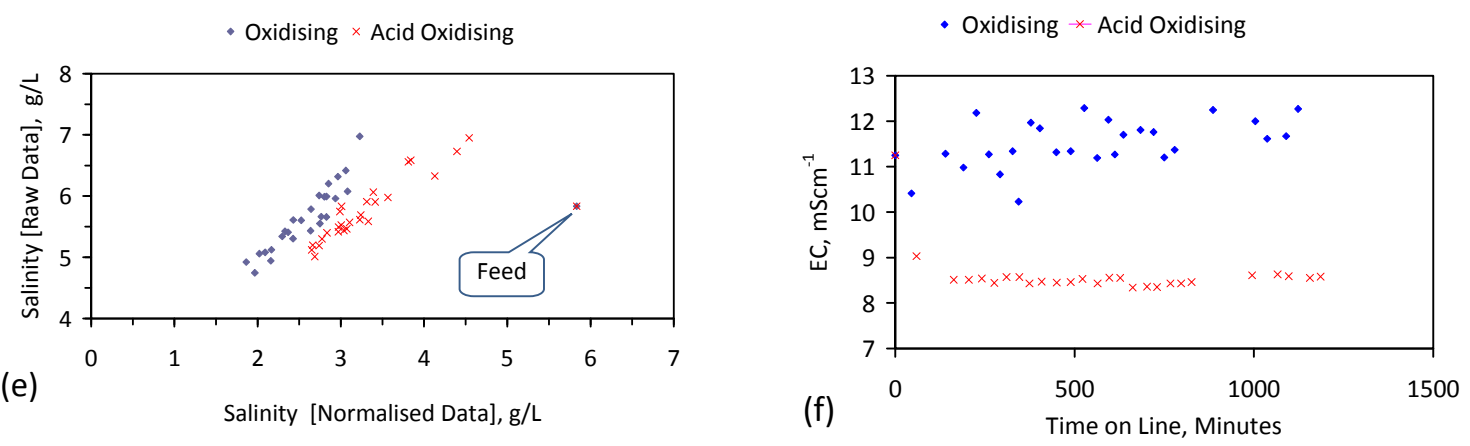

Figure C36. ZVM TPA example Trial E146]. 16th Reuse; Operating Temperature: $13-20{ }^{\circ} \mathrm{C}$; Oxidising Environment: Water volume in the reactor $=0.24 \mathrm{~m}^{3}$; ZVM TPA from Trial E145 in a cartridge $=0.4 \mathrm{~kg}$; Air flow $=120 \mathrm{~L} \cdot \mathrm{h}^{-1}$. Acid Oxidising Environment: Water volume in the reactor $=5.4 \mathrm{~L}$; ZVM TPA from Trial E144 in a cartridge $=0.4 \mathrm{~L}$; Gas flow $\left(80 \% \mathrm{~N}_{2}+20 \% \mathrm{CO}_{2}\right)=3.3 \mathrm{~L} \cdot \mathrm{h}^{-1}$. (a) Eh $v s$. time; (b) $\mathrm{pH} v s$. time; (c) $\mathrm{pH} v s$. Eh; (d) Salinity $v s$. time; (e) Salinity calculated from normalised data $v s$. salinity calculated from raw data; (f) EC vs. time.
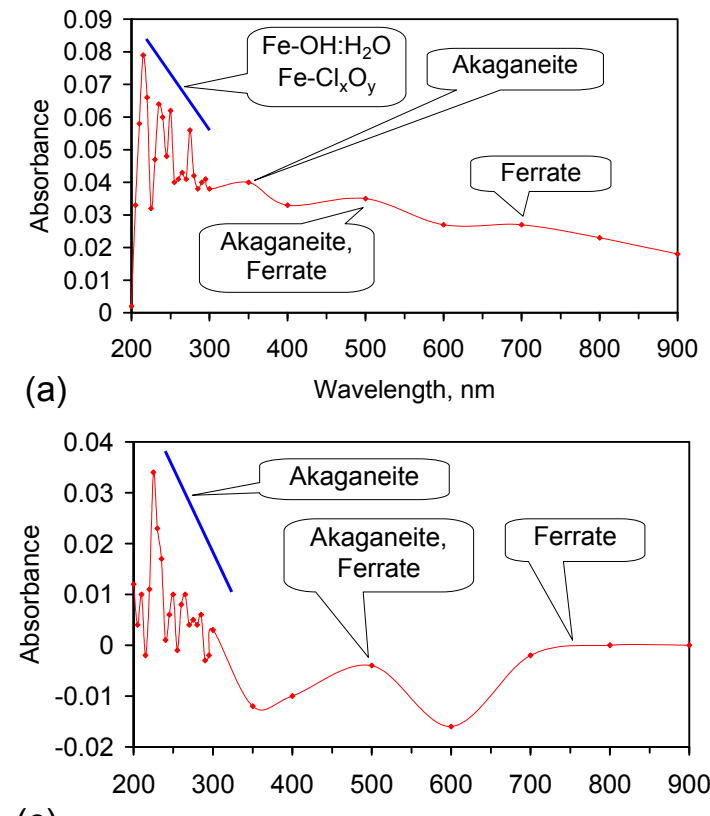

(c)

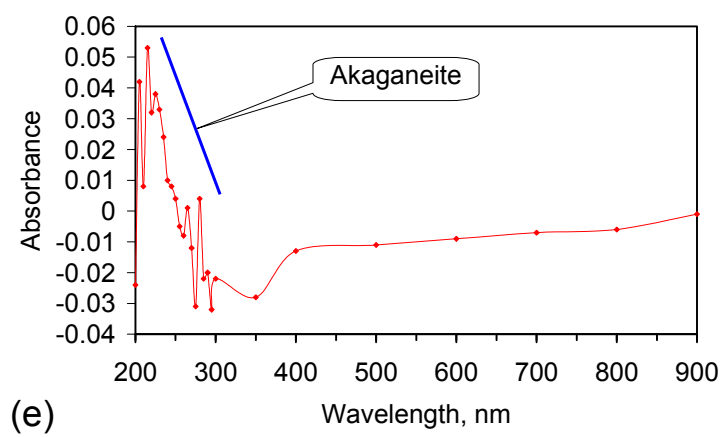

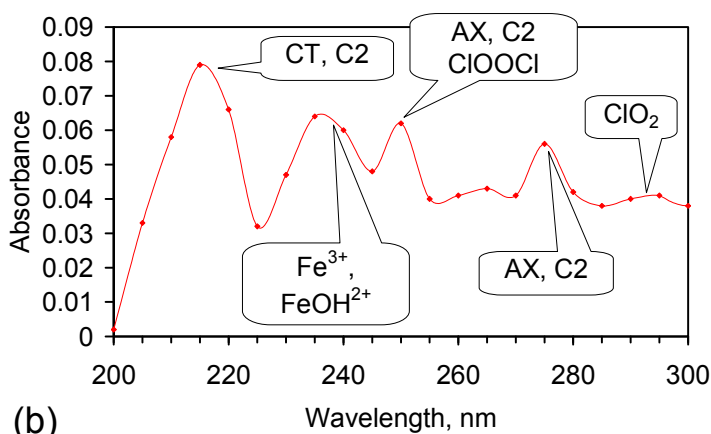

(b)
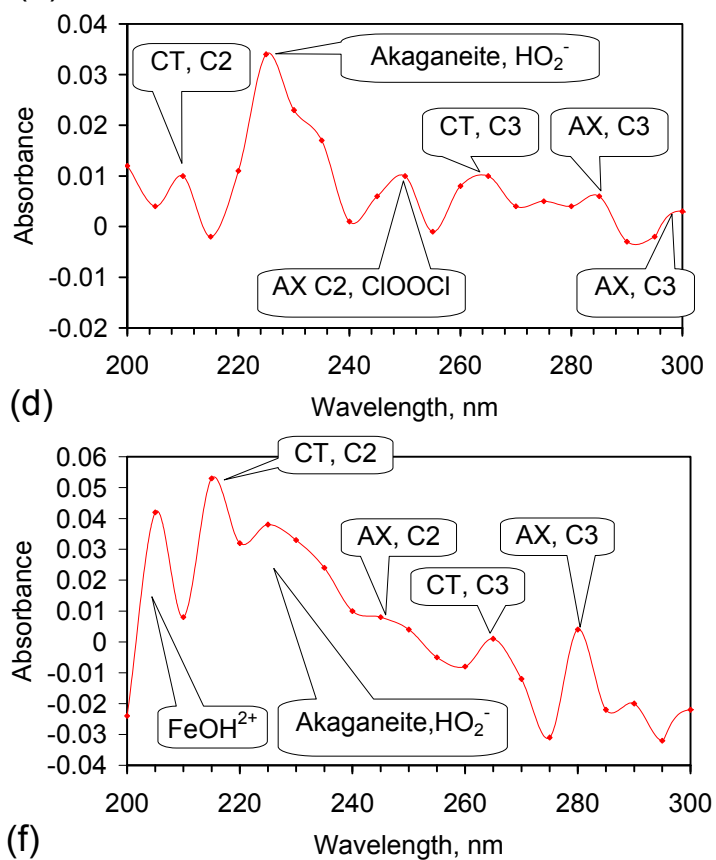

Figure C37. Cont. 


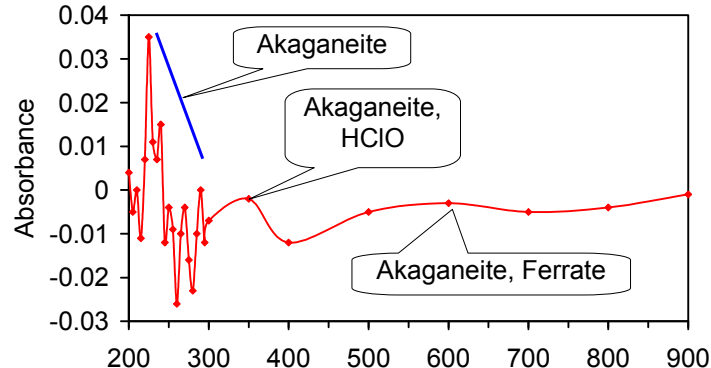

(g)

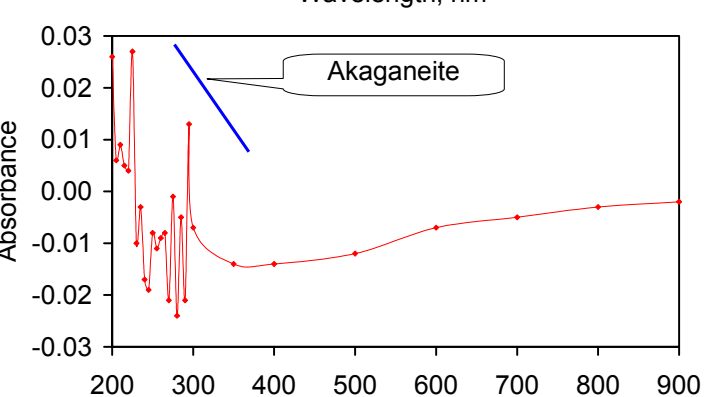

(i)

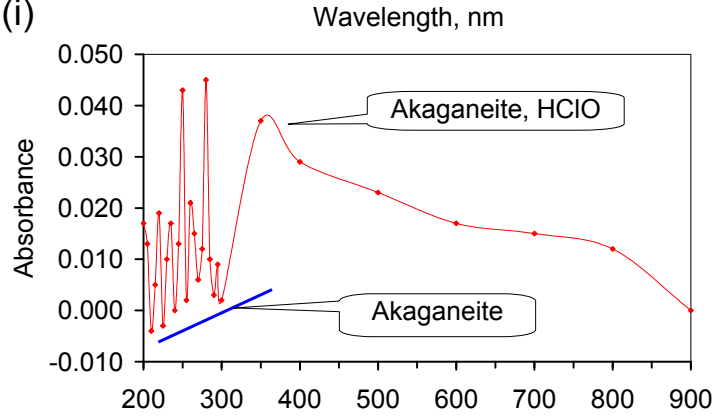

(k)

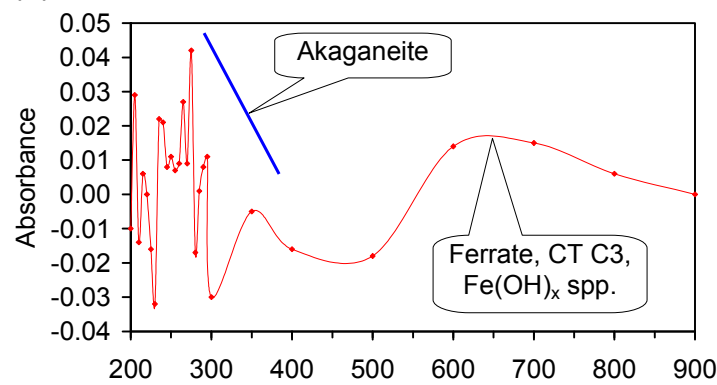

(m)

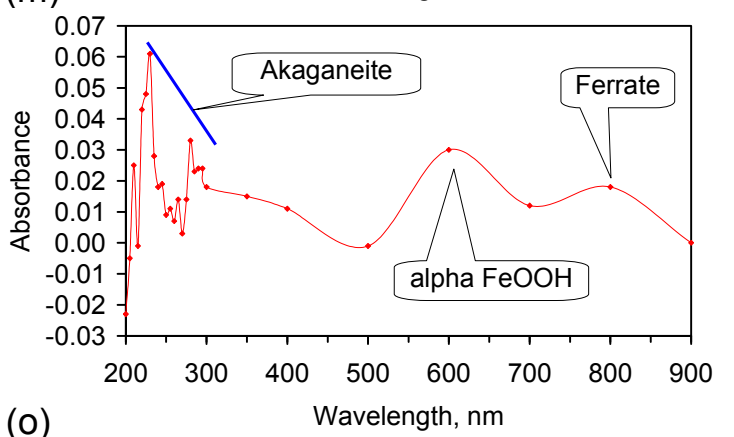

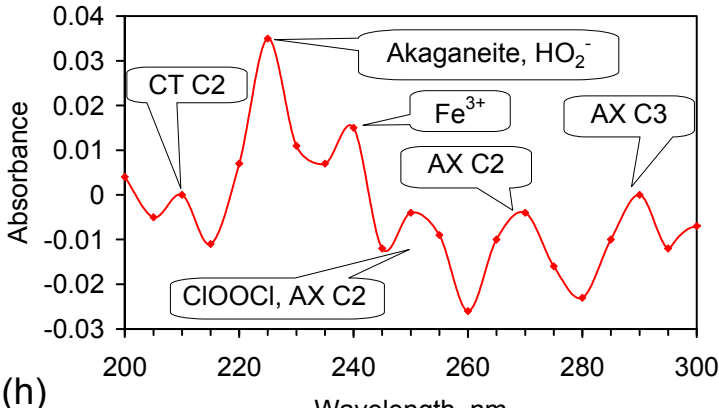

(h)

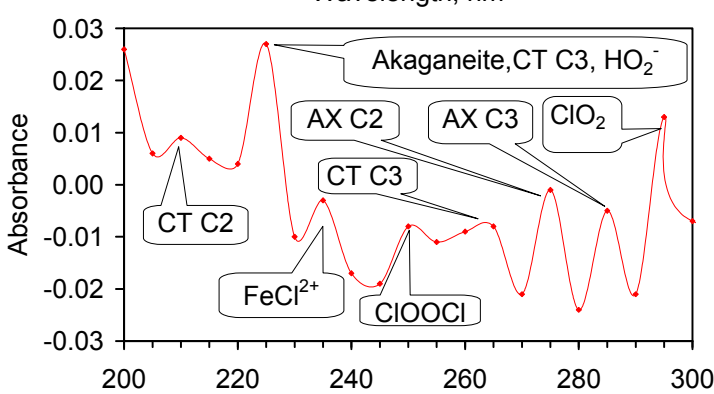

(j)

Wavelength, nm

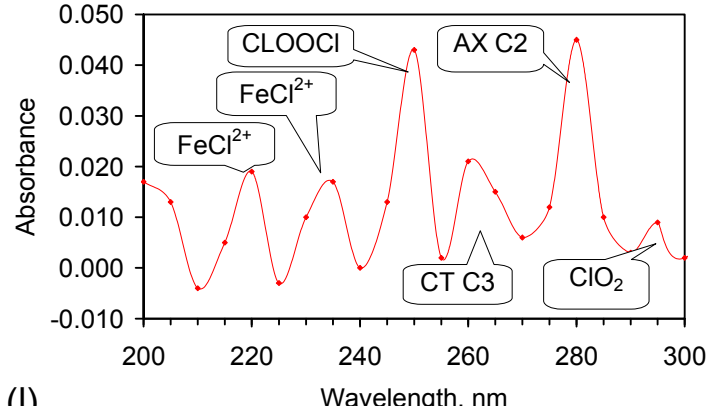

(I)

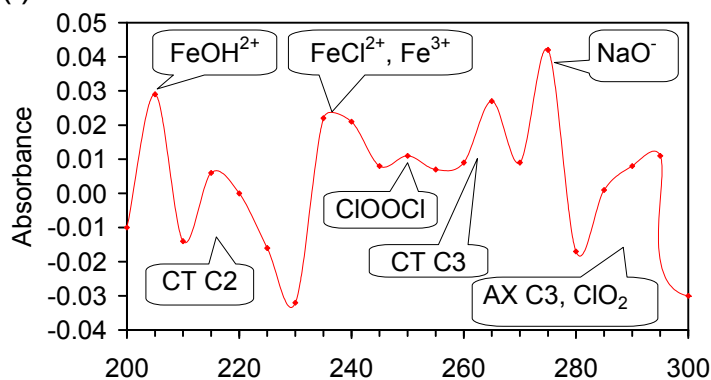

(n)

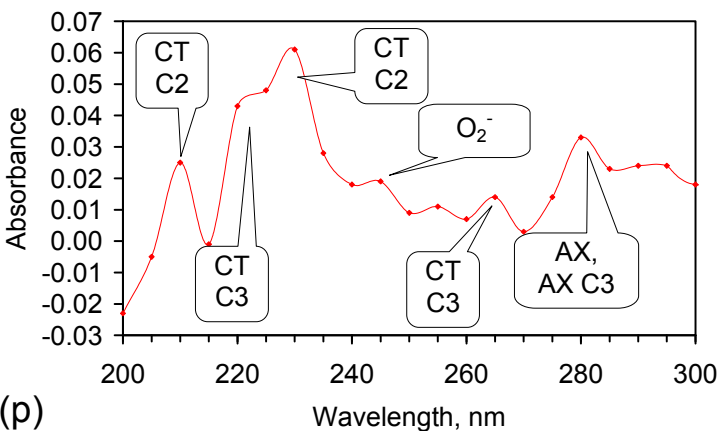

Figure C37. Cont. 

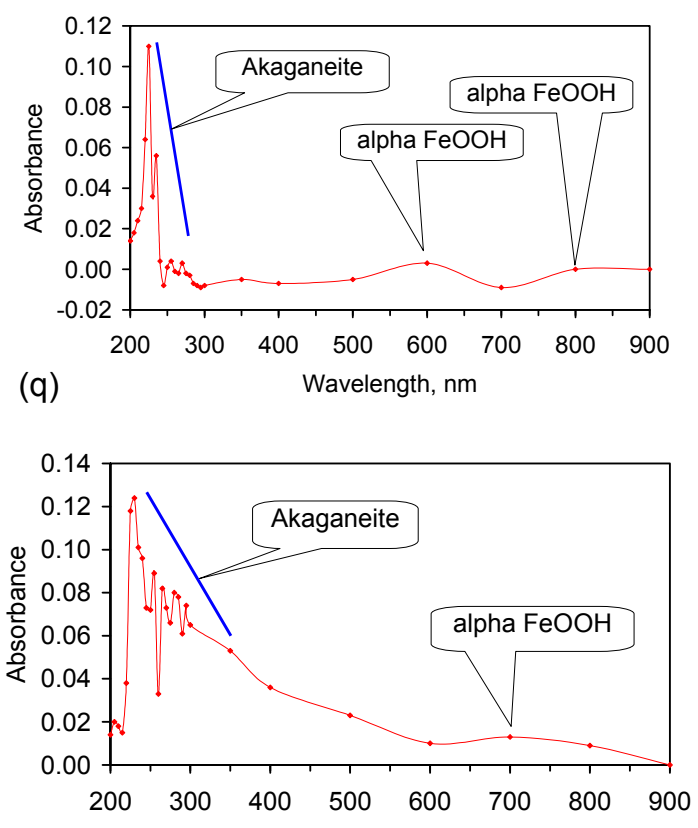

(s)

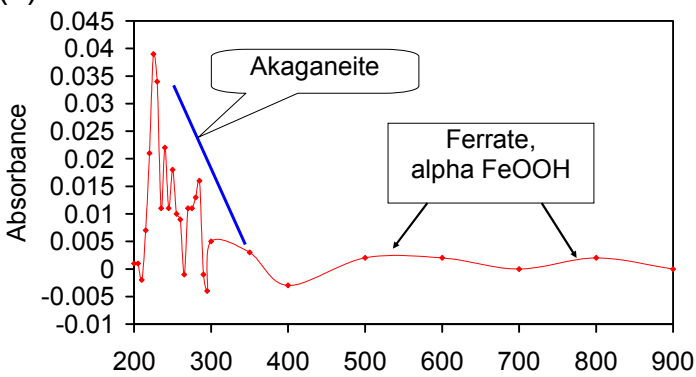

(u)

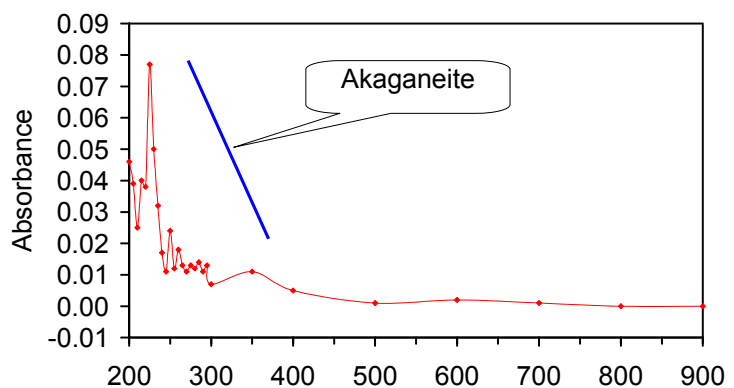

(w)

Wavelength, nm

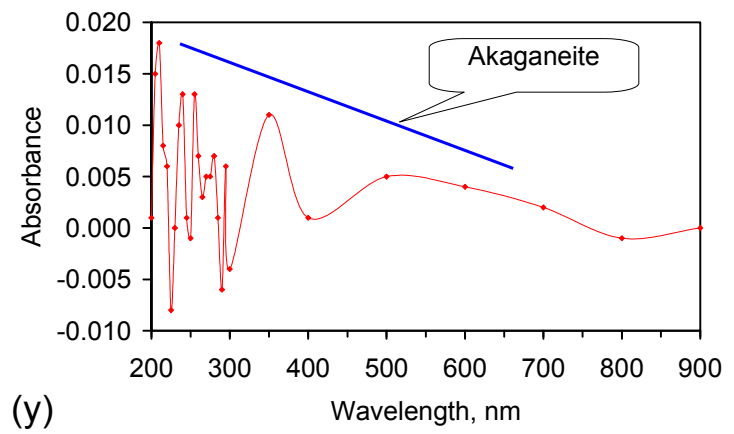

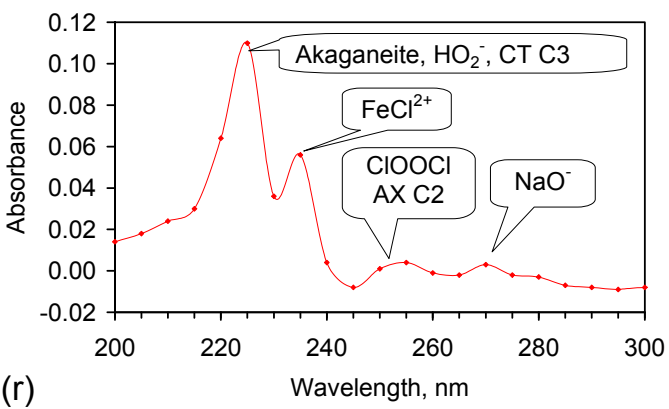

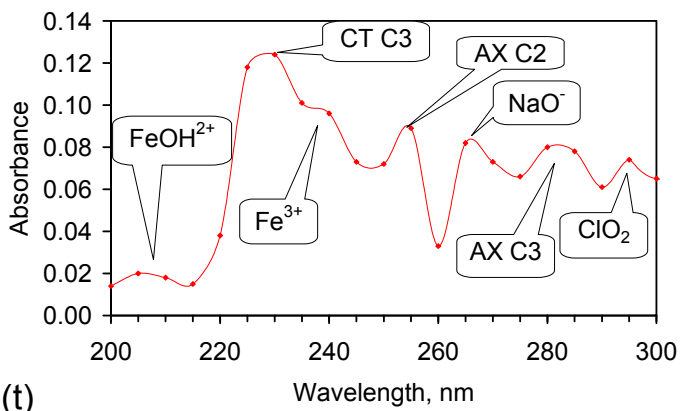

$(\mathrm{t})$

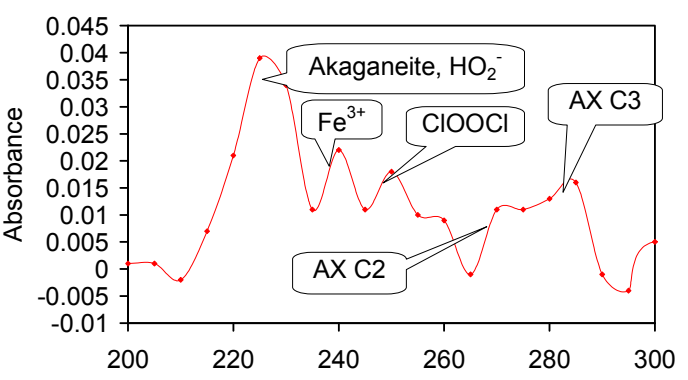

(v)

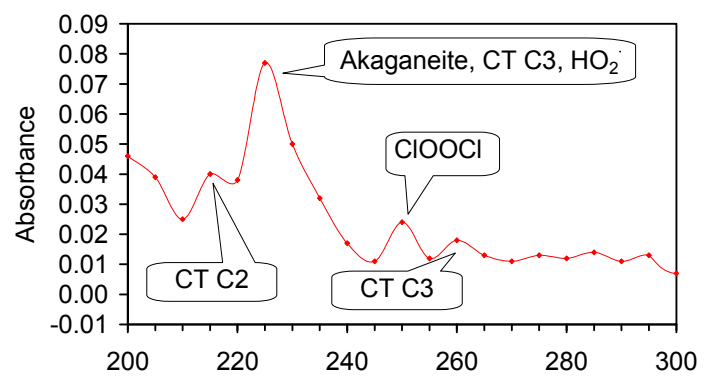

(x)

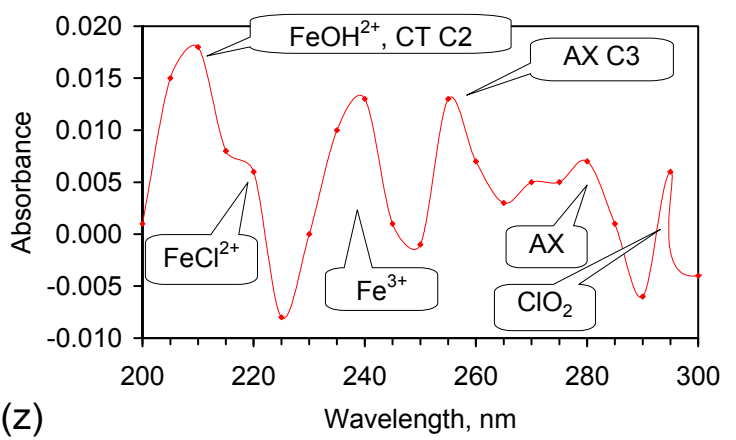

Figure C37. Cont. 

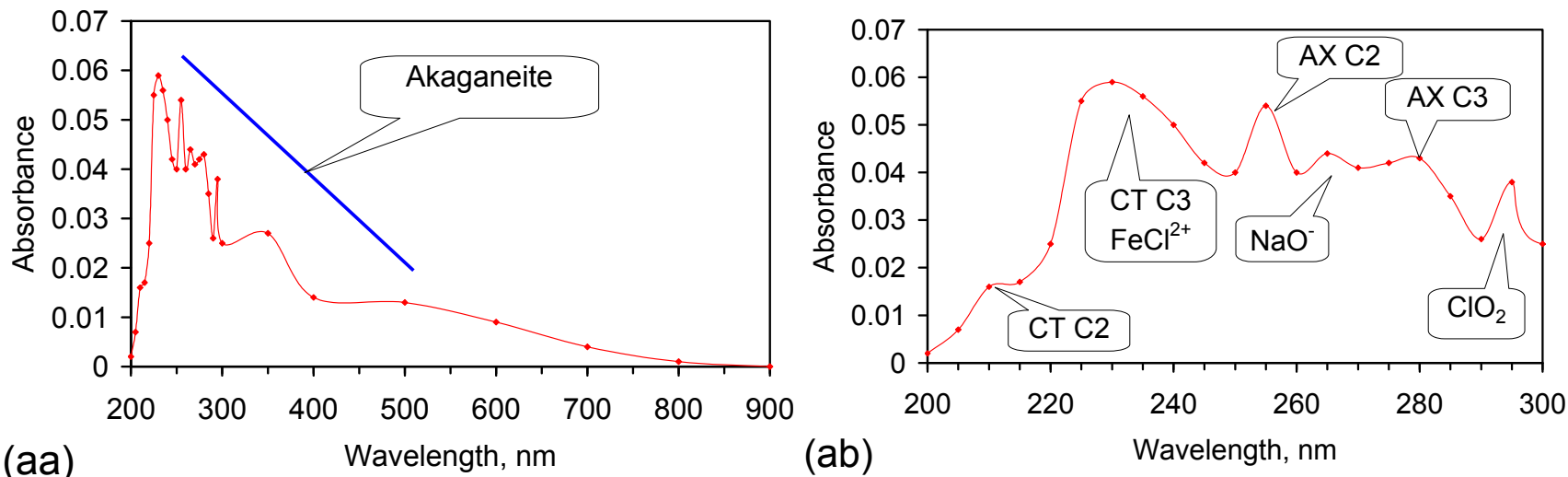

(aa)

(ab)
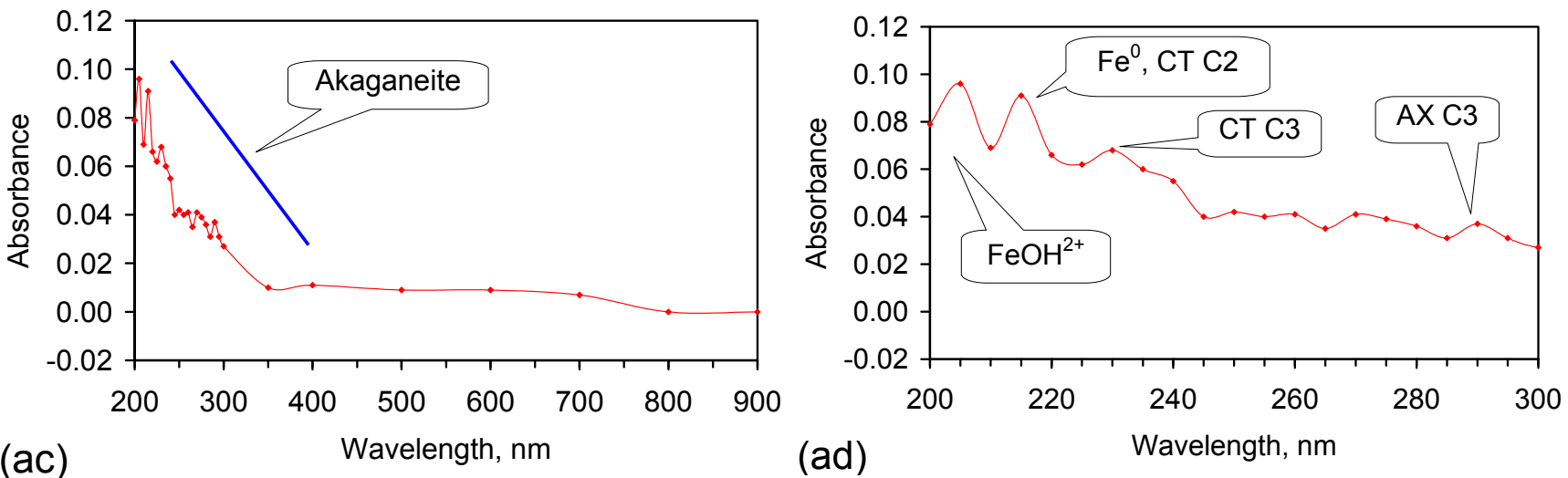

(ac)

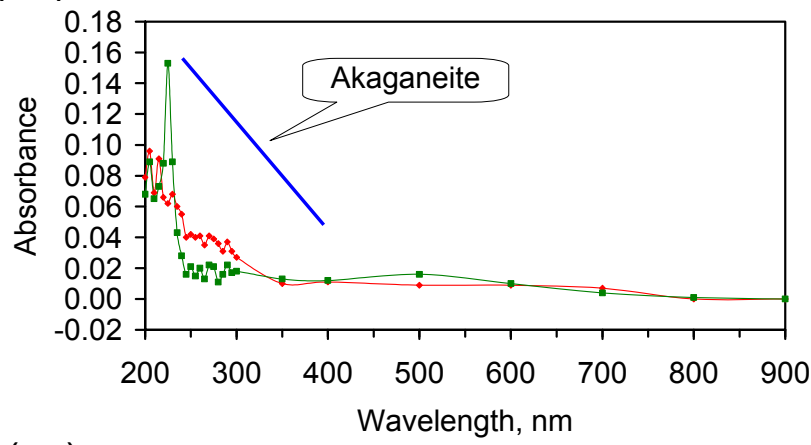

(ae)

- Air - CO2

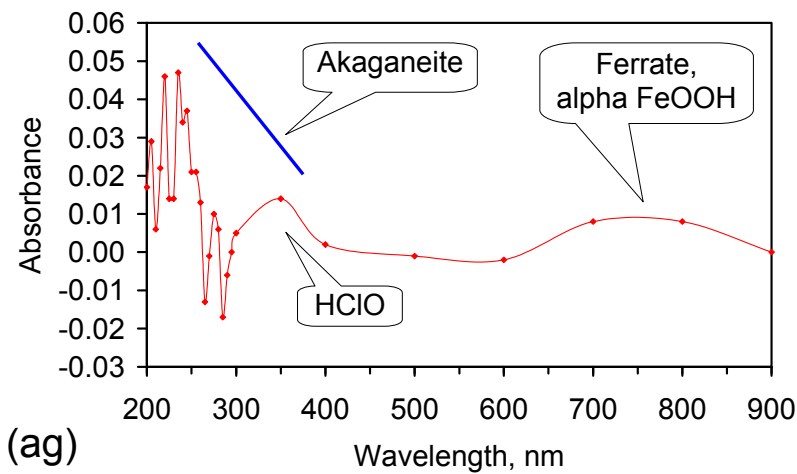

(ad)

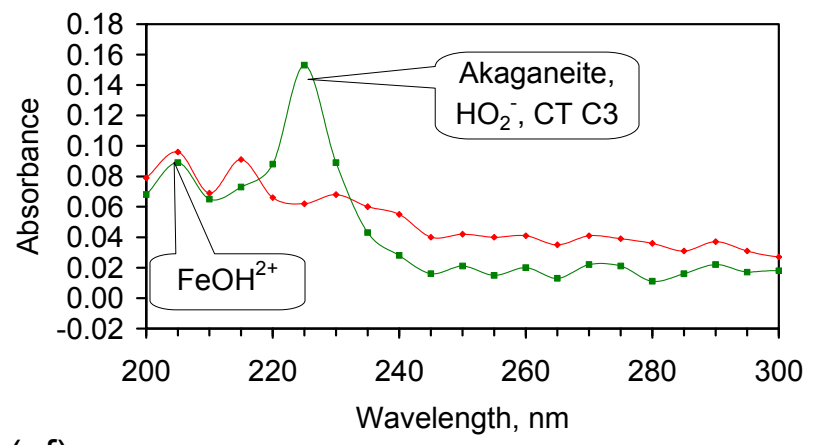

(af)

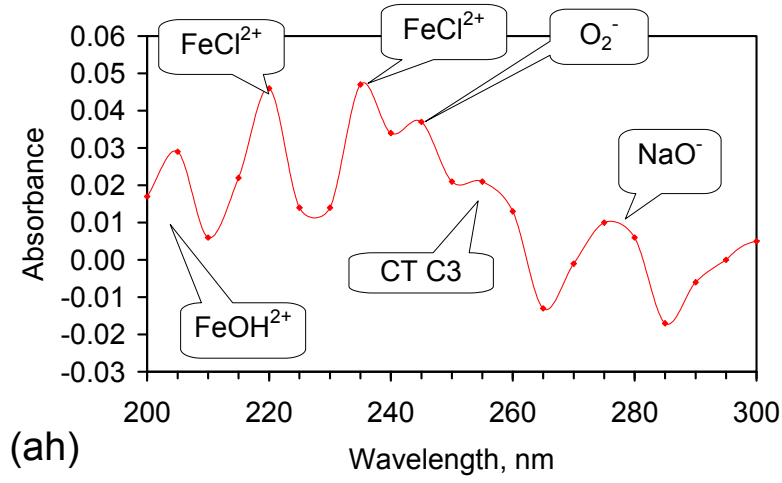

Figure C37. Cont. 

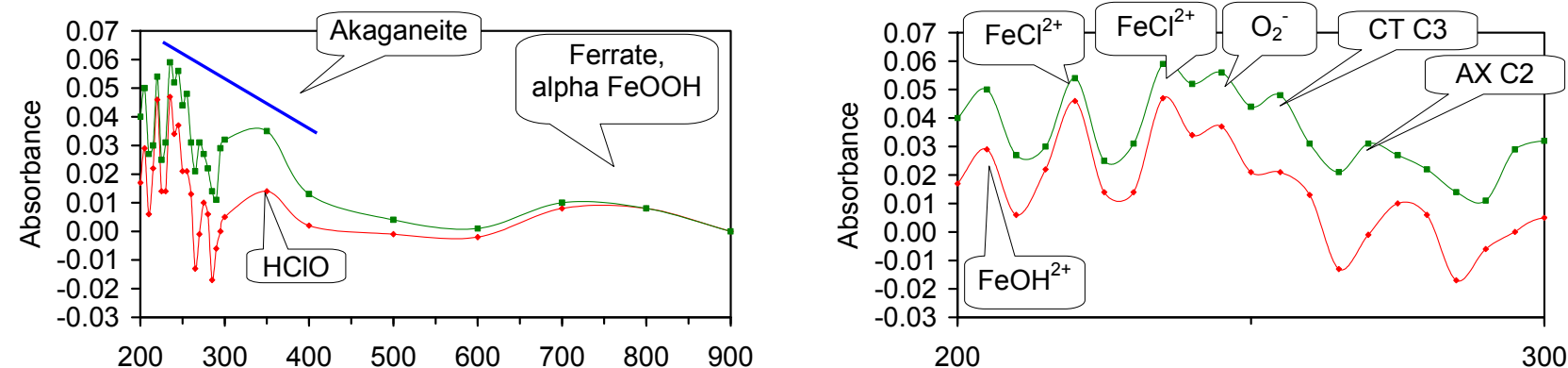

(ai) Wavelength, $\mathrm{nm}$

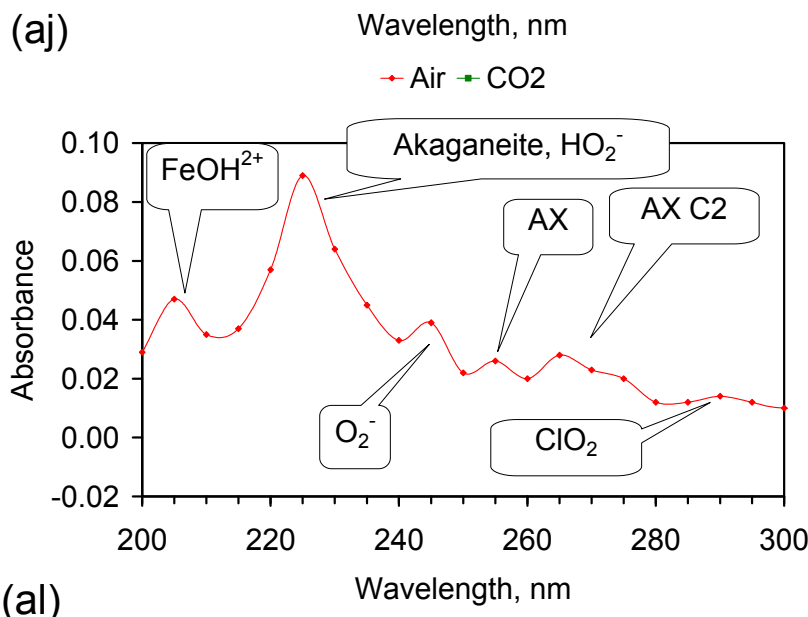

(ak)

$\rightarrow$ Air - $-\mathrm{CO} 2$
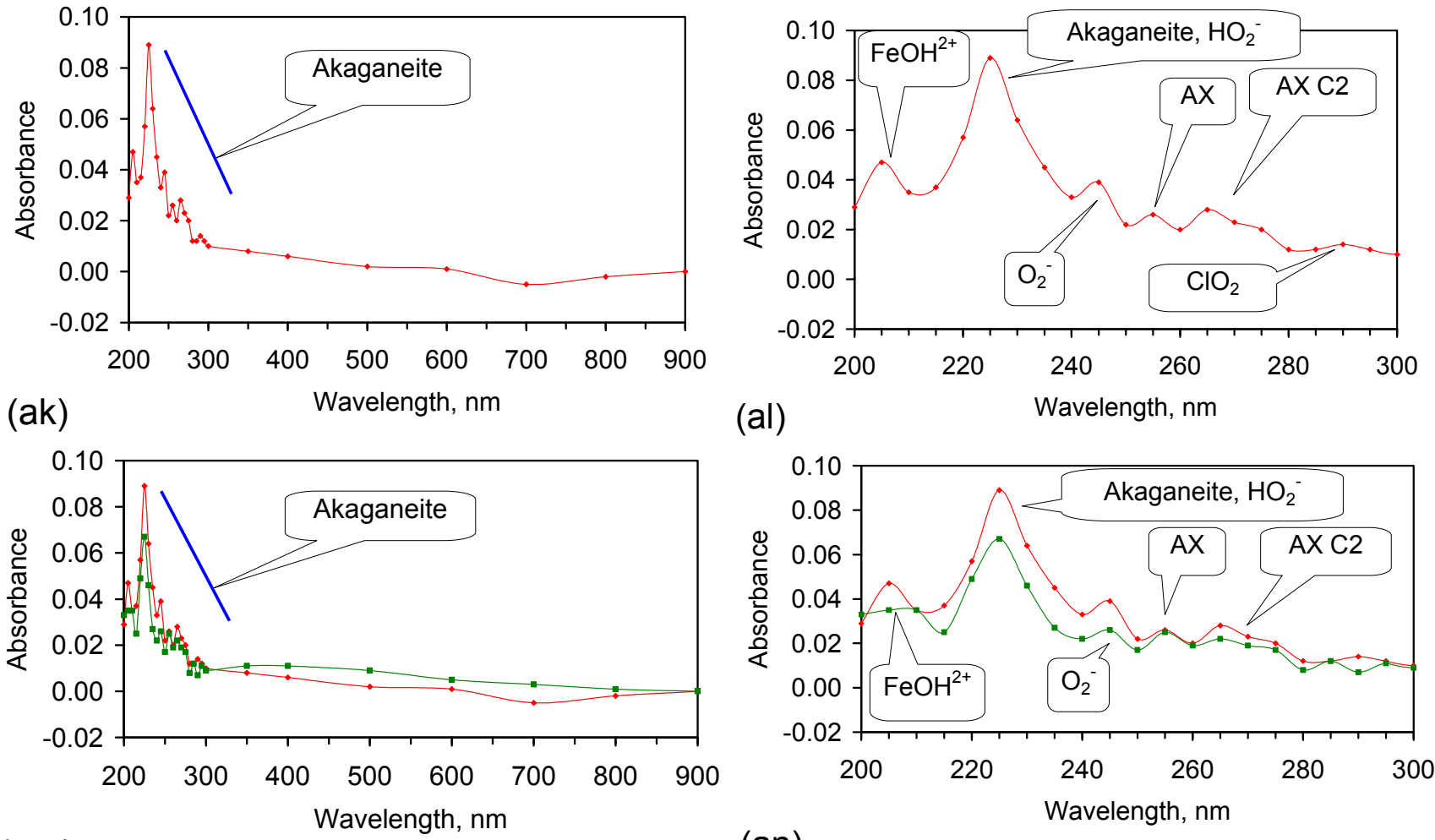

(am)

(an)

- Air - $\mathrm{CO} 2$
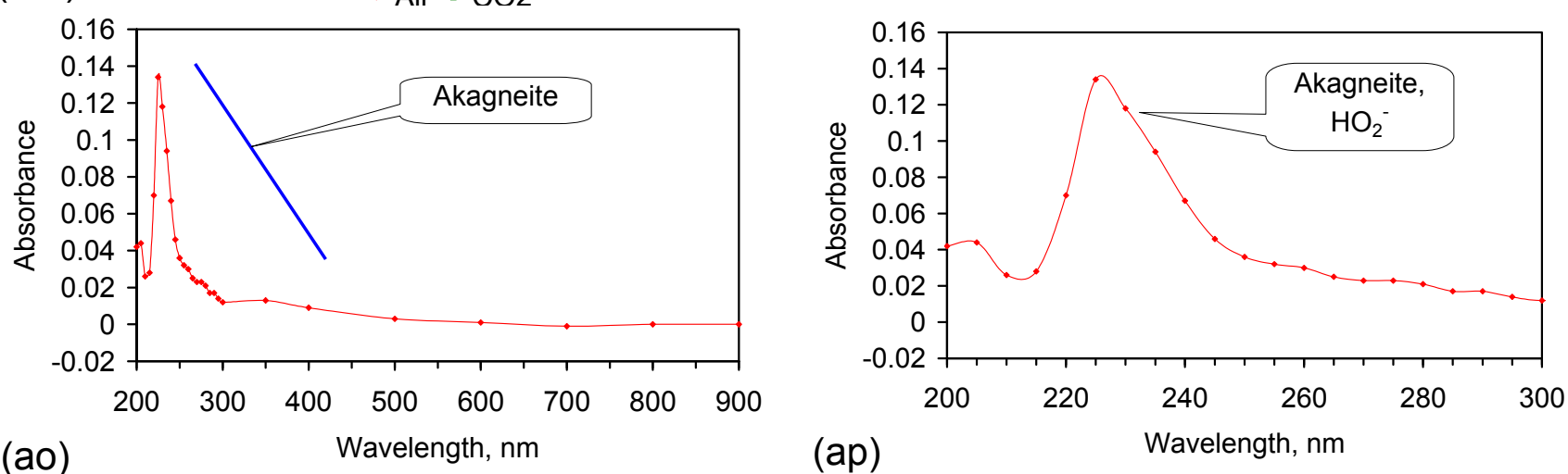

Figure C37. Cont 

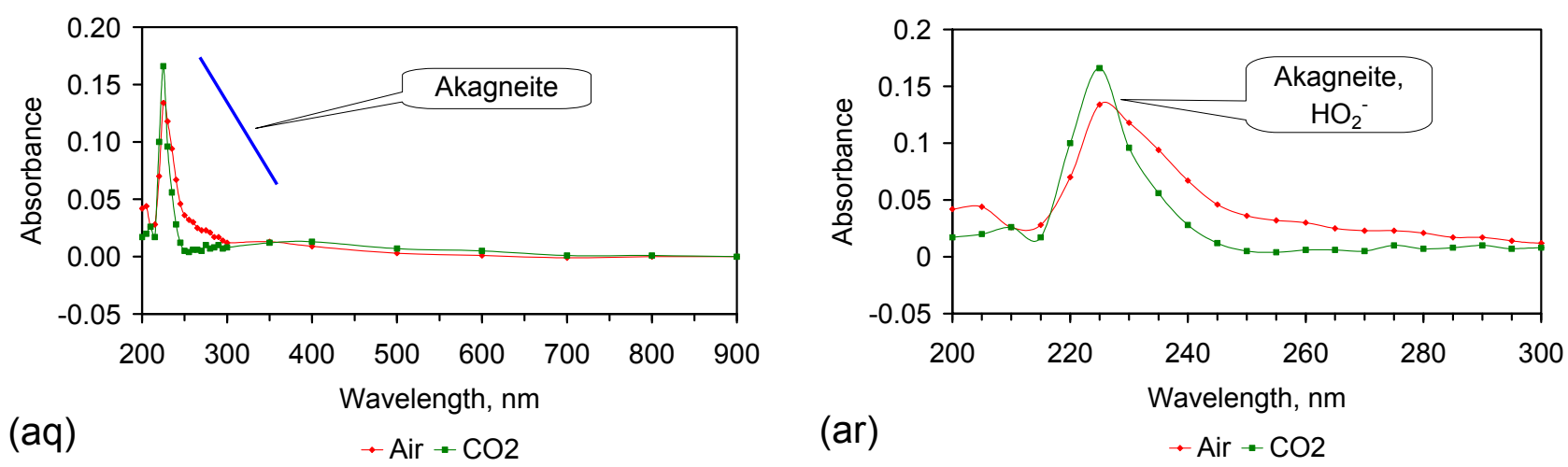

Figure C37. Nano-particle UV-Visible spectrograms: (a) Trial E145, 200-900 nm; (b) Trial E145, 200-300 nm; (c) Trial E146, 200-900 nm; (d) Trial E146, 200-300 nm;

(e) Trial E146, 1st Reuse, 200-900 nm; (f) Trial E146, 1st Reuse, 200-300 nm;

(g) Trial E146, 2nd Reuse, 200-900 nm; (h) Trial E146, 2nd Reuse, 200-300 nm;

(i) Trial E146, 3rd Reuse, 200-900 nm; (j) Trial E146, 3rd Reuse, 200-300 nm;

(k) Trial E146, 4th Reuse, 200-900 nm; (l) Trial E146, 4th Reuse, 200-300 nm;

(m) Trial E146, 5th Reuse, 200-900 nm; (n) Trial E146, 5th Reuse, 200-300 nm;

(o) Trial E146, 6th Reuse, 200-900 nm; (p) Trial E146, 6th Reuse, 200-300 nm;

(q) Trial E146, 7th Reuse, 200-900 nm; (r) Trial E146, 7th Reuse, 200-300 nm;

(s) Trial E146, 8th Reuse, 200-900 nm; (t) Trial E146, 8th Reuse, 200-300 nm;

(u) Trial E146, 9th Reuse, 200-900 nm; (v) Trial E146, 9th Reuse, 200-300 nm;

(w) Trial E146, 10th Reuse, 200-900 nm; (x) Trial E146, 10th Reuse, 200-300 nm;

(y) Trial E146, 11th Reuse, 200-900 nm; (z) Trial E146, 11th Reuse, 200-300 nm; (aa) Trial E146, 12th Reuse, 200-900 nm; (ab) Trial E146, 12th Reuse, 200-300 nm; (ac) Trial E146, 13th Reuse (air feed), 200-900 nm; (ad) Trial E146, 13th Reuse (air feed), 200-300 nm; (ae) Trial E146, 13th Reuse (air and $\mathrm{CO}_{2}$ feed), 200-900 nm; (af) Trial E146, 13th Reuse, (air and $\mathrm{CO}_{2}$ feed), 200-300 nm; (ag) Trial E146, 14th Reuse (air feed), 200-900 nm; (ah) Trial E146, 14th Reuse (air feed), 200-300 nm; (ai) Trial E146, 14th Reuse (air and $\mathrm{CO}_{2}$ feed), 200-900 nm; (aj) Trial E146, 14th Reuse, (air and $\mathrm{CO}_{2}$ feed), 200-300 nm; (ak) Trial E146, 15th Reuse (air feed), 200-900 nm; (al) Trial E146, 15th Reuse (air feed), 200-300 nm; (am) Trial E146, 15th Reuse (air and $\mathrm{CO}_{2}$ feed), 200-900 nm; (an) Trial E146, 15th Reuse, (air and $\mathrm{CO}_{2}$ feed), 200-300 nm; (ao) Trial E146, 16th Reuse (air feed), 200-900 nm; (ap) Trial E146, 16th Reuse (air feed), 200-300 nm; (aq) Trial E146, 16th Reuse (air and $\mathrm{CO}_{2}$ feed), 200-900 nm; (ar) Trial E146, 16th Reuse, (air and $\mathrm{CO}_{2}$ feed), 200-300 nm.

\section{Appendix D. ZVM TP and ZVM TPA Compositions}

This Appendix provides details of the ZVM TP and ZVM TPA compositions used in this study (Tables D1-D3). Details of the ZVM TP control experiment (Figure D1), and details of the salinity decline patterns in ST1a-ST5j (Figures D2-D6). The surface area of the ZVM particles used to construct the ZVM TP and ZVM TPA was $0.017 \mathrm{~m}^{2} \cdot \mathrm{g}^{-1}[6]$. 
Table D1. ZVM TP Manufacturing Processes and Trials; $\mathrm{Cu}$ sheathed pellets are $15 \mathrm{~mm}$ OD. MDPE sheathed pellets are $20 \mathrm{~mm}$ and $25 \mathrm{~mm}$ OD. A (g) indicates that the trial group was manufactured in a gaseous environment. All other trial groups were manufactured in an aqueous environment. Trial Group 9 (PS14) was constructed from fine steel wool.

\begin{tabular}{|c|c|c|c|c|}
\hline $\begin{array}{l}\text { Trial } \\
\text { Group }\end{array}$ & $\begin{array}{c}\text { Manufacturing } \\
\text { Process Type }\end{array}$ & ZVM TP Usage & Trials & Trial Results \\
\hline 1 & $\mathrm{~B}$ & Particles & PS1-PS4, PS16 & Table 1, Tables C1-C4; Figure C1 \\
\hline 2 & $\mathrm{~A}$ & Particles & PS5, PS15 & Table 1, Tables C1-C4; Figure C2 \\
\hline 3 & $\mathrm{C}$ & Particles & PS8 & Figure $\mathrm{C} 2$ \\
\hline 4 & $\mathrm{C}$ & Particles & PS9 & Figure $\mathrm{C} 2$ \\
\hline 5 & $\mathrm{C}$ & Particles & PS10 & Figure $\mathrm{C} 2$ \\
\hline 6 & $\mathrm{D}$ & Particles & PS11 & Table 1, Tables C1-C4; Figure C3 \\
\hline 7 & $\mathrm{D}$ & Particles & PS12 & Figure C3 \\
\hline 8 & $\mathrm{D}$ & Particles & PS13 & Figure C3 \\
\hline 9 & $A(g)$ & $\mathrm{Cu}$ sheathed pellets & PS14 & Table 1, Tables C1-C4; Figure C3 \\
\hline 10 & $\mathrm{D}$ & Container & CSD1a-CSD1d & Table 5 \\
\hline 11 & B & $\mathrm{Cu}$ sheathed pellets & $\begin{array}{c}\text { AS4-AS6, ST1a-ST5j, } \\
\text { ST6a-ST6d }\end{array}$ & $\begin{array}{l}\text { Table 1, Tables } \mathrm{C} 1-\mathrm{C} 4 ; \\
\text { Figures } \mathrm{C} 4-\mathrm{C} 10\end{array}$ \\
\hline 12 & A & $\mathrm{Cu}$ sheathed pellets & AS1-AS3 & Figure $\mathrm{C} 11$ \\
\hline 13 & $\mathrm{C}$ & $\mathrm{Cu}$ sheathed pellets & ST8a & Figure $\mathrm{C} 12$ \\
\hline 14 & $\mathrm{C}$ & $\begin{array}{c}\text { MDPE } \\
\text { sheathed pellets }\end{array}$ & ST8b-ST8e & Table 1, Tables C1-C4; Figure C12 \\
\hline 15 & $\mathrm{C}$ & $\begin{array}{c}\text { MDPE } \\
\text { sheathed pellets }\end{array}$ & MT1a-MT1d & Table 1, Tables C1-C4; Figure C13 \\
\hline 16 & $\mathrm{C}$ & $\begin{array}{c}\text { MDPE } \\
\text { sheathed pellets }\end{array}$ & MT2a-MT2d & Table 1, Tables C1-C4; Figure C14 \\
\hline 17 & $\mathrm{D}$ & $\begin{array}{c}\text { MDPE } \\
\text { sheathed pellets }\end{array}$ & MT3a-MT3d & Table 1, Tables C1-C4; Figure C15 \\
\hline 18 & $\mathrm{D}$ & $\begin{array}{c}\text { MDPE } \\
\text { sheathed pellets }\end{array}$ & MT4a-MT4d & Table 1, Tables C1-C4; Figure C16 \\
\hline 19 & B & $\begin{array}{c}\text { Reused } \mathrm{Cu} \\
\text { sheathed pellets }\end{array}$ & $\begin{array}{c}\text { ST7a (originally used as } \\
\text { ST2d); ST7b (originally used } \\
\text { as ST2g); ST7c (originally } \\
\text { used as ST3d); ST7d } \\
\text { (originally used as ST2f); } \\
\text { ST7e (originally used as } \\
\text { ST3b); ST7f (originally used } \\
\text { as ST3f); }\end{array}$ & Figure $\mathrm{C} 17$ \\
\hline
\end{tabular}


Table D2. ZVM molar compositional ratios used to manufacture ZVM TP. Data in Table 1 from PS7 refer to $50 \mathrm{~nm} \mathrm{Fe}{ }^{0}$ (Nanofer Star), $a_{\mathrm{s}}=20 \mathrm{~m}^{2} \cdot \mathrm{g}^{-1}$ [28] (Manufacturing Process Type C; 1 Mole $n-\mathrm{Fe}^{0}+2.14$ Moles $\mathrm{Al}^{0}+0.85$ Moles $\mathrm{Cu}^{0}$ ). The Nanofer Star was obtained from Nano Iron s.r.o., Stetanikova 116, Rajhrad, 66461 Czech Republic.

\begin{tabular}{ccccccccccc}
\hline $\begin{array}{c}\text { Trial } \\
\text { Group }\end{array}$ & $\mathbf{F e}$ & $\mathbf{A l}$ & $\mathbf{C u}$ & $\mathrm{MnO}_{2}$ & $\mathbf{Z n O}$ & $\mathrm{CaCO}_{3}$ & $\mathrm{MgCO}_{3}$ & $\mathrm{~K}_{2} \mathrm{CO}_{3}$ & $\mathbf{C}$ & $\mathbf{C a O}$ \\
\hline 1 & 1 & 0.3950 & 0.040 & 0.006 & - & - & - & - & - & - \\
2 & 1 & 1.4200 & 0.162 & - & - & - & - & - & - & - \\
3 & 1 & 0.1100 & - & - & 0.110 & - & - & - & - & - \\
4 & 1 & 0.1580 & 0.006 & - & - & 0.0900 & 0.060 & 0.017 & 0.16 & - \\
5 & 1 & 0.5200 & 0.019 & - & - & - & - & - & - & - \\
6 & 1 & - & - & - & 0.056 & 0.2086 & 0.152 & - & - & - \\
7 & 1 & 0.8400 & 0.090 & - & 0.068 & 0.0640 & 0.090 & - & - & - \\
8 & 1 & 0.9700 & 0.040 & - & - & 0.0530 & 0.090 & - & - & 0.07 \\
9 & 1 & - & - & - & - & - & - & - & - & - \\
10 & 1 & 0.3200 & - & - & - & - & - & - & - & - \\
11,19 & 1 & 0.3950 & 0.040 & 0.006 & - & - & - & - & - & - \\
12 & 1 & 1.4200 & 0.162 & - & - & - & - & - & - & - \\
13 & 1 & 0.1100 & - & - & 0.110 & - & - & - & - & - \\
14 & 1 & 0.1100 & - & - & 0.110 & - & - & - & - & - \\
15 & 1 & 0.1580 & 0.006 & - & - & 0.0900 & 0.060 & 0.017 & 0.16 & - \\
16 & 1 & 0.5200 & 0.019 & - & - & - & - & - & - & - \\
17 & 1 & 0.8100 & 0.080 & 0.100 & 0.070 & 0.1500 & 0.100 & - & 0.06 & - \\
18 & 1 & 0.8200 & 0.040 & - & - & 0.1100 & 0.080 & - & 0.14 & - \\
\hline
\end{tabular}

Table D3. ZVM molar compositional ratios used to manufacture ZVM TPA. K-Feldspar $\left(11.3 \% \mathrm{~K}_{2} \mathrm{O}+3.2 \% \mathrm{NaO}+18.5 \% \mathrm{Al}_{2} \mathrm{O}+65.8 \% \mathrm{SiO}_{2}\right)$; Manufacturing Process Type $\mathrm{E}=$ dry mixing in air. $\mathrm{Al}=5 \mathrm{~mm}$ punchings.

\begin{tabular}{|c|c|c|c|c|c|c|c|c|}
\hline $\begin{array}{l}\text { Trial } \\
\text { Group }\end{array}$ & $\begin{array}{c}\text { Manufacturing } \\
\text { Process Type }\end{array}$ & $\begin{array}{c}\text { ZVM TP } \\
\text { Usage }\end{array}$ & Trials & Trial Results & $\begin{array}{c}\text { Cartridge } \\
\text { Size, L } \\
\end{array}$ & $\mathrm{Fe}, \mathrm{g}$ & $\begin{array}{c}\text { K-Feldspar, } \\
\text { g } \\
\end{array}$ & $\mathbf{A l}, \mathbf{g}$ \\
\hline 20 & E & Cartridge & E143a-E143k & Tables C5-C8 & 0.4 & 135 & 97 & - \\
\hline 21 & $\mathrm{E}$ & Cartridge & E144a-E144f & Tables C9-C12 & 0.4 & 51 & 90 & 38 \\
\hline 22 & $\mathrm{E}$ & Cartridge & E145 & Figure $\mathrm{C} 18$ & 2.0 & 449 & 1000 & - \\
\hline 23 & $\mathrm{E}$ & Cartridge & E146a-E146p & $\begin{array}{c}\text { Table C13, } \\
\text { Figures C19-C37 }\end{array}$ & 0.4 & 124 & 276 & - \\
\hline
\end{tabular}

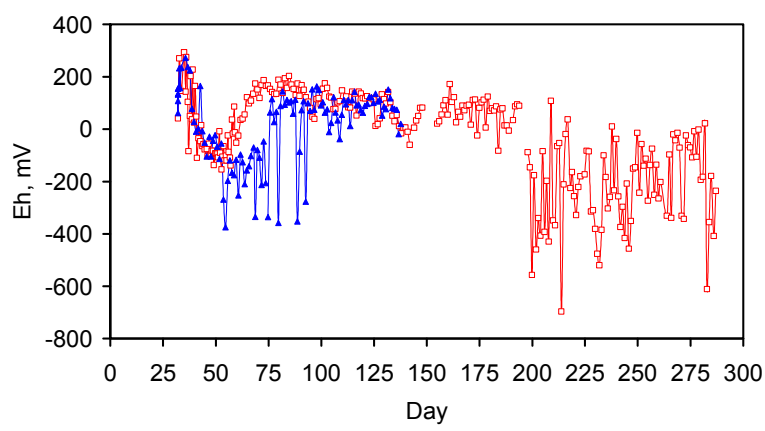

(a) $\rightarrow$ PS1 + PS1C

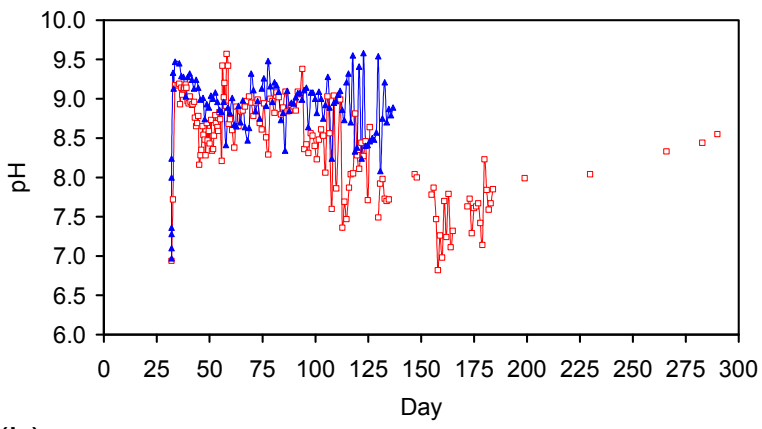

(b)

Figure D1. Cont. 


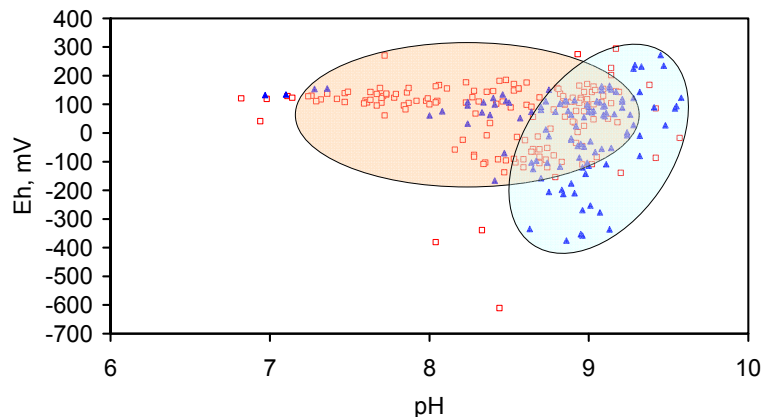

(c)

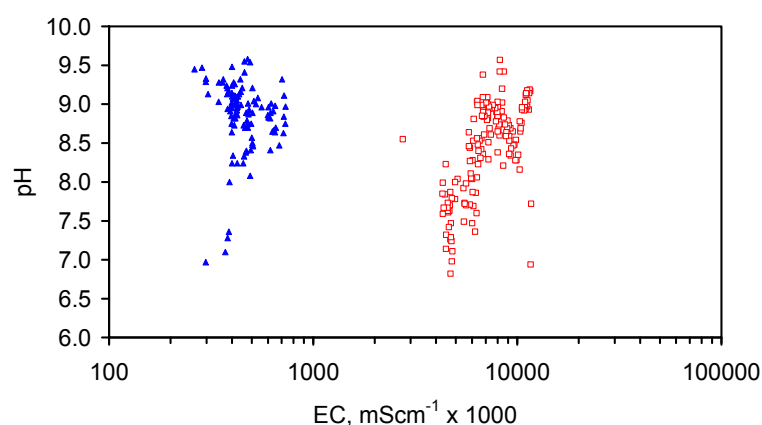

(e)

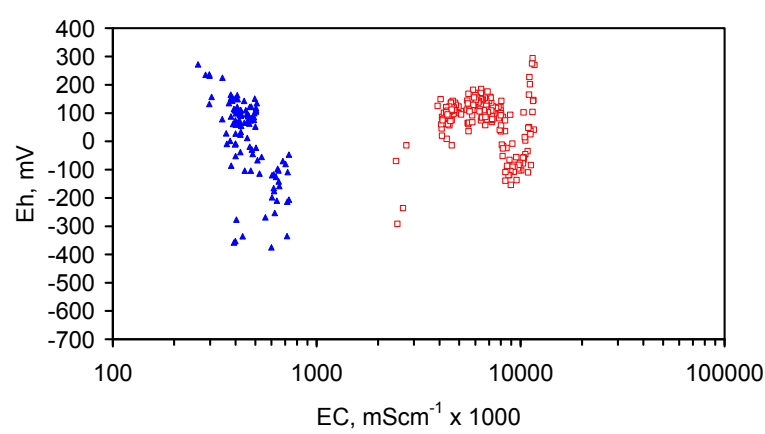

(d)

-PS1 A PS1C

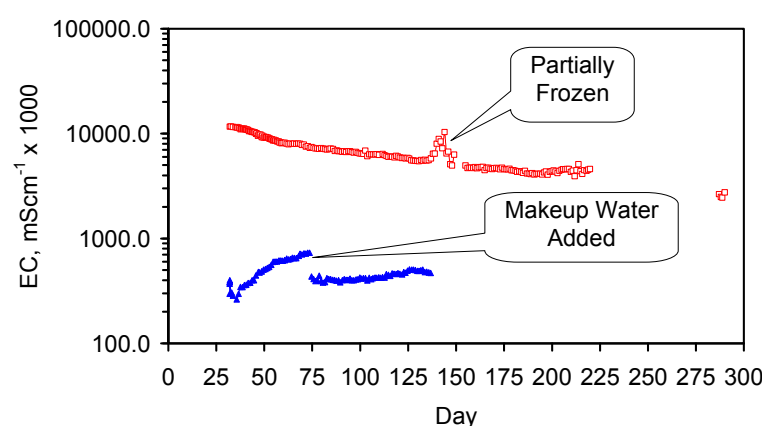

(f)

$\rightarrow \mathrm{PS} 1+\mathrm{PS} 1 \mathrm{C}$

Figure D1. (a) Eh vs. day; (b) $\mathrm{pH}$ vs. day; (c) $\mathrm{pH}$ vs. EC; (d) Eh vs. EC; (e) $\mathrm{pH}$ vs. EC; (f) $\mathrm{EC} v s$. day. ZVM TP $=$ particulate material placed in water at a concentration of PS1 $=30 \mathrm{~g} \cdot \mathrm{L}^{-1}$; PS1C $=20 \mathrm{~g} \cdot \mathrm{L}^{-1}$. Reactor Size: $0.3 \mathrm{~L}$; Feed Water volume: $0.2 \mathrm{~L}$.

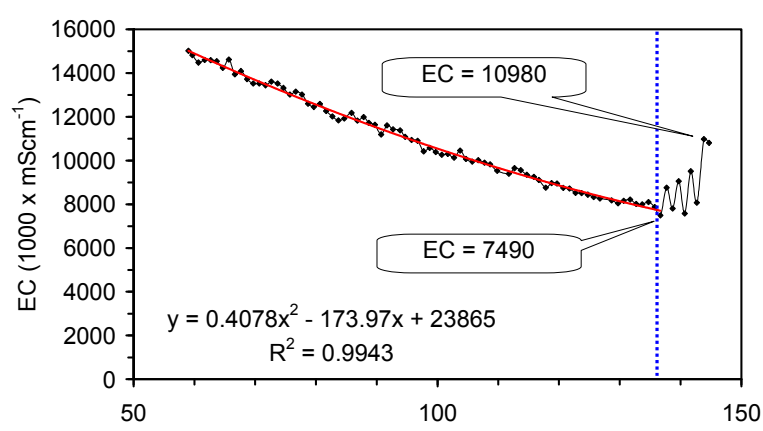

(a)

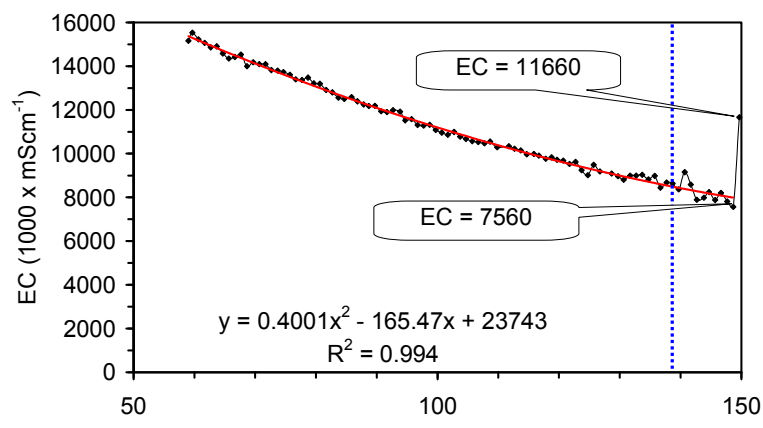

(c)

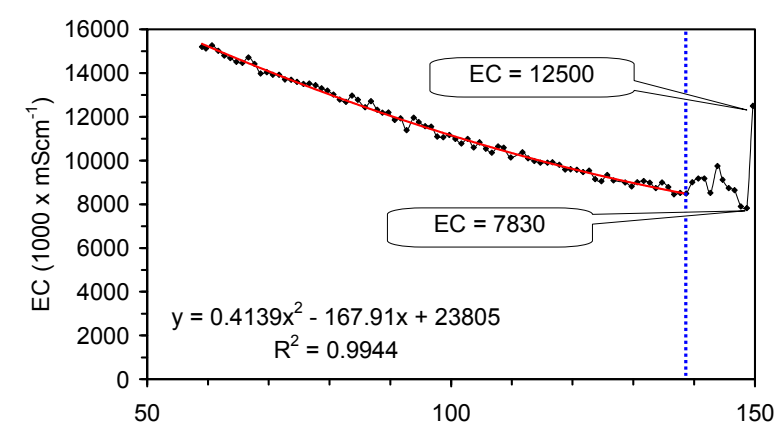

(b)

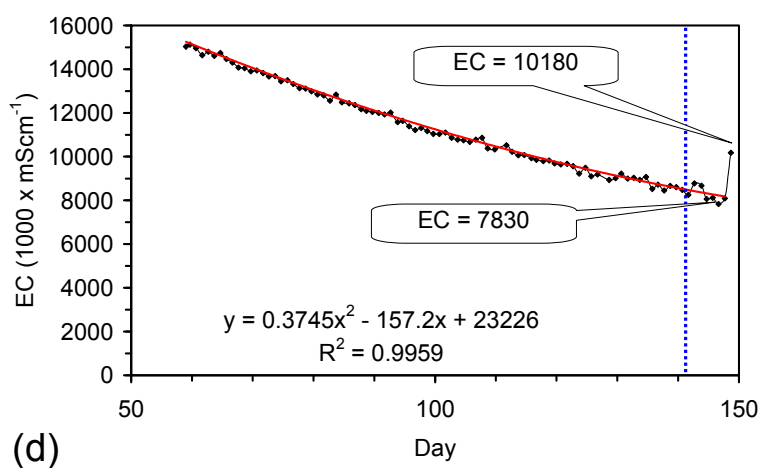

Figure D2. Cont. 

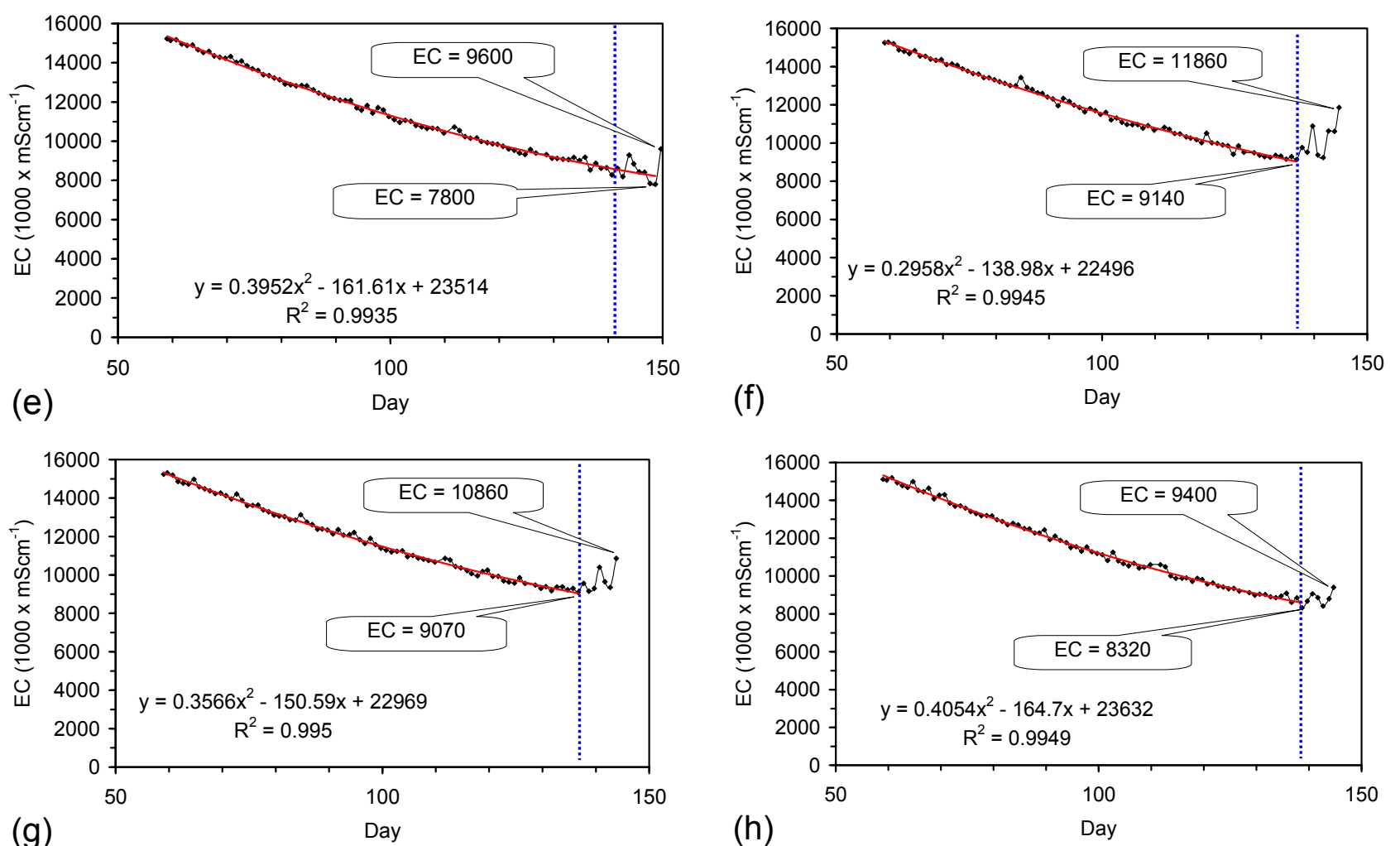

(g)

Day
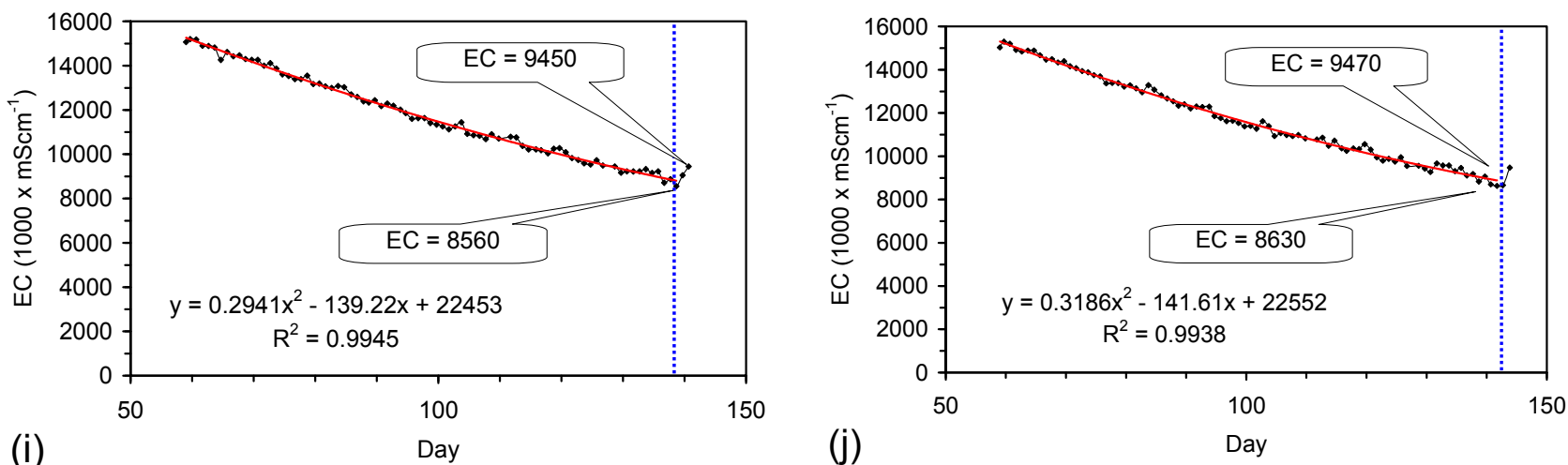

Figure D2. Feed Water $\mathrm{EC}=15.200 \mathrm{mS} \cdot \mathrm{cm}^{-1}$. (a) $\mathrm{S} 1: \mathrm{T} 1 ; D=0.0087 ; R^{2}=0.9941$; $Z=18.3 ; \mathrm{Cu}=36.7 ;$ (b) S1:T2; $D=0.0075 ; R^{2}=0.993 ; Z=23.1 ; \mathrm{Cu}=31.9 ;$ (c) S1:T3; $D=0.0074 ; R^{2}=0.9912 ; Z=25.3 ; \mathrm{Cu}=44.7 ;$ (d) S1:T4; $R^{2}=0.9937 ; D=0.0071$; $Z=26.7 ; \mathrm{Cu}=38.3 ;$ (e) S1:T5; $D=0.0071 ; R^{2}=0.9891 ; Z=21.7 ; \mathrm{Cu}=38.3$; (f) S1:T6; $D=0.0069 ; R^{2}=0.9938 ; Z=28.3 ; \mathrm{Cu}=36.7 ;(\mathrm{g}) \mathrm{S} 1: \mathrm{T} 7 ; D=0.0068 ; R^{2}=0.9938 ;$ $Z=31.9 ; \mathrm{Cu}=32.0 ;$ (h) S1:T8; $D=0.0074 ; R^{2}=0.9935 ; Z=30.1 ; \mathrm{Cu}=30.1 ;$ (i) S1:T9; $D=0.0069 ; R^{2}=0.9938 ; Z=23.3 ; \mathrm{Cu}=36.7 ;(\mathbf{j}) \mathrm{S} 1: \mathrm{T} 10 ; D=0.0066 ; R^{2}=0.9925$; $Z=25.1 ; \mathrm{Cu}=43.1$. Vertical blue-dashed line represents start of the freezing event (indicated by ice formation). $D=$ Exponential Constant $D ; R^{2}=$ Exponential coefficient of determination; $Z=Z \mathrm{ZVM} \mathrm{g} \cdot \mathrm{L}^{-1} ; \mathrm{Cu}=\mathrm{Cu}^{0}$ pellet shell weight $\mathrm{g} \cdot \mathrm{L}^{-1}$. Trials commenced on Day 59. T1-T10 $=$ Trial numbers. Data extracted from a larger data set in Figure C5. 


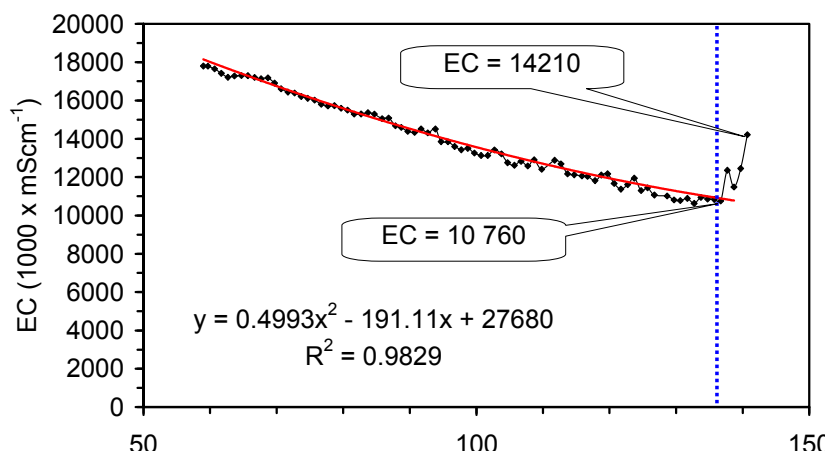

(a)

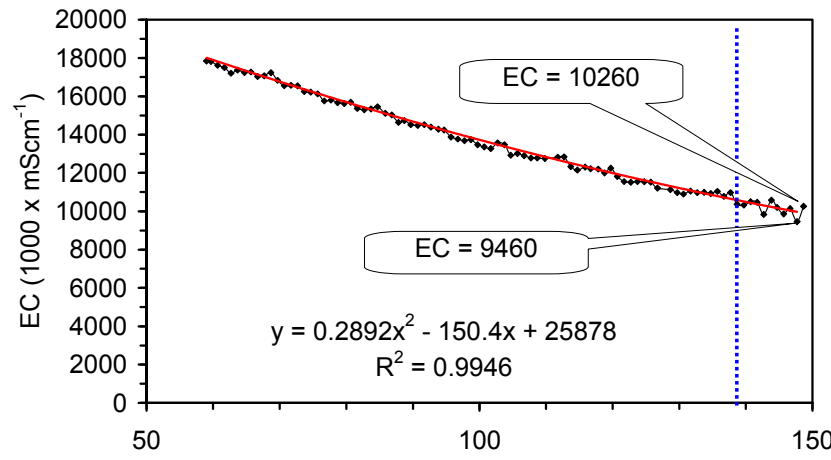

(c)

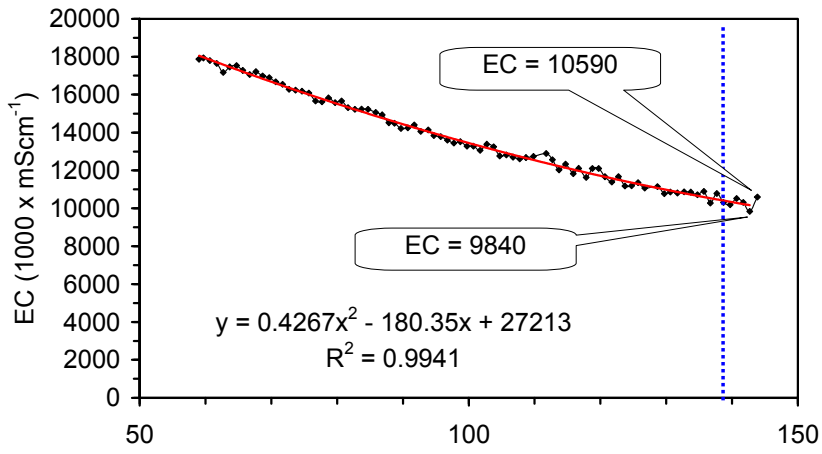

(e)

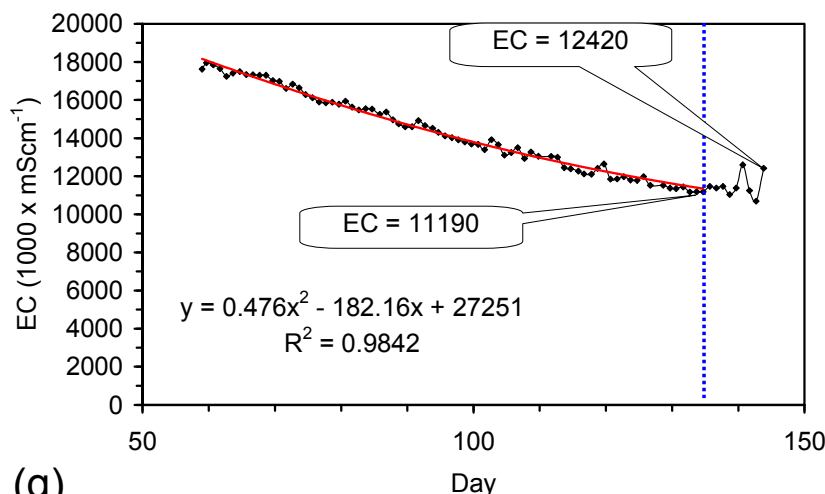

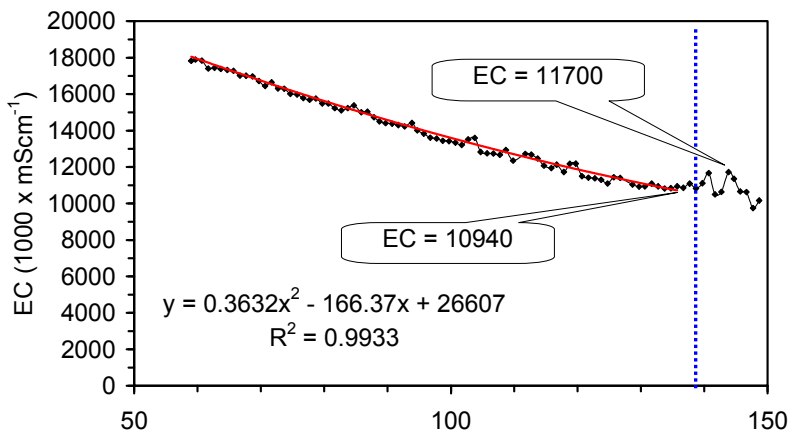

(b)

Day

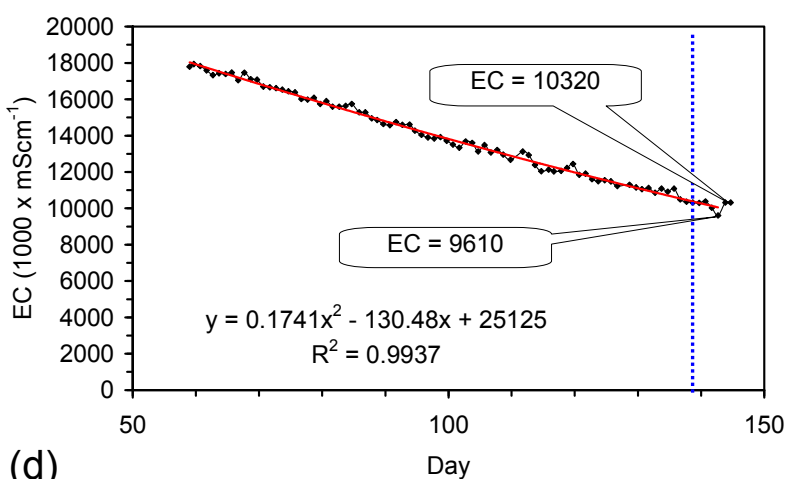

(d)
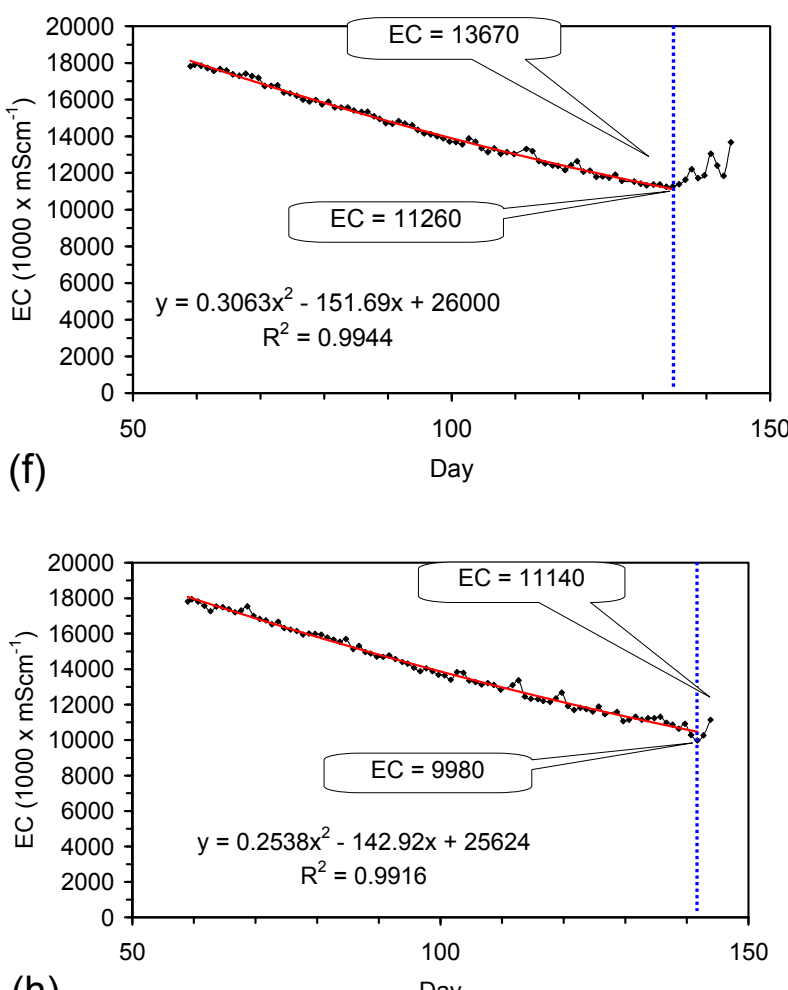

(h)

Figure D3. Cont. 

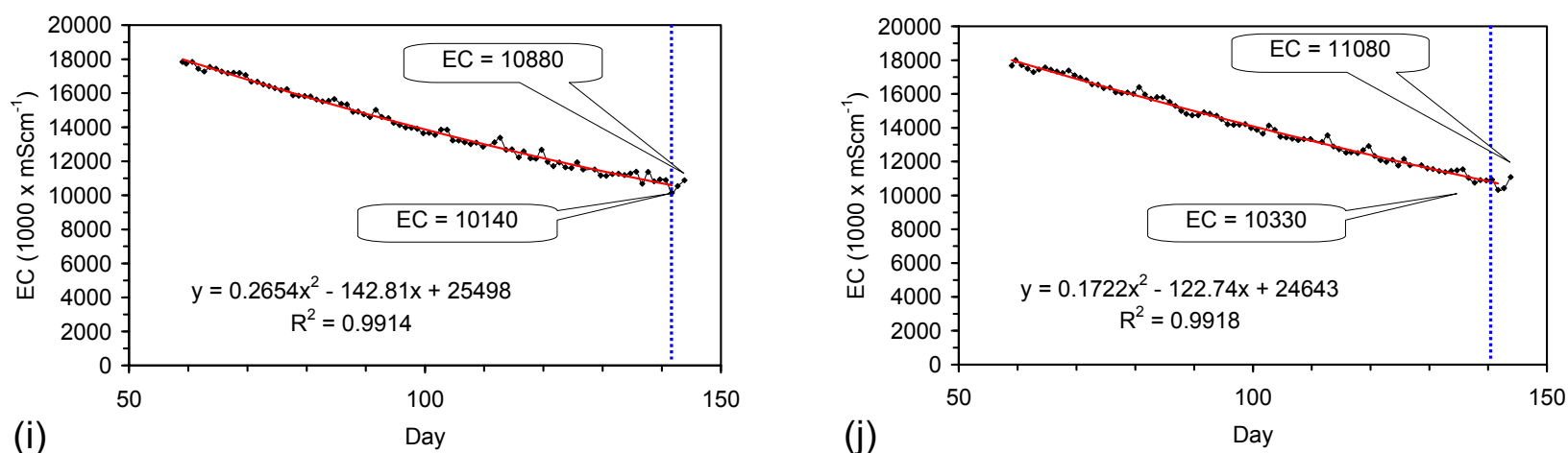

Figure D3. Feed Water $\mathrm{EC}=17.660 \mathrm{mS} \cdot \mathrm{cm}^{-1}$. (a) $\mathrm{S} 2: \mathrm{T} 1 ; D=0.0066 ; R^{2}=0.9321$; $Z=28.5 ; \mathrm{Cu}=41.5 ;(\mathbf{b}) \mathrm{S} 2: \mathrm{T} 2 ; D=0.0067 ; R^{2}=0.9188 ; Z=30.0 ; \mathrm{Cu}=40.0 ;(\mathbf{c}) \mathrm{S} 2: \mathrm{T} 3 ; D$ $=0.0066 ; R^{2}=0.9246 ; Z=25.0 ; \mathrm{Cu}=35.0 ;$ (d) S2:T4; $D=0.0070 ; R^{2}=0.9916$; $Z=25.0 ; \mathrm{Cu}=35.0 ;$ (e) S2:T5; $D=0.0069 ; R^{2}=0.9925 ; Z=33.5 ; \mathrm{Cu}=41.5 ;$ (f) S2:T6; $D=0.0065 ; R^{2}=0.994 ; Z=26.5 ; \mathrm{Cu}=38.5 ;$ (g) S2:T7; $D=0.0055 ; R^{2}=0.6045$; $Z=26.5 ; \mathrm{Cu}=38.5 ;$ (h) S2:T8; $D=0.0066 ; R^{2}=0.9902 ; Z=23.5 ; \mathrm{Cu}=36.5$; (i) S2:T9; $D=0.0064 ; R^{2}=0.9896 ; Z=26.5 ; \mathrm{Cu}=38.5 ;$ (j) $\mathrm{S} 2: \mathrm{T} 10 ; D=0.0063 ; R^{2}=0.9091$; $Z=33.5 ; \mathrm{Cu}=41.5$. Vertical blue-dashed line represents start of the freezing event (indicated by ice formation). $D=$ Exponential Constant $D ; R^{2}=$ Exponential coefficient of determination; $Z=\mathrm{ZVM} \mathrm{g} \cdot \mathrm{L}^{-1} ; \mathrm{Cu}=\mathrm{Cu}^{0}$ pellet shell weight $\mathrm{g} \cdot \mathrm{L}^{-1}$. Trials commenced on Day 59. T1-T10 = Trial numbers. Data extracted from a larger data set in Figure C6.

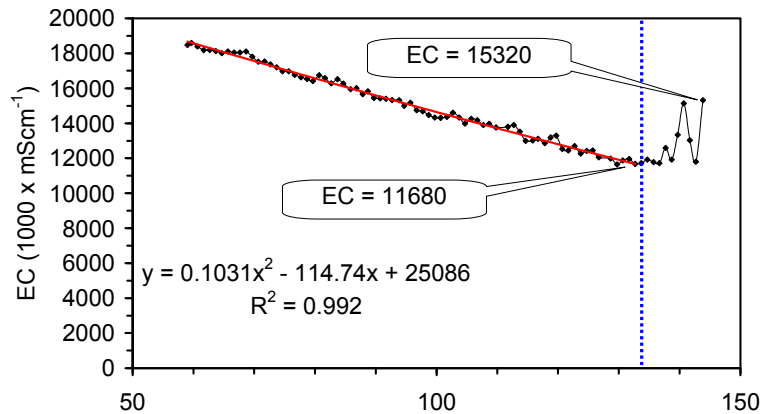

(a)

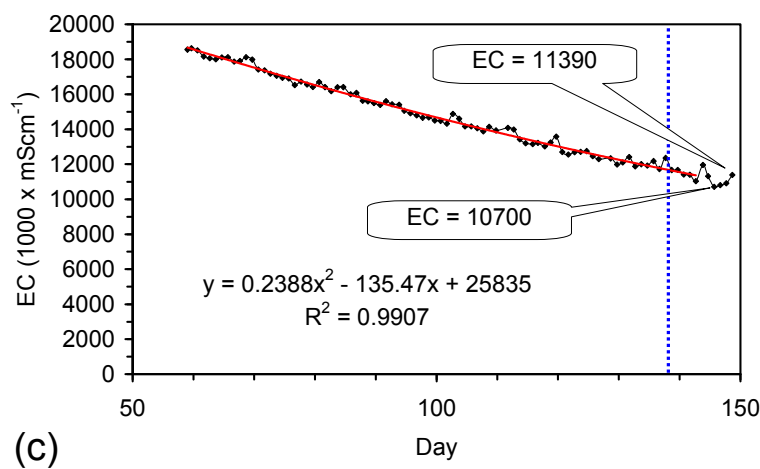

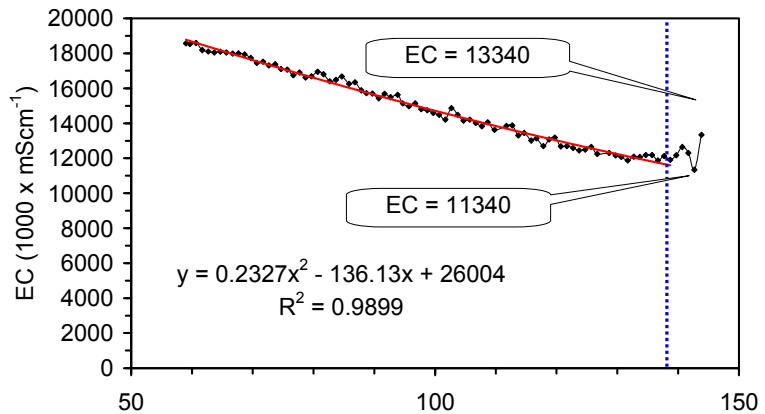

(b)

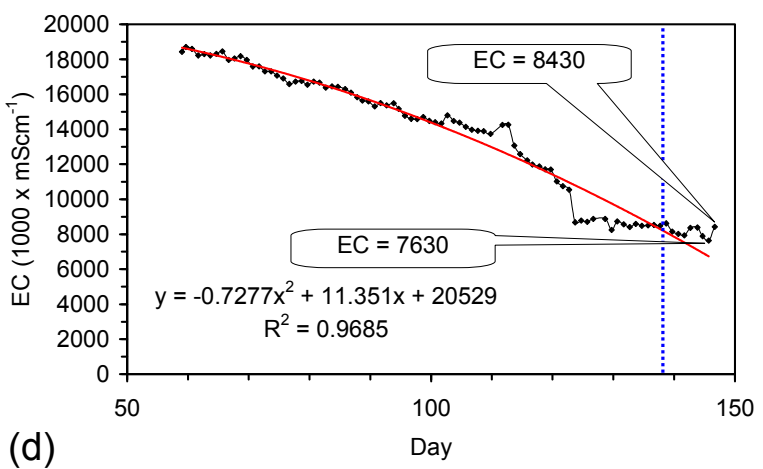

Figure D4. Cont. 

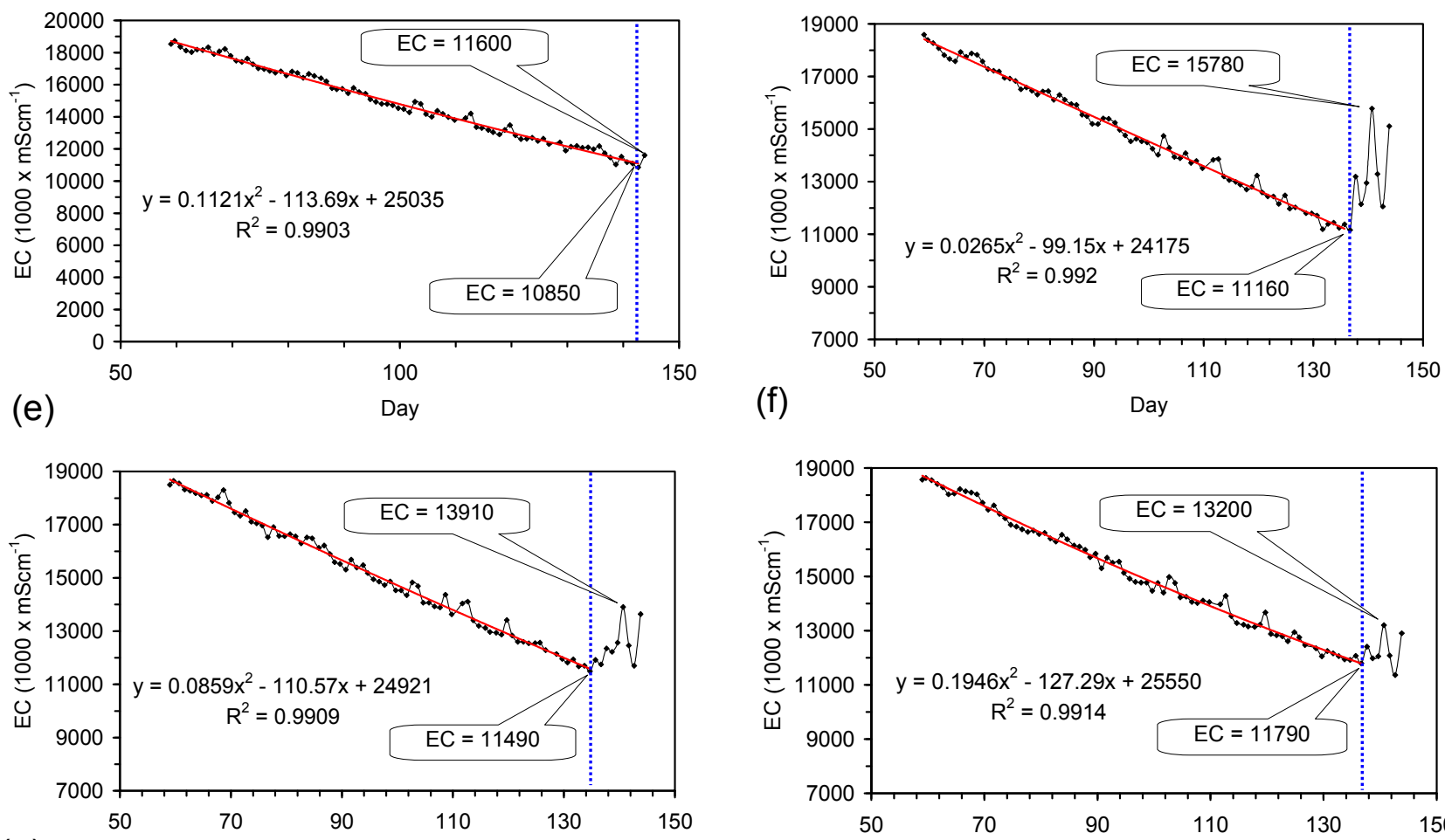

(g)
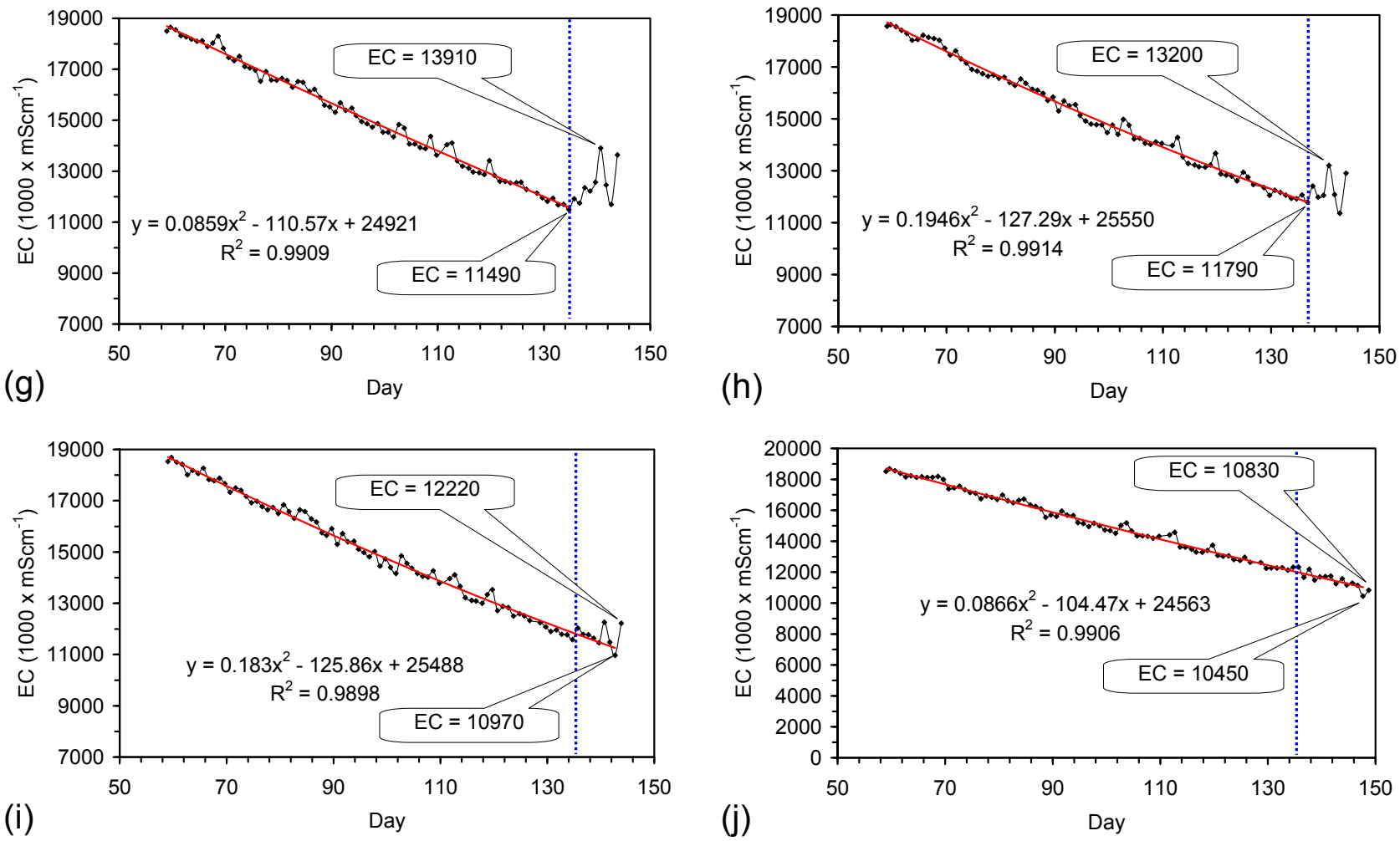

Figure D4. Feed Water $\mathrm{EC}=18.480 \mathrm{mS} \cdot \mathrm{cm}^{-1}$. (a) $\mathrm{S} 3: \mathrm{T} 1 ; D=0.0063 ; R^{2}=0.9899$; $Z=32.0 ; \mathrm{Cu}=43.0 ;(\mathbf{b}) \mathrm{S} 3: \mathrm{T} 2 ; D=0.0061 ; R^{2}=0.9888 ; Z=25.0 ; \mathrm{Cu}=35.0 ;(\mathbf{c}) \mathrm{S} 3: \mathrm{T} 3 ; D$ $=0.0060 ; R^{2}=0.9896 ; Z=30.0 ; \mathrm{Cu}=40.0 ;$ (d) S3:T4; $D=0.0109 ; R^{2}=0.9158$; $Z=30.0 ; \mathrm{Cu}=40.0 ;$ (e) S3:T5; $D=0.0062 ; R^{2}=0.9881 ; Z=26.5 ; \mathrm{Cu}=33.5 ;$ (f) S3:T6; $D=0.0064 ; R^{2}=0.9875 ; Z=57.5 ; \mathrm{Cu}=92.5 ;(\mathrm{g}) \mathrm{S} 3: \mathrm{T} 7 ; D=0.0063 ; R^{2}=0.9888 ;$ $Z=82.5 ; \mathrm{Cu}=92.5 ;$ (h) S3:T8; $D=0.0060 ; R^{2}=0.9907 ; Z=65.0 ; \mathrm{Cu}=79.5 ;$ (i) S3:T9; $D=0.0061 ; R^{2}=0.9879 ; Z=72.0 ; \mathrm{Cu}=83.0 ;(\mathrm{j}) \mathrm{S} 3: \mathrm{T} 10 ; D=0.0059 ; R^{2}=0.9876$; $Z=66.5 ; \mathrm{Cu}=78.0$. Vertical blue-dashed line represents start of the freezing event (indicated by ice formation). $D=$ Exponential Constant $D ; R^{2}=$ Exponential coefficient of determination; $Z=\mathrm{ZVM} \mathrm{g} \cdot \mathrm{L}^{-1} ; \mathrm{Cu}=\mathrm{Cu}^{0}$ pellet shell weight $\mathrm{g} \cdot \mathrm{L}^{-1}$. Trials commenced on Day 59. T1-T10 = Trial numbers. Data extracted from a larger data set in Figure C7. 


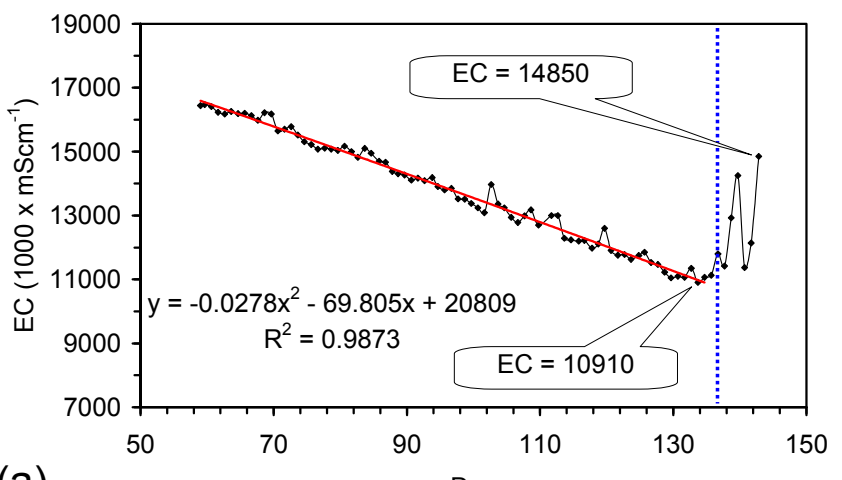

(a)
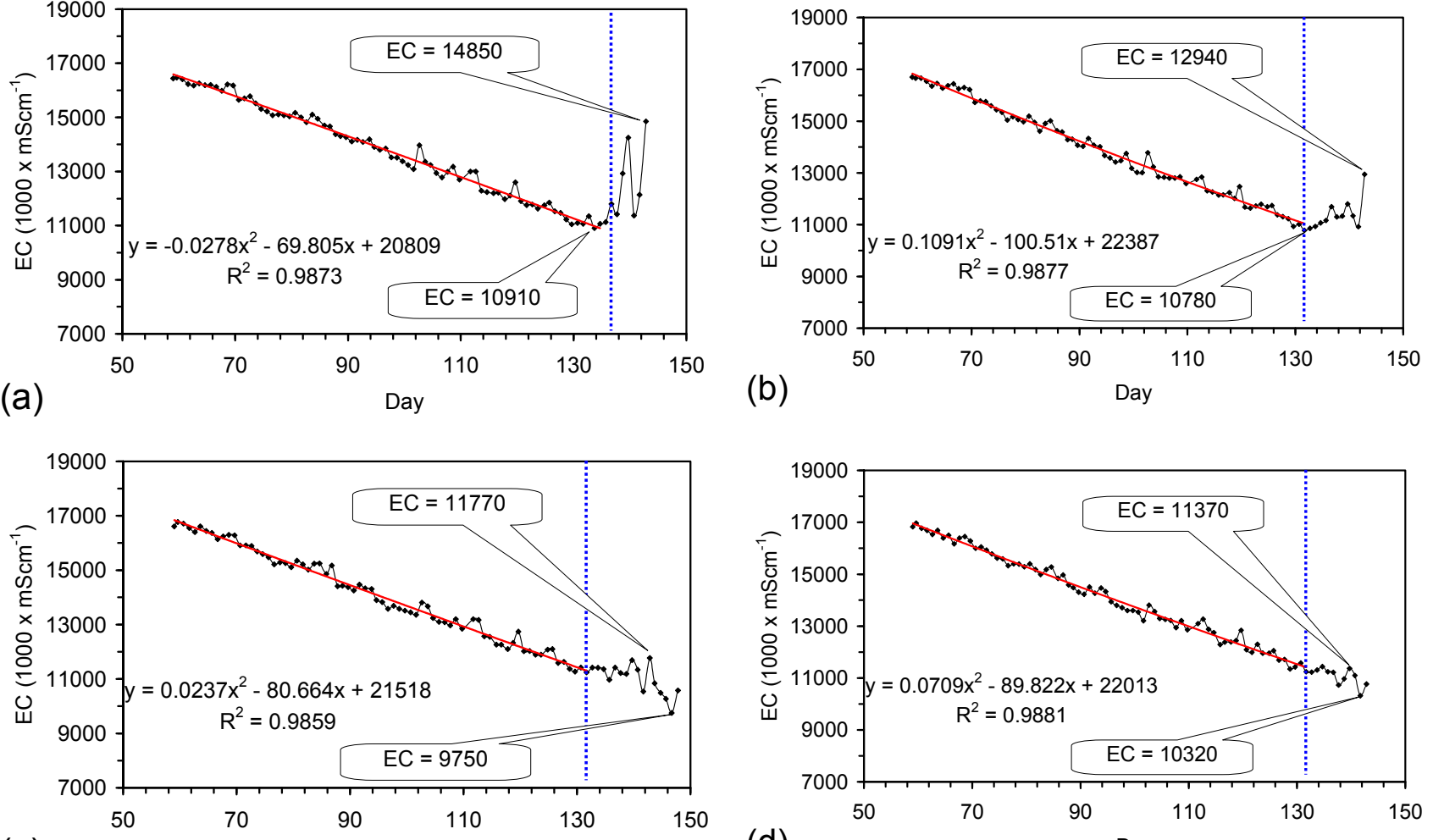

(c)

Day
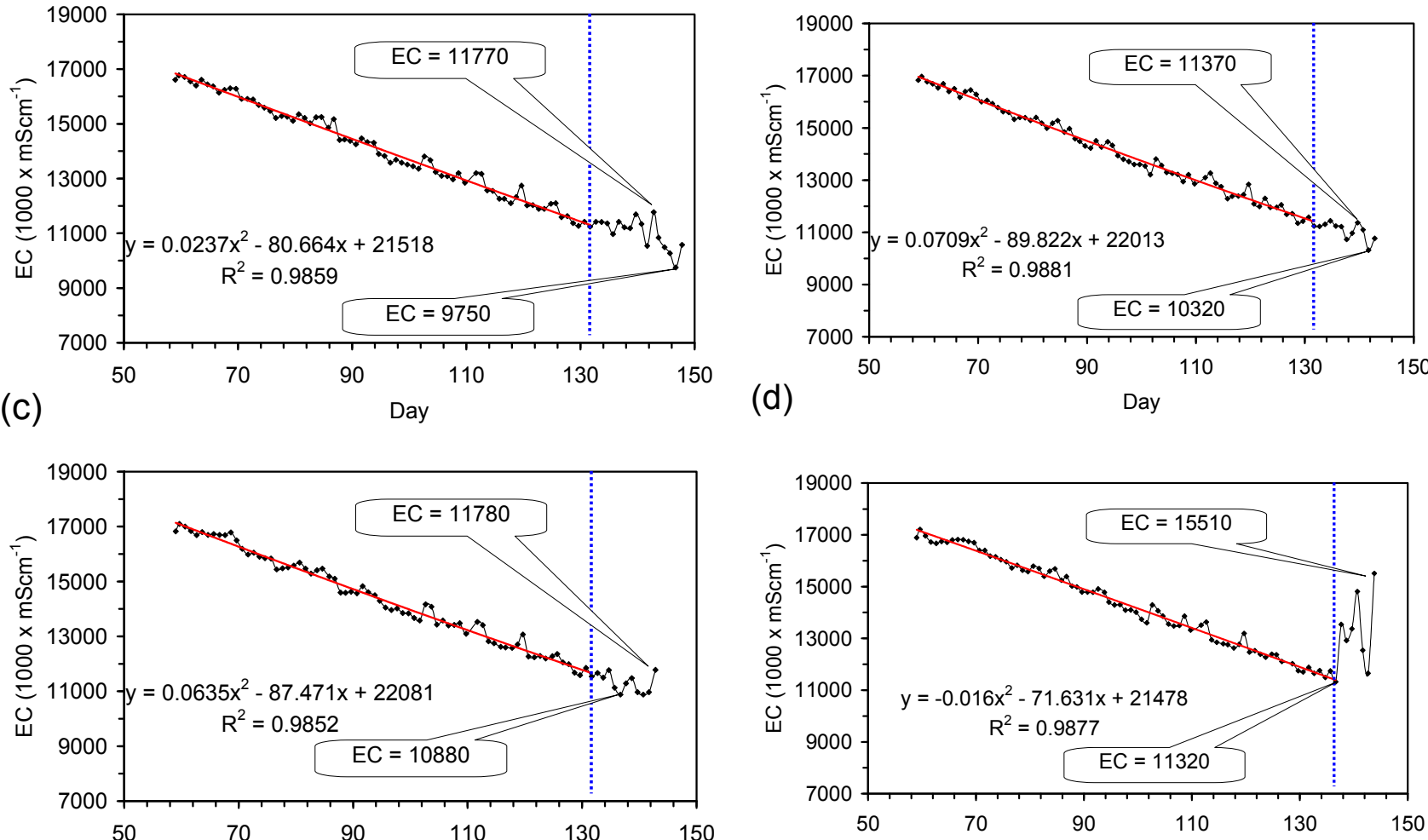

(e)

Day

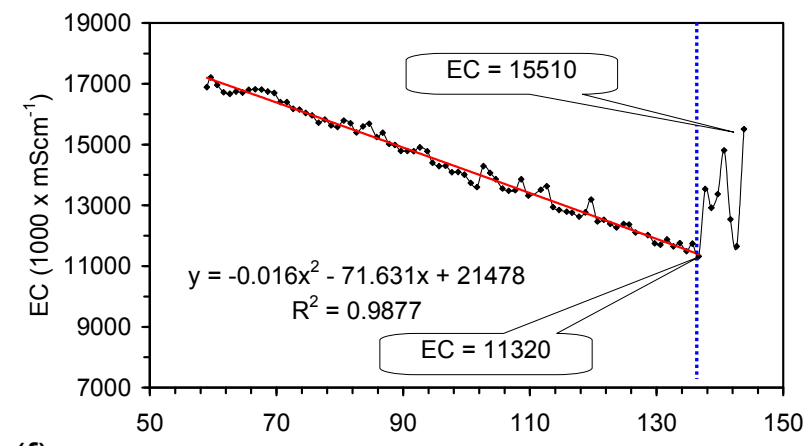

(f)

Day
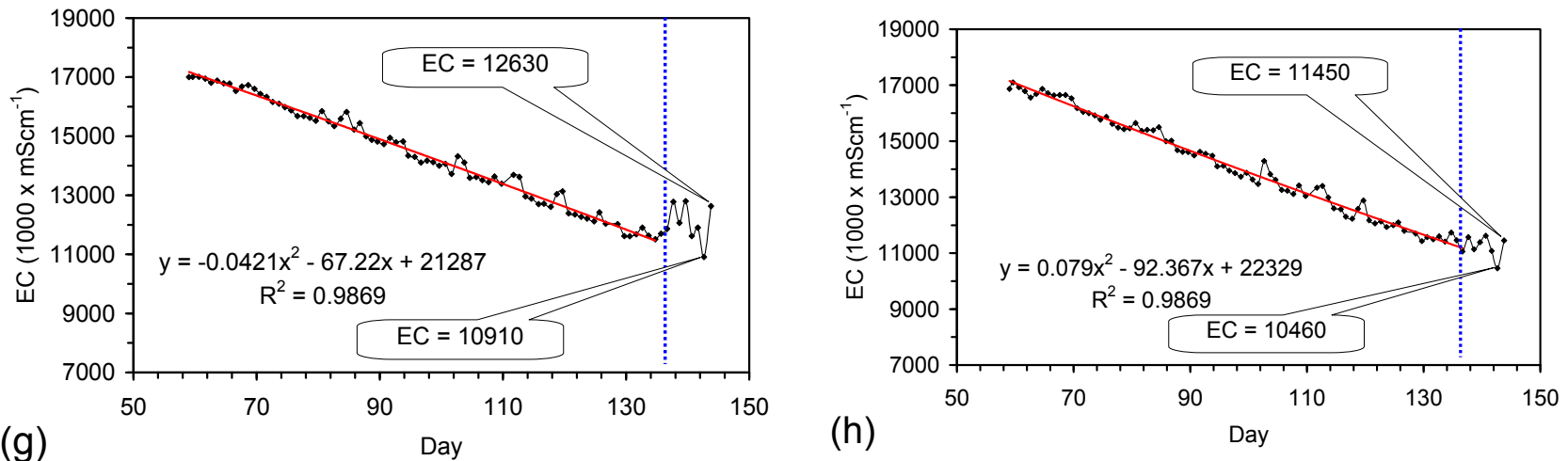

Figure D5. Cont. 

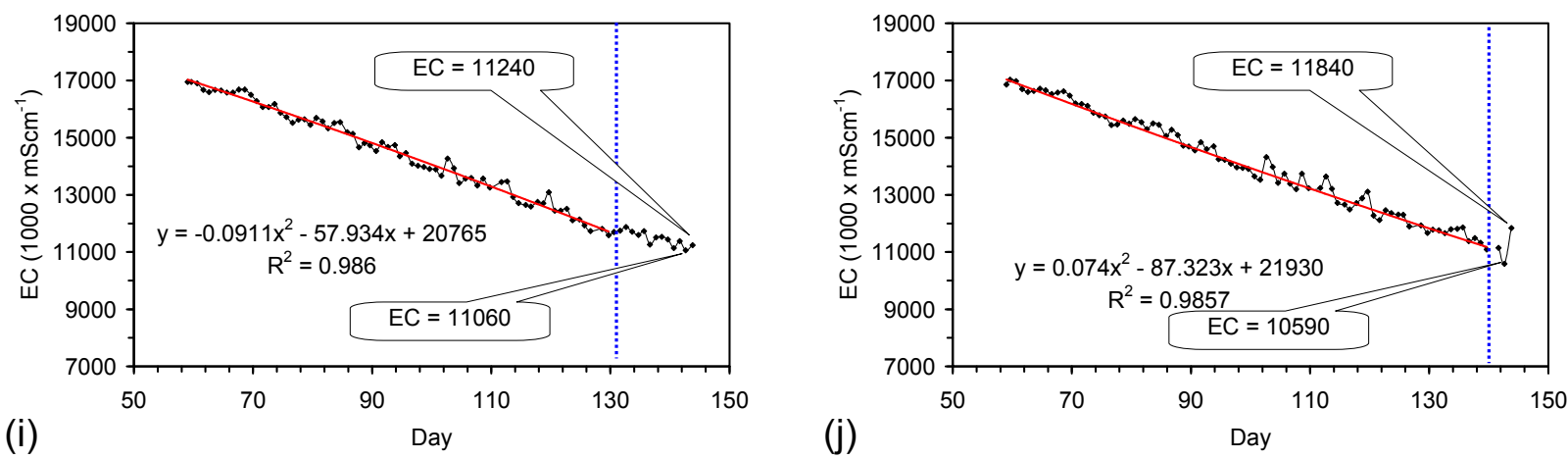

Figure D5. Feed Water $\mathrm{EC}=16.960 \mathrm{mS} \cdot \mathrm{cm}^{-1}$. (a) $\mathrm{S} 4: \mathrm{T} 1 ; D=0.0055 ; R^{2}=0.9832$; $Z=50.0 ; \mathrm{Cu}=80.0 ;$ (b) $\mathrm{S} 4: \mathrm{T} 2 ; D=0.0058 ; R^{2}=0.986 ; Z=55.5 ; \mathrm{Cu}=79.5 ;$ (c) S4:T3; $D=0.0055 ; R^{2}=0.9832 ; Z=50.0 ; \mathrm{Cu}=75.0 ;$ (d) S4:T4; $D=0.0054 ; R^{2}=0.9859$; $Z=63.5 ; \mathrm{Cu}=46.2 ;$ (e) S4:T5; $D=0.0053 ; R^{2}=0.9835 ; Z=87.5 ; \mathrm{Cu}=52.5 ;$ (f) S4:T6; $D=0.0053 ; R^{2}=0.9846 ; Z=44.0 ; \mathrm{Cu}=55.5 ;\left(\right.$ g) $\mathrm{S} 4: \mathrm{T} 7 ; D=0.0053 ; R^{2}=0.9824$; $Z=49.0 ; \mathrm{Cu}=46.0 ;$ (h) S4:T8; $D=0.0055 ; R^{2}=0.9852 ; Z=66.5 ; \mathrm{Cu}=73.5 ;$ (i) S4:T9; $D=0.0052 ; R^{2}=0.9804 ; Z=36.0 ; \mathrm{Cu}=59.0 ;(\mathbf{j}) \mathrm{S} 4: \mathrm{T} 10 ; D=0.0052 ; R^{2}=0.9839$; $Z=44.5 ; \mathrm{Cu}=65.5$. Vertical blue-dashed line represents start of the freezing event (indicated by ice formation). $D=$ Exponential Constant $D ; R^{2}=$ Exponential coefficient of determination; $Z=\mathrm{ZVM} \mathrm{g} \cdot \mathrm{L}^{-1} ; \mathrm{Cu}=\mathrm{Cu}^{0}$ pellet shell weight $\mathrm{g} \cdot \mathrm{L}^{-1}$. Trials commenced on Day 59. T1-T10 = Trial numbers. Data extracted from a larger data set in Figure C8.
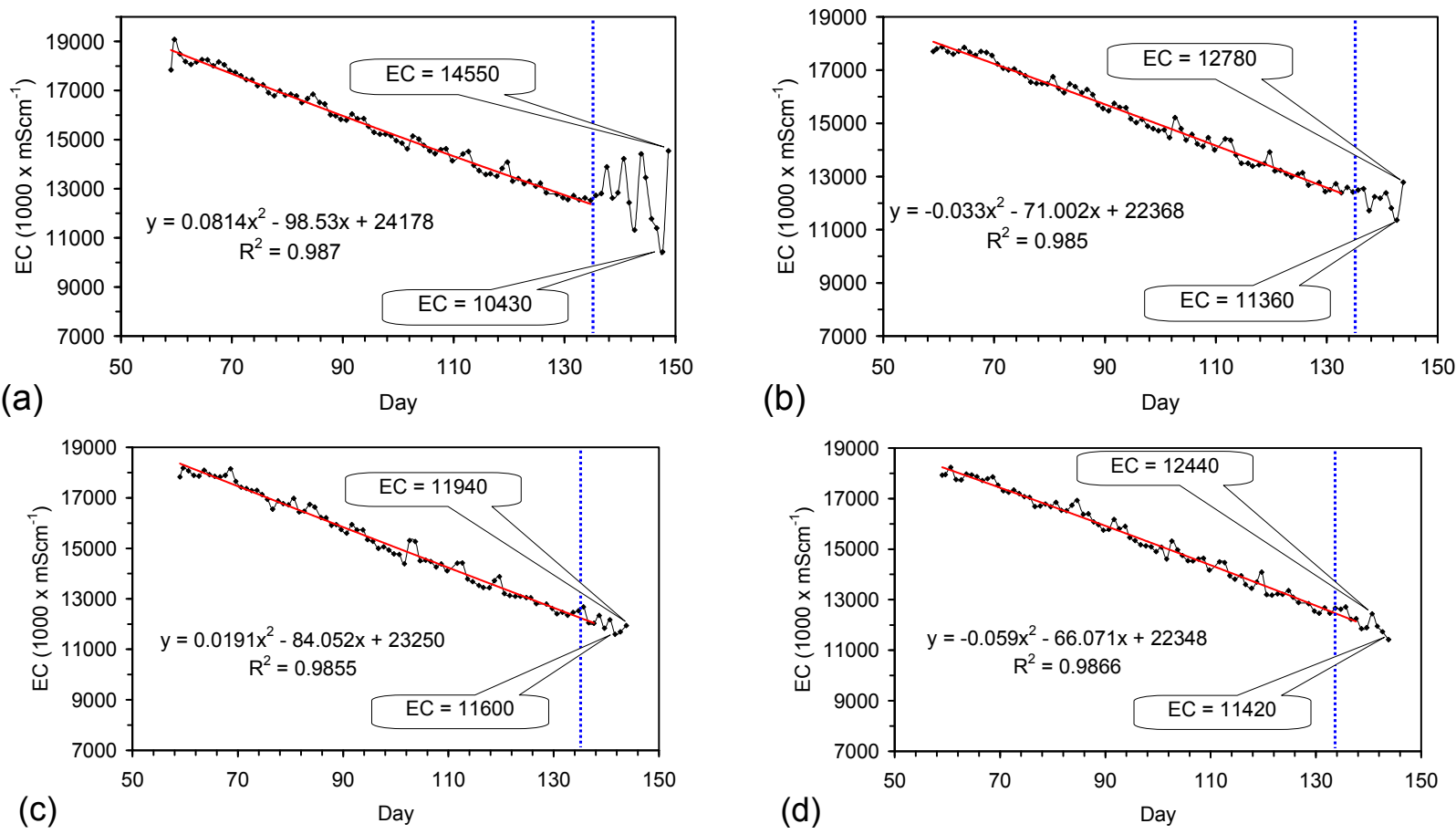

Figure D6. Cont. 


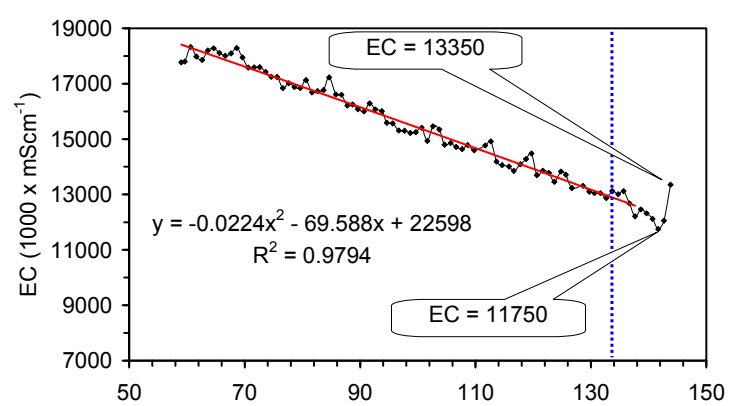

(e)

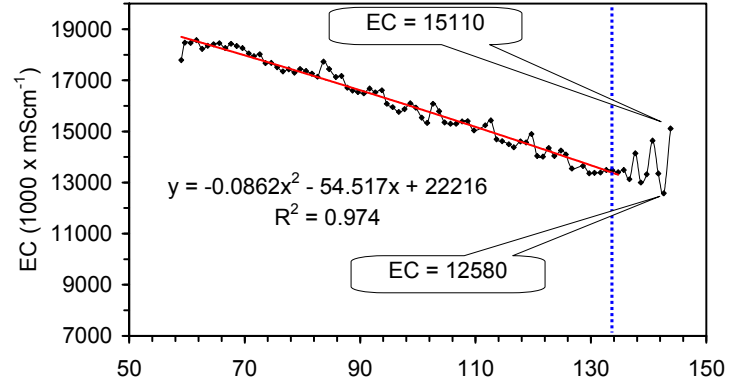

(g)

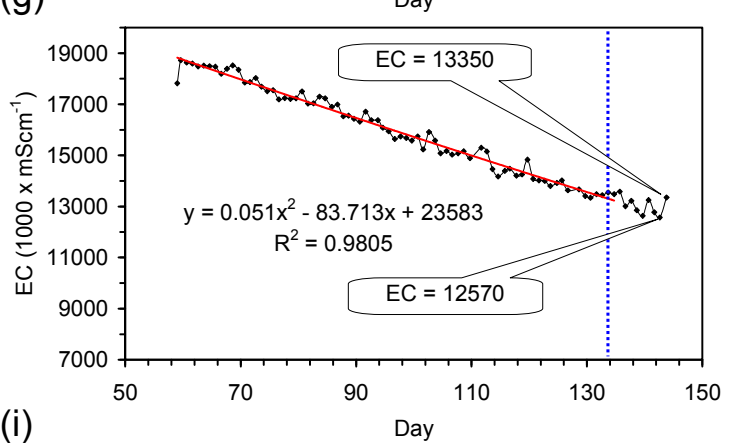

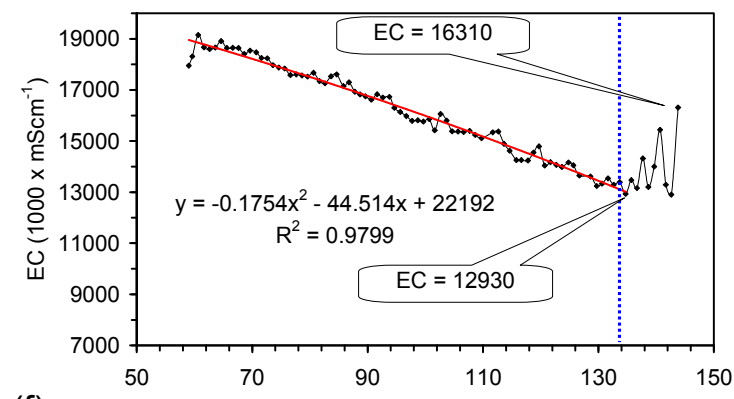

(f)

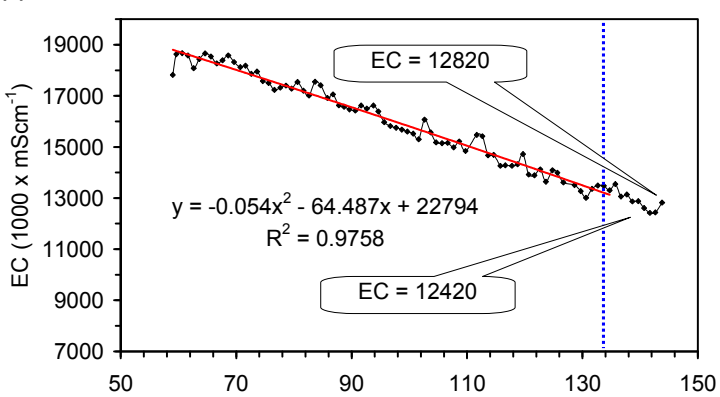

(h)

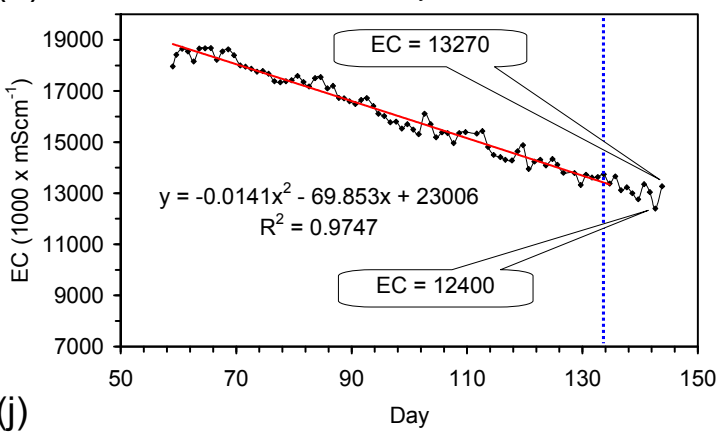

Figure D6. Feed Water $\mathrm{EC}=17.890 \mathrm{mS} \cdot \mathrm{cm}^{-1}$. (a) $\mathrm{S} 5: \mathrm{T} 1 ; D=0.0054 ; R^{2}=0.9867$; $Z=64.0 ; \mathrm{Cu}=86.0 ;(\mathbf{b}) \mathrm{S} 5: \mathrm{T} 2 ; D=0.0051 ; R^{2}=0.9819 ; Z=47.5 ; \mathrm{Cu}=57.5 ;(\mathbf{c}) \mathrm{S} 5: \mathrm{T} 3 ; D$ $=0.0053 ; R^{2}=0.9837 ; Z=48.0 ; \mathrm{Cu}=72.0 ;$ (d) S5:T4; $D=0.0051 ; R^{2}=0.9825$; $Z=62.5 ; \mathrm{Cu}=97.5 ;$ (e) S5:T5; $D=0.0048 ; R^{2}=0.9775 ; Z=94.0 ; \mathrm{Cu}=130.5 ;$ (f) S5:T6; $D$ $=0.0049 ; R^{2}=0.9737 ; Z=47.5 ; \mathrm{Cu}=92.5 ;(\mathrm{g}) \mathrm{S} 5: \mathrm{T} 7 ; D=0.0042 ; R^{2}=0.7628$; $Z=38.0 ; \mathrm{Cu}=102.0 ;$ (h) S5:T8; $D=0.0044 ; R^{2}=0.7484 ; Z=46.0 ; \mathrm{Cu}=94.0 ;$ (i) S5:T9; $D=0.0043 ; R^{2}=0.7532 ; Z=39.5 ; \mathrm{Cu}=95.5 ;$ (j) S5:T10; $D=0.0042 ; R^{2}=0.7373$; $Z=72.5 ; \mathrm{Cu}=57.5$. Vertical blue-dashed line represents start of the freezing event (indicated by ice formation). $D=$ Exponential Constant $D ; R^{2}=$ Exponential coefficient of determination; $Z=\mathrm{ZVM} \mathrm{g} \cdot \mathrm{L}^{-1} ; \mathrm{Cu}=\mathrm{Cu}^{0}$ pellet shell weight $\mathrm{g} \cdot \mathrm{L}^{-1}$. Trials commenced on Day 59. T1-T10 = Trial numbers. Data extracted from a larger data set in Figure C9.

\section{Appendix E. Interpretation of Salinity}

Salinity can be measured by directly measuring $\mathrm{Cl}^{-}$ion concentrations in a laboratory, e.g., [21,25], Table C1, or can be measured using calibrated electrical conductivity (EC) [27], or UV-visible spectrometry $[215,216]$ equipment.

Standard salinity calibration analyses assume that the water contains two components: $\mathrm{H}_{2} \mathrm{O}+$ $\mathrm{NaCl}[27,215,216]$. These analyses assume in a two component system that EC (and absorbance) decrease as the water salinity decreases [27,215,216]. 
Dissolution of ZVM to form $\mathrm{Fe}^{n^{+}}$ions (and entrained ZVM particles) will both increase $\mathrm{EC}$ and absorbance. If the water also contains other components which are removed by the ZVM, then decreases in EC or absorbance may also reflect their removal [27].

The salinity assessment methodology [27,215,216] is extended in this study (incorporating examples using ZVM TPA, when appropriate) as follows:

(1) Assessment of salinity using UV-visible spectrometry

(a) Determination of control samples and salinity using UV-visible spectrometry, when nano-particles are absent;

(b) Determination of salinity when nano-particle formation results in the product water absorbance being greater than the feed water absorbance, and the nano-particles can be removed by settlement;

(c) Determination of salinity when nano-particle formation results in the product water absorbance being less than the feed water absorbance during desalination;

(2) Assessment of salinity using EC

(a) Determination of control samples and salinity using EC, when nano-particles are absent;

(b) Determination of salinity when EC shows an initial rise due to nano-particle formation followed by a decline during desalination;

(c) Determination of salinity removed when the water volume reduces during desalination;

(3) Assessment of salinity using UV-visible spectrometry and EC

(a) Determination of salinity when nano-particle formation results in absorbance increasing with time, while EC initially rises before remaining stable at an elevated level.

\section{E1. Assessment of Product Water Salinity Using UV-Visible Spectrophotometry}

There is a relationship between wavelength, absorbance and ion concentration, for most ions and ion adducts (including $\mathrm{NaCl}$ [215,216], $\mathrm{Cl}_{x} \mathrm{O}_{y}$ [217-220], $\mathrm{Cl}_{2}^{-}$[220], $\mathrm{Cl}_{x} \mathrm{O}_{y} \mathrm{H}_{z}$ [218], $\mathrm{O}_{x} \mathrm{H}$ [221-225], $\mathrm{O}_{x^{n^{-}}}$[225], $\mathrm{FeOOH}$ [93,226], $\mathrm{Fe}(\mathrm{OH})_{x}$ [226], $n-\mathrm{Fe}^{0}$ [227]). Absorbance increases (or decreases), at specific wavelengths, as the ion concentration increases [228]. Nano-particles of akaganeite (beta-FeOOH) can accrete in multi-layered polyionic layers [90]. The average number of accreting layers can be assessed from the absorbance at a wavelength of $225 \mathrm{~nm}$ relative to a normalised base layer [90].

The absorbance can be measured relative to a fresh water standard (or another standard), or can be normalized (by setting absorbance at a reference wavelength (in the range 600-1000 nm) to zero) [228].

In this study a control set of water samples was constructed by dissolving halite $(\mathrm{NaCl})$ in water. A total of 43 control water samples were created, where each $2.3 \mathrm{~L}$ sample had a different salinity. This data set formed the basis for the assessment of salinity in the product waters during desalination using ZVM TPA (Figures C19-C36).

The standard wavelength scan recorded absorbance at $5 \mathrm{~nm}$ intervals between 200 and $300 \mathrm{~nm}$, absorbance at $350 \mathrm{~nm}$, and absorbance at $100 \mathrm{~nm}$ intervals between 400 and $900 \mathrm{~nm}$. 


\section{E1.1. Equations Used in the Assessment of Salinity: Control Samples}

Absorbance vs. wavelength was calculated for 43 saline control water samples relative to the freshwater standard over the spectral range 200-900 nm (e.g., Figure E1a). All raw spectra were normalized [228] to provide an absorbance value at $900 \mathrm{~nm}$ of zero. The normalized data was also corrected for changes in absorbance associated with differences in the optical properties of the quartz cuvette used for the freshwater standard and the saline control water samples [228]. The effect of this normalisation correction [228] is illustrated in Figure E1b.
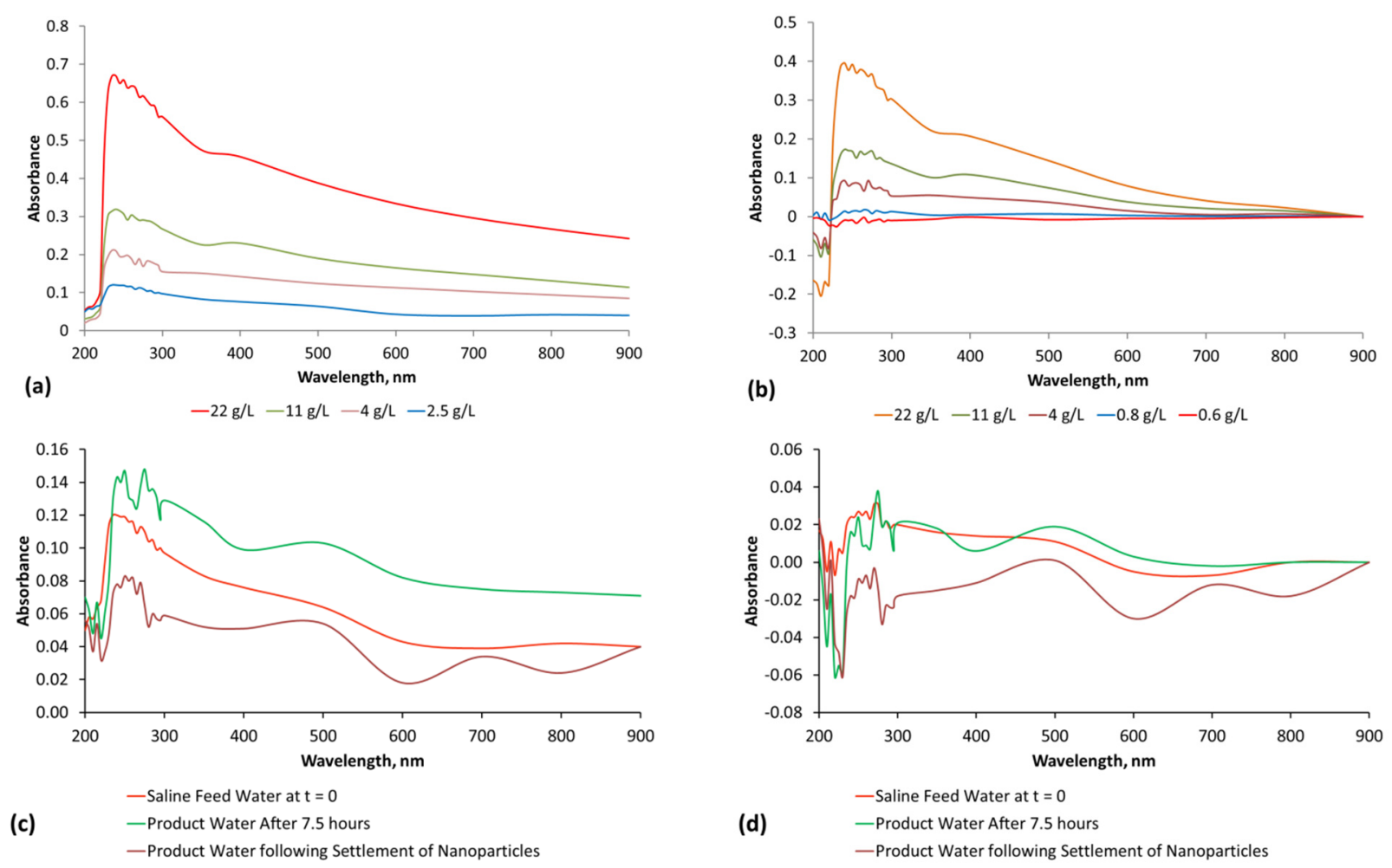

Figure E1. Absorbance (relative to reference freshwater control sample) vs. wavelength for different concentrations of halite $\left(\mathrm{g} \cdot \mathrm{L}^{-1}\right)$. (a) Raw control data set, absorbance relative to freshwater; (b) Normalized control data set; (c) Example Product Water after $7.5 \mathrm{~h}$ : Raw data, absorbance relative to freshwater. Assessed Salinity of settled product water: Average $=1.63 \mathrm{~g} \cdot \mathrm{L}^{-1}$; Standard deviation $=0.41 \mathrm{~g} \cdot \mathrm{L}^{-1}, n=27$; Feed water salinity $=$ $2.467 \mathrm{~g} \cdot \mathrm{L}^{-1}$; (d) Example Product Water after $7.5 \mathrm{~h}$ : Normalised data [absorbance relative to freshwater] following normalisation to $900 \mathrm{~nm}$. Salinity of settled product water: Average $=0.71 \mathrm{~g} \cdot \mathrm{L}^{-1}$; Standard deviation $=0.833 \mathrm{~g} \cdot \mathrm{L}^{-1}, n=27$. Feed water salinity $=2.467 \mathrm{~g} \cdot \mathrm{L}^{-1}$; Settlement period $=18.5 \mathrm{~h}$; Water volume treated $=240 \mathrm{~L}$.

The normalised absorbance at 27 different wavelengths (200-800 nm) was cross plotted against measured salinity. 27 calibration regression equations (one for each wavelength measurement), which relate absorbance to salinity at the specific wavelength, were calculated using the trend line function in MS Excel 2010 (Table E1). Each regression calibration equation, for each wavelength, is based on the 43 measured calibration data points. 
Table E1. Equations used to calculate salinity. Calibrated using Cheshire Halite. Valid Range $=0$ to $22 \mathrm{gNaCl} \cdot \mathrm{L}^{-1}$. Applicability: two component system only, water + dissolved halite. $x_{\text {raw }}=$ raw absorbance value at the measured wavelength of the partially desalinated water. $x_{\text {initial }}=$ the raw absorbance value at the measured wavelength of the feed water. $x=$ the normalized absorbance value at the measured wavelength of the partially desalinated water. This is calculated as $x=\left[x_{\text {raw }}\right.$ (at a specific wavelength) $]-\left[x_{\text {raw }}\right.$ (at a wavelength of $900 \mathrm{~nm})] . R=$ the initial salinity of the feed water, $\mathrm{g} \cdot \mathrm{L}^{-1}$. Absorbance is referenced to the freshwater $\left(0 \mathrm{~g} \mathrm{NaCL} \mathrm{L}^{-1}\right)$ control sample.

\begin{tabular}{|c|c|c|}
\hline \multirow{2}{*}{ Wavelength, nm } & Normalized Absorbance & Raw Absorbance \\
\hline & Salinity, $\mathbf{g} \cdot \mathbf{L}^{-1}$ & Salinity, $g \cdot L^{-1}$ \\
\hline 200 & Salinity, $\mathrm{g} \cdot \mathrm{L}^{-1}=766.28 x^{2}-3.2388 x+1.8149$ & Salinity, $\mathrm{g} \cdot \mathrm{L}^{-1}=\left[x_{\text {raw }} / x_{\text {initial }}\right] \cdot \mathrm{R}$ \\
\hline 205 & Salinity, $\mathrm{g} \cdot \mathrm{L}^{-1}=636.34 x^{2}-10.996 x+1.8025$ & Salinity, $\mathrm{g} \cdot \mathrm{L}^{-1}=\left[x_{\text {raw }} / x_{\text {initial }}\right] \cdot \mathrm{R}$ \\
\hline 210 & Salinity, $\mathrm{g} \cdot \mathrm{L}^{-1}=533.61 x^{2}+6.1084 x+1.8424$ & Salinity, $\mathrm{g} \cdot \mathrm{L}^{-1}=\left[x_{\text {raw }} / x_{\text {initial }}\right] \cdot \mathrm{R}$ \\
\hline 215 & Salinity, $\mathrm{g} \cdot \mathrm{L}^{-1}=784.61 x^{2}+3.7002 x+1.8436$ & Salinity, $\mathrm{g} \cdot \mathrm{L}^{-1}=\left[x_{\text {raw }} / x_{\text {initial }}\right] \cdot \mathrm{R}$ \\
\hline 220 & Salinity, $\mathrm{g} \cdot \mathrm{L}^{-1}=866.19 x^{2}+32.111 x+1.8318$ & Salinity, $\mathrm{g} \cdot \mathrm{L}^{-1}=\left[x_{\text {raw }} / x_{\text {initial }}\right] \cdot \mathrm{R}$ \\
\hline 225 & Salinity, $\mathrm{g} \cdot \mathrm{L}^{-1}=450.66 x^{2}+33.898 x+1.5123$ & Salinity, $\mathrm{g} \cdot \mathrm{L}^{-1}=\left[x_{\text {raw }} / x_{\text {initial }}\right] \cdot \mathrm{R}$ \\
\hline 230 & Salinity, $\mathrm{g} \cdot \mathrm{L}^{-1}=118.7 x^{2}+27.487 x+1.3347$ & Salinity, $\mathrm{g} \cdot \mathrm{L}^{-1}=\left[x_{\text {raw }} / x_{\text {initial }}\right] \cdot \mathrm{R}$ \\
\hline 235 & Salinity, $\mathrm{g} \cdot \mathrm{L}^{-1}=7.8675 x^{2}+52.237 x+0.9155$ & Salinity, $\mathrm{g} \cdot \mathrm{L}^{-1}=\left[x_{\text {raw }} / x_{\text {initial }}\right] \cdot \mathrm{R}$ \\
\hline 240 & Salinity, $g \cdot \mathrm{L}^{-1}=11.138 x^{2}+49.401 x+0.957$ & Salinity, $\mathrm{g} \cdot \mathrm{L}^{-1}=\left[x_{\text {raw }} / x_{\text {initial }}\right] \cdot \mathrm{R}$ \\
\hline 245 & Salinity, $\mathrm{g} \cdot \mathrm{L}^{-1}=38.641 x^{2}+42.294 x+0.948$ & Salinity, $\mathrm{g} \cdot \mathrm{L}^{-1}=\left[x_{\text {raw }} / x_{\text {initial }}\right] \cdot \mathrm{R}$ \\
\hline 250 & Salinity, $\mathrm{g} \cdot \mathrm{L}^{-1}=18.317 x^{2}+47.257 x+1.0025$ & Salinity, $\mathrm{g} \cdot \mathrm{L}^{-1}=\left[x_{\text {raw }} / x_{\text {initial }}\right] \cdot \mathrm{R}$ \\
\hline 255 & Salinity, $\mathrm{g} \cdot \mathrm{L}^{-1}=37.841 x^{2}+43.73 x+1.0558$ & Salinity, $\mathrm{g} \cdot \mathrm{L}^{-1}=\left[x_{\text {raw }} / x_{\text {initial }}\right] \cdot \mathrm{R}$ \\
\hline 260 & Salinity, $\mathrm{g} \cdot \mathrm{L}^{-1}=10.321 x^{2}+52.13 x+1.0098$ & Salinity, $\mathrm{g} \cdot \mathrm{L}^{-1}=\left[x_{\text {raw }} / x_{\text {initial }}\right] \cdot \mathrm{R}$ \\
\hline 265 & Salinity, $\mathrm{g} \cdot \mathrm{L}^{-1}=20.714 x^{2}+49.407 x+0.9941$ & Salinity, $\mathrm{g} \cdot \mathrm{L}^{-1}=\left[x_{\text {raw }} / x_{\text {initial }}\right] \cdot \mathrm{R}$ \\
\hline 270 & Salinity, $\mathrm{g} \cdot \mathrm{L}^{-1}=27.368 x^{2}+48.753 x+1.0832$ & Salinity, $\mathrm{g} \cdot \mathrm{L}^{-1}=\left[x_{\text {raw }} / x_{\text {initial }}\right] \cdot \mathrm{R}$ \\
\hline 275 & Salinity, $\mathrm{g} \cdot \mathrm{L}^{-1}=27.115 x^{2}+47.752 x+1.1226$ & Salinity, $\mathrm{g} \cdot \mathrm{L}^{-1}=\left[x_{\text {raw }} / x_{\text {initial }}\right] \cdot \mathrm{R}$ \\
\hline 280 & Salinity, $\mathrm{g} \cdot \mathrm{L}^{-1}=32.059 x^{2}+52.604 x+0.9819$ & Salinity, $\mathrm{g} \cdot \mathrm{L}^{-1}=\left[x_{\text {raw }} / x_{\text {initial }}\right] \cdot \mathrm{R}$ \\
\hline 285 & Salinity, $\mathrm{g} \cdot \mathrm{L}^{-1}=27.529 x^{2}+55.578 x+0.9332$ & Salinity, $\mathrm{g} \cdot \mathrm{L}^{-1}=\left[x_{\text {raw }} / x_{\text {initial }}\right] \cdot \mathrm{R}$ \\
\hline 290 & Salinity, $\mathrm{g} \cdot \mathrm{L}^{-1}=19.31 x^{2}+59.508 x+0.8993$ & Salinity, $\mathrm{g} \cdot \mathrm{L}^{-1}=\left[x_{\text {raw }} / x_{\text {initial }}\right] \cdot \mathrm{R}$ \\
\hline 295 & Salinity, $\mathrm{g} \cdot \mathrm{L}^{-1}=29.723 x^{2}+62.585 x+0.8414$ & Salinity, $\mathrm{g} \cdot \mathrm{L}^{-1}=\left[x_{\text {raw }} / x_{\text {initial }}\right] \cdot \mathrm{R}$ \\
\hline 300 & Salinity, $g \cdot L^{-1}=17.616 x^{2}+65.145 x+0.8971$ & Salinity, $\mathrm{g} \cdot \mathrm{L}^{-1}=\left[x_{\text {raw }} / x_{\text {initial }}\right] \cdot \mathrm{R}$ \\
\hline 350 & Salinity, $\mathrm{g} \cdot \mathrm{L}^{-1}=56.721 x^{2}+83.129 x+0.9896$ & Salinity, $\mathrm{g} \cdot \mathrm{L}^{-1}=\left[x_{\text {raw }} / x_{\text {initial }}\right] \cdot \mathrm{R}$ \\
\hline 400 & Salinity, $\mathrm{g} \cdot \mathrm{L}^{-1}=116.87 x^{2}+77.832 x+1.0311$ & Salinity, $\mathrm{g} \cdot \mathrm{L}^{-1}=\left[x_{\text {raw }} / x_{\text {initial }}\right] \cdot \mathrm{R}$ \\
\hline 500 & Salinity, $\mathrm{g} \cdot \mathrm{L}^{-1}=302.83 x^{2}+101.92 x+1.2602$ & Salinity, $\mathrm{g} \cdot \mathrm{L}^{-1}=\left[x_{\text {raw }} / x_{\text {initial }}\right] \cdot \mathrm{R}$ \\
\hline 600 & Salinity, $g \cdot \mathrm{L}^{-1}=1385 x^{2}+158.9 x+1.3455$ & Salinity, $\mathrm{g} \cdot \mathrm{L}^{-1}=\left[x_{\text {raw }} / x_{\text {initial }}\right] \cdot \mathrm{R}$ \\
\hline 700 & Salinity, $\mathrm{g} \cdot \mathrm{L}^{-1}=7993.4 x^{2}+187.23 x+1.6814$ & Salinity, $\mathrm{g} \cdot \mathrm{L}^{-1}=\left[x_{\text {raw }} / x_{\text {initial }}\right] \cdot \mathrm{R}$ \\
\hline 800 & Salinity, $\mathrm{g} \cdot \mathrm{L}^{-1}=22,332 x^{2}+100.29 x+1.6396$ & Salinity, $\mathrm{g} \cdot \mathrm{L}^{-1}=\left[x_{\text {raw }} / x_{\text {initial }}\right] \cdot \mathrm{R}$ \\
\hline 900 & - & Salinity, $\mathrm{g} \cdot \mathrm{L}^{-1}=\left[x_{\text {raw }} / x_{\text {initial }}\right] \cdot \mathrm{R}$ \\
\hline
\end{tabular}

\section{E1.2. Assessment of Salinity: Real Time Analyses}

Real time salinity analyses were undertaken by measuring the product water salinity absorbance relative to both the feed water and the freshwater standard. 27 estimates of salinity were made using both the raw data set and the normalised data set (Table E1). The average salinity was calculated as the average of the salinities calculated for the wavelengths 200 to $800 \mathrm{~nm}$ using the equations in Table E1. 
The reported average salinity is calculated as:

$$
\begin{aligned}
\text { Average Salinity }= & (\Sigma[\text { Salinity at each absorbance value }] \mathrm{i}) / n, \text { for } i=1 \text { to } n \\
& n=\text { number of estimates of salinity }
\end{aligned}
$$

The average salinity is defined in this study as the water salinity. Salinity was calculated using both the raw data set and the normalised data set (Figures C18-C36).

\section{E1.3. Salinity Calculation when Product Water Absorbance > Feed Water Absorbance}

The situation where product water absorbance is greater than feed water absorbance arises due to the release of nano-particles and nano-ions from ZVM, ZVM TP and ZVM TPA. The assessment of salinity in this situation is demonstrated using the example illustrated in Figure E1c.

Figure E1c illustrates a typical example of a product water containing increased absorbance after 7.5 $h$ in the reaction environment. The normalised absorbance relationship is shown in Figure E1d. The presence of nano-particles is demonstrated by the increase in absorbance over the wavelength spectrum $>250 \mathrm{~nm}$ and the development of absorbance peaks and troughs (Figure E1c,d).

The example product water was extracted from the reactor and allowed to stand for $18.5 \mathrm{~h}$. This allowed some (but not all) of the nano-particles to settle. The resultant product water absorbance spectrum (Figure E1c,d) has a lower absorbance than the feed water spectrum. This indicates that the formation of nano-particles occurred while the water was desalinating.

The time period required to allow for settlement is a function of particle size, particle shape and particle density.

In each example the absorbance of the settled product water is less than the absorbance of the feed water. This change indicates that the product water salinity is less than the feed water salinity. It also allows the amount of desalination that has occurred to be determined using the regression equations (Table E1) defined from the control data set (Figure E1a,b).

In this example (Figure E1c,d) the raw data salinity assessment indicates a reduction in salinity from 2.467 to $1.63 \mathrm{~g} \cdot \mathrm{L}^{-1}$ (Figure E1c). The normalised data salinity assessment indicates a reduction in salinity from 2.467 to $0.71 \mathrm{~g} \cdot \mathrm{L}^{-1}$ (Figure E1c). The absorbance peaks at 500 and $700 \mathrm{~nm}$ indicate that some entrained nano-particles are still present in the water (Figure E1c,d).

The structure and composition of the entrained nano-particles can be assessed by subtracting the product water absorbance following settlement from the product water absorbance prior to settlement $[66,202]$.

\section{E1.4. Salinity Estimation from Raw Spectrum vs. Normalized Spectrum}

The formation of nano-particles (Figure E1c,d) will result in average salinity values based on raw absorbance spectra providing a higher estimate of salinity than calculations based on normalized spectra. This is demonstrated by the raw and normalized product water spectra in Figure E1c,d.

Placement of ZVM [20] or ZVM TPA [5] in saline water commonly results in the formation of a particle swarm of nano-particles which are associated with increasing EC [5,20]. This can result in the salinity assessed using raw and normalized data increasing during all or part of the treatment period (e.g., 
Figure C31e). More commonly, increases in salinity assessed using raw data are higher than salinities assessed using normalized data during reactor operation.

An example is illustrated in Figure E2a. In this example, the initial rise in salinity calculated from the raw absorbance spectra is followed by gradual decreases in salinity with time. These changes are accompanied by decreases in salinity calculated using the normalized absorbance spectra. The salinity calculated from the raw absorbance spectra, following settlement of the nano-particles, can approach the salinity calculated using the normalized absorbance spectra.
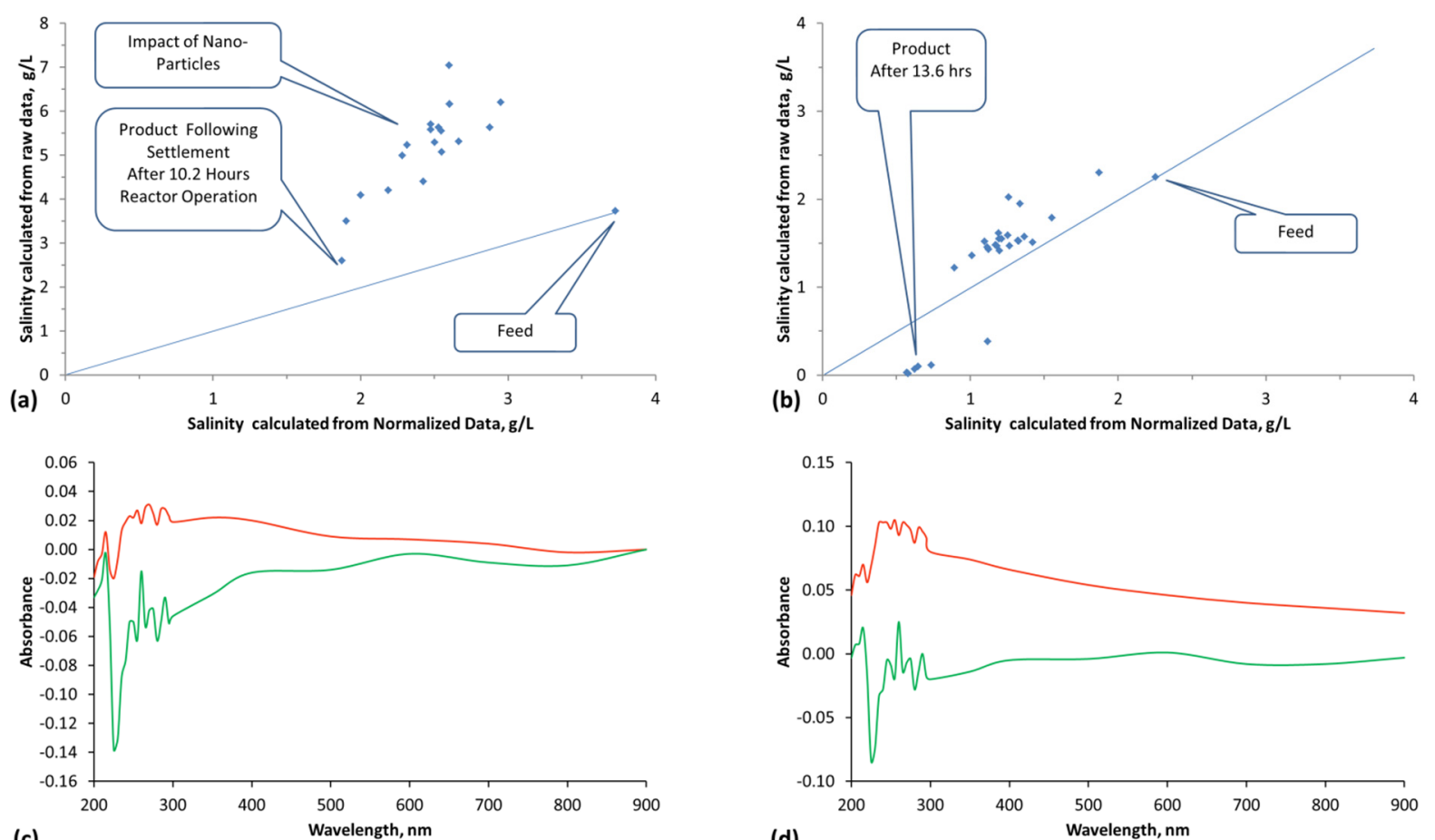

(c)

-Saline Feed Water at $\mathrm{t}=0 \quad$-Product water after 13.6 hours

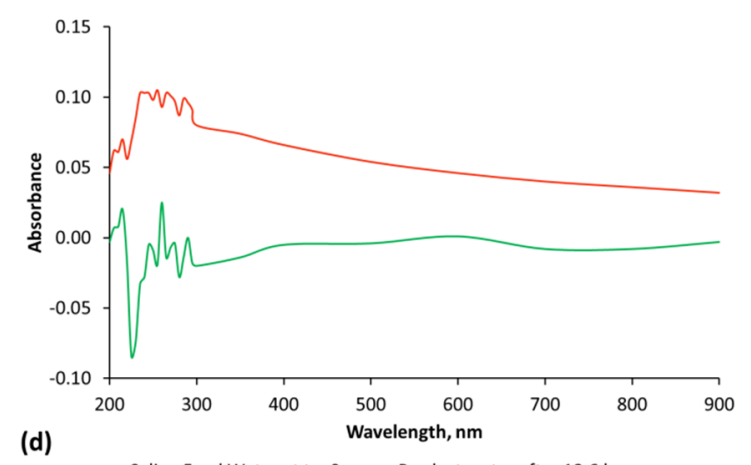

Figure E2. Salinity calculated from raw spectra and normalized cuvette corrected spectra. Reactor contains $0.24 \mathrm{~m}^{3}$. Operating temperature of water $=15-22{ }^{\circ} \mathrm{C}$ (varying with atmospheric temperature). Reusable cartridge contains $0.4 \mathrm{~kg}$ ZVM TPA when new. Saline water constructed by dissolving halite (Cheshire) in spring water. (a) Feed water salinity and growth of nano-particle concentration during reactor operation (10.2 h) and product salinity following settlement; (b) Feed water salinity and minor growth of nano-particle concentration during reactor operation and product salinity after $13.6 \mathrm{~h}$; (c) Normalized feed water and product water absorbance after $13.6 \mathrm{~h}$; (d) Raw feed water and raw product water absorbance after $13.6 \mathrm{~h}$.

The absorbance increase due to nano-particle formation can be less than the absorbance decrease due to salinity removal. In this situation the salinity assessed using both raw spectra and normalized spectra will decline with time. An example is illustrated in Figure E2b-d.

\section{E2. Salinity Estimation from Electrical Conductivity}

A conventional two component (water $+\mathrm{NaCl}$ ) water salinity analysis [27] calculates the feed water salinity as: 


$$
\mathrm{EC}=[A]+[B]
$$

where $A=\mathrm{EC}$ attributable to components other than $\mathrm{NaCl}$ in the feed water [27]. $B=\mathrm{EC}$ attributable to $\mathrm{NaCl}$ in the feed water [27].

There is a linear relationship between EC and salinity of the form:

$$
\text { Salinity, } \mathrm{g} \cdot \mathrm{L}^{-1}=[F][\mathrm{EC}]-[c]
$$

The operating instructions associated with most salinity (and EC) meters define: $[F]$ as 0.5 , and $[c]$ as zero. In practice, $[F]$ will be within the range 0.5 to 0.55 [27]. Most salinity studies using Equation (50), define $[c]$ as zero.

The actual values of $[F]$ and $[c]$ are water composition and measuring equipment specific. They may also vary with temperature.

A control regression relationship between EC and water salinity was established (Figure E3). This relationship establishes that EC can be used as a direct measure of salinity and defines $[F]$ as 0.501 and $[c]$ as 0.1 . This regression relationship was used to define salinity from EC in this study.

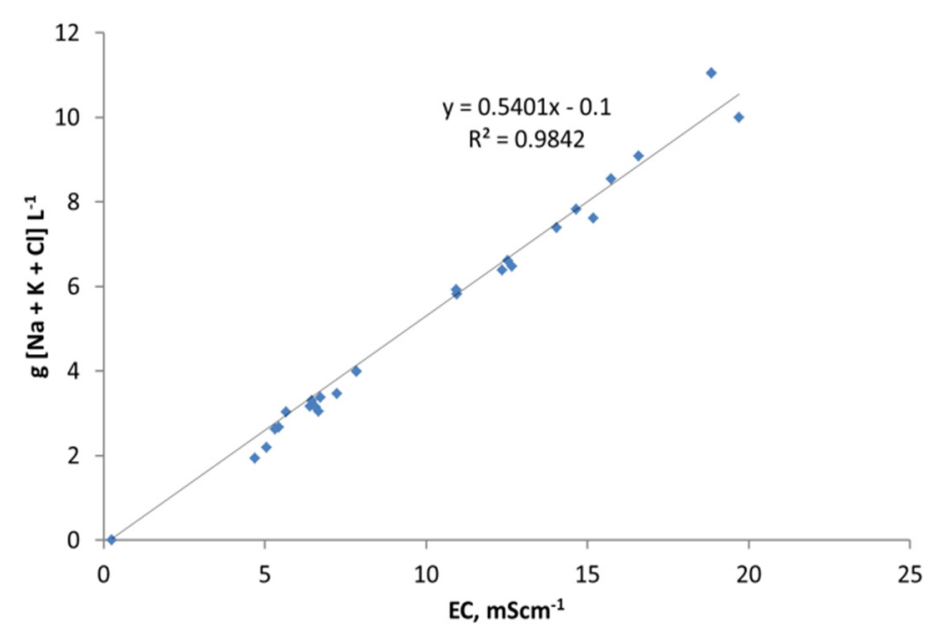

Figure E3. Control Relationship between measured EC and measured direct ion concentrations of $\mathrm{Na}+\mathrm{K}+\mathrm{Cl} . n=27$. Temperature $=4-6{ }^{\circ} \mathrm{C}$.

\section{E2.1. Salinity Estimation When EC Shows an Initial Rise Followed by an EC Decline}

The formation of nano-particles and nano-ions in water containing ZVM [5,6,20], or ZVM TPA [5] results in an initial rise in EC.

When EC shows an initial rise the interpretation methodology used in this study is:

$$
\mathrm{EC}=[A]+[B]+[C]
$$

where $C=$ EC attributable to nano-particles (or ions) added to the water by the ZVM (e.g., FeOOH, $\left.\mathrm{Fe}(\mathrm{OH})_{x}, \mathrm{Fe}_{x} \mathrm{O}_{y} \mathrm{H}_{z}\right)[27]$.

Aggregation and settlement of the nano-particles and nano-ions with time [5,6], and precipitation of ions (other than $\mathrm{NaCl}$ ) [5,6,18], results in a gradual decrease in $\mathrm{EC}[5,6]$.

Mass balances indicate that the general decline in EC with time, $t$, is calculated [27] as:

$$
\mathrm{EC}_{t}=[A]+[B]+[C]-[D]-[E]
$$


where $[D]=\mathrm{EC}$ attributable to removed $\mathrm{NaCl}[27] ;[E]=\mathrm{EC}$ attributable to removed components in the water, other than $\mathrm{NaCl}$ [27].

\section{E2.2. Salinity Estimation When the Volume of Water Reduces with Time}

Water volumes in static water bodies reduce with time due to evaporation and water consumption by ZVM (e.g., $\mathrm{Fe}^{0}+n \mathrm{H}_{2} \mathrm{O}=\mathrm{Fe}(\mathrm{OH})_{n}+n \mathrm{H}^{+}+n \mathrm{e}^{-}$). In a static water body containing no $\mathrm{ZVM}$, reductions in water volume due to evaporation (or freezing) will result in an increase in EC as the amount of $\mathrm{NaCl}$ held in the residual water remains constant.

The ZVM TP examples in Figures $\mathrm{C} 1-\mathrm{C} 15$ demonstrate increases in EC which are associated with partial freezing of the water where the majority of the $\mathrm{NaCl}$ is retained in the residual liquid water. They also demonstrate water volume reduction with time (e.g., Table 1, Table C1).

In these circumstances a mass balance analysis allows the amount of salt removed during desalination to be assessed.

The mass balance procedure adopted here is:

1. The residual salt concentration at time, $t$, in the reduced water body volume is $\left[\mathrm{RS}_{t=t}\right]\left(\mathrm{g} \cdot \mathrm{L}^{-1}\right)$.

2. The initial water volume at time $t=0$ is $\left[\mathrm{W}_{t=0}\right]$.

3. The water volume at time $\mathrm{t}=\mathrm{t}$ is $\left[\mathrm{W}_{t=t}\right]$.

4. The residual salt concentration at time $t$ in the water body volume is expressed here in terms of the original feed water volume is $\left[\mathrm{RS}_{\mathrm{a}}\right]\left(\mathrm{g} \cdot \mathrm{L}^{-1}\right)$, where:

$$
\begin{gathered}
\text { Residual Salt }\left[\mathrm{RS}_{\mathrm{a}}\right], \mathrm{g} \cdot \mathrm{L}^{-1}=\left(\left[W_{t=t}\right] /\left[W_{t=0}\right]\right)\left[\mathrm{RS}_{t=t}\right] \\
\text { e.g., } 1.25 \mathrm{~g} \cdot \mathrm{L}^{-1}=0.5 \mathrm{~L} / 1.0 \mathrm{~L} \times 2.5 \mathrm{~g} \cdot \mathrm{L}^{-1}
\end{gathered}
$$

5. The mass balance requires that the amount of $\mathrm{NaCl}$ removed is

$$
\begin{gathered}
\text { Salt Removed, } \mathrm{g} \cdot \mathrm{L}^{-1}=\left[\mathrm{S}_{t=0}\right]-\left[\mathrm{RS}_{\mathrm{a}}\right] \\
\text { where }\left[\mathrm{S}_{t=0}\right]=\text { salinity, } \mathrm{g} \cdot \mathrm{L}^{-1} \text {, at time } t=0 .
\end{gathered}
$$

In an open water body, the water volume $\left[\mathrm{W}_{t=t}\right]$ will be affected by five parameters:

$$
\left[W_{t=t}\right]=\left[W_{t=0}\right]-\left[W_{\mathrm{ZVM}}\right]-\left[W_{\text {Evap }}\right]-\left[W_{\text {outflow }}\right]+\left[W_{\text {Precip }}\right]+\left[W_{\text {Inflow }}\right]
$$

Where, $\left[W_{\mathrm{ZVM}}\right]=$ water removed by ZVM; $\left[W_{\text {Evap }}\right]=$ water removed by evaporation; $\left[W_{\text {outflow }}\right]$ = water removed from the water body, this includes leakage and infiltration; $\left[W_{\text {Precip }}\right]=$ water received from rainfall; $\left[W_{\text {Inflow }}\right]=$ water added to the water body.

This mass balance creates three patterns of EC change (associated with desalination) when ZVM TP is added to saline water:

1. EC rises, when water is removed at a rate, which is disproportionately larger than the rate of $\mathrm{NaCl}$ removal.

2. EC falls, when water is removed at a rate, which is disproportionately less than the rate of $\mathrm{NaCl}$ removal.

3. EC remains constant, when water is removed at a rate, which is similar to the rate of $\mathrm{NaCl}$ removal.

This creates a situation where an initial assessment based solely on the observation of a constant EC, may indicate no change in salinity. If the product water volume is less than the feed water volume, then 
the mass balance analysis (Equations (53) and (54)) will indicate that some $\mathrm{NaCl}$ removal has occurred.

\section{E3. Salinity Assessment When Nano-Particles Are Released from the ZVM TP/TPA}

In water containing ZVM [5,6,20], or ZVM TP/TPA [5,6], EC can rise due to the release of nano-particles. In this situation, application of Equation (52) requires the EC rise attributable to nano-particle formation to be separated from the EC decline associated with desalination.

The amount of desalination that has occurred under these circumstances can be assessed from a combination of EC and UV-visible spectroscopy data.

For example:

1. The EC may rise with time to a new equilibrium level, e.g., Figure E4a.

2. A UV-visible analysis of the data may establish that nano-particle formation (and addition) to the water continues after the EC has stabilised (Figure E4b).

In this example, nano-particle additions to the water continue after the $\mathrm{EC}$ has stabilised. Since the addition of nano-particles to water will increase EC by an amount $[C]$, it follows that following EC stabilisation, any increases in $[C]$ (resulting from nano-particle formation) are matched by a decrease in $\mathrm{EC}[D]$ which is associated with $\mathrm{NaCl}$ removal.
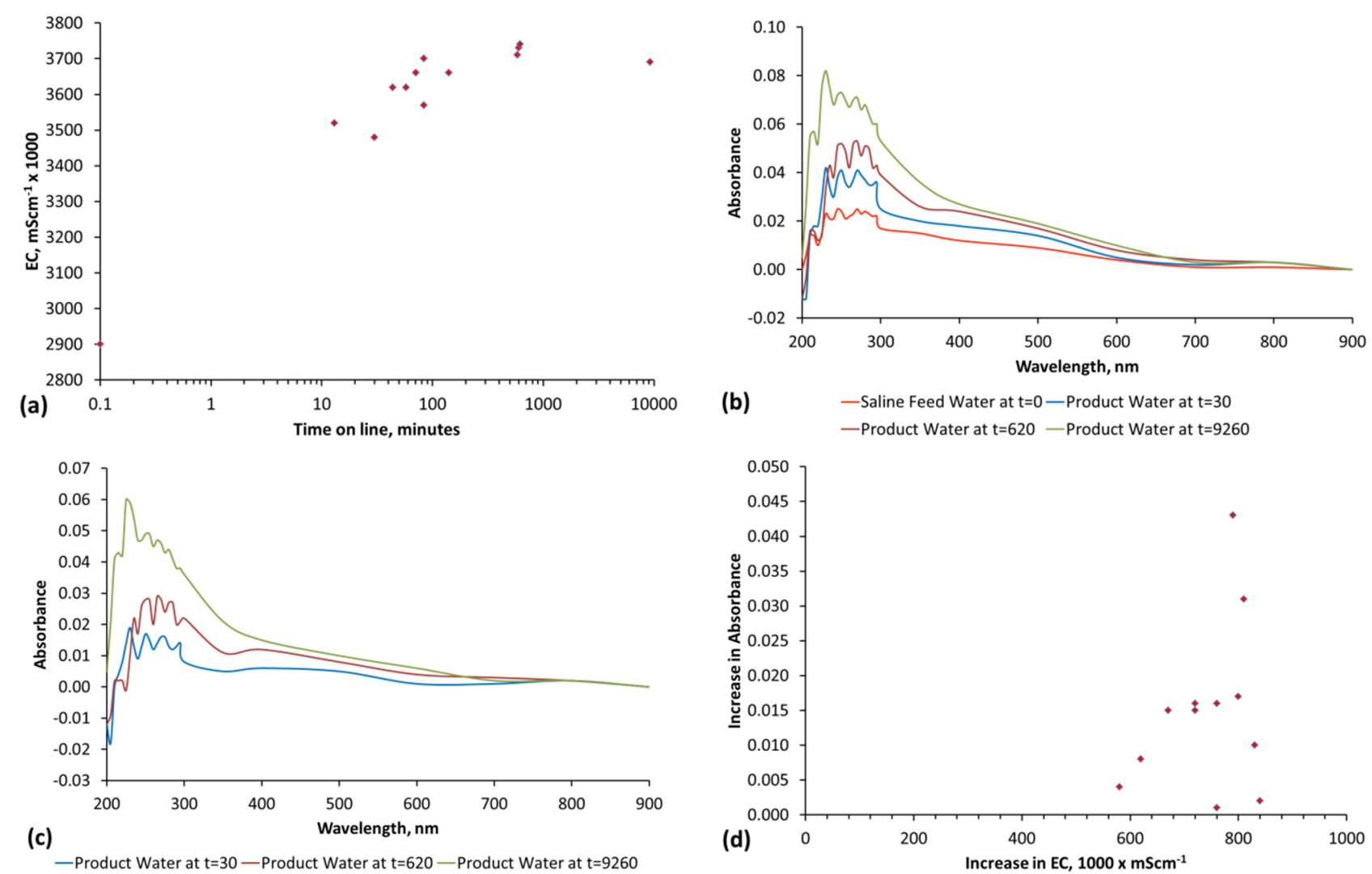

Figure E4. Cont. 

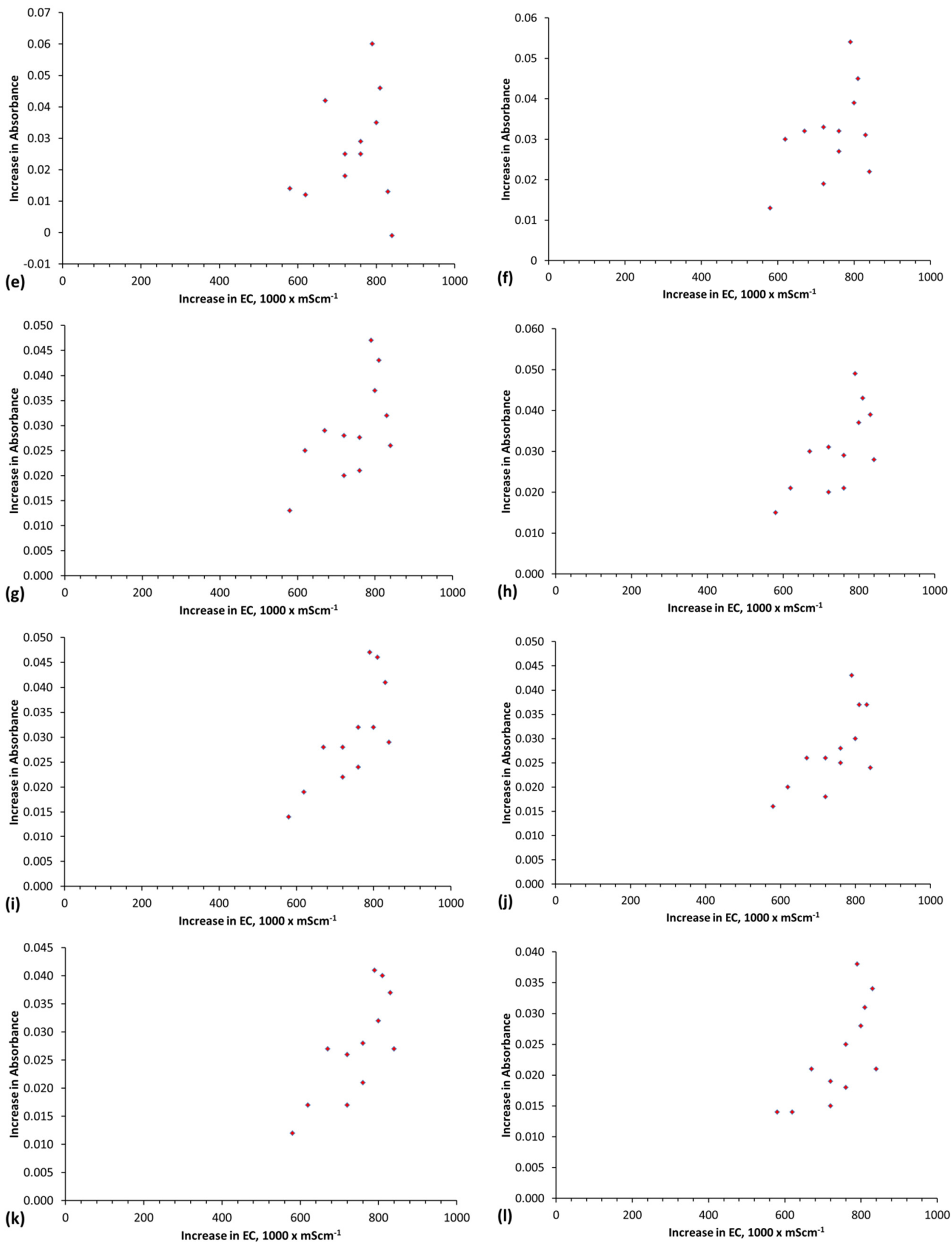

Figure E4. Cont. 

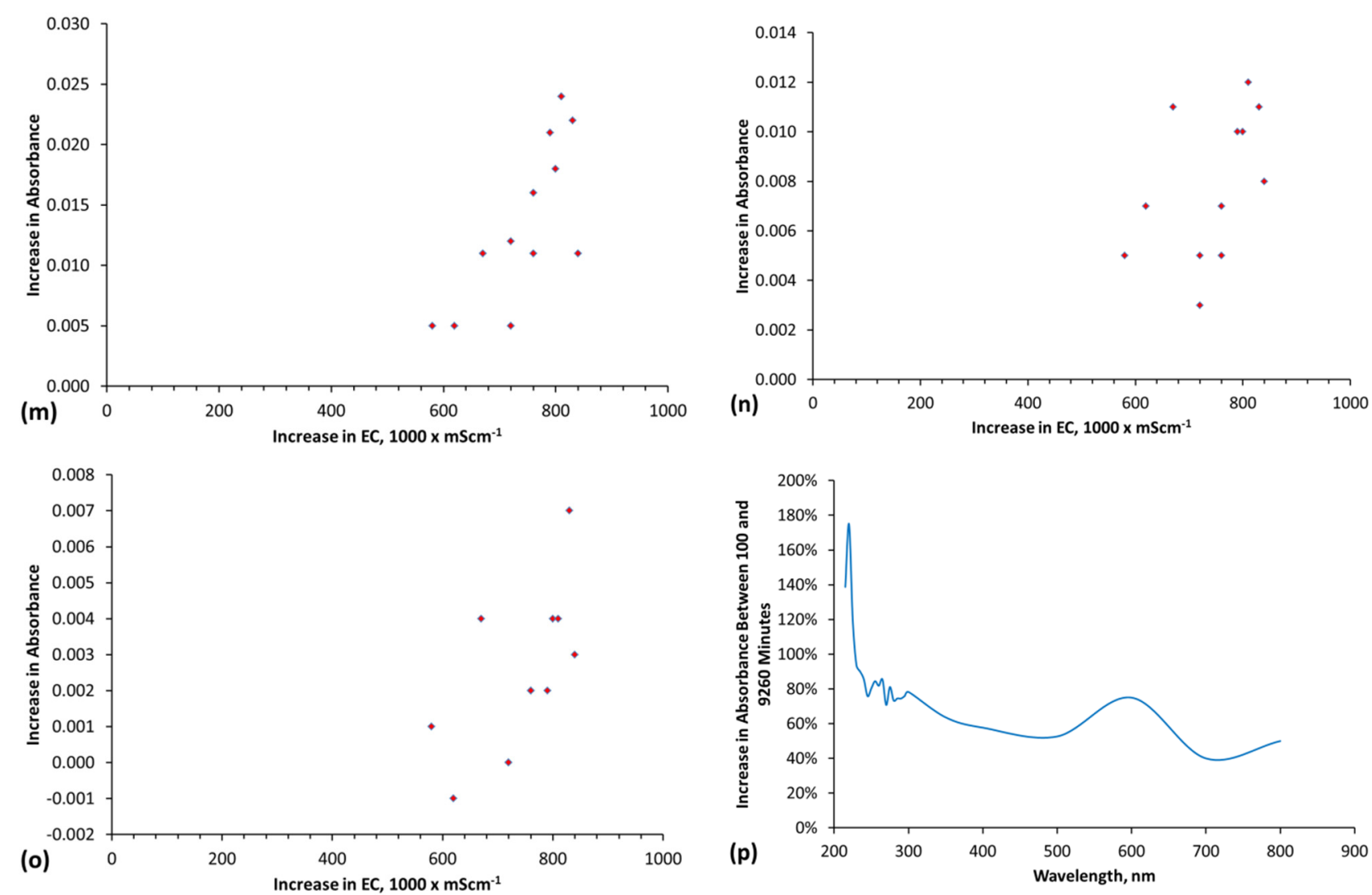

Figure E4. ZVM TPA example. (a) EC vs. Time; (b) Product water absorbance (relative to fresh water) as a function of time, $t . t=$ minutes; (c) Increase in absorbance due to nano-particles as a function of time; Relationship between increase in absorbance at different wavelengths and the increase in EC: (d) $215 \mathrm{~nm}$; (e) $225 \mathrm{~nm}$; (f) $235 \mathrm{~nm}$; (g) $245 \mathrm{~nm}$; (h) $255 \mathrm{~nm}$; (i) $265 \mathrm{~nm}$; (j) $275 \mathrm{~nm}$; (k) $285 \mathrm{~nm}$. (l) $295 \mathrm{~nm}$; (m) $350 \mathrm{~nm}$; (n) $500 \mathrm{~nm}$; (o) $700 \mathrm{~nm}$; (p) Increase in absorbance between 100 and $9260 \mathrm{~min}$. Reactor details: batch processing: $0.24 \mathrm{~m}^{3}$ water volume; initial water salinity $=1.33 \mathrm{~g} \cdot \mathrm{L}^{-1}$; Operating Temperature $=15-22{ }^{\circ} \mathrm{C}$ (atmospheric); Reactor location: External; ZVM TP cartridge: 0.4 kg: Feed Water: $\mathrm{EC}=2.9 \mathrm{mS} \cdot \mathrm{cm}^{-1} ; \mathrm{Eh}=0.181 \mathrm{~V} ; \mathrm{pH}=6.24 ; T=16.5^{\circ} \mathrm{C}$; Product Water: $\mathrm{EC}=3.69 \mathrm{mS} \cdot \mathrm{cm}^{-1} ; \mathrm{Eh}=0.173 \mathrm{~V} ; \mathrm{pH}=7.65 ; T=15^{\circ} \mathrm{C}$.

In the example illustrated in Figure E4a,b, $[A]=0.249 \mathrm{mS} \cdot \mathrm{cm}^{-1} ;[B]=2.651 \mathrm{mS} \cdot \mathrm{cm}^{-1}$. Decreases in $\mathrm{NaCl}$ concentration will reduce $[B]$ and will reduce salinity. The observed product water EC after $9260 \mathrm{~min}=3.69 \mathrm{mS} \cdot \mathrm{cm}^{-1}$ (Figure E4a). The increase in EC (assuming no desalination) is:

$$
\begin{gathered}
\mathrm{EC}=[A]+[B]+[C] \\
3.69=0.249+2.651+[C] \\
{[C]=3.69-[0.249+2.651]=0.79}
\end{gathered}
$$

where $C=$ EC attributable to nano-particles added to the feed water by the ZVM TP. 


\section{Identification of EC Due to Salinity Decline, when EC Rises Due to Nano-Particle Addition}

Stabilisation of the EC after a time, $t$, (e.g., Figure E4a) can occur as a direct result of either: (i) a cessation of nano-particle addition to the water; or (ii) continued addition of nano-particles to the water which is combined with $\mathrm{NaCl}$ removal from the water.

The difference in absorbance between the absorbance at $t=n$ and $t=0$ represents the absorbance added by the nano-particles. In the example illustrated in Figure E4a,b, the absorbance added by the nano-particles (Figure E4b,c) continues to increase following stabilisation of the EC (Figure E4a).

A cross-plot of EC increase $v s$. absorbance increase (at various wavelengths) shows a consistent pattern, where the initial increases in EC are associated with an increase in absorbance (Figure E4d-o). Once a critical maximum increase in EC is achieved, further increases in absorbance occur without increasing EC (Figure E4d-o).

Increases in absorbance with time indicate that the concentration of nano-particles in the water is increasing with time. Therefore the EC attributable to nano-particles $[C]$ will increase with time.

In Figure E4a, the EC becomes constant after $80 \mathrm{~min}$ of operation. This indicates that during the initial 80 min of operation $[C]>[E]$. Thereafter $[C]$ approximates to $[E]$. Figure E4p demonstrates that the absorbance (and EC) attributable to nano-particles increases, between 100 and 9260 operational minutes, by between $60 \%$ and $175 \%$. The nano-particle absorbance pattern (Figure E4p) is consistent (Table 3) with hydrated $n$-FeOOH (akaganeite) species being present in the water.

The expected increase in $[C]$ (from Figure E4a,p) associated with this increase in nano-particle abundance is $0.48-1.4 \mathrm{mS} \cdot \mathrm{cm}^{-1}$, where $0.48=0.6$ (from Figure E4p) $\times[C](0.79$, defined in Equation (56), and $1.4=1.75$ (from Figure E4p) $\times[C](0.79$, defined in Equation (56).

It follows that $[C]$ ranges between $[0.79+0.48]$ and $[0.79+1.4]$. The expected EC without desalination (i.e., if $[D]=0$ ), and without cation and anion removal (i.e., $[E]=0$ ) is therefore calculated as:

$$
\begin{gathered}
\mathrm{EC}_{9260 \min }=[A]+[B]+[C]-[D]-[E] \\
\mathrm{EC}_{9260 \mathrm{~min}}=[0.249]+[2.651]+[1.27 \text { to } 2.19]-[0]-[0] \\
\mathrm{EC}_{9260 \min }=4.17 \text { to } 5.09 \mathrm{mS} \cdot \mathrm{cm}^{-1}
\end{gathered}
$$

The observed EC9260 $\mathrm{min}=3.69 \mathrm{mS} \cdot \mathrm{cm}^{-1}$ (Figure E4a). The EC has remained constant after 80 to 100 min operation (Figure E4a). If $[A]$ remains unchanged (i.e., $[E]=0$ ), then $[D]$ is between 0.48 and $1.4 \mathrm{mS} \cdot \mathrm{cm}^{-1}$, calculated as EC9260 min (assuming no desalination (4.17 to $5.09 \mathrm{mS} \cdot \mathrm{cm}^{-1}$ )) - observed EC9260 min $\left(3.69 \mathrm{mS} \cdot \mathrm{cm}^{-1}\right)$.

The presence of ZVM results in a reduction in feed water cation and anion concentrations. Therefore, $[A]_{9260 \mathrm{~min}}$ is between 0 and $0.249 \mathrm{mS} \cdot \mathrm{cm}^{-1}$. If $[A]$ is reduced to $0 \mathrm{mS} \cdot \mathrm{cm}^{-1}$ (i.e., $[E]=0.249 \mathrm{mS} \cdot \mathrm{cm}^{-1}$ ) it follows that:

$$
\begin{gathered}
\mathrm{EC}_{9260 \mathrm{~min}} 3.69 \mathrm{mS} \cdot \mathrm{cm}^{-1}=[A]+[B]+[C]-[D]-[E] \\
\mathrm{EC}_{9260 \mathrm{~min}}=[0.249]+[2.651]+[1.27 \text { to } 2.19]-[0.729 \text { to } 1.649]-[0.249] \\
\mathrm{EC}_{9260 \mathrm{~min}}=3.69 \mathrm{mS} \cdot \mathrm{cm}^{-1}
\end{gathered}
$$


The water salinity at $9260 \mathrm{~min}$ is assessed as:

$$
\begin{gathered}
\text { Salinty } 9260 \mathrm{~min}, \mathrm{mS} \cdot \mathrm{cm}^{-1}=[B]-[D] \\
\text { EC9260 } \mathrm{min}=[2.651]-[0.729 \text { to } 1.649] \\
\text { Salinty } 9260 \mathrm{~min}=1.002-1.922 \mathrm{mS} \cdot \mathrm{cm}^{-1}
\end{gathered}
$$

The regression relationship between measured EC and measured salinity (Figure E3) indicates that the salinity of the water after $9260 \mathrm{~min}$ (6.4 days) is between 0.441 and $0.938 \mathrm{gNaCl} \cdot \mathrm{L}^{-1}$. The salinity removed is between 0.39 and $0.89 \mathrm{~g} \cdot \mathrm{L}^{-1}$.

Figure E4 establishes that changes in EC can be directly linked to increases in absorbance which are associated with the formation of nano-particles in the water. Nano-particles, when present as precipitants, will settle when the water is taken out of the reaction environment (Figure E4c-f). Therefore following settlement,

$$
C=C_{1}+C_{2}+C_{3}
$$

where, $C_{1}=$ entrained nano-particles and ions which impact on EC; $C_{2}=$ dissolved ions which do not have a major impact on absorbance; $C_{3}=$ entrained nano-particles which would be removed by a longer settlement period.

\section{Appendix F. Summary of the Interaction between Fe Corrosion, Eh, pH, EC and Salinity Removal}

Zero Valent Metal (native metal with an oxidation state of zero) is stable and will not oxidize if the water Eh and $\mathrm{pH}$ is maintained at specific levels [19]. The trials (Appendix C) demonstrate that the water $\mathrm{pH}$ was maintained between $\mathrm{pH}=5$ and $\mathrm{pH}=12$ (typically between $\mathrm{pH}=7$ and $\mathrm{pH}=9$ ).

Under these conditions (at 1 atmosphere pressure and at $25^{\circ} \mathrm{C}$ ),

(1) Aluminium will remain at its water-metal contact as $\mathrm{Al}^{0}$ provided that the Eh is less than [19]:

$$
\mathrm{Eh}, \mathrm{V}=-1.55-0.0591 \mathrm{pH}
$$

At higher Eh the dominant product species is $\mathrm{Al}_{2} \mathrm{O}_{3}$ (typically $\mathrm{Al}(\mathrm{OH})_{3}$ ), and the dominant oxidation state is $\mathrm{Al}^{\mathrm{III}}$. At a $\mathrm{pH}$ above 8.5 [19] some of the $\mathrm{Al}_{2} \mathrm{O}_{3}$ will be present at $\mathrm{AlO}_{2}^{-}$[19]. The relationships between $\mathrm{Eh}$ and $\mathrm{pH}$ for the different equilibrium aluminium species are provided by: [19,229-231]. The $\mathrm{Eh}$ and $\mathrm{pH}$ of the product water (Figures $\mathrm{C} 1-\mathrm{C} 17$ ) indicate that the $\mathrm{Al}^{0}$ is held outside the passivation range, and that the dominant corrosion ion will be $\mathrm{AlO}_{2}^{-}[19,230]$. The transition from $\mathrm{Al}^{0}$ to $\mathrm{AlO}_{2}{ }^{-}$results in both water consumption and the production of $\mathrm{H}^{+}$(e.g., $\mathrm{Al}+2 \mathrm{H}_{2} \mathrm{O}=\mathrm{AlO}_{2}^{-}+4 \mathrm{H}^{+}($ads $)+3 \mathrm{e}^{-} ;[19,229-231]$

(2) Copper will remain at its water-metal contact as $\mathrm{Cu}^{0}$ provided that the Eh is less than [19]:

$$
\mathrm{Eh}, \mathrm{V}=0.41-0.0591 \mathrm{pH}
$$

Between this Eh (Equation (62) and the Eh defined in Equation (63), $\mathrm{Cu}$ is present as $\mathrm{Cu}_{2} \mathrm{O}$ (i.e., $\mathrm{Cu}^{\mathrm{I}}$ ). At higher $\mathrm{Eh}$ it is present as $\mathrm{CuO}$ (i.e., $\mathrm{Cu}^{\mathrm{II}}$ ). Equation (63) provides the precipitant boundary between $\mathrm{Cu}^{\mathrm{I}}$ and $\mathrm{Cu}^{\mathrm{II}}$ corrosion species [19]:

$$
\mathrm{Eh}, \mathrm{V}=0.669-0.0591 \mathrm{pH}
$$


The Eh and $\mathrm{pH}$ of the product water (Figures $\mathrm{C} 1-\mathrm{C} 17$ ) indicate that the $\mathrm{Cu}^{0}$ is held outside the passivation range for much of the reaction time, with the dominant precipitated products (in saline water) likely to be $\mathrm{CuO}$ and $\mathrm{Cu}_{2} \mathrm{O}[19,232-234]$.

(3) Iron will remain at its water-metal contact as $\mathrm{Fe}^{0}$ provided that the Eh is less than [19]:

$$
\text { Eh, } \mathrm{V}=-0.44 \log \left(\mathrm{Fe}^{2+}(\mathrm{aq})\right) \text { for } \mathrm{pH}=6 \text { for } \log \left(\mathrm{Fe}^{2+}\right)=0 \text { and } \mathrm{pH}=9 \text { for } \log \left(\mathrm{Fe}^{2+}\right)=-6
$$

At higher $\mathrm{pH}(\mathrm{pH} \geq 9)$ the boundary is defined as [19]:

$$
\mathrm{Eh}, \mathrm{V}=-0.047-0.0591 \mathrm{pH}
$$

The Eh and $\mathrm{pH}$ of the product water (Figures $\mathrm{C} 1-\mathrm{C} 17$ ) indicate that the $\mathrm{Fe}^{0}$ is held outside the passivation range for much of the reaction time, with the dominant precipitated products (in saline water) likely to be $\mathrm{Fe}_{2} \mathrm{O}_{3}$ species, i.e., $\mathrm{FeOOH}[19,235]$.

\section{F1. Oxidation of $\mathrm{Fe}^{\mathrm{0}}$}

$\mathrm{Fe}^{0}$ has an oxidation number of zero. The oxidation number of iron increases as it corrodes $\quad[18,19,67-78,82-104,111-114,162-168,172-176,190,203,204,208,235-240] . \quad$ The initial corrosion product is $\mathrm{Fe}^{\mathrm{II}}$ (e.g., white rust, $\mathrm{Fe}(\mathrm{OH})_{2}$ ). The $\mathrm{Fe}^{\mathrm{II}}$ gradually replaces the $\mathrm{Fe}^{0}$. With increased oxidation, the white rusts are replaced by, or template the formation of green rusts (platy combinations of $\mathrm{Fe}^{\mathrm{II}}$ and $\mathrm{Fe}^{\mathrm{III}}$ ) (Figure $\mathrm{F} 1$ ). These are then replaced with increased oxidation by yellow to brown to red, to purple, to black rusts (FeOOH). Figure F1 illustrates the morphology of these different rust types and the key features which are involved in the removal of $\mathrm{NaCl}$. Figure $\mathrm{F} 1$ demonstrates a number of important points [18,19,72-78,82-100,102-104,137-140,162-168,172-176,190,203,204,208,235-240]:

1. During corrosion the $\mathrm{Fe}^{0}$ core is initially oxidized to $\mathrm{Fe}(\mathrm{OH})_{2}$.

2. The $\mathrm{Fe}(\mathrm{OH})_{2}$ acts as a template for $\mathrm{FeOOH}$ growth (rusty purple) around the particle (Figure F1). i.e., a $\mathrm{Fe}^{0}$ particle will corrode to have an $\mathrm{Fe}^{0}$ core, an $\mathrm{Fe}(\mathrm{OH})_{2}$ inner layer (or $\mathrm{Fe}_{3} \mathrm{O}_{4}$ inner layer) and an $\mathrm{FeOOH}$ outer layer.

3. The FeOOH templates the formation of green rust $\left(\mathrm{Na}_{(a=1-c-b)} \mathrm{Fe}_{(b=1-c-a)}^{\mathrm{II}} \mathrm{Fe}^{\mathrm{III}} c(\mathrm{OH})_{2}\right]^{x^{-}}$. $\left.\left[(x / n) \mathrm{Cl}^{n^{-}} \cdot m \mathrm{H}_{2} \mathrm{O}\right]^{x+}\right)$ sheets growing into the water body from the corroded Fe particle. With increased oxidation these plates gradually transform to $\mathrm{FeOOH}$. In the presence of $\mathrm{Cl}^{-}$ions, any $\alpha-\mathrm{FeOOH}$ (goethite) or $\gamma$-FeOOH (lepidocrocite) which may initially form, transforms to $\beta$ $\mathrm{FeOOH}$ (akaganeite) over time. In the presence of $\mathrm{HCO}_{3}{ }^{-}, \mathrm{CO}_{3}{ }^{2-}$ ions, $\mathrm{Cl}^{-}$is replaced in the green rust by $\mathrm{CO}_{3}{ }^{2-}$. In the presence of $\mathrm{SO}_{4}{ }^{2-}$ ions, $\mathrm{Cl}^{-}$(and $\mathrm{CO}_{3}{ }^{2-}$ ions) are replaced by $\mathrm{SO}_{4}{ }^{2-}$. In the presence of $\mathrm{SO}_{4}{ }^{2-}$ ions, goethite is the dominant $\mathrm{FeOOH}$ species and any akagneite formed will transform to goethite. In the presence of high concentrations of $\mathrm{HCO}_{3}{ }^{-}, \mathrm{CO}_{3}{ }^{2-}$ ions the green rust (and some of the $\mathrm{FeOOH}$ ) may be replaced by $\mathrm{FeCO}_{3}$ [236]. In freshwater, lepidiocrocite and goethite are the dominant $\mathrm{FeOOH}$ species. A more detailed analysis of the interaction of $\mathrm{HCO}_{3}{ }^{-}, \mathrm{CO}_{3}{ }^{2-}, \mathrm{Cl}^{-}$, and $\mathrm{SO}_{4}{ }^{2-}$ ions is provided in Section 6.

4. The dissolved $\mathrm{Fe}^{n^{+}}$ions in the water are oxidized to form spherulites of $\mathrm{FeOOH}$ which are entrained in the water. 


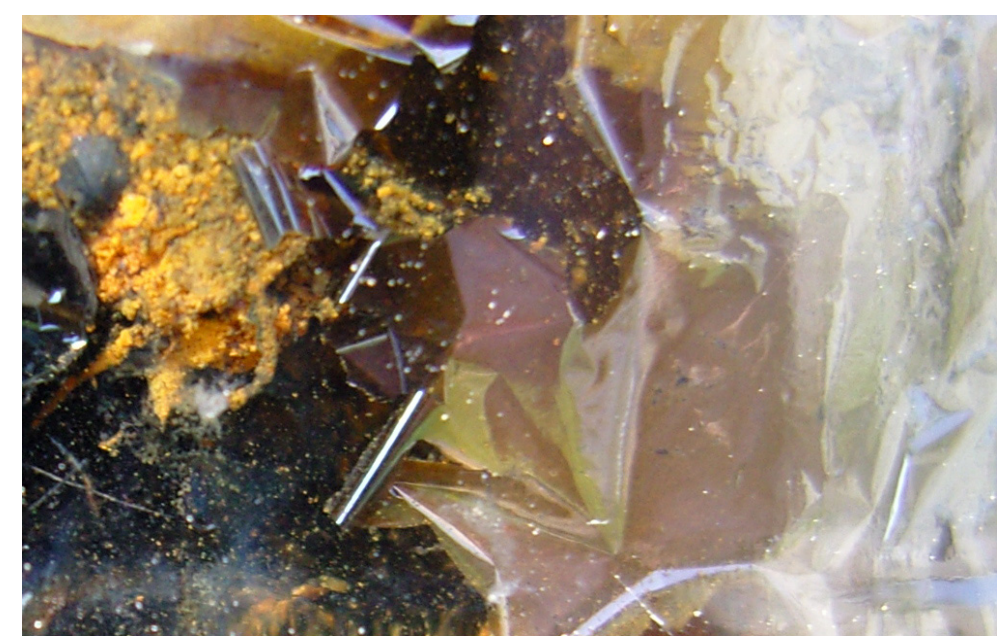

Figure F1. Corrosion features associated with fibrous $(0.1 \mathrm{~mm}$ diameter $) \mathrm{Fe}^{0}$ in saline water [PS14], photographed following conclusion of the desalination trial. Black $=$ water filled porosity. Orange/yellow spheroids $=$ hydrated $\beta$-FeOOH $\cdot m \mathrm{H}_{2} \mathrm{O}\left(\mathrm{Fe}^{3+} \mathrm{O}(\mathrm{O}, \mathrm{Cl})\right)$ formed by precipitation of $\mathrm{Fe}^{3+}$ ions in the water. Dark grey nodules surrounded by orange spheroids = bog iron $\left(\mathrm{Fe}_{3} \mathrm{O}_{4}\right.$, magnetite). Off white to green and purple sheets growing into the water from the bright white rods $=$ mixed valance green rust complex $\left(\mathrm{Na}_{(a=1-c-b)} \mathrm{Fe}_{(b=1-c-a)} \mathrm{Fe}^{\mathrm{II}}{ }_{c}{ }_{c}(\mathrm{OH})_{2}\right]^{x-} \cdot\left[(x / n) \mathrm{Cl}^{n-} \cdot m \mathrm{H}_{2} \mathrm{O}\right]^{x+}$, where $\left.a+b+c=1\right)$ formed from the accretion of $\mathrm{Fe}^{2+}$ and $\mathrm{Fe}^{3+}$ ions in the water. The bright white rods of $\mathrm{Fe}(\mathrm{OH})_{2}$ pseudomorph after and surround a $\mathrm{Fe}^{0}$ core. They are the initial corrosion product. They are initially replaced at the water interface by purple, $\beta$-FeOOH. These act as a template for green rusts $\left(\mathrm{Na}_{(a=1-c-b)}^{\mathrm{I}} \mathrm{Fe}_{(b=1-c-a)} \mathrm{Fe}^{\mathrm{II}}{ }_{c}(\mathrm{OH})_{2}\right]^{x-} \cdot\left[(x / n) \mathrm{Cl}^{n-} \cdot m \mathrm{H}_{2} \mathrm{O}\right]^{x+}$, where $\left.a+b+c=1\right)$ sheets. The green rusts are gradually replaced by $\left(\beta-\mathrm{Fe}^{3+} \mathrm{O}(\mathrm{O}, \mathrm{Cl}) \cdot n \mathrm{H}_{2} \mathrm{O}\right)$. The increase in the proportion of $\mathrm{Fe}^{\mathrm{III}}$ species is initially signified by a rusty purple color which is then replaced by a yellow color when the precipitate is dominated by highly hydrated $\mathrm{FeOOH} \cdot m \mathrm{H}_{2} \mathrm{O}$. The purple $\mathrm{FeOOH}$ becomes increasingly yellow in color with increased hydration. Fe corrosion species in this photograph have been identified by their color and morphology. The left edge (centre) of the photograph truncates a trapped hydrogen gas bubble. The formation of the grey precipitate is associated with the upper surface of the gas bubble. Field of view $=2 \mathrm{~cm}$. The common colors of the various $\mathrm{Fe}_{2} \mathrm{O}_{3}, \mathrm{Fe}_{3} \mathrm{O}_{4}$ corrosion species are: (i) hematite = red; (ii) maghemite = reddish brown; (iii) magnetite = black; (iv) goethite = yellow brown; (v) = lepidococite = orange; (vi) ferrihydrite = red-brown; (vii) akaganeite $=$ purple to red brown/purple to orange/yellow; (viii) layered double hydroxides (white and green rusts) $=$ white to green. The purple colour indicates the incorporation of $\mathrm{Na}^{+}$(see Appendix $\mathrm{H}$ ).

$\mathrm{NaCl}$ is removed from the overlying water body by:

1. Entrapment in the growing $\mathrm{FeOOH}$ and $\left(\mathrm{Na}_{(a=1-c-b)}^{\mathrm{I}} \mathrm{Fe}^{\mathrm{II}}{ }_{(b=1-c-a)} \mathrm{Fe}^{\mathrm{III}}{ }_{c}(\mathrm{OH})_{2}\right]^{x^{-}}$ $\left.\left[(x / n) \mathrm{Cl}^{n^{-}} \cdot m \mathrm{H}_{2} \mathrm{O}\right]^{x^{+}}\right)$sheets;

2. Concentration in the pore water and hydration shells surrounding the $\mathrm{FeOOH}$ and $\left.\left(\mathrm{Na}_{(a=1-c-b)}^{\mathrm{I}} \mathrm{Fe}_{(b=1-c-a)} \mathrm{Fe}^{\mathrm{II}}{ }_{c}(\mathrm{OH})_{2}\right]^{x-} \cdot\left[(x / n) \mathrm{Cl}^{n^{-}} \cdot m \mathrm{H}_{2} \mathrm{O}\right]^{x^{+}}\right)$sheets. 
The relationship between $\mathrm{Fe}$ corrosion and the presence of $\mathrm{NaCl}$ in the water is described further in Appendices $\mathrm{G}$ and $\mathrm{H}$.

\section{F2. Relationship between Eh, pH, Ion Concentration, and Equilibrium Constant, $K$}

For any reaction at STP and at $\mathrm{pH}=0$, its standard electropotential is defined as $\Delta E^{0}$. This $\Delta E^{0}$ is related to the Standard Gibbs Free Energy $\Delta G^{0}$ for the reaction through the equation $[18,19,150]$ :

$$
\Delta G^{0}=-n F \Delta E^{0}
$$

where $n=$ number of electrons transferred and $F=$ Faraday constant. These two parameters, $\Delta E^{0}$ and $\Delta G^{0}$ are related to the equilibrium constant, $K$, standard heat of formation, $\Delta H^{0}$, temperature $(\mathrm{K}), T$, and the standard entropy $\Delta S^{0}$ through the equations $[18,19,150]$ :

$$
\begin{gathered}
\Delta G^{0}=\Delta H^{0}-T \Delta S^{0} \\
\Delta G^{0}=-\mathrm{R} T \times \ln K \\
\Delta E^{0}=\mathrm{R} T / n F \times \ln K
\end{gathered}
$$

where $\mathrm{R}=$ gas constant It follows from Equation (67), that if the temperature changes, then $K, \Delta E, \Delta G$, $\Delta H, \Delta S$ are also known for the new temperature at a constant $\mathrm{pH}$.

$\Delta E^{0}$ which is defined at $\mathrm{pH}=0$, can be redefined for the $\mathrm{pH}$ observed in the water at time $t$, where for a reaction converting one ion to another the observed Eh indicates [19]:

$$
\mathrm{Eh}=\Delta E^{0}-0.0591 \mathrm{~m} / n \times \mathrm{pH}+0.0591 / n \times \log \left(M_{\mathrm{P}} / M_{\mathrm{R}}\right)
$$

$m=$ number of hydrogen ions transferred; $M_{\mathrm{P}}=$ Molar concentration of product ion; $M_{\mathrm{R}}=$ molar product of the reactant ion.

The limits of domain between two solid corrosion products, or ZVM and a solid corrosion product become [19]:

$$
\mathrm{Eh}=\Delta E^{0}-0.0591 \mathrm{~m} / \mathrm{n} \times \mathrm{pH}
$$

The limits of domain between an ion and a solid corrosion product becomes [19]:

$$
\begin{gathered}
\mathrm{Eh}=\Delta E^{0}-0.0591 \mathrm{~m} / n \times \mathrm{pH}+0.0591 / n \times \log \left(M_{\mathrm{P}}\right) \text { or for } \mathrm{pH} \text { independent reactions } \\
\mathrm{Eh}=\Delta E^{0}+0.0591 / n \times \log \left(M_{\mathrm{P}}\right) \text { or for Eh independent reactions } \\
\log \left(M_{\mathrm{P}}\right)=-\mathrm{d}-\mathrm{pH}
\end{gathered}
$$

$\mathrm{d}=\mathrm{a}$ constant $[19]$.

It follows from these relationships that if the temperature, Eh and $\mathrm{pH}$ are known for a reaction where $\Delta E^{0}$, or $\Delta G^{0}$ is known, that $\mathrm{K}, \Delta E, \Delta G, \Delta H, \Delta S$ are also known.

\section{F2.1. Measurement of Eh}

Most standard redox meters determine ORP (oxidation reduction potential). They use either platinum, or gold electrodes, and can be supplied in a $\mathrm{Ag} / \mathrm{AgCl}(\mathrm{KCl}) \mathrm{gel}$. Eh is the value referenced to the standard hydrogen electrode (SHE). The relevant measurement standards are defined in British Standard (BS ISO 11271:2002 BS 7755-3.14:2002 [241]) and the international standard ISO 11271:2002 [242]. Depending 
on the instrument manufacturer, the Eh is either measured directly by the instrument (following use of a suitable calibration fluid, e.g., calomel, $\mathrm{KCl}$, quinhydrone), or the Eh is calculated as [243-248]:

$$
\mathrm{Eh}, \mathrm{mV}=\mathrm{ORP}+E_{\mathrm{m}}
$$

ORP $=$ Oxidation - reduction potential, $\mathrm{mV}$, measured by a standard $\mathrm{pH} / \mathrm{ORP}$ meter, ORP meter, or ORP electrode. $E_{\mathrm{m}}$ varies with temperature and is calculated as:

$$
E_{\mathrm{m}}=E_{\mathrm{SHE}}-E_{\mathrm{Ref}}
$$

$E_{\mathrm{SHE}}=$ The $\mathrm{Eh}$ of the standard hydrogen electrode (e.g., $E_{\mathrm{SHE}}=-2.3591 T+483.82$ ); $T=$ temperature, ${ }^{\circ} \mathrm{C} ; E_{\mathrm{Ref}}=$ The ORP reading in the calibration fluid (e.g., $3 \mathrm{M} \mathrm{KCl}$ saturated with $\left.\mathrm{Ag} / \mathrm{AgCl}, E_{\mathrm{Ref}}=-1.6284 T+259.18\right)$. A variety of different calibration fluids and correlations are available.

\section{F2.2. Removal of $\mathrm{NaCl}$ in a Redox Environment}

$\mathrm{NaCl}$ remains as $\mathrm{Na}^{+}$and $\mathrm{Cl}^{-}$ions in an aqueous environment [19]. These ions can be incorporated in two Fe corrosion species, ferrous hydroxychloride (Green Rust) [69,75] and akaganeite [70,87,88,96] (Figure F1).

Alternatively they can be held in the hydration shells surrounding $\mathrm{FeOOH}$ spp. and the green rust. In this instance, the relationship between $\mathrm{Eh}$ and $\mathrm{pH}$ may control the relative amount of $\mathrm{NaCl}$ held in the hydration shells:

$$
\mathrm{Eh}=\Delta E^{0}-0.0591 \mathrm{~m} / n \times \mathrm{pH}+0.0591 / n \times \log \left(M_{\mathrm{HS}} / M_{\mathrm{RS}}\right)
$$

where $M_{\mathrm{HS}}=\mathrm{NaCl}$ held in hydration shells; $M_{\mathrm{RS}}=$ residual $\mathrm{NaCl}$ held in the water. The total amount of $\mathrm{NaCl}, M_{\mathrm{ts}}$, in the reaction environment is:

$$
M_{\mathrm{tS}}=M_{\mathrm{HS}}+M_{\mathrm{RS}}
$$

Once the hydration shells become saturated, $\log \left(M_{\mathrm{HS}} / M_{\mathrm{RS}}\right)$ will remain constant. $\log \left(M_{\mathrm{HS}} / M_{\mathrm{RS}}\right)$ is a measure of the residual salinity $[F]$ in the water where $[F]=([A]-[D])$, and $[F],[A]$ and $[D]$ can be measured. $M_{\mathrm{HS}}$ is a function of $[D]$ and $M_{\mathrm{RS}}$ is a function of $[F]$. It follows that the salinity which results in the hydration shells become saturated $[F]$ will result in a constant EC being observed.

This situation is defined in this study as an equilibrium position, but could be defined as pseudo-equilibrium position or a steady state position. In Figures $\mathrm{C} 5-\mathrm{C} 9$, the abrupt switch from a declining EC with time, to a constant EC (or slightly declining EC) with time, is accompanied by relatively constant values of $\mathrm{pH}$ and Eh. This suggests, from Equation (73) that the constant EC represents a period where $\log \left(M_{\mathrm{HS}} / M_{\mathrm{RS}}\right)$ is constant (i.e., is in a stable equilibrium).

If $\mathrm{EC}$, Eh and $\mathrm{pH}$ are constant, then it follows that the chemical relationship between the $\mathrm{NaCl}$ dissolved in the water and the $\mathrm{NaCl}$ which has been removed by the ZVM TP is in equilibrium. All references to equilibrium involving a steady state $\mathrm{EC}, \mathrm{pH}$ and $\mathrm{Eh}$ in this study reflect this definition.

It follows from Equations (66)-(68) that if the equilibrium value of Eh is known, that the equilibrium values of $K, \Delta E, \Delta G, \Delta H, \Delta S$ are also known.

Figure F2 illustrates a typical example where EC stabilizes to an equilibrium position. This equilibrium position is associated with a stable Eh and $\mathrm{pH}$ (Figure C5). The example demonstrates 134 oscillations in EC, which can be interpreted [18] as galvanic charge:discharge cycles. 
The exponential decline in EC, under this model, reflects a specific capacity (specific capacitance) which reduces with time. The Columbic efficiency, at the point equilibrium is reached is $0 \%$.

The Columbic efficiency, $C_{e}[122]$ is calculated as,

$$
C_{e}=t_{d} / t_{c} \times 100
$$

$t_{d}=$ discharge time: $t_{c}=$ charging time.

FeOOH nano-rods grown on a carbon substrate have been demonstrated to operate as capacitors over 5000 charge:discharge cycles without a decrease in capacitance [129]. The specific capacitance of the $\mathrm{FeOOH}$ decreases as the structure becomes laminated [129], e.g., through the accretion of green rust layers (Figure F1), or accretion and coalescence of FeOOH colloids (Figure F1). Increasing the C:Fe $\mathrm{FII}^{\mathrm{III}}$ proportion can increase the specific capacitance [130], e.g., through the presence of $\mathrm{CO}_{3}{ }^{2-}$ ions, as demonstrated by PS15 and PS16. The structuring of the FeOOH nanorods as colloidal, or spherical, or flower like structures can increase their specific capacitance [131], e.g., Figure F1.

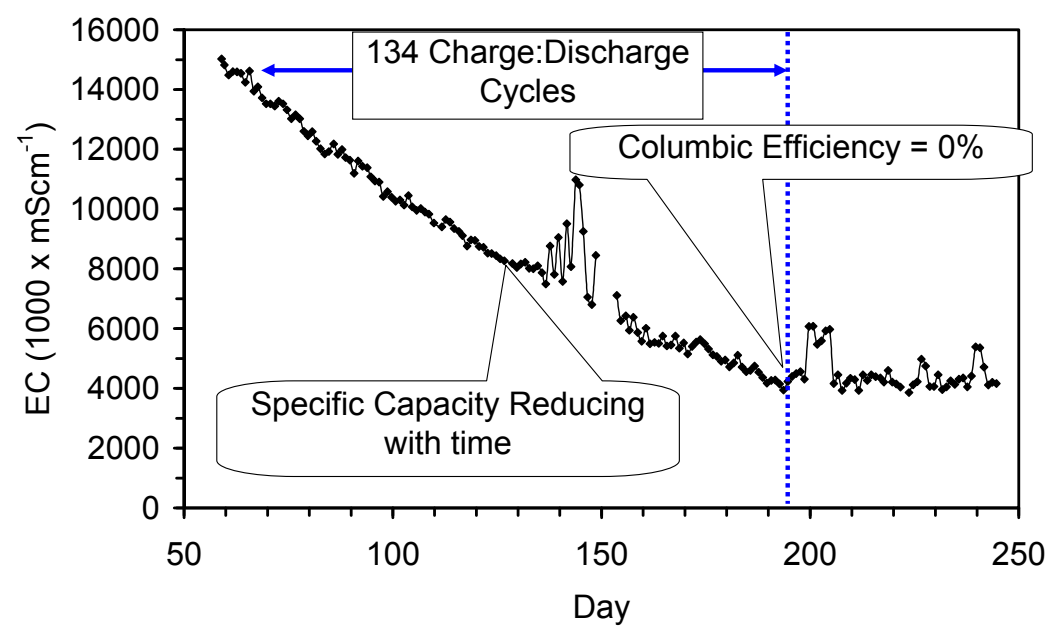

Figure F2. Impact of progressively reducing water salinity on the rate of desalination with time. ZVM TP Trial ST1a: Extracted from Figure C5.

\section{F3. Relationship between EC and Reaction Kinetics}

Salinity reduction by reaction, catalysis, or adsorption involves reaction kinetics [18]. This allows quantitative data such as EC (or salinity) to be reconfigured in terms of temperature, $T, \mathrm{ZVM}$ TP/TPA concentration, particle size and particle surface area [18].

An understanding of how EC changes are related to reaction kinetics can allow the rate of desalination to be increased, the cost of desalination to be decreased, and both the amount of, and composition of, the ZVM TP to be optimised. It can also provide a commercial and technical basis for understanding both the desalination behaviour and variability associated with a specific batch of ZVM TP.

The interaction of kinetics with desalination can be assessed as follows:

1. If $[A]$ is small and [C] is small, then EC at time $t$ can be assessed [27] as:

$$
\mathrm{EC}_{t}=[F]=[A]-[D]
$$

2. The magnitude of $[D]$ is a function of the reaction rate, $k$, where [18]: 


$$
k_{\text {observed }}=k_{\text {actual }} \times\left[P_{\mathrm{w}}\right] \times\left[a_{\mathrm{s}}\right]
$$

Where $\left[P_{\mathrm{w}}\right]=$ amount of ZVM, $\mathrm{g} \cdot \mathrm{L}^{-1} ;\left[a_{\mathrm{s}}\right]=$ surface area of ZVM, $\mathrm{m}^{2} \cdot \mathrm{g}^{-1}$.

$k_{\text {observed }}=$ observed reaction rate; $k_{\text {actual }}=$ actual reaction rate.

3. For a constant $\left[P_{\mathrm{w}}\right],[D]$ will decrease as $\left[a_{\mathrm{s}}\right]$ decreases (i.e., the length of time required to reduce the salinity of water from $x \mathrm{~g} \cdot \mathrm{L}^{-1}$ to $y \mathrm{~g} \cdot \mathrm{L}^{-1}$ will increase as $\left[a_{\mathrm{s}}\right]$ decreases).

4. $k_{\text {observed }}$ is therefore a function of $\left[P_{\mathrm{w}}\right]$ and $\left[a_{\mathrm{s}}\right]$.

5. The cost of desalination reduces as: (i) $\left[P_{\mathrm{w}}\right]$ decreases; (ii) $\left[a_{\mathrm{s}}\right]$ decreases; and (iii) $k_{\text {actual }}$ increases.

This model (Equation (77)) assumes [18] that the ZVM TP acts as a catalyst (or adsorbent), the number of catalytic/adsorbent sites is a function of surface area $\left[a_{\mathrm{s}}\right]$, and the number of catalytic/adsorbent sites remains constant with time.

If the ZVM TP acts as a catalyst (or reactant) where the process involves adsorption and desorption, then a proportion of the available sites at time $t=0$ may be unavailable at time $t=n$. The same situation will also arise if the ZVM TP becomes progressively oxidised with time, or reacts with components in the water with time. In this instance the magnitude of [D] becomes a function of the reaction rate, $k,[18]$ where:

$$
k_{\text {observed }}=k_{\text {actual }} \times\left[P_{\mathrm{w}}\right] \times\left[a_{\mathrm{s}}\right] \times\left[a_{\mathrm{a}}\right]
$$

Where $\left[a_{\mathrm{a}}\right]=$ the proportion of sites present in the ZVM that are available at time $t$. $\left[a_{\mathrm{a}}\right]$ will decrease with time as sites become utilised/blocked. $\left[a_{\mathrm{a}}\right.$ ] can increase with time, if the growing Fe corrosion products create new sites (e.g., Figure F1).

\section{F3.1. Assessment of the Impact of Changing $\left[a_{s}\right]$ and $\left[a_{a}\right]$ on Salinity}

The measured $24 \mathrm{~h}$ regression relationship between $\mathrm{Cl}^{-}$concentration in the feed and product waters at $t=0$ [21] can be used to demonstrate the impact of changing $\left[a_{\mathrm{s}}\right]$ and $\left[a_{\mathrm{a}}\right]$ on desalination.

The impact of decreasing $\left[a_{\mathrm{s}}\right]$ is to increase the length of time it takes for the water salinity to reduce from a level $[x]$ to a level $[y]$ where:

Predicted 24 h salinity change for $\left[a_{\mathrm{s}}\right]=1$, (Regression Equation from [21]):

$$
\left[W \mathrm{~s}_{t=1}\right]=1.1\left[W \mathrm{~s}_{t=0}\right]^{0.98}
$$

Corrected $24 \mathrm{~h}$ salinity change for $c=\left(\left[P_{\mathrm{w}}\right] \times\left[a_{\mathrm{s}}\right] \times\left[a_{\mathrm{a}}\right]\right)_{\text {actual }} /\left(\left[P_{\mathrm{w}}\right] \times\left[a_{\mathrm{s}}\right] \times\left[a_{\mathrm{a}}\right]\right)_{\text {reference }}=0.5$

$$
\left[C W_{t=1}\right]=\left[W \mathrm{~s}_{t=0}\right]-\left(c\left(\left[W \mathrm{~s}_{t=0}\right]-\left(1.1\left[W \mathrm{~s}_{t=0}\right]^{0.98}\right)\right)\right.
$$

where $\left[W \mathrm{~S}_{t=0}\right]=$ water salinity at $t=0 ;\left[W_{\mathrm{S} t=1}\right]=$ water salinity at $t=1 .\left[C W_{t=1}\right]=$ water salinity at $t=1$ corrected for the change in $\left[P_{\mathrm{w}}\right],\left[a_{\mathrm{s}}\right]$ and $\left[a_{\mathrm{a}}\right]$ relative to the reference standard used to calculate the regression correlation [21]. Reference standards: $\left[P_{\mathrm{w}}\right]=20 \mathrm{~g} \cdot \mathrm{L}^{-1} ;\left[a_{\mathrm{s}}\right]=77.26 \mathrm{~m}^{2} \cdot \mathrm{g}^{-1} ;\left[a_{\mathrm{a}}\right]=1.0[20,21]$.

A value of $\left[a_{\mathrm{s}}\right]_{\text {actual }} /\left[a_{\mathrm{s}}\right]_{\text {reference }}=0.5$ indicates that the effective surface area is half the surface area of the reference standard [21] used to construct the regression relationship (e.g., $38.6 \mathrm{~m}^{2} \cdot \mathrm{g}^{-1}$ ).

The impact of reducing $\left[a_{\mathrm{a}}\right]$ is to reduce the amount of desalination that can occur for a specific value of $\left[a_{\mathrm{s}}\right]$ as $\left[a_{\mathrm{a}}\right]=\left[a_{\mathrm{a}}\right]_{\text {actual }} /\left[a_{\mathrm{a}}\right]_{\text {reference: }}$ 
Predicted $24 \mathrm{~h}$ salinity change for $\left[a_{\mathrm{s}}\right]_{\text {actual }} /\left[a_{\mathrm{s}}\right]_{\text {reference }}=1$

$$
\left[W_{t=1}\right]=1.1\left[W_{t=0}\right]^{0.98}
$$

Corrected $24 \mathrm{~h}$ salinity change for $\left[a_{\mathrm{s}}\right]=1.0 ;\left[a_{\mathrm{a}}\right]=0.9$

$$
\left[C W_{t=t+1}\right]=\left[W_{t=t}\right]-\left(\left[a_{t+1}\right]\left(\left[W_{t=t+1}\right]-\left(1.1\left[W_{t=t}\right]^{0.98}\right)\right)\right.
$$

$$
\left[a_{t+1}\right]=\left(\left[a_{\mathrm{s}}\right]_{\text {actual }} /\left[a_{\mathrm{s}}\right]_{\text {reference }}\right) \times\left(\left[a_{\mathrm{a}}\right]_{\text {actual }} /\left[a_{\mathrm{a}}\right]_{\text {reference }}\right) \times\left(\left[P_{\mathrm{w}}\right]_{\text {actual }} /\left[P_{\mathrm{w}}\right]_{\text {reference }}\right) \times
$$

$$
\left([k]_{\text {actual }} /[k]_{\text {reference }}\right)
$$

The impact of changing the $\left[a_{\mathrm{s}}\right]$ and $\left[a_{\mathrm{a}}\right]$ ratios (when $\left[P_{\mathrm{w}}\right]$ remains constant) is shown in Figure F3. In Figure F3 the following calculation assumptions are made:

$$
\begin{gathered}
{\left[a_{\mathrm{s}}\right]=\text { Reference ZVM Surface Area, } \mathrm{m}^{2} \cdot \mathrm{g}^{-1}=77.26 \mathrm{~m}^{2} \cdot \mathrm{g}^{-1}} \\
{\left[P_{\mathrm{w}}\right]=\text { Reference ZVM concentration, } \mathrm{g} \cdot \mathrm{L}^{-1}=8 \mathrm{~g} \cdot \mathrm{L}^{-1}} \\
{\left[a_{\mathrm{a}}\right]=\text { Reference \% of ZVM surface area available for adsorption }=100 \%}
\end{gathered}
$$

Curve fitting can be used to replicate the EC declines associated with ZVM TP desalination (Figures C1-C17). This allows the relative success of the various ZVM TP pre-treatments (and ZVM compositional combinations) to be evaluated. These pre-treatments are designed to take ZVM with a low $\left[a_{\mathrm{s}}\right]$ and increase the associated $k_{\text {actual. }}$

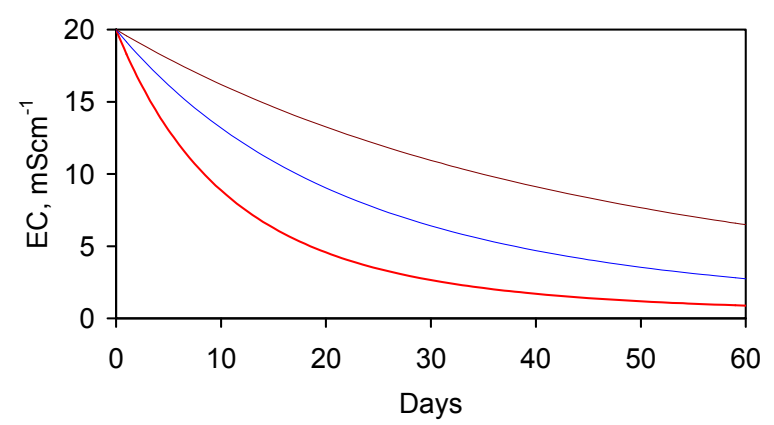

(a)

$$
-[\text { as }]=1-[\text { as }]=0.5-[\text { as }]=0.25
$$

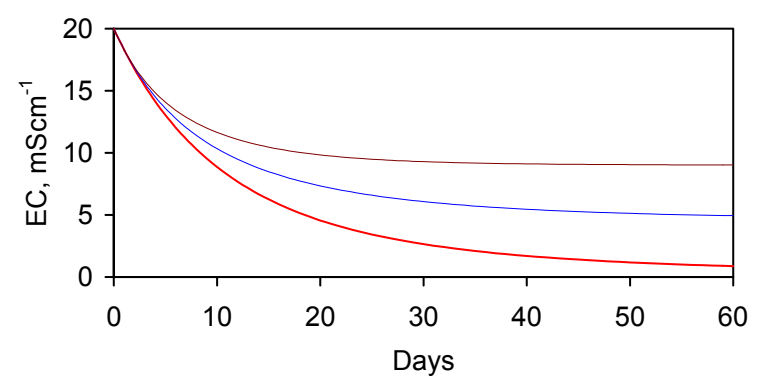

(b)

Figure F3. Expected decline in EC with time. (a) Impact of changing $\left[a_{\mathrm{s}}\right]$ when $\left[a_{\mathrm{a}}\right]=1.0$; $\left[P_{\mathrm{w}}\right]=1.0 ;(\mathbf{b})$ Impact of changing $\left[a_{\mathrm{a}}\right]$ when $\left[a_{\mathrm{s}}\right]=1.0 ;\left[P_{\mathrm{w}}\right]=1.0$. Equation based on $\mathrm{Cl}^{-}$ adsorption rates for $\mathrm{Fe}^{0}[21] .\left[a_{\mathrm{a}}\right]=\left(\left[a_{\mathrm{s}}\right]_{\text {actual }} /\left[a_{\mathrm{s}}\right]_{\text {reference }}\right) ;\left[a_{\mathrm{a}}\right]=\left(\left[a_{\mathrm{a}}\right]_{\text {actual }} /\left[a_{\mathrm{a}}\right]_{\text {reference }}\right)$; $\left[P_{\mathrm{w}}\right]=\left(\left[P_{\mathrm{w}}\right]_{\text {actual }} /\left[P_{\mathrm{w}}\right]_{\text {reference }}\right)$.

\section{G. Fe Corrosion Species Involved in Desalination}

The precipitated Fe corrosion species which could potentially be present in the ZVM TP/TPA + water during desalination fall into three groups [18,19,67-78,82-100,102,104,111-114,162-168,172-176, 190,203, 204,208,236-240]:

1. Reduced Fe corrosion products, e.g., magnetite $\left(\mathrm{Fe}_{3} \mathrm{O}_{4}\right)$ and related species.

2. White and green rusts, i.e., $\mathrm{Fe}(\mathrm{OH})_{2}$ and layered hydroxides (green rusts).

3. Brown rusts, i.e., $\mathrm{Fe}(\mathrm{OH}) 3, \mathrm{FeOOH}$ spp.

The dominant precipitant (either in the water as entrained particles, or accreting onto surfaces), is controlled by the temperature, pressure, $\mathrm{Eh}, \mathrm{pH}$, and both the relative and absolute concentrations of $\mathrm{Cl}^{-}, \mathrm{HCO}_{3}{ }^{-}, \mathrm{CO}_{3}{ }^{2-}, \mathrm{S}^{2-}, \mathrm{HS}^{-}, \mathrm{SO}_{4}{ }^{2-}, \mathrm{OH}^{-}, \mathrm{Fe}^{n^{+}}$, and $\mathrm{H}^{+}$ions in the water [19]. 
Detailed historical experiments documented in this study have clearly identified a number of reaction pathways which consistently occur. These pathways are:

(1) In freshwater containing no $\mathrm{Cl}^{-}, \mathrm{HCO}_{3}{ }^{-}, \mathrm{CO}_{3}{ }^{2-}, \mathrm{S}^{2-}, \mathrm{HS}^{-}, \mathrm{SO}_{4}{ }^{2-}$ ions the reaction sequence is as follows:

(a) Stage 1: $\mathrm{Fe}^{0}$ corrodes to $\mathrm{Fe}(\mathrm{OH})_{2}$

(b) Stage 2: $\mathrm{Fe}(\mathrm{OH})_{2}$ corrodes to $\mathrm{Fe}(\mathrm{OH})_{3}$ and $\mathrm{FeOOH}$ (lepiocrocite and goethite). $\mathrm{H}^{+}$(ads) ions may reduce $\mathrm{Fe}(\mathrm{OH})_{2}$ which is adjacent to the $\mathrm{Fe}^{0}$ to $\mathrm{Fe}_{3} \mathrm{O}_{4}$ (magnetite).

(2) In freshwater containing no $\mathrm{Cl}^{-}, \mathrm{S}^{2-}, \mathrm{HS}^{-}, \mathrm{SO}_{4}{ }^{2-}$ and containing $\mathrm{HCO}_{3}{ }^{-}, \mathrm{CO}_{3}{ }^{2-}$ ions the reaction sequence is as follows:

(a) Stage 1: $\mathrm{Fe}^{0}$ corrodes to $\mathrm{Fe}(\mathrm{OH})_{2}$

(b) Stage 2: $\mathrm{Fe}(\mathrm{OH})_{2}$ corrodes to $\mathrm{GR} 1\left(\mathrm{CO}_{3}{ }^{2-}\right)$ which corrodes to $\mathrm{Fe}(\mathrm{OH})_{3}$ and $\mathrm{FeOOH}$ (lepiocrocite and goethite). $\mathrm{H}^{+}(\mathrm{ads})$ ions may reduce $\mathrm{Fe}(\mathrm{OH})_{2}$ which is adjacent to the $\mathrm{Fe}^{0}$ to $\mathrm{Fe}_{3} \mathrm{O}_{4}$ (magnetite). In the presence of $\mathrm{SO}_{4}{ }^{2-}$ ions $\mathrm{GR} 1$ is replaced by $\mathrm{GR} 2\left(\mathrm{SO}_{4}{ }^{2-}\right)$ and the $\mathrm{CO}_{3}{ }^{2-}$ ions are expelled into the water.

(3) In saline water containing no $\mathrm{HCO}_{3}{ }^{-}, \mathrm{CO}_{3}{ }^{2-}, \mathrm{S}^{2-}, \mathrm{HS}^{-}, \mathrm{SO}_{4}{ }^{2-}$ ions the reaction sequence is as follows:

(a) Stage 1: $\mathrm{Fe}^{0}$ corrodes to $\mathrm{Fe}(\mathrm{OH})_{2}$

(b) Stage 2: $\mathrm{Fe}(\mathrm{OH})_{2}$ corrodes to $\mathrm{GR} 1\left(\mathrm{Cl}^{-}\right)$. The $\mathrm{GR} 1\left(\mathrm{Cl}^{-}\right)$corrodes to form $\mathrm{FeOOH}$. The dominant $\mathrm{FeOOH}$ sp. is akaganeite. Any lepiocrocite and goethite which form as an intermediate stage are transformed over the longer term to akaganeite. $\mathrm{H}^{+}$(ads) ions may reduce $\mathrm{Fe}(\mathrm{OH})_{2}$ which is adjacent to the $\mathrm{Fe}^{0}$ to $\mathrm{Fe}_{3} \mathrm{O}_{4}$ (magnetite).

(4) In saline water containing $\mathrm{HCO}_{3}{ }^{-}, \mathrm{CO}_{3}{ }^{2-}$ ions and no $\mathrm{S}^{2-}, \mathrm{HS}^{-}, \mathrm{SO}_{4}{ }^{2-}$ ions the reaction sequence is as follows:

(a) Stage 1: $\mathrm{Fe}^{0}$ corrodes to $\mathrm{Fe}(\mathrm{OH})_{2}$

(b) Stage 2: $\mathrm{Fe}(\mathrm{OH})_{2}$ corrodes to $\mathrm{GR} 1\left(\mathrm{CO}_{3}{ }^{2-}\right)$. The $\mathrm{GR} 1\left(\mathrm{CO}_{3}{ }^{2-}\right)$ corrodes to form $\mathrm{FeOOH}$. The dominant $\mathrm{FeOOH}$ sp is akaganeite. Any lepiocrocite and goethite which form as an intermediate stage are transformed over the longer term to akaganeite. $\mathrm{H}^{+}$(ads) ions may reduce $\mathrm{Fe}(\mathrm{OH})_{2}$ which is adjacent to the $\mathrm{Fe}^{0}$ to $\mathrm{Fe}_{3} \mathrm{O}_{4}$ (magnetite). In the presence of $\mathrm{SO}_{4}{ }^{2-}$ ions GR1 is replaced by GR2 $\left(\mathrm{SO}_{4}{ }^{2-}\right)$ and the $\mathrm{Cl}^{-}$or $\mathrm{CO}_{3}{ }^{2-}$ ions are expelled into the water and the final $\mathrm{FeOOH}$ product is goethite. In the presence of $\mathrm{S}^{2-}, \mathrm{HS}^{-}$ions, $\mathrm{Fe}(\mathrm{OH})_{2}$ and $\mathrm{FeOOH}$ corrode to $\mathrm{Fe}_{x} \mathrm{~S}_{y}$ and $\mathrm{S}$ precipitates.

The trials documented in Figures $\mathrm{C} 1-\mathrm{C} 37$ were operated in saline water containing $1000-22,000 \mathrm{mgCl}{ }^{-} \cdot \mathrm{L}^{-1}, 10-150 \mathrm{mg} \cdot \mathrm{L}^{-1}\left[\mathrm{HCO}_{3}{ }^{-}, \mathrm{CO}_{3}{ }^{2-}\right]$, no $\left[\mathrm{S}^{2-}, \mathrm{HS}^{-}\right]$and $1-5 \mathrm{mg} \cdot \mathrm{L}^{-1} \cdot \mathrm{SO}_{4}{ }^{2-}$ ions the reaction sequence. Consequently the species expected are $\mathrm{Fe}(\mathrm{OH})_{2}, \mathrm{GR} 1\left(\mathrm{Cl}^{-}\right), \mathrm{FeOOH}$ (akaganeite) and $\mathrm{Fe}_{3} \mathrm{O}_{4}$ (magnetite). The $\mathrm{Eh}, \mathrm{pH}$ regimes indicate that the dominant corrosion product entrained in the water is $\mathrm{FeOOH}$.

Any chemical analysis of ZVM TP during desalination (e.g., Figure F1) is likely to demonstrate the presence of white rust, green rust, magnetite, and akagangeite, but may also demonstrate the presence of 
goethite and lepidocrocite $[68,204]$. These create anodic and cathodic sites within the ZVM TP/TPA and surrounding water $[18,203]$, and as demonstrated in this study, this allows currents, voltages, resistance, and capacitance to be measured.

The overall process of $\mathrm{Na}^{+}$and $\mathrm{Cl}^{-}$capture by the charged $\mathrm{Fe}$ corrosion products remains unknown, but is investigated further in Appendix $\mathrm{H}$.

\section{Appendix H. Identification of the Radicals Involved in NaCl Removal}

The anion and cation analyses (Tables $\mathrm{C} 1-\mathrm{C} 4$ ) demonstrate that there is no net increase in soluble Fe ions in the product water relative to the feed waters when the desalination involves ZVM TP. Small concentrations of entrained nano-Fe corrosion products (and $n$-Fe) can create substantial increases in water EC. In these situations measurement of an absorbance spectrum of fresh product water $[G]$, and measurement of an absorbance spectrum of the product water after the water has been allowed to rest and some of the entrained particles have been allowed to settle $[H]$ will allow the UV-visible absorbance spectrum $[J]$ of the entrained (settled) particles to be determined (Table 3). For each wavelength analysed:

$$
[J=[G]-[H]
$$

The UV-Visible spectra of the low concentrations of entrained nano-particles in the water associated with the E146 trial were determined (Figure C37). These spectra indicate that the dominant nano-particle is hydrated akaganeite (Table 3).

Each spectra displays a number of peaks and troughs over the spectral range 200-300 nm. These peaks can be interpreted in terms of the $\mathrm{OH}$ radicals, $\mathrm{Fe}$ ions, $\mathrm{Cl}$ ions, and $\mathrm{Na}$ ions.

The absorbance associated with the $\mathrm{OH}$ radical $\left(\left[\mathrm{O}_{x} \mathrm{H}-\mathrm{H}_{2} \mathrm{O}\right]^{{ }^{n+l-}}\right)$ can result from a dissolved gas phase transition (associated with the air, or $\mathrm{N}_{2}: \mathrm{CO}_{2}$ gas feed). This type of transition is termed $\mathrm{AX}$ [32].

Absorbance associated with the $\mathrm{OH}$ radical $\left(\left[\mathrm{O}_{x} \mathrm{H}-\mathrm{H}_{2} \mathrm{O}\right]^{\bullet n^{+/}}\right)$involving the transfer of an electron from a closed shell solvent (e.g., $\mathrm{H}_{2} \mathrm{O}$ ) into the valance hole of a radical solute is termed CT [32].

The absorption peaks associated with specific molecular species and ions at different wavelengths include:

(1) $\mathrm{Fe}^{0}$ [227]: $216 \mathrm{~nm}, 268 \mathrm{~nm}$ (minor);

(2) $\mathrm{Fe}^{\mathrm{III}}$ species [208,237]:

(a) $\mathrm{FeCl}^{2+}: 220 \mathrm{~nm}, 235 \mathrm{~nm}$;

(b) $\mathrm{FeCl}_{2}^{+}: 339 \mathrm{~nm}$;

(c) $\mathrm{Fe}^{3+}: 240 \mathrm{~nm}$;

(d) $\mathrm{FeOH}^{2+}: 205-207 \mathrm{~nm} ; 240 \mathrm{~nm} ; 297-301 \mathrm{~nm}$;

(e) $\mathrm{Fe}(\mathrm{OH})^{2+}: 300 \mathrm{~nm}$;

(f) $\mathrm{Fe}_{2}(\mathrm{OH})_{2}{ }^{4+}: 335 \mathrm{~nm}$;

(g) $\mathrm{FeCl}_{4}^{-}: 317 \mathrm{~nm}, 365 \mathrm{~nm}$;

(3) Fe-Ion exchange material [226]: 500-550 nm;

(4) Ferrate $\left(\mathrm{FeO}_{4}{ }^{2-}\right)[102,103]: 450-550 \mathrm{~nm} ; 700-900 \mathrm{~nm}$;

(5) $\mathrm{ClO}_{2}$ [217]: $292 \mathrm{~nm}$;

(6) $\mathrm{ClO}^{-}[228]: 290 \mathrm{~nm}$; 
(7) $\mathrm{NaClO}$ [228]: $291.4 \mathrm{~nm}$;

(8) $\mathrm{HClO}[217]: 360 \mathrm{~nm}$;

(9) $\mathrm{ClOOCl}[219]: 250 \mathrm{~nm}$;

(10) $\mathrm{OH}-\mathrm{H}_{2} \mathrm{O} \bullet$ Radical Structures [221-224];

(a) $\mathrm{AX}$ transition (adsorption of $\mathrm{OH}$ radical from the gas phase):

(i) Free OH: $263 \mathrm{~nm} ; 277-288 \mathrm{~nm} ; 299-306 \mathrm{~nm}$;

(ii) $\mathrm{OH}-\mathrm{H}_{2} \mathrm{O} \cdot$ Structures- $\mathrm{AX}$ transition: H-bond donor structure $\mathrm{C} 1: 244 \mathrm{~nm} ; 289 \mathrm{~nm}$; 310-334 nm;

(iii) $\mathrm{OH}-\mathrm{H}_{2} \mathrm{O} \cdot$ Structures-AX transition: H-bond acceptor structure $\mathrm{C} 3: 263 \mathrm{~nm} ; 278-290 \mathrm{~nm}$; 299-300 nm; $327 \mathrm{~nm}$;

(iv) $\mathrm{OH}-\mathrm{H}_{2} \mathrm{O} \cdot$ Structures-AX transition: hemi-bonded structure $\mathrm{C} 2: 220 \mathrm{~nm} ; 252 \mathrm{~nm}$; $266-282 \mathrm{~nm}$;

(b) $\mathrm{CT}$ transition (adsorption of $\mathrm{OH}$ radical from the water):

(i) H-bond acceptor structure C3: 223-229 nm; 245-249 nm; 258-265 nm; $676 \mathrm{~nm}$;

(ii) $\mathrm{OH}-\mathrm{H}_{2} \mathrm{O}$ Structures - $\mathrm{CT}$ transition: hemi-bonded structure $\mathrm{C} 2: 211-217 \mathrm{~nm} ; 228-231 \mathrm{~nm}$;

(11) $\mathrm{HO}_{2}^{-}$[225]: $225 \mathrm{~nm}$;

(12) $\mathrm{O}_{2}^{-}$[225]: $245 \mathrm{~nm}$;

(13) $\mathrm{Cl}^{-}$[238]: 210-220 nm;

(14) $\mathrm{NaO}^{-}$[249]: 262/8 nm, 275/6 nm, $301 \mathrm{~nm}, 324 / 8 \mathrm{~nm}, 337 \mathrm{~nm}, 351 \mathrm{~nm}, 365 \mathrm{~nm}, 395 \mathrm{~nm}$.

Analysis of the absorbance in the 200-300 nm wavelength (Figure C37) indicates the presence of a variety of $\mathrm{OH}-\mathrm{H}_{2} \mathrm{O}$ radicals, which are either derived from the solute (water, $\mathrm{CX}$ series) or gas interactions (AX series). The dominant radical structure is a CT-hemi-bonded, or CT H-bond acceptor structure (e.g., $\mathrm{HO}_{2}^{-}$).

The dominant AX-series radicals (Figure C37) are H-bond acceptor radicals and hemibonded radicals. The dominant CT-series radicals (Figure C37) are also H-bond acceptor radicals and hemibonded radicals. H-bond acceptor radicals can take the form $\left[\left(\mathrm{H}_{2} \mathrm{O}\right)_{n}\left(\mathrm{H}_{3} \mathrm{O}^{+}\right)_{m}\left(\mathrm{O}_{x} \mathrm{H}\right)_{y}\right] \cdot$ (and include radicals containing the $\mathrm{HO}_{2}{ }^{-}$ion), or hemibonded radicals or dimers. The $\left(\mathrm{O}_{x} \mathrm{H}\right)_{y}$ ion complex can be charged. Proton based structures are preferred by $\left(\mathrm{H}_{2} \mathrm{O}\right)_{n}{ }^{(+)}$radicals, while hemibonded structures are preferred by $(\mathrm{HCl})_{n}{ }^{{ }^{(+)}}$radicals.

A higher proportion of $\mathrm{HO}_{2}{ }^{-}$bonded radicals can be present when the feed gas includes $\mathrm{CO}_{2}($ Figure C37af,ar).

The observation (e.g., Figure $\mathrm{C} 37 \mathrm{aj})$ that $\mathrm{Cl}$ can be bound to $\mathrm{Fe}\left(\mathrm{as} \mathrm{FeCl}^{2+}\right)$ is consistent with existing akaganeite and GR1 models. $\mathrm{Cl}$ (Figure $\mathrm{C} 37 \mathrm{j}$,ag) can be present as $\mathrm{ClOOCl}, \mathrm{ClO}_{2}$ and $\mathrm{HClO}$ within the hydrated nano-particle structure. Some of the $\mathrm{ClO}_{2}$ identified in Figure $\mathrm{C} 37$ will be $\mathrm{ClO}^{-}$(e.g., Figure $\mathrm{C} 37 \mathrm{j}) . \mathrm{ClO}^{-}$and $\mathrm{ClO}_{2}$ have virtually identical spectral peaks at $290 / 292 \mathrm{~nm}$. Conventional modeling of the hydrated shell assumes that the $\mathrm{Cl}$ is held as $\mathrm{Cl}^{-}$, and does not assume that the water is highly oxygenated, or that the $\mathrm{Cl}$ is held in $\mathrm{H}_{2} \mathrm{O}$ radicals [96]. 
The $\mathrm{ClO}^{-}$can be formed via the reaction of an $\mathrm{OH}-\mathrm{H}_{2} \mathrm{O}$ couplet with $\mathrm{Cl}^{-}$, e.g.,

$$
\begin{gathered}
\mathrm{Cl}^{-}+\mathrm{OH}^{-}=\mathrm{HClO}+2 \mathrm{e}^{-} \\
\mathrm{ClO}^{-}+0.5 \mathrm{H} 2=\mathrm{HClO}+\mathrm{e}^{-} \\
\mathrm{E} 1: \mathrm{Cl}^{-}+\mathrm{OH}^{-}=\mathrm{ClO}^{-}+\mathrm{H}^{+}+2 \mathrm{e}^{-} \\
\mathrm{E} 2: \mathrm{Cl}^{-}+\mathrm{OH}^{-}=\mathrm{ClO}^{-}+0.5 \mathrm{H}_{2}+\mathrm{e}^{-} \\
\Delta H^{0}=122.9 \mathrm{~kJ} \cdot \mathrm{M}^{-1} ; \Delta G^{0}=122.9 \mathrm{~kJ} \cdot \mathrm{M}^{-1} ; \Delta E^{0}=-0.623 \mathrm{~V} \\
\Delta H^{0}=122.9 \mathrm{~kJ} \cdot \mathrm{M}^{-1} ; \Delta G^{0}=122.9 \mathrm{~kJ} \cdot \mathrm{M}^{-1} ; \Delta E^{0}=-1.24 \mathrm{~V} \\
\mathrm{Eh}=\Delta E^{0}-0.0591 m / n \times \mathrm{pH}+0.0591 / n \times \log \left[\mathrm{Cl}^{-} / \mathrm{ClO}^{-}\right] \\
\text {Eh }(\mathrm{E} 1), \mathrm{V}=-0.623-0.02955 \times \mathrm{pH}+0.02955 \times \log \left[\mathrm{Cl}^{-} / \mathrm{ClO}^{-}\right] \\
\text {Eh }(\mathrm{E} 2), \mathrm{V}=-1.24-0.0591 \times \mathrm{pH}+0.0591 \times \log \left[\mathrm{Cl}^{-} / \mathrm{ClO}^{-}\right] \\
\mathrm{E} 3: 2 \mathrm{Cl}^{-}+\mathrm{O}_{2}^{-}=2 \mathrm{ClO}+2 \mathrm{e}^{-} \\
\Delta H^{0}=-107.1 \mathrm{~kJ} \cdot \mathrm{M}^{-1} ; \Delta G^{0}=-36.8 \mathrm{~kJ} \cdot \mathrm{M}^{-1} ; \Delta E^{0}=0.381 \mathrm{~V} \\
\text { Eh }(\mathrm{E} 3), \mathrm{V},=0.381-0.02955 \times \mathrm{pH}+0.02955 \times \log \left[\mathrm{Cl}^{-} / \mathrm{ClO}^{-}\right] \\
m=\text { number of } \mathrm{H}^{+} \text {ions} ; n=\mathrm{number} \text { of electrons transferred }
\end{gathered}
$$

The Eh-pH relationships required by Equation (82) to produce $\mathrm{ClO}^{-}$were not observed in trials E145, E146. $\mathrm{O}_{2}{ }^{-}$ions were observed in the nano-particles, e.g., Figure $\mathrm{C} 37 \mathrm{p}$. This provides an alternative reaction route, e.g.,

$$
\begin{gathered}
\mathrm{E} 3: 2 \mathrm{Cl}^{-}+\mathrm{O}_{2}{ }^{-}=2 \mathrm{ClO}^{-}+2 \mathrm{e}^{-} \\
\Delta H^{0}=-107.1 \mathrm{~kJ} \cdot \mathrm{M}^{-1} ; \Delta G^{0}=-36.8 \mathrm{~kJ} \cdot \mathrm{M}^{-1} ; \Delta E^{0}=0.381 \mathrm{~V} \\
\text { Eh }(\mathrm{E} 3), \mathrm{V},=0.381-0.02955 \times \mathrm{pH}+0.02955 \times \log \left[\mathrm{Cl}^{-} / \mathrm{ClO}^{-}\right]
\end{gathered}
$$

The Eh-pH relationships required by Equation (83) to produce $\mathrm{ClO}^{-}$were observed in trials E145, E146 (Figures C19-C36). This indicates that the first stage in the desalination process involves $\mathrm{O}_{2}$, e.g., Figure C37ah,aj:

$$
\begin{gathered}
\mathrm{O}_{2}+\mathrm{FeOH}^{+}=\mathrm{FeOH}^{2+}+\mathrm{O}_{2}{ }^{-} \\
\Delta H^{0}=33.9 \mathrm{~kJ} \cdot \mathrm{M}^{-1} ; \Delta G^{0}=48.0 \mathrm{~kJ} \cdot \mathrm{M}^{-1} ; \Delta E^{0}=-0.497 \mathrm{~V} \\
\text { Eh }(\mathrm{E} 4), \mathrm{V}=-0.497-0.0591 \times \mathrm{pH}+0.0591 \times \log \left[\mathrm{FeOH}^{+} / \mathrm{FeOH}^{2+}\right]
\end{gathered}
$$

An alternative route is:

$$
\begin{gathered}
\mathrm{O}_{2}+\mathrm{Fe}^{2+}=\mathrm{Fe}^{3+}+\mathrm{O}_{2}^{-} \\
\Delta H^{0}=40.6 \mathrm{~kJ} \cdot \mathrm{M}^{-1} ; \Delta G^{0}=74.2 \mathrm{~kJ} \cdot \mathrm{M}^{-1} ; \Delta E^{0}=-0.768 \mathrm{~V} \\
\text { Eh }(\mathrm{E} 5), \mathrm{V}=-0.768-0.0591 \times \mathrm{pH}+0.0591 \times \log \left[\mathrm{Fe}^{2+} / \mathrm{Fe}^{3+}\right] \\
\mathrm{Fe}^{2+}=\mathrm{Fe}^{3+}+\mathrm{e}^{-} \\
\mathrm{O}_{2}+\mathrm{e}^{-}=\mathrm{O}_{2}{ }^{-} \\
\Delta H^{0}=0 \mathrm{~kJ} \cdot \mathrm{M}^{-1} ; \Delta G^{0}=0 \mathrm{~kJ} \cdot \mathrm{M}^{-1}
\end{gathered}
$$

In addition to the reaction route forming akaganeite/GR1 via a $\mathrm{FeCl}_{\mathrm{m}}^{\mathrm{n}+}$ structure (e.g., Figure $\mathrm{C} 37 \mathrm{n}$,ar,ah), the analyses (Figure $\mathrm{C} 37$ ) indicate that a reaction route via $\mathrm{ClO}^{-}$(or $\mathrm{ClO}_{2}$ ) is responsible for the removal of some $\mathrm{Cl}^{-}$. Some $\mathrm{ClO}-\mathrm{OCl}$ dimer structures were observed, e.g., Figure $\mathrm{C} 37 \mathrm{j}, 1$. They may be formed as: 


$$
\begin{gathered}
\mathrm{ClO}^{-}=\mathrm{ClO}+\mathrm{e}^{-} \\
\Delta H^{0}=-4.6 \mathrm{~kJ} \cdot \mathrm{M}^{-1} ; \Delta G^{0}=83.7 \mathrm{~kJ} \cdot \mathrm{M}^{-1} \\
2 \mathrm{ClO}=\mathrm{ClO}-\mathrm{OCl} \\
\Delta H^{0}=0 \mathrm{~kJ} \cdot \mathrm{M}^{-1} ; \Delta G^{0}=0 \mathrm{~kJ} \cdot \mathrm{M}^{-1}
\end{gathered}
$$

Studies of $\mathrm{Fe}^{\mathrm{III}}$ crystallization in the presence of $\mathrm{ClO}_{x}{ }^{n-}$ ions have demonstrated that they assist in the formation of polymerized (polymeric) $\mathrm{FeOOH}$ structures [250]. Previous studies have focused on the use of $\mathrm{ClO}_{4}{ }^{n^{-}}$ions $[239,250]$. They have established that goethite is the predominant polymeric $\mathrm{FeOOH}$ structure in the presence of $\mathrm{ClO}_{4}{ }^{n^{-}}$ions, while akaganeite is the dominant $\mathrm{FeOOH}$ structure in the presence of $\mathrm{Cl}^{-}$ions [239]. The $\mathrm{ClO}^{-}, \mathrm{ClO}-\mathrm{OCl}$ and $\mathrm{HClO}$ structures incorporated within hydrated akaganeite nano-particles (including the ionic and hydrated shells) can be attributed to the oxygenated reaction conditions used in Trials E145, E146 (Figures C19-C36).

The entrapment of $\mathrm{NaCl}$ in the growing polymeric $\mathrm{FeOOH} / \mathrm{GR} 1$ structures may take the form:

$$
\mathrm{NaCl}=\mathrm{Na}^{+}+\mathrm{Cl}^{-}
$$

Reaction Demonstrated by Figure C37 at wavelength $245 \mathrm{~nm}$

$$
\mathrm{O}_{2}+\mathrm{e}^{-}=\mathrm{O}_{2}^{-}
$$

Reaction demonstrated by $\mathrm{pH}$ changes with time (Figures $\mathrm{C} 19-\mathrm{C} 36)$

$$
0.5 \mathrm{O}_{2}{ }^{-}+\mathrm{H}_{2} \mathrm{O}=\mathrm{HO}-\mathrm{OH}+2 \mathrm{e}^{-}=2 \mathrm{OH}^{-}
$$

Reaction Demonstrated by Figure C37 at wavelength $225 \mathrm{~nm}$

$$
\mathrm{HO}-\mathrm{OH}+\mathrm{OH}^{-}=\mathrm{HO}_{2}{ }^{-}+\mathrm{H}_{2} \mathrm{O}
$$

Reactions Demonstrated by Figure C37 at wavelength $290 \mathrm{~nm}$

$$
2 \mathrm{Cl}^{-}+\mathrm{O}_{2}^{-}=2 \mathrm{ClO}^{-}+2 \mathrm{e}^{-}
$$

Reactions Demonstrated by Figure C37 at wavelength $250 \mathrm{~nm}$

$$
\begin{gathered}
\mathrm{ClO}^{-}=\mathrm{ClO}+\mathrm{e}^{-} \\
\mathrm{Cl}^{-}+\mathrm{H}_{2} \mathrm{O}+\mathrm{O}_{2}=\mathrm{OH}^{-}+\mathrm{HO}-\mathrm{OCl} \\
\mathrm{ClO}^{-}+\mathrm{H}_{2} \mathrm{O}_{2}=\mathrm{ClO}+\mathrm{OH}+\mathrm{OH}^{-} \\
\mathrm{ClO}^{-}+\mathrm{HO}_{2}^{-}=\mathrm{ClO}+0.5 \mathrm{O}_{2}^{-}+\mathrm{OH}^{-} \\
2 \mathrm{ClO}=\mathrm{ClO}-\mathrm{OCl} \\
\mathrm{ClO}+\mathrm{OH}=\mathrm{HO}-\mathrm{OCl}
\end{gathered}
$$

Reaction [238] demonstrated by Figure C37 at $240 \mathrm{~nm}$

$$
\mathrm{O}_{2}^{-}+\mathrm{Fe}^{2+}=\mathrm{Fe}^{3+}+\mathrm{O}_{2}{ }^{2-}
$$

Reactions demonstrated by Figure $\mathrm{C} 37$ at $265 \mathrm{~nm}$ and $275 \mathrm{~nm}$

$$
2 \mathrm{Na}^{+}+\mathrm{O}_{2}{ }^{2-}=2 \mathrm{NaO}^{-}
$$

It has been suggested [190] that during desalination the Fe corrosion products behave as electrochemical, switchable, redox moieties, where the initial $\mathrm{Fe}^{0}$ is modified during corrosion to contain tethered cathodic (e.g., $\mathrm{H}^{+}, \mathrm{FeH}^{n^{+}}, \mathrm{FeO}(\mathrm{OH})_{n}{ }^{x^{+}}$) groups and tethered anodic (e.g., $\mathrm{O}^{n^{-}}, \mathrm{OH}^{-}, \mathrm{O}_{2} \mathrm{H}^{-}$, $\mathrm{FeO}(\mathrm{OH})_{n}{ }^{x-}$ ) groups, where the tethered cathodic groups form ion adducts with anions and the tethered anodic groups form ion adducts with cations. This study has established (Figure C37) that the ions attached to the tethering sites (which can include akaganeite, goethite, lepidocrocite and ferrate) include: (i) anions: $\mathrm{NaO}^{-}, \mathrm{ClO}^{-}, \mathrm{OH}^{-}, \mathrm{O}_{n}{ }^{m^{-}}, \mathrm{HO}_{2}^{-}$; (ii) neutral species: $\mathrm{ClO}-\mathrm{OCl}, \mathrm{HO}-\mathrm{OCl}, \mathrm{HClO}, \mathrm{ClO}_{2}$; (iii) cations: $\mathrm{Fe}^{3+}, \mathrm{FeOH}^{2+}, \mathrm{FeCl}^{2+}$. 
The presence of purple $\mathrm{FeOOH}$ species (Figure F1) is indicative of $\mathrm{Na}$ inclusion. Na inclusion can take the form (e.g., Figure C37), $2 \mathrm{FeOOH}+2 \mathrm{NaO}^{-}=\mathrm{Fe}(\mathrm{OH})_{2}+\mathrm{Na}_{2} \mathrm{FeO}_{4}+2 \mathrm{e}^{-}$[251]. Ferrate(IV) salts form at temperatures of $<30{ }^{\circ} \mathrm{C}$ [251,252] from the anodic corrosion reaction series reaction $\left(\mathrm{Fe}^{0}+8 \mathrm{OH}^{-}=\mathrm{FeO}_{4}{ }^{2-}+2 \mathrm{H}_{2} \mathrm{O}+6 \mathrm{e}^{-}\right)$and the cathodic reaction $\left(2 \mathrm{H}_{2} \mathrm{O}=2 \mathrm{H}^{+}+2 \mathrm{OH}^{-}\right)$and $\mathrm{FeO}_{4}{ }^{2-}+2 \mathrm{Na}^{+}=\mathrm{Na}_{2} \mathrm{FeO}_{4}[250]$. Their yield is maximized by a current density of $3 \mathrm{~mA} \cdot \mathrm{cm}^{-2}$, and the current efficiency increases as the carbon content of the Fe increases, e.g., a current efficiency of $>70 \%$ applies when the Fe contains $>0.9 \% \mathrm{C}$ [252]. The formation of the ferrate salt is facilitated by the presence of $\mathrm{ClO}^{-}$(Figure $\left.\mathrm{C} 37\right)\left(\mathrm{Fe}^{2+}+4 \mathrm{OH}^{-}+2 \mathrm{ClO}^{-}=\mathrm{FeO}_{4}{ }^{2-}+2 \mathrm{Cl}^{-}+2 \mathrm{H}_{2} \mathrm{O}\right.$ [253]). The ferrate formation is facilitated by the analyte (pore water) containing $>0.02 \mathrm{wt} \% \mathrm{Cl}^{-}$, and is optimized by a weight ratio in the pore waters of $\mathrm{NaOH}: \mathrm{NaCl}$ (or $\mathrm{OH}: \mathrm{Cl}$ ) of between 25:1 and 5000:1 [254]. This indicates that $\mathrm{Cl}$ removal in $\mathrm{GR} 1$ and $\mathrm{FeOOH}$ from the analyte facilitates the subsequent removal of $\mathrm{Na}^{+}$by the $\mathrm{FeOOH}$ structures (Figure $\mathrm{F} 1$ ). The $\mathrm{Cl}^{-}$ion catalyses the formation of ferrate at the $\mathrm{FeOOH}$ - water interface, and within the corroded Fe products, where it facilitates transport of the ferrate in bulk solution to the FeOOH-water interface [254]. The efficiciency of the ferrate formation process increases with temperature in the range $0-60{ }^{\circ} \mathrm{C}$ [254]. At $44{ }^{\circ} \mathrm{C}$, with a current of $0.17 \mathrm{~A}$, and voltage of $2.79 \mathrm{~V}$ (current density $=48 \mathrm{~mA} \cdot \mathrm{cm}^{-2}$ ), the current efficiency (of ferrate production) is $>92 \%$ [254]. Figure 11 indicates that the natural current density of the ZVM TP (Cell 2) was $0.6 \mathrm{~mA} \cdot \mathrm{cm}^{-2}$. The current efficiency of ferrate production and $\mathrm{Na}$ removal decreases with decreasing temperature [254]. This decrease can only be offset partially by increasing the current density.

The ZVM TP data (Figures 11-13) establishes (Figure H1) that fresh ZVM TP/ZVM (L 1 , L2, L5) and ZVM TP following desalination $\left(\mathrm{L}_{4}\right)$ occupy different fields. The fresh ZVM TP/ZVM has a lower current density: voltage ratio than the ZVM TP following desalination (Figure H1). These observations allow measurements of current and voltage to be used to assess the likely potential effectiveness of a ZVM TP batch for desalination. This analysis indicates that desalination will effectively cease, when the ZVM TP looses the ability to incorporate addition $\mathrm{Na}$ ions into a corrosion product.

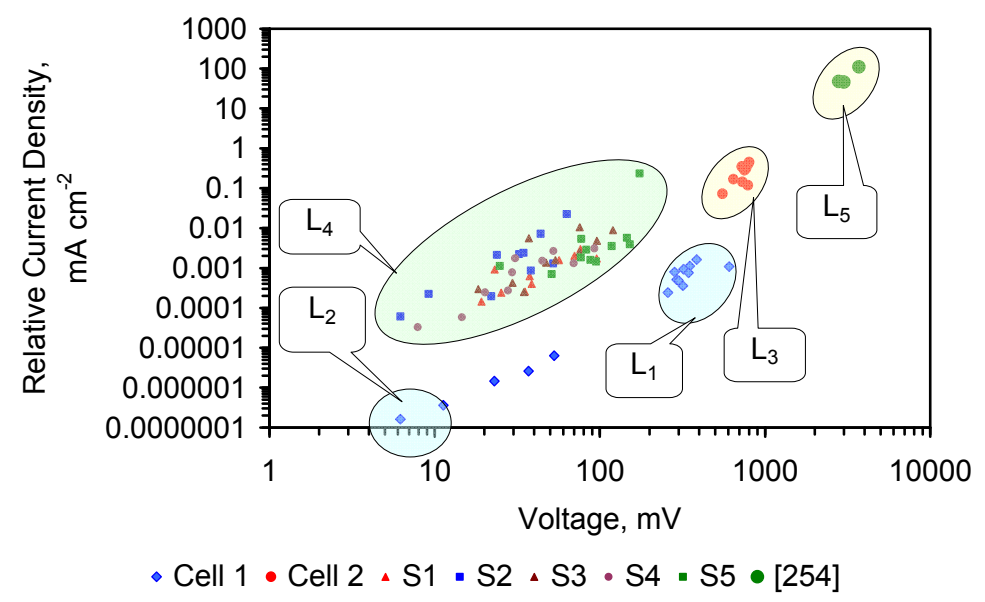

Figure H1. Relationship between current density and voltage associated with ZVM TP. $\mathrm{L}_{1}$ to $\mathrm{L}_{4}$ are defined in Figure 13. $\mathrm{L}_{5}$ is the measured relationship between voltage and current density associated with a current efficiency $\left(\mathrm{Fe}^{3+}\right.$ removal to form ferrate) of $50 \%-92 \%$ over $1 \mathrm{~h}$ at $35-50{ }^{\circ} \mathrm{C}$ [254]. Relative current density, $\mathrm{mA} \cdot \mathrm{cm}^{-2}=48 \times(($ Voltage $(\mathrm{V}) \times$ Current $(\mathrm{A})) /(0.17 \times 2.79))[254]$. 


\section{References}

1. Zang, Y.; Liu, Y.; Jing, Y.; Zhao, Z.; Quan, X. Steady performance of a zero valent iron packed anaerobic reactor for azo dye waste water treatment under variable influent quality. J. Environ. Sci. 2012, 24, 720-727.

2. Li, S.; Wang, W.; Yan, W.; Zhang, W.X. Nanoscale zero valent iron (nZVI) for the treatment of concentrated $\mathrm{Cu}(\mathrm{II})$ wastewater: A field demonstration. Environ. Sci. Process Impacts 2014, 16, 524-533.

3. Ma, L.; Zhang, W.-X. Enhanced biological treatment of industrial waste water with bi-metallic zero-valent iron. Environ. Sci. Technol. 2008, 42, 5384-5389.

4. Rima, J.; Rahme, K.; Assaker, K. Advanced oxidation of olive mill waste water OMW by an oxidative free-radical process induced with zero valent iron. J. Food Res. 2014, 3, 70-82.

5. Antia, D.D.J. Sustainable zero-valent metal (ZVM) water treatment associated with diffusion, infiltration, abstraction and recirculation. Sustainability 2010, 2, 2988-3073.

6. Antia, D.D.J. Modification of aquifer pore water by static diffusion using nano-zero-valent metals. Water 2011, 3, 79-112.

7. Gavaskar, A.; Tatar, L.; Condit, W. Cost and Performance Report: Nanoscale Zero-Valent Iron Technologies for Source Remediation; Contract Report CR-05-007-ENV; Naval Facilities Engineering Command, Engineering Service Center (NAVFAC): Port Hueneme, CA, USA, 2005; p. 44.

8. Cunningham, J.A.; Reinhard, M. Injection-extraction treatment well pairs: An alternative to permeable reactive barriers. Ground Water 2002, 40, 599-607.

9. Mackenzie, K.; Schierz, A.; Georgi, A.; Kopinke, F.-D. Colloidal activated carbon and carbo-iron-novel materials for in-situ groundwater treatment. Glob. NEST J. 2008, 10, 54-61.

10. Cundy, A.B.; Hopkinson, L.; Whitby, R.L.D. Use of iron-based technologies in contaminated land and groundwater remediation: A review. Sci. Total Environ. 2008, 400, 42-51.

11. Noubactep, C.; Care, S.; Crane, R. Nanoscale metallic iron for environmental remediation: Prospects and limitations. Water Air Soil Pollut. Mar. 2012, 223, 1363-1382.

12. Matlochova, A.; Placha, D.; Rapantova, N. The application of nanoscale materials in groundwater remediation. Pol. J. Environ. Stud. 2013, 22, 1401-1410.

13. Zhang, W.-X. Dispersed Zero-Valent Iron Colloids. U.S. Patent US7128841 B2, 11 March 2004.

14. Truex, M.J.; Vermeul, V.R.; Mendoza, D.P.; Fitz, B.G.; Mackley, R.D.; Oostrom, M.; Wietsma, T.W.; Macbeth, T.W. Injection of zero valent iron into an unconfined aquifer using shear thinning fluids. Groundw. Monit. Remediat. 2011, 31, 50-58.

15. Wilkin, R.T.; Puls, R.W.; Sewell, G.W. Long-term performance of permeable reactive barriers using zero valent iron: Geochemical and microbiological effects. Ground Water 2003, 41, 493-503.

16. Henderson, A.D.; Demond, A.H. Long-term performance of zero valent iron permeable reactive barriers: A critical review. Environ. Eng. Sci. 2007, 24, 401-423.

17. Faisal, A.A.H.; Abbas, T.R.; Jassam, S.H. Removal of zinc from contaminated groundwater by zero-valent iron permeable reactive barrier. Desalin. Water Treat. 2014, doi:10.1080/ 19443994.2014.928908. 
18. Antia, D.D.J. Groundwater water remediation by static diffusion using nano-zero valent metals $[\mathrm{ZVM}]\left(\mathrm{Fe}^{0}, \mathrm{Cu}^{0}, \mathrm{Al}^{0}\right), n$-FeH ${ }^{++}, n-\mathrm{Fe}(\mathrm{OH}) x, n-\mathrm{FeOOH}, n$-Fe- $\left[\mathrm{O}_{x} \mathrm{H}_{y}\right]^{\left(n^{+/-}\right)}$. In Nanomaterials for Environmental Protection, 1st ed.; Kharisov, B.I., Kharissova, O.V., Dias, H.V.R., Eds.; Wiley Inc.: Hoboken, NJ, USA, 2014; Chapter 1, pp. 3-25.

19. Pourbaix, M. Atlas of Electrochemical Equilibria in Aqueous Solutions, 1st ed.; NACE International, Cebelcor: Houston, TX, USA, 1974.

20. Fronczyk, J.; Pawluk, K.; Michniak, M. Application of permeable reactive barriers near roads for chloride ions removal. Ann. Wars. Univ. Life Sci. SGGW Land Reclaim. 2010, 42, 249-259.

21. Fronczyk, J.; Pawluk, K.; Garbulewski, K. Multilayer PRBs - Effective technology for protection of the groundwater environment in traffic infrastructures. Chem. Eng. Trans. 2012, 28, 67-72.

22. Kozin, P.A.; Bolly, J.-F. Proton binding and ion exchange at the akaganeite/water interface. J. Phys. Chem. C 2013, 117, 6409-6419.

23. Ahn, H.; Jo, H.Y.; Kim, G.-Y.; Koh, Y.-K. Effect of $\mathrm{NaCl}$ on $\mathrm{Cr}(\mathrm{VI})$ reduction by granular zero valent iron (ZVI) in aqueous solutions. Mater. Trans. 2012, 53, 1324-1329.

24. Gatcha-Bandjun, N.; Noubactep, C.; Mbenguela, B.L. Water treatment with $\mathrm{Fe}^{0} / \mathrm{H}_{2} \mathrm{O}$ systems: Learning from internal electrolysis. Fresenius Environ. Bull. 2014, 23, 2663-2669.

25. Hwang, Y.; Kim, D.; Shin, H.-S. Inhibition of nitrate reduction by $\mathrm{NaCl}$ adsorption on a nano-zero valent iron surface during concentrate treatment for water reuse. Environ. Technol. 2015, $36,1178-1187$.

26. Soares, C.G.; Garbatov, Y., Zayed, A.; Wang, G. Non linear corrosion model for immersed steel plates accounting for environmental factors. Trans. Soc. Naval Arch. Mar. Eng. 2005, 113, 306-322.

27. Misstear, B.; Banks, D.; Clark, L. Water Wells and Boreholes, 1st ed.; Wiley Inc.: Hoboken, NJ, USA, 2006.

28. Egal, M.M.; Ramamurthy, A.S. Nanofer ZVI: Morphology, particle characteristics, kinetics and applications. J. Nanomater. 2014, doi:10.1155/2014/152824.

29. Xie, K.; Li, J.; Lai, Y.; Lu, W.; Zhang, Z.; Liu, Y.; Zhou, L.; Huang, H. Highly ordered iron oxide nanotube arrays as electrode for electrochemical energy storage. Electrochem. Commun. 2011, 13, 657-660.

30. Wada, Y.; Bierkens, M.F.P. Sustainability of global water use: Past reconstruction and future projections. Environ. Res. Lett. 2014, 9, doi:10.1088/1748-9326/9/10/104003.

31. Amarasinghe, U.A.; Smakhtin, V. Global Water Demand Projections: Past, Present and Future; Report 156; International Water Management Institute (IWMI): Columbo, Sri Lanka, 2014.

32. Knapp, K.C.; Baerenklau, K.A. Ground water quantity and quality management: Agricultural production and aquifer salinization over long time scales. J. Agric. Resour. Econ. 2006, 31, 616-641.

33. Panta, S.; Flowers, T.; Lane, P.; Doyle, R.; Haros, G.; Shaala, S. Halophyte agriculture: Success stories. Environ. Exp. Bot. 2014, 107, 71-83.

34. Food and Agricultural Organization (FAO). The State of the World's Land and Water Resources for Food and Agriculture (SOLAW)—Managing Systems at Risk; Food and Agricultural Organization of the United Nations and Earth Scan: Abingdon, UK, 2011. 
35. Payen, S.; Basset-Mens, C.; Follain, S.; Grunberger, O.; Marlet, S.; Nunez, M.; Perret, S. Pass the salt please! From a review to a theoretical framework for integrating salinization impacts in food LCA. In Proceedings of the 9th International Conference on Life Cycle Assessment in the Agri-Foods Sector, San Francisco, CA, USA, 8-10 October 2014. Available online: http://lcafood2014.org/papers/140.pdf (accessed on 26 June 2015).

36. Al Hashemi, R.; Zarreen, S.; Al Raisi, A.; Al Marzooqi, F.A.; Hasan, S.W. A review of desalination trends in Gulf Cooperation Council Countries. Int. Interdiscip. J. Sci. Res. 2014, 1, 72-96.

37. Sorour, M.; Hani, H.A.; Shaalan, H.F.; Al-Bazedi, G.A. Preliminary techno-economics assessment of developed desalination/salt recovery facility based on membrane and thermal techniques. Desalin. Water Treat. 2014, doi:10.1080/19443994.2014.94775.

38. Venkatesan, R. Comparison between LTTD and RO process of sea-water desalination: An integrated economic, environmental and ecological framework. Curr. Sci. 2014, 106, 378-386.

39. Shanghai CNPC Powder Material Co. Ltd. Pure Electrolytic Carbonyl Atomized Sponge with High Purity Reduced Iron Powder. Available online: http://uk.alibaba.com/product/234481077-pureelectrolytic-carbonyl-atomized-sponge-reduced.html (accessed on 3 July 2015).

40. Chengdu Punda Metal Material Co. Ltd. Reduced Iron Powder, Available online: http://uk.alibaba.com/product/60277383280-Reduced-Iron-Powder.html (accessed on 3 July 2015).

41. Guizhou Dade Zhaoshen Building Materials Co. Ltd. Iron Powder/Nano Iron Powder/Reduced Iron Powder. Available online: http://uk.alibaba.com/product/60076279979-Iron-Powder-nanoiron-powder-reduced.html (accessed on 3 July 2015).

42. Shanghai Xingyue Energy Technology Co. Ltd. High Purity Competitive Iron Powder Price Ton. Available online: http://uk.alibaba.com/product/60029958942-High-purity-competitive-ironpowder-price.html (accessed on 3 July 2015).

43. Gansu Winshine Metallurgy Chemicals Co. Ltd. Micron Carbonyl Iron Powder, Available online: http://uk.alibaba.com/product/1815265627-Micron-carbonyl-iron-powder.html?s=p (accessed on 3 July 2015).

44. Chinese Standards, Carbon Structural Steels, GB/T 700-2006; Available online: http://www. chinesestandard.net/PDF-English-Translation/GBT700-2006.html (accessed on 3 July 2015).

45. Anyang Jinxiang Goods and Materials Co. Ltd. Carbon Structural Steel Used as Building_Materials Q235C U12358. Available online: http://jinxiangen.en.alibaba.com/product/ 60085795767-800580517/Carbon_structural_steel_used_as_building_materials_Q235C_U12358.html (accessed on 26 June 2015).

46. Chengdu Nuclear 857 New Materials Co. Ltd. China Factory Outlet Price Water-Atomized Iron Powder. Available online: http://www.alibaba.com/product-detail/China-factory-outlet-pricewater-atomized_1320161433.html?spm=a2700.7724838.35.1.bpBwCt (accessed on 3 July 2015).

47. Zheng Zhou Dongyao Nano Materials Co. Ltd. Nano Fe Powder, Iron Powder Price. Available online: http://uk.alibaba.com/product/60233340038-nano-Fe-powder-iron-powderprice.html (accessed on 3 July 2015).

48. Zheng Zhou Dongyao Nano Materials Co. Ltd. Iron Powder Nano Ferrum Powder Price/Iron Fe Nano Powder. Available online: http://uk.alibaba.com/product/60262863989-nano-iron-powderprice-iron-Fe.html (accessed on 3 July 2015). 
49. Chengdu Best New Materials Co. Ltd. Best10N Iron Gate Door Prices/Nano Iron Powder Available online: http://www.alibaba.com/product-detail/Best10N-iron-gate-door-prices-nano_ 60244110679.html (accessed on 5 July 2015).

50. Chengdu Best New Materials Co. Ltd. Best10N CIF Price of Nano Iron Powder Price Available online: http://www.alibaba.com/product-detail/Best10N-CIF-price-of-nano-iron_60243197709. html?spm=a2700.7724838.35.1.mqK1kf (accessed on 3 July 2015).

51. Shanghai Ruizheng Chemical Technology Co. Ltd. Nano-Iron Powder Available online: http://www. alibaba.com/product-detail/nano-iron-powder_60181455696.html?spm=a2700.7724838.35.1. XSGeDs (accessed on 3 July 2015).

52. Shanghai CNPC Powder Material Co. Ltd. Nano Low Oxide Content Carbonyl Iron Powder Price. Available online: http://uk.alibaba.com/product/60217902707-nano-low-oxide-content-carbonyliron.html (accessed on 3 July 2015).

53. Chengdu Nuclear 857 New Materials Co. Ltd. Competitive Price Iron Carbonyl Powder from Nuclear CDH857 Factory. Available online: http://uk.alibaba.com/product/60026003051competitive-price-iron-carbonyl-powder-from.html (accessed on 3 July 2015).

54. Chengdu Huarui Industrial Co. Ltd. Carbonyl Iron Powder for Powder Metallurgy, http:/www.alibaba.com/product-detail/Carbonyl-Iron-powder-for-powder-metallurgy_180825 8920.html?spm=a2700.”7724838.35.1.ZJ9KG2\&s=p (accessed on 3 July 2015).

55. Shanghai CNPC Powder Material Co. Ltd. Low Price 99\% Hyperpure Superfine Carbonyl UItrafine Iron Powder Iron Alloy Powder. Available online: http:/www.alibaba.com/productdetail/Low-Price-99-Hyperpure-Superfine-Carbonyl_60117436046.html?spm=a2700.7724838.

35.1.ZJ9KG2 (accessed on 3 July 2015).

56. Guizhou Dade Zhaoshen Building Materials Co. Ltd. Supply Nano Iron Powder/Reduced Iron Powder. Available online: http://uk.alibaba.com/product/60227762429-Supply-nano-iron-powderreduced-iron.html (accessed on 3 July 2015).

57. Chengdu Best New Materials Co. Ltd. Best10H Iron Powder Price Ton. Available online: http://uk.alibaba.com/product/60238493033-Best10H-iron-powder-price-ton.html (accessed on 3 July 2015).

58. Zouping Changshan Town Zefeng Fertilizer Factory, Iron (Fe) Powder Competitive Price. Available online: http://www.alibaba.com/product-detail/Iron-Fe-Powder-Competitive-price_14 21082390.html?spm=a2700.7724838.35.1.p24b5G (accessed on 3 July 2015).

59. Shanghai Xingyue Energy Technology Co. Ltd. High Purity Competitive Reduced Iron Powder Price. Available online: http://www.alibaba.com/product-detail/High-purity-competitive-reducediron-powder_60031676891.html?spm=a2700.7724838.35.1.1EU2qr (accessed on 3 July 2015).

60. Lingshou County Jiaqi Mineral Processing Factory. Manufacture Iron Powder Price. Available online: http:/www.alibaba.com/product-detail/manufacture-iron-powder-price_553077006.html? $\mathrm{spm}=\mathrm{a} 2700.7724838 .35 .1 .1$ EU2qr (accessed on 3 July 2015).

61. Soochow Hengqiu Graphene Technology Co. Ltd. 99.99\% Purity 40nm Iron Metal Nanoparticles Nano Ferrous Powders. Available online: http://www.alibaba.com/product-detail/99-99-Purity40nm-Iron-Metal_60136367986.html?spm=a2700.7724838.35.1.4CKA6f (accessed on 3 July 2015). 
62. International Chamber of Commerce. The New Incoterms ${ }^{\circledR} 2010$ Rules. Available online: http://www.iccwbo.org/products-and-services/trade-facilitation/incoterms-2010/ (accessed on 29 June 2015).

63. Ramberg, J. ICC Guide to INCOTERMS® 2010; No.720E; International Chamber of Commerce (ICC) Publication: Paris, France.

64. DHL Express. Basic Overview of The Incoterms ${ }^{\circledR} 2010$ Rules. Available online: http://www. dhl.co.uk/content/dam/downloads/g0/logistics/conditions/Incoterms_2010_EN_v2.pdf (accessed on 3 July 2015).

65. Owen, T. Fundamentals of UV-Visible Spectroscopy; Hewlett-Packcard Co.: Palo Alto, CA, USA, 1996.

66. NanoComposix. UV/Vis/IR Spectroscopy Analysis of Nanoparticles; NanoComposix: San Diego, CA, USA, 2012.

67. Taylor, R.M. Influence of chloride on the formation of iron oxides from Fe(II) chloride I: Effect of $[\mathrm{Cl}] /[\mathrm{Fe}]$ on the formation of magnetite. Clays Clay Miner. 1984, 32, 167-174.

68. Perez, F.R.; Barrero, C.A.; Walker, A.R.H.; Garcia, K.E.; Nomura, K. Effects of chloride concentration, immersion time and steel composition on the spinel phase formation. Mater. Chem. Phys. 2009, 117, 214-223.

69. Remazeilles, C.; Refait, P. Formation, fast oxidation and thermodynamic data of Fe(II) hydroxychlorides. Corros. Sci. 2008, 50, 856-864.

70. Refait, P.; Remazeilles, C. On the formation of beta-FeOOH (akaganeite) in chloride containing environments. Corros. Sci. 2007, 50, 844-857.

71. Refait, P.; Genin, J.M.R. The mechanism of oxidation of ferrous hydroxychloride beta- $\mathrm{Fe}_{2}(\mathrm{OH})_{3} \mathrm{Cl}$ in chloride containing aqueous solution: The formation of beta-FeOOH akaganeite, an X-ray diffraction, Mossbauer spectroscopy and electrochemical study. Corros. Sci. 1997, 39, 539-553.

72. Drissi, S.H.; Refait, P.; Abdelmoula, M.; Genin, J.M.R. The preparation and thermodynamic properties of $\mathrm{Fe}(\mathrm{II})-\mathrm{Fe}(\mathrm{III})$ hydroxide-carbonate (green rust a): Pourbaix diagram of iron in carbonate containing aqueous media. Corros. Sci. 1995, 37, 2025-2041.

73. Abdelmoula, M.; Refait, P.; Drissi, S.H.; Mihe, J.P.; Genin, J.M.R. Conversion electron Mossbauer spectroscopy and $\mathrm{X}$-Ray diffraction studies of the formation of carbonate containing green rust one by corrosion of metallic iron in $\mathrm{NaHCO}_{3}$ and $\left(\mathrm{NaHCO}_{3}+\mathrm{NaCl}\right)$ solution. Corros. Sci. 1996, 38, 623-633.

74. Refait, P.; Drissi, S.H.; Pytkiewicz, J.; Genin, J.M.R. The anodic species competition in iron aqueous corrosion: Role of various green rust compounds. Corros. Sci. 1997, 39, 1699-1710.

75. Refait, P.; Abdelmoula, M.; Genin, J.M.R. Mechanisms of formation and structure of green rust one in aqueous corrosion of iron in the presence of chloride ions. Corros. Sci. 1998, 40, 1547-1560.

76. Al-Moubaraki, A.H.; Al-Judaibi, A.; Asiri, M. Corrosion of C-steel in the Red Sea: Effect of immersion time and inhibitor concentration. Int. J. Electrochem. Sci. 2015, 10, 4252-4278.

77. Ruby, C.; Aissa, R.; Gehin, A.; Cortot, J.; Adelmoula, M.; Genin, J.-M. Green rusts synthesis by coprecipitation of $\mathrm{Fe}^{\mathrm{II}}-\mathrm{Fe}^{\mathrm{III}}$ ions and mass balance diagram. C. R. Geosci. 2006, 338, 420-443.

78. Kyzas, G.Z.; Peleka, E.N.; Deliyanni, E.A. Nanocrystalline akaganeite as adsorbent for surfactant removal from aqueous solutions. Materials 2013, 6, 184-197. 
79. He, J.; Hong, S.; Zhang, L.; Gan, F.; Ho, Y.-S. Equilibrium and thermodynamic parameters of adsorption of methylene blue onto rectorite. Fresnius Environ. Bull. 2010, 19, 2651-2656.

80. Zeng, Y.; Zeng, Z.; Ju, T.; Zhang, F. Adsorption-performance and mechanism of perchloroethylene on a novel nano composite $\beta$-FeOOH-AC. Microporous Mesoporoous Mater. 2015, 210, 60-68.

81. Wang, Z.; Ma, Y.; He, H.; Pei, C.; He, P. A novel reusable nanocomposite: FeOOH/CBC and its adsorptive property for methyl orange. Appl. Surf. Sci. 2015, 332, 456-462.

82. Xu, Z.; Liang, J.; Zhou, L. Template-Free hydrothermal synthesis of $\beta-F e O O H$ nanorods and ther catalytic activity in the degradation of methyl orange by a photo-fenton-like process. Open J. Inorg. Non-Met. Mater. 2013, 3, 58-65.

83. Zarzycki, P.; Kerisit, S.; Rosso, K.M. Molecular dynamics study of Fe(II) adsorption, electronic exchange, and mobility at goethite $(\alpha-\mathrm{FeOOH})$ surfaces. J. Phys. Chem. 2015, 119, 3111-3123.

84. Kersten, M.; Karabacheva, S.; Vlasova, N.; Branscheid, R.; Schurk, K.; Stanjek, H. Surface complexation modelling of arsenate adsorption by akaganeite $(\beta-\mathrm{FeOOH})$-Dominant granular ferric hydroxide. Colloids Surf. A Physiochem. Eng. Asp. 2014, 448, 73-80.

85. Kozin, P.A.; Boily, J.-F. Mineral surface charge development in mixed electrolyte solutions. J. Colloid Interface Sci. 2014, 418, 246-253.

86. Zhang, Y.-X.; Jia, Y. A facile solution approach for the synthesis of akaganeite $(\beta-\mathrm{FeOOH})$ nanorods and their ion exchange mechanism towards As(V) ions. Appl. Surf. Sci. 2014, 290, 102 106.

87. Mackay, A.L. Beta-Ferric oxyhydroxide. Mineral. Mag. 1960, 32, 545-557.

88. Mackay, A.L. Beta-Ferric oxyhydroxide-Akaganeite. Mineral. Mag. 1962, 33, 270-280.

89. Yabuuchi, N.; Komaba, S. Recent research progress on iron- and manganese-based positive electrode materials for rechargeable sodium batteries. Sci. Technol. Adv. Mater. 2014, 15, doi:10.1088/1468-6996/15/4/043501.

90. Dante, S.; Hou, Z.; Risbud, S.; Stroeve, P. Nucleation of iron oxy-hydroxide nanoparticles by layerby-layer polyionic assemblies. Langmuir 1999, 15, 2176-2182.

91. Hu, Y.; Chen, K. Crystal splitting in the growth of $\beta-\mathrm{FeO}(\mathrm{OH})$. J. Cryst. Growth 2007, 308, $185-188$.

92. Song, H.-J.; Liu, L.; Jia, X.-H. Synthesis of multiwalled carbon nanotubes/ $\beta-F e O O H$ nanocomposites with high adsorption capacity. J. Nanopart. Res. 2012, 14, doi:10.1007/s11051-012-1290-x.

93. Parameshwari, R.; Priyadarshini, P.; Chandrasekaran, G. Optimization, structural, spectroscopic and magnetic studies on stable akaganeite nanoparticles via co-precipitation method. Am. J. Mater. Sci. 2011, 1, 18-25.

94. Konishi, H.; Yamashita, M.; Uchida, H.; Mizuki, J. Characterisation of rust layer formed on Fe, $\mathrm{Fe}-\mathrm{Ni}$ and $\mathrm{Fe}-\mathrm{Cr}$ alloys exposed to $\mathrm{Cl}$-rich environment by $\mathrm{Cl}$ and $\mathrm{Fe} \mathrm{K}$-edge XANES measurements. Mater. Trans. 2005, 46, 329-336.

95. Post, J.E.; Heany, P.J.; von Dreele, R.B.; Hanson, J.C. Neutron and temperature resolved synchrotron X-ray powder diffraction study of akaganeite. Am. Mineral. 2003, 88, 782-788.

96. Yue, J.; Jiang, X.; Yu, A. Experimental and theoretical study on the $\beta$-FeOOH nanorods: Growth and conversion. J. Nanopart. Res. 2011, 13, 3961-3974. 
97. Singh, S.S.; Kodama, H. Effect of the presence of aluminum ions in iron solutions on the formation of iron oxyhydroxides $(\mathrm{FeOOH})$ at room temperature under acidic environment. Clays Clay Miner. 1994, 42, 606-616.

98. Garcia, K.E.; Barrero, C.A.; Morales, A.L.; Greneche, J.M. Characterization of akaganeite synthesed in the presence of $\mathrm{Al}^{3+}, \mathrm{Cr}^{3+}$ and $\mathrm{Cu}^{2+}$ ions and urea. Mater. Chem. Phy. 2008, 112, 120126.

99. Ishikawa, T.; Katoh, R.; Yasukawa, A.; Kandori, K.; Nakayama, T.; Yuse, F. Influence of metals on the formation of $\beta$-FeOOH particles. Corros. Sci. 2001, 43, 1727-1738.

100. Nesterova, M.; Moreau, J.; Banfield, J.F. Model biomimetic study of templated growth and assembly of nanocrystalline FeOOH. Geochim. Cosmochim. Acta 2003, 67, 1177-1187.

101. Peulon, S.; Baraize, Q.; Chausse, A. Iron compounds electrodeposited onto a transparent semiconductor: Synthesis and characterization by UV-vis spectroscopy. Electrochim. Acta 2007, $52,7681-7688$.

102. Tiwari, D.; Lee, S.-M. Ferrate (VI) in the treatment of waste waters: A new generation green chemical. In Waste Water Treatment and Reutilization, 1st ed.; Einschlag, F.S.G., Ed.; Intech: Rijeka, Croatia, 2011; Chapter 12, pp. 241-276.

103. Liu, Y.-C.; Xie, J.-L. Electrochemical preparation of sodium ferrate (VI) using silicon iron as anode in non-diaphragm electrobath. J. Sichuan Univ. (Nat. Sci. Ed.) 2004, 41, 373-378.

104. Geng, F.; Zhao, Z.; Geng, J.; Cong, H.; Cheng, H.-M. A simple and low temperature hydrothermal route for the synthesis of tubular alpha FeOOH. Mater. Lett. 2007, 61, 4794-4796.

105. Sherman, D.M.; Waite, T.D. Electronic spectra of $\mathrm{Fe}^{3+}$ oxides and oxide hydroxides in the near IR to near UV. Am. Mineral. 1985, 70, 1262-1269.

106. Villalba, J.C.; Constantino, V.R.I.; Anaissi, F.J. Iron oxyhydroxide nanostructured in montmorillonite clays: Preparation and characteristics. J. Colloid Interface Sci. 2010, 349, 49-55.

107. Szali, Z.; Kiss, K.; Jakab, G.; Sipos, P.; Belucz, B.; Nemeth, T. The use of UV-VIS-NIR reflectance spectroscopy to identify iron minerals. Astron. Nachr. 2013, 334, 940-943.

108. Castellan, G.W. Physical Chemistry, 3rd ed; Addison Wesley: Reading, MA, USA, 1983.

109. Janacek, K.; Sigler, K. Osmotic pressure: Thermodynamic basis and units of measurement. Folio Microbiol. 1996, 44, 2-9.

110. Combes, J.M.; Manceau, A.; Calas, G.; Bottero, J.Y. Formation of ferric oxides from aqueous solutions: A polyhedral approach by X-ray absorption spectroscopy: I. Hydrolysis and formation of ferric gels. Geochim. Cosmochim. Acta 1989, 53, 583-594.

111. Rustad, J.R.; Felmy, A.R.; Hay, B.P. Molecular statics calculations for iron oxide and oxyhydroxide minerals: Towards a flexible model of the reactive mineral-water interface. Geochim. Cosmochim. Acta 1996, 60, 1553-1562.

112. Hiemstra, T.; van Riemsdijk, W.H. Adsorption and surface oxidation of Fe(II) on metal (hydr)oxides. Geochim. Cosmochim. Acta 2007, 71, 5913-5933.

113. Ghose, S.K.; Waychunas, G.A.; Trainor, T.P.; Eng, P.J. Hydrated goethite ( $\alpha$-FeOOH) (100) interface structure: Ordered water and surface functional groups. Geochim. Cosmochim. Acta 2010, 74, 1943-1953.

114. Majzian, J.; Mazeina, L.; Navrotsky, A. Enthalpy of water adsorption and surface enthalpy of lepidocrocite ( $\gamma$-FeOOH). Geochim. Cosmochim. Acta 2007, 71, 615-623. 
115. Keller, A.A.; Garner, K.; Miller, R.J.; Lenihan, H.S. Toxicity of nano-zero valent iron to freshwater and marine organisms. PLoS ONE 2012, 7, e43983.

116. Kozin, P.A. Charge Development at Iron Oxyhydroxide Surfaces. Ph.D. Thesis, Umea University, Umea, Sweden, 2014.

117. Sverjensky, D.A. Prediction of surface charge on oxides in salt solutions: Revisions for $1: 1\left(\mathrm{M}^{+} \mathrm{L}^{-}\right)$ electrolytes. Geochim. Cosmochim. Acta 2005, 69, 225-257.

118. Kozin, P.A.; Shchukarev, A.; Bolly, J.-F. Electrolyte ion binding at iron oxyhydroxide mineral surfaces. Langmuir 2013, 29, 12129-12137.

119. Tourky, A.R.; Azim, A.A.A.; Anwar, M.M. Effect of carbon content on the corrosion and passivity of iron. Corros. Sci. 1965, 5, 301-317.

120. Zhao, X.; Johnston, C.; Grant, P.S. A novel hybrid supercapacitor with a carbon nanotube cathode and an iron oxide/carbon nanotube composite anode. J. Mater. Chem. 2009, 46, 8755-8760.

121. Li, Y.; Kang, L.; Bai, G.; Li, P.; Deng, J.; Liu, X.; Yang, Y.; Gao, F.; Liang, W. Solvothermal synthesis of $\mathrm{Fe}_{2} \mathrm{O}_{3}$ loaded activated carbon as electrode materials for high performance electrochemical capacitors. Electrochem. Acta 2014, 134, 67-75.

122. Xu, L.; Xia, J.; Xu, H.; Yin, S.; Wang, K.; Huang, L.; Wang, L.; Li, H. Reactable ionic liquid assisted solvothermal synthesis of graphite like $\mathrm{C}_{3} \mathrm{~N}_{4}$ hybridized alpha $\mathrm{Fe}_{2} \mathrm{O}_{3}$ hollow microspheres with enhanced supercapacitive performance. J. Power Sources 2014, 245, 866-874.

123. Nasibi, M.; Golozar, M.A.; Rashed, G. Nano iron oxide $\left(\mathrm{Fe}_{2} \mathrm{O}_{3}\right) /$ carbon black electrodes as electrode material for electrochemical capacitors: Effect of the nano-particles dispersion quality. Mater. Chem. Phys. 2013, 139, 12-16.

124. Chaudhari, N.K.; Chaudhari, S.; Yu, J.-S. Cube like alpha $\mathrm{Fe}_{2} \mathrm{O}_{3}$ supported on ordered multimodal porous carbon as high performance electrode material for supercapacitors. ChemSusChem 2014, 7, 3102-3111.

125. Lin, Y.; Wang, X.; Qian, G.; Watkins, J.J. Additive driven self assembly of well ordered mesoporous carbon/iron oxide nanoparticle composites for supercapacitors. Chem. Mater. 2014, 26, 2128-2137.

126. Sethuraman, B.; Purushothaman, K.K.; Muralidharan, G. Synthesis of mesh-like $\mathrm{Fe}_{2} \mathrm{O}_{3} / \mathrm{C}$ nano-composite via greener route for high performance supercapacitors. $R S C A d v$. 2014, 4, 46314637.

127. He, X.; Zhao, N.; Qiu, J.; Xiao, N.; Yu,M.; Yu, C.; Zhang, Z.; Zheng, M. Synthesis of hierarchial porous carbons for supercapacitors from coal tar pitch with nano- $\mathrm{Fe}_{2} \mathrm{O}_{3}$ as template and activation agent coupled with KOH activation. J. Mater. Chem. A 2013, 1, 9440-9448.

128. Chen, L.-F.; You, Z.Y.; Wang, J.J.; Li, Q.-X.; Tan, Z.-Q.; Zhu, Y.-W.; Yu, S.-H. Metal like fluoride doped beta $\mathrm{FeOOH}$ nanorods grown on carbon cloth for scalable high performance supercapacitors. Nano Energy 2015, 11, 119-128.

129. Xiao, T.; Yang, C.; Lu, Y.; Zeng, F. One-Pot hydrothermal synthesis of rod-like FeOOH/reduced grapheme oxide composites for supercapacitor. J. Mater. Sci. Mater. Electron. 2014, 25, 3364-3374. 
130. Barik, R.; Jena, B.K.; Dash, A.; Mohapatra, M. In situ synthesis of flowery shaped alpha $\mathrm{FeOOH} / \mathrm{Fe}_{2} \mathrm{O}_{3}$ nanoparticles and their phase dependent supercapacitive behaviour. RSC Adv. 2014, 4, 18827-18834.

131. Lee, K.K.; Ng, R.W.Y.; She, K.K.; Chin, W.S.; Sow, C.H. Vertically aligned iron (III) oxyhydroxide/oxide nanosheets grown on iron substrates for electrochemical charge storage. Mater. Lett. 2014, 118, 150-163.

132. Jayalakshmi, M.; Balasubramanian, K. Solution combustion synthesis of $\mathrm{Fe}_{2} \mathrm{O}_{3} / \mathrm{C}, \mathrm{Fe}_{2} \mathrm{O}_{3}-\mathrm{SnO}_{2} / \mathrm{C}$, $\mathrm{Fe}_{2} \mathrm{O}_{3}-\mathrm{ZnO} / \mathrm{C}$ composites and their electrochemical characterization in non-aqueous electrolyte for supercapacitor application. Int. J. Electrochem. Sci. 2009, 4, 878-886.

133. Chen, L.-F.; Yu, Z.-Y.; Ma, X.; Li, Z.-Y.; Yu, S.H. In situ hydrothermal growth of ferric oxides on carbon cloth for low cost and scalable high-energy-density supercapacitors. Nano Energy 2014, 9, 345-354.

134. Tang, O.; Wang, W.; Wang, G. The perfect matching between the low cost $\mathrm{Fe}_{2} \mathrm{O}_{3}$ nanowire anode and $\mathrm{NiO}$ nanoflake cathode significantly enhances the energy density of asymmetric supercapacitors. J. Mater. Chem. A 2015, 3, 6662-6670.

135. Kang, L.; Xie, L.; Li, P.; Liu, T.; Zhang, X.; Luo, J.; Liang, W. One-Step combustion synthesis of CNTs doped $\mathrm{Fe}_{2} \mathrm{O}_{3} / \mathrm{C}$ nanocomposites as electrode materials for supercapacitors. Fuller. Nanotub. Carbon Nanostruct. 2015, 23, 715-720.

136. Kulal, P.M.; Dubal, D.P.; Lokhande, C.D.; Fulari, V.J. Chemical synthesis of $\mathrm{Fe}_{2} \mathrm{O}_{3}$ thin films for supercapacitor applications. J. Alloys Compd. 2011, 509, 2567-2571.

137. Sun, S.; Lang, J.; Wang, R.; Kong, L.; Li, X.; Yan, X. Identifying pseudocapacitance of $\mathrm{Fe}_{2} \mathrm{O}_{3}$ in an ionic liquid and its application in asymmetric supercapacitors. J. Mater. Chem. A 2014, 2, $14550-14556$.

138. Tan, H.T.; Ru, X.; Yu, H.; Liu, W.; Xu, C.; Zu, Z.; Hng, H.H.; Yan, Q. Aqueous based chemical route towards ambient preparation of multicomponent core-shell nanotubes. ACS Nano 2014, 8, 4004-4014.

139. Li, J.; Wu, Q.; Zan, G. Facile synthesis and high electrochemical performance of porous carbon composites for supercapacitors. RSC Adv. 2014, 4, 35186-35192.

140. Luo, P.-W.; Yu, J.-G.; Shi, Z.-Q.; Huang, H.; Liu, L.; Zhao, Y.-N.; Li, G.-D.; Zou, Y.-C. Preparation and supercapacitive properties of $\mathrm{Fe}_{2} \mathrm{O}_{3}$ /active carbon nanocomposites. Chem. Res. Chin. Univ. 2012, 28, 780-783.

141. Zhu, C.; Saito, G.; Akiyama, T. A facile solution combustion synthesis of nanosized amorphous iron oxide incorporated in a carbon matrix for use as a high-performance lithium ion battery anode material. J. Alloys Compd. 2015, 633, 424-429.

142. Wang, J.; Gao, M.; Wang, D.; Li, X.; Dou, Y.; Liu, Y.; Pan, H. Chemical vapor deposition prepared bi-morphological carbon coated $\mathrm{Fe}_{3} \mathrm{O}_{4}$ composites as anode materials for lithium ion batteries. $J$. Power Sources 2015, 282, 257-264.

143. Valvo, M.; Lindgren, F.; Lafont, U.; Bjorefors, F.; Edstrom, K. Towards more sustainable negative electrodes in Na-ion batteries via nanostructured iron oxide. J. Power Sources 2014, 245, $967-$ 978.

144. Huang, B.; Tai, K.; Zhang, M.; Xiao, Y.; Dillon, S.J. Comparative study of Li and Na electrochemical reactions with iron oxide nanowires. Electrochim. Acta 2014, 118, 143-149. 
145. Shimizu, K.; Boily, J.F. Electrochemical signatures of crystallographic orientation and counterion binding at the hematite water interface. J. Phys. Chem. C 2015, 119, 5988-5994.

146. Perry, J.H. Chemical Engineers Handbook, 2nd ed.; McGraw Hill: New York, NY, USA, 1941.

147. Gil-Lalaguna, N.; Sanchez, J.L.; Murillo, M.B.; Gea, G. Use of sewage sludge combustion ash and gasification ash for high temperature desulphurization of different gas streams. Fuel 2015, 141, 99-106.

148. McManus, D.; Martell, A.E. The evolution, chemistry, and applications of cheleted iron hydrogen sulphide removal and oxidation process. J. Mol. Catal. A Chem. 1997, 117, 289-297.

149. Kotanigawa, T.; Takahashi, H.; Yokoyama, S.; Yanamoto, M.; Maekawa, Y. Mechanism for formation of sulphate in S-promoted iron oxide catalysts for coal liquefaction. Fuel 1988, 67, 927931.

150. Ebbing, D.D.; Gammon, S.D. General Chemistry, 6th ed.; Houghton Mifflin Co.: Boston, MA, USA, 1999.

151. EU. Council Directive 98/83/EC of 3 November 1998 on the quality of water intended for human consumption. Available online: http://eur-lex.europa.eu/legal-content/en/ALL/?uri=CELEX: 31998L0083 (accessed on 26 June 2015).

152. World Health Organization (WHO). Guidelines for Drinking Water Quality; WHO: Geneva, Switzerland, 2011.

153. Karthika, I.N.; Dheenadayalan, M.S. Study of groundwater quality at selected locations in Dindigul District, India. J. Adv. Chem. Sci. 2015, 1, 67-69.

154. Bureau of Indian Standards (BIS). Indian Standard Drinking Water-Specification, (Second Revision); IS 10500; BIS: New Delhi, India, 2012.

155. Cornell, R.M.; Schwertmann, U. The Iron Oxides: Structure, Properties, Reactions, Occurrences and Uses; Wiley Inc.: Hoboken, NJ, USA, 2006.

156. Han, B.; Choi, J.H.; Dantzig, J.A.; Bischof, J.C. A quantitative analysis on latent heat of an aqueous binary mixture. Cryobiology 2006, 52, 146-151.

157. Ueda, K. Modeling of dissolved oxygen concentration recovery in water bodies and application to hypoxic water bodies. World Environ. 2013, 3, 52-59.

158. Lougee, L.A.; Bollens, S.M.; Avent, S.R. The effects of haloclines on the vertical distribution and migration of zooplankton. J. Exp. Mar. Biol. Ecol. 2002, 278, 111-134.

159. Tianjin Yandong Mining Co. Ltd. Low Price Chinese Natural Potassium Feldspar with high $\mathrm{K}_{2} \mathrm{O}$ Available online: http://www.alibaba.com/product-detail/Low-Price-Chinese-Natural-PotassiumFeldspar_1940165894.html (accessed on 3 July 2015).

160. Mantra Minerals Private Ltd. High Grade Potash Feldspar for Ceramic Competitive Price India Available online: http:/www.alibaba.com/product-detail/High-grade-Potash-Feldspar-forceramic_116467809.html (accessed on 3 July 2015).

161. Jiangxi Jiali Biochemical High Tech Co. Ltd. High Quality Potash Feldspar in Hot Sale. Available online: http:/www.alibaba.com/product-detail/High-Quality-Potash-Feldspar-InHot_60137109155. html?s=p (accessed on 3 July 2015).

162. Antia, D.D.J. Water remediation-Water remediation using nano-zero-valent metals (n-ZVM). In CRC Concise Encyclopedia of Nanotechnology, 1st ed.; Kharisov, B.I., Kharissova, O.V., Ortiz- 
Mendez, U., Eds.; CRC Press, Taylor \& Francis Group: Boca Raton, FL, USA, 2015; Chapter 84, ISBN 9781466580343, (In Press).

163. Olowe, A.A.; Genin, J.M.R. The mechanism of oxidation of ferrous hydroxide in sulphated aqueous media: Importance of the initial ratio of the reactants. Corros. Sci. 1991, 32, 965-984.

164. Refait, P.; Genin, J.M.R. The transformation of chloride containing green rust one into sulphated green rust two by oxidation in mixed $\mathrm{Cl}^{-}$and $\mathrm{SO}_{4}{ }^{2-}$ aqueous media. Corros. Sci. 1994, 36, $55-65$.

165. Simon, L.; Refait, P.; Genin, J.M.R. Transformation of Fe(II)-Fe(III) hydroxysulphite into hydroxysulphate green rusts. Hyperfine Interact. 1998, 112, 217-222.

166. Genin, J.M.R.; Olowe, A.A.; Refait, P.; Simon, L. On the stoichiometry and Pourbaix diagram of $\mathrm{Fe}(\mathrm{II})-\mathrm{Fe}(\mathrm{III})$ hydroxyl-sulphate or sulphate containing green rust 2: An electrochemical and Mossbauer spectroscopy study. Corros. Sci. 1996, 38, 1751-1762.

167. Oh, S.J.; Kwon, S.J.; Lee, J.-Y.; Yoo, J.-Y.; Choo, W.-Y. Oxidation of $\mathrm{Fe}^{2+}$ ions in sulphate and chloride containing aqueous media. Corrosion 2002, 58, 498-504.

168. Davesne, E.; Dideriksen, K.; Christiansen, B.C.; Sonne, M.; Ayala-Luis, K.B.; Koch, C.B.; Hansen, H.C.B.; Stipp, S.L.S. Free energy of formation of green rust sodium sulphate $\left(\mathrm{NaFe}_{6}{ }_{6} \mathrm{Fe}^{\mathrm{III}}{ }_{3}(\mathrm{OH})_{18}\left(\mathrm{SO}_{4}\right)_{2(\mathrm{~s})}\right)$. Geochim. Cosmochim. Acta 2010, 74, 6451-6467.

169. Ning, J.; Zheng, Y.; Young, D.; Brown, B.; Nesic, S. A thermodynamic study of hydrogen sulphide corrosion of mild steel. Corrosion 2014, 70, 375-389.

170. Descostes, M.; Vitorge, P.; Beaucaire, C. Pyrite dissolution in acidic media. Geochim. Cosmochim. Acta 2004, 68, 4559-4569.

171. Wearing, C.L. Changes in Fluxes of Dissolved Organic Carbon (DOC) from Small Catchments in Central Scotland. Ph.D. Thesis, University of Stirling, Stirling, UK, 2008.

172. Refait, P.; Nguyen, D.D.; Jeannin, M.; Sable, S.; Langumier, M.; Sabot, R. Electrochemical formation of green rusts in deaerated seawater like solutions. Electrochim. Acta 2011, 56, 6481-6488.

173. Reffass, M.; Sabot, R.; Saavall, C.; Jeannin, M.; Creus, J.; Refait, P. Localised corrosion of carbon steel in $\mathrm{NaHCO}_{3} / \mathrm{NaCl}$ electrolytes: Role of Fe(II) containing compounds. Corros. Sci. 2006, 48, 709-726.

174. Lee, C.T.; Qin, Z.; Odziemkowski, M.; Shoesmith, D.W. The influence of groundwater anions on the impedence behaviour of carbon steel corroding under anoxic conditions. Electrochem. Acta 2006, 51, 1558-1568.

175. Xin, J.; Zheng, X.; Han, J.; Shao, H.; Kolditz, O. remediation of trichloroethylene in xanthan gum coated microscale zero valent iron (XG-mZVI) in groundwater: Effects of geochemical constituents. Chem. Eng. J. 2015, 271, 164-172.

176. Genin, J.M.R.; Ruby, C.; Gehin, A.; Refait, P. Synthesis of green rusts by oxidation of $\mathrm{Fe}(\mathrm{OH})_{2}$, their products of oxidation and reduction of ferric oxyhydroxides: Eh-pH Pourbaix diagrams. C. R. Geosci. 2006, 338, 433-446.

177. United Nations Educational Scientific and Cultural Organization (UNESCO). The United Nations World Water Development Report; UNESCO: Paris, France, 2014,

178. Quist-Jensen, C.A.; Macedonio, F.; Drioli, E. Membrane technology for water production in agriculture: Desalination and waste water reuse. Desalination 2015, 364, 17-32. 
179. Blandin, G.; Verliefde, A.R.D.; Tang, C.Y.; le Clech, P. Opportunities to reach economic sustainability in forward osmosis-reverse osmosis hybrids for seawater desalination. Desalination 2015, 363, 26-36.

180. Bundschuh, J.; Ghaffour, N.; Mahmoudi, H.; Goosen, M.; Mushtaq, S.; Hoinkis, J. Low-cost low enthalpy geothermal heat for freshwater production: Innovative applications using thermal desalination process. Renew. Sustain. Energy Rev. 2015, 43, 196-206.

181. Burn, S.; Hoang, M.; Zarzo, D.; Olewiak, F.; Campos, E.; Bolto, B.; Barron, O. Desalination techniques-A review of the opportunities in agriculture. Desalination 2015, 364, 2-26.

182. Avrin, A.-P.; He, G.; Kammen, D.M. Assessing the impacts of nuclear desalination and geoengineering to address China's water shortages. Desalination 2015, 360, 1-7.

183. Zotalis, K.; Dialynas, E.G.; Mamassis, N.; Angelakis, A.N. Desalination technologies: Hellenic Experience. Water 2014, 6, 1134-1150.

184. Dubai Electricty and Water Authority 2015 Slab Tariff, 2 March 2015; Dubai Electricty and Water Authority, Government of Dubai. Available online: http://www.dewa.gov.ae/tariff/ tariffdetails.aspx (accessed on 1 May 2015).

185. Barron, O.; Ali, R.; Hodgson, G.; Smith, D.; Qureshi, E.; McFarlane, D.; Campos, E.; Zarzo, D. Feasibility assessment of desalination application in Australian traditional agriculture. Desalination 2015, 364, 33-45.

186. Suresh, M.; Gurugnanam, B.; Vasudevan, S.; Rao, S.V.L.; Kumaravel, S. Groundwater quality assessment for irrigation uses in Upper Thirumanimuthar sub basin, Cauvery river, Tamil Nadu, India. J. Appl. Geochem. 2010, 12, 95-105.

187. Varade, A.M.; Yenkie, R.O.; Kodate, J. Assessment of water quality in and around Hingna area of Nagpur District, Maharashtra for irrigational purposes. J. Appl. Geochem. 2013, 15, 488-505.

188. Ayers, R.S.; Westcot, D.W. Water Quality for Agriculture; Irrigation and Drainage Paper No. 29, Rev. 1, Reprinted 1989, 1994; Food and Agriculture Organization of the United Nations: Rome, Italy, 1994.

189. Terjung, W.H.; Hayes, J.T.; Ji, H.-Y.; O-Rourke, P.A.; Todhunter, P.E. Crop water requirements for rainfed and irrigated rice (Paddy) in China. Arch. Meteorl. Geophys. Bioclimatol. Ser. B 1984, 34, 181-202.

190. Antia, D.D.J. Desalination of groundwater and impoundments using nano-zero valent iron, $\mathrm{n}-\mathrm{Fe}^{0}$. Meterol. Hydrol. Water Manag. 2015, 3, 21-38.

191. Guan, X.; Sun, Y.; Qin, H.; Li, J.; Lo, I.M.C.; He, D.; Dong, H. The limitations of applying zero-valent iron technology in contaminants sequestration and the corresponding counter measures: The development in zero valent iron technology in the last two decades (1994-2014). Water Res. 2015, 75, 224-248.

192. Zhao, D.; Xu, Y. In Situ Remediation of Inorganic Contaminants Using Stabilized Zero-Valent Iron Nano-Particles. U.S. Patent 7,635,236 B2, 30 March 2006.

193. Tepong-Tsinde, R.; Phukan, M.; Nassi, A.; Noubactep, C.; Ruppert, H. Validating the efficiency of the MB discoloration method for the characterization of $\mathrm{Fe}^{0} / \mathrm{H}_{2} \mathrm{O}$ systems ussing accelerated corrosion by chloride ions. Chem. Eng. J. 2015, 279, 353-362. 
194. Wang, C.; Zhao, H.; Wang, H.; Liu, L.; Xiao, C.; Ma, D. The effects of ionic additives on the aqueous phase Fischer Tropsch synthesis with a ruthenium nonparticle catalyst. Catal. Today 2012, $183,143-153$.

195. Antia, D.D.J. Low temperature oil polymerisation and hydrocarbon expulsion from continental shelf and continental slope sediments. Indian J. Pet. Geol. 2009, 16, 1-30.

196. Antia, D.D.J. Hydrocarbon Formation in Immature Sediments. Adv. Pet. Explor. Dev. 2011, 1, 1-13.

197. Antia, D.D.J. Polymerisation theory-Formation of hydrocarbons in sedimentary strata (hydrates, clays, sandstones, carbonates, evaporites, volcanoclastics) from $\mathrm{CH}_{4}$ and $\mathrm{CO}_{2}$ : Part I. Polymerisation concept, kinetics, sources of hydrogen and redox environment. Indian J. Pet. Geol. 2009, 17, 49-86.

198. Antia, D.D.J. Polymerisation theory-Formation of hydrocarbons in sedimentary strata (hydrates, clays, sandstones, carbonates, evaporites, volcanoclastics) from $\mathrm{CH}_{4}$ and $\mathrm{CO}_{2}$ : Part II: Formation and interpretation of stage 1 to stage 5 oils. Indian J. Pet. Geol. 2010, 17, 11-70.

199. Antia, D.D.J. Polymerisation theory-Formation of hydrocarbons in sedimentary strata (hydrates, clays, sandstones, carbonates, evaporites, volcanoclastics) from $\mathrm{CH}_{4}$ and $\mathrm{CO}_{2}$ : Part III: Hydrocarbon expulsion from the hydrodynamic flow regimes contained within a generating pressure mound. Indian J. Pet. Geol. 2010, 18, 1-50.

200. Antia, D.D.J. Polymerisation theory-Formation of hydrocarbons in sedimentary strata (hydrates, clays, sandstones, carbonates, evaporites, volcanoclastics) from $\mathrm{CH}_{4}$ and $\mathrm{CO}_{2}$ : Part IV: Polymerisation modelling of sequestered carbon dioxide and waste organic liquids to hydrocarbons. Indian J. Pet. Geol. 2011, 18, 1-45.

201. Li, M.; Shi, Z.-M.; Liu, Y.-B. Crevice corrosion of K60 in dry desertification saline soil. J. Iron Steel Res. Int. 2013, 20, 76-80.

202. Stefansson, A.; Lemke, K.H.; Seward, T.M. Iron (III) complexation in hydrothermal solutions-An experimental and theoretical study. In Proceedings of the 15th International Conference on the Properties of Water and Steam, Berlin, Germany, 7-11 September 2008; pp. 1-7.

203. Nesic, S. Key issues related to the internal corrosion of oil and gas pipelines-A review. Corros. Sci. 2007, 49, 4308-4338.

204. Perez, F.R.: Barrero, C.A.; Amache, O.; Sanchez, L.C.; Garcia, K.E.; Walker, A.R.H. Structural properties of iron phases formed on low alloy steels immersed in sodium chloride rich solutions. Physica B 2009, 404, 1347-1353.

205. Hasan, B.O.; Sadek, S.A. Corrosion behaviour of carbon steel in oxygenated sodium sulphate solution under different operating conditions. Adv. Chem. Eng. Res. 2013, 2, 61-71.

206. Ismail, A.; Adan, N.H. Effect of oxygen concentration on corrosion rate of carbon steel in seawater. Am. J. Eng. Res. 2014, 3, 64-67.

207. Xu, X.; Cao, C.; Zhou, Y. Facile synthesis of single crystalline mesoporous hematite nano-rods with enhanced supercapacitive performance. Electrochim. Acta 2015, 156, 257-262.

208. Branan, C. Rules of Thumb for Chemical Engineers, 4th ed.; Elsevier: Amsterdam, The Netherlands, 2005.

209. Green, D.W.; Perry, R.H. Perry's Chemical Engineers Handbook, 8th ed.; McGraw-Hill: New York, NY, USA, 2008. 
210. Curran, G. Water for Livestock: Interpreting Water Quality Tests; Primefact No. 533; New South Wales Department of Primary Industry: Orange, New South Wales, Australia, 2007.

211. Masters, D.G.; Benes, S.E.; Norman, H.C. Biosaline agriculture for forage and livestock production. Agric. Ecosyst. Environ. 2007, 119, 234-248.

212. PIRSA. Livestock Industries Livestock Water Intakes and Salinity Tolerances; Fact Sheet, No. 03/07; Government of South Australia, Primary Industries and Resources SA: Adelaide, Australia, 2006.

213. Glauert, S. Livestock and Water Salinity; Farm Note: 249; Government of Western Australia, Department of Agriculture and Food: Perth, Australia, 2007.

214. New South Wales Government, Department of Primary Industries (NSW DPI). Water Requirements for Sheep and Cattle; Prime Facts 326; NSW DPI: Sydney, Australia, 2014.

215. Di Noto, V.; Mecozzi, M. Determination of seawater salinity by ultraviolet spectroscopic measurement. Appl. Spectrosc. 1997, 61, 1294-1302.

216. Chai, B.-H.; Zheng, J.-M.; Zhao, Q.; Pollack, G.H. Spectroscopic studies of solutes in aqueous solution. J. Phys. Chem. A 2008, 112, 2242-2247.

217. Wang, Q.; Chen, K.; Li, J.; Xu, J.; Liu, S. Simultaneous determination of chlorine dioxide and hypochlorous acid in bleaching system. Bioresources 2011, 6, 1868-1879.

218. Toniolo, A.; Persico, M.; Pitea, D. Theoretical photoabsorption spectra of $\mathrm{ClOOCl}$ and $\mathrm{Cl}_{2} \mathrm{O}$. J. Phys. Chem. A 2000, 104, 7278-7283.

219. Young, I.A.K.; Jones, R.L.; Pope, F.D. The UV and visible spectra of chlorine peroxide: Constraining the atmospheric photolysis rate. Geophys. Res. Lett. 2014, 41, 1781-1788.

220. Neta, P.; Hule, R.E.; Ross, A.B. Rate constants for reactions of inorganic radicals in aqueous solution. J. Phys. Chem. Ref. Data 1988, 17, 1027-1039.

221. Chipman, D.M. Absorption spectrum of OH radical in water. J. Phys. Chem. A 2008, 112, 1337213381.

222. Hammerum, S. Alkyl radicals as hydrogen bond acceptors: Computational evidence. J. Am. Chem. Soc. 2009, 131, 8627-8635.

223. Bill, A.; Lakajka, Z. The hydroperoxy radical as a hydrogen bond acceptor: $\mathrm{HOO}-\mathrm{HCl}$ complexes-Ab initio study. J. Comput. Chem. 2006, 27, 287-295.

224. Do, H.; Beseley, N.A. Proton transfer or hemibonding? The structure and stability of radical cation clusters. Phys. Chem. Chem. Phys. 2013, 15, 16214-16219.

225. Bielski, B.H.J.; Cabelli, D.E.; Arudi, R.L. Reactivity of $\mathrm{HO}_{2} / \mathrm{O}_{2}{ }^{-}$Radicals in Aqueous Solution. $J$. Phys. Chem. Ref. Data 1985, 14, 1041-1100.

226. Bosinceanu, R.; Sulitanu, N. Synthesis and characterization of $\mathrm{FeO}(\mathrm{OH}) / \mathrm{Fe}_{3} \mathrm{O}_{4}$ nanoparticles encapsulated in zeolite matrix. J. Optoelectron. Adv. Mater. 2008, 10, 3482-3486.

227. Yuvakkumar, R.; Elango, V.; Rajendran, V.; Kannan, N. Preparation and characterization of zero valent iron nanoparticles. Dig. J. Nanomater. Biostruct. 2011, 6, 1771-1776.

228. Thomas, O.; Burgess, C. UV-Visible spectrophotometry of water and waste water. Tech. Instrum. Anal. Chem. 2007, 27, 1-360.

229. Gimenez, P.; Rameau, J.J.; Reboul, M.C. Experimental pH potential diagram of aluminium for seawater. Corrosion 1981, 37, 673-682. 
230. Younis, A. Protection of Aluminium Alloy (AA7075) from Corrosion by Sol Gel Technique. Ph.D. Thesis, Chemnitz University of Technology, Chemnitz, Germany, 2012.

231. Nestoridi, M. The Study of Aluminium Anodes for High Power Density Al-Air Batteries with Brine Electrolytes. Ph.D. Thesis, University of Southampton, Southampton, UK, 2008.

232. Arjmand, F.; Adrianens, A. Influence of $\mathrm{pH}$ and chloride concentration on the corrosion behaviour of unalloyed copper in $\mathrm{NaCl}$ solution: A comparative study between the micro and macro scales. Materials 2012, 5, 2439-2464.

233. Bojinov, M.; Makela, K. Corrosion of Copper in Anoxic 1 M NaCl Solution; Report 2003-45; VTT Technical Research Centre of Finland, Posiva OY: Eurajoki, Finland, 2003.

234. Alfantazi, A.M.; Ahmed, T.M.; Tromans, D. Corrosion behaviour of copper alloys in chloride media. Mater. Des. 2009, 30, 2425-2430.

235. Beverskog, B.; Puigdomenech, I. Revised Pourbaix diagram for iron at $25-300{ }^{\circ}$ C. Corros. Sci. 1996, 38, 2121-2135.

236. Azoulay, I.; Remazeilles, C.; Refait, P. Determination of standard Gibbs Free energy of formation of chukanovite and Pourbaix diagrams of iron in carbonated media. Corros. Sci. 2012, 58, 229236.

237. Bottero, J.-Y.; Manceau, A.; Villieras, F.; Tchoubar, D. Structure and mechanisms of formation of FeOOH $(\mathrm{Cl})$ polymer. Langmuir 1994, 10, 316-319.

238. Bagheri, S.; Chandrappa, K.G.; Hamid, S.B.A. Generation of hematite nanoparticles via sol-gel method. Res. J. Chem. Sci. 2013, 3, 62-68.

239. Ristic, M.; Music, S.; Godec, M. Properties of gamma-FeOOH, alpha-FeOOH and alpha- $\mathrm{Fe}_{2} \mathrm{O}_{3}$ particles precipitated by hydrolysis of $\mathrm{Fe}^{3+}$ ions in perchlorate containing aqueous solution. J. Alloys Compd. 2006, 417, 292-299.

240. Bouniol, P. Influence of iron on water radiolysis in cement based materials. J. Nucl. Mater. 2010, 403, 167-183.

241. BS ISO 11271:2002, BS 7755-3.14:2002, Soil Quality. Determination of Redox Potential. Field Method, November 2002. Available online: http://shop.bsigroup.com/ProductDetail/?pid= 000000000030040608 (accessed on 3 July 2015).

242. ISO 11271:2002, Soil Quality_Determination of Redox potential_Field Method. Available online: http://www.iso.org/iso/iso_catalogue/catalogue_tc/catalogue_detail.htm?csnumber=34002 (accessed on 3 July 2015)

243. Jardim, W.F. Medicao e interpretacao de valores do potencial redox (EH) em matrizes ambientais. Quim. Nova 2014, 37, 1233-1235.

244. Ricca. Oxidation-Reduction Potential (ORP); Technical Reference Document \#19; Ricca Chemical Company: Arlington, TX, USA, 2005; Available online: http://www.riccachemical. com/Documents/TRD19.pdf (accessed on 26 June 2015).

245. Striggow, B. Field Measurement of Oxidation-Reduction Potential (ORP); SESDPROC-113-R1; US Environmental Protection Agency: Athens, GA, USA, 2013.

246. Thermo. Water Analysis Instruments Online Library ORP $-\mathrm{mV}, \mathrm{RmV}$, and Eh. Available online: https://static.fishersci.com/cmsassets/downloads/segment/Scientific/pdf/WaterAnalysis/ Log121TipORPmVRmVandEh.pdf (accessed on 26 June 2015). 
247. Unisense. Redox and Reference Electrode Manual; Unisense a/s: Aarhus, Denmark, 2012. Available online: http://www.unisense.com/files/PDF/Manualer/Redox\%20Sensor\%20Manual.pdf (accessed on 26 June 2015).

248. Van Walt. Reporting Redox (ORP Reporting); Van Walt Ltd.: Surrey, UK, 2012. Available online: http://www.vanwalt.com/pdf/information-sheets/RedoxReporting.pdf (accessed on 26 June 2015).

249. Nazaruk, J.; Gudej, J. Flavonoid compounds from the flowers of Cisium Rivulare (Jacq.) All. Acta Pol. Pharm. Drug Res. 2003, 63, 87-89.

250. Hsu, P.H. Appearance and stability of hydrolyzed $\mathrm{Fe}\left(\mathrm{ClO}_{4}\right)_{3}$ solutions. Clays Clay Miner. 1973, 21, 267-277.

251. Ockermann, L.T.; Schreyer, J.M. Preparation of sodium ferrate. J. Am. Chem. Soc. 1951, $73,5478$.

252. Jiang, J.-Q.; Lloyd, B. Progress in the development and use of ferrate (VI) salt as an oxidant and coagulant forwater and waste water treatment. Water Res. 2002, 36, 1397-1408.

253. El Maghraoui, A.; Zerouale, A.; Ijjaali, M.; Mohamed, S. Synthesis and characterization of ferrate (VI) alkali metal by wet method. Int. J. Mod. Eng. Res. 2012, 2, 4521-4523.

254. Deininger, J.P.; Dotson, R.L. Process for the Electrochemical Production of Sodium Ferrate (Fe(VI)). U.S. Patent 4,535,257, 1 July 1983.

(C) 2015 by the authors; licensee MDPI, Basel, Switzerland. This article is an open access article distributed under the terms and conditions of the Creative Commons Attribution license (http://creativecommons.org/licenses/by/4.0/). 